\title{
Nematodes
}

and Their Role in the

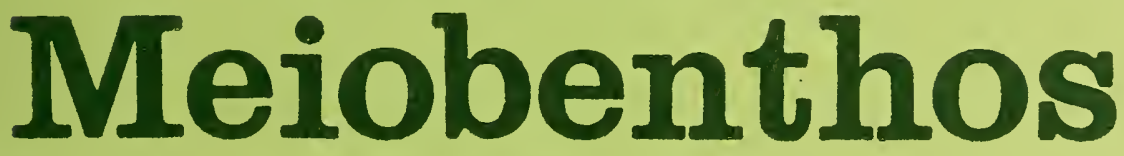

$$
\begin{aligned}
& \text { T. A. PLATONOVA } \\
& \text { V. V. GAL'TSOVA }
\end{aligned}
$$


Nematodes constitute a numerous and widely distributed group in world fauna. They inhabit seas, fresh waters, and soil. Many are parasites. Since representatives of the class Nematoda are numerous, their role in the national economy and the life of man is significant. Hence a comprehensive study of nematodes is well warranted.

Nematodes are typical inhabitants of the benthos; their entire development and subsequent life cycle take place in benthic surroundings. Some namatodes, however, lead a pleustonic mode of life. Often nematodes are found in different types of overgrowths.

The present work concerns related groups of free-living marine nematodes, which were earlier combined in the family Leptosomatidae (order Enoplida). The numerous and varied forms included in this family have long prompted taxonomists to split the family Leptosomatidae into several subfamilies, or to transfer some genera to other families of the order. Descriptions of 73 species of nematodes detected to date in the seas of the Soviet Union, and included in 14 genera and 4 families, are presented in the taxonomic sections of this book. 


Nematodes and Their Role in the Meiobenthos 

AKADEMIYA NAUK SSSR

Zoologicheskii Institut

ACADEMY OF SCIENCES, USSR

Institute of Zoology

\section{STUDIES ON MARINE FAUNA}

[Issledovanie Fauny Morei]

VOLUME XV (XXIII)

\section{Nematodes and Their Role \\ in the Meiobenthos}

[Nematody i ikh Rol'v Meiobentose]

T.A. PLATONOVA and V.V. GAL'TSOVA

Nauka Publishers, Leningrad, 1976

Translated from Russian

Published for the Smithsonian Institution Libraries and the National Science Foundation, Washington, D.C.,

by Amerind Publishing Co. Pvt. Ltd., New Delhi 1985 
(C) 1985 Oxonian Press Pvt. Ltd., New Delhi

Translated for the Smithsonian Institution Libraries, pursuant to an agreement with the National Science Foundation, Washington, D.C.,

by Amerind Publishing Co. Pvt. Ltd., 66 Janpath, New Delhi 110001

Translator: Surendra Sharma

General Editor: Dr. V.S. Kothekar

Printed at Printsman Press, Faridabad, India 


\section{Foreword}

Nematodes constitute a numerous and widely distributed group in world fauna. They inhabit seas, fresh waters, and soil. Many are parasites. Since representatives of the class Nematoda are numerous, their role in the national economy and the life of man is significant. Hence a comprehensive study of nematodes is well warranted.

Free-living nematodes have been studied very little compared to parasitic nematodes. Yet a study of the former is imperative considering the place they occupy in the biocenose. Nematodes live in almost every type of biotope in seas-pure and silted sands, silt and clay, shells and shingles. Many species of algae are infested by them; they are also found in hydroids, sponges, bryozoans, and other invertebrates. Nematodes have been found at various depths in seas-from the littoral zone to depths of several thousand meters (Ditlevsen, 1926).

Nematodes are typical inhabitants of the benthos; their entire development and subsequent life cycle take place in benthic surroundings. Some nematodes, however, lead a pleustonic mode of life (Steiner, 1922a). Often nematodes are found in different types of overgrowths. Free-living nematodes of marine biocenoses are reviewed by V.V. Gal'tsova (p. 215) in the present work.

Gal'tsova notes that due to their abundance, nematodes play a significant role in the trophic chain and breakdown of organic substances in the benthic community.

The study of free-living marine nematodes began in the 1860's, covering mainly the species composition, anatomy, and morphology of different species of this group. These works are too numerous to be listed here; relevant references are noted in the text at appropriate places.

The ecology, biology, and zoogeography of free-living marine nematodes have received less attention than their systematics and morphology. Information regarding the geographic distribution of this group is, therefore, negligible.

The ecology of nematodes has only recently attracted the attention of researchers, mainly in the last twenty years.

Filip'ev has made major contributions to the fauna of free-living nematodes in the seas of the Soviet Union. His published works cover 4 nematodes of the Black Sea (1918-1921, 1922a), nematodes of the order 
Enoplida inhabiting the northern seas of the Soviet Union (1927), and two smaller works-one on nematodes of the Sea of Azov (1922c) and the other on nematodes of the Arctic Ocean (1946).

The present work concerns related groups of free-living marine nematodes, which were earlier combined in the family Leptosomatidae (order Enoplida). The numerous and varied forms included in this family have long prompted taxonomists to split the family Leptosomatidae into several subfamilies, or to transfer some genera to other families of the order.

Before discussing a revision of the family Leptosomatidae, it should be noted that two superfamilies must be distinguished in the order Enoplida -Leptosomatoidea and Enoploidea (p. 69). The families Leptosomatidae, Anticomidae, and Triodontolaimidae are included in the superfamily Leptosomatoidea and the other two families-Rhabdodemaniidae and Crenopharyngidae-included in the superfamily Enoploidea.

The inclusion of these five families in the order Enoplida means recognition of a significant number of primitive features within the limits of the order. Keeping this in mind, the present work discusses revision of Leptosomatidae from the old point of view, as well as revision of some lower families of both superfamilies of the order Enoplida.

"Descriptions of 73 species of nematodes detected to date in the seas of the Soviet Union, and included in 14 genera and 4 families, are presented in the taxonomic sections of this book." The material comprised the authors' personal collections from the Black, Barents, and Okhotsk seas, and the Sea of Japan; collections preserved in the Institute of Zoology, Academy of Sciences of the USSR; and preparations of Filip'ev containing not only type specimens, but samples of other species described by him. More recent material includes specimens from the Barents Sea collected by E.F. Gur'yanova, P.B. Ushakov, and O.G. Kusakin, and specimens from the Kara, Laptev, Bering, and Chukchi seas collected by P.B. Ushakov and G.P. Gorbunova. Material from Sakhalin and Kuril islands was also examined, which had been collected during the 1947 to 1948 Kuril-Sakhalin expedition organized by the Institute of Zoology, Academy of Sciences of the USSR. Lastly, M.N. Kiselova, a worker in the Institute of Biology of the Southern seas, kindly loaned us his collection of nematodes from that region.

We are very grateful to all the persons mentioned above whose material served as a basis for the present work.

We are further grateful to Yu.V. Mamkaev and Ya.I. Starobogatov for their friendly criticism during the writing of this work, and indebted to A.A. Strel'kov who edited the manuscript. 


\section{Contents}

FOREWORD

LOWER ENOPLIDA OF THE SEAS OF THE SOVIET UNION-T.A. Platonova

List of Species of Lower Enoplida of the Soviet Union Introduction

Anatomy and Morphology

Phylogenetic Relations and Taxonomic Basis

Ecology

.. $\mathrm{V}$

Geographic Distribution

Collection and Processing of Nematodes

Systematics

... 1

... 3

... 7

... 7

.. 39

... 55

... 62

... 68

... 69

References

... 203

FREE-LIVING MARINE NEMATODES AS A COMPONENT OF THE MEIOBENTHOS OF CHUPA INLET OF THE WHITE SEA-V.V. Gal'tsova

.. 215

Introduction

... 217

Physical and Geographic Characters of the Region under Study

Terminology, Material, and Methodology

. . 220

. . 222

Quantitative Characters of the Meiobenthos of Kruglo'e Bay

.. 232

. . 255

... 259

Taxonomic Review of Species

Quantitative Distribution of Leading Species of

Nematodes in the Littoral Zone of Kruglo'e Bay

. . 298

Influence of Important Factors on Living Conditions and Population Dynamics of Nematodes

. . 323

Conclusions

. . 350

References

.. 354 



\section{Lower Enoplida of the Seas of the Soviet Union}





\section{List of Species of Lower Enoplida of the Soviet Union}

\section{Class NEMATODA}

Subclass ADENOPHOREA

\section{Order ENOPLIDA}

\section{Superfamily LEPTOSOMATOIDEA}

\section{Family LEPTOSOMATIDAE}

1. Subfamily Leptosomatinae

1. Genus Leptosomatum Bastian, 1865

1. L. arcticum Filipjev, $1916 \ldots \ldots \ldots \ldots \ldots \ldots \ldots \ldots \ldots \ldots$

2. L. grebnickii Filipjev, $1916 \ldots \ldots \ldots \ldots \ldots \ldots \ldots \ldots . \ldots 77$

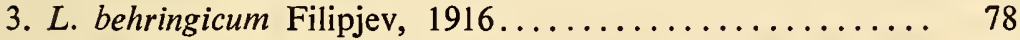

4. L. bacillatum (Eberth, 1863)................... 79

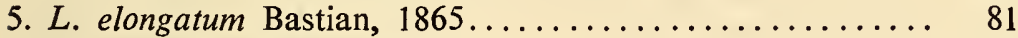

6. L. punctatum (Eberth, 1863).................. 82

7. L. tetrophtalmum Saveljev, $1912 \ldots \ldots \ldots \ldots \ldots \ldots \ldots . \ldots . \ldots$

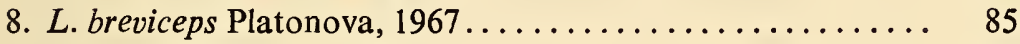

9. L. gracile Bastian, $1865 \ldots \ldots \ldots \ldots \ldots \ldots \ldots \ldots \ldots \ldots \ldots$

2. Genus Leptosomatides Filipjev, 1918

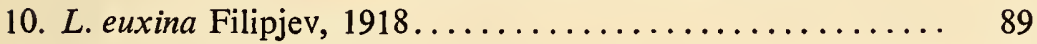

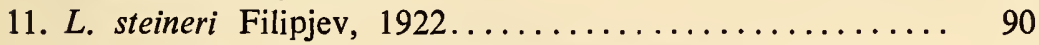

12. L. inocellatus Platonova, $1967 \ldots \ldots \ldots \ldots \ldots \ldots \ldots . \ldots 2$

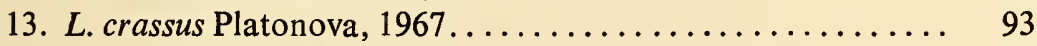

14. L. acutipapillosus sp. nov.................... 95

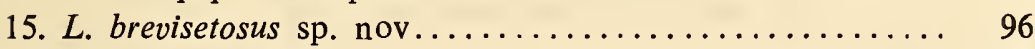

16. L. marinae sp. nov........................ 98 
3. Genus Leptosomella Filipjev, 1927

17. L. acrocerca Filipjev, $1927 . \ldots \ldots \ldots \ldots \ldots \ldots \ldots \ldots . \ldots 0$

2. Subfamily SYNONCHINAE

4. Genus Synonchus Cobb, 1893

18. S. murmanicus Filipjev, $1927 \ldots \ldots \ldots \ldots \ldots \ldots \ldots \ldots . \ldots 3$

5. Genus Anivanema gen. nov.

19. A. magna sp. nov.......................... 105

3. Subfamily Thoracostomatinae

6. Genus Deontostoma Filipjev, 1916

20. D. papillatum (Linstow, 1903)................. 109

21. D. arcticum (Saveljev, 1912)................... 110

22. D. lobatum (Steiner, 1916).................. 112

7. Genus Pseudocella Filipjev, 1927

23. P. trichodes (Leucart, 1849).................... 116

24. P. elegans (Ditlevsen, 1926)................... 118

25. P. saveljevi (Filipjev, 1927).................. 120

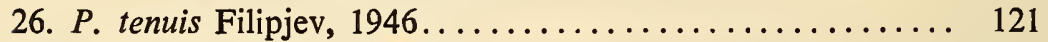

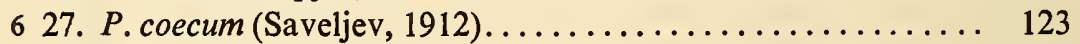

28. $P$. gracilis sp. nov........................ 124

29. P. pesudocellum (Filipjev, 1927) ............... 126

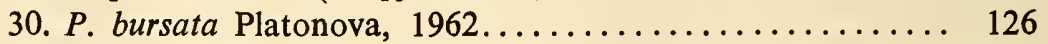

31. P. minor Platonova, $1962 \ldots \ldots \ldots \ldots \ldots \ldots \ldots \ldots \ldots . \ldots \ldots$

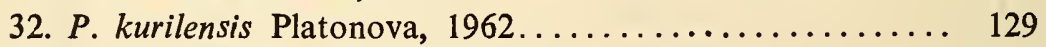

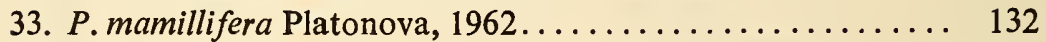

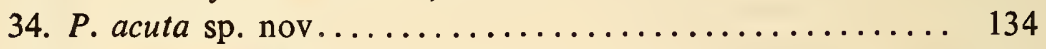

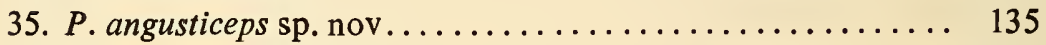

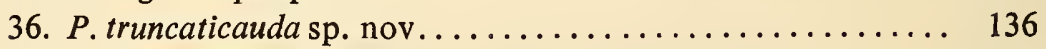

37. $P$. rarisetosa sp. nov...................... 138

38. P. raddae sp. nov......................... 139

\section{Family ANTICOMIDAE}

4. Subfamily Anticominae

8. Genus Odontanticoma gen. nov.

39. $O$. dentifer sp. nov...................... 143

40. O. murmanica (Filipjev, 1927)............... 145 
9. Genus Anticoma Bastian, 1865

41. A. eberthi Bastian, $1865 \ldots \ldots \ldots \ldots \ldots \ldots \ldots \ldots \ldots . \ldots . \ldots 149$

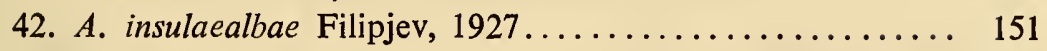

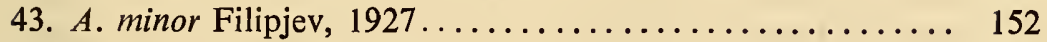

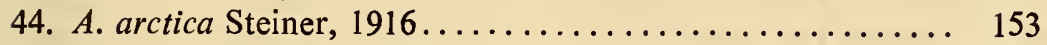

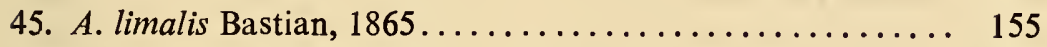

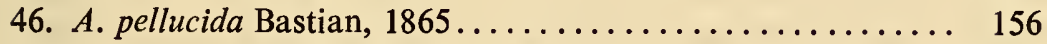

47. A. novozemelica (Filipjev, 1927)............... 158

48. A. brevisetosa Platonova, $1967 \ldots \ldots \ldots \ldots \ldots \ldots \ldots . \ldots . \ldots . \ldots$

49. A. filipjevi Platonova, $1967 \ldots \ldots \ldots \ldots \ldots \ldots \ldots \ldots . \ldots \ldots$

50. A. tenuicaudatoides Gerlach and Riemann, 1974....... 162

51. A. grandis Platonova, $1967 \ldots \ldots \ldots \ldots \ldots \ldots \ldots \ldots . \ldots \ldots$

52. A. behringiana sp. nov...................... 164

53. A. curta sp. nov.......................... 166

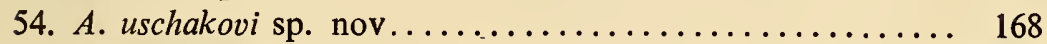

55. A. pacifica sp. nov........................ 169

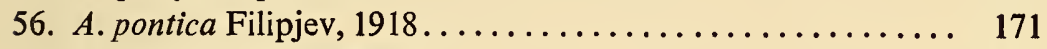

57. A. platonovae Sergeeva, $1972 \ldots \ldots \ldots \ldots \ldots \ldots \ldots \ldots . \ldots \ldots$

5. Subfamily Platycominae

10. Genus Platycomopsis Ditlevsen, 1926

58. P. mesjatzevi (Filipjev, 1927)................... 175

6. Subfamily BARBonEMATINAE

11. Genus Barbonema Filipjev, 1927

59. B. setifera Filipjev, $1927 \ldots \ldots \ldots \ldots \ldots \ldots \ldots \ldots . \ldots . \ldots$

\section{Superfamily ENOPLOIDEA}

3. Family CRENOPHARYNGIDAE fam. nov.

12. Genus Crenopharynx Filipjev, 1934

60. C. marioni (Southern, 1914).................... 182

61. C. gracilis (Linstow, 1900)..................... 184

62. C. armatus sp. nov........................ 186

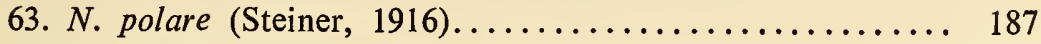

64. $N$. boreale sp. nov...................... 188 


\section{Family RHABDODEMANIIDAE}

14. Genus Rhabdodemania Baylis and Daubney, 1926

65. $R$. minor (Southern, 1914) ................... 192

66. $R$. gracilis (Ditlevsen, 1919).................... 193

67. R. edentula Platonova, $1974 \ldots \ldots \ldots \ldots \ldots \ldots \ldots \ldots \ldots . \ldots \ldots$

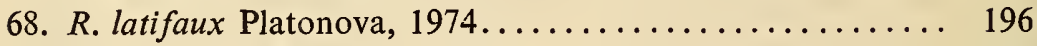

69. $R$. hexonchia Platonova, $1974 \ldots \ldots \ldots \ldots \ldots \ldots \ldots \ldots . \ldots \ldots$

70. $R$. pontica Platonova, $1965 \ldots \ldots \ldots \ldots \ldots \ldots \ldots \ldots . \ldots \ldots$

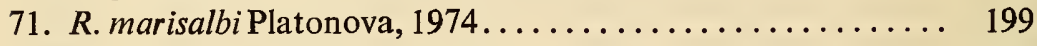

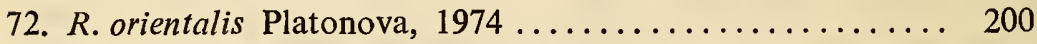

73. R. angustissima Platonova, $1974 \ldots \ldots \ldots \ldots \ldots \ldots \ldots . . \ldots 1$ 


\section{Introduction}

\section{ANATOMY AND MORPHOLOGY}

8 Size and shape of body. As a group free-living marine Enoplida are large-sized nematodes. Of the families investigated, representatives of Leptosomatidae proved the longest with a length of 30 to $50 \mathrm{~mm}$ (10 to $20 \mathrm{~mm}$ on the average), while nematodes of Anticomidae and Rhabdodemaniidae are the shortest, not exceeding 7.0 to $8.0 \mathrm{~mm}(3.0$ to $4.0 \mathrm{~mm}$ on the average). In family Crenopharyngidae forms somewhat longer than those in family Anticomidae predominate, ranging from 5.0 to 6.0 $\mathrm{mm}$ in length.

Nematodes are distinguished from many other organisms in that no clear-cut demarcation occurs between the head and the body. The following sections can be delineated in the body: 1) anterior trophic-sensory section, including oral organs, entire esophagus with chemo- and tangoreceptors, and the nerve ring, which is the main part of the nervous system; 2) middle trophic-genital section, with midgut and gonads; and 3) caudal section with caudal glands for attachment and such sensory organs as setae and papillae. A.A. Paramanov (1962) has observed that promorphologically two types of symmetries are evident in the trophic-sensory section of the body-bilateral symmetry as the base with radial symmetry superimposed. Organs situated in the trophic-genital section promorphologically correspond to bilateral symmetry in disposition. In the caudal section radial symmetry of the organs is observed, which should be considered a derivative of the bilateral symmetry. Thus radial structures are typical of the most mobile and active body parts, i.e., trophic-sensory and caudal sections, which serve as the central part of the sensory apparatus.

At first glance it would seem that the shape of the body in all nematodes is rather uniform. However, a closer scrutiny reveals that shape varies from filiform to pyriform. Variations encountered in free-living and plant nematodes are discussed here. It has been observed that in representatives of lower Enoplida a thin cylindrical and fusiform shape is much more common. A fusiform body is characteristic of nematodes of family Anticomidae; their body considerably tapers at both ends, narrowing in the region of the trophic-sensory and caudal sections. The tail in 
anticomids is long and consists of two parts-base widely conical and rest extremely narrow and cylindrical.

In Crenopharyngidae the body shape is similar to that in Anticomidae but longer and tapering in the trophic-sensory section is not so abrupt. In representatives of family Leptosomatidae the body is slender, cylindrical, and tapers rather smoothly in the trophic-sensory part; the tail is 9 usually short and bluntly rounded. In Rhabdodemaniidae the trophicsensory end of the body narrows quite smoothly near the cephalic end; the tail is rather long, wide, and pointed at the tip.

As suggested by de Man the shape of the nematode body can be characterized by indices expressing ratios of its individual parts. In addition to these indices, measurements have also been given in the form of a formula as suggested by Cobb and modified by Filip'ev (1916).

Cuticle. Represented by a thick membrane covering the nematode body externally and also extending inside the oral aperture, esophagus, hind gut, vagina, and cervical pore. In all probability the cuticle of freeliving nematodes plays a dual role-it protects their body from damage and serves as an external skeleton. It plays a particularly important role for nematodes inhabiting sea-breaker zones in which sharp particles of the bottom are moved about. The firmness of the cuticle in different groups of nematodes is ensured in various ways. In nematodes of the orders Chromadoridae and Desmoscolecidae the cuticle is annulated; it is also reinforced with different sclerotized structures such as spherical bodies, bands, denticles, etc., acquiring a great complexity. The cuticle of lower enoplids is relatively simple. In most cases it is absolutely smooth and very thick. In species of Leptosomatum and Leptosomatides extremely fine fasicles of criss-crossed fibers underlie the cuticle and play a supporting role, imparting great strength to the membrane. These fibers usually occur only in the anterior part of the nematode body.

On the surface of the cuticle longitudinal and lateral structures, termed "lateral fields," extend along both sides of the body. These lateral cuticular fields generally have their own pattern, which is distinct from the pattern of the cuticle. Along these fields small ridges occur, divided by longitudinal lines. The lateral fields lie against the longitudinal thickening of the hypoderm. Paramonov (1962) suggests that since the lateral field is situated between two masses of muscles (laterodorsal and lateroventral), it may be compared to a lateral cuticular crest, which is formed under the bilateral mechanical influence of these muscular masses. From this idea Paramonov concludes that the genesis of the lateral fields is associated with the locomotor function of the muscles. Thus the supporting role of the cuticle is revealed in the process of locomotion. This phenomenon (when external skeletal structures play a supporting role for musculature) is quite widespread in the animal world and hence nema- 
todes are no exception in this respect.

Histologically the cuticle of enoplids is represented by a noncellular membrane secreted by the hypoderm. It is multilayered. As shown by Timm (1953), the cuticle in Leptosomatum acephalatum consists of six layers: an external homogeneous cortical layer, thin external layer with oblique fibers, thicker layer with fibers running at an angle to the previous layer, two layers similar to each other in structure which stain differently, and the innermost layer or basement membrane consisting of longitudinal fibers.

Studies of Thoracostoma coronatum and Deontostoma magnificum revealed that their cuticle is similar in structure to that of Leptosomatum acephalatum; hence Timm assumed that in all nematodes of family Leptosomatidae the cuticle is similar in structure. The cuticle lining the inner parts of the body consists of a different number of layers, that lining the rectum consists of three layers, while that lining the vulva consists of six and is sclerotized.

The relative thickness of the cuticle is directly related to its structure. The cuticle of enoplids, devoid of supportive structures, is significantly thicker than the annulated and sclerotized cuticle of chromadorids and 10 desmoscolecids, since its strength depends only on its thickness. For example, in Cyatholaimus and Chromadora (order Chromadorida) the thickness of the cuticle constitutes only $1 / 40$ to $1 / 50$ of the body width, while in enoplids the cuticle is much thicker.

Understandably in smaller forms, 2.0 to $5.0 \mathrm{~mm}$ long, the cuticle is thinner (2.0 to $5.0 \mu \mathrm{m}$ ) than in larger forms, up to 20 to $30 \mathrm{~mm}$ long, in which it may achieve a thickness of 17 to $20 \mu \mathrm{m}$. For this reason the absolute thickness of the cuticle should not be taken into consideration and only its relative thickness in comparison to size and thickness of the body examined. ${ }^{1}$ Species of Thoracostoma, Deontosoma, and Pseudocella have a cuticle about $1 / 14$ to $1 / 20$ of the body width; Leptosomatum and Leptosomatides-1/15 to 1/18; Synonchus and Cylicolaimus-1/12 to 1/17; and Anticoma-1/14 to $1 / 20$. The thickness of the cuticle reduces only rarely to $1 / 25$ to $1 / 30$ of the body width (as in the case of Anticoma behringiana, Anticoma elegans and Anticoma filipjevi). In Rhabdodemaniidae the thickness of the cuticle constitutes about $1 / 12$ to $1 / 16$ of the body width.

Setae and papillae. These play the role of sensory organs. As outgrowths of the cuticle, they are thought to be derived from it. In lower enoplids a great variety in shape, size, and location is seen. Papillae are firmly attached to the body and immovable. Six in number, they are

IThickness of the cuticle and the corresponding width of the body were measured by me in the region of the nerve ring. 
arranged in a circle around the oral aperture immediately behind the lips. In some free-living marine nematodes, labial papillae resemble setae (Filip'ev, 1921). In my material, Leptosomatides acutipapillosus possessed such setaceous papillae. In larger leptosomatids (Thoracostoma, Deontostoma, Pseudocella) papillae are well developed and distinctly visible. In Anticomidae labial papillae are arranged as in Leptosomatidae but due to their small size barely discernible. Contrary to females, which have only labial papillae, many males possess a system of preanal papillae (see p. 37).

Setae are the same in origin as the papillae but articulate with the body. All the nematodes of the families described by me have a crown of ten cephalic setae located immediately behind the cephalic capsule; eight are situated in pairs submedially and two single ones situated laterally. If interlobular grooves (p. 37) are present, the cephalic setae are located in them. The shape and size of the cephalic setae vary considerably within the limits of a genus.

In addition to cephalic setae, in many free-living nematodes setae also occur in the preneural region (anterior end of the nematode body from the head to the nerve ring). However, among leptosomatids these setae are absent in a number of species. In Leptosomatum kerguelensis they are rudimentary and transformed into papillae; in $L$. clavatum these setae are totally absent. It should be noted that in nematodes of Leptosomatum these setae are generally very small and, probably, tending toward reduction. In species of Thoracostoma, Deontostoma, and Pseudocella setae are invariably present but again generally small in size.

The setaceous armature in species of Synonchinae (family Leptosomatidae) varies notably. Synonchus murmanicus has a few small setae dispersed in the preneural part of the body. Anivanema magna is armed with long and powerful setae situated in regular longitudinal rows. In Eusynonchus hirsutus the entire preneural part is covered with longitudinal rows of fine and long setae.

The preneural setae in Anticoma (family Anticomidae) warrant special attention. Their arrangement in two longitudinal lateral rows, each

11 comprising three to eight setae, seems a characteristic feature of this genus. There are no setae outside these two rows in the preneural region of Anticoma. As shown by Micoletzky (1930) and Wieser (1953b), the number of setae changes with age. Adult Anticoma campbelli (Wieser, 1953c) have four to five setae in each row, while younger forms have only one to two. Hence until the last molt the number of cervical setae in Anticoma cannot be established.

The nature of the cervical setae in Paranticoma, and also in members of the family Anticomidae, is very interesting. These setae merge into a powerful spine inside which lies the duct of the cervical gland. 
In addition to cephalic and cervical setae, males of many nematodes have a group of preanal setae, functionally entering into the composition of the copulatory organs (p. 37).

Lastly, small setae are present at the tip of the tail near the aperture of the caudal glands.

Head. A study of the head of nematodes of the order Enoplida is very important in the systematics of this group. Complex formations in the anterior end of the body, partly from the external cover (cuticle) and partly from the anterior end of the digestive system, together constitute a single structure in a morphological and functional sense. The degree of development and individual details of structure of these formations are considered the most important taxonomic features of the order Enoplida.

Works by Wieser (1953a) and Inglis (1964) in particular present a comparative anatomical analysis of the anterior body end of enoplids. Due to the fact that some of the propositions by Wieser were subjected to detailed criticism by Inglis, the scheme of the latter author appears better founded and I have utilized his terminology, translating some terms into Russian. The internal layer of the cuticle is significantly thickened at the place where the anterior end of the esophagus comes close to it; this thickening, resembling a cylinder or truncated cone, is called the cephalic capsule (Figure 1, 8). According to Inglis (1964) it consists of an endoand mesocuticle. The outer covering of the anterior end of the esophagus also has a thickened cuticle. This thickening is labeled the esophageal capsule (Figure 1,9) (according to Wieser, 1954-pharyngeal capsule). The junction of the esophageal and cephalic capsules is accentuated by a thickened wall encircling the body, which is called the cephalic ring (Figure 1,5). Wieser calls this structure the "stomodeal ring". However, the former name appears more appropriate because Inglis showed that nerves innervating the labial sense organs always extend under this ring; for this reason the latter should be associated with the cephalic capsule and not with the esophagus. One more sclerotized structure-the cervical capsule-which is distinguished from the cephalic capsule by striations or punctation, is situated behind the cephalic capsule, often merging with it and extending into it (Figure 1, 10).

In Leptosomatidae and Anticomidae the cephalic capsule extends forward beyond the cephalic ring, a feature not seen in representatives of a number of other families of the order. However, its anterior part is always more weakly developed than the posterior part. Sometimes the anterior and posterior parts are so well demarcated that the cephalic capsule seems to consist of two separate elements. Kreis (1928) observed this phenomenon in species Pseudocella saveljevi (under the name Thoracostoma conicaudatum) and Pseudocella filipjevi and spoke of primary and secondary capsules (primaer-und sekunderkapsel). 
In a number of cases, for example in Thoracostoma, Deontostoma, Pseudocella, and Parabarbonema, the anterior margin of the cephalic capsule forms six protuberances supplied with nerves; these extend toward

12 the labial papillae and thus play the role of supporting structures (Figure $1,11)$. The posterior part of the cephalic capsule may be divided into six lobes-four sublateral, one dorsal, and one ventral (Figure 1, 12). The lobes are separated from each other by interlobular grooves or furrows resembling arches or narrow fissures, each of which generally has a round anteriorly widened portion-the fenestra (Figure 1, 13). The lateral interlobular grooves, in which the amphids are situated, are much wider than the others. The margins of the lobes of the cephalic capsule may be smooth, or uneven, or wavy with more or less deep marginal grooves. The lobes may or may not exhibit openings or loculi of various shapes.

The oral cavity commences with the mouth and communicates with the esophageal cavity in the simplest cases (Figure 1,5). With the development of sclerotized lips and deepening of the oral cavity, the oral opening varies in shape, becoming hexagonal or even circular for example. The oral cavity of Leptosomatidae in the original form is almost nil (for example in Leptosomatum). However, in other Leptosomatidae and also in other families of the order, it may change substantially. In species in which the esophagus reaches almost up to the anterior end of the body, as usually happens in Leptosomatidae and Anticomidae, the oral cavity remains undivided. However, in most families of the order the esophagus does not reach the anterior end; consequently two parts of the oral cavity communicate with each other-the onchial cavity, formed by the widening of the anterior esophagus (Figure 1,7), and the buccal cavity situated in front of the onchial cavity (Figure 1,3). Differences in the nature of the oral armature correspond to this division. The onchial cavity may exhibit falcate or lamellar processes-the onchia (Figure 1,6). The onchia move by the action of the musculature of the esophagus, which undergoes specialization at this place and splits into separate muscular fascicles. All the structures of the buccal cavity are not directly connected with the musculature and are brought into motion only through the displacement of three thickened plates formed from the lining of the onchial cavity. The armature of the buccal cavity may be of two types-small denticles situated individually or in groups (odontia), or as in the case of Enoplida plates of thickened cuticle in the cavity (jaws) (Figure 1,2). The jaws, as shown by Inglis (1964), form through the fusion of the cuticular lining of this cavity with the so-called buccal rods (longitudinal thickenings or ridges formed from the cuticle), and play the role of supporting structures in forms devoid of odontia. Due to the fact that in Leptosomatidae and Anticomidae a distinct division into buccal and onchial cavities does not appear, onchia in representatives of these families may be arranged near 
the oral aperture and never form jaws; the only buccal armature in this case comprises odontia, or plates formed by their fusion. Moreover, odontia may be arranged at the level of the anteriormost onchia. Such an arrangement is in conformity with the circumstance that the esophageal musculature, in the form of anterior specialized muscles, extends far in front and is attached to the bases of the onchia.

In the anterior part of the body of representatives of order Enoplida a number of different cuticular elements are present, such as the cephalic capsule with the cuticle of the body wall covering both sides, cuticular lining of the oral cavity, and the esophageal capsule. These three structures, together with the tissues underlying them, confine externally both dorsally and ventrally a ring-shaped space filled with a liquid and termed the cephalic bladder (Inglis, 1964) (Figure 1, 4). Strictly speaking the cephalic bladder is precisely ring-shaped only in those forms in which the

13 esophageal capsule is situated far away from the anterior end of the body and the oral cavity is narrower than the diameter of the integument around it. Even in such a case, however, it should be borne in mind that the oral cavity is trigonal and the entire ring appears to be represented by three separate parts corresponding to the sections of the esophagus, divided by narrow crosspieces in those places where the corners of the esophageal space come extremely close to the body wall (along the radius of the esophagus). In Leptosomatidae and Anticomidae, however, it often happens that the cephalic bladder is subdivided not into three, but into six parts due to specialized muscles extending toward the onchia and passing along the middle of the esophageal sections, crossing the parts of the cephalic bladder corresponding to each section, and thus dividing it into halves (three sections, each divided into two, for a total of six). The size of the bladder depends on the distance between the anterior body end and the esophagus. In Leptosomatum the esophagus extends almost to the anterior body end and hence there is no cephalic bladder. In Anticoma and genera close to it the cephalic bladder is very poorly developed. In those genera (Parabarbonema, Synonchus, Thoracostoma, and others) in which the esophageal capsule falls short of the anterior end by a significant distance, the cephalic bladder is well developed.

When the oral cavity is significantly developed, for example in Cylicolaimus and genera close to it, the size of the cephalic bladder shrinks due to an increase in the transverse diameter of the space of the oral cavity.

Thus a detailed study of the cephalic end makes it possible to draw some conclusions regarding the taxonomic structure of lower enoplids. In representatives of Leptosomatidae two lines of development can be

14 traced: first, reinforcement of the cephalic and esophageal capsule and development of the cephalic bladder; and second, development of the oral cavity. Anticomidae is characterized by poor development of the cephalic capsule and the oral cavity. 


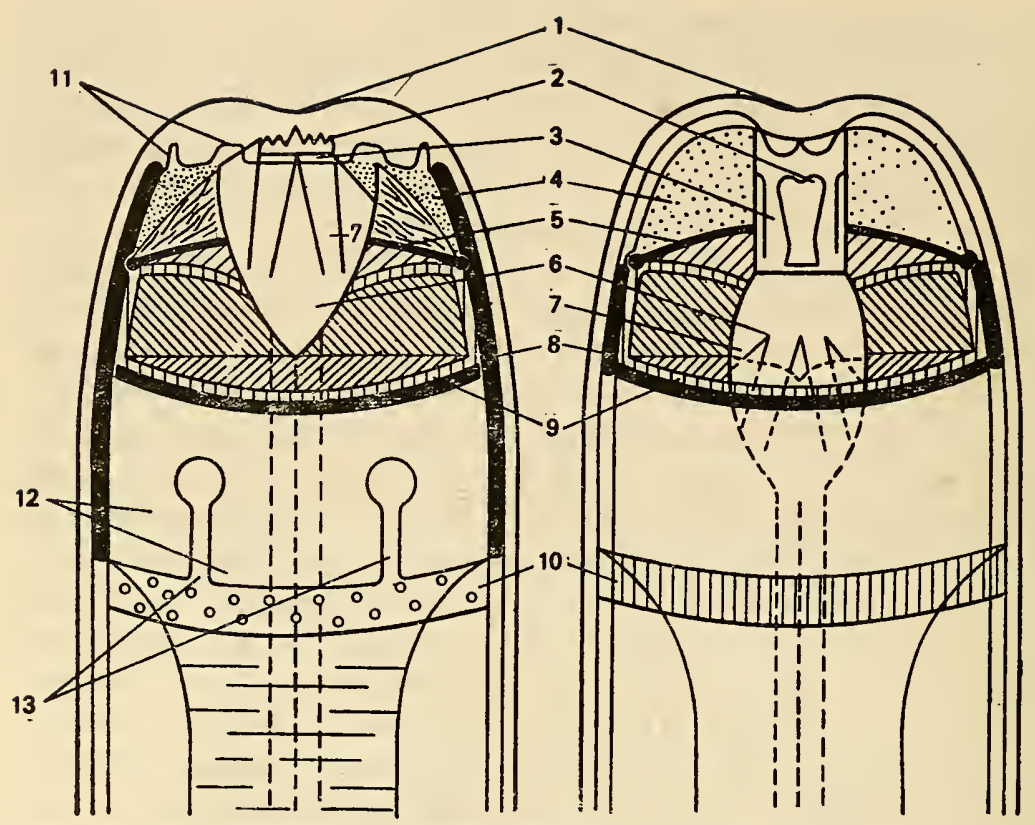

Figure 1. Scheme of head structure of nematodes of superfamilies Leptosomatoidea (left) and Enoploidea (right).

1-oral aperture; 2-odontia (mandibles); 3-buccal cavity; 4-cephalic bladder; 5-cephalic girdle or ring; 6-onchia; 7-onchial cavity; 8-cephalic capsule; 9-esophageal capsule; 10-cervical capsule; 11-anterior protuberances of cephalic capsule; 12 -lobes of cephalic capsule;

13-interlobular grooves.

Hypoderm. The compact layer of the hypoderm, replacing the epithelium, underlies the cuticle which covers the body. The hypoderm has a distinctly cellular structure in free-living marine and a few fresh-water nematodes; it is syncytial in parasitic and most plant nematodes. The nuclei of the cells of the hypoderm disintegrate into a number of smaller nuclei (Martini, 1909). Localized thickenings of the hypoderm press into the pseudocoel and form four longitudinal cords-usually two lateral, one ventral, and one dorsal.

In nematodes of the order Enoplida there are eight hypodermal cords. In addition to the four mentioned above, four submedial cords are present. The cells of these cords are usually more stretched in width than in length. The hypoderm situated between the cords contains no nuclei. In transverse section the number of cells forming these cords differs in different leptosomatids. Thus three cells occur in Synonchus strasseni (Türk, 1903), five to six cells in Thoracostoma setosum (de Man, 1904), and four 
to five cells in Leptosomatum acephalatum (Timm, 1953). According to the observations of Filip'ev (1916) the greater number of cells in the hypoderm is related to their increase in other organs also. According to Timm (1953) the dorsal and ventral cords in leptosomatids commence as a double row of large cells at the level of the amphids, while the lateral ones commence as a single row of large cells immediately behind the amphids, but beyond the eyes change into a layer consisting of a large number of cells (there are three rows of cells in the case of Leptosomatum acephalatum). Dorsal and ventral cords are wide anterior to the nerve ring but narrow behind it. Cells in the hypodermal cords are usually arranged in a single row between the eyes and the nerve ring. Beyond the nerve ring these cells reduce greatly in size (especially in the dorsal cord) and hence it is difficult to detect them. Lateral cords widen toward the base of the esophagus, become significantly thickened, and then extend along the entire body. These cords flatten, especially in sexually mature females, in the gonadal region. Throughout their length from the esophagus to the anus the lateral cords look like a thin, single, stretched cell, while the ventral cord alternately appears single-celled and double-celled. In the postanal region the ventral cord, wide in transverse section, consists of two cells. The dorsal cord disappears altogether but the lateral cords extend right up to the caudal glands and terminate at some distance from their openings.

The cells of different cords vary in form as well as in function (Filip'ev, 1921). Those of the dorsal and ventral cords accumulate fat and hence their shape is usually round, while those of the lateral cords may be rectangular or highly stretched.

Musculature. The nonspecialized musculature of the nematode is represented by a single layer of elongated, fusiform muscle cells underlying the hypoderm. It is divided into longitudinal muscular fields by the hypodermal cords. According to Schneider (1866) all nematodes can be divided into two groups on the basis of the number of cells in the muscular fields viz., "polymyarian" (large number of cellular rows in each muscular field with varying number of cells) and "meromyarian" (reduced and fixed small number of cells in each field). All representatives of order Enoplida belong to the first group. According to Timm (1953) in Leptosomatum acephalatum there are six to seven rows of cells in each muscular field in the anterior esophageal region, but commencing from the nerve ring and right up to the terminus the number of cell rows increases to ten to twelve.

15 As already mentioned, the somatic muscle cells of nematodes are fusiform. That part of the cell pressing (bulging) into the pseudocoel consists of only sarcoplasm with a nucleus and without myofibrillae. Myofibrillae are situated in the remaining part either in the shape of a 
longitudinal groove (coelomyarian type) or in the shape of a flat field (platymyarian type). The specialized musculature of nematodes of the family Leptosomatidae was studied in detail by Timm (1953), but mainly in Leptosomatum acephalatum.

The valve of the caudal glands is stretched backward by a thin muscle which passes through the middle of these glands. In nematodes of Leptosomatum and Thoracostoma the retractor of the caudal glands has nuclei in its dorsal wall.

Esophageal and intestinal musculature are represented by short muscles extending from the body wall to the esophagus and intestine. These muscles are barely separated from each other and lie somewhat above or below the cardia. They support the mesenteric tissue, which at the level of the cardia is rather profuse, and exhibit no fixed pattern in disposition.

De Man (1886) described four median muscles in Enoplus communis of the family Enoplidae, proceeding anteriorly from the base of the esophagus, merging with four sublateral muscles, and binding them with the body near the submedian line. Each muscle consists of a single cell. Türk (1903) described similar musculature for Synonchus and Timm (1953) for Leptosomatum.

The structure of the specialized musculature of the head of enoplids was studied in detail by Inglis (1964); hence in analyzing these structures I have used his information extensively.

The musculature of the head is actually the end results of the transformation of the anterior end of the esophagus, which developed a series of separate muscles corresponding to the cephalic capsule. All these muscles are attached to the onchial region; the armature of the buccal cavity is completely devoid of musculature. These muscles originate from the external surface of the esophagus. The muscles of the head are represented, so to speak, by two rings situated transversely to the body axis, one of which lies inwardly and somewhat behind the other. Let us tentatively label the first ring posterior and the second anterior. Each ring consists of a few muscles. Moreover, their definite combination repeats itself in each esophageal section. In each section of the esophagus there are three muscles in the anterior ring and four in the posterior one, which are so arranged that the ends of the muscles of the anterior ring pass through the initial parts of the muscles of the posterior ring. In the anterior ring there is a medial unpaired muscle, narrow and thin at the

16 posterior margin but widening and thickening toward the anterior end (Figure 2,1 ). It is bordered by a pair of muscles which are always significantly smaller and thinner (Figure 2,2). In the posterior ring paired medial muscles are also found but they are separated from each other by the initial part of the medial muscle of the anterior ring (Figure 2, 3). Paired lateral muscles (Figure 2, 4) also border the medial muscles of the 
posterior ring. The muscles of the anterior ring extend forward and inward up to their attachment with the onchial plate. The medial paired muscles of the posterior ring are also attached to the onchial plate but situated somewhat lower than the muscles of the anterior ring. The lateral muscles of the posterior ring are attached to the thin cuticle fringing the onchial plate.

The nonspecialized musculature of the esophagus in which the muscles are situated radially follows the specialized muscles of the head. This changeover from the two rings of specialized muscles to the radial musculature of the esophagus takes place abruptly with no distinct zone of transition. It should be noted that the opening through which the nerve passes to the labial sensory organs occurs between the medial and lateral muscles of the posterior ring.

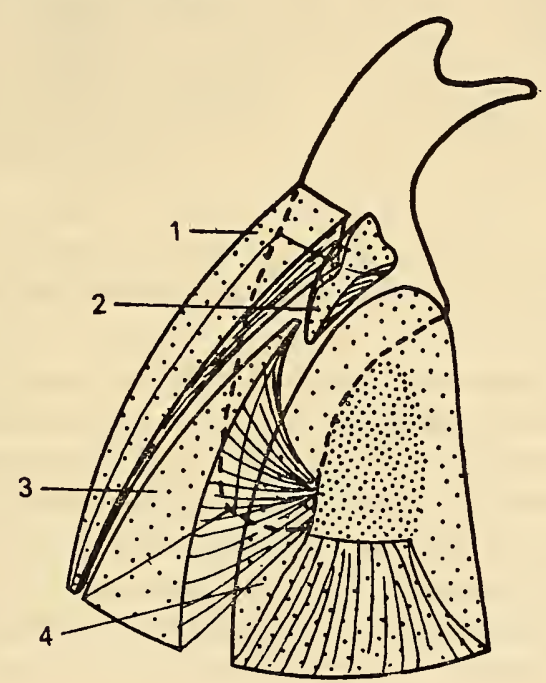

Figure 2. Cephalic musculature of Enoplidae (only one section shown) (from Inglis, 1964).

1-medial unpaired muscle of anterior ring; 2-paired muscle of anterior ring; 3-medial paired muscle of posterior ring; 4-paired lateral muscle of posterior ring.

A similar arrangement of specialized muscles is mainly characteristic of representatives of family Enoplidae, which were studied by Inglis. I am inclined to assume that a similar scheme of muscular arrangement is also characteristic of lower representatives of the order. The beautiful diagrams of de Man (1904) substantiate this assumption, where in transverse sections taken in the cephalic region of Deontostoma antarcticum and Thoracostoma setosum all the muscles described by Inglis (Figure 3) 
can be easily traced. It should be noted that in Anticomidae and the majority of Leptosomatidae the cephalic muscles pass forward through the cephalic bladder, dividing the latter into six small pockets or obliterating it altogether.

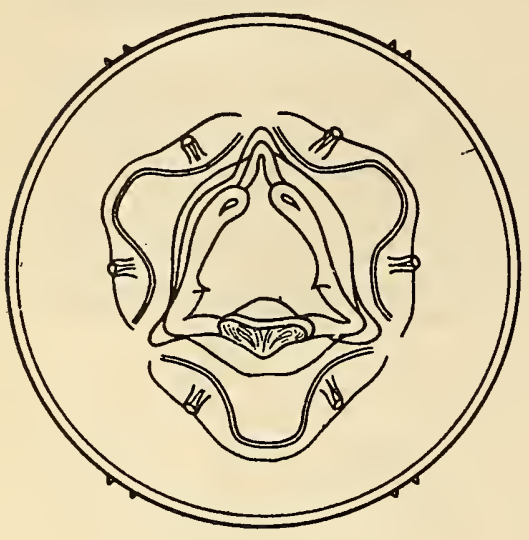

A

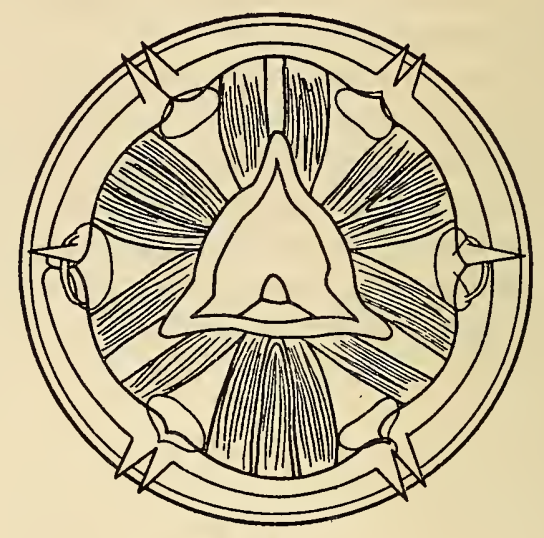

B

Figure 3. Structure of apical end of head of Thoracostoma (section at level of labial papillae-A; cephalic setae-B) (from de Man, 1904).

Specialized musculature of female. A V-shaped muscle extends from the subdorsal body wall to the dorsal part of the rectum, which originates from the posterior part of the rectum. This muscle bears two thin lateral connectives which approach the middle part of the caudal glands and are

17 bound to the dorsal body wall by a third connective. Large nuclei lie in the central part of these connectives. Two small muscles, encircling the lower part of the caudal gland and extending toward the anterior part of the rectum, originate from the subdorsal body wall. These muscles raise the dorsal body wall during defecation.

Ten to twelve pairs of muscles, extending from the ventrolateral body wall toward the vagina and vulva, originate from the anterior and posterior parts of the vulva. The lateralmost pair bind the uterus and the vagina, while the centralmost pair bind the lips of the vulva. There is one nucleus in each of these muscles. All the nuclei are situated at one level, i.e., near the place of origin of the vulval muscles from the body wall. The number of pairs of these muscles probably varies in different species. Thus in Leptosomatum acephalatum there are 10 to 12 such muscles, while in Thoracostoma coronatum there are 6 to 8.

Five to six pairs of muscles, extending from the dorsolateral wall to the dorsal side of the vagina, are situated in the region of the vulva. They widen the vagina at the time eggs pass into it from the uterus. Two thick 
muscles, each with one large nucleus, lie anterior and posterior to the vagina. These close the vulval opening. Two muscle cells lie dorsal to the vulva. Probably, they also assist in closing the vulval opening. In Thoracostomum coronatum there are two very large muscles on each side of the vagina which keep it closed.

The sphincter of the uterus is a highly reduced muscle situated near the uterine neck just ahead of the vagina. The muscular layer which on widening forms the sphincter extends further in the shape of a thin muscular investment around the vagina.

Specialized musculature of male. The V-shaped anal muscle of the male extends from the subdorsal wall of the body toward the posterior anal lip. The nucleus of this muscle lies near the body wall.

The copulatory musculature of the male is represented by numerous, thin, paired muscles (about 40 pairs), extending from the ventral side of the lateral walls to the subventral side of the body and terminating in the anterior part of the anus. Two to three pairs of short muscles extend from the ventrolateral wall of the body to the anterior lip of the anus; their function is to lift the anal lip. Türk (1903) described the copulatory muscles situated behind the anus in the case of Synonchus. Timm (1953) could not find similar muscles in Leptosomatum acephalatum.

The retractor musculature of the spicules is represented by paired muscles originating dorsal to the body wall, extending toward the lateral wall, and reaching the capituli of the spicules.

The protractor musculature of the spicules also consists of paired muscles. They form a longitudinal layer on the dorsal surface of the spicular pouch. Their nuclei are elongated.

The retractor musculature of the gubernaculum likewise consists of paired muscles which extend from the dorsal wall of the body and pass by the proximal end of the gubernaculum. In males the intestino-somatic musculature commences immediately after the esophagus, and consists of a thick muscular projection which surrounds the intestine but does not adhere to it. This projection is actually a series of irregular blocks of muscular tissues, which are attached to the somatic muscular layer or the body wall. Nuclei are usually found in the sarcoplasm of the muscular layer but may also be situated between the muscular projection (case) and the somatic layer. The testes and vas deferens may also be partially surrounded by the muscular case in the posterior part of the body. The muscular case then consolidates in large muscular blocks which are attached to the testes beyond their distal end.

Glands. These are always unicellular. In leptosomatids glands of the lateral fields look like large cells with a dark granular content. They are connected to the body wall by slender ducts. Near the outlet of these 18 ducts a seta is often present. Bastian (1865) was the first to discover these 
glands. Subsequently they were described by de Man (1893) in Thoracostoma coronatum; by Marion (1870) in Thoracostoma zolae; by Jägerskiöld (1901) in Cylicolaimus magnus and Jaegerskioeldia acuticaudata; by Türk (1903) in Synonchus, Tuerkiana, and Paratuerkiana; by de Man (1904) in Thoracostoma setosum and Deontostoma antarcticum; and by Steiner (1916) in Leptosomatides steineri.

Marion thought these glands served an adhesive function, secreting a substance whereby the nematode attaches itself to the substratum. Jägerskiöld assigned an excretory function to these glands. Zur Strassen (1904) considered them supporting cells of the nerve endings. Filip'ev (1921) deemed their nature glandular; surprisingly he reports these glands mostly for leptosomatids, whereas earlier authors mention them only for certain species in other groups of nematodes.

The cervical gland or renette is represented by a large unicellular structure in the anterior part of the nematode body (Figure 4). This gland is filled with a white secretion and stains darkly with hematoxylin. Two types of cervical glands are distinguishable: pyriform, with thick body, and short and slender duct; and tubular, with long stretched body, and long, thick duct. The renette body commences usually in the anterior part of the intestine or slightly above it, i.e., at the base of the esophagus. Usually this gland lies along the ventral line but sometimes it bends toward the dorsal side. In Anticoma (family Anticomidae) this gland is much larger and hence readily detected. It usually commences from the

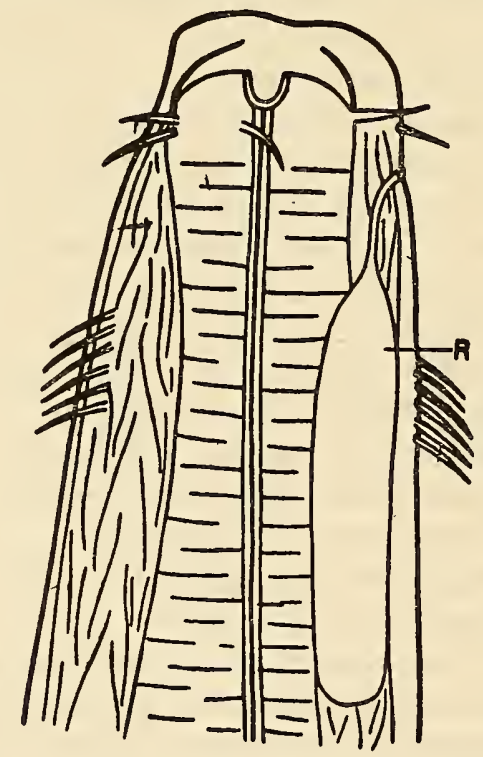

Figure 4. Anterior end of Anticoma (R-renette). 
base of the esophagus and may open either in the pre- or postneural region. The position of the opening serves as a diagnostic character for species identification (pp. 148-174). Sometimes the glandular pore is highly displaced toward the anterior end and may open at the level of the amphids.

In species of Leptosomatidae the presence of the renette has proved controversial. According to Jägerskiöld (1901), Türk (1903), Steiner (1916), and Timm (1953) even the most thorough examination did not reveal the presence of this gland in Synonchus, Tuerkiana, Paratuerkiana, Cylicolaimus, Thoracostoma, nor in Leptosomatum acephalatum and Leptosomatides steineri. Filip'ev (1916) described the cervical pore in Deontostoma papillatum and de Man (1893) in Thoracostoma coronatum; the cervical gland per se they declared absent. Filip'ev (1921) expressed the possibility that the gland disappears during the cycle of development of the nematode.

The nature of the function of this gland was resolved after a long debate. Golovin (1902), Rauther (1907, 1909), and Stefansky (1922) investigated this problem experimentally by staining nematodes with vital stains. They arrived at the same conclusion-that the renette serves as an organ of excretion and osmoregulation. Stefansky (1922) and Paramonov (1962) positively attribute these functions to the renette but do not consider it the only organ of excretion. The excretory function is carried out by the renette, caudal glands, esophagus, and intestine.

In nematodes of the subclass Adenophorea the renette is compact and massive; a dendroid and very complex structure is characteristic of the renette in all members of the subclass Secernentea.

As indicated by Paramonov (1962), with a reduction in the protonephridial system in the ancestors of nematodes, a need for its replacement arose. In the earlier nematode stages of phylogenesis the excretory system was probably very bulky and consisted of a number of dermal glands. Afterwards, during the process of oligomerization three caudal and one cervical gland formed.

It seems to me that the absence of a renette in species of Leptosomatidae points to the fact that the process of its formation is still in the initial stages. In those forms in which this gland is absent its function is probably carried out by the glands of the lateral fields, caudal glands, the esophagus, and the intestine. The presence of glands in the lateral fields in leptosomatids (Filip'ev, 1921) also seems to support this idea. The fact that the renette also happens to be an organ of osmoregulation is substantiated by its absence in typical marine leptosomatids in which there is little need for such. Representatives of Anticomidae, largely found in pure fresh-water bodies, require a special organ of osmoregulation and the renette is quite well developed in anticomids. Its presence also bespeaks 
the higher organization of Anticomidae.

There are three caudal glands, one on the dorsal side and two on the ventral.

Leidig (1854), followed by Eberth (1863), described these glands in the caudal region of nematodes. These scientists introduced the term "caudal gland". In structure these glands are reminiscent of the cervical gland and stain deeply with hematoxylin (Jägerskiöld, 1901). Like the cervical, two types of caudal glands are also distinguishable-tubular 20 and pyriform. In lower enoplids both types are found (Figure 5), while various types may be seen in closely related forms. Hence this character lacks taxonomic significance. As can be seen from Figure 5, between the two aforementioned types of glands intermediate forms occur. All three caudal glands open at the extremity of the tail through a common caudal pore situated, most often, terminally. Occasionally this pore is somewhat displaced toward the ventral side. The caudal cone, sometimes longitudi-
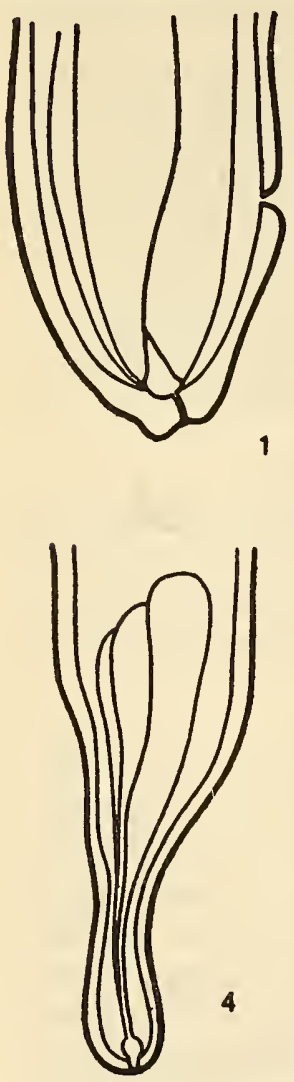

Figure 5. Shapes of caudal glands in lower Enoplida.

1-Leptosomatum; 2 to 4-Synonchus; 5-Rhabdodemania; 6-Leptosomatides. 
nally striated (Figure 5, 1 and 2), usually lies in this pore. Cuticular folds usually develop around the caudal cone and provide support. The substance secreted by the caudal glands becomes firm on contact with water and hence these glands have been labeled "adhesive glands".

Body cavity. Primary form of body cavity-schizocoel devoid of epithelial lining and formed as a result of dispersion and disintegration of mesodermal cells. In more primitive nematodes it is usually difficult to observe the schizocoel as it is filled with nerve, muscle, and phagocytic cells. This led to the denial of its existence by Jägerskiöld (1901) in Cylicolaimus and Jaegerskioeldia, by Türk (1903) in leptosomatids of the Mediterranean Sea, and by Timm (1953) in species of Leptosomatum, since none of these authors could detect a schizocoel in their material. De Man (1904) discovered only narrow slits in Thoracostoma setosum.

In intestinal and saprozoic nematodes living in an anisotonic medium the body cavity is represented by larger spaces containing liquid. In the changeover of nematodes to tissue parasitism in an isotonic medium the body cavity disappears and is filled with inflated cells which are parenchymatous in character (Filip'ev, 1937).

Phagocytic cells are located inside the body cavity. They are spherical and filled with a lustrous granular content. They have been studied in great detail by Golovin (1901). In nematodes placed in vital stains these cells stain quite rapidly. Other cells lose their stain on storage while phagocytic cells retain their stain for a long period; furthermore the stain sometimes crystallizes in their cytoplasm. These cell have an acidic reaction. Golovin directly proved their phagocytic nature; in transected worms they ingested India ink directly from sea water. Shimkevich (1899) was the first to record their phagocytic nature.

Phagocytic cells are scattered in large number throughout the length of the nematode body. According to Filip'ev (1921), the number ranges from 100 to 220 in nematodes of the order Enoplida. In some nematodes their disposition is irregular, while in others they are arranged mainly along the ventral line. Such a type of arrangement is characteristic of species of Leptosomatum and Leptosomatides.

These cells are more systematically disposed in more highly organized families of free-living nematodes such as Cyatholaimidae, Chromadoridae, and Axonolaimidae but their number markedly reduced. In Axonolaimus setosus, for example, there are only two large phagocytic cells (Filip'ev, 1918, 1921). They are comparable to the large phagocytic cells of parasitic nematodes.

Lipid cells are also present in the body cavity of nematodes. True, they have not been studied much and information about them is very scanty. Türk discovered such cells in Synonchus strasseni. They are dendritic in shape and situated around the intestine. Rauther (1907) observed 
them in Cylicolaimus and Thoracostoma. Shimkevich (1899) and Golovin (1901) considered them homologues of phagocytic cells.

The observations of Timm (1953) in his more recent works should be noted. He has described similar cells in Leptosomatum acephalatum. In the female a paired row of such cells lies freely in the body cavity along the uterine region. A large number are disposed around the oviduct. The nucleus of these cells is located in the center of the cellular body. Some

21 of these cells are bifurcated (bifid) at one end. They are supported by the mesenteric connectives which link them with the body wall.

In Enoplus these cells branch and form a network on the intestine. They do not branch in Deontostoma magnificum.

Nervous system. The nervous system of nematodes parasitic in animals has been studied in detail, that of phytonematodes less so, and that of free-living nematodes almost not at all. Details of the nervous system of Paroncholaimus zernovi (family Oncholaimidae, order Enoplida) have been given by Filip'ev $(1912,1921)$, providing a basis for assuming that within the limits of the order Enoplida the general structural plan of the nervous system is similar. The scheme proposed by Filip'ev has been followed here. The nervous system of nematodes represents an extremely low level of organization. It is usually located in the hypoderm and only motor nerves and some part of the central nervous system distinguishable. The nerve ring or so-called circumesophageal ring constitutes its core and encircles the esophagus in its anterior half. In various species of Enoplida this ring occupies a different position in this part of the esophagus. Fibers and a small number of nerve cells enter into the composition of the nerve ring; Filip'ev (1912) has distinguished three types on the basis of their composition:

1. Total absence of any semblance of ganglia; nerve cells arranged in a single layer around the esophagus.

2. Barely discernible ganglia (which, as a matter of fact, are only groups of cells).

3. Readily distinguishable ganglia, densely fused with special "accompanying" and "supporting" cells.

Only the first type is seen in Enoplida-total absence of ganglia and presence of just a single layer of nerve cells around the esophagus. Nerve cords in the body of nematodes of the order Enoplida are situated as follows (Figure 6): The major and most powerful nerve-the ventral nerve, a pair of subventral nerves, a pair of subdorsal nerves, and a dorsal nerve located in the postneural part of the body. Two nerves occur on each side in the region of the lateral fields; Filip'ev labeled them the upper and lower lateral nerves. The ventral nerve splits into superficial inner fibers. The latter extend from the hypoderm and not reaching the level of the nerve ring join it in two nerve roots; the superficial nerve fibers 
extend into the hypoderm right up to the level of the nerve ring and, here, like the inner fibers join the nerve ring in two nerve roots in the plane perpendicular to the body surface. Ultimately a small part of the superficial fibers extends further, into the preneural section. The subventral nerves merge with the roots of the inner fibers of the ventral nerve at the place of its junction with the nerve ring. Somewhat behind the ventral nerve the upper lateral nerves divide into two groups of nerve fibers, one extending into the preneural part and the other forming the nerve root joining the nerve ring. Subdorsal nerves take a sharp turn and from the hypoderm where they are located run deep and merge with the roots of the upper lateral nerves. The lower lateral and dorsal nerves do not communicate with the nerve ring and extend past it into the anterior part 22 of the body. Thus six nerve cords of the postneural part extend into the preneural part-the dorsal, two dorsolateral, two ventrolateral, and the ventral. Two pairs of submedial and one pair of lateral nerves are situated deeper than these trunks, near the esophagus, and originate from the nerve cells situated anterior end posterior to the nerve ring. The submedial nerves exclusively innervate organs of the anterior body end. The lateral nerves branch into peripheral offshoots which form a compact system that innervates the amphids and various setae. Nerves running from the posterior body end and reaching the peripheral surface likewise innervate different setae.

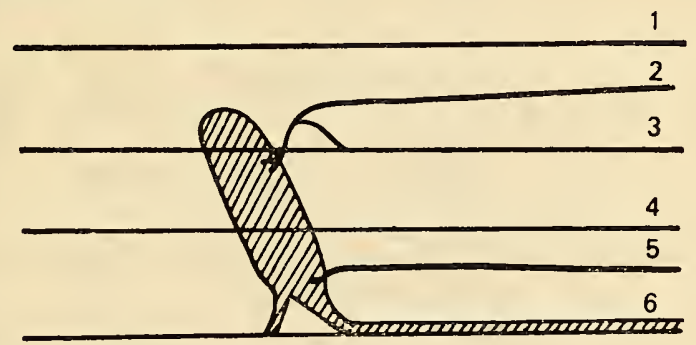

Figure 6. Schematic diagram of the nervous system of nematodes of order Enoplida.

Nerves: 1-dorsal; 2-subdorsal; 3-dorsolateral; 4-ventrolateral; 5-subventral; 6-ventral.

Innervation of the organs of the posterior section of the body of freeliving nematodes has not been well studied. One can only state that the copulatory organs, bursat musculature of the male, and the vulval region of the female are innervated by offshoots of the ventral and submedial nerves.

Organs of sense. Tangoreceptors. In all nematodes these organs are concentrated mainly in the cephalic region; however, in males they also 
occur in the caudal section of the body. Cephalic setae, anal setae, and papillae supplied with nerves serve as tangoreceptors. As these have been discussed above, further comment is not necessary here.

Chemoreceptors: These are the lateral organs or amphids and constitute organs of chemical sensitivity. These are three main types of amphids in nematodes-cyathiform, circular, and spiral. Their structure is a most stable feature and usually characteristic of a large taxonomic group. Cyathiform amphids, causing a depression in the cuticle, are characteristic of the entire orser Enoplida. A papilla with a nerve end intrudes into the closed posterior part. The anterior part of the amphid opens exteriorly. Amphid size in lower enoplids varies greatly; the width may range from $1 / 2$ to $1 / 8$ of the corresponding body diameter. Form is also variable, from circular to cyathiform to oval or elongated in both transverse and longitudinal directions (Figure 7). Location likewise is not constant; amphids may be situated immediately behind the cephalic capsule as in the case of leptosomatids (Leptosomatum, Leptosomatides), in the lateral interlobular grooves (Synonchus, Thoracostoma, Deontostoma, Pseudocella), or at some distance from the cephalic capsule; usually, however, this distance does not exceed two to three times the diameter of the head. In anticomids the amphids are arranged somewhat below the level of the cephalic setae and their size varies greatly in different species. It is interesting to note that in genus Rhabdodemania amphids are generally absent.

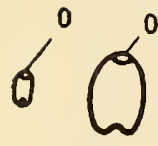

1

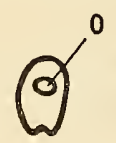

3

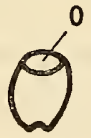

4

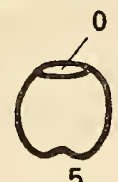

5

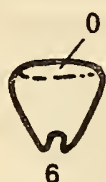

6

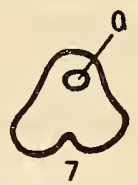

7

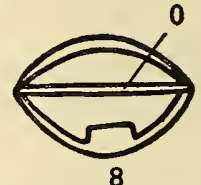

8

Figure 7. Shapes of amphids in nematodes of families Leptosomatidae and Anticomidae.

1-Anticoma; 2 to 4-Pseudocella; 5 to 7-Leptosomatum; 8-Platicomopsis (o-opening of amphid).

The functions of amphids have long been debated and range from glandular (de Man, 1886) to auricular (Marion, 1870; Bütschli, 1873). Zur Strassen (1904) put forward the proposition that amphids are organs of chemical sensitivity, i.e., chemoreceptors. This point of view is the 23 most widely held today. However, the problem of the function of amphids as chemoreceptors cannot be considered conclusively resolved as experimental data supporting this supposition are still inadequate.

Inglis (1964), proceeding from the fact that the function of amphids as chemoreceptors has not been confirmed experimentally, is inclined to attribute to them an altogether different function, namely, receptors of 
mechanical tension of the cuticle. Inglis' idea is extremely interesting, but unfortunately lacks experimental supportive confirmation.

Photoreceptors. Unlike the amphids, the shape of which is characteristic of a definite taxonomic group, photosensitive structures appear convergently in different groups of free-living nematodes. The presence or absence of these structures and their shape are features used in species diagnosis.

Photosensitive organs are always situated in the preneural region of nematodes. Of all the groups of nematodes studied in the present work, they were found only in leptosomatids (Leptosomatum, Leptosomatides, Thoracostoma, Deontostoma, and Pseudocella); their structure is quite complex (Figure 8) except in the last two genera. Each organ consists of dark red or brown pigment in a compact structure, which is circular or cyathiform with the lens situated anteriorly. Such "eyes" occur along the sides of the esophagus and their lenses project somewhat sideways. They are usually situated at the same level but in some cases (for example in Leptosomatides euxina) one may be situated much above the other. Some-

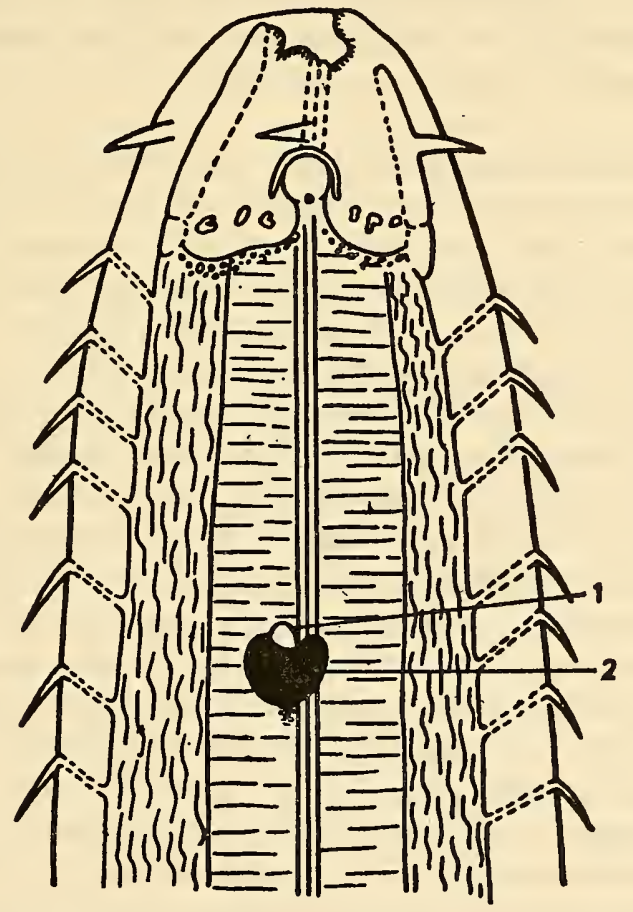

Figure 8. Structure of photosensitive organ in nematodes of genus Thoracostoma.

1-light-refractive lens; 2-pigment bowl. 
times the pigment projects beyond the limits of the pigment bowl and forms a small dendroid overflow behind it.

In Thoracostoma and Pseudocella a tendency toward reduction of the photosensitive organs is observed. In Thoracostoma most species have "eyes" exhibiting the structure described above, but a number, for example $T$. schizoepistilium, $T$. philippinensis, $T$. anocellatum, $T$. parasetosum, and $T$. brunni are completely devoid of photosensitive organs. In $T$. setosum only the pigment bowl is present; the lens is absent.

In species of Pseudocella "eyes" with lenses are seldom found. Usually the photosensitive pigment occurs not in a compact mass, but in small spots of irregular shape and light red in color. Sometimes the pigment is dispersed in longitudinal strips with a series of lateral offshoots. Some representatives of this genus are absolutely devoid of pigment; in my material no pigment was discernible in Pseudocella bursata, $P$. mamillifera, $P$. acuta, and $P$. angusticeps.

24 It seems to me that in Thoracostoma and Pseudocella a process of gradual reduction of photosensitive structures is taking place but no loss in their occurrence. The reason for this is that these two genera are more highly organized in all the remaining details of their structure than in species of the genus Deontostoma and still more than in those of Leptosomatum.

Digestive system. The digestive system of nematodes commences with an oral opening which in some leads into an oral cavity. The latter is extremely varied in structure in lower enoplids as noted above. Here I shall only mention that there are species within the limits of the group of lower enoplids which are absolutely devoid of an oral cavity as well as species with a well-developed and armed oral cavity.

Wieser (1953b) divided all free-living marine nematodes into four groups on the basis of the structure of their oral cavity. Among lower enoplids, three of these four groups are found. Nematodes lacking a distinct buccal capsule belong to the first group. Capturing food in such a case is effected by sucking with the help of the esophageal muscles. Anticoma, Paranticoma, Anticomopsis, Crenopharynx, Antopus, Barbonema, Leptosomatum, Leptosomatides, Leptosomella, Platycoma, Platicomopsis, and Triodontolaimus should be included in this group.

Nematodes with a small oral cavity armed with small teeth or plates to scrape aquatic plants, algae, etc., or bacterial film on various underwater objects, belong to the second group. Representatives of Synonchynae and Thoracostominae (Leptosomatidae) belong to this group.

Finally, nematodes with an extremely large oral cavity with a thick sclerotized lining and powerful onchia which can pierce the membrane of aquatic plants and suck the contents of their cells belong to the third group. Furthermore, there are possibly predators which swallow small 
organisms. Lower enoplids differ sharply with respect to type of food ingested and mode of feeding, which is reflected in the variation of structure of the oral apparatus.

The esophagus, which is comparatively uniform in shape in lower enoplids, follows immediately after the oral capsule. Usually the esophagus is straight and widens gradually toward the base. The esophagus of lower enoplids never exhibits true or pseudo bulbs. In transverse section the esophagus exhibits a triradial lumen lined internally with a cuticle with angles intruding inward and musculature arranged in the shape of three longitudinal bands, forming three sections in the esophagus (one dorsal and two subventral). Esophageal glands are situated (see below) in the middle of each section.

The musculature of the esophagus has been studied fairly well in parasitic nematodes (Looss, 1896; Schneider, 1902; Goldschmidt, 1904; Martini, 1916) and in free-living nematodes (Rauther, 1907; Filip'ev, 1921). It has been established that the esophagus in both groups is similar in structure. The tissue is composed of muscular, epithelial, nerve, and glandular cells. Muscular and epithelial cells are so closely arranged that their cellular boundaries are distinguished with great difficulty. The former contain radial muscular fibrillae, one end of which is attached to the internal angles of the esophageal tube and the other to the superficial layer of the esophagus. In lower enoplids muscular bands extend continuously throughout the esophagus. In those nematodes in which the esophagus has bulbs the epithelial tissue may be interrupted by the muscular tissue, forming a membrane in the region of the latter and thus imparting to the esophagus great firmness. Several epidermal cells, also containing fibrillae, extend from the anterior angles of the esophageal tube to its surface and are situated along the angles. As distinguished from those described above, these are not contractile but elastic fibers. Derivatives of the epidermal cells represent the external firm membrane 25 of the esophagus. Thus the muscular cells are surrounded, so to speak, by epithelial ones. It should be noted that the number of muscular and epithelial cells of the esophagus is greater in free-living nematodes than in parasitic ones. Thus in Ascaris there are 24 and in Synonchus 42. Moreover, the number in each species is constant (Filip'ev, 1921).

Rauther (1907) suggested that besides its basic function, the esophagus also fulfills an excretory one. In his experiments different vital stains accumulated and were then excreted in the angular bands of the esophagus. In his opinion the pigment strips sometimes observed in the esophagus are actually an accumulation of excrement in the esophageal lumen which is subsequently excreted. The lumen of the esophagus is lined with a cuticle that differs sharply from the external cuticle covering the body. Sometimes bulges are observed in the esophageal cuticle of 
lower enoplids which resemble a stripe in longitudinal sections (Filip'ev, 1921). At the posterior end of the esophagus, where it joins the intestine, a special structure can be isolated which is known as the cardia. In the anterior part of the intestine the cardia projects in the shape of a triangle. Functionally, it serves as a valve, obstructing the movement of food from the intestine back to the esophagus. According to Filip'ev (1921) the cardia consists of clearly distinguishable cells devoid of musculature. Here Filip'ev differs in opinion from Türk (1903) who discovered a large number of nuclei and annulated muscular fibrillae in the cardia of Synonchus. Steiner (1915) noted the presence of sclerotized reinforcement in the cardia of Leptosomatum sabangense.

Timm (1953) in studying the cardia in sections from Leptosomatum acephalatum noted that it consists of esophageal tissue surrounded by a thin annular sphincter which, in turn, is surrounded by the nerve cells of the intestine.

The intestine of lower enoplids, like that of all, free-living nematodes, is represented by a straight simple tube devoid of all outgrowths and blind pouches such as seen in parasitic nematodes. The intestinal wall consists of a single layer of cells. The number of intestinal cells varies considerably in different groups of nematodes. Thus in nematodes of Leptosomatidae and Oncholaimidae the number of cells is significantly more than in Monhysteridae and Chromadoridae (Bütschli, 1873; de Man, 1888; Cobb, 1893a).

According to Timm (1953) the number of intestinal cells in free-living nematodes varies from 123 to 5,000 and two types are distinguishable: unspecialized isocytes and specialized heterocytes. Isocytes are represented by rectangular cells of equal height. Heterocytes are oval cells, the size of which exceeds that of the isocytes by two to three times. As distinguished from the isocytes, these cells have a rough basophilic reticular net. Timm did not observe them in all leptosomatids. He found them in Leptosomatum acephalatum but not in Deontostoma magnificum and Thoracostoma coronatum. Türk (1903) observed them in Synonchus strasseni.

In addition to the foregoing cells, a rod-shaped layer ("rood border" according to Hyman, 1951; "bacillary layer" according to Timm, 1953) also occurs in the intestinal wall, in which rod-shaped basophilic elements can be distinguished. These structures have been described in detail by Timm (1953) for Leptosomatum acephalatum; Rauther (1907) did not find them in Cylicolaimus.

Inside the intestinal tube lies a smooth radially striated cuticle, and outside it a basal membrane formed partially from the intestinal cells and partially from the connective tissue (Martini, 1916).

In the middle part of the body in sexually mature individuals the intestine may be compressed by the gonads. 
Timm (1953) noted that the intestine of males and females can be distinguished by cellular composition. For example, in Leptosomatum acephalatum he found that the intestine of males consisted not only of a smaller number of cells, but also fewer oval cells, and that the cells were flatter, almost cubical, and very much larger than in females.

The rectum (or hind gut) in females passes through the intestino-rectal valve surrounded by epithelial tissue. The entire rectum is lined with the outer cuticle, turned inside, which may extend even farther, i.e., into the intestine. Timm (1953) observed that in sections taken from the part somewhat anterior to the rectum in Leptosomatum acephalatum there were numerous digitiform structures directed into the lumen of the intestine. Probably numerous folds of the cuticle (digitiform in shape) occur here. The rectum is encircled by a thin muscular sphincter. In males the rectum and sperm duct fuse not far from the anus.

Glands participating in the process of digestion are closely associated with the digestive tract. According to Türk (1903) and Rauther (1907) the anterior part of these glands is represented by a simple tube, while the posterior part is dendroid. The dorsal gland differs somewhat from the subventral glands. Thus in Cylicolaimus and Synonchus the unbranched part of the dorsal gland runs farther backward than that in the subventral ones. Esophageal glands open either directly into the oral cavity or, in the case of its absence, into the esophagus somewhat posterior to the cephalic capsule. The position of the external openings of these glands varies in different species of nematodes. In nematodes of family Leptosomatidae the openings of the subventral glands are shifted more toward the anterior end and the dorsal gland is somewhat posterior in position. The duct of the subdorsal gland in Leptosomatum acephalatum opens immediately behind the oral cavity. In Thoracostoma coronatum this duct opens on a small denticle situated in the oral cavity. When two subdorsal glands are present, their ducts open at the same level but not on the same denticle. In Deontostoma magnificum the outlet of the dorsal gland opens on the dorsal denticle and the ducts of the subventral glands open somewhat anteriorly (Timm, 1953). Rauther (1907) discovered accessory "lateral" ducts of the glands at the level of the eyes in a Thoracostoma sp. Timm found such ducts in Deontostorna magnificum.

Reproductive system. The female reproductive system of nematodes is represented by a continuous tube, different sections of which serve respectively as the ovary, oviduct, uterus, and vagina (Figure 9). In lower enoplids these tubes comprise a pair, one anteriad and the other posteriad. The anterior and posterior position of the reproductive tubes is a secondary phenomenon. Originally these tubes were situated bilaterally. That they are situated on the right and left side of the intestines bespeaks this fact. Subsequently one tube reflexed and the other remained in its 
original position. This occurred due to the intense stretching of the body in length and narrowing of the diameter (Filip'ev, 1921; Steiner, 1922b; Hyman, 1951; Paramonov, 1962).

In free-living nematodes the reproductive tubes are always positioned as described above. A bilateral arrangement of the reproductive tubes can be observed only in some parasitic (Ascaris) and phytonematodes (representatives of family Heteroderidae).
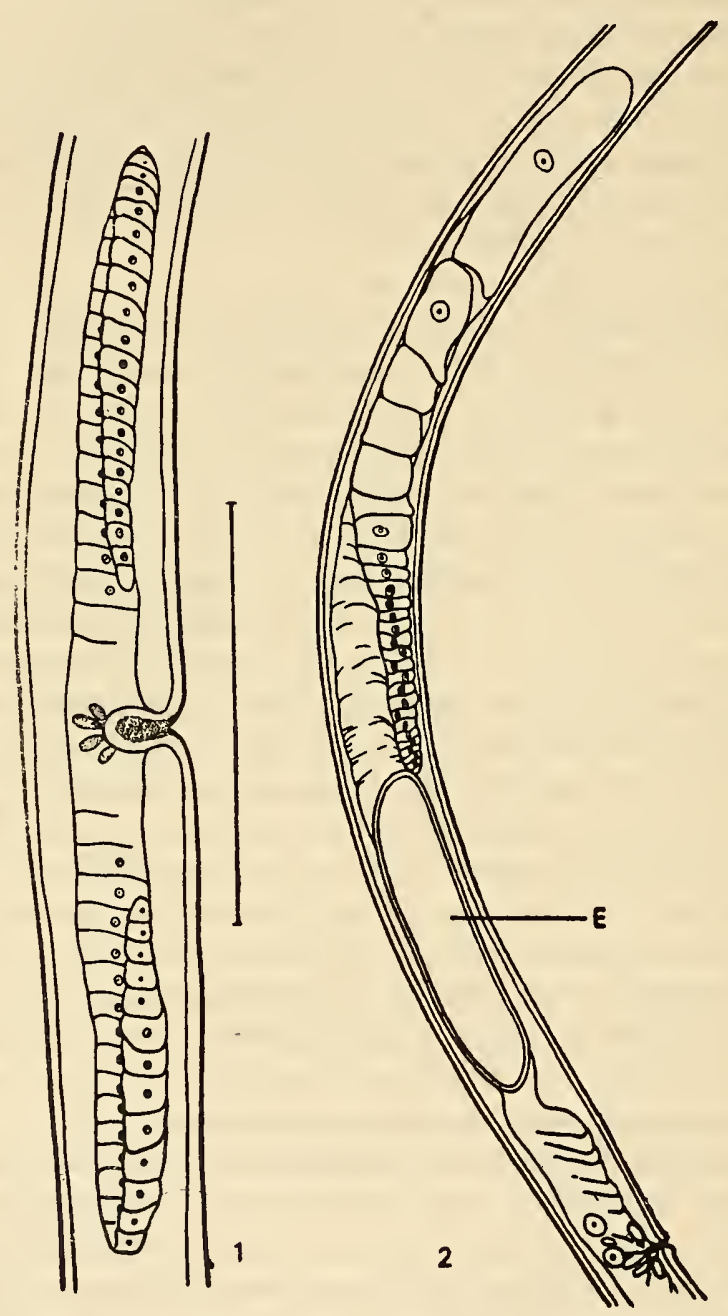

Figure 9. Structure of female reproductive system of nematodes.

1-reproductive tube of Thoracostoma; 2-anterior reproductive tube of Pseudocella (one large egg $\mathrm{E}$ visible in figure). 
The terminal part of the ovaries of lower enoplids is always reflexed. The reflexed part is significant in length, usually not less than half the length of the straight part, but sometimes equal to it in length, i.e., the ends of the gonads reach the vagina (Anticoma).

The ends of the gonads from which the oogonia separate are syncytial in nature. The oogonia occur first in a cluster and then form a single row.

27 Externally the ovary is covered by a thin epithelium consisting of flat and stretched cells (Cobb, 1893; de Man, 1886).

The ovaries are somewhat displaced toward the dorsal side and attached to the muscular layer near the distal end of the uterus.

The cells of the ovarian epithelium may differ significantly in shape and size in different species of lower enoplids. Thus in Thoracostoma coronatum a large flat epithelial cell extends the length of the ovary. In Leptosomatum acephalatum extremely small cells are situated along the short germinal zone, but cells of pyramid shape are situated in the zone of growth; these are significantly larger than the cells of the germinal zone. Before the bend of the ovary the cells become very large and oval. As the genital tracts of nematodes are represented by a single continuous tube, demarcating the ovary and the oviduct becomes somewhat difficult. de Man (1886) distinguished these sections on the basis of their histology. In such a case the ovary is very long and the oviduct represented by a short area continuous with the uterus. Jägerskiöld (1901) and Filip'ev (1921) distinguished these two sections on the basis of their morphology, considering the ovary the entire part between the uterus and the depression in the contracted part of the blind sac. The oviduct is represented by that part of the reproductive tube which is separated due to the fact that the former does not join the end of the ovary itself, but a little posteriorly. Mature eggs are stored in this sac.

In sexually mature females the oviduct exhibits disintegrating spongy tissue throughout its length all along the surface of the ventral body wall between the intestine and the ovary. In such a condition the passage is almost invisible. In younger specimens the wall of the ovary has not disintegrated and the passage is distinctly visible. Timm (1953) observed such a phenomenon in Leptosomatum acephalatum but gave no explanation. In this same species he notes the absence of any trace of a spermatheca isolated from the reproductive canal. Spermatozoa were present in the uterus in the region of egg formation in the ovary. In many species spermatozoa often concentrate in the anterior part of the ovary, immediately behind the zone of egg formation. This region probably plays the role of the spermatheca.

28 Between the oviduct and uterus lies the zone of egg formation in which extremely large cells occur, filling the lumen of the reproductive canal. These cells surround the eggs within the limits of the egg-forming zone 
or closely adhere to the eggs entering the uterus. The eggs either pass across the center of these cells or along one side. While entering this zone the eggs are devoid of a shell, but on exiting covered with a firm shell. Timm (1953) considers the function of these large active cells to be shell formation. They probably secrete an enzyme which activates the eggs to form a shell.

The uterus is represented by a relatively wider tube in which the walls consist of flat epithelial cells. Muscular fibers run only along its proximal end. Near the vagina the uterus has a reduced sphincter of thick muscular cells which is located on the ventral side. Unlike a large number of free-living nematodes (Chromadoridae and some Oncholaimidae) which have an unpaired uterus merging near the vagina, in lower enoplids the vagina is always paired and the passages of the two uteri separate.

The number and size of eggs vary considerably even within the limits of a single species. In the uterus of females of different species I have counted from one to nine eggs. The smallest eggs, 50 to $60 \mu \mathrm{m}$ long, I found in Anticoma and the largest, 1,200 $\mu \mathrm{m}$ long, in Pseudocella bursata. Egg size, as mentioned above, varies within the limits of one and the same species. Thus in Leptosomatum tetrophtalmum eggs ranged from 154 to $206 \mu \mathrm{m}$ in length, in L. kerguelensis-103 to $236 \mu \mathrm{m}$, in Leptosomatides crassus -154 to $360 \mu \mathrm{m}$, in L. acutipapillosum-154 to $257 \mu \mathrm{m}$, and in Pseudocella trichodes-206 to $412 \mu \mathrm{m}$.

The female genital pore (vulva) is situated on the ventral side, most often midbody. Sometimes it is shifted posteriorly and very rarely anteriorly. In females of some nematodes sclerotized granules encircle the vulval slit. Filip'ev (1922a) found this peculiarity in Leptosomatides steineri. I found it in other species-Platycomopsis mesjatzevi and Deontostoma arcticum. These granules are frequently found in species of genera Leptosomatum and Leptosomatides. In my material granules surrounding the vulval aperture occurred in four species of genus Leptosomatum and two species of Leptosomatides. .

It is interesting to note that in females of Paracylicolaimus brevisetosus I detected two vulval slits (Platonova, 1970). This phenomenon is an abnormality. A similar case has been described by Paramonov (1926).

The male genital tubes of lower enoplids are represented by paired testes which pass into two seminal vesicles and merge into a single vas deferens. The latter transforms into an unpaired muscular ejaculatory duct opening into the cloaca. The copulatory organ also opens into the cloaca.

As in the case of female gonads, in males also one testis is anteriad and the other posteriad (Figure 10). The beginning of the testis is represented by a syncytium, giving rise to spermatogonia. Mature spermatozoa collect in the posterior end of the testis or in the seminal vesicle. 
The testis is covered externally by a thin epithelium composed of longitudinally stretched fusiform cells (de Man, 1886) or by an extremely thin and flat epithelium (Jägerskiöld, 1901).

The anterior part of the vas deferens consists of numerous low cells with indistinct cellular outlines. The number of cells decreases toward the posterior part of the vas deferens and their outlines become more distinct. The ejaculatory duct, situated next, consists of two rows of cells compressed longitudinally. There is almost no musculature in the ante-

29 rior part of the duct but well-developed musculature present in the posterior part (Jägerskiöld, 1901; Türk 1903; Filip'ev, 1916).

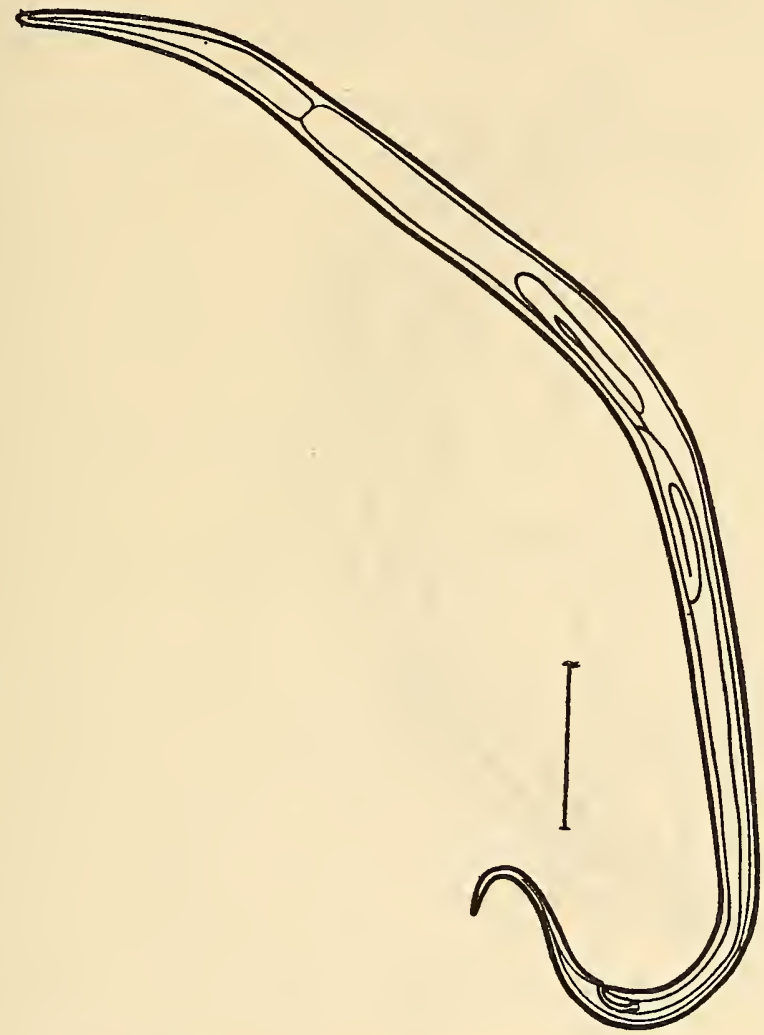

Figure 10. Diagrammatic sketch of reproductive tube in male.

The copulatory system of males is situated in a special sac of the cloaca and consists of a pair of spicules and a gubernaculum (Figure 11). The spicules are hollow sclerotized organs which curve variously. A plasmatic substance, part of those epidermal cells which form the spicules, develops inside them (Filip'ev, 1921). One can demarcate the capitulum of each 
spicule at the proximal end from the constriction (cervix) following it. The body of the spicule has a lumen in the middle and a thin membrane in the ventral curvature, i.e., the velum. Sclerotized structures directing the movements of the spicules have been labeled "ruleks". This term was introduced in Soviet literature by Filip'ev to replace "gubernaculum", proposed by Looss. The gubernaculum may be paired or single. Mostly it is situated on the dorsal side of the spicules but sometimes ventrally (Platycomopsis mesjatzevi). Sometimes the gubernaculum is altogether absent (Platycoma cephalata, Anticoma longisetosa, A. graciliceps, A. filipjevi, A. uschakovi, A. behringiana, A. brevisetosa, and Paranticoma antarctica).

Filip'ev $(1921,1927)$ established some types of spicule structures

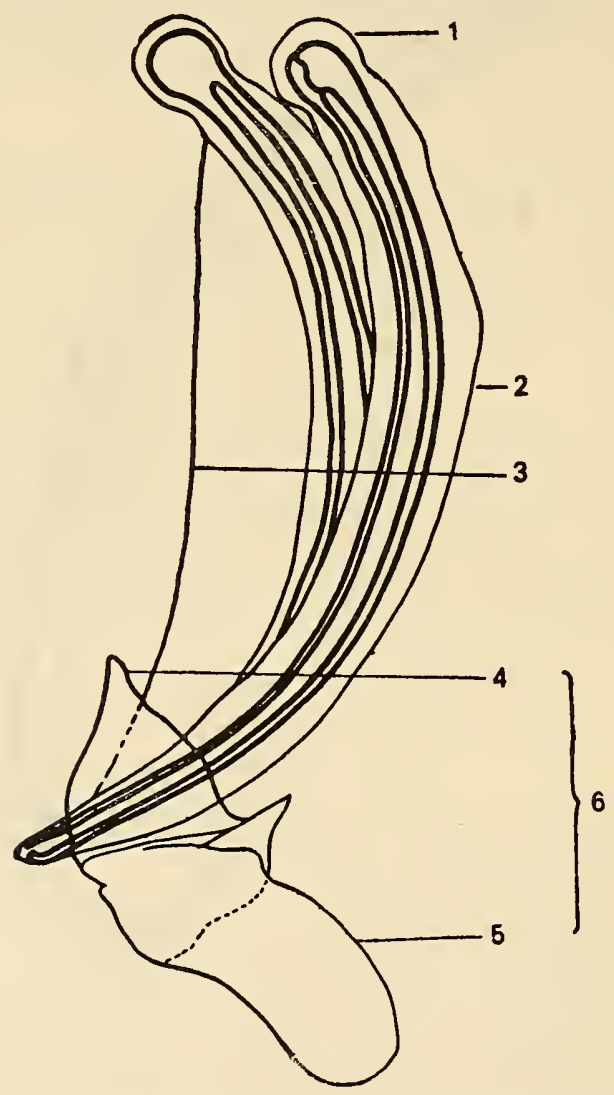

Figure 11. Diagrammatic structure of spicular apparatus of nematodes of genus Pseudocella.

1-capitulum of spicule; 2-body of spicule; 3-velum; 4-ventral process of gubernaculum; 5-dorsal process of gubernaculum; 6-gubernaculum. 
(straight, arcuate, broad, lamelliform, flat, elongated, and complex), under which he formed subgroups. Of the seven main types, three are characteristic of lower enoplids: 1) arcuate (curved spicules which almost do not broaden in the middle; well-developed and complex gubernaculum always present); 2) broad (distinguished from the preceding type by

30 flatter shape and presence of velum); and 3) lamelliform (with velum on ventral side). Broad spicules are characteristic of Leptosomatum, Platycomopsis, Rhabdodemania, and the majority of the species of Synonchinae, Barbonematinae, and Platycominae. Arcuate spicules are characteristic of Cylicolaimus, Leptosomatides, Deontostoma, Thoracostoma, and Pseudocella. Filip'ev placed representatives of Anticomidae under the third type, namely, lamelliform spicules.

It seems to me that this scheme of classification is much too broad. Anticoma, placed by Filip'ev under the lamelliform type, includes a significant diversity of spicule shapes. In my material for this genus I found arcuate, broad, and lamelliform spicules, with the gubernaculum either situated ventrally, dorsally, or absent (Figure 12).

In Leptosomatum the spicular shape is fairly uniform. These organs are slightly curved, sometimes with a narrow capitulum, and widen in the anterior third; the gubernaculum is simple in structure (without processes) and dorsally situated. All the species of this genus may be grouped under spicules of the broad type. Platycomopsis is characterized by weakly curved spicules, broad in the distal half, and a ventrally situated gubernaculum. Species of Rhabdodemania have spicules similar to those of Leptosomatum; Barbonema and Platycoma have broad, tubular spicules; Cylicolaimus, Leptosomatides, Deontostoma, Thoracostoma, and Pseudocella have arcuate spicules. However, some species of Deontostoma, Thoracostoma, and Pseudocella have lamelliform spicules, namely, Deontostoma antarcticum, Thoracostoma setosum, and Pseudocella trichodes. This group is characterized by a complex gubernaculum which always has a dorsal and rarely a ventral process. Often the gubernaculum is paired and forms a "funnel" in which the distal part of the spicules is located. In Crenopharynx the spicules are rather unique; they are very slender and long with a small round capitulum, and a simple slitlike gubernaculum. Crenopharynx is close to species of the family Phanodermatidae with respect to spicular structure.

Thus the structure of the copulatory apparatus within the limits of lower enoplids is highly diversified.

The sexual armature of the male, in addition to spicules, includes cop31 ulatory papillae, setae, and an accessory organ. Papillae and setae are situated in two submedial rows in the anal region. Slightly anterior to the anus an unpaired glandular structure occurs, constituting an accessory organ. It resembles a large papilla externally but inside one finds rather 

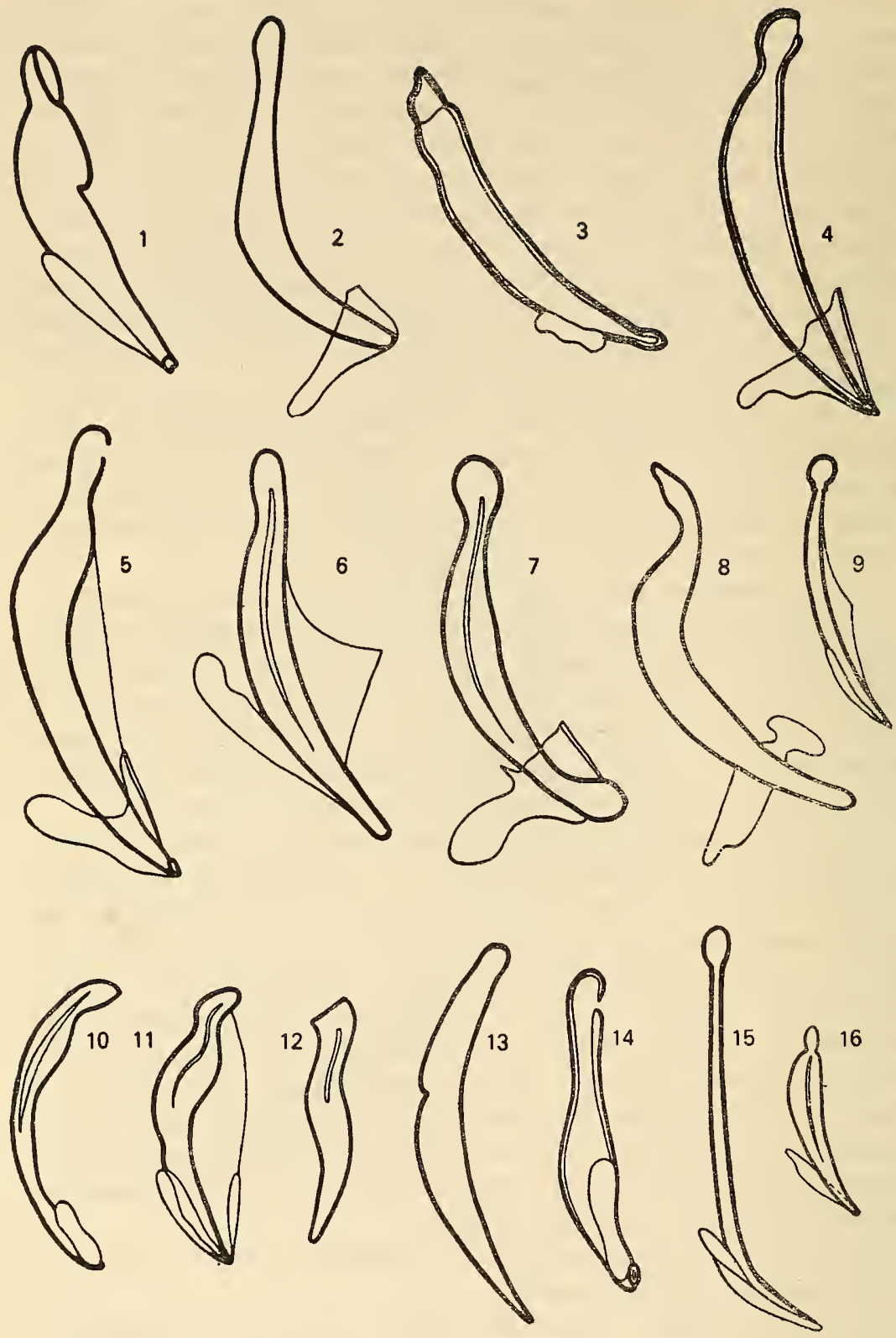

Figure 12. Types of spicular apparatus in lower Enoplida.

1 to 2-Leptosomatum; 3 to 4-Synonchus; 5-Deontostoma; 6-Thoracostoma; 7-Pseudocella; 8-Cylicolaimus; 9 to 11-Anticoma; 12-Barbonema; 13-Platycoma; 14-Platycomopsis; 15-Crenopharynx; 16-Rhabdodemania. 
well-developed sclerotized tubes, annulations, or hemispheres. Sometimes sclerotized processes, directed downward or upward, are also present. The structure of the accessory organ and number and disposition of papillae and setae may serve as reliable species indexes. All these auxiliary copulatory armatures may be partially or fully absent. Representatives

32 of Rhabdodemania and Leptosomatum lack setae, papillae, and accessory organs. In species of Anticoma an accessory organ of the tubular type is always present but setae and papillae absent. In species of Crenopharynx, on the contrary, accessory organs are absent but preanal setae invariably present. In Deontostoma, Thoracostoma, and Pseudocella an accessory organ, papillae, and setae are usually present. Very rarely papillae or setae may be atrophied but an accessory organ invariably developed. When all three are present, the structure of the accessory organ as well as the disposition of the papillae and setae may vary significantly. In Deontostoma arcticum papillae with setae commence near the anus and extend a fairly significant distance. The accessory organ is situated in the middle of this row of papillae. In Deontostoma papillatum the papillae bear no setae and commence not from the anus but from the accessory organ. Males of Deontostoma antarcticum have only an accessory organ; papillae and setae are totally atrophied in them. In Leptosomatum inocellatum setae commence immediately behind the anus and papillae devoid of setae lie somewhat above the level of the accessory organ.

\section{PHYLOGENETIC RELATIONS AND TAXONOMIC BASIS}

\section{Position of Order Enoplida in the Classification of Nematodes}

The origin of nematodes and the position of their different groups in the taxonomic system of the class have yet to be conclusively resolved. Winslow $(1960$, p. 341) remarks that the position of nematodes in the classification of the animal kingdom and their phylogenetic relations have, as it were, slipped from the consciousness of researchers and hence their position is one of incertitude. In my opinion the latter contention is overly cautious. At present, most scientists engaged in the study of this group consider free-living marine nematodes extremely primitive and original forms (Filip'ev, 1921, 1934a; Schuurmans-Stekhoven, 1931; Hyman, 1951; Paramonov, 1962; and others). But Winslow is right that the question of the evolution of the class as a whole has yet to be fully resolved.

Researchers of this group have directed their attention mainly to parasitic nematodes and hence we now have considerable morphological, embryological, histological, and other data on this group. However, parasitic nematodes, being a specialized and highly organized group, can- 
not alone illuminate the evolution of this class. The answer to this question must be sought among the most primitive and less specialized group of nematodes. For this reason, before searching for affinities between nematodes and other groups of animals, it is essential to note relations between orders and families within the class per se.

I do not claim to have conclusively established these affiliations as the amount of anatomical and histological information available in literature is, to my regret, inadequate. Hence only preliminary observations regarding this problem are given.

Filip'ev (1921) rightly suggested that highly simple forms, which exhibit no features of reduction or (atrophy), should be considered the most primitive nematodes, since the evolution of this group followed a line of specialization and simplification of some organic systems. Such nematodes belong to the order Enoplida.

33 Class Nematoda is divided into two subclasses-Secernentea comprising highly specialized and parasitic forms, and subclass Adenophorea in which mainly free-living forms, together with enoplids, a smaller number of parasitic nematodes, and phytonematodes are included. The families studied by me under the order Enoplida include exclusively marine forms. Of these families, Leptosomatidae comprises the least reduced and specialized group of nematodes with respect to structure and, for this reason, may probably be considered the most primitive family among freeliving nematodes. The primitivity of this group is expressed in a number of anatomical and morphological peculiarities of structure.

The nervous system of nematodes of various groups is structured as follows. Around the nerve ring - the central part of the nervous systemnerve cells in species of Enoplida are situated in the most primitive manner; ganglia are totally absent and the nerve cells lie in a simple layer around the esophagus. In free-living nematodes of Monhysterida (Siphonolaimus, Solenolaimus) anatomically well defined, densely fused ganglia are present. In parasitic nematodes (Ascaris, Mermis, Ancylostoma) the situation of the cells of the central nervous system reflects an intermediate position between these two groups, i.e., less well-defined ganglia represented by only a group of cells. This is probably explained by a secondary reduction of the nervous system caused by a parasitic mode of life.

The peripheral nervous system has an extremely complex structure in species of Enoplida, while in free-living smaller forms, such as nematodes of Monhysterida, this nervous system is quite simple. A similar phenomenon is observed in parasitic nematodes (Filip'ev, 1921).

Probably the original form of the nematode nervous system should be considered such a structure as is found in enoplids, where the degree of integration of the central nervous system is very minimal and the peripheral nervous system exhibits no features of reduction. In more highly 
organized free-living nematodes a distinct process of ganglionization, which leads to greater integration of the central nervous system, is observed. But reduction of the peripheral nervous system, brought about by the process of general reduction of cellular composition, accompanies this. Reduction of the central and peripheral nervous systems of parasitic nematodes is effected by a parasitic mode of life. In addition to a weakly integrated central nervous system and a highly developed peripheral system, nematodes of the order Enoplida have the most primitively constructed organs of chemical sensitivity-the amphids-which are cyathiform in shape. Other orders of free-living nematodes have more complexly constructed amphids-round, horseshoe-shaped, or spiral.

The body cavity in various groups of nematodes is developed to different degrees. In leptosomatids, where it has not been seen by a number of authors (Jägerskiöld, 1901; Türk, 1903; de Man, 1904; Timm, 1953), the body cavity is least developed. It is poorly developed in other families of the order Enoplida (Filip'ev, 1921). In other orders of free-living nematodes it is present as a small slit and achieves fuller development in saprozoic forms and intestinal parasites (Filip'ev, 1937). Thus the near absence of a body cavity in leptosomatids also points to their lower stage of organization.

Within the limits of the class the process of oligomerization of a number of organs has taken place (Dogel', 1954). This process can be observed by comparing the setaceous armature of free-living and parasitic nematodes.

Setae are extremely numerous and best developed in free-living nematodes, especially in marine forms (Filip'ev, 1918, 1921; Dogel', 1954). In parasitic forms they are considerably reduced. The original number of cephalic sensory organs of nematodes should be taken as six labial papillae and a crown of ten cephalic setae. In parasitic forms (Ascaridata, Spirurata, and others) the number of papillae and setae decreases either as a result of fusion or as a result of reduction. In free-living nematodes, in addition to cephalic setae, other setae are scattered all over the body or at least over the anterior end. In nematodes of the order Enoplida the crown of cephalic setae is usually situated in a single circle; in some species these setae are equal in length, while in others the four sublateral setae may be longer than the others. Only in Oxystomatidae is the crown of cephalic setae distinguished by two types-anterior, comprising six shorter setae, and posterior, comprising four relatively longer setae.

Beyond the limits of the order Enoplida the crown of cephalic setae has undergone more significant change. In most nematodes of the orders Chromadorida and Monhysterida the anterior crown bears structures resembling papillae and the posterior crown comprises four setae. In some nematodes of the order Desmoscolecida the four setae of the second 
circle resemble cornuate processes. In some Chromadorida and Desmoscolecida a number of setae situated on the body merge with each other, forming powerful and strictly localized setae employed for locomotion. Preanal setae in some Desmoscolecida fuse and acquire the significance of copulatory setae. Thus, on the basis of the foregoing examples, one can distinctly trace the change of function and oligomerization of setae which originally had a sensory function.

In most species of Enoplida, especially in lower representatives, the cephalic crown of setae has a much simpler, nonproliferative structure, and the setae on the body are numerous and irregularly scattered. All these setae have only a sensory function. Such a type of arrangement of setae in nematodes is apparently more primitive.

Dermal glands are also subject to oligomerization. These glands are numerous within Leptosomatidae, while only a lone cervical gland is seen in Anticomidae.

Oligomerization can also be seen in the reproductive system. Paired reflexed gonads, paired genital ducts, and paired uteri fusing only near the genital pore should be considered the original form in nematodes. A reduction in the reproductive system takes place within the limits of the class. The commencement of this process is already evident in Enoplida, in some species of Oncholaimus (Filip'ev, 1921) where one female genital tube is significantly shorter than the other. In some cases even complete atrophy of one of the female genital tubes is seen. More often the anterior genital tube (Oncholaimidae) is reduced and less often the posterior genital tube (Oxystominidae).

No sign of reduction or fusion of organs is observed in the structure of the reproductive system of female leptosomatids and anticomids. Since no gonadal reduction or fusion of the reproductive tubes has occurred in them, the gonads are always reflexed. More often a single unpaired female genital tube is found in parasitic nematodes, but the phenomenon of polymerization may also be observed exceptionally. Thus there are four genital tubes in Polydelphis, six in Hexametra, and even nine to eleven in Turgida. This is considered quite natural for parasitic forms in connection with the need to produce a large number of eggs.

Paired gonads are extremely rare among males compared to females. Thus in Chromadorida males with a single testis are more common, in

35 Monhysterida the testis may be single or paired, in Enoplida the testes are generally paired, but in lower groups of this order they are always paired. The genital ducts (vas deferens and ejaculatory duct) are always unpaired in males. Sometimes oligomerization is evident in even the male copulatory apparatus; of the two spicules, one may be atrophied, which is mostly observed in parasitic nematodes.

Thus the female and male reproductive systems in leptosomatids are 
least reduced and hence this group is considered much more primitive than the remaining groups of nematodes.

Phagocytic cells in nematodes of Enoplida are usually very numerous and scattered irregularly over the body. Their number in Leptosomatidae and Oncholaimidae ranges from 150 to 220 or more, and in Enchelidiidae never more than 70 . Their structure and situation in enchelidiids are similar to those in oncholaimids. A more regular disposition of these cells is seen in Oxystominidae, where they concentrate near the lateral fields (Bütschli, 1874; de Man, 1907). In most leptosomatids the phagocytic cells are numerous and scattered irregularly over the body, but in Leptosomatides euxina they are situated mainly along the ventral line. In species of Chromadorida these cells are arranged in a few longitudinal rows (up to eight in number). In Araeolaimida the number of phagocytic cells is considerably reduced; in Axonolaimus setosus there are only two phagocytic cell (Filip'ev, 1918, 1921).

Extremely numerous and irregularly scattered phagocytic cells are thus found in enoplids.

It is interesting to review the changes in cellular composition of individual organs and tissues of nematodes. In nematodes of the order Enoplida eight cords formed by the hypoderm may be present; these cords invariably project. Submedian cords vary in number and may be absent in some species (Filip'ev, 1921). In such cases the total number of cords may decrease to four. In more highly organized free-living and parasitic nematodes the number of these cords is always constant and equal to four. Fluctuations in cellular composition of the lateral cords have been observed in Leptosomatidae. In Synonchus strasseni three to five rows of cells have been recorded (Türk, 1903), in Thoracostoma setosum five to six rows in the median cords (de Man, 1904), and in Leptosomatum acephalatum four to five rows in the lateral cords (Timm, 1953). Filip'ev (1916) relates the number of cellular rows in the hypodermal cords to the change in number of cells in other organs. The number of intestinal cells in different nematodes varies considerably (Bütschli, 1873; de Man, 1888; Maupas, 1900; Filip'ev, 1918, 1921; Timm, 1953). Their number is maximal in Leptosomatidae and Oncholaimidae of the order Enoplida and minimal in the orders Chromadorida and Monhysterida. In many monhysterids the intestine consists in all of one or two rows of cells. It should be noted that besides the large number of cells constituting the intestine in enoplids, Timm (1953) has observed considerable variation in the number of cells within the limits of species in some leptosomatids.

In the muscular fields situated between the hypodermal cords cellular composition also varies. As is well known, all members of the order Enoplida belong to the polymyarian group, i.e., a large number of cells occur in each muscular field. The majority of free-living nematodes also belong 
to this group. Enoplids have a very large number of cells in the muscular fields (up to 12; Timm, 1953). A small number of free-living nematodes-Monhysteridae and Rhabditoides-and parasitic nematodes belong to the meromyarian group. Even a total degeneration of muscles (Filip'ev, 1934) has taken place in phytonematodes of the genera Heterodera and Allantonema. The same phenomenon has been observed in Meloidogyne.

During ontogenesis all nematodes pass through the stage of meromyarian musculature when the number of muscle cells is constant (Mar-

36 tini, 1903, 1906). By preserving this stage, adult meromyarian nematodes with a constant number of cells develop (Martini, 1908). With the multiplication of muscle cells the polymyarian type is obtained. It seems to me that Filip'ev is absolutely right in his assertion that it would be erroneous to consider young meromyarian individuals the ancestors of all meromyarian forms. Meromyarian forms should be cosidered regressive or neotenic but not primitive.

To summarize, of all these orders enoplids are the lowest organized group: cuticle smooth and totally devoid of protective armature of any kind; cephalic setae usually situated in one circle; amphids cyathiform; nervous system simple; and esophagus devoid of diverticula. Such features indicate the primitive structure of enoplids.

\section{Taxonomy and Phylogenetic Relation of Families of Order Enoplida}

To understand the problem of the taxonomic position of families of the order Enoplida attention should be given to the differences observed by Inglis in the cephalic structure and oral cavity of Leptosomatidae and Anticomidae on the one hand, and most representatives of the order on the other. In representatives of Leptosomatidae, especially higher ones such as Thoracostoma, the buccal cavity is poorly expressed and is not topographically demarcated from the onchial cavity; consequently the onchia are displaced far toward the anterior end and situated almost at the level of the odontia. Supporting structures, if developed, form as processes of the cephalic capsule. Because of the fusion of the buccal and onchial cavities and the anterior position of the onchia, the specialized musculature of the esophagus extends far forward toward the bases of the onchia, where it is attached after crossing the cephalic bladder. Nonspecialized musculature in the posterior part of the esophagus remains undifferentiated, which is expressed exteriorly in the nonalveolar appearance of the esophagus. The same is observed in representatives of Anticomidae; the only differences are that the cephalic capsule and oral cavity with all its armature are weakly expressed.

An entirely different picture is seen in representatives of Phanoder- 
matidae, Enoplidae, Oncholaimidae, and Enchelidiidae. Here the oral cavity is distinctly differentiated topographically into the anterior buccal cavity and the posterior onchial cavity; buccal rods may be situated in the former which play the role of supporting structures or develop later into mandibles, while in the posteriorly situated onchial cavity these rhabdoid structures develop into onchia. The sclerotized lining of both cavities may fuse imperceptibly, forming onchiobuccal plates, to the posterior (onchial) half of which the specialized musculature is attached, ensuring movement of the entire complex. Due to the posterior position of the onchia, the specialized musculature does not extend to the posterior margin of the buccal cavity and, consequently, does not cross the cephalic bladder. The nonspecialized musculature of the posterior part of the esophagus is differentiated into separate fascicles which externally impart an alveolar appearance to this part of the esophagus.

For a clear-cut picture of these undoubtedly independent lines of evolutionary development, one must imagine the structure of a hypothetical form which could have been their common ancestor. The cephalic capsule of such a form should resemble a cap at the anterior end of the body, i.e., of that part where the musculature of the esophagus joins the body wall. The cephalic and esophageal capsules in this form should not be differentiated and the cephalic bladder should be absent. The triradial internal lumen of the esophagus should open abruptly as a triangular 37 oral opening so that there would be practically no buccal cavity. The lumen in the anterior part of the esophagus should remain constant in diameter throughout its entire length so that, strictly speaking, there would be no onchial cavity. Here, one could project that part of the esophagus would later develop into the onchial cavity. Because of the complete absence of oral armature, there would be no need for specialized musculature. The musculature of the esophagus would remain undifferentiated throughout its length.

Such a hypothetical form is very similar to members of the genus Leptosomatum. This gives one grounds for assuming the first evolutionary line (Leptosomatidae, Anticomidae, and Oxystominidae) or their primitive representatives as ancestral in relation to the second line, i.e., Enoplidae, Phanodermatidae, and others. Since it is indisputable that such forms as Leptosomatum are the most primitive within the limits of the first evolutionary line, it is clear that Leptosomatidae is the most primitive in this order.

In the order Enoplida, in addition to the families studied by Inglis (1964), there are other families related to these two phylogenetic branches; unfortunately information about them is absolutely inadequate to judge their taxonomic position. Of the two families grouped under the superfamily Tripiloidea and often considered the most primitive in the order 
(de Coninck, 1965), Ironidae belongs to the leptosomatid-anticomid branch (Inglis, 1964). Tripilidae cannot be regarded as the most primitive in the order due to the presence of some specialized peculiarities of the esophagus, in particular the development of the esophago-intestinal valve. Lauratonematidae also cannot be regarded as primitive due to the reduction of the posterior gonad in males, and the annulated nature of its cuticle; the latter is uncharacteristic of representatives of the order as a whole.

If the evolution of the head in Leptosomatidae is examined, two parallel, but to some extent independent, processes can be traced. The first process is intensification of development of the cephalic and esophageal capsule, and the second process the formation and development of the oral cavity. The initial stages of the first process can be traced among genera close to Leptosomatum. In Leptosomatides and Paraleptosomatides the cephalic capsule is developed more powerfully than in Leptosomatum and there is every reason to assume that a developed cephalic bladder is also present. Moreover, in Leptosomatides conisetosum a depression occurs in the posterior margin in which the cephalic setae are situated. In Leptosomatum reducta there are outgrowths in the cephalic capsule resembling the supporting structures observed by Inglis in some of the forms studied by him. The commencement of the second process-development of the oral cavity-is also evident to some extent in nematodes of the group Leptosomatum. Mawson $(1956,1958 \mathrm{~b})$ observed a distinct oral cavity in Leptosomatides conisetosum. Both of these processes are developed in genera clustering around Synonchus and Thoracostoma. Genera of this group have a powerful cephalic capsule or often supporting structures in the anterior part. Sometimes they have a cephalic capsule continuing strongly backward or uniting in this part with the cervical capsule, which has deep clefts along its posterior margin. Representatives of these genera also have a fully developed esophageal capsule and a conspicuous cephalic bladder which is usually divided into six parts by the radii of the esophagus and fascicles of specialized musculature. At the same time they have an oral cavity in which onchia and odontia are present. True, the oral cavity is rather small in size.

In the other group of genera, those close to Cylicolaimus, the cephalic capsule has not attained the significant development seen in the previous group, and at best resembles the cephalic capsule of some species of Leptosomatides. Contrarily, here the oral cavity is quite well developed (at least in males of those genera exhibiting sexual dimorphism). Moreover, widening of the oral cavity has taken place mainly at the expense of the onchial cavity, while the buccal cavity retains a relatively insignificant depth. Concomitantly, some peculiar types of cephalic bladder are seen; the bladder may extend significantly along the body but be reduced to a 
narrow ring between the large oral cavity and the body wall. Structures such as odontia sometimes develop in the anterior part of the oral cavity; large onchia are situated somewhat posteriorly. The absence of onchia is probably explained by their wearing out since otherwise the reason for the development of an extensive onchial section in the oral cavity would not be understandable.

Thus three distinctly defined groups of genera, of which one is primary and the other two derived independently from it, are observed in Leptosomatidae.

Sometimes the genus Triodontolaimus, with only a single speciesTriodontolaimus acutus (Villot)-is placed as a subfamily, in addition to the group of genera discussed above, in the family Leptosomatidae. The problem of its phylogenetic connection with the present Leptosomatidae is fairly complex. Judging from the description of de Man (1893, p. 116), the cephalic capsule in T. acutus is absent or at best very poorly developed. On the basis of his description, one can only gather that the head is posteriorly limited and demarcated from the rest of the body by a thin suture (p. 116); unfortunately this suture is not depicted in the illustrations. de Man makes no mention of the esophageal capsule, directing his attention to the presence of three symmetrical "teeth" with wide and concave bases. Subsequent information, namely, that musculature binds these bases, makes one assume that these "teeth" are onchia. The shifting forward of the onchia and the indivisibility of the small oral capsule indisputably indicate the relation of Triodontolaimus to the phylogenetic branch, Leptosomatidae-Oxystominidae. Simultaneously, the combination of peculiarities noted above (weak development of the cephalic capsule and powerfully developed onchia located in a comparatively small oral cavity) compel one to assume that Triodontolaimus is an extremely unique lateral offshoot of this phylogenetic branch. Hence it cannot be included in Leptosomatidae and merits isolation in an independent family. Because information on the morphology of Triodontolaimus is so meager, it seems more appropriate to assume that this group is derived from extremely primitive representatives of the family Leptosomatidae.

To solve the problem of the position of the family Anticomidae, it is necessary to establish whether the structural simplicity of the cephalic end is primary or simply the result of secondary simplification. An examination of the main group of genera of this family, clustering around Anticoma, revealed that some forms, such as Cephalanticoma chitwoodi (Inglis, 1964), possess an adequately developed cephalic capsule, a poorly developed cephalic bladder, and a small oral cavity with distinct onchia. In Odontanticoma the cephalic capsule is almost negligible but the oral cavity well developed (apparently at the cost of its onchial part). 
These peculiarities, in association with small size, seem to indicate that the structural simplicity of the anticomid head is the result of secondary simplification due to general reduction in size. The presence of a renette also bespeaks the phylogenetic advancement of anticomids. The genus Parabarbonema, with only one species-P. barba Inglis, 1964-occupies an intermediate position between anticomids and leptosomatids. The structure of the cephalic capsule in this species is almost identical to that in members of Leptosomatides. The oral cavity is small and armed with three large onchia. Thus the anterior end of the body of anticomids could be regarded as the end result of simplification of the form type Parabar-

39 bonema. Parabarbonema is distinguished from Anticoma by the absence of a renette.

The taxonomic position of the other two groups of genera, clustered around Platycoma and Barbonema, is not really clear since information concerning these two genera is very scanty. Nevertheless both groups contain representatives with a highly reduced or even totally reduced cephalic capsule and an extremely small oral cavity; however, small but distinct onchia are present in Proplatycoma sudafricana (Inglis, 1964). Furthermore, one cannot refrain from mentioning the well-known resemblance in spicule structure in Parabarbonema and Barbonema.

Until fuller elucidation of the peculiarities of various anatomical characters is forthcoming, it is better to consider genera clustered around Platycoma and Barbonema independent of Anticoma and genera close to it, and also independent of ancestors analogous to Parabarbonema. The absence of a renette in Parabarbonema bespeaks the possibility of keeping Anticoma and genera close to it isolated in contrast to other genera in this family. If leptosomatids progressed along the path of complexity of the cephalic capsule and oral cavity, anticomids retrogressed along the path of simplification of these structures which, among other reasons, confirms the evolutionary independence of the family.

Two groups included by a number of authors in the composition of the family Leptosomatidae have been deliberately omitted by me in the foregoing discussion. Rhabdodemania has been variously included in the family Leptosomatidae (Filip'ev 1927; Schulz, 1932; Schuurmans-Stekhoven, 1946; Schuurmans-Stekhoven and Mawson, 1955), Oncholaimidae (Southern, 1914; Ditlevsen, 1926), Enoplidae (Wieser, 1959; Inglis, 1964; de Coninck, 1965), and sometimes established as an independent family (Filip'ev, 1934). As shown by Inglis (1964), Rhabdodemania belongs to the evolutionary branch Phanodermatidae-Enoplidae on the basis of structure of the anterior end of the body, and consequently must be excluded from the family Leptosomatidae. However, it is not easy to establish the position of this genus within the limits of the phylogenetic branch. Inglis (1964) in transferring this genus to Enoplidae, understood by him 
in a very broad sense, notes features of its similarity with the family Enchelidiidae. Contrarily, de Coninck (1965) aligns Rhabdodemania with the family Enoplidae in a special subfamily, Rhabdodemaniinae, including therein the genera Chaetonema, Trichenoplus, Trileptium, and Donsinema. In my opinion, the latter four genera have very little in common with Rhabdodemania in the construction of the anterior end of the body. I think it is more appropriate to isolate Rhabdodemania as a separate group (separate family), occupying a somewhat intermediate position among enoplids with unequal onchia (Saveljevia, Parasaveljevia, Oxyonchus), i.e., between Oncholaimidae and Enchelidiidae.

The taxonomic position of the genus Crenopharynx merits special discussion. Species now related to this genus were earlier included in Stenolaimus (Filip'ev 1927; Schuurmans-Stekhoven, 1950), and usually placed close to Anticoma or even listed as its synonym. Filip'ev (1934) suggested the name Crenopharynx for that group of species which has characters in common with Stenolaimus and placed the genus in Phanodermatidae (Filip'ev, 1927). Subsequently many authors related the genus Crenopharynx to the family Phanodermatidae, guided by the predominantly alveolar structure of the esophagus. Inglis (1964) showed that the structures of the buccal cavity of Phanodermatidae and Enoplidae were homologous through a detailed analysis of the cephalic structure of $\mathrm{Cre}$ nopharynx eina. On these grounds he emphasized the need for including Crenopharynx in Phanodermatidae. However, this inclusion is improper. The homologue only proves the affinity of this genus to the phylogenetic line Phanodermatidae-Enoplidae and does not substantiate its inclusion 40 in either family. Crenopharynx can be sharply distinguished from presentday Phanodermatidae, type Phanoderma, as well as the aberrant genus Dayellus isolated by me in a separate family, by the presence of a triangular oral opening, primitive cephalic capsule with undeveloped cephalic bladder, and shallow buccal cavity devoid of distinctly formed buccal styli. Hence one is compelled to isolate Crenopharynx in an independent family to which it seems to me, the genus Nasinema should also be transferred. The genus Nasinema was formerly included by Filip'ev in Phanodermatidae.

The structure of the head, oral cavity, esophagus (alveolar in the posterior half), and general shape of the body bring Nasinema and Crenopharynx close together.

Representatives of the family Crenopharyngidae occupy, apparently, a much lower position in the phylogenetic branch to which they belong. Such an interpretation explains the similarity in structure of the cephalic end of Crenopharyngidae and Anticomidae. A poorly developed cephalic capsule and oral cavity are found so often among anticomids and lower leptosomatids that the similarity of these features cannot be overlooked. 


\section{Taxonomy of Family Leptosomatidae}

The family Leptosomatidae was first established as a subfamily of Enoplidae by Filip'ev in his works of 1916 and 1918 to 1921 and only later raised to the rank of family (de Coninck and Schuurmans-Stekhoven, 1933).

Leptosomatidae comprises a primitive group of free-living marine nematodes with poorly expressed features of specialization. Filip'ev (1927) has stated that the specialization of this family is of such a low order that leptosomatids do not represent a single group but rather a series of isolated genera. However, descriptions of genera of Leptosomatidae since 1930 have directed my thoughts not to isolated genera, but to distinct groups of genera. It seems to me that these groups would be better classified as separate subfamilies.

Leptosomatinae, an extremely primitive subfamily, includes the genera Leptosomatum, Leptosomatides, Leptosomella, Leptosomatina, and Paraleptosomatides for which a short cephalic capsule with relatively fine walls and a narrow cephalic ring are characteristic. The oral cavity is absent. In most of these genera the tail is short and bluntly rounded. Leptosomella has a rather long and conical tail which narrows soon after the anus. Extremely short cephalic setae are also characteristic of this group. Usually the cervical setae, if present, are short. Only Leptosomatina Allgen, 1951 and Leptosomella Filip'ev 1927, which probably will be combined in the future due to many features of similarity, have long cephalic setae. It is regrettable that Filip'ev described his genus only on the basis of females and Allgen on the basis of males. As the material of these two genera was not available to me I cannot propose their combination at present and tentatively treat Leptosomatina and Leptosomella as independent genera.

In speaking about the merger of these two genera I have in view their type species-Leptosomella acrocerca and Leptosomatina longisetum respectively. They are very close in such characters as shape of head, presence of long cephalic setae, absence of eyes, thick cuticle, and absence of cervical setae. These very characters have been given by the authors as diagnostic features of the genera. Allgen later (1958a) described another species of Leptosomatina, namely, $L$. appendixocaudatum, in which the cephalic structure is entirely different from that in L. longisetum, and for which extremely short cephalic setae and an accessory organ

41 of unique structure are characteristic (latter absent in L. longisetum). The differences between $L$. longisetum, and $L$. appendixocaudatum appear to me so incomparably greater than the differences between Leptosomatina longisetum and Leptosomella acrocera that a study of supplementary material will no doubt lead to their combination in one genus and the 
isolation of Leptosomatina appendixocaudatum in an independent genus.

Of all the genera belonging to this group, Leptosomatum has the simplest spicular apparatus, i.e., weakly curved spicules and simple gubernaculum devoid of processes. All the remaining genera have a gubernaculum provided with a process, which may be only dorsal or dorsal and ventral.

Thoracostomatinae, isolated by de Coninck (1965), is characterized first and foremost by a highly developed cephalic capsule. It includes such genera as Thoracostoma, Deontostoma, Pseudocella, and Synonchus with genera close to it. The genus Synonchus originally embraced so many varied forms that many authors had a tendency, totally justified, to divide it into several subgenera. A contrary attempt to unite all forms with a well-developed cephalic capsule and clavate tail created much confusion in the taxonomy of this group. The fact that a series of species were transferred to Thoracostoma and some even to Leptosomatum (Villot, 1875) on the basis of the structure of the cephalic capsule, exacerbated this confusion. Cobb (1893a, p. 411) described the genus Synonchus as follows: "Worms of this genus are closely related to those of Oncholaimus. They have a pharynx armed with teeth in which the dorsal one is predominant and the remainder rudimentary. The pharynx is so small that the teeth occupy almost all the space when the mouth is closed... . A ventral accessory organ is present in males anterior to the anus." A detailed description of the two species of this genus-S. hirsutus and $S$. fasciculatus-came later.

Linstow (1900) described the Artic species Enoplus edentatus in which the oral capsule lacks sclerotized plates and teeth, which characterize representatives of this genus. Due to the absence of the most distinctive character of the genus Enoplus, namely, sclerotized jaws, Jägerskiöld (1901) considered it improper to include this species in Enoplus and transferred it to Thoracostoma. He also gave a detailed description of a new species, Thoracostoma acuticaudata, but observed that he was relating it to Thoracostoma only tentatively, suggesting that future studies might isolate it in an independent genus. de Man (1904) held the same point of view. Türk (1903) gave a detailed description of two Neapolitan species which he included in Thoracostoma. Southern (1914) described two species from the southern coast of Ireland and assigned them to a new genus, Fiacra $-F$. brevisetosa and $F$. longisetosa. He considered the genus established by him close to Thoracostoma, Enoplus, and Tridontolaimus, and conceded that with future studies his species might have to be transferred to two different genera.

Filip'ev (1916) suggested the combination of all species with a conical tail, described as Thoracostoma, in a new genus-Jaegerskioeldia-with the type species Thoracostoma acuticaudata (Jägerskiöld). Later Filip'ev 
(1927), acknowledging he had not known earlier about Cobb's description of the genus Synonchus (Cobb, 1893a), accepted the synonymy of these genera. Observing the great diversity of species in this genus, Filip'ev (1927) divided it into three subgenera: 1) Fiacra [type species, $S$. $(F$.) longisetosum] with long cephalic setae, large amphids, large arcuate spicules, and labial teeth; 2) Synonchus s. str. [type species, $S$. (S.) fasciculatus] with cephalic setae of average size, large amphids, large spicules, and without labial teeth; and 3) Jaegerskioeldia [type species, S. (J.).

42 acuticaudata] with extremely short cephalic setae, small amphids, short spicules, and without labial teeth.

Quite recently it has been suggested (de Coninck, 1965) that these subgenera be elevated to independent genera. On studying those forms which constitute the genus Synonchus in its new dimensions, I have arrived at the conclusion that the latter is a composite group but undoubtedly liable to division into a series of genera. Thus, in addition to isolating the above-mentioned Synonchus, Fiacra, and Jaegerskioeldia, I also isolate Eusynonchus (type species, Fiacra brevisetosa), Tuerkiana (type species, Thoracostoma strasseni), and Paratuerkiana (type species, Thoracostoma comes), the descriptions of which are given in the taxonomic part of this work.

Thoracostoma (Synonchoides) galatheae, described by Wieser (1956), combines characters of Synonchus (short cephalic capsule and buccal capsule with triangular plates) and Thoracostoma (shape of tail). As such, the form is isolated here in the subgenus Synonchoides of the genus Thoracostoma, stipulating that future studies will probably elevate it to the rank of genus. Another subgenus, Corythostoma, described by Wieser in the same work, also deserves in my opinion to be raised to the rank of genus as it differs notably from Thoracostoma in the structure of its cephalic capsule. The cephalic capsule of Corythostoma is wide and short with extremely wide, uniform interlobular grooves. The lateral grooves are not distinguishable in any way from the subventral and subdorsal grooves.

I propose that all the genera enumerated above be combined in the subfamily Synonchinae of the family Leptosomatidae. Macronchus Inglis, 1964 should also be transferred here; the author himself expressed doubts about its affinity with Synonchus. Finally, Anivanema, described by me in the present work, has likewise been placed in the family Leptosomatidae.

The history of the genus Thoracostoma warrants review. This genus was established by Marion in 1870 for four species from the Mediterranean Sea: $T$. echinodon, $T$. dorylaimus, $T$. montredonense, and $T$. zolae. To this genus Marion assigned worms with a long, almost nonattenuated body, with a sharply truncated head and a short tail. The presence of 
permanent eyes and the absence of an accessory organ in the genital apparatus of the male (papillae present instead) are also characteristic of the genus, but a sclerotized cephalic capsule is the most important diagnostic feature. Species which had earlier been assigned to different genera-Hemipsilus (Leuckart, 1849), Enoplus (Eberth, 1863; Schneider, 1866), and Leptosomatum (Bastian, 1865; Villot, 1875)-were subsequently included in this genus. Later all nematodes with a sclerotized cephalic capsule were likewise included in the genus Thoracostoma. The significant difference in the structure of cephalic capsules compelled taxonomists to subsequently define a series of independent genera in Leptosomatidae, namely, Tridontolaimus de Man, 1893; Rhabdodemania Baylis and Daubney, 1926; Synonchus (Jaegerskioeldia) Filipjev, 1916; Platycoma Cobb, 1893; Metacylicolaimus Stekhoven, 1946; Cylicolaimus de Man, 1890; Synonchus Cobb, 1893; Deontostoma Filipjev, 1916; Leptosomatides Filipjev, 1918; and also a genus already placed in another family-Phanoderma Bastian, 1865.

At the commencement of the twentieth century the limits of Thoracostoma were more or less firmly established. In 1916 Filip'ev isolated from Thoracostoma a new genus-Deontostoma. Filip'ev regarded the presence of a ventral process in the cephalic capsule of Thoracostoma and its absence in Deontostoma one of the basic differences between these two genera. He labeled this process rather inappropriately the "ventral tooth." This term misled foreign authors (Wieser, 1953c; Mawson, 1958a) and hence they refused to recognize the independence of genus Deontostoma.

On the basis of a thorough study of the work of Filip'ev and the material at my disposal, I consider it necessary to restore the independence of the genus isolated by Filip'ev (Platonova, 1962). The genus Deontostoma differs significantly from Thoracostoma in cephalic structure as well as in structure of the spicular apparatus. The cephalic capsule of representatives of Deontostoma is almost equal in width near the top and base and its entire wall is of the same thickness; as a result it has a radially symmetrical structure and appears symmetrical in a lateral view. In representatives of Thoracostoma the cephalic capsule narrows considerably from the base to the top; its ventral wall is significantly longer and thicker than the dorsal wall and due to this fact the capsule has a bilateral symmetrical structure and appears asymmetrical in a lateral view.

The spicules of males of Deontostoma are rather uniformly curved in their proximal part and devoid of sharp angles and grooves. The gubernaculum has distinct dorsal and ventral processes which are joined together by a curved plate. When they fuse, the halves of the gubernaculum form a sort of funnel in which the distal parts of the spicules lie. In Thoracostoma the spicules have a sharp break approximately midlength 
and a velum often occurs on their internal margin. The terminal part of the gubernaculum encloses the distal end of the spicules. The processes of the gubernaculum are directed dorsally and although closely apposed to the spicule body are situated at a sharp angle to it.

These are the most distinctive characters differentiating Deontostoma and Thoracostoma. Several minor characters are detailed below.

Filip'ev (1927) divided Thoracostoma into two subgenera-Thoracostoma s. str. and Pseudocella. He related nematodes with distinct photosensitive eyes and the above-described spicular structure to subgenus Thoracostoma. To the subgenus Pseudocella he transferred species completely devoid of photosensitive pigment, or with pigment scattered throughout the anterior end of the body, or very rarely species with eyes always devoid of a lens. The spicules in this subgenus are smoothly arcuate and notably narrower than those of the subgenus Thoracostoma s. str. The gubernaculum has a caudal process directed at right angles to the longitudinal axis of the spicules. Filip'ev predicted that these two subgenera would be elevated to independent genera with the passage of time. Wieser (1956) notes that the structure of the spicular apparatus is a much more important character for the division of these two subgenera than the presence or absence of photosensitive organs since in all cases the latter may be totally absent even in Thoracostoma s. str.

A study of the species of Pseudocella permits me to supplement the diagnosis of this subgenus given by Filip'ev. All three genera are combined in a single subfamily, Thoracostominae, of the family Leptosomatidae.

If leptosomatids of the subfamily Thoracostominae reveal a tendency toward greater complexity of the cephalic capsule, then the genera Cylicoliamus, Ritenbenkia, and Metacylicoliamus exhibit complexity of the oral capsule. In this group together with greater complexity of the cephalic capsule, developed significantly less however than in Thoracostominae, one finds a powerful oral capsule with a thick sclerotized lining armed with onchia. Representatives of Metacylicolaimus have a relatively wide but not very deep oral cavity in which blunt onchia jut out. In Ritenbenkia the oral cavity is significantly longer than that in the previous genus, its wall much thicker, and the onchia and sclerotized plates arranged around the oral opening. Maximum development of the oral cavity occurs in Cylicolaimus, where it is very extensive, thick-walled, and usually armed with large teeth situated in its depth.

44. Such a characteristic feature as the presence of a highly developed oral cavity and associated changes in the structure of the head permit one to combine the above-mentioned genera with Paracylicolaimus in the subfamily Cylicolaiminae. 


\section{Taxonomy of Family Anticomidae}

Like leptosomatids, anticomids were also isolated in a separate subfamily within Enoplidae by Filip'ev in his works of 1916 and 1918 to 1921. In much later works $(1927,1934)$ Filip'ev transferred the genus Anticoma to Leptosomatinae. de Coninck (1965) assigned Anticominae to the family Leptosomatidae but Hope and Murphy (1972) raised it to the rank of a family.

The family Anticomidae includes many diverse genera that can be grouped into different subfamilies. The genera Anticoma, Paranticoma, and Anticomopsis, as well as Cephalanticoma and Odontanticoma, newly described in the present work, Antopus (with a single species, $A$. serialis) and Stenolaimus (with a single species, $S$. lepturus) can all be included in Anticominae.

For a long time Stenolaimus occupied in extremely uncertain position in the classification of Anticomidae. Filip'ev (1934), conceding its heterogeneity, proposed S. lepturus as a synonym for Anticoma and proposed the genus Crenopharynx for the species Stenolaimus marioni, retaining it in the family Phanodermatidae. I agree with this concept only because this genus really is in need of a similar division into two independent genera. But Stenolaimus lepturus considerably differs from the genus Anticoma in structure of the spicules and situation and number of cervical setae, and must indisputably be regarded as an independent genus of the subfamily Anticominae. The position of Crenopharynx has already been discussed.

Barbonema and Parabarbonema differ so much from each other that each deserves isolation in a special subfamily-Barbonematinae and Parabarbonematinae.

Platycoma and Platycomopsis should also constitute a separate subfamily.

\section{ECOLOGY}

The ecology of free-living nematodes has been studied little and needs special attention and collection of material. As the basic purpose of this work is the taxonomic revision of the lower Enoplida, I had to utilize to some extent the casual and fragmentary information available while examining some problems regarding the ecology of this group.

The opinion that free-living nematodes were highly eurybiont prevailed among nematologists for many years. Kreis (1934) proposed that while inhabiting those parts of the sea which are advantageous to their existence, these nematodes do not exhibit a distinct affinity for definitive biotopes. This means that one and the same nematode species may be 
found at different depths and in entirely different conditions, inhabiting littoral aquatic plants and sublittoral silts nonselectively.

Schuurmans-Stekhoven (1931) studied the nematode fauna of the North Sea and Zuider Zee and discovered a large number of euryhaline forms among these organisms.

Gerlach (1958) notes that differences in biotopes with respect to fauna of free-living marine nematodes are not large; this fauna lives mainly in sandy beds and sublittoral facies. He thinks that the major percentage of

45 these species are eurybionts. Gerlach, however, has noted a rather significant difference in nematodes in the littoral zone on the basis of biotopes.

It has also been established by Gerlach $(1953,1958)$ and Wieser $(1951,1953,1960)$ that the distribution of nematodes reflects not so much a variety of biotopes, as a peculiarity in substratum, in particular the degree of its disintegration. In the distribution of nematodes on the basis of their association with various types of algae, species affinity of algae is not so significant as its external form, size, and degree of fragmentation of thallus. The same may be said about the substratum. Silt, fine sand, pebbles, and coarse sand should be examined first of all for the presence of interstices which may serve as shelters for the worms (p. 324).

Wieser (1953) has given an interesting ecological classification of freeliving nematodes. It is based on the structure of the oral apparatus, which reflects the nature of feeding and consequently to some extent the type of life led by these organisms. All free-living nematodes are divided by Wieser into four groups (Figure 13).

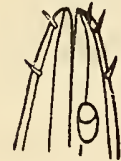

$1 \mathrm{~A}$

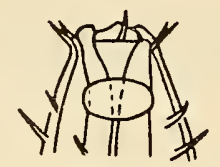

$1 \mathrm{~B}$

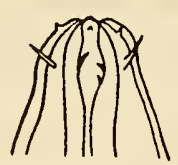

$2 A$

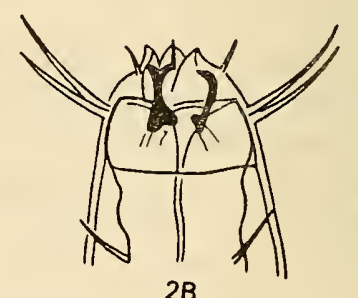

$2 B$

Figure 13. Types of structure of the oral cavity of nematodes

(from Wieser, 1953b).

1A-Anticoma; $1 B$-Paramonhystera; 2A-Microlainus; $2 B-$ Enoploides.

1. Group 1A. Forms lacking a distinct oral cavity and any kind of oral armature. Type of feeding, simply sucking with the help of the esophageal muscles. Food, detritus consisting of fine soft particles. Thrive among algae in the littoral zone and soft beds in the sublittoral.

2. Group 1B. Forms with well-developed cyathiform, conical, or cylindrical oral cavity which, like the previous group, are also devoid of an oral armature. Feeding as in group 1A. In addition, intake of detritus 
effected by movement of lips and mouth. Food, detritus consisting of larger particle (including diatoms). Inhabit soft sand rich in detritus.

3. Group 2A. Oral cavity well-developed and armed with small sclerotized denticles or plates. Nematodes capable of scraping the surface of algae or piercing their membrane to suck cellular sap. Food, epiphytes and algae. Inhabit almost all biotopes.

4. Group 2B. Oral cavity large with a powerful armature of different types. Feeding as in the previous group but most of these nematodes are predators, swallowing small organisms, including other nematodes. Live in the littoral zone in coarse sand poor in detritus, and the sublittoral among shells and sand with larger particles.

Species of Leptosomatidae and Anticomidae play a significant role in the fauna of free-living marine nematodes. The number of their species ranges from 5 to 46 (or from 2 to $19 \%$ in relation to the total number of nematodes studied). My data and that collected from literature is presented in the Table which follows.

In some cases leptosomatids may be the predominant group. In my analysis of Lake Kergelen there were nematodes representing ten different families, of which $50.7 \%$ belong to Leptosomatidae (Platonova, 1968). In material also collected from Lake Kergelen, Schuurmans-Stekhoven

Proportion of lower Enoplida in the fauna of nematodes of some seas

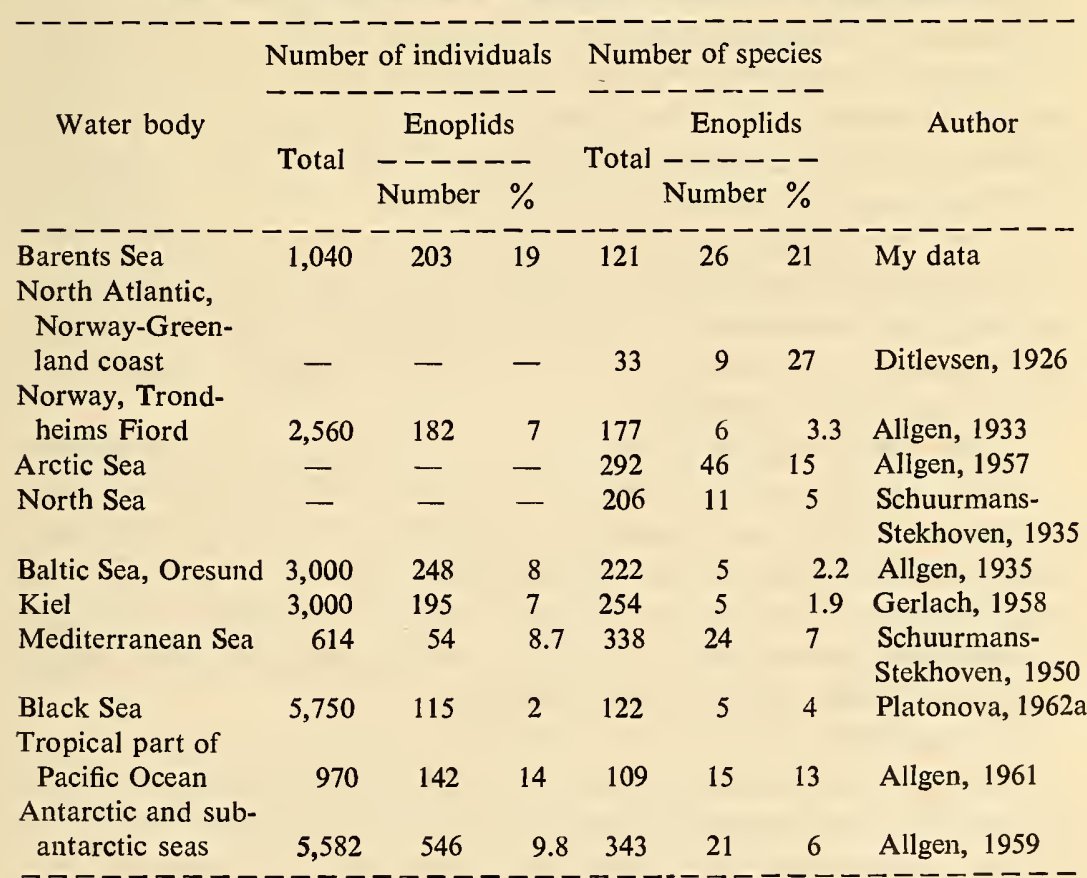


and Mawson (1955) found that leptosomatids constituted $88.0 \%$ of the total population of nematodes.

It must be noted that when a ladle with a small catchment area, say 20 to $40 \mathrm{~cm}^{2}$ (for example, the standard earthen bowls and other devices for making probes into the meiobenthos) was used for collecting nematodes, leptosomatids were rarely caught. They were most frequently found in bottom-combing probes where the sweep of the catching device was considerably larger. This fact, which I have noted a number of times, most probably indicates that the average distance between individuals of this group in nature is many times more than in other usually smaller marine nematodes. Possibly this is due to the larger size of leptosomatids (compared to other representatives of the meiobenthos in general and all other nematodes in particular) and also due to their greater mobility.

Hence leptosomatids should be included in the category of organisms of the macrobenthos in spite of their relatively smaller size. A predominant majority of other free-living nematodes are organisms of the meiobenthos, which is supported by their being found in large numbers during standard meiobenthic probes.

Biotopes. All the families examined in the present work are found by and large in all biotopes, from littoral water plants to deep water silt.

Leptosomatids live mainly among larger types of algae with a less fragmented thallus. These are usually brown algae (Fucus, Ascophyllum, Laminaria, Alaria) and rather rarely red algae (Porphyra, Rhodimenia, Halosaccion, Litothamnion, and Corallina). There are numerous nematodes in these which belong to group 1A according to the classification of

47 Wieser (1953). Representatives of this group cannot utilize the algae they inhabit as food material due to the structure of their oral apparatus. Most probably the algae provide them with shelter and mechanical protection against the impact of sea breakers. As is well known, nematodes live in the surface layers of the seabed (Cobb, 1929; Filip'ev, 1934) and for this reason those which live in the zone of sea breakers and the littoral belt need that type of defense.

Wieser (1951) states that smaller forms of nematodes inhabit algae with a highly fragmented thallus (for example Ceramium) and large forms usually inhabit larger algae with a slightly truncated thallus. My observations confirm Wieser's. Among shrublike and highly dismembered algae I found small forms of Chromadoridae in abundance, but larger leptosomatids (average size 6 to $15 \mathrm{~mm}$ ) in larger types of brown algae. Group 1B does not include lower Enoplida.

Representatives of group 2A are found in algae of the littoral zone in very significant numbers: some (for example Pseudocella trichodes) may be considered exclusive inhabitants of this biotope. They are capable of utilizing algae not only for shelter but also as food on the basis of their 
oral structure. Group 2B was represented in my material by just six species of two genera-Cylicolaimus and Rhabdodemania. In the littoral zone these nematodes are almost nonexistent. Information in literature on the distribution of other species of these genera support my observations.

Fine sand and gravel are only slightly inhabited by nematodes as these organisms are easily swept away by waves from ground not protected by algae.

Silted sand in the sublittoral zone provides favorable conditions of habitation for nematodes. Here the impact of sea breakers is not felt, food reserves are sufficient, and far better aeration insured compared to silt. As shown by Wieser (1960) the degree of ground siltation exerts a great influence on the development of nematode fauna. Little silt preserves the interstices in which nematodes take refuge. When such spaces are filled by silt, a severe impoverishment of nematode fauna takes place. All three groups-1 A, 2A, 2B-are widely represented in this biotope. As mentioned above, group $2 \mathrm{~B}$ is found almost exclusively in silted sand beds of the sublittoral zone. Wieser $(1951,1953)$ believes that species of this group are capable of feeding on small organisms as well as algae, because of the presence of a large and well-armed oral cavity. Proceeding from the fact that species of this group are found very rarely in algae and live mainly in silted sand grounds, one may assume that these nematodes are mainly predators. As far as mollusks are concerned, Filip'ev (1927) and Schuurmans-Stekhoven (1950) think that this biotope always contains a rich fauna of nematodes. But leptosomatids are found among mollusks (lamellibranchs) rather rarely and usually singly. However, Filip'ev (1918) claims he often found species Leptosomatum bacillatum among bivalve mollusks.

Biotopes containing large numbers of invertebrates (independent of their taxonomic groups) are particularly rich in nematodes. Areas rich in polychaetes, mollusks, echinoderms, and sponges are equally rich in nematodes. Probably as a result of the vital functions of these organisms, the substratum is enriched with nutritive material utilized by nematodes.

Temperature. I have no experimental data on the influence of temperature on nematode fauna. Only this observation can be made: Deontostoma arcticum, Pseudocella arcticum, $P$. coecum, and $P$. trichodes are found predominantly in cold seas of the Arctic basin, while Eusynonchus 48 hirsutus, Leptosomatum bacillatum, and Leptosomatides euxina live in the warm waters of the Black Sea and the Mediterranean Sea. Leptosomatum elongatum may be considered eurythermal as it has been found in the cold waters of the subantarctic, Barents Sea, and Greenland Sea, as well as in the warm waters of tropical parts of the Indian and Pacific Oceans. Data on the remaining species discussed in this work are so meager that 
at present it is difficult to comment on the influence of temperature on them.

The influence of temperature on nematode fauna is detailed by Gal'tsova in the present volume (p. 327).

Salinity. Filip'ev (1927), Schuurmans-Stekhoven (1931), and Allgen (1935) observed a reduction in number of free-living marine nematodes in relation to lower salinities. This is clearly evident for nematodes of family Leptosomatidae and Anticomidae. Most species of these families may be considered stenohaline. Fauna comprising leptosomatids and anticomids is much richer with respect to species in seas with a normal oceanic salinity (46 species, see Table). In such seas species of Leptoso. matidae constitute $27 \%$ in relation to the total number of nematode species. In seas with lower salinities (Black Sea-17\%, Baltic Sea in region of Gulf of Kiel-13 to $19 \%$, and considerably diluted waters of Trondheims Fiord, Sea of Norway) the number of species of leptosomatids and anticomids falls to 4.0 to $6.0 \%$ or $1.9 \%$. In the Sea of Azov (Filip'ev, 1922c; Mordukhai-Boltovskii, 1960) and in the eastern part of the Baltic Sea (Filip'ev, 1929; Schneider, 1906) leptosomatids are entirely absent.

Representatives of Thoracostomatinae (Thoracostoma, Deontostoma, Pseudocella) are probably rather sensitive to lower salinity. Thus in the western part of the Baltic Sea species of these genera are found very rarely and usually singly, while in the Black Sea they are totally absent. The subfamily Leptosomatinae (Leptosomatum, Leptosomatides, Leptosomella) is usually found in seas with normal salinity. However, two species of Leptosomatum (L. punctatum and L. bacillatum) and Leptosomatides euxina inhabit the Black Sea.

The family Anticomidae is, as a whole, more euryhaline. Moreover, species of Anticoma, which live in all seas except those with very low salinities, are the most euryhaline. Rhabdodemaniidae is adapted to great fluctuations of salinity. In my material there were specimens of Rhabdodemania from the Okhotsk, Barents, White, and Black Seas. According to Allgen (1929a) and Gerlack (1958) species of the genus are also found in the western part of the Baltic Sea.

The possibility is not ruled out that there may be other factors affecting the prevalence of leptosomatid fauna in the Black and Baltic Seas, but indubitably the considerable dilution of water is significant.

The problem of the ecological characteristics of individual species is incomparably more complex. Diversity of habitat and extremely wide distribution of species in various seas and under various conditions (depth, nature of the bottom, and salinity) indicate that many species of this group have adapted to a wide range of ecological factors.

It seems to me that the eurybiont nature of free-living marine nema- 
todes has been rather exaggerated. In my material there were no species encountered in all biotopes in equal measure. Moreover, some species exhibit a distinct affinity for definite conditions. For example, Pseudocella trichodes is an inhabitant of large littoral algae, while $P$. tenius and $P$. elegans live predominantly in depths of about 300 to $400 \mathrm{~m}$ in brown sublittoral silts.

It is difficult to express an opinion on the ecological affinity of species encountered in extremely diverse biotopes. At first sight they appear widely eurybiont and are so regarded by a number of authors (Schulz, 1932; Kreis, 1934; and others). However, it seems to me a careful analysis of the prevalence of these species makes it possible to pinpoint the biotope in which a definite species is encountered on a large scale or, at any rate, in a larger percentage than in other biotopes. Such a phenomenon bespeaks, first of all, the affinity of a species for certain conditions; the solitary occurrence of specimens of species in other biotopes can be attributed to wider limits of adaptation inherent in free-living nematodes, especially primitive marine forms. Sometimes cases of occurrence of nematodes of a single species in biotopes markedly different from each other can be explained by their drifting with fragments of algae or erosion of beds by sea breakers. Nematodes are also subject to wide-flung dispersal by currents due to their ability to cling to the surface film of the water. An example of a widely distributed species is Pseudocella kurilensis; definite conclusions about its ecological affinity can be derived from its prevalence. This species was found at five places in the littoral zones of Kuril Islands in pieces of algae; however, in all five places only solitary specimens were collected. Contrarily, as many as 49 specimens were found among a dense mass of sponges caught in a probe at $25 \mathrm{~m}$ depth on a slightly silted bed. In all probability the latter biotope is favorable for the prevalence of this species.

The species Leptosomatides brevisetosum seems to thrive in the littoral zone where it can find shelter in thickets of large algae, although solitary specimens have been recorded from a sandy bottom at a depth of $53 \mathrm{~m}$.

It seems to me that grouping nematodes, as done by Wieser (1953), on the basis of their oral apparatus without taking into account their physiological indexes is incorrect. For example, in my material three species of Pseudocella would fall in group 2A but they apparently thrive under notably different conditions. $P$. trichodes is an inhabitant of littoral algae, while $P$. tenuis and $P$. elegans live in sublittoral silts. It is possible that $P$. trichodes is a more oxygen-loving form than $P$. tenuis and P. elegans.

The foregoing account shows that in spite of the few studies done to date the ecological characteristics of the family have been sufficiently defined to reveal its primitiveness. For a better understanding of the 
ecology of this group, obviously more field and experimental studies are needed.

\section{GEOGRAPHIC DISTRIBUTION}

The geographic distribution of free-living marine nematodes of this group is steeped in confusion and even vacuity.

In the 1920's and 1930's many researchers considered free-living marine nematodes cosmopolitan. The hypothesis was put forward that zonal climatic factors play no role in the distribution of nematodes (Steiner, 1915; Kreis, 1934). Chitwood (1936a, 1936b, 1937, 1951, 1960) disputed this point of view on the grounds that species found by him on the coast of America differed significantly from those found on the European coast. Authors of a number of contemporary studies (Gerlach, Mawson, Meyl, Timm, and Wieser) subscribe to this point of view and believe that among free-living marine nematodes there are far fewer cosmopolitan forms than indicated earlier. Thus Wieser (1953c) found an extremely small number of species of nematodes, common in the fauna studied by him, on the coast of Chile and in coastal waters of Europe. Gerlach (1955) studied the fauna of marine nematodes of the Pacific coast 50 of Central America, and Meyl $(1956,1957)$ nematodes of the coast of Brazil; they found a large number of new forms not seen in areas studied earlier.

Schuurmans-Stekhoven (1950) in his comprehensive work on nematodes of the Mediterranean Sea compared this fauna with that of the North, Baltic, Mramor, Black, and Azov Seas. He established that species of nematodes common to the North, Baltic, and Mediterranean Seas do not exceed $15 \%$ of all the nematode fauna of the Mediterranean Sea. Contrarily, the Mramor, Black, and Azov Seas have a much larger number of species common to the Mediterranean Sea (34.79\%). For the Mramor this figure was $65.0 \%$, the Black $29.5 \%$, and the Azov $33.3 \%$. Thus the fauna of the Mediterranean Sea reveals greater similarity to the fauna of the Mramor, Black, and Azov Seas than that of the more northern seas of Europe. Such an interrelation of the nematode fauna of these seas should be expected if the distribution of these organisms is subject to the same biogeographic phenomena as other groups of marine benthic organisms.

Data presented in a number of works by Allgen (1956a, 1956b, 1956c, $1957 \mathrm{a}, 1958 \mathrm{~b}, 1958 \mathrm{c})$ are none too clear in this respect. This author compares regions situated great distances apart. Comparing the Norwegian nematode fauna with that of other regions he states that at different points of the Norwegian coast significant percentages of species are found which are common to the Mediterranean Sea, tropical seas along 
the coasts of Australia and South America, and also the Antarctic and subantarctic.

In other works (1934a, 1954b) Allgen has stated that several species are bipolar in distribution. All the bipolar species in the northern hemisphere live mainly in temperate waters (coast of Norway, England, and France) and in the southern hemisphere in the subantarctic region (islands of Terra del Fuego, Falklands, Campbell, Kergelen, MacCoury, Tasmania, New Zealand) or even in the Antarctic. Thus the distribution of these nematodes is similar to other groups of bipolar organisms. It is interesting that while discussing the reasons for the bipolar distribution of nematodes, Allgen refutes the present theory about the bipolarity of species; their settling in various oceanic depths (Chun, 1897), along the western coasts of continents, particularly in relation to Quaternary glaciation (Ortmann, 1896; Berg, 1920), and bipolarity as a result of a uniformly wide distribution during the Tertiary period (Deryugin, 1915). Allgen holds that bipolar species as well as species known to exist only in one hemisphere are, as a matter of fact, much more widely distributed and their known occurrences are casual and fail to reflect the size of the area of occurrence. Thus in his zoogeographic concepts Allgen reverts to the old opinion that free-living marine nematodes are cosmopolitan forms.

Not negating the possibility of a bipolar distribution of nematodes, I nonetheless hold that for an accurate analysis of this problem a thorough morpho-systematic study of bipolar species is essential. In the works mentioned above Allgen includes two species of Leptosomatidae among bipolar species. The first, Pseudocella elegans, was discovered by Ditlevsen (1922) in the subantarctic but as he had only one specimen, not sexually mature, he gave no description. Ditlevesen later discovered (1926) a large number of sexually mature nemotodes in Skagerrak, which he considered identical to the subantarctic specimen, and gave a description of the species. It seems to me that on the basis of the foregoing account one cannot conclude that this species is bipolar in distribution.

Allgen labeled the second species, Thoracostoma coronatum, bipolar 51 in distribution because he annexed it with Triceratonema campbelli. I cannot accept this contention because the identification of these two forms is erroneous; the former should be considered a Mediterranean form and the latter Antarctic.

Rhabdodemania minor, Leptosomatum arcticum, Deontostoma arcticum, and Pseudocella trichodes appear at first glance to be species with a bipolar distribution.

Rhabdodemania minor has been recorded from the coast of Ireland to that of Murmansk and once recorded by Allgen (1959) from the coast of Antarctica. The occurrence of this species in the Antarctic Ocean appears 
dubious to me as only one female and two immature specimens were recorded, as a result of which identification could have been inaccurate. Specimens of Leptosomatum arcticum were recorded by Filip'ev from the Barents Sea near Murmansk (1916) and near the coast of Novaya Zemlya (1927). Mawson (1958b) found this species in the Antarctic and subantarctic. There are sufficient grounds to assume that here the authors were dealing with two different species. The species described by Filip'ev was based on a single female specimen and later a sexually immature specimen found by him near the coast of Novaya Zemlya. A large number of nematodes with mature males and females were at the disposal of Mawson. Having no opportunity to compare the males, on the basis of which a precise species identification is possible, Mawson made a mistake in identification and considered these two different species one.

The bipolar distribution of Deontostoma arcticum appears more valid. This species is often found in the lower Arctic and in boreal waters. It has occurred in large numbers along the southern coast of Chile (Wieser, 1953c) and in the Antarctic and subantarctic (Mawson, 1956, 1958b). Pseudocella trichodes is a species widely distributed in the littoral zone in Arctic and boreal waters, living mainly among larger algae. Allgen $(1951,1959)$ indicates the occurrence of this species on the south coast of Australia (one sexually immature specimen) and in the subantarctic in the sandy and silted-sand benthos of the sublittoral zone. Leptosomatum gracile and Synonchus fasciculatus have been recovered from the North Atlantic and Arctic Oceans. They were also detected by Allgen in the subantarctic region.

Thus the problem of the bipolarity of distribution of marine nematodes requires, in my opinion, a special exhaustive study.

If the distribution of marine nematodes is mainly subject to the same zoogeographic laws as the distribution of all other groups of marine benthic organisms, then one may essay, albeit in general outlines only, a zoogeographic classification of species and isolate groups of species characteristic for different seas. It should be noted beforehand, however, that specialists of other groups of marine benthos deal with organisms for which the zoogeographic characteristics are fairly clear. For marine nematodes this problem is still in the process of elucidation. To explain this phenomenon I want only to show the potentiality of a zoogeographic analysis of distribution of lower Enoplida. Marine nematodes in general have been studied too little to permit an exhaustive review. With the manifestation of affinity (adaptation) of an individual species to one or another zoogeographic entity, one can be guided by the scheme of zonation of the seas (to be exact, sublittoral) proposed by Ekman (1935, 1953), which is universally recognized.

Odontanticoma murmanica, Anticoma insulaealbae, Leptosomatum 
tetrophtalmum, Leptosomatides steineri, Pseudocella tenuis, and P. coecum are known from numerous points only in the Kara and Barents Seas. On the basis of their type of distribution they can probably be considered Arctic species. Other Arctic species include Deontostoma magnificum and Ritenbenkia micropapillata, and species described earlier in this work-Anticoma filipjevi, A. grandis, and Pseudocella gracilis. But since 52 these species were only found singly, it is difficult to make a statement about their distribution.

Anticoma arcticum A. minor, Rhabdodemania minor, $R$. gracilis, $R$. scandinavia and Synonchus murmanicus should probably be considered arctico-boreal species, because of their occurrence in the Kara and Barents Seas as well as in the boreal waters of Europe (North Sea and coast of England).

I cannot assign a number of species to a definite group because they constitute solitary specimens. However, as their habitats are widely dispersed in the Kara, Barents, and Norwegian Seas, the North Atlantic, and the North Sea, it may be that the following species will eventually be regarded as arctic, arctico-boreal, or less probably boreal species: Anticoma strandi, A. brevisetosa, Odontanticoma vanoorti, Crenopharynx armatus, Barbonema setifera, Platycomopsis cobbi, P. mesjatzevi, Leptosomatides microlaimum, L. crassus, Leptosomatum arcticum, L. groenlandicum, L. breviceps, Leptosomella acrocerca, Pseudocella conicaudata, $P$. saveljevi, $P$. filipjevi, and Deontostoma lobatum. There is an analogous collection of species known to occur only singly from the Bering Strait, Commander Islands, and the northern part of the Sea of Azov: Anticoma behringiana, A. curta, A. uschakovi, Rhabdodemania ochotensis, $R$. brevicaudata, Leptosomatum papillatum, L. grebnickii, L. behringicum, Pseudocella acuta, P. angusticeps, and Deontostoma papillatum. Like the species in the previous list, they are also arctico-boreal or upper boreal. However, at present it is not possible to define their biogeographic characters.

Anticoma eberthi, A. limalis, Crenopharynx marioni, Rhabdodemania laticauda, Leptosomatum gracile, Metacylicolaimus filicaudatus, $M$. obtusidens, M. flagellicaudatus, M. effilatus, and Fiacra longisetosa may be considered boreal-European forms distributed along the coasts of Norway, in the North and Baltic Seas, and along the coasts of England and France. From the records of solitary specimens it is possible that the following species may belong to this group: Anticoma zosterae, A. microseta, Barbonema horridum, Rhabdodemania striata, R. major, Platycomopsis effilatus, Leptosomatum caecum, Jaegerskioeldia acuticaudata, and Eusynonchus brevisetosus.

Species found by me near South Sakhalin and Kuril Islands may apparently be considered boreal or even lower boreal-Pacific forms: 
Odontanticoma dentifer, Leptosomatum acutipapillosum, L. brevisetosum, Anivanema magna, Pseudocella bursata, P. kurilensis, P. mamillifera, and $P$. truncaticauda. Probably Rhabdodemania illgi from the Pacific coast of North America, known only from one habitat, could be transferred to this group.

A significant number of anticomids and leptocomids live in the Mediterranean Sea. Frequently found species include: Anticoma pellucida, Platycoma cephalata, Crenopharynx paralepturus, Leptosomatum punctatum, L. bacillatum, Anivanema magna, Cylicolaimus (?) jaegerskioeldi, Eusynonchus hirsutus, Tuerkiana strasseni, Paratuerkiana comes, Deontostoma montredonense, Thoracostoma coronatum, and T. zolae.

Anticoma tyrrhenica, Crenopharynx metagracilis, C. brevicaudatus, Pseudocella cavernicola, and P. citronicauda have been recorded as isolated cases from the Mediterranean Sea. It is important to note that some of the species go beyond the limits of the Mediterranean Sea and are distributed in the north up to the coast of England, while others are not known beyond the limits of this sea.

From the Black Sea only five species have been recorded: Anticoma pontica, Leptosomatides euxina, Rhabdodemania pontica, Leptosomatum punctatum and $L$. bacillatum. Of these, the first three have been discovered only in the Black Sea to date.

53 In the Indo-West Pacific (Southeast Asia: Malayan Archipelago and along the Indian coast) single finds have been recorded for these species: Anticoma ditlevseni, A. aberrans, A. procera, A. profunda, Anticomopsis filicauda, A. tenuicollis, Paranticoma elegans, $P$. bandaensis, $P$. profunda, Platycomopsis filiappendicatus, Leptosomatum ranjhai, L. keiense, Leptosomatides reducta, Leptosomatina longisetum, Thoracostoma philippinensis, and T.karachense. To date these species have not been discovered outside the limits of this region.

Steiner and Albin (1933) and Allgen (1951) recorded the following species of anticomids and leptosomatids along the Pacific coast of Central America: Anticomopsis tenuis, Leptosomatum pedroense, Deontostoma microlobatum, D. anchorilobatum, D. jollaensis, D. californicum, and Pseudocella panamaense. Only isolated specimens were found, however.

Anticomids and leptosomatids are particularly numerous in the Antarctic and subantarctic. Species repeatedly encountered include: Anticoma longissima, A. dahli; A. tenuis, A. filicauda, A. subsimilis, A. major, A. columbia, A. campbelli, A. australis, A. wieseri, Paranticoma antarctica, Crenopharynx antarcticus, Platycomopsis dimorphica, Deontosoma auclandiae, D. antarcticum, Thoracostoma anocellatum, $T$. vallini, T. angustifissulatum, T. campbelli, $T$. setosum, T. australe, Pseudocella brachychaites, $P$. tabarini, and $P$. polychaetes. Species found only once: Anticoma lata, A. kerguelensis, A. extensa, A. longisetosa, A. graciliceps, 
Paranticoma odhneri, P. tubuliphora, Anticomopsis gibbonensis, Crenopharynx serialis, C. crassus, Rhabdodemania calicolaimus, Platycomopsis paracobbi, Leptosomatum australe, $L$. crassicutis, L. kerguelense, L. clavatum, Leptosomatides conisetosum, Deontostoma papillosum, D. demani, Thoracostoma chilensis, $T$. schizoepistylium, $T$. parasetosum, and $T$. brunni. The study of marine nematodes is too inadequate to permit a statement as to which species are exclusively adapted to the subantarctic and which to the Antarctic. However, it may be noted that most of these species are known from both the subantarctic and the Antarctic.

The distribution of four species of Anticoma has given rise to doubts. Anticoma pellucida is widely distributed in the Mediterranean Sea. It has also been detected in the North Sea and the North Atlantic as far as the Barents Sea. Allgen (1927b) recorded this species for the subantarctic. $A$. acuminata has also been mainly found in the Mediterranean Sea and adjacent seas; it has also been recorded from Zond Islands (Micoletzky, 1930), the Pacific coast of North America (Wieser, 1959), and in Antarctic and subantarctic waters (Allgen, 1959). A. limalis is often found in the Arctic, North Atlantic, North Sea, and the western part of the Baltic Sea. Allgen recorded this species near the coast of California (1947b), for the Pacific and Atlantic coasts of Central America (1947a, 1951), the Caribbean Sea, the Philippines, the Hawaiian Islands, and the Antarctic and subantarctic (1959). A. similis has been recorded from the coast of Australia, Terra del Fuego, in the subantarctic, Antarctic, and Zond Islands. Probably these four species could have been classed as cosmopolitan had their taxonomic status not undergone so much confusion. As is mentioned in the taxonomic part of this work, some were combined repeatedly into one species and then separated subsequently. The limits of these species have not yet been distinctly defined. Hence the problem of their distribution must remain open.

Three species of Leptosomatum also appear at first glance to be cosmopolitan in distribution. L. bacillatum is widely distributed in the Mediterranean and adjacent seas and has also been recorded from the Norwegian and Caribbean Seas, on the coast of California and South Australia, and in the subantarctic and Antarctic. However, Allgen (1940a, 1943, 1947, 1951, 1959) had insufficient material at his disposal: most of it comprised females and sexually immature specimens. For this reason I am inclined to consider $L$. bacillatum a Mediterranean species. L. sabangense was first 54 recorded from the islands of Zond by Steiner (1915). Later this author mentions the discovery of this species along the coast of Venezuela; as only a single sexually immature specimen was found I fear his identification may have been erroneous. Micoletzky recorded this species from the Red Sea (1922) and Allgen from the Mediterranean Sea, the coast of California, Panama (along the Pacific coast), Australia, and the Falkland 
Islands. In every instance only one to three specimens were recovered and these too were sexually immature. For this reason I consider it an Indo-West-Pacific species. L. elongatum is widely distributed in the arctic and boreal regions. It has been found in the Mediterranean Sea, in the tropical part of the Indian Ocean, in the Pacific Ocean, on the coast of Panama and California, on the western coast of Australia, in the subantarctic and Antarctic.

It is extremely difficult to determine the geographic distribution of some species. Anticoma ditlevseni was first recorded by Micoletzky near the islands of Zond (233 specimens). Most of the specimens were sexually mature. Allgen has recorded the occurrence of one female of this species from the coast of Norway. Anticomopsis typicus was also recorded for the first time by Micoletzky near the islands of Zond. Luc and de Coninck (1959) discovered a male and female of this species in LaManshe. Wieser (1953c) recorded Pseudocella kreisi for the first time on the coast of Chile (one specimen which was sexually immature). Later (1956), he found one male off Sri Lanka (Ceylon) at a depth of 3,400 m. Thoracostoma steineri was described by Micoletzky (1922) on the basis of one female specimen found in the Red Sea. Later (1930) he found a significant number of sexually mature specimens of this species on the islands of Zond. Allgen found this species in the Mediterranean Sea and on the coast of California. Schuurmans-Stekhoven $(1943,1950)$ also discovered it in the Mediterranean Sea but his description differs significantly from that given by Micoletzky.

The material presented, it seems to me, bears testimony to the fact that free-living marine nematodes are not universally (ubiquitously) distributed organisms. Each zoogeographic region corresponds strictly to a well-defined group of species. Most of the data about the extremely wide distribution of species reflects an inadequate study of their systematics.

Studies of the zoogeographic characteristics of genera of lower enoplids are almost impossible today. All the genera, irrespective of species composition, are transoceanic and only some, mainly monotypic ones, have an affinity for definite regions.

In conclusion, it must be stated that the main problem in the analysis of the geographic distribution of nematodes is inadequate study of their fauna in most regions of the world. An accumulation of faunistic information in the future should significantly elucidate their zoogeographic analysis.

\section{COLLECTION AND PROCESSING OF NEMATODES}

Collecting nematodes is a very simple but laborious process. Information on this procedure is available in the works of Filip'ev (1926b) and 
Goodey (1959). In the littoral zone samples are collected manually from the benthos and algae at rather shallow depths with the help of dredges operated from a boat. In the sublittoral zone benthos is scooped up by standard equipment used for such purposes, i.e., various types of trawls and dredges. Extracting nematodes from the seabed is not so easy. The method of "thorough-wash" is preferable for obtaining nematodes in a more concentrated mass. In this method the probe situated in Koch's cup is shaken vigorously and the contents poured into another container. Only larger, coarse particles of the benthos remain at the bottom of Koch's cup. This operation is repeated several times. The poured-off water contains nematodes and fine particles of benthos. It is filtered through a sieve with a fine mesh (No.69) to remove the fine particles of silt. The benthos remaining on the sieve and containing a large number of nematodes is examined under a binocular microscope in Bogorov's chamber. Worms thus isolated are preserved in $70^{\circ}$ alcohol or $4 \%$ formalin.

55 When nematodes are collected from algae the latter is shredded and separated in a large glass container. The material is then filtered through a sieve of large mesh to separate the algal fragments. The filtrate, containing small fragments of algae and nematodes, is subsequently passed through a sieve of fine mesh (No. 69). The remaining mass is either preserved as a whole or subjected to selection; nematodes freed from foreign particles and floating in clean water are preserved.

To make preparations of nematodes the worms are transferred from the preservation medium to a mixture of equal volumes of $96^{\circ}$ alcohol, distilled water, and glycerine, and kept there for 3 to 12 days depending on the size and transparency of the nematodes. In this mixture the nematodes become transparent, after which they are transferred to pure glycerine for 12 to 20 hours. Nematodes processed in this manner are mounted in a glycerine-gelatin medium.

\section{Systematics}

Certain clarifications are necessary before proceeding with the taxonomic classification of Enoplida. First of all, the order Enoplida is divided into two superfamilies-Enoploidea and Leptosomatoidea. A characterization of each superfamily is presented, followed by a key to families which, in addition to serving the purpose of identification, gives some idea about the size of each superfamily. This information is essential to my later detailed discussion of the four families-two from each superfamily. 
Species earlier assigned to just family Leptosomatidae and recorded from marine bodies of the Soviet Union are described herein and redistributed in four families-Leptosomatidae, Anticomidae, Rhabdodemaniidae, and Crenopharingidae. Species present in my material are not only described but depicted in original illustrations. All the measurements of body parts are based on my own material. For species not represented in my material but described by other authors from these seas, I have presented the published descriptions which, because they vary in style, could not be fitted into the scheme adoped for describing species at my disposal. Descriptions taken from literature are asterisked. Species encountered in the seas of the Soviet Union are numbered in the keys.

\section{Order ENOPLIDA S chuurmans-Stekhoven and Coninck, 1933}

Free-living nematodes of rather large size, complete in organization, and subject to less reduction (Filip'ev 1918, p. 37). Characters: cuticle almost always smooth, but nematodes of the family Lauratonematidae with annulations constitute an exception. Oral opening encircled by six papillae (occasionally setae); another circle, consisting of ten papillae, or two circles, one consisting of six and the other of four setae (occasionally papillae) situated on head. Occasionally setae of first circle totally reduced. Amphids cyathiform with transverse slit either elliptical or longitudinally elongated. Esophagus almost cylindrical, sometimes gradually broadening toward base. Esophageal glands often open sublaterally in lower part of oral cavity. Esophagi characteristic of the order either fuse with the cuticle anteriorly or show signs of an earlier attachment, disappearing subsequently due to powerful development of the oral cavity. Oral cavity later loses its capacity to extrude due to weak development and differentiation of muscles of anterior end of esophagus. Structure of oral cavity highly variable. Genital tubes mostly paired; family Lauratonematidae exceptional in which females have reproductive tubes with a reduced posterior part.

\section{Key to Superfamilies of Order Enoplida}

561 (2). Esophagus with wavy margin in posterior part, rarely cylindrical. Oral cavity sharply divided into two parts: buccal cavity with jaws or buccal stylets or simply lined with sclerotized cuticle, and onchial cavity often armed with onchia. Esophageal musculature extends anteriorly only up to anterior margin of onchial cavity......... 
2. Enoploidea Baird, 1853.

2(1). Esophagus cylindrical and without wavy margin. Oral cavity either not expressed or without sharp division into buccal and onchial parts. Onchia, if present, displaced toward oral opening due to protrusibility of oral musculature almost up to oral opening......

.1. Leptosomatoidea Filipjev, 1918.

\section{Superfamily LEPTOSOMATOIDEA Filipjev, 1918}

Sclerotized cephalic capsule well developed in many representatives. Oral cavity either completely reduced or with a simple structure and not divided into buccal and onchial parts. Additionally, its armature never represented by jaws or buccal stylets. Of the derivatives of the buccal cavity, only development of odontia (Cylicolaimus for example) possible. More often in forms with oral armature, odontia represented by onchia (derivatives of onchial cavity), which are notably shifted toward oral opening due to protrusibility of esophageal musculature. Esophagus widens gradually from anterior end toward base; alveolate structure never observed in posterior half. Cuticle covering the body thick, smooth, and often with fascicles of intersecting fibers in external layer. Amphids in most forms round or cyathiform. Some representatives of Oxystominidae have extremely narrow, and longitudinally elongated amphids.

\section{Key to Families of Superfamily Leptosomatoidea}

1 (8). Cephalic setae (10 in number) situated in single circle. Amphids usually cyathiform.

2 (7). Cephalic capsule either poorly or well developed; oral cavity cyathiform, sometimes extremely short or not developed at all.

3 (4). Cephalic capsule very poorly developed; oral cavity armed with three onchia which resemble mandibles

Triodontolaimidae de Coninck, 1965. ......... [Only species: Triodontolaimus acutus (Villot, 1875)].

4 (3). Oral cavity unarmed or its armature represented by typical onchia.

5 (6). Cephalic capsule either absent or so poorly developed as to be undetectable. Body tapers distinctly toward both ends.......... ....................... Anticomidae Filipjev, 1918.

6(5). Cephalic capsule always present and represented by powerful sclerotized structure in a number of forms. Body tapers slightly toward anterior end but negligibly toward posterior end........ .................... Leptosomatidae Filipjev, 1916.

7 (2). Cephalic capsule absent; oral cavity in the shape of a long, narrow cylinder.................... Ironidae de Man, 1876. 
578 (1). Cephalic setae situated in two circles (six plus four); some setae reduced in some forms. Amphids with large openings, sometimes highly elongated in longitudinal direction............... .Oxystominidae Micoletzki, 1924.

\section{Family LEPTOSOMATIDAE Filipjev, 1916}

Large free-living marine nematodes, ranging from 10 to $50 \mathrm{~mm}$ in length. Cuticle thick, often multilayered. Ten cephalic setae always arranged in one circle. Mouth encircled by six papillae. Some genera with eyes or spots of photosensitive pigment. Esophagus straight, without bulbs. Cardia large, triangular. Most characteristic features of family: presence of sclerotized cephalic capsule with various degrees of complexity evident in endocuticle. More or less developed oral cavity armed with onchia or odontia in a number of forms. Gonads always paired and no sign of their reduction ever observed. Females with paired gonads, genital ducts, and uteri. Only testes paired in males, which later merge into an unpaired vas deferens and ejaculatory duct. Spicular apparatus of males highly diverse in structure but always consists of a pair of spicules and a gubernaculum. Gubernaculum with paired or unpaired processes. Most species of this family have an accessory organ, anal setae, and papillae. Caudal glands three, tubular or fusiform, and almost always open terminally at the tip of the tail.

\section{Key to Subfamilies of Family Leptosomatidae}

1 (4). Cephalic capsule highly developed, thick-walled.

2 (3). Interlobular grooves of cephalic capsule differentiated into narrow furrows and wide fenestrae; lateral grooves differ in shape from the

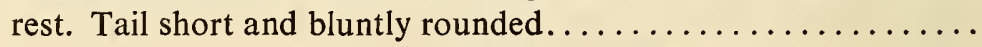

3. Thoracostominae de Coninck, 1965.

3 (2). Interlobular grooves of cephalic capsule not differentiated and uniform in shape. Tail elongated and claviform.............. .................... Synonchinae Platonova, 1970.

4 (1). Cephalic capsule poorly developed, thin-walled.

5 (6). Oral cavity highly developed, thick-walled, and armed with onchia. ..Cylicolaiminae Platonova, 1970. 6 (5). Oral cavity not developed....... Leptosomatinae Filipjev, 1916.

\section{Subfamily LEPTOSOMATINAE Filipjev, 1916}

Nematodes with poorly developed, short cephalic capsule. Cephalic suture straight or slightly wavy and without interlobular grooves. Lepto- 
somatides conisetosum, with a cephalic suture with a deep groove, constitutes an exception. ${ }^{1}$ Amphids always situated below line of cephalic suture. Cephalic ring narrow. Oral cavity poorly developed, almost absent. Esophagus encircled by nerve ring between anterior third and fourth part. Sclerotized granules sometimes present around the vulval slit on cuticular surface. Tail short and bluntly rounded in most representatives of family. Cephalic and preneural setae extremely short; latter 58 sometimes absent. Posterior body end in males may or may not be armed with setae. Well-developed photosensitive eyes present in most representatives of subfamily.

\section{Key to Genera of Subfamily Leptosomatinae}

1 (2). Tail claviform.............. Leptosomelia Filipjev, 1927.

2(1). Tail conical, rounded, or acicular.

3 (6). Eyes present.

4 (5). Gubernaculum small, without processes.................

.1. Leptosomatum Bastian, 1865.

5 (4). Gubernaculum large, with large dorsal process.............

2. Leptosomatides Filipjev, 1918.

6(3). Eyes absent.

7 (8). Spicules with velum. Gubernaculum with ventral and dorsal processes.................Paraleptosomatides Mawson, 1956.

(Two species: P. spiralis Mawson, 1956

and P. elongatus Mawson, 1956.)

8 (7). Spicules without velum. Gubernaculum with dorsal process only. .Leptosomatina Allgen, 1951. (Two species: L. longisetum Allgen, 1951 and $\mathbf{L}$. appendixocaudatum Allgen, 1957.)

\section{Genus Leptosomatum Bastian, 1865}

Bastian, 1865: 144; Eberth, 1863: 18 (Phanoglene non Nordmann, 1841); de Man, 1893; 102; Filip'ev, 1961: 65; 1918: 42.

Type species. L. elongatum Bastian, 1865.

Nematodes of large size. Body tapers slightly toward anterior end and almost not at all posteriorly. Head slightly truncated. Cephalic capsule, though poorly developed, with walls which may vary significantly in width. Cephalic ring varies in position within limits of upper half of

IIt is possible that this species will be transferred in the future to another genus or even to another subfamily. Having no material at my disposal, I could not solve this problem just now. 
cephalic capsule. Labial papillae distinct. Cephalic setae similar to preanal setae but occasionally rudimentary with appearance of small papillae. Anal setae absent. Amphids circular. Oral cavity poorly developed. Esophagus immediately apposed to oral opening. Lips and anterior part of esophageal wall often sclerotized and thickened. Vulva situated midbody. Spicules simple in structure and slightly arcuate; in some species only proximal part curves sharply. Gubernaculum small and simple in structure. Most species with preanal glands but no distinct accessory organ on outlet on wall surface. Accessory organ well developed only in L. keiense and L. ranjhai; preanal papilla also present in latter species.

In the description of species of both Leptosomatum and Leptosomatides figures in Cobb's formula indicate the distances of the following parts of the body from the anterior end: 1 . posterior end of cephalic capsule; 2 . pigmented eyes; 3 . nerve ring; 4 . base of esophagus; 5 . commencement of anterior genital tube; 6 . vulva; 7 . commencement of posterior genital tube; and 8. anus.

For the male the first four measurements are those given for the female. The dash which follows indicates the middle of the male body. The last figure indicates the distance from the anterior end to the anus. The corresponding width of the body is given below the line for those parts of the body described above.

\section{Key to Species of Genus Leptosomatum}

1 (38). Photosensitive eyes in preneural region.

2 (37). One pair of photosensitive eyes present, consisting of pigment bowl and light-refracting lens.

593 (4). Cephalic capsule very short; width exceeds length six times....

8. L. breviceps Platonova, 1967.

4 ( 3). Cephalic capsule significantly longer; width exceeds length by not more than three times.

5 (12). Cephalic setae well developed.

6( 7). Head highly flattened............. australe Linstow, 1906.

7 ( 6). Head anteriorly rounded.

8 (9). Amphids situated from anterior end at a distance equal to 3.5 times the cephalic diameter......... Micoletzky Inglis, 1971.

9 ( 8). Amphids situated from anterior end at a distance equal to 1.0 to 1.5 times the cephalic diameter.

10 (11). Width of amphids equal to one-third corresponding body width. ..................... 6. . punctatum (Eberth, 1863).

11 (10). Width of amphids equal to one-fourth corresponding body width................... keiense Micoletzky, 1930. 
12( 5). Cephalic setae either rudimentary, resembling papillae, or more often absent.

13 (18). Males with accessory organ.

14 (15). Cuticular rays present on cephalic capsule.............. .L. ranjhai Timm, 1960.

15 (14). Cuticular rays absent on cephalic capsule.

16 (17). Lens-shaped broadening occurs in anterior part of esophagus. 4. L. bacillatum (Eberth, 1863).

17 (16). Lens-shaped broadening does not occur in anterior part of esophagus................... . L. gracile Bastian, 1865.

18 (13). Males without accessory organ.

19 (26). Cephalic setae rudimentary and do not project on surface of cuticle.

20 (21). Cephalic setae pierce cuticle and form a coronet on cephalic capsule................. crassicutis Platonova, 1958.

21 (20). Coronet on cephalic capsule absent.

22 (23). Head broadens and appears clavate in region of cephalic setae. . ...................... clavatum Platonova, 1958.

23 (22). Broadening of head in cephalic region not evident.

24 (25). Amphids cordate..........L. kerguelense Platonova, 1958.

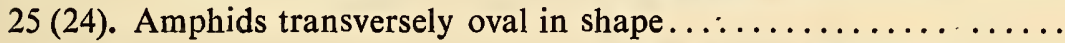

.................... sabangense (Steiner, 1915).

26 (19). Cephalic setae short but nonetheless project on cuticular surface.

27 (28). Tail extremely short; length does not exceed three-fourths of anal diameter................ pedroense Allgen, 1947.

28 (27). Tail length exceeds anal diameter.

29 (30). Body diameter near eyes equal to 2.5 times cephalic diameter. . ...................... L. behringicum Filipjev, 1916.

30 (29). Body diameter equal to twice cephalic diameter.

31 (34). Eyes situated at a distance twice cephalic diameter from anterior end.

32 (33). Lateral organs equal to one-sixth cephalic diameter from anterior end............... L. grebnickii Filipjev, 1916.

33 (32). Lateral organs equal to one-tenth cephalic diameter from anterior end................ L. arcticum Filipjev, 1916.

34 (31). Eyes situated at a distance thrice cephalic diameter from anterior end.

35 (36). Spicular capitulum demarcated from body of spicule by a distinct necklike constriction......5. L. elongatum Bastian, 1865.

6036 (35). Spicules with no necklike constriction.................

.L. acephalatum Chitwood, 1936.

37 ( 2). Two pairs of photosensitive eyes present; on pair consists of pig- 
ment bowl and light-refracting lens and second pair simple collection of pigment........ 7. L. tetrophtalmum Saveljev, 1912. 38 ( 1). Photosensitive eyes absent.

39 (40). Cephalic setae extremely long; length equal to one-half cephalic diameter.................. caecum Ditlevsen, 1923.

40 (39). Cephalic setae short.

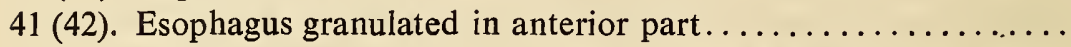

42 (41). Esophagus not granulated.

43 (44). Width of amphid one-sixteenth corresponding cephalic diameter. .L. abissale Allgen, 1915. 44 (43). Width of amphid one-third corresponding cephalic diameter. . .L. groenlandicum Allgen, 1954.

1. Leptosomatum arcticum Filipjev, 1916 (Figure 14)

Filip'ev, 1916: 66-68, tab IV, fig. 1; Mawson 1958b: 315, fig. la-c.

$$
1 \text { ㅇ: } \begin{array}{crrrrrrr}
20 & 120 & 335 & 1,275 & 6,200 & 7,550 & 9,100 & 10,725 \\
\hline 52 & 73 & 140 & 170 & \begin{array}{c}
- \\
\mathrm{b}=9 ;
\end{array} \mathrm{c}=62 ; \mathrm{V}=69 \% .
\end{array}
$$

Body elongated, fairly thick, and tapers to almost $1 / 4$ midbody diameter at anterior end and to $5 / 7$ midbody diameter at posterior end. Width of cephalic capsule 2.6 its length. Cephalic ring situated midlength of cephalic capsule. Cephalic suture slightly sinuous. Labial papillae rather short. Cephalic setae, like cervical ones, extremely short; length does not exceed $4.0 \mu \mathrm{m}$ (1/13 corresponding diameter). Amphids $7.0 \mu \mathrm{m}$ in diameter and situated $30 \mu \mathrm{m}$ from anterior end (1/40 esophageal length). Eyes situated $120 \mu \mathrm{m}$ from anterior end (1/10 esophageal length).

61 Size of pigment bowl $5.0 \mu \mathrm{m} \times 9.0 \mu \mathrm{m}$; diameter of lens $7.0 \mu \mathrm{m}$. Esophageal wall near mouth highly sclerotized. Esophagus thin and widens slightly in posterior part. Nerve ring situated $335 \mu \mathrm{m}$ from anterior end (approximately $1 / 4$ esophageal length). Vagina thick-walled. Sclerotized granules scattered on cuticle around vulva. Genital tubes not detected.

Filip'ev, who described the species, mentions the following characters which distinguish it from other species: 1) L. elongatum-small size, small amphids, and better developed cephalic capsule; 2) L. bacillatum-twice larger but has smaller amphids and eyes; 3 ) L. terrophtalmum-absence of additional pair of eyes situated behind original eyes and more submedian position of vulva; 4) L. grebnickii-structure of cephalic capsule and much larger amphids; 5) $L$. behringicum-significantly better developed cephalic capsule, much larger amphids, and eyes and setal armature slightly reduced. 


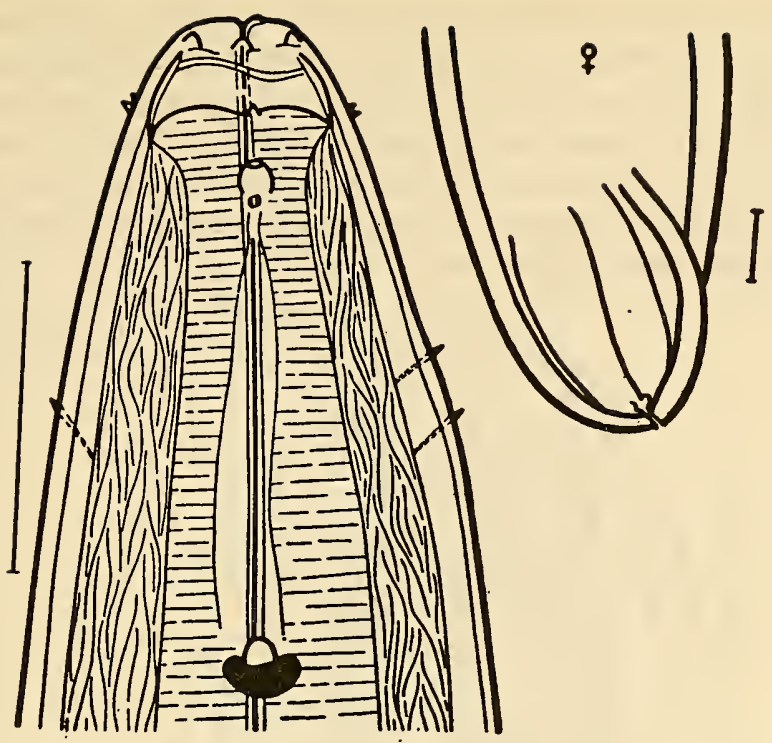

Geographic distribution. Barents Sea (littoral and sublittoral zones up to a depth of $5.0 \mathrm{~m}$, among Lithothamnion sp. and Laminaria sp.). Occurrence in subantarctic (Mawson, 1958b) dubious.

\section{Leptosomatum grebnickii Filipjev, 1916 (Figure 15)}

Filip'ev, 1916: 68-70, tab. IV, fig. 2.

Holotype : : Zoological Institute, Academy of Sciences, USSR. Collection nos. 5778,5779 .

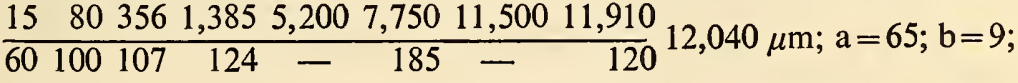

$$
\begin{aligned}
& c=92 ; V=64 \% \text {. }
\end{aligned}
$$

Body large and tapers to $1 / 5$ midbody diameter at anterior end and to 5/7 midbody diameter at posterior end. Caudal length equal to width. Cuticle $7.0 \mu \mathrm{m}$ thick, with fascicles of intersecting fibers. Cephalic capsule better developed than in L. arcticum; width 2.2 length. Cephalic ring situated in middle of cephalic capsule and narrower than in L. arcticum. Cephalic suture barely visible. Labial papillae larger and wider than in L. arcticum. Cephalic and cervical setae short, $5.0 \mu \mathrm{m}$ (1/12 corresponding diameter). Amphids situated $30 \mu \mathrm{m}$ from anterior end (1/4 esophageal 
length); diameter of amphids $9.0 \mu \mathrm{m}$ (1/6 corresponding body diameter). Eyes $80 \mu \mathrm{m}$ from anterior end (1/17 esophageal length). Pigment bowl $8.0 \mu \mathrm{m} \times 12.0 \mu \mathrm{m}$; diameter of lens $9.0 \mu \mathrm{m}$. Esophageal wall near oral opening greatly thickened. Nerve ring at a distance of $365^{\circ} \mu \mathrm{m}$ from anterior end (1/4 length of esophagus). Esophagus long, narrow, and widens slightly toward posterior end. Sclerotized granules scattered around vulva on cuticle. Genital tubes not detected.

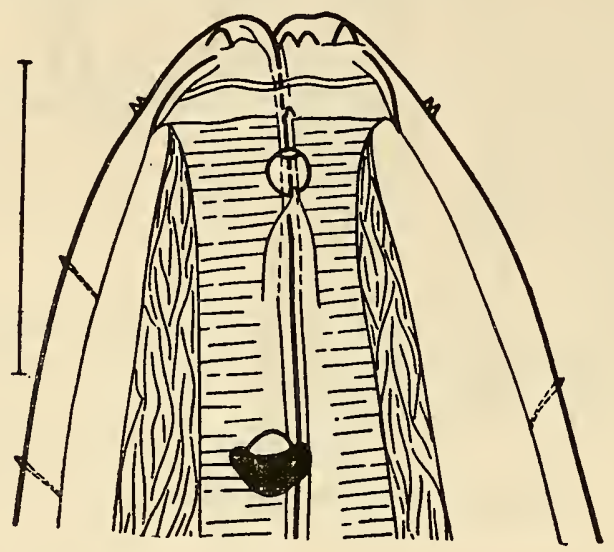

Figure 15. Leptosomatum grebnickii.

Very close to L. arcticum in structure, but differs from latter in wider, 62 shorter, and significantly less sclerotized cephalic capsule; significantly narrower cephalic ring; and much larger amphids.

Geographic distribution. Barents Sea.

3. Leptosomatum behringicum Filipjev, 1916 (Figure 16)

Filip'ev, 1916: 70-72.

Holotype $9:$ Zoological Institute, Academy of Sciences, USSR. Collection nos. 5780,5781 .

$$
\begin{aligned}
& \begin{array}{cccccccc}
80 & 82 & 295 & 1,100 & 2,650 & 5,300 & 8,700 & 9,673 \\
\hline 50 & 100 & 115 & 145 & - & 170 & - & 80
\end{array} 9,750 \mu \mathrm{m} ; \mathrm{a}=57 ; \mathrm{b}=9 \text {; } \\
& \mathrm{c}=126 ; \mathrm{V}=56 \% \text {. }
\end{aligned}
$$

Body tapers to $5 / 28$ midbody diameter at anterior end and to $1 / 2$ midbody diameter at posterior end. Tail extremely short; length almost equal to width in anal region. Cuticle $4.0 \mu \mathrm{m}$ thick, with fascicles of intersecting fibers. Cephalic capsule extremely short and wide; width exceeds length by 3.7 times. Cephalic ring very narrow and situated in upper part of cephalic capsule. Cephalic suture slightly sinuous. Labial papillae extremely minute. Cephalic setae also short, $2.0 \mu \mathrm{m}$ long $(1 / 25$ 
corresponding diameter). Cervical setae not detected. Amphids situated $25 \mu \mathrm{m}$ from anterior end (1/40 esophageal length). Diameter of amphids $5.0 \mu \mathrm{m}$ (1/9 corresponding body diameter). Eyes situated $82 \mu \mathrm{m}$ from anterior end of body (1/13 esophageal length). Pigment bowl small, only $5.0 \mu \mathrm{m} \times 8.0 \mu \mathrm{m}$; diameter of lens $5.0 \mu \mathrm{m}$. Esophageal wall sclerotized in oral region. Esophagus slender and broadens slightly in posterior part. Nerve ring situated $295 \mu \mathrm{m}$ from anterior end (1/4 esophageal length). Vulva situated midbody. Eggs spherical and 150 to $160 \mu \mathrm{m}$ in diameter. Genital tubes not detected.

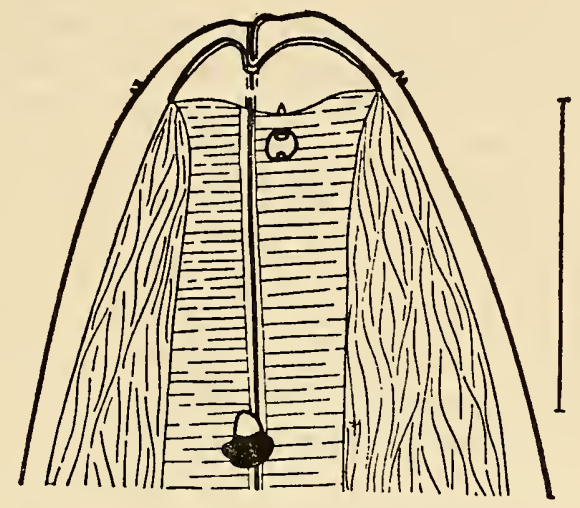

Figure 16. Leptosomatum behringicum.

Structurally close to $L$. grebnickii but distinguished from it in: 1) more weakly developed labial papillae; 2) more weakly developed setaceous armature; 3 ) position of cephalic ring situated in upper part of cephalic capsule in present species; 4) smaller size of amphids; and 5) smaller size of eyes.

Geographic distribution. Barents Sea.

\section{Leptosomatum bacillatum (Eberth, 1863) (Figure 17)}

Eberth, 1863: 19, 20, tab. II, figs. 1 to 4 (Phanoglene); Bastian, 1865: 146; Marion, 1870: 17, 18, pl. C., fig. 2 (Stenolaimus macrosoma); de Man, 1876: 103, tab. 8, fig. 9a, b: Filip'ev, 1918: 44-48, tab. 1, fig. 1; Allgen, 1940a: 488, Fig. 1a, b; Schuurmans-Stekhoven, 1950: 25-28, fig. 1a, b.

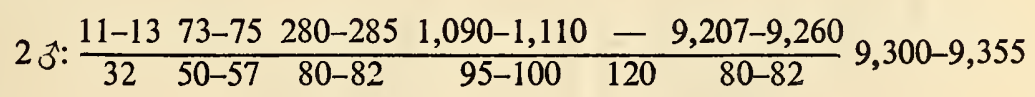

$$
\begin{aligned}
& \mu \mathrm{m} ; \mathrm{a}=78-79 ; \mathrm{b}=8-9 ; \mathrm{c}=98-100 .
\end{aligned}
$$

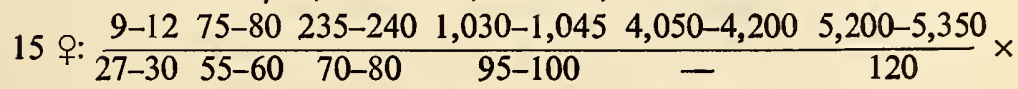




$$
\begin{gathered}
\times \frac{6,350-6,400 \quad 8,522-8,620}{80-85} 8,600-8,700 \mu \mathrm{m} ; \mathrm{a}=69-74 ; \mathrm{b}=8-9 ; \\
\mathrm{c}=110-145 ; \mathrm{V}=60 \% .
\end{gathered}
$$

Body tapers to $1 / 4$ midbody diameter at anterior end and $2 / 3$ at posterior end. Head rounded. Tail length almost equal to width. Cuticle bilayered and 5.0 to $6.0 \mu \mathrm{m}$ thick; thickness of exterior layer $1.0 \mu \mathrm{m}$. Fascicles of intersecting fibers extend into outer layer of cuticle. Cephalic capsule thick-walled; width three times length. Cephalic ring situated in uppermost part of cephalic capsule. Cephalic suture and labial papillae barely discernible. Cephalic and cervical setae extremely small, not exceeding $1.5 \mu \mathrm{m}(1 / 20$ corresponding diameter). Amphids situated 18 to $25 \mu \mathrm{m}$ from anterior end (1/50 esophageal length) and $8.9 \mu \mathrm{m} \times 7.5 \mu \mathrm{m} \mathrm{(1/4} \mathrm{to}$ $1 / 5$ corresponding body diameter). Diameter of amphid opening $2.5 \mu \mathrm{m}$. Eyes situated 73 to $80 \mu \mathrm{m}$ from anterior end (1/13 to $1 / 14$ esophageal length). Pigment bowl $12.0 \mu \mathrm{m} \times 10.0 \mu \mathrm{m}$; diameter of lens $5.0 \mu \mathrm{m}$. Esophageal walls thick in this region. Two grooves with thick sclerotized walls form lens-shaped dilatations 15 to $18 \mu \mathrm{m}$ from anterior end in wall of esophagus. Nerve ring situated 235 to $285 \mu \mathrm{m}$ from anterior end (1/4 esophageal length). Esophagus and genital tubes usual in size for such structures. Uterus occupies $2 / 3$ of entire genital tube. Eggs 200 to 250 $\mu \mathrm{m} \times 70$ to $80 \mu \mathrm{m}$. Spicules straight, with rectangular head curved at an angle, and $90 \mu \mathrm{m}$ long. Length of gubernaculum $25 \mu \mathrm{m}$. Accessory organ and anal papillae present but barely visible in my preparations.

The important characters distinguishing this species from others in the genus are: 1) lens-shaped expansions in anterior part of esophagus; and 2) straight spicules with almost rectangular head curved at an angle to the spicular body.
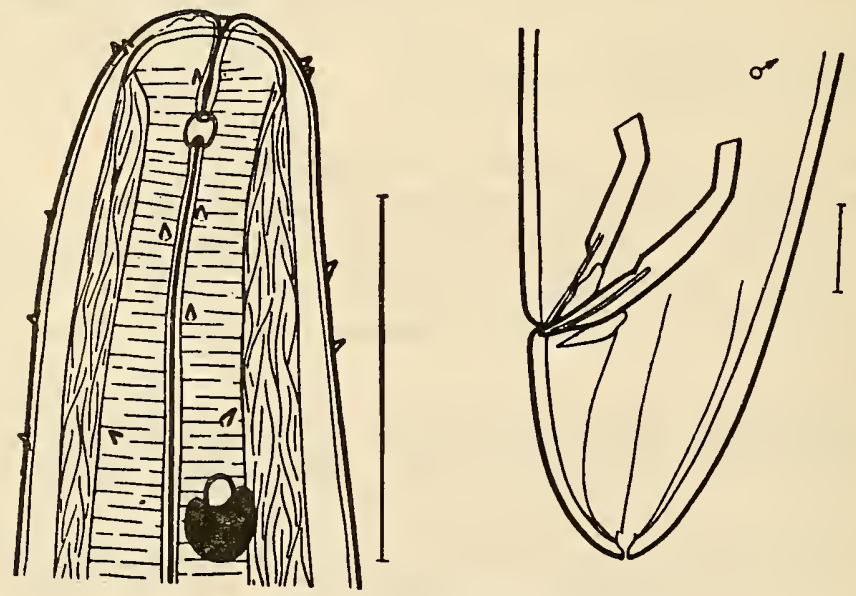

Figure 17. Leptosomatum bacillatum. 
Geographic distribution. Black Sea (along the coastal strip among algae and on banks of mussels in silty and sandy benthos in a depth range of 10 to $96 \mathrm{~m}$ ) and Mediterranean and Red Seas.

The distribution of this species given by Allgen is dubious. It is diffcult to explain its presence on the coast of Norway (1940a), the Pacific coast of Panama and California (1947c), the Hawaiian Islands (1951), and all along the coast of Argentina right up to Terra del Fuego (1959). The occurrence of this species in the subantarctic and on the coast of Norway are particularly questionable, especially since the author had only one female specimen for Norway. It seems to me that another species of this genus was involved. Identification of females of species of this genus is a very difficult task.

64 5. Leptosomatum elongatum Bastian, 1865 (Figure 18)

Bastian, 1865: 145, pl. XII, figs. 156, 157; de Man, 1893: 103-107, pl. VI, fig. 9.

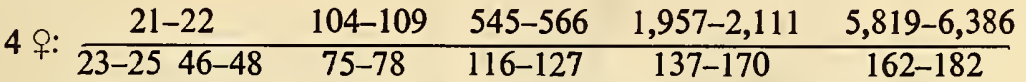

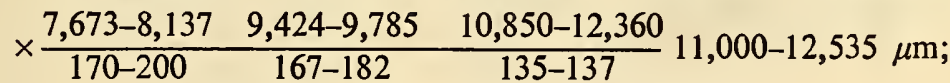

$$
\begin{aligned}
& a=61-74 ; b=6 ; c=72-81 ; V=63-65 \% \text {. }
\end{aligned}
$$

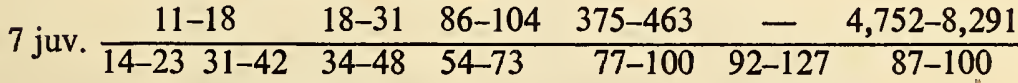

$$
\begin{aligned}
& \times 4,827-8,428 \mu \mathrm{m} ; \mathrm{a}-53-66 ; \mathrm{b}-4-5 ; \mathrm{c}-63-65 \text {. }
\end{aligned}
$$

Body rather long and tapers to $10 / 37$ to $5 / 21$ midbody diameter at anterior end and $5 / 6$ to $5 / 7$ at posterior end. Length of tail equal to width. Cuticle 8.0 to $9.0 \mu \mathrm{m}$ thick, with fascicles of intersecting fibers. Cephalic capsule with rather thick walls; width at base exceeds length by 2.2 times. Cephalic ring rather massive. Cephalic setae short, $2.32 \mu \mathrm{m}$ long ( $1 / 20$ corresponding diameter). Cervical setae even shorter, $1.5 \mu \mathrm{m}$ long. Amphids 29 to $34 \mu \mathrm{m}$ from anterior end (1/60 esophageal length) and $7.0 \mu \mathrm{m}$ in diameter (1/8 corresponding body diameter). Eyes situated 104 to $109 \mu \mathrm{m}$ from anterior end (1/20 esophageal length). Pigment bowl $9.28 \mu \mathrm{m} \times 11.6 \mu \mathrm{m}$; diameter of lens $5.8 \mu \mathrm{m}$. Lips somewhat thick. Nerve ring situated 545 to $566 \mu \mathrm{m}$ from anterior end (1/4 esophageal length). Length of anterior female genital tube 1,751 to $1,854 \mu \mathrm{m}$ and reflexed part 1,030 to $1,236 \mu \mathrm{m}$; of posterior tube 1,648 to $1,751 \mu \mathrm{m}$, and reffexed part 1,030 to $1,133 \mu \mathrm{m}$. In one female eggs $412 \mu \mathrm{m} \times 133 \mu \mathrm{m}$ were detected in each uterine branch. Vulva surrounded by sclerotized granules and situated somewhat posterior to midbody.

Regrettably there was no male of this species in my material. Hence the distinctive features of this species are restricted to the cephalic struc- 


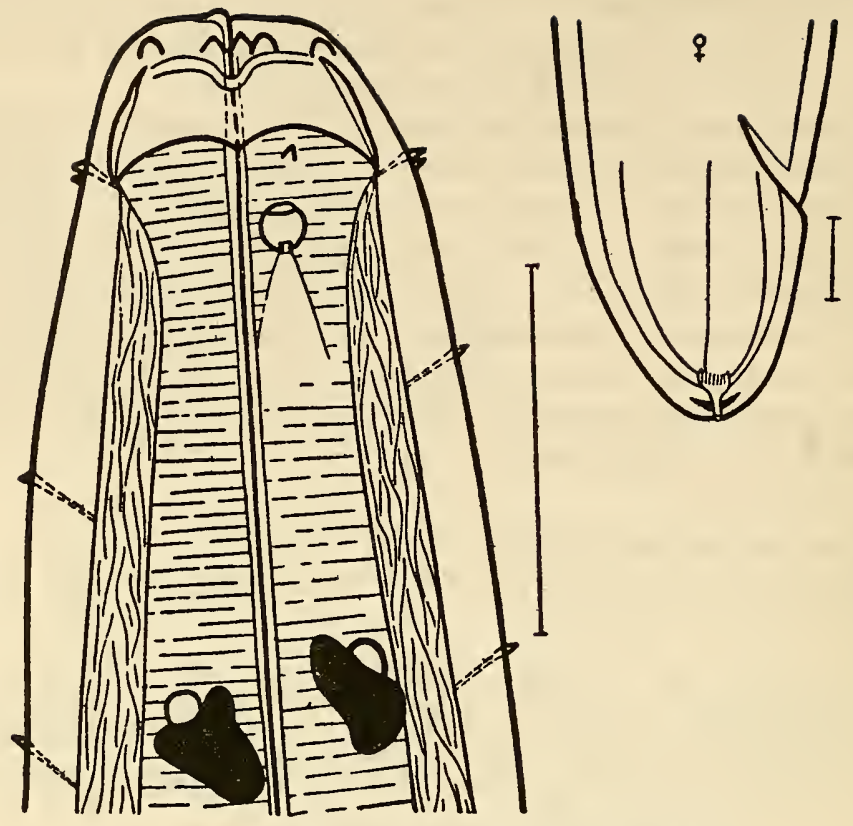

Figure 18. Leptosomatum elongatum Bastian.

65 ture, namely, its thick walls, cephalic ring situated in the upper part of capsule, and a distinct cephalic suture forming wide semicircular grooves separated by acicular projections.

Geographic distribution. This species in all probability is cosmopolitan. It has been found in the Barents Sea (predominantly in the littoral zone among shells or in sand), the Mediterranean Sea, coast of California, tropical part of the Indian Ocean, coast of Australia, and in the Antarctic and subantarctic.

6. Leptosomatum punctatum (Eberth, 1863) (Figure 19)

Eberth, 1863: 20, 21, tab. 2, figs. 5-7 (Phanoglene); Bastian, 1865: 145; Filip'ev, 1918: 48-50, tab. I, fig. 2.

$$
\begin{aligned}
& 1 \text { ऊ }: \begin{array}{cccccc}
8 & 105 & 350 & 1,080 & - & 7,905 \\
26 & 50 & 80 & 95 & 100 & 80
\end{array} 8,010 \mu \mathrm{m} ; \mathrm{a}=80 ; \mathrm{b}=7 ; \mathrm{c}=77 \text {. } \\
& 1 \text { ㅇ: } \begin{array}{cccccccc}
10 & 100 & 360 & 1,100 & 4,006 & 4,158 & 5,437 & 8,359 \\
\hline 25 & 48 & 80 & 90 & - & 120 & - & 90
\end{array} 8,470 \mu \mathrm{m} \text {; } \\
& a=70 ; b=8 ; c=76 ; V=49 \% \text {. }
\end{aligned}
$$

Body tapers to $1 / 3$ midbody diameter at anterior end and $10 / 13$ at posterior end. Cuticle bilayered; outer and inner layers equal in thickness, $6.0 \mu \mathrm{m}$ on the average. Cephalic capsule thick-walled; width exceeds 
length by 3.2 times. Cephalic suture barely discernible. Cephalic ring not distinct in my preparations; it appeared narrow and was situated midlength of the head. Labial papillae short. Cephalic and cervical setae rather long. Cephalic setae $6.0 \mu \mathrm{m}$ long (1/4 corresponding diameter); cervical setae slightly shorter, $5.0 \mu \mathrm{m}$ long. Amphids situated $30 \mu \mathrm{m}$ from anterior end (1/30 esophageal length); diameter of amphids $8.0 \mu \mathrm{m}(1 / 3$ corresponding diameter). Eyes situated $105 \mu \mathrm{m}$ from anterior end (1/10 esophageal length). Pigment bowl $10 \mu \mathrm{m}$ wide; diameter of lens $4.0 \mu \mathrm{m}$. Anterior margin of cephalic capsule forms rectangular depression in oral region which Filip'ev (1918) called a "pocket". Esophageal wall highly sclerotized near oral opening; thickening extends up to level of amphids. Esophagus rather narrow, almost not expanding posteriorly. Male spicules approximately uniform in width almost throughout their length, 66 narrowing only in the distal (sharply curved) part in the middle, and 65 $\mu \mathrm{m}$ long. Gubernaculum $20 \mu \mathrm{m}$ long. Accessory organ situated $112 \mu \mathrm{m}$ anterior to anus. Anal papillae absent.
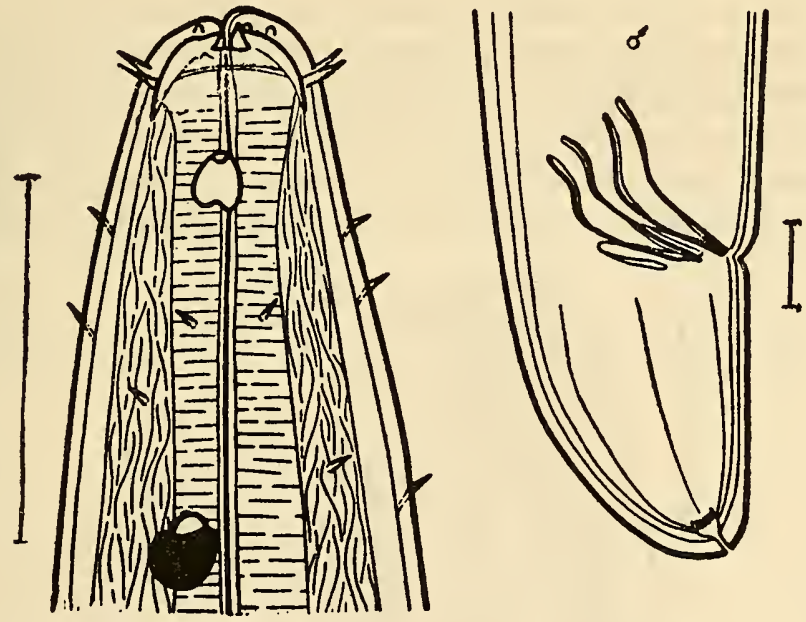

Figure 19. Leptosomatum punctatum.

Close to $L$. bacillatum, but differs in the following characters: 1) cephalic setae much longer, constituting $1 / 4$ corresponding cephalic diameter versus $1 / 20$ in L. bacillatum; 2) cuticular pockets present lateral to oral aperture in L. punctatum; and 3) spicules curved in middle portion (spicules straight in L. bacillatum).

Geographic distribution. Found mainly in the Black Sea in silt and among shells in a depth range of 40 to $100 \mathrm{~m}$, and in algae of the coastal belt of the Mediterranean Sea. 
7. Leptosomatum tetrophtalmum Saveljev, 1912 (Figure 20) Savel'ev, 1912: 124.

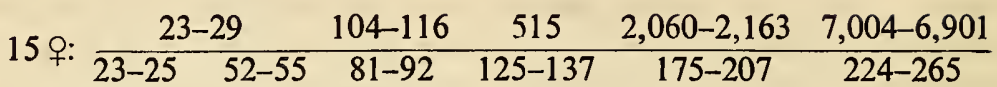

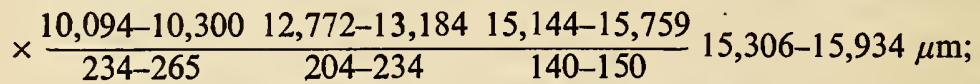

$$
\begin{aligned}
& a=58-73 ; b=7-8 ; c=91-94 ; V=61-65 \% \text {. }
\end{aligned}
$$

Body very long and tapers to $1 / 4$ midbody diameter at anterior end and $2 / 3$ at posterior end. Caudal length slightly exceeds width. Cuticle thick, 9.3 to $10.4 \mu \mathrm{m}$, with fascicles of intersecting fibers. Cephalic capsule well developed but its wall not very thick. Cephalic suture distinctly visible and slightly sinuous. Width of cephalic capsule exceeds length by 1.8 times. Thin cephalic ring situated in anterior third of cephalic capsule. Labial papillae rather large, distinct. Cephalic setae short, $3.5 \mu \mathrm{m}$ long (1/15 corresponding diameter). Cervical setae $2.0 \mu \mathrm{m}$ long. Amphids with very thick wall, situated 23 to $34 \mu \mathrm{m}$ from anterior end of body (equal to $1 / 60$ to $1 / 90$ esophageal length), spherical, and $7.0 \mu \mathrm{m}$ in diameter (1/9 corresponding body diameter). Eyes situated 104 to $116 \mu \mathrm{m}$ from anterior end (1/18 to $1 / 20$ esophageal length). Pigment bowl 8.1 to $9.2 \mu \mathrm{m} \times 11.6 \mu \mathrm{m}$; diameter of lens 5.8 to $6.9 \mu \mathrm{m}$. Two more pigment spots situated posterior to original eyes. Oral cavity absent. Esophageal wall highly sclerotized in oral region. Nerve ring situated $515 \mu \mathrm{m}$ from

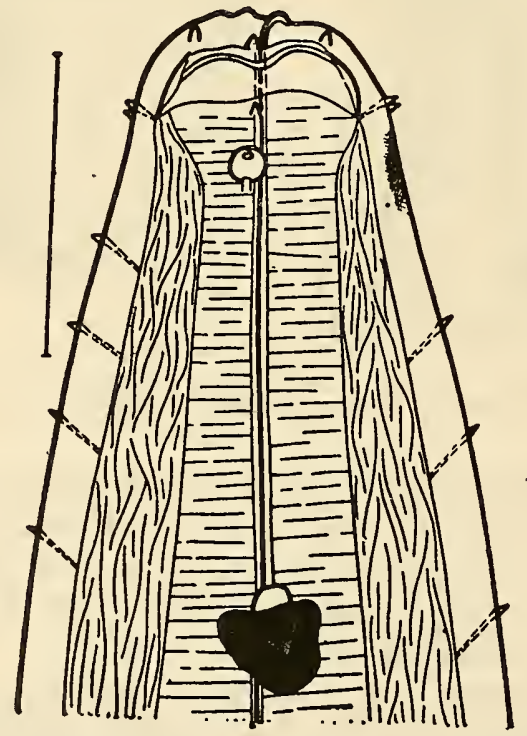

Figure 20. Leptosomatum tetrophtalmum. 
anterior end (1/4 esophageal length). Length of anterior female genital tube 3,090 to $3,399 \mu \mathrm{m}$, and of posterior tube 2,678 to $2,884 \mu \mathrm{m}$; respective lengths of reflexed parts 1,751 to 1,854 and 1,339 to $1,442 \mu \mathrm{m}$. Sclerotized granules occur around vulva on cuticle. Four to eight eggs 154 to $206 \mu \mathrm{m} \times 154$ to $185 \mu \mathrm{m}$ found in each branch of uterus.

Distinguishing characters of this species: 1) large size; 2) presence of short setae; 3) thick-walled amphids, spherical in shape; and 4) presence of additional pigment spots without lens situated behind main eyes. The 67 last feature is the most important from a diagnostic point of view.

Geographic distribution. Limited to the Barents Sea. Found in Lake Mogil'noe, Kola Bay, and on the shores of Novaya Zemlya.

8. Leptosomatum breviceps Platonova, 1967 (Figure 21)

Platonova, 1967: 829, fig. 1.

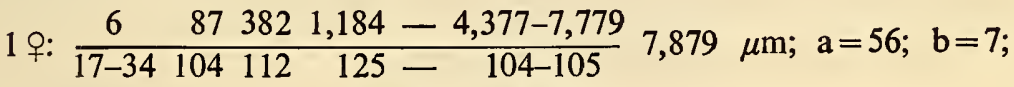

$$
\begin{aligned}
& \mathrm{c}=79 ; \mathrm{V}=56 \% \text {. }
\end{aligned}
$$

Body tapers to $1 / 4$ midbody diameter at anterior end and 10/13 at posterior end. Tail length equal to width. Cuticle $6.7 \mu \mathrm{m}$ thick. Cephalic capsule extremely short; width exceeds length six times. Wall of cephalic capsule rather thin. Narrow cephalic ring passes medially through cephalic capsule. Cephalic suture straight. Labial papillae distinct; cephalic setae much longer than cervical ones. Length of cephalic setae $5.8 \mu \mathrm{m}$ (1/6 corresponding diameter), and that of cervical setae $1.2 \mu \mathrm{m}$. Amphids situated $23.2 \mu \mathrm{m}$ from anterior end (1/50 esophageal length).
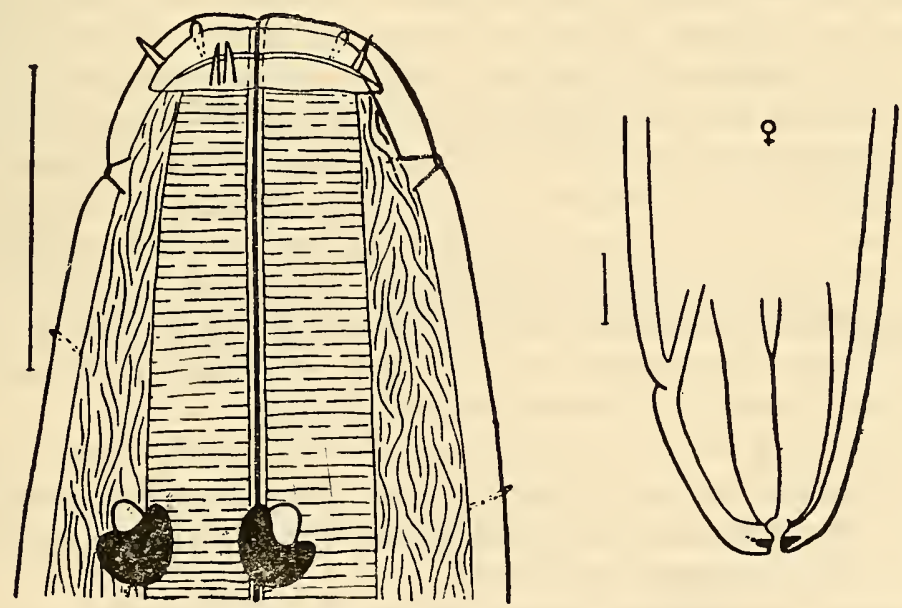

Figure 21. Leptosomatum breviceps. 
Eyes situated $76 \mu \mathrm{m}$ from anterior end (1/13 esophageal length). Pigment bowl $13.9 \mu \mathrm{m} \times 12.7 \mu \mathrm{m}$; diameter of lens $5.8 \mu \mathrm{m}$. Nerve ring situated $382 \mu \mathrm{m}$ from anterior end ( $1 / 3$ esophageal length). Vulva situated at midbody. Female specimen examined was sexually immature and hence tubes not visible.

Distinguishing features of this species: 1) extremely short cephalic capsule (width six times greater than length; 2) medial situation of cephalic ring in cephalic capsule; 3) rather long cephalic setae; and 4) short cervical setae, $1 / 5$ length of cephalic setae.

Geographic distribution. This species has been found only in Kol'sk Gulf of the Barents Sea among Lithothamnion sp.

\section{*9. Leptosomatum gracile Bastian, 1856 (Figure 22)}

Bastian, 1865; 145; pl. XII, figs. 158-160; Steiner, 1916: 610-620, tab. 16, fig. 27c, d; tab. 29, fig. 27a, b, e-g; tab. 30, fig. 27h-o (description).

1 ㅇ: $\mathrm{L}=13.3 \mathrm{~mm} ; \mathrm{a}=68 ; \mathrm{b}=6 ; \mathrm{c}=74$.

Cephalic capsule very short and thin-walled. Cephalic suture at level of cephalic papillae. Labial papillae distinct and usually situated in a group of six somewhat posterior to oral opening. Cephalic setae transform into papillae. Contrary to all other representatives of this family in number and situated in one circle, in L. gracile only six cephalic papillae were detected by Steiner. Neither papillae nor setae occur on the body. Amphids large, situated a short distance posterior to lateral cephalic setae, and with notably thickened anterior wall. In addition to welldeveloped eyes with lenses, pigment spots of irregular shape also occur near the pigment bowls. Of the three lips encircling oral opening, dorsal one highly thickened, sclerotized, and markedly projects above the other two. Esophageal wall also sclerotized. Nerve ring encircles esophagus at border of its anterior third. Vulval opening encircled by rather thick sclerotized lips. Cuticle around lips covered with minute sclerotized granules.

Despite the very brief description given by Bastian, Steiner noted the fallacy of making $L$. gracile synonymous with $L$. elongatum Bastian as done by de Man (1893). After studying specimens from the Barents Sea, Steiner arrived at the conclusion that species L. elongatum and L. gracile, although very similar, are nevertheless not identical.

Distinguishing features of this species: 1) cephalic capsule more weakly developed than in L. elongatum; 2) six cephalic papillae versus ten setae in L. elongatum; and 3) in addition to photosensitive eyes, irregular pigment spots also present in L. gracile.

Geographic distribution. Barents Sea and English Channel (shores of England). 

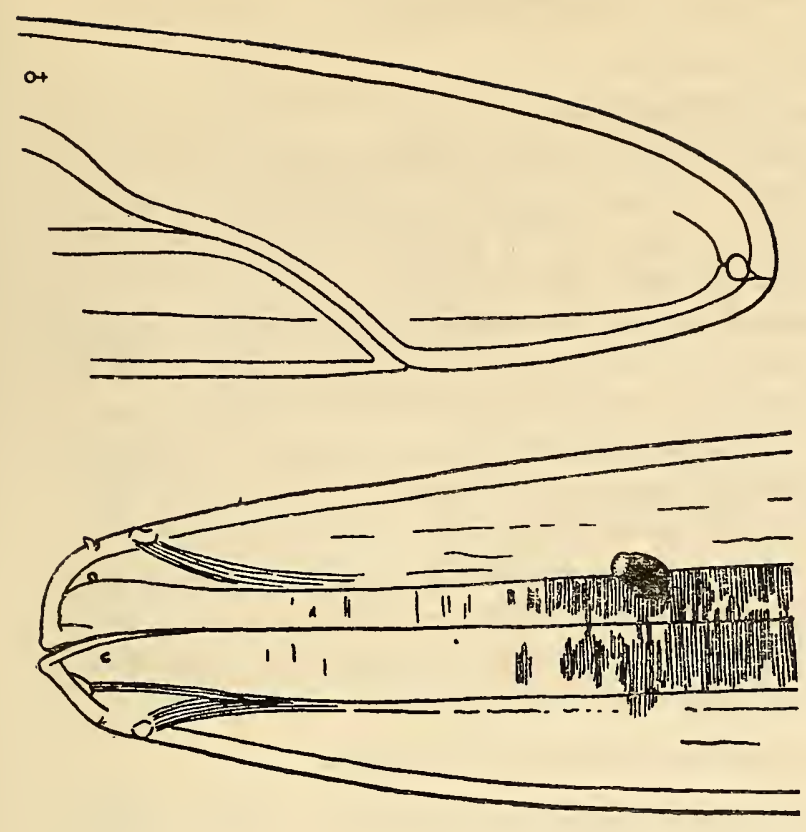

$\frac{6}{2}$

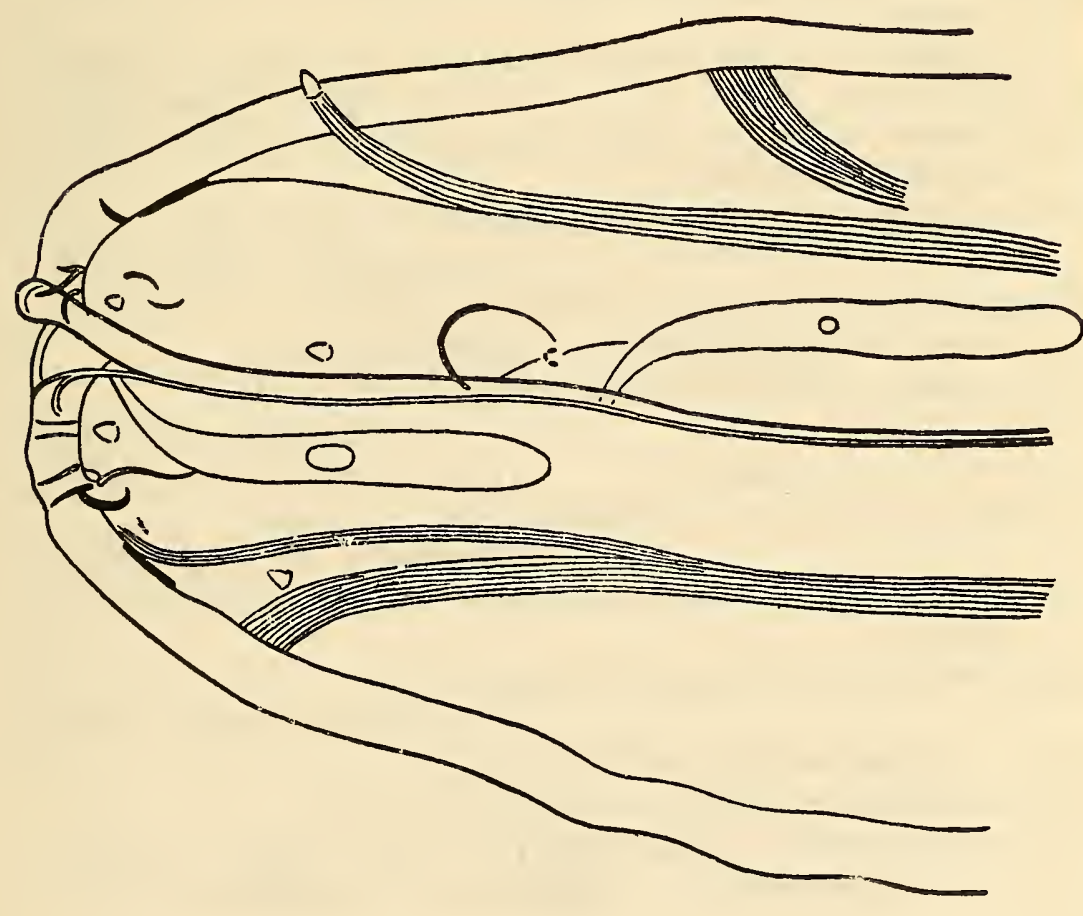




\section{Genus Leptosomatides Filipjev, 1918}

Filip'ev, 1918: 50, 51; 1922a: 98.

Type species: L. euxina Filipjev, 1918.

Nematodes of this genus highly resemble species of Leptosomatum in size, shape, and structure of cephalic capsule. Labial papillae distinctly visible, sometimes pointed, reminiscent of setae but usually short and blunt. Cephalic and cervical setae generally short. Unlike species of Leptosomatum, anal setae or papillae or sometimes both present in males of Leptosomatides. Amphids usually round and often taper toward posterior end. Oral cavity poorly developed. Vulva displaced posterior to midbody. Each spicule divided into two more or less equal parts-narrower proximal and wider distal. Occasionally velum situated on ventral aspect. Gubernaculum more complex than in species of Leptosomatum; always with paired capituli directed at right angles to spicular body. Dorsal process always present. Sometimes ventral process also present. Gubernaculum per se forms funnel around distal part of spicules. Well-developed accessory organ invariably present.

\section{Key to Species of Genus Leptosomatides}

1 (10). Amphids large; width exceeds one-eighth corresponding head diameter.

2( 3). Cephalic setae long; length about one-fifth corresponding head diameter................... reducta Timm, 1959.

3 ( 2). Cephalic setae short; length does not exceed one-tenth corresponding head diameter.

4 ( 5). Small denticles present in anterior part of esophagus........ ....................... antarcticum Mawson, 1956.

5 (4). Denticles absent in anterior part of esophagus.

6 (9). Sclerotized granules present on cuticle around vulva.

7 ( 8). Cervical setae reduced. Body slender $(a=74$ to 91$) \ldots \ldots \ldots$ 16. L. marinae sp. nov.

8 ( 7). Cervical setae present.........13. L. crassus Platonova, 1967.

9 ( 6). Sclerotized granules on cuticle around vulva absent......... 12. L. inocellatus Platonova, 1967.

10 ( 1). Amphids small; width less than one-eighth corresponding head diameter.

11 (12). Labial papillae acicular and resemble setae ..............

12 (11). Labial papillae blunt, usual in shape.

13 (16). Gubernaculum with dorsal and ventral processes.

14 (15). Suture of cephalic capsule forms rather deep groove......... ....L. conisetosum Schuurmans-Stekhoven and Mawson, 1955. 
15 (14). Suture of cephalic capsule sinuous but does not form deep groove..................... L. brevisetosus sp. nov.

16 (13). Gubernaculum with only dorsal process.

17 (18). Males devoid of preanal papillae.

L. microlaimum Allgen, 1957.

18 (17). Males with preanal papillae.

19 (20). Cephalic setae long; length one-ninth corresponding head diameter................... L. euxina Filipjev, 1918.

20 (19). Cephalic setae short; length does not exceed one-twentieth corresponding head diameter.....11. L. steineri Filipjev, 1922.

10. Leptosomatides euxina Filipjev, 1918 (Figure 23)

Filip'ev, 1918: 51-54, tab. 1, fig. 3; 1922a; 98-100, tab. 1, fig. 1.

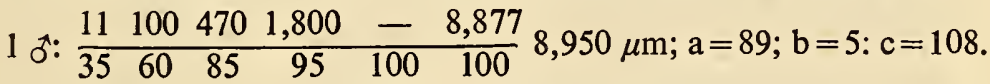

$$
\begin{aligned}
& 1 \text { ㅇ: } \begin{array}{ccccccccc}
14 & 113 & 555 & 1,815 & 4,567 & 7,768 & 8,897 & 10,988 \\
39 & 53 & 86 & 100 & 115 & 120 & 112 & 98
\end{array} 1,078 \mu \mathrm{m} ; \mathrm{a}=92 \text {; } \\
& \mathrm{b}=6 ; \mathrm{c}=123 ; \mathrm{V}=70 \% \text {. }
\end{aligned}
$$

Body tapers to $2 / 5$ midbody diameter at anterior end, but does not taper toward posterior end. Head narrow. Length of tail exceeds width by 1.2 times. Cuticle bilayered and $7.5 \mu \mathrm{m}$ thick. Cephalic capsule with walls of average thickness. Cephalic suture distinct and only slightly sinuous. Capsule width exceeds length three times. Thin cephalic ring crosses cephalic capsule medially. Labial papillae small. Cephalic setae $4.0 \mu \mathrm{m}$ long (1/9 corresponding diameter). Cervical setae slightly shorter, $3.0 \mu \mathrm{m}$. Amphids small, rounded, $5.0 \mu \mathrm{m}$ in diameter (1/8 corresponding body diameter), and situated $16 \mu \mathrm{m}$ from anterior end (1/100 esophageal length). Eyes situated asymmetrically: one lies $80 \mu \mathrm{m}$ and the other 140 $\mu \mathrm{m}$ from anterior end (1/20 and 1/13 esophageal length respectively). Pigment bowl $13 \mu \mathrm{m} \times 13 \mu \mathrm{m}$; diameter of lens $4.0 \mu \mathrm{m}$. Esophageal wall highly sclerotized in oral region and markedly thickened at level of amphids. Nerve ring situated $470 \mu \mathrm{m}$ from anterior end (1/4 esophageal length). Two mature eggs, $430 \mu \mathrm{m} \times 90 \mu \mathrm{m}$, found in each uterine branch. Spicules of males unequal in length; left spicule $110 \mu \mathrm{m}$ long and right $90 \mu \mathrm{m}$. Neither has a distinct capitulum. Proximal part of spicules uniform in width, middle broadens considerably, almost doubles in width, and distal end blunt. Gubernaculum paired with fairly long processes, $65 \mu \mathrm{m}$. Ten pairs of protuberances with setae situated anterior to anus. Accessory organ present with lateral alate fortifying structures on cuticle.

Distinguishing features of this species: 1) location of amphids, which lie close to cephalic capsule, at a distance of $1 / 100$ esophageal length from 71 anterior end; 2) thickening of esophageal wall at level of amphids; 

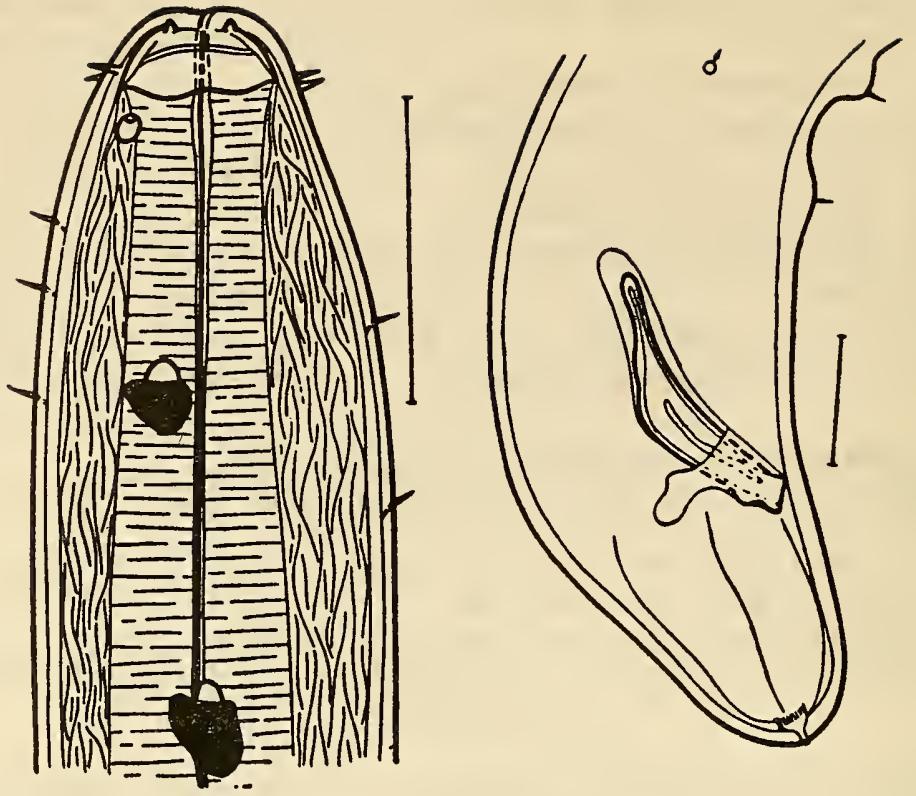

Figure 23. Leptosomatides euxina.

3) unequal length of spicules; and 4) unequal distance of eyes from anterior end.

Geographic distribution. Limited to the Black Sea where it has been found in depths ranging from 25 to $200 \mathrm{~m}$ among shells and in phaseolin and terebellid silts.

\section{Leptosomatides steineri Filipjev, 1922 (Figure 24)}

Filip'ev, 1922a: 98; 1946: 159, fig. 2; Platonova, 1967: 829.

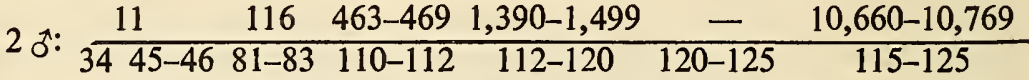

$$
\begin{aligned}
& \times 10,780-10,894 \mu \mathrm{m} ; \mathrm{a}=85-90 ; \mathrm{b}=8 ; \mathrm{c}=87 \text {. } \\
& 13 \text {; ; } \begin{array}{ccccc}
17 & 104-116 & 433-510 & 1,566-1,823 & 5,686-6,973 \\
\hline 2942-52 & 81-94 & 122-132 & 137-162 & 150-187
\end{array} \\
& \times \begin{array}{ccc}
5,692-9,033 & 7,952-10,887 & 9,703-12,844 \\
\hline 155-287 & 145-200 & 112-137
\end{array}, 853-12,994 \mu \mathrm{m} ; \\
& a=63 ; b=6-7 ; c=63-93 ; V=66-71 \% \text {. }
\end{aligned}
$$

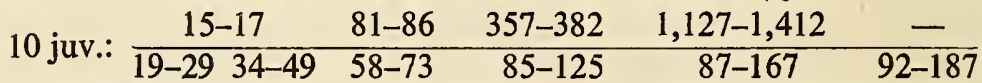

$$
\begin{aligned}
& \times \frac{5,247-9,527}{75-125} 5,359-9,652 \mu \mathrm{m} ; \mathrm{a}=52-59 ; \mathrm{b}=5-8 ; \mathrm{c}=46-77 \text {. }
\end{aligned}
$$


Body long, tapers to $1 / 3$ to $1 / 4$ midbody diameter at anterior end and $2 / 3$ at posterior end in female; no posterior attenuation seen in male. Length of tail almost equal to width. Cuticle thick, 10 to $14 \mu \mathrm{m}$; fascicles of intersecting fibers present in outer layer. Cephalic capsule extremely short: width exceeds length by four times; wall very thick. Cephalic suture barely discernible and almost straight. Cephalic ring very narrow and lies in upper third of cephalic capsule. Labial'papillae large. Cephalic setae extremely short, $2.3 \mu \mathrm{m}$ long ( $1 / 20$ corresponding diameter); cervical setae still shorter, $1.2 \mu \mathrm{m}$ long. Amphids situated 17 to $29 \mu \mathrm{m}$ from anterior end (1/60 to $1 / 80$ esophageal length). Amphids $6.9 \mu \mathrm{m} \times$ $725.8 \mu \mathrm{m}$; width $1 / 9$ to $1 / 10$ corresponding diameter. Eyes situated $116 \mu \mathrm{m}$ from anterior end (1/12 to $1 / 15$ esophageal length). Pigment bowl 9.3 $\mu \mathrm{m} \times 12.7 \mu \mathrm{m}$; diameter of lens $8.1 \mu \mathrm{m}$. Nerve ring situated 433 to 510 $\mu \mathrm{m}$ from anterior end ( $1 / 3$ esophageal length). Length of anterior female genital tube 1,236 to $2,575 \mu \mathrm{m}$, posterior tube 1,030 to $2,163 \mu \mathrm{m}$, and their reflexed parts $927-2,060 \mu \mathrm{m}$ and 721 to $1,442 \mu \mathrm{m}$ respectively. One egg, 412 to $515 \mu \mathrm{m} \times 133$ to $154 \mu \mathrm{m}$, seen in each uterine branch. Male spicules smoothly arcuate in midsection; length $137 \mu \mathrm{m}$ and width in narrowest part $17.5 \mu \mathrm{m}$ and in widest part $25 \mu \mathrm{m}$. Gubernaculum with long $(30 \mu \mathrm{m})$ process. One postanal and 17 preanal pairs of papillae present on tail. Accessory organ with complex sclerotized skeleton situ-

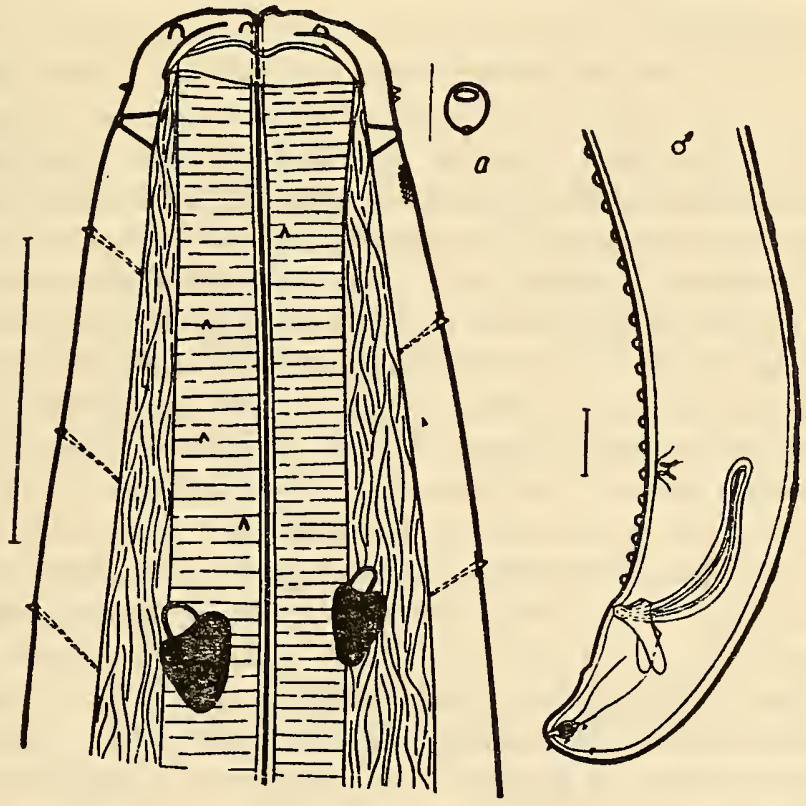

Figure 24. Leptosomatides steineri (a-amphid). 
ated anterior to anus at a distance of $125 \mu \mathrm{m}$ and provided with four processes, two directed dorsally and two ventrally.

Distinguishing features of this species: 1) extremely short cephalic capsule; 2) extremely short cephalic setae; 3 ) smoothly curved spicules of equal length; 4) one pair of postanal and 17 pairs of preanal papillae; and 5) accessory organ with complex structural processes (dorsal and ventral).

Geographic distribution. Arctic species. Found in Kara Sea in depths ranging from 140 to $360 \mathrm{~m}$ in sandy silt.

12. Leptosomatides inocellatus Platonova, 1967 (Figure 25)

Platonova, 1967: 829, fig. $1(3,4)$.

1 o

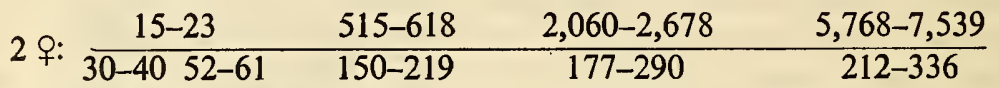

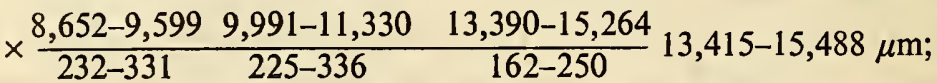

$a=45-58 ; b=6 ; c=70-108 ; V=52-64 \%$.

73

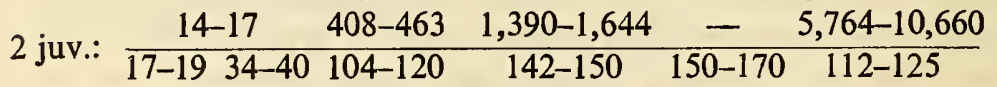

$$
\begin{aligned}
& \times 5,889-10,835 \mu \mathrm{m} ; \mathrm{a}=39-64 ; \mathrm{b}=4-8 ; \mathrm{c}=47-62 \text {. }
\end{aligned}
$$

Body extremely long, tapers to $1 / 4$ to $1 / 5$ midbody diameter at anterior end and to $5 / 6$ to $10 / 13$ at posterior end. Length of tail almost equal to width. Cuticle very thick, 13 to $17 \mu \mathrm{m}$, bilayered, with intersecting fascicles of fibers in outer layer. Cephalic capsule short; width exceeds length three times. Cephalic wall rather thin. Cephalic suture faintly discernible and straight. Narrow cephalic ring situated medially in cephalic capsule. Labial papillae short. Cephalic setae short, but rather thick and massive, and 4.6 to $6.0 \mu \mathrm{m}$ long ( $1 / 10$ to $1 / 13$ corresponding diameter). Cervical setae somewhat short, 3.5 to $4.0 \mu \mathrm{m}$ long, situated in small pits, occasionally in groups of three to nine. Preanal setae of males significantly longer, up to $20 \mu \mathrm{m}$ long. Amphids situated 29 to $35 \mu \mathrm{m}$ (1/50 to $1 / 70$ esophageal length) from anterior end, large, stretched longitudinally, 10.0 to $11.6 \mu \mathrm{m}$ long, and width $1 / 6$ corresponding diameter. Eyes absent. Nerve ring 510 to $618 \mu \mathrm{m}$ from anterior end (1/4 esophageal length). Vulva median or posteromedian. Sclerotized granules around vulva absent. Length of anterior genital tube 1,545 to $2,884 \mu \mathrm{m}$, its bent part 1,133 to $2,678 \mu \mathrm{m}$, of posterior tube 1,200 to $2,020 \mu \mathrm{m}$, and of reflexed parts 1,133 to $1,648 \mu \mathrm{m}$. Sexually mature females with one egg 772 to $669 \mu \mathrm{m}$ [sic] $\times 175$ to $257 \mu \mathrm{m}$ in each uterine branch. In females two to three pairs of papillae present on tail. Anterior male gonad $262 \mu \mathrm{m}$ and posterior $1,442 \mu \mathrm{m}$ long. Spicules equal in length but different in shape; right spicule smoothly arcuate, 
with slightly thickened capitulum, followed by neck (cervix) widening into spicular body; left spicule significantly more irregular in shape. Spicular length $237 \mu \mathrm{m}$. Length of gubernaculum $50 \mu \mathrm{m}$. Accessory organ situated $150 \mu \mathrm{m}$ anterior to anus. Setae in anal region number 20 pairs, of which 6 are postanal. Anterior to these setae lie 17 pairs of papillae.

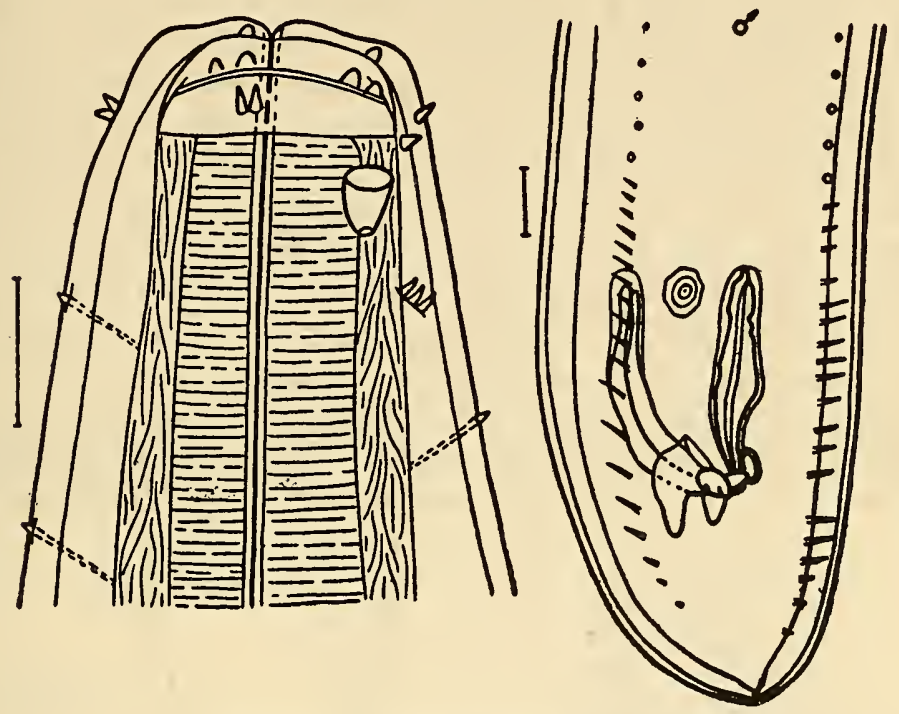

Figure 25. Leptosomatides inocellatus.

74 Distinguishing features of this species: 1) extremely thick cuticle; 2) cervical setae gathered in groups in small pits; 3) large amphids, stretched longitudinally; 4) complete absence of eyes and photosensitive pigment; 5) presence of two to three pairs of papillae on tail of female; 6) absence of sclerotized granules around vulva; 7) spicules significantly different in shape; and 8 ) presence of 20 pairs of setae and 17 pairs of papillae in anal region of male.

Geographic distribution. To date found only in the Kara Sea at depths ranging from 200 to $800 \mathrm{~m}$.

13. Leptosomatides crassus Platonova, 1967 (Figure 26)

Platonova, 1967: 829-831, fig. 1 (5-7)

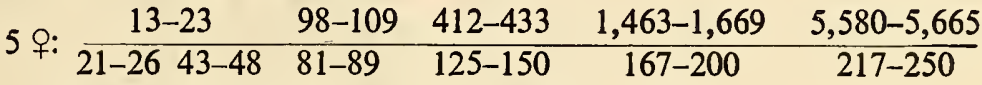

$$
\begin{aligned}
& \times \frac{6,407-7,828 \quad 9,191-9,888}{225-250} \frac{9,497-12,154}{135-150} 9,622-12,329 \mu \mathrm{m} \text {; } \\
& a=48-51 ; b=7-8 ; c=70-77 ; V=64-67 \% \text {. }
\end{aligned}
$$




$$
\begin{aligned}
& 5 \text { juv.: } \begin{array}{cccrc}
10-11 & 50-63 & 220-270 & 980-991 & - \\
18-21 \quad 28-31 & 50-58 & 76-82 & 95-105 & 115-120
\end{array} \\
& \times \frac{4,032-4,287}{90-95} 4,203-4,437 \mu \mathrm{m} ; \mathrm{a}=30-35 ; \mathrm{b}=4 ; \mathrm{c}=30-34 \text {. }
\end{aligned}
$$

Body tapers to $1 / 5$ midbody diameter at anterior end and $5 / 8$ at posterior end. Length of tail almost equal to width. Cuticle thick, 11.6 to $14.0 \mu \mathrm{m}$, with fascicles of intersecting fibers in outer layer. Cephalic capsule with rather thick wall but poorly expressed cephalic suture; width exceeds length by 2.5 times. Extremely narrow cephalic ring situated in upper third of cephalic capsule. Labial papillae distinct. Cephalic setae extremely short, $2.32 \mu \mathrm{m}$ in length (1/20 corresponding diameter). Cervical setae $1.6 \mu \mathrm{m}$ long. Amphids 23 to $34 \mu \mathrm{m}$ from anterior end $(1 / 60$ 75 esophageal length) and 8.0 to $7.0 \mu \mathrm{m}$ wide (1/6 to $1 / 8$ corresponding diameter). Eyes 98 to $109 \mu \mathrm{m}$ from anterior end (1/14 to $1 / 15$ esophageal length). Pigment bowl $8.12 \mu \mathrm{m} \times 15.08 \mu \mathrm{m}$; diameter of lens 7.0 to 8.0 $\mu \mathrm{m}$. Esophageal wall sclerotized in oral region. Nerve ring 412 to $433 \mu \mathrm{m}$ from anterior end (1/3 esophageal length). Length of anterior female genital tube 1,957 to $2,575 \mu \mathrm{m}$, of posterior tube 1,554 to $2,060 \mu \mathrm{m}$, and
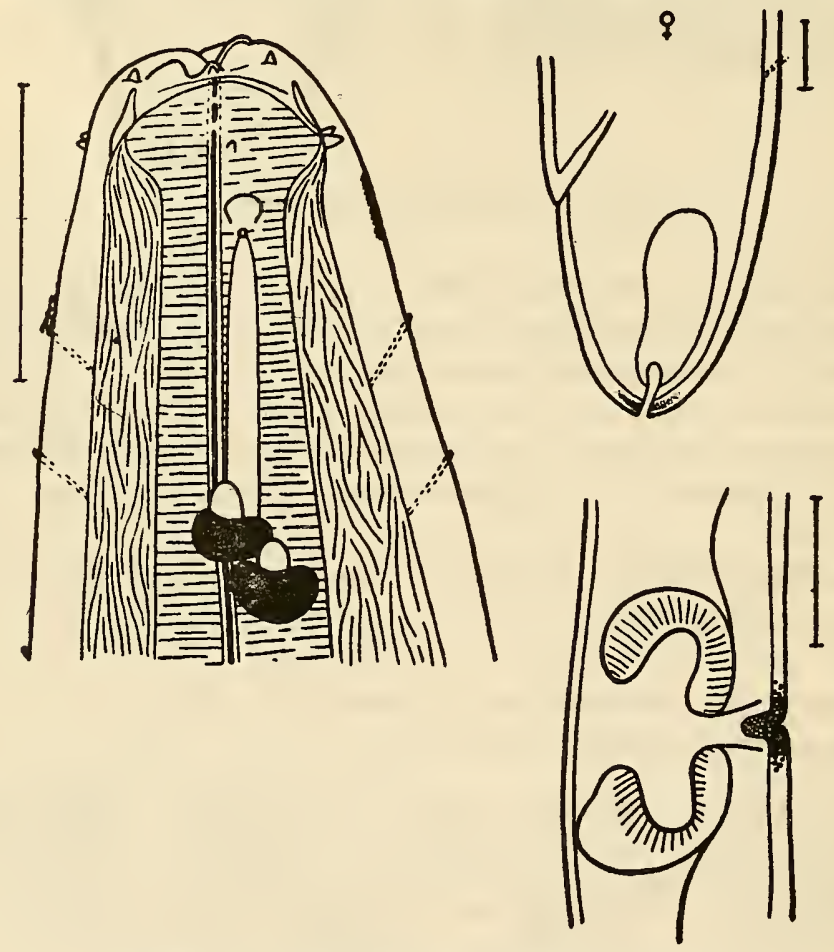

Figure 26. Leptosomatides crassus (below vulva). 
of reflexed parts 515 to $1,030 \mu \mathrm{m}$ and 824 to $927 \mu \mathrm{m}$ respectively. Four to eight eggs, 154 to $360 \mu \mathrm{m} \times 824$ to $206 \mu \mathrm{m}$, found in uteri.

This species is distinguished from others in the genus (except L. steineri) by the following features: 1) long and broad body covered with thick cuticle; 2) relatively long cephalic capsule; and 3) extremely short cephalic and cervical setae. L. crassus differs from $L$. steineri in: 1) wider body; 2) cephalic capsule almost two times longer; 3 ) amphids situated closer to anterior end; 4) esophageal wall much thicker in oral region; 5) greater number of eggs in uteri of $L$. crassus (up to eight) than in $L$. steineri [in my material only one each, but according to Filip'ev (1946) up to four]. It should be noted that Filip'ev (1916) gives more taxonomic importance to such characters as size and number of eggs.

Geographic distribution. Found only in the Barents Sea in the littoral zone, predominantly under offshoots of brown algae.

14. Leptosomatides acutipapillosus sp. nov. (Figure 27)

Holotype o: Institute of Zoology, Academy of Sciences, USSR. Collection No. 7034.

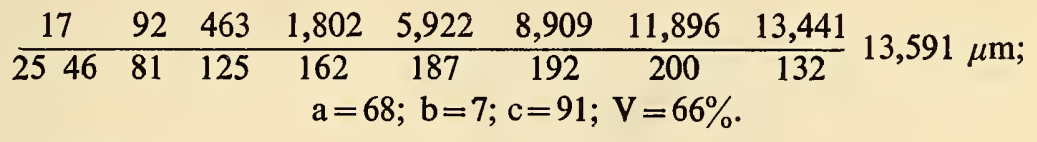

Paratypes.

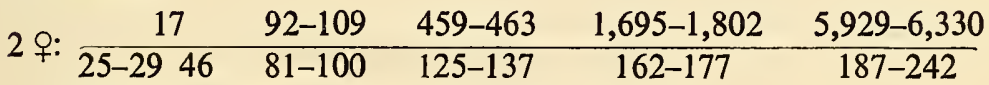

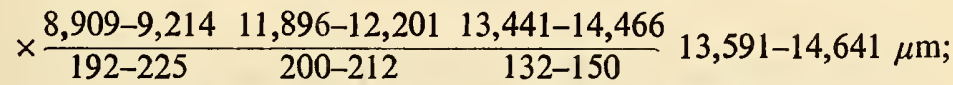

$$
\begin{aligned}
& a=65-68 ; b=7-9 ; c=84-91 ; V=62-66 \% \text {. }
\end{aligned}
$$

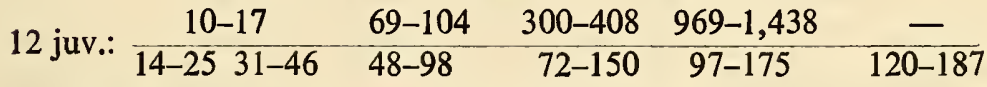

$$
\begin{aligned}
& \times \frac{5,304-8,339}{87-125} 5,429-8,469 \mu \mathrm{m} ; \mathrm{a}=44-48 ; b=5-6 ; \mathrm{c}=44-70 \text {. }
\end{aligned}
$$

Body tapers to $1 / 4$ to $1 / 5$ midbody diameter at anterior end and $5 / 7$ to $2 / 3$ at posterior end. Head round, tail small, slightly conically stretched and bluntly rounded at end. Length of tail exceeds width by 1.2 times. Cuticle bilayered, 9.0 to $10.0 \mu \mathrm{m}$ thick, with fascicles of intersecting fibers situated in outer layer. Cephalic capsule with fairly thin wall and barely discernible suture. Narrow cephalic ring situated in upper third of cephalic capsule. Width of latter exceeds length by 2.7 times. Labial papillae with characteristic structure, pointed, and resemble setae. Cephalic setae short, $3.5 \mu \mathrm{m}$ in length (1/13 corresponding body diameter). Cervical papillae $2.3 \mu \mathrm{m}$ long. Amphids $29 \mu \mathrm{m}$ from anterior end (1/60 eso- 
phageal length) and $8.1 \mu \mathrm{m}$ wide ( $1 / 7$ to $1 / 8$ corresponding body diameter). Eyes 92 to $109 \mu \mathrm{m}$ (1/16 to $1 / 18$ esophageal length). Pigment bowl 10.4 to $12.7 \mu \mathrm{m}$; diameter of lens $7.0 \mu \mathrm{m}$. Nerve ring situated about $1 / 4$ length of esophagus from anterior end. Length of anterior female genital tube 2,884 to $2,987 \mu \mathrm{m}$, of posterior tube 2,987 to $3,000 \mu \mathrm{m}$, and of reflexed parts 2,060 to 1,751 and 1,554 to $1,957 \mu \mathrm{m}$ respectively. Two to eight eggs, 154 to $257 \mu \mathrm{m} \times 133$ to $154 \mu \mathrm{m}$, found in each uterus.
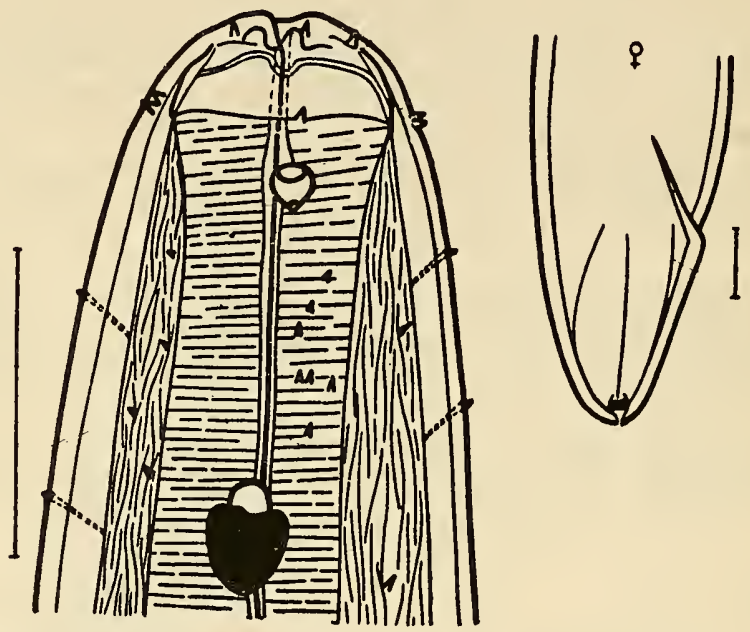

Figure 27. Leptosomatides acutipapillosus sp. nov.

76 Distinguishing features of this species: 1) conically stretched but obtusely rounded tail of female; 2) labial papillae pointed and resemble thick setae. Thick cuticle, relatively long cephalic capsule, and amphids with large openings are also characteristic of this species. Structurally close to $L$. crassus but further distinguished from it by shape of tail, pointed labial setae, somewhat wider cephalic ring and its lower position, and longer cephalic setae.

Geographic distribution. The only place of occurrence of this species has been the Sea of Okhotsk; found at a depth of $25 \mathrm{~m}$ in silted benthos.

\section{Leptosomatides brevisetosus sp. nov. (Figure 28)}

Holotype $\sigma^{*}$ : Institute of Zoology, Academy of Sciences, USSR. Collection No. 6128.

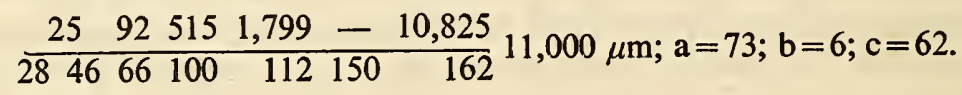




\section{Paratypes.}

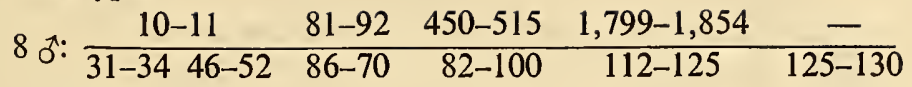

$$
\begin{aligned}
& \times \frac{9,840-11,857}{137-160} 10,000-12,000 \mu \mathrm{m} ; \mathrm{a}=73-92 ; \mathrm{b}=6-7 ; \mathrm{c}=62-84 \text {. }
\end{aligned}
$$

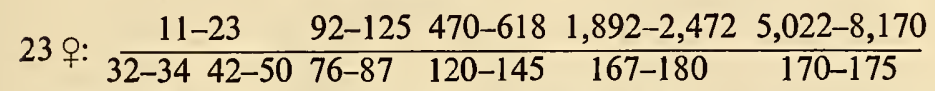

$$
\begin{aligned}
& \times \frac{10,000-11,951 \quad 10,935-14,938 \quad 11,800-17,441}{180-250 \quad 1200-200[\mathrm{sic}] \quad 140-150} 12,000-17,616 \mu \mathrm{m} \text {; } \\
& a=56-80 ; b=6-8 ; c=70-100 ; V=75-80 \% \text {. }
\end{aligned}
$$

Body tapers to $2 / 5$ to $1 / 3$ midbody diameter at anterior end and $10 / 13$ to $5 / 8$ at posterior end. In males body in region of spicular apparatus somewhat wider than midwidth. Cuticle thick, $7.5 \mu \mathrm{m}$, with fascicles of intersecting fibers in outer layer. Labial papillae short but very wide. Cephalic and cervical setae papillate, very short, with rounded ends. Length of cephalic setae $2.0 \mu \mathrm{m}$ (1/15 to $1 / 16$ corresponding diameter). Cephalic capsule short; length 2.8 times less than width. Cephalic suture barely discernible and sinuous. Cephalic ring shifted more anteriorly: situated in first quarter of capsule. Lips sclerotized. Faily large amphids, width $8.12 \mu \mathrm{m}$ (1/8 corresponding diameter), situated 25 to $32 \mu \mathrm{m}$ from anterior end. Eyes 81 to $100 \mu \mathrm{m}$ from anterior end. Pigment bowl 11.6

$77 \mu \mathrm{m} \times 11.6 \mu \mathrm{m}$; diameter of lens $5.8 \mu \mathrm{m}$. Nerve ring 450 to $618 \mu \mathrm{m}$ from anterior end (1/4 esophageal length). Length of anterior female genital tube 3,000 to $3,200 \mu \mathrm{m}$, of posterior tube 2,884 to $2,900 \mu \mathrm{m}$, and of reflexed parts 1,700 to $1,820 \mu \mathrm{m}$ and 2,000 to $2,060 \mu \mathrm{m}$ respectively. Vulval lips thick and muscular with upper lip covering lower one. Genital armature of male represented by spicular apparatus, accessory organ, seven to nine pairs of pretubal, and one pair of postanal papillae. Length of spicules 140 to $170 \mu \mathrm{m}$. Each spicule divided into two parts: distal part significantly wider than proximal. Gubernaculum with dorsal and ventral processes. Accessory organ 150 to $160 \mu \mathrm{m}$ from anus, with sclerotized cyathiform supports with two alate processes, one proceeding anteriorly and the other posteriorly.

Distinguishing features of this species: 1) amphids situated at a distance equal to two cephalic lengths from anterior end of body, i.e. situated farther away from anterior end compared to other species of the genus; 2) characteristic shape of amphids, anteriorly wide and tapering rather abruptly posteriorly; 3 ) absence of anal setae; 4) pretubal and postanal situation of papillae in males, but no papillae between anus and accessory organ; 5) cyathiform sclerotized structures with alate processes supporting accessory organ from inside; 6) distinct division of spicules into narrow proximal part and wide distal part; 7) presence of dorsal and 

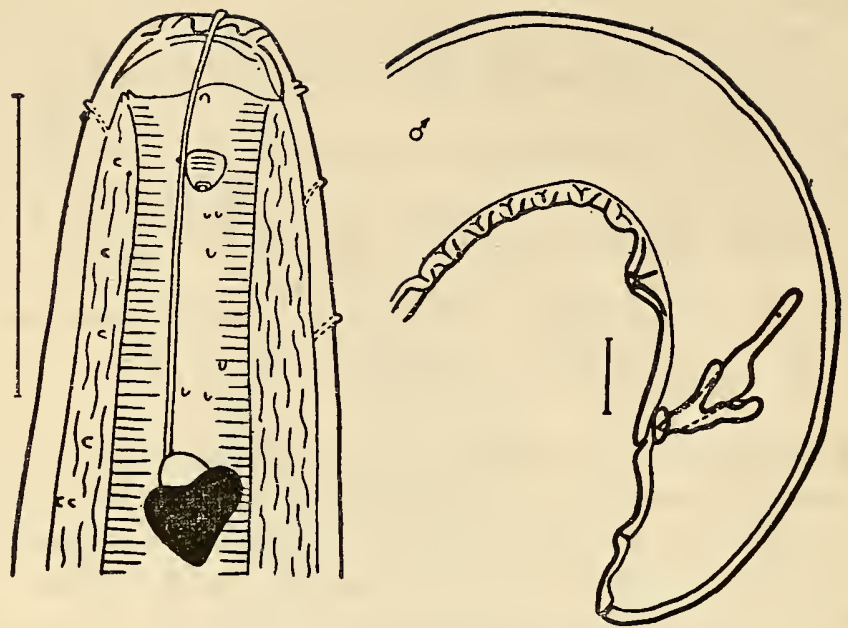

Figure 28. Leptosomatides brevisetosus sp. nov.

ventral processes on gubernaculum; and 8) extremely short, papillate cephalic and cervical setae.

Geographic distribution. Sea of Okhotsk (Kuril Islands). Found in the littoral zone under offshoots of algae and in sandy benthos.

\section{Leptosomatides marinae sp. nov. (Figure 29)}

Holotype $\sigma^{*}$ : Institute of Zoology, Academy of Sciences, USSR. Collection No. 7880.

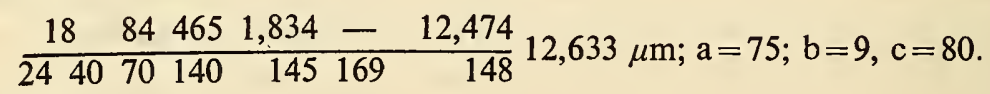

\section{Paratypes.}

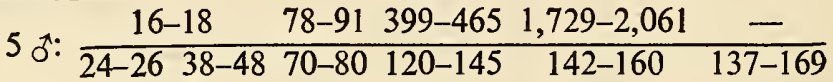

$$
\begin{aligned}
& \times \frac{10,573-14,323}{130-182} 10,719-14.522 \mu \mathrm{m} ; \mathrm{a}=75-94 ; \mathrm{b}=6-7 ; \mathrm{c}=73-80 \text {. }
\end{aligned}
$$

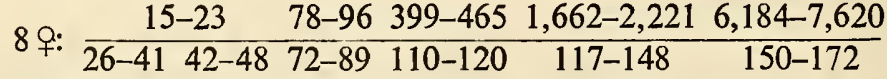

$$
\begin{aligned}
& \times \frac{8,578-10,844 \quad 10,706-14,900}{12,701-15,964} 12,847-16,623 \mu \mathrm{m} \text {; } \\
& a=75-93 ; b=6-8 ; c=88-117 ; V=64-70 \% \text {. }
\end{aligned}
$$

Body tapers to $1 / 4$ midbody diameter at anterior end and to not less than $2 / 3$ at posterior end. Tail length somewhat exceeds width. Cuticle thick, $13.2 \mu \mathrm{m}$, and bilayered. Cephalic capsule thin-walled and width twice length. Narrow cephalic ring lies in upper part of cephalic capsule. 
Cephalic setae very small and papillate. Cervical setae reduced. Amphids $8.4 \mu \mathrm{m} \times 6.0 \mu \mathrm{m}$ and situated immediately behind cephalic capsule. Eyes 80 to $90 \mu \mathrm{m}$ from anterior end (1/20 esophageal length). Pigment bowl $12.0 \mu \mathrm{m} \times 9.6 \mu \mathrm{m}$; diameter of lens $6.0 \mu \mathrm{m}$. Nerve ring situated in anterior third of esophagus. Length of anterior female genital tube 2,128 to $3,724 \mu \mathrm{m}$, of posterior tube 2,128 to $4,056 \mu \mathrm{m}$, and of reflexed parts 1,303 to $2,128 \mu \mathrm{m}$ and 1,130 to $2,261 \mu \mathrm{m}$ respectively. Ten eggs found in uterus. Vulval aperture encircled by sclerotized granules. Length of anterior male genital tube 2,257 to $2,926 \mu \mathrm{m}$ and posterior tube 1,130 to $2,660 \mu \mathrm{m}$. Spicules straight, wide, without capitulum, slightly acicular at proximal end, and with small protuberances on dorsal margin. Length of spicules 150 to $160 \mu \mathrm{m}$. Gubernaculum large, 80 to $98 \mu \mathrm{m}$ long, with an expansion at proximal end and pointed process directed ventrally. Accessory organ 150 to $180 \mu$ m anterior to anus.
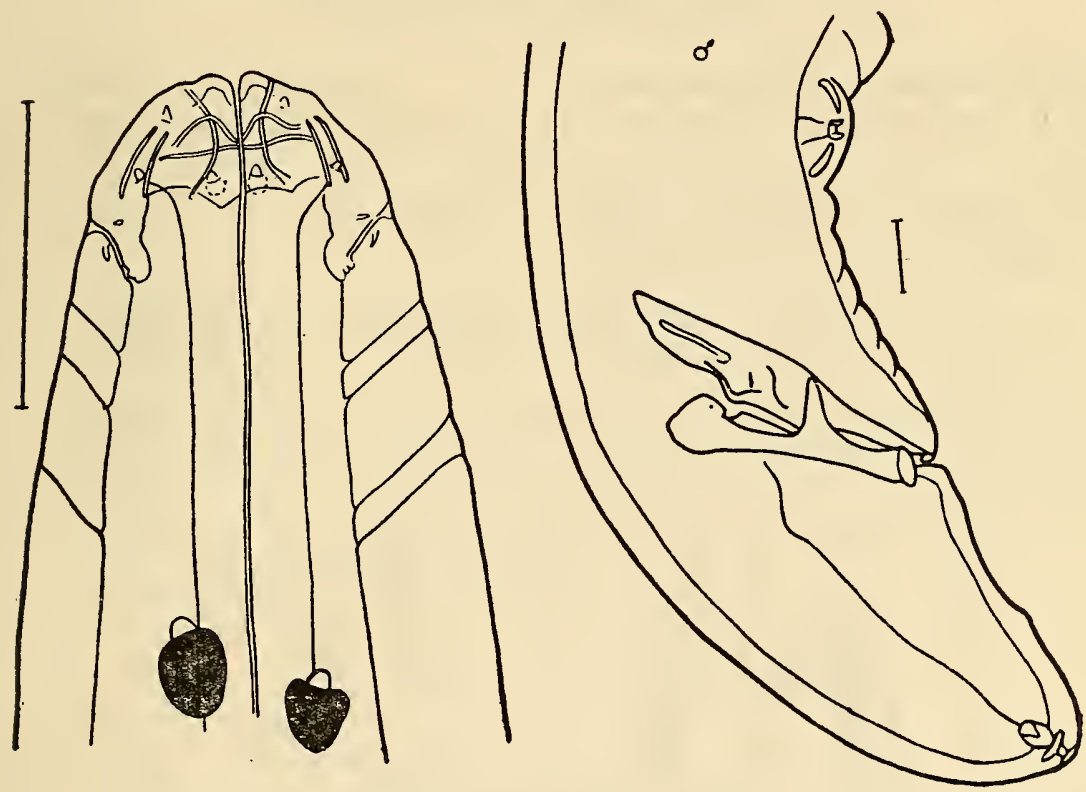

Figure 29. Leptosomatides marinae sp. nov.

This species is related to that group of forms in which females have sclerotized granules around the vulva. Structure of the spicular apparatus similar to that of L. euxina, but the gubernaculum differs significantly in structure.

79 Geographic distribution. Found around Kuril Islands-Kunashir (Gulf of Izmena) and Iturup (Pacific coast)-at a depth of 4.0 to $19.0 \mathrm{~m}$ in silted-sand among offshoots of algae, but more often in"sponges. 
Filip'ev, 1927: 79.

Type species. Leptosomella acrocerca Filipjev, 1927.

Nematodes of this genus are significantly smaller in size than representatives of the two preceding genera. Cephalic capsule consists of three domes with an irregular suture. Oral cavity almost undeveloped. Cephalic setae long. In each pair of subventral and subdorsal setae one seta notably shorter than the other. Cervical setae absent. Distinct cervical gland present. Tail elongated and acicular.

Only one species has been discovered to date in the seas of the Soviet Union.

Key to Species of Genus Leptosomella

1 (2). Photosensitive eyes with lens............ phaustra Inglis, 1971. 2 (1). Photosensitive eyes without lens. . 17. L. acrocerca Filipjev, 1927.

*17. Leptosomella acrocerca Filipjev, 1927 (Figure 30)

Filip'ev, 1927: 80 (description).
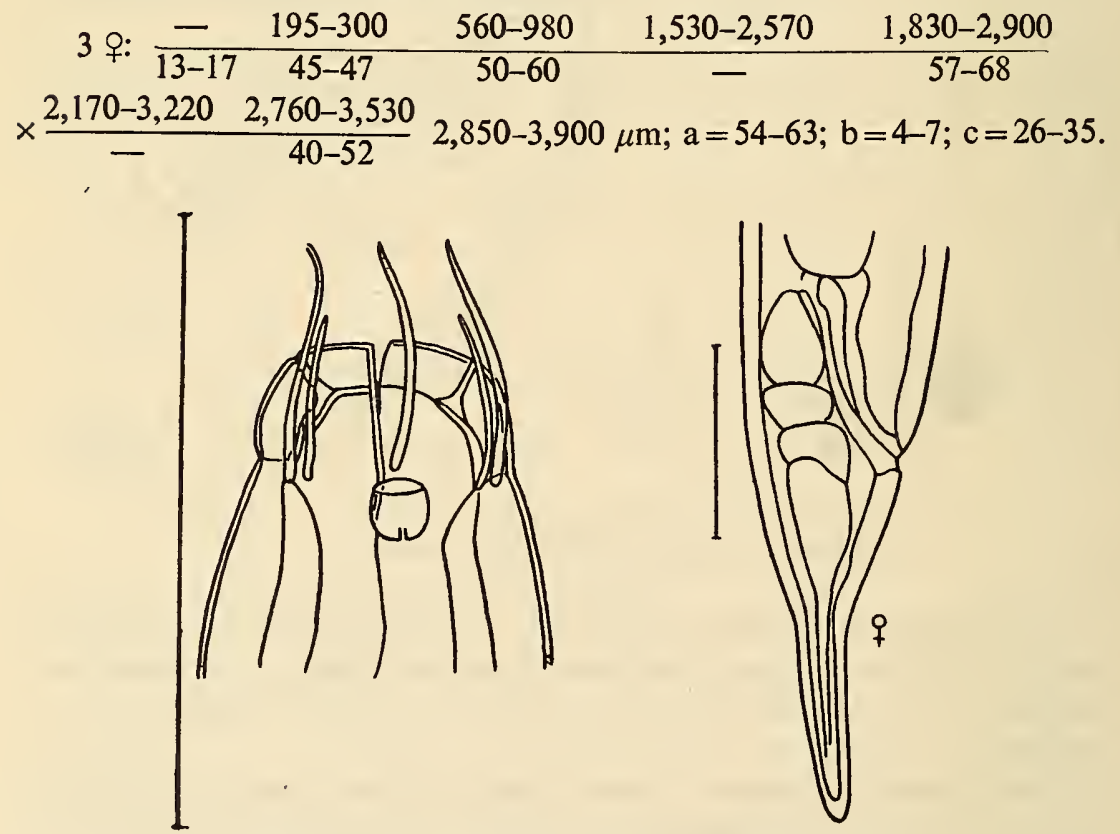

Figure 30. Leptosomella acrocerca (from Filip'ev 1927). 
Body filiform and tapers posteriorly from preanal region. Tail conical and narrows notably toward posterior end. Cuticle smooth and comparatively thick $(4.0 \mu \mathrm{m})$. Head truncated; notably narrows at level of ce80 phalic suture. Labial papillae distinct. Of the ten cephalic setae six are longer-13 to $15 \mu \mathrm{m}$ in length (almost equal to cephalic diameter). Amphids situated immediately behind cephalic setae. Cephalic suture distinct. Cervical gland extremely large, $25 \mu \mathrm{m} \times 60 \mu \mathrm{m}$, and situated against posterior part of esophagus; its duct distinctly visible and its pore situated at a distance of 50 to $57 \mu \mathrm{m}$ from anterior end. Nerve ring situated in anterior quarter of esophagus. Cardia $15.0 \mu \mathrm{m} \times 9.0 \mu \mathrm{m}$ in size. Rectum 40 to $45 \mu \mathrm{m}$ long. Eggs $200 \mu \mathrm{m} \times 40 \mu \mathrm{m}$ in size. Vagina thick-walled.

Geographic distribution. Found only once in the Barents Sea at a depth of $36 \mathrm{~m}$ in gravel.

\section{Subfamily SynonChINAE Platonova, 1970}

Cephalic capsule short, rather thin-walled, but distinctly developed. Cephalic suture may be straight, but often bends and forms lobes and grooves. Interlobular grooves wide and not divided into furrows; formed by smoother curve of cephalic suture. All grooves identical in shape; lateral ones, in which amphids are located, do not differ in any way from the rest. Amphids may be situated inside lateral grooves as well as below level of cephalic suture. Cephalic ring narrow. Oral cavity small, often armed with onchia. Nerve ring encircles esophagus most often in its anterior third. Tail in majority of genera stretched but claviform at end. Posterior end in males covered with a large number of setae. Preneural part of body in both male and female usually covered with numerous long setae. Photosensitive eyes absent.

\section{Key to Genera of Subfamily Synonchinae}

1 (4). Tail short, wide, and blunt.

2(3). Posterior margin of cephalic capsule serrated............. ...................... Synonchoides Wieser, 1956.

(one species: S. galatheae Wieser, 1956).

3 ( 2). Posterior margin of cephalic capsule smooth, not serrated.... ..................... Corythostoma Wieser, 1956.

(two species: C. kreisi Wieser, 1956. and C. triaulolaimus Hope, 1967).

4 ( 1). Tail elongated, claviform at end.

5 ( 8 ). Interlobular grooves narrow near posterior margin of capsule. 
6( 7). Oral cavity armed with one dorsal tooth

Tuerkiana Platonova, 1970.

7 ( 6). Oral cavity armed with three teeth

................. Anivanema Platonova, gen. nov.

8 ( 5). Interlobular grooves broad near posterior margin of capsule.

9 (14). Gubernaculum of spicular apparatus funnel-shaped.

10 (11). Amphids large, their width constituting one-third to one-half of corresponding body diameter..........Fiacra Southern, 1914.

11 (10). Amphids small, their width constituting one-eighth to oneseventh of corresponding body diameter.

12 (13). Oral cavity armed with three small teeth...

13 (12). Oral cavity armed with one large tooth.

Eusynonchus Platonova, 1970.

Paratuerkiana Platonova, 1970.

14 ( 9). Gubernaculum different shape (not funnel-shaped).

15 (16). Oral cavity not armed; totally devoid of teeth.............

Jaegerskioeidia Filipjev, 1916.

$8116(15)$. Oral cavity armed.

17 (18). Oral cavity armed with three teeth, of which dorsal tooth much larger than two subventral ones...... 4. Synonchus Cobb, 1893.

18 (17). Oral cavity armed with three teeth of equal size and three serrated plates...........................

(one species: M. shealsi Inglis 1964).

\section{Genus Synonchus Cobb, 1893}

Cobb, 1893: 411, 412.

Type species: Synonchus fasciculatus Cobb, 1893.

Cephalic suture slightly wavy but does not form distinct interlobular grooves. Amphids situated below posterior margin of cephalic capsule. Oral cavity armed with one large dorsal and two small subventral onchia. Setae present in preneural region but sometimes small and few. Accessory organ present, but structure undescribed in type species. Spicules arcuate with distinct capituli. Gubernaculum simple in structure, without ventral process. Tail elongated and claviform at end.

In descriptions of species of genera Synonchus and Anivanema given below, figures in Cobb's formula denote distances from anterior end of body to: 1 . posterior end of cephalic capsule; 2 . nerve ring; 3 . base of esophagus; 4. commencement of anterior genital tube; 5 . vulva; 6 . commencement of posterior genital tube; and 7. anus.

As stated earlier, measurements according to the formula are fewer for males. 
1 (2). Length of cephalic setae and width of amphids constitute onethird of corresponding diameters....S. fasciculatus Cobb, 1893.

2 (1). Length of cephalic setae constitutes one-tenth of corresponding diameter.............. S. murmanicus Filipjev, 1927.

18. Synonchus murmanicus Filipjev, 1927 (Figure 31)

Filip'ev, 1927: 88-90, pl. I, fig. 11, a-d.

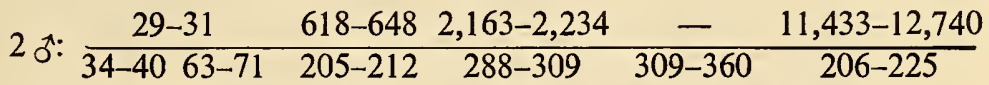

$$
\begin{aligned}
& \times 11,790-13,100 \mu \mathrm{m} ; \mathrm{a}=32-42 ; \mathrm{b}=5-6 ; \mathrm{c}=32-42 \text {. } \\
& 2 \text { q: } \begin{array}{rccccc}
29-34 & 618 & 2,163 & 4,223 & 6,798-7,828 & 9,785 \\
\hline 40-4663 & 167-200 & 216-309 & 360 & 257-329 & 339
\end{array} \\
& \times \frac{11,948-13,184}{185-206} 12,308-13,472 \mu \mathrm{m} ; \mathrm{a}=36-52 ; \mathrm{b}=6 ; \mathrm{c}=34-47 ; \mathrm{V}=51-55 \% \text {. }
\end{aligned}
$$

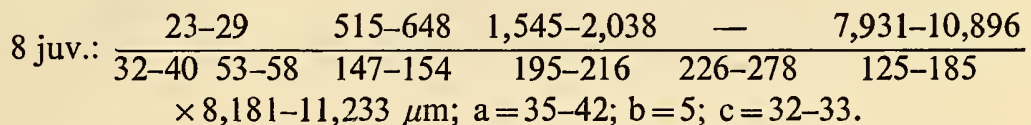

Large nematodes. Body tapers to $10 / 43$ to $1 / 5$ midbody diameter at anterior end and $2 / 3$ to $10 / 17$ at posterior end. Cephalic end rounded anteriorly. Tail of female conical and pointed toward end; that of male highly attenuate, elongated. Cuticle thick, 17 to $20 \mu \mathrm{m}$, and bilayered. Fascicles of intersecting fibers present in outer layer, due to which cuticle appears finely annulated. Width of cephalic capsule exceeds length by 2.0 to 2.3 times. Cephalic ring situated in middle of cephalic capsule. Lateral walls of latter with highly sclerotized thickenings. Labial papillae extremely small. Cephalic setae very short, $5.8 \mu \mathrm{m}$ in length $(1 / 10$ corresponding diameter). Cervical papillae $2.2 \mu \mathrm{m}$ and anal 17.5 to $20.0 \mu \mathrm{m}$ long. Amphids situated immediately behind cephalic capsule and 9.0 to

$8211.0 \mu \mathrm{m}$ wide (1/6 to $1 / 7$ corresponding diameter). Nerve ring situated beyond anterior third of esophagus. Length of anterior female genital tube $2,575 \mu \mathrm{m}$, of posterior tube $2,987 \mu \mathrm{m}$, and of reflexed parts $1,751 \mu \mathrm{m}$ and $1,854 \mu \mathrm{m}$ respectively. One egg, $721 \mu \mathrm{m} \times 226 \mu \mathrm{m}$, present in each uterine branch. Vulva situated slightly posterior to midbody. Spicules slightly curved, almost uniform in width throughout their length; taper slightly toward distal end and sharply at proximal to form pointed capitulum. Length of spicules $175 \mu \mathrm{m}$ and width in midsection $17 \mu \mathrm{m}$. Gubernaculum simple in structure, without processes, and projects slightly over ventral surface of spicules. Accessory organ 237 to $250 \mu \mathrm{m}$ anterior to anus. Setae situated in anal region number 24 pairs; one pair almost at tip of tail. Caudal glands tubular. 


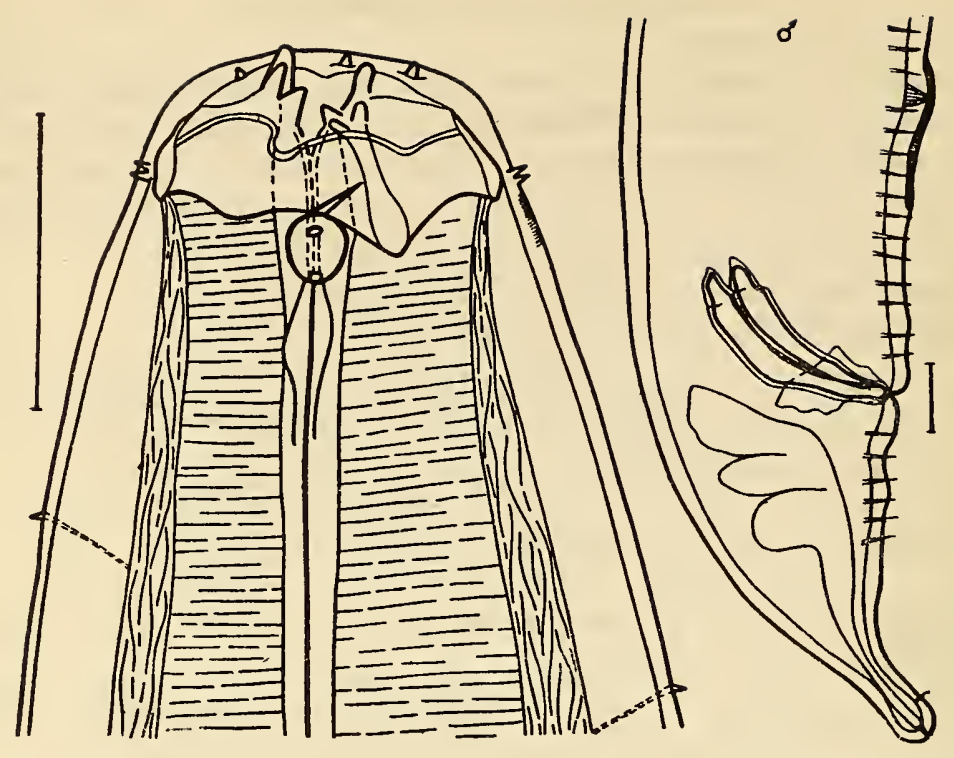

Figure 31. Synonchus murmanicus.

Distinguishing features of this species: 1) slightly wavy cephalic suture; 2) highly sclerotized thickenings of lateral walls of cephalic capsule; 3 ) short cephalic and cervical setae; 4) weakly arcuate spicules almost uniform in width throughout their length, with pointed capitulum significantly narrower than spicule body; 5) gubernaculum simple in structure, without processes; and 6) presence of about 20 pairs of setae in anal region of male.

Geographic distribution. Found only in the Barents Sea, predominantly in a depth range of 30 to $40 \mathrm{~m}$, in silted sand.

\section{Genus Anivanema gen. nov.}

Type species. A. magna sp. nov.

Very large worms. Cephalic capsule well developed and reminiscent of Thoracostoma in structure. Interlobular grooves very deep, narrowing toward posterior margin of cephalic capsule. Margins of cephalic lobes serrated. Amphids large and situated in upper wider part of interlobular grooves. Three large onchia of equal length situated in upper part of oral cavity. Cephalic and preneural setae long and thick. Tail elongated and claviform at end. 
83 19. Anivanema magna gen. nov., sp. nov (Figure 32)

Holotype o: Institute of Zoology, Academy of Sciences, USSR. Collection No. 6591.

$$
\begin{array}{ccccccc}
34 & 1030 & 1,957 & 9,167 & 12,978 & 15,779 & 22,413 \\
\hline 4069 & 187 & 225 & 228 & 232 & 230 & 200 \\
a & =98 ; b=19 ; c=64 ; & V=57 \% .
\end{array}
$$

Body tapers to $1 / 6$ midbody diameter at anterior end, but almost does not taper toward posterior end. Head anteriorly truncated. Tail tapers posteriorly from anus but terminates as a bulb. Cuticle thick, $10.0 \mu \mathrm{m}$. Cephalic capsule with deep interlobular grooves; depth $11.6 \mu \mathrm{m}$. Cephalic ring situated at end of first third of cephalic capsule; width at base of ring exceeds that at top by 1.7 times. Labial papillae well developed and wide. Cephalic and cervical setae long and thick.

Cephalic setae $17.4 \mu \mathrm{m}$ long ( $1 / 3$ corresponding body diameter) and cervical $15 \mu \mathrm{m}$ long. Minute setae present on caudal bulb. Amphids large and situated in grooves of cephalic capsule. Oral cavity small, with thick sclerotized walls. Nerve ring encircles esophagus somewhat above its middle. Length of anterior female genital tube $3,810 \mu \mathrm{m}$, of posterior tube $2,800 \mu \mathrm{m}$, and of reflexed parts $3,000 \mu \mathrm{m}$ and $2,200 \mu \mathrm{m}$ respectively. One egg, $1,050 \mu \mathrm{m} \times 220 \mu \mathrm{m}$, detected in genital tract. Vulva shifted slightly posterior to midbody.
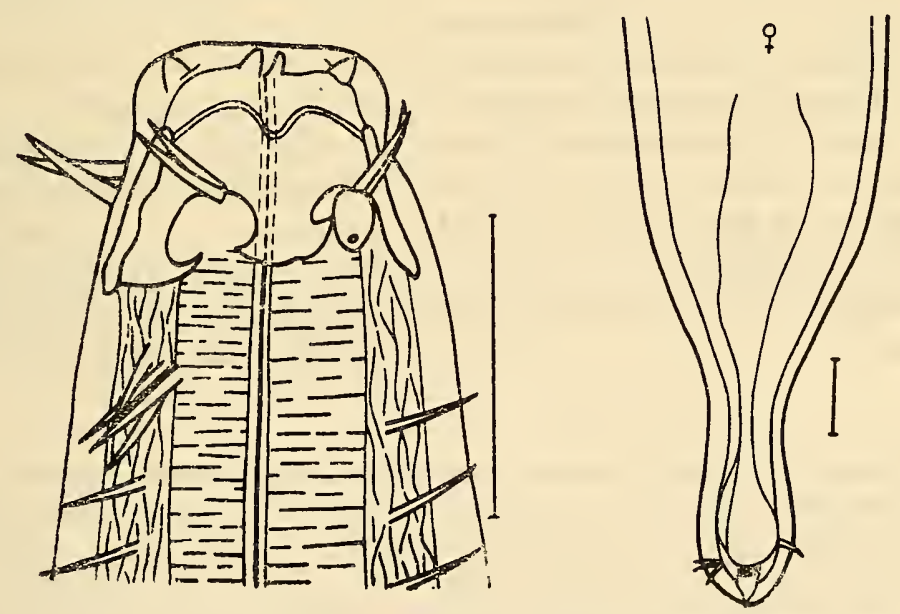

Figure 32. Anivanema magna gen. nov., sp. nov.

Distinguishing features of this species: 1) well-developed cephalic capsule with deep interlobular grooves; 2) long and strong setae, especially cephalic ones; 3) large and distinct labial papillae; and 4) extremely large size of body. 
Geographic distribution. Found in the Gulf of Aniva in the Sea of Okhotsk in gravel at a depth of $23 \mathrm{~m}$.

\section{Subfamily Thoracostomatinae de Coninck, 1965}

Cephalic capsule powerfully developed, long, and thick-walled. Interlobular grooves very deep and divided into furrows and fenestrae which vary in shape. Lateral interlobular grooves, inside which amphids are situated, always significantly wider and differ in shape from subdorsal and subventral grooves. Cephalic lobes may be smooth or with perforations of different size and shape. Cephalic ring varies considerably in width and location. Oral cavity poorly developed and usually unarmed. Nerve ring encircles esophagus usually at border of its anterior third or at its midsection. Tail wide, short, and obtusely rounded. Setae present on body but in very small numbers; shorter in length than those of representatives of subfamily Synonchinae. Photosensitive eyes or spots of photosensitive pigment always present in preneural part.

\section{Key to Genera of Subfamily Thoracostomatinae}

1 (2). Cephalic capsule with three distinct anteriorly directed processes. ......................... Triceratonema gen. nov.

2 (1). Cephalic capsule of different shape.

3 (6). Cephalic capsule asymmetrical; ventral wall significantly thicker and longer than dorsal and forms a protuberance in front.

4 (5). Process of gubernaculum situated at a right angle to longitudinal axis of spicules............ Pseudocella Filipjev, 1946.

5 (4). Process of gubernaculum forms an acute angle with longitudinal axis of spicules............. Thoracostoma Marion, $1870 .^{3}$

6 (3). Cephalic capsule symmetrical; entire wall even in length and thickness...................6. Deontostoma Filipjev, 1916.

${ }^{3}$ This genus includes the following species: Thoracostoma echonodon, Marion, 1870; T. zolae Marion, 1870; T. coronatum (Eberth, 1863); T. setosum (Linstow, 1896); T. chilense Steiner, 1922; T. steineri Micoletzky, 1922; T. vallini Allgen, 1927; T. philippinensis Allgen, 1951; T. australe Mawson, 1953; T. anocellatum SchuurmansStekhoven and Mawson, 1955; T. angustifissulatum Mawson, 1956; T. bruuni Wieser, 1956; T. scizoepistylium Mawson, 1958; T. parasetosum Mawson, 1958; T. karachiense Timm, 1959; and T. trachygaster Hope, 1967.

Descriptions of species by Allgen (T.penduli Allgen, 1954; T. bracylobatum Allgen, 1954; T. multipapillosum Allgen, 1957; T. microchaetum Allgen, 1957; T. sivertseni Allgen, 1958; $T$. unifenestratum Allgen, 1959; T. falklandiae Allgen, 1959; and $T$. microfenestratum Allgen, 1959) are so unsatisfactory and the illustrations so sketchy that I could not determine to which genus they should be assigned. 
Genus Triceratonoma gen. nov.

Type species. Thoracostoma campbelli Ditlevsen, 1922.

Large nematodes. Powerful cephalic capsule notably differs in structure from cephalic capsule of other representatives of this subfamily. Instead of a single ventral outgrowth, there are three well-developed cornuate processes in Triceratonema, directed anteriorly and situated along the oral angles-one ventral and two sublateral. These outgrowths join into a narrow cephalic ring in the first third of the cephalic capsule. A strip of fine sclerotized granules occurs immediately behind the capsule. Large photosensitive eyes with lens also present. Spicules with small capituli; curve sharply in their anterior third. Velum situated on ventral margin of spicules. Gubernaculum well developed, especially in distal part; process directed dorsally at an acute angle to body of spicules.

Key to Species of Genus Triceratonema gen. nov.

1 (2). Lobes of cephalic capsule with isolated large perforations; margins smooth. Strip of sclerotized granules situated beyond cephalic capsule. Spicules curve sharply in proximal third............ .................... campbelli (Ditlevsen, 1922).

852 (1). Lobes of cephalic capsule with numerous minute perforations; margins highly sinuate. Sclerotized granules behind cephalic capsule absent. Spicules curve smoothly................. T. microlobatum (Allgen, 1947).

\section{Genus Deontostoma Filipjev, 1916}

Marion, 1870: 27 (Thoracostoma); Linstow, 1892: 61; 1903: 276 (Leptosomatum); Savel'ev, 1912: 124 (Thoracostoma); Filip'ev 1916: 73; Platonova, 1962: 201; Hope, 1967: 323.

\section{Type species: Deontostoma arcticum Filipjev, 1916.}

Extremely large representatives of family Leptosomatidae, 10 to 37 $\mathrm{mm}$ long. Head usually truncated in front. Cephalic capsule cylindrical and does not narrow from base to top. All walls uniform in width and length and for this reason capsule appears symmetrical in profile. Cephalic suture may bend, forming marginal grooves. Cephalic lobes either entire or with small perforations of irregular shapes. Cephalic ring usually situated in anterior third of capsule. Nerve ring encircles esophagus in anterior third of cephalic capsule. Labial papillae massive and wide. Cephalic and cervical setae short; anal setae of male significantly longer. Photosensitive eyes present in all species of the genus. Vulva median or slightly posteromedian. 
Labia of vulva may be unequal in width or protrude over body surface to various degrees. Spicules characteristic, rather uniformly curved in proximal part, and devoid of sharp grooves and angles. Gubernaculum with well-expressed dorsal and ventral processes joined by a curved plate. After fusing, halves of gubernaculum form a sort of funnel in which the distal part of the spicules lie. Twenty pairs of preanal papillae, some supplied with setae, situated anterior to anal opening in male. Accessory organ of male, or rather its sclerotized part, differs in structure in different species of the genus. In some cases this part is tubular or resembles a pivotal needle, while in others it is cyathiform.

In the description of species of genus Deontostoma the figures in Cobb's formula denote the distance of the following parts of the body from the anterior end: 1. posterior end of cephalic capsule; 2. eyes; 3. nerve ring; 4 . base of esophagus; 5 . commencement of anterior genital tube; 6 . vulva; 7. commencement of posterior genital tube; and 8. anus.

Measurements are fewer for males than for females (see description of genus Leptosomatum).

\section{Key to Species of Genus Deontostoma}

1(4). Interlobular grooves not divided into furrows and fenestrae; open widely posteriorly.

2(3). Spicules with well-developed capituli and numerous protuberances................ montredonense (Marion, 1870).

3 ( 2). Spicules without distinctly defined capituli and protuberances. .......................... zeae (Inglis, 1964).

4 ( 1). Interlobular grooves distinctly divided into furrows and fenestrae.

5 (6). Four pairs of large rhomboid processes situated anterior to accessory organ...... D. californicum (Steiner and Albin, 1933).

6( 5). Rhomboid processes anterior to accessory organ absent.

7 ( 8 ). Section of preanal region in male densely covered with papillate setae.................. D. papillosum (Ditlevsen, 1922).

868 ( 7). Preanal region in male devoid of setae.

9 (26). Pigmented eyes present.

10 (13). Two pairs of pigmented eyes present: one pair distinct compact structures and second in shape of spots with vague contours.

11 (12). Esophageal lumen dilates in upper part of cephalic capsule.... ....................22. D. lobatum (Steiner, 1916).

12 (11). Esophageal lumen without dilatation in upper part of cephalic capsule................. p. pacifica (Murphy, 1965).

13 (10). Only single pair of pigmented eyes present.

14 (21). Gubernaculum always with a ventrally directed process. 
15 (18). Spicules with velum.

16 (17). Accessory organ resembles a sucker

D. auclandiae (Ditlevsen, 1922).

17 (16). Accessory organ cyathiform with processes directed anteriorly and posteriorly........... D. antarcticum (Linstow, 1892).

18 (15). Spicules without velum.

19 (20). Cephalic capsule very wide and short; width twice length...... .D. washingtonensis (Murphy, 1965).

20 (19). Cephalic capsule much narrower; width exceeds length not more than 1.5 times............. D. magnificum (Timm, 1951).

21 (14). Gubernaculum without ventrally directed process.

22 (23). Small hollow spine situated in middle part of gubernaculum. . .................... D. arcticum (Saveljev, 1912).

23 (22). Spine in gubernaculum absent.

24 (25). Spicules with velum; preanal papillae in male thick and buttonshaped .............20. D. papillatum (Linstow, 1903).

25 (24). Spicules without velum; preanal papillae in male normal in structure..................... jae (Inglis, 1964).

26 (9). Pigmented eyes absent.......... D. demani (Mawson, 1956).

20. Deontostoma papillatum (Linstow, 1903) (Figure 33)

Linstow, 1903: 276, tab. 18, figs. 9, 10 (Leptosomatum); Filip'ev, 1916: 79-82, tab. IV, fig. 5.

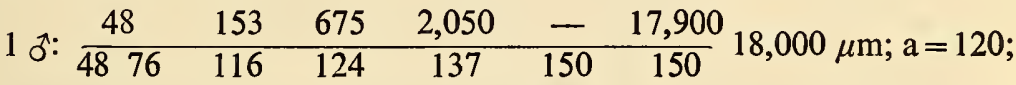

$$
\begin{aligned}
& b=8 ; c=180 \text {. }
\end{aligned}
$$

Body tapers to $1 / 3$ midbody diameter at anterior end, but does not taper toward posterior end. Cuticle thick, $11.6 \mu \mathrm{m}$. Cephalic capsule tapers 1.5 times from base to top. Cephalic ring wide and situated at apical part of cephalic capsule. Cephalic lobes without perforations; margins sinuate and form shallow grooves $23.2 \mu \mathrm{m}$ deep. Labial papillae wide, tapering slightly upwards. Cephalic and cervical setae extremely short and thin (length 1.32 and $3.45 \mu \mathrm{m}$ respectively). Eyes situated three times length of cephalic capsule from anterior end. Pigment bowl $5.8 \mu \mathrm{m} \times 11.6 \mu \mathrm{m}$ and lens $8.1 \mu \mathrm{m} \times 4.6 \mu \mathrm{m}$. Spicular apparatus consists of two wide massive spicules of equal length $(215 \mu \mathrm{m})$. Maximum width of spicules $75 \mu \mathrm{m}$ and minimum $25 \mu \mathrm{m}$. Gubernaculum $115 \mu \mathrm{m}$ long, with two processes-a wide and massive ventral one and a narrower dorsal one. Both processes closely apposed to body of spicules. Accessory organ with tubular sclerotized base situated at a distance of $100 \mu \mathrm{m}$ anterior to anus. Seven pairs of preanal papillae situated anterior to accessory organ. 


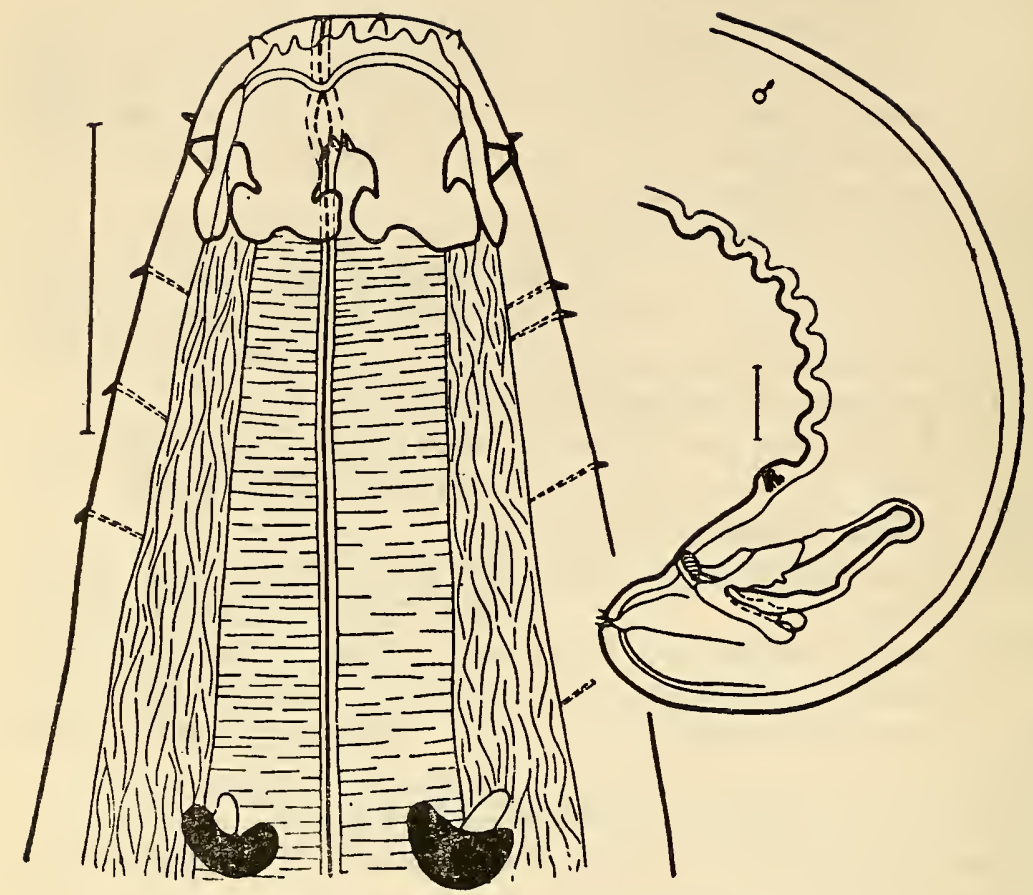

Figure 33. Deontostoma papillatum.

Distinguishing features of this species: 1) spicules extremely wide, massive, and encircled by two powerful processes of gubernaculum in distal part; 2) presence of seven pairs of very well-defined preanal papillae projecting on body surface in shape of buttons (species so-named because

87 of this feature); 3) cephalic lobe of capsule without punctations but highly sinuate contours; and 4) cephalic ring wide and situated in apical part of cephalic capsule.

Geographic distribution. Known only from the Barents Sea.

\section{Deontostoma arcticum (Saveljev, 1912) (Figure 34)}

Filip'ev, 1916: 75-79, tab, IV, fig. 4; Schuurmans-Stekhoven, 1946: 15, fig. 1a-d. Thoracostoma-Savel'ev, 1912: 124; Allgen, 1933: 496; Wieser, 1953c: 28, fig. 11a-g; Mawson, 1956: 46, 47, fig. 6a-d; 1958b: 317, 318.

$$
\begin{aligned}
& \text { 2 ㅊ: } \begin{array}{ccccc}
46-52 & 175-185 & 765-882 & 2,516-2,942 & - \\
\hline 5271-75 & 104-112 & 187-192 & 262-362 & 370
\end{array} \\
& \times \frac{24,832-27,825}{190-200} 25,000-28,000 \mu \mathrm{m} ; \mathrm{a}=74-77 ; \mathrm{b}=9 ; \mathrm{c}=154-160 \text {. }
\end{aligned}
$$




$$
\begin{aligned}
& \text { 2 ㅇ: } \begin{array}{ccccc}
41-46 & 162 & 721-787 & 2,575 & 11,845-12,360 \\
\hline 46 \quad 69-89 & 137 & 175-187 & 250 & -
\end{array}
\end{aligned}
$$

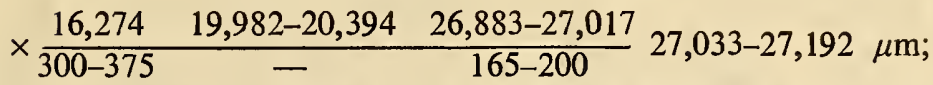

$$
\begin{aligned}
& a=72-91 ; b=10 ; c=155-180 ; V=59-60 \% \text {. }
\end{aligned}
$$

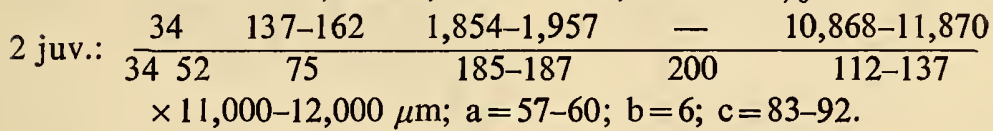

Body tapers to $1 / 5$ midbody diameter at anterior end and not less than $2 / 3$ at posterior end. Cuticle thick, 10.4 to $14.0 \mu \mathrm{m}$. Cephalic capsule narrows to half from base upwards. Cephalic ring situated in first third of cephalic capsule. Cephalic lobes entire. Cephalic suture sinuate and forms small marginal grooves. Shape of interlobular grooves varies significantly (Figure 34). Sometimes they consist of wide fenestrae, the contours of which form offshoots below and long narrow furrows; in other cases contours of fenestrae more irregular and they themselves 88 change into narrow but short furrows. Depth of interlobular grooves 23.2 to $26.6 \mu \mathrm{m}$. Labial papillae short and massive. Length of cephalic setae 4.6 to $5.8 \mu \mathrm{m}$ (1/10 to $1 / 15$ corresponding diameter) and of cervical papillae 2.3 to $5.8 \mu \mathrm{m}$. Anal setae of male also very short. Eyes situated at a distance of 3.5 to 4.0 times width of cephalic capsule. Size of pigment bowl 10.6 to $17.4 \mu \mathrm{m} \times 10.6$ to $15.8 \mu \mathrm{m}$. Large eggs, 618 to 206 $\mu \mathrm{m}$, seen in uterine tubes of female; three eggs found in anterior branch and one in posterior branch. Vulva slightly posterior to midbody and located in small depression; upper lip projects over lower one. Extremely small sclerotized granules situated around vulva on cuticular surface. Spicular apparatus consists of a pair of spicules with capituli differing in shape (Figure 34). Length of spicules $200 \mu \mathrm{m}$, maximum width 25 to 30 $\mu \mathrm{m}$, and minimum 12.5 to $15.0 \mu \mathrm{m}$. Gubernaculum funnel-shaped and envelopes spicules at their distal end. Length of gubernaculum 100 to $125 \mu \mathrm{m}$ and its dorsal process $30 \mu \mathrm{m}$. Hump-shaped accessory organ with sclerotized tube passing through it, situated 212 to $225 \mu \mathrm{m}$ anterior to anus. Twenty-one to twenty-three pairs of preanal papillae bearing short and thin setae situated anterior to accessory organ.

This species is very close to Deontostoma antarcticum in structure but differs from the latter as follows: 1) lobes of cephalic capsule not perforated; 2) cephalic suture forms marginal grooves; 3 ) spicules without ventral velum; 4) shape of gubernaculum with ventral part much more 89 massive and merging with dorsal part to form a more compact and narrower funnel; 5) accessory organ tubular in shape; and 6) vulva situated in depression, with prominent upper lip, and surrounded by minute sclerotized granules.

Nematodes classified under this species by Schuurmans-Stekhoven 

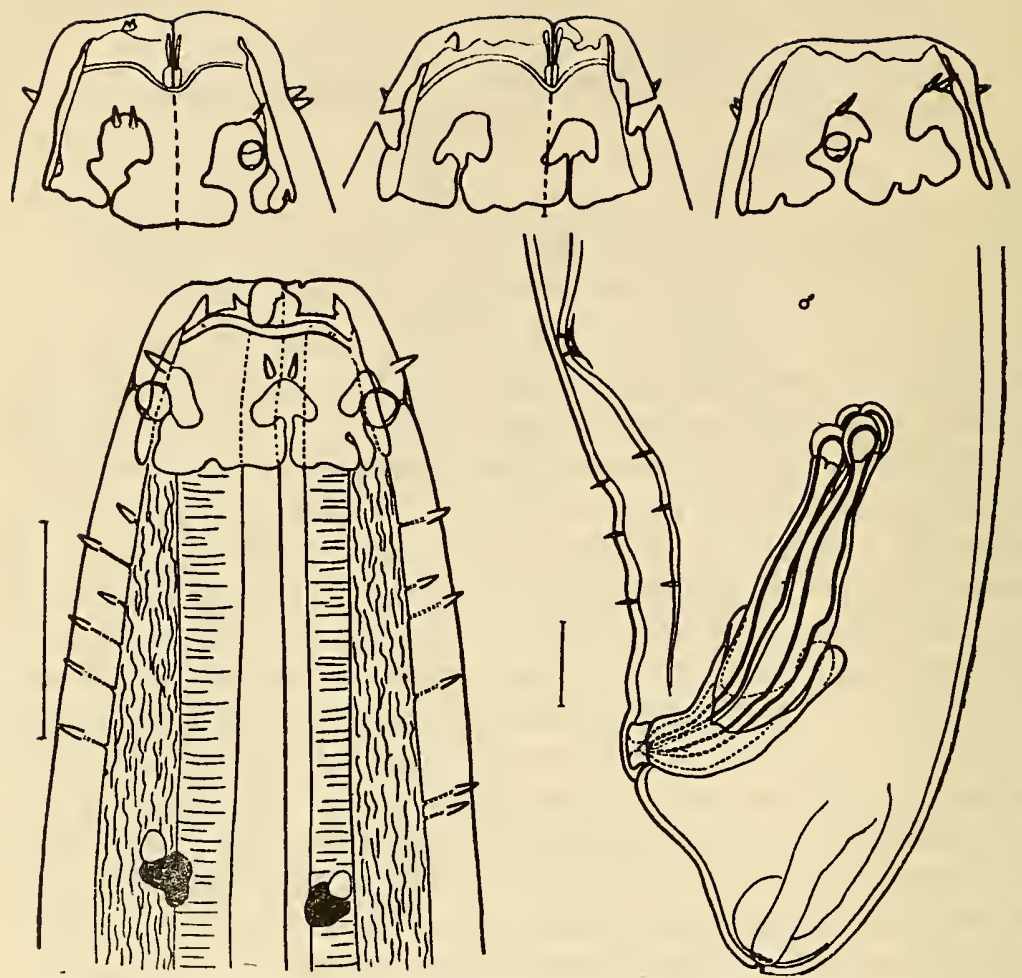

Figure 34. Deontostoma arcticum.

(Variability_of interlobular grooves of cephalic capsule.)

(1946) differ significantly from $D$. arcticum in absence of eyes, structure of cephalic capsule, and shape of amphids. It is regretted that in the material of Schuurmans-Stekhoven there were no males, making identification very difficult. Nevertheless the form should probably be considered an independent species.

Geographic distribution. Bipolar. Found in the Barents Sea (in littoral zone among brown algae), Norwegian Sea, and North Sea, and also in Antarctic and subantarctic waters.

\section{*22. Deontostoma lobatum (Steiner, 1916) (Figure 35)}

Steiner, 1916: 620-623, tab. 16, fig. 29a, tab. 31, fig. 29b (Thoracostoma) (description).

$$
\mathrm{L}=6,196 \mu \mathrm{m} ; \mathrm{a}=45 ; \mathrm{b}=5 ; \mathrm{c}=57 \text {. }
$$

Body covered with thick cuticle. Cephalic capsule almost does not narrow from base to top. Cephalic lobes without punctations and their 


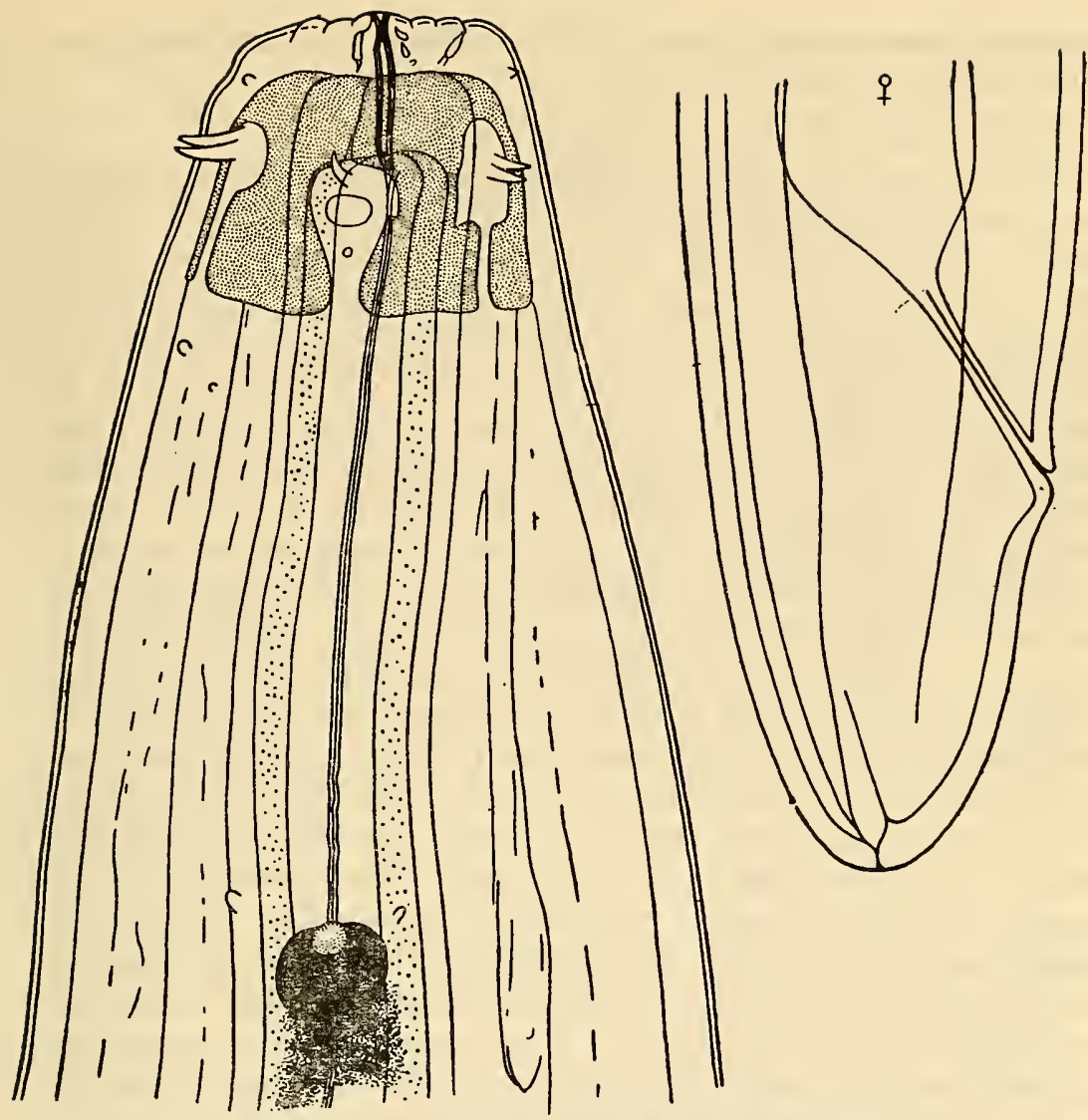

Figure 35. Deontostoma lobatum (from Steiner, 1916).

90 margins smooth (devoid of marginal grooves). Interlobular grooves with narrow furrows and rounded fenestrae. Labial papillae situated low, at level of upper margin of capsule. Cephalic setae short and wide. Cervical setae also short, occasionally dispersed throughout anterior part of body, mainly between anterior end and eyes. In addition to one pair of eyes, with pigment bowl and lens, another pair of irregular pigment spots are situated at a significant distance posterior to first pair. Esophageal lumen with dilatation in anterior part; walls of dilatation with a depression, opposite to which lies a dentoid process. Pores of esophageal glands open near dentoid process.

Geographic distribution. Barents Sea.

\section{Genus Pseudocella Filipjev, 1927}

Leuckart, 1849: 149 (Hemipsilus) (in part); Schneider, 1866: 58 (Enoplus) (in part); Bütschli, 1875: 42 (Thoracostoma) (in part); Filip'ev, 
1916: 82 (Thoracostoma) (in part); 1927: 93; Wieser, 1954: 175; Platonova, 1962: 204; Hope, 1967: 309.

Type species. Hemipsilus trochodes Leucart, 1849.

Body 6.0 to $29.0 \mathrm{~mm}$ long. Cephalic capsule in the shape of a slightly truncated cone, distinctly narrowing from base to top. Ventral wall of cephalic capsule significantly well developed in length and thickness; hence in lateral view of capsule ventral wall looks like a stout, blunt protuberance directed anteriorly, and consequently capsule appears asymmetrical. Cephalic ring may differ in width but usually situated at posterior limit of first third of cephalic capsule. Band of sclerotized granules may lie posterior to capsule. Nerve ring encircles esophagus in its anterior third or fourth part. Labial papillae small but distinct. Cephalic and cervical setae longer than in representatives of genus Deontostoma. Characteristic peculiarity of the genus: absence of clearly expressed eyes provided with light-refracting lens. Instead of eyes, either a compact pigment spot present or, more often, photosensitive pigment dispersed in the form of large irregular spots all over anterior end of esophagus. In some species photosensitive pigment absent. Vulva usually situated midbody; lips equal in width. Spicular apparatus differs considerably from that of genus Deontostoma. Spicules regularly arcuate and always with small but distinctly defined capituli and neck. Gubernaculum with two large processes of rectangular shape directed backward at right angles to longitudinal axis of spicules. In some species of this genus asymmetry in the development of the spicular apparatus is apparent, with one spicule significantly shorter than the other. Processes of the gubernaculum also asymmetrical. Anal setae and papillae of male vary considerably in number. Sometimes pretubal papillae absent but in some species even accessory organ absent.

In the description of species of genus Pseudocella given below, the figures in Cobb's formula denote the distance of the following parts from the anterior end: 1. posterior end of cephalic capsule; 2. nerve ring; 3. base of esophagus; 4 . commencement of anterior genital tube; 5 . vulva; 6. commencement of posterior genital tube; and 7. anus.

Figures are fewer for males than for females (see p. 74).

\section{Key to Species of Genus Pseudocella}

1 (2). Cervical setae absent........... . obliqua (Ditlevsen, 1926).

2( 1). Cervical setae present.

913 (4). Interlobular grooves undeveloped....P. filipjevi (Kreis, 1928).

4 ( 3). Interlobular grooves well developed.

5 (12). Subdorsal and subventral interlobular grooves with distinct furrows. 
6( 7). Subdorsal and subventral interlobular grooves narrow near posterior margin of cephalic capsule....P. tabarini (Inglis, 1958).

7 ( 6). Subdorsal and subventral interlobular grooves do not narrow near posterior margin of cephalic capsule.

8 (9). Tail long, with pointed digitiform process at end.......... .................... citronicauda (Wieser, 1954).

9( 8). Tail short and obtusely rounded.

10 (11). Cephalic capsule tapers distinctly from base to top; subdorsal and subventral interlobular grooves broaden posteriorly and form a triangle.............. polychaites Mawson, 1958.

11 (10). Cephalic capsule does not taper toward top; subdorsal and subventral interlobular grooves do not form an abrupt dilatation.

.P. kreisi (Wieser, 1953).

12 ( 5). Subdorsal and subventral interlobular grooves with well-defined furrows.

13 (24). Apophysis present on ventral aspect of tail of males.

14 (15). Process on tail of males resembles a bursa and provided with papillae................30. P. bursata Platonova, 1962.

15 (14). Apophysis on tail of males differs in structure; looks like a blunt protuberance.

16 (19). Cephalic ring narrow and situated in middle part of cephalic capsule.

17 (18). Large sclerotized granules present posterior to cephalic capsule. Photosensitive pigment merges into a single large spot........

36. P. truncaticauda sp. nov.

18 (17). Sclerotized granules absent behind cephalic capsule. Photosensitive pigment dispersed in isolated small spots. ............ 23. P. trichodes (Leucart, 1849).

19 (16). Cephalic ring wide and situated in upper part of cephalic capsule.

20 (23). One unpaired accessory organ present.

21 (22). Lateral interlobular grooves with additional notches along margin which look like narrow slits. Amphids round......... ................. P. mamillifera Platonova, 1962.

22 (21). Lateral interlobular grooves with wide additional notches in upper part of margin. Amphids longitudinally elongated...... 37. P. rarisetosa sp. nov.

23 (20). In addition to unpaired accessory organ, pair of organs situated anterior to former............. $\mathrm{P}$. angusticeps $\mathrm{sp}$. nov.

24 (13). Apophysis absent on ventral aspect of tail of males.

25 (26). Narrow longitudinal furrows extend along cephalic lobes...... P. panamaense (Allgen, 1947).

26 (25). Longitudinal furrows absent on cephalic lobes.

27 (28). Cervical setae commence above level of cephalic suture, more or 
less from middle of amphids P. wieseri Hope, 1967.

28 (27). Cervical setae commence below level of cephalic suture.

29 (38). Fenestrae in subdorsal and ventral interlobular grooves circular.

30 (31). Cephalic setae extremely short; length does not exceed one-tenth of corresponding diameter....P. brachychaites Mawson, 1958.

9231 (30). Cephalic setae significantly long; length not less than one-fourth of corresponding diameter.

32 (33). Small pointed onchium present on dorsal side of oral cavity.... 29. P. pseudocellum (Filipjev, 1916).

33 (32). Onchia absent in oral cavity.

34 (35). Spicules unequal in length; right spicule longer by one-fourth than left................. cavernicola (Wieser, 1954).

35 (34). Spicules equal in length.

36 (37). Photosensitive pigment totally absent. Spicules with small velum....................... P. acuta sp. nov.

37 (36). Photosensitive pigment present. Spicules without velum...... 38. P. raddae sp. nov.

38 (29). Fenestrae of subdorsal and subventral interlobular grooves anchor-shaped.

39 (46). Gubernaculum funnel-shaped, highly developed on all sides, and encloses distal part of spicules.

40 (41). Capituli of spicules rectangular.......28. P. gracilis sp. nov.

41 (40). Capituli of spicules round.

42 (43). Anchor-shaped additional cleft present above lateral interlobular grooves................29. P. tenuis Filipjev, 1946.

43 (42). Additional cleft above lateral interlobular grooves absent.

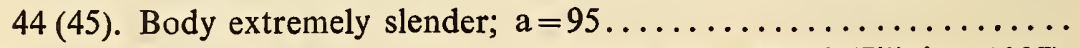
25. P. saveljevi (Filipjev, 1927).

45 (44). Body significantly wide: $a=35$ to 56 .

24. P. elegans (Ditlevsen, 1926).

46 (39). Gubernaculum not funnel-shaped, and does not enclose distal part of spicules.

47 (48). Gubernaculum small; dorsal process not developed......... ......................31. P. minor Platonova, 1962.

48 (47). Gubernaculum large; dorsal process well developed.

49 (50). Cephalic ring narrow and situated in middle of cephalic capsule. .27. P. coecum (Saveljev, 1912).

50 (49). Cephalic ring wide and situated in upper part of cephalic capsule................32. P. kurilensis Platonova, 1962.

23. Pseudocella trichodes (Leucart, 1849) (Figure 36)

Leucart, 1849: 149, tab. 3, figs. 1, 2, (Hemipsilus); Schneider, 1866; 58 (Enoplus denticaudatus); Bütschli, 1874: 42, tab. 8, fig. 33a-d; Savel'ev, 
1912: 126; de Man, 1922: 251, Fig. 42a-b (Thoracostoma schneideri); de Man, 1888: 22, tabs. 2-3, figs. 12-12b; Linstow, 1900: 126, tab. 7, figs. 36-37; Southern, 1914: 39; Filip'ev, 1916; 88, tab. 4, fig. 7; Ditlevsen, 1919: 181 (T. denticaudatum); Filip'ev, 1927: 94-97, pl. I, fig. 12a-b; Kreis, 1928: 147; Allgen, 1935: 16; Schuurmans-Stekhoven, 1935a: 12 ( $T$. trichodes), fig. 75; Allgen, 1957b: 8; 1959; 22, fig. 6a-b; Gerlach, 1958; 85; Steiner, 1916: 623, tab. 17, fig. 30a-b (Thoracostoma sp.); Platonova, 1967: 832 .

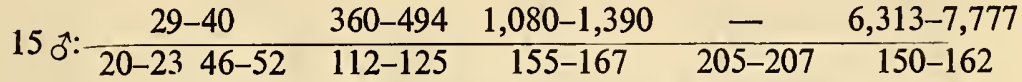

$$
\begin{aligned}
& \times 6,393-7,948 \mu \mathrm{m} ; \mathrm{a}=32-38 ; \mathrm{b}=4-6 ; \mathrm{c}=39-53 \text {. }
\end{aligned}
$$

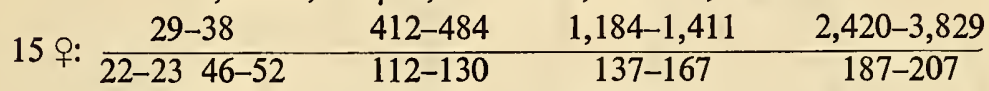

$$
\begin{aligned}
& \times \frac{4,119-5,631}{5,921-7,436} \frac{6,693-9,236}{175-200} 6,843-9,473 \mu \mathrm{m} ; \\
& \mathrm{a}=33-57 ; \mathrm{b}=6-7 ; \mathrm{c}=60-90 ; \mathrm{V}=56-61 \% \text {. } \\
& 15 \text { juv.: } \begin{array}{llllc}
24-39 & 309-463 & 844-1,338 & - & 3,522-6,797 \\
\hline 1739-42 & 100-125 & 112-167 & 130-137 & 85-115
\end{array} \\
& \times 3,647-6,922 \mu \mathrm{m} ; \mathrm{a}=28-46 ; \mathrm{b}=4-5 ; \mathrm{c}=36-69 \text {. }
\end{aligned}
$$

93 Body rather elongated and tapers to $1 / 3$ to $1 / 4$ midbody diameter at anterior end, but almost does not taper posteriorly. Cuticle relatively thick, 8.1 to $10.0 \mu \mathrm{m}$. Tail rather short, rounded, and curves ventrally in males. Dentoid projection present on ventral aspect of tail. Cephalic capsule usual shape for this genus, tapering from base upward to half its length. Extremely narrow cephalic ring situated in anterior third of cephalic capsule. Lobes of cephalic capsule entire and without perforations. Small and narrow folds present on surface of lobes. Marginal grooves absent. Sublateral interlobular grooves resemble narrow furrows and dilate into wide round fenestrae. Amphids slightly elongated longitudinally; width $9.2 \mu \mathrm{m}$. Photosensitive pigment situated posterior to cephalic capsule at a distance somewhat less than its length. Longitudinal bands of pigment extend further. Labial papillae well defined. Length of cephalic setae 5.8 to $8.1 \mu \mathrm{m}$, and cervical 3.4 to $4.6 \mu \mathrm{m}$. Anal setae of male vary significantly in length: preanal setae $4.0 \mu \mathrm{m}$, and postanal $12.5 \mu \mathrm{m}$. Extremely small setae situated along margin of caudal pore. Nerve ring situated at end of first third of esophagus. Length of anterior female genital tube 1,493 to $2,060 \mu \mathrm{m}$, of posterior tube 1,648 to 2,369 , and of reflexed parts 721 to $1,030 \mu \mathrm{m}$ and 824 to $1,236 \mu \mathrm{m}$ respectively. One to four eggs, 206 to $412 \mu \mathrm{m} \times 103$ to $123 \mu \mathrm{m}$, seen in uteri. Spicules unequal in size and shape. Usually left spicule (187 to $200 \mu \mathrm{m}$ ) longer, than right one (172 to $175 \mu \mathrm{m})$. Left spicule with larger capitulum, tapering into a significantly narrower body; blunt process occurs in upper part of spicu- 
lar body. Right spicule more regular in form; narrow capitulum tapers into small cervix, which broadens into spicular body. Velum attached to spicules from ventral side. Gubernaculum paired; 32 to $40 \mu \mathrm{m}$ long. Accessory organ 112 to $150 \mu \mathrm{m}$ anterior to anus. Eight to ten pairs of preanal papillae situated anterior to accessory organ.

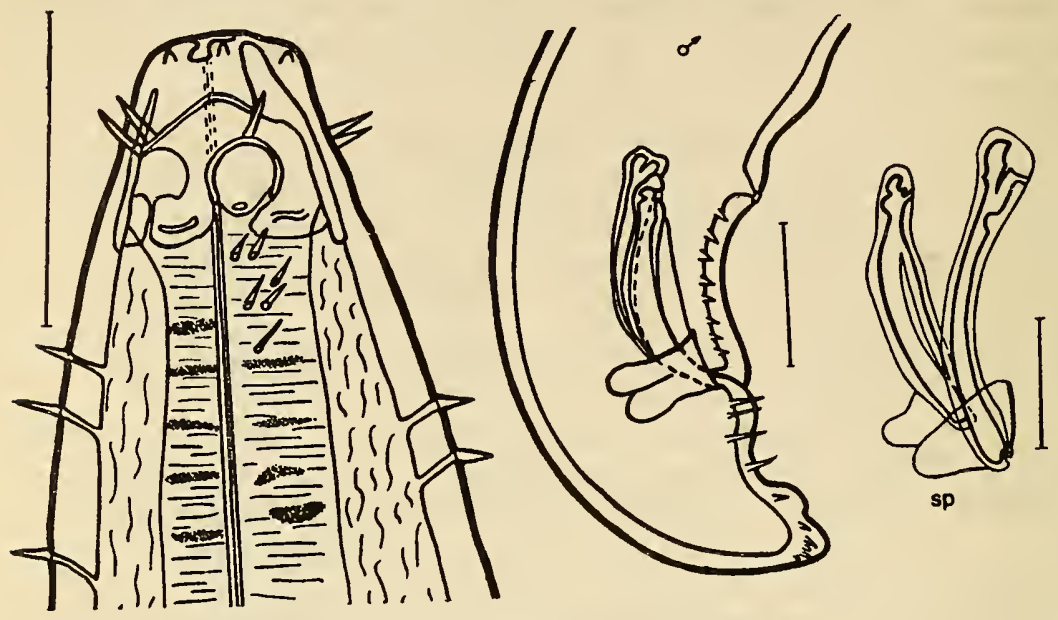

Figure 36. Pseudocella trichodes.

Distinguishing features of this species: 1) folds on lobes of cephalic capsule; 2) extremely narrow cephalic ring; 3) absence of marginal grooves in lobes of cephalic capsule; 4) characteristic form of interlobular grooves; 5) great differences in length of pre- and postanal setae in male; 94 6) characteristic structure of spicules, clearly differing from each other in shape and size; and 7) presence of dentoid process on ventral aspect of tail of males.

Geographic distribution. Found mainly in the seas of the Arctic basin, North Sea, and along western part of the Baltic Sea. Inhabits mainly littoral zone among brown algae. I do not accept Allgen's view that this species is ubiquitous (Allgen, 1957b). Even if the two findings of this species in the southern hemisphere on the southern shores of Australia and Argentina are taken into account (Allgen, 1951, 1959), this species can easily be considered bipolar in distribution.

24. Pseudocella elegans (Ditlevsen, 1926) (Figure 37)

Ditlevsen, 1926: 25 , tab. 5, figs. 3, 5, tab. 6, fig. 3, tab. 7, figs. 3-4 (Thoracostoma); Schuurmans-Stekhoven, 1935a: 14, fig. 76A-B; 1946: 17-19, fig. 2A-F; Filip'ev, 1946: 159; Allgen, 1957b: 8; Platonova, 1967: 832. 


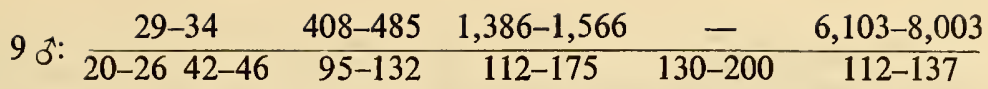

$$
\begin{aligned}
& \times 6,237-8,203 \mu \mathrm{m} ; \mathrm{a}=37-56 ; \mathrm{b}=4-5 ; \mathrm{c}=32-46 \text {. }
\end{aligned}
$$

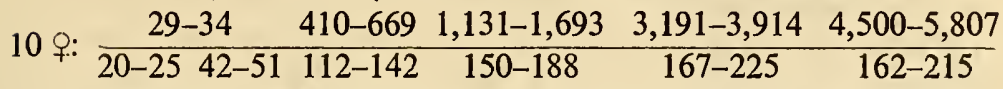

$$
\begin{aligned}
& \times \frac{6,045-7,867}{7,311-9,618} 7,486-9,793 \mu \mathrm{m} ; \mathrm{a}=36-51 ; \mathrm{b}=5-6 \text {; } \\
& \mathrm{c}=42-58 ; \mathrm{V}=50-63.5 \% \text {. }
\end{aligned}
$$

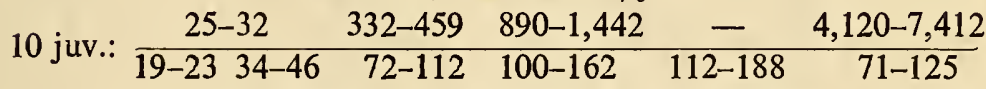

$$
\begin{aligned}
& \times 4,232-7,562 \mu \mathrm{m} ; \mathrm{a}=38-42 ; \mathrm{b}=5 ; \mathrm{c}=38-51 \text {. }
\end{aligned}
$$

Body average in size, tapers to $1 / 7$ to $1 / 10$ midbody diameter at anterior end and almost does not taper toward posterior end. Cuticle 9.28 to $15.0 \mu \mathrm{m}$ thick. Lobes of cephalic capsule rounded, sometimes with small number of fenestrae. Margin of cephalic capsule smooth, does not form peripheral (marginal) grooves. Depth of interlobular grooves 9.3 to 15.0 $\mu \mathrm{m}$. Sublateral interlobular grooves narrow, anchor-shaped, while lateral interlobular grooves rounded and wide, with slit-shaped furrow on upper part. Amphid, 8.1 to $11.6 \mu \mathrm{m} \times 4.6$ to $8.1 \mu \mathrm{m}$, situated in cavity of each interlobular groove. Ditlevsen (1926) in describing this species mistook the slit-shaped furrows in the upper part of the lateral grooves for horseshoe amphids; hence he proposed the transference of this species to another genus. Sensory organs represented by cephalic setae 6.9 to 8.1 $\mu \mathrm{m}$ long, cervical setae 5.8 to $6.9 \mu \mathrm{m}$, and in males anal setae 12.5 to 15.0 $\mu \mathrm{m}$. Photosensitive pigment dispersed throughout anterior body end; does not form small or large clusters. Length of anterior female genital tube 1,545 to $2,060 \mu \mathrm{m}$, of posterior tube 1,442 to 1,854 , and of reflexed parts 824 to $1,030 \mu \mathrm{m}$ and 824 to $1,080 \mu \mathrm{m}$ respectively. One to three eggs, 204 to $357 \mu \mathrm{m} \times 102$ to $153 \mu \mathrm{m}$, found in uterus. Length of anterior testis with seminal vesicles 515 to $721 \mu \mathrm{m}$ and posterior testis 597 to 927 $\mu \mathrm{m}$. Spicules unequal in length, 125 and $200 \mu \mathrm{m}$ respectively. Either left or right spicule may be longer. Spicules equal in length exceptionally. Round capitulum tapers rather abruptly into narrow cervix on proximal end of spicule; midlength, spicules dilate again. Gubernaculum paired; structures fuse to form a funnel which encloses spicular bodies. Small velum present on ventral surface of spicules, and two processes, 30 to 40 $\mu \mathrm{m}$ long, present on dorsal surface. Accessory organ 87.5 to $125 \mu \mathrm{m}$ anterior to anus; five to six pairs of papillae situated anterior to accessory organ.

Distinguishing features of this species: 1) rather small length in view of significant width; 2) sublateral grooves anchor-shaped; 3) absence of marginal grooves; 4) spicules unequal in length, with distinctly expressed round capitulum; and 5) gubernaculum paired; structures fuse and form a 

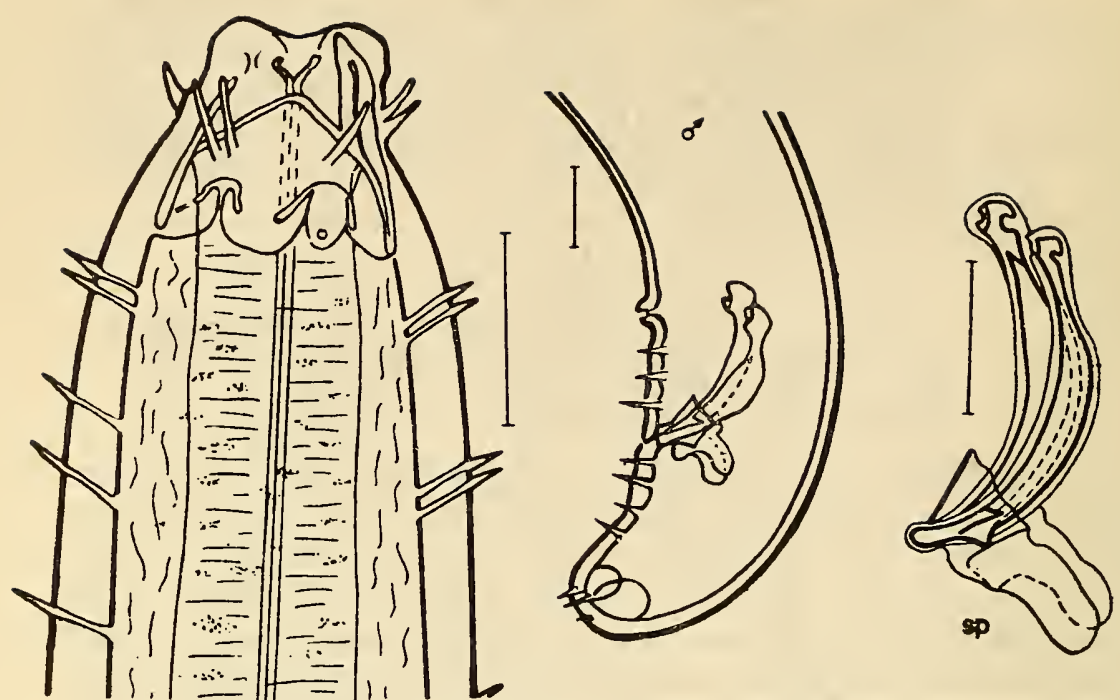

94

Figure 37. Pseudocella elegans.

funnel enclosing spicular bodies.

Geographic distribution. Arctic-boreal species. Found in the Kara Sea (in depths ranging from 300 to $400 \mathrm{~m}$ in sandy silt), Greenland Sea, and Baltic Sea. One sexually immature specimen of this species Ditlevsen claims he collected in the subantarctic (Lake Campbell); this find appears dubious.

\section{Pseudocella saveljevi (Filipjev, 1927) (Figure 38)}

Filip'ev, 1927: 97, 98, pl. 1, fig. 13a-c (Thoracostoma); Kreis, 1928: 143-145, tab. 1, fig. 3 (T. conicaudatum); Platonova, 1967: 832.

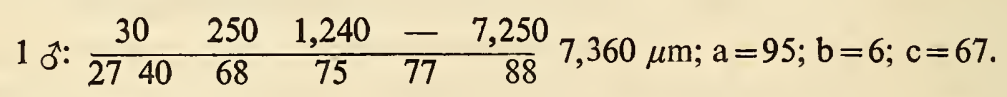

Body average in size, tapers to $1 / 3$ midbody diameter at anterior end, and slightly broadens toward posterior end due to development of male copulatory apparatus. Cuticle 5.0 to $6.0 \mu \mathrm{m}$ thick. Cephalic capsule rather short and broadens slightly toward base. Relatively wide cephalic ring situated in uppermost part of cephalic capsule. Lobes of cephalic capsule with narrow slit-shaped perforations. Median lobes with deep marginal grooves. Subventral and subdorsal interlobular grooves anchorshaped. Narrow horseshoe-shaped cleft visible in upper part of wide lateral grooves. Band of extremely small sclerotized granules situated behind cephalic capsule. Labial papillae small. Length of cephalic and 
cervical setae $7.0 \mu \mathrm{m}$ and anal setae $12.5 \mu \mathrm{m}$. Photosensitive pigment dispersed throughout anterior end of body. Nerve ring situated at border of first quarter of esophagus. Spicules unequal in length, left $105 \mu \mathrm{m}$, and right $112 \mu \mathrm{m}$, uniformly curved, with capituli of different shape. Gubernaculum paired; structures fuse and form funnel enveloping spicular bodies. Length of gubernacular process $65 \mu \mathrm{m}$. Accessory organ $65 \mu \mathrm{m}$ anterior to anus. Four pairs of preanal papillae situated anterior to accessory organ. Ten pairs of anal setae present in anal region.

This species is close to Pseudocella coecum in structure but differs from it in: 1) significantly small size; 2) structure of cephalic capsule: presence 96 of slit-shaped punctations on lobes of cephalic capsule, presence of marginal grooves on median lobes, presence of small sclerotized granules behind cephalic capsule, and extremely wide cephalic ring; and 3) number of preanal papillae (four pairs versus eight to nine pairs in $P$. coecum).

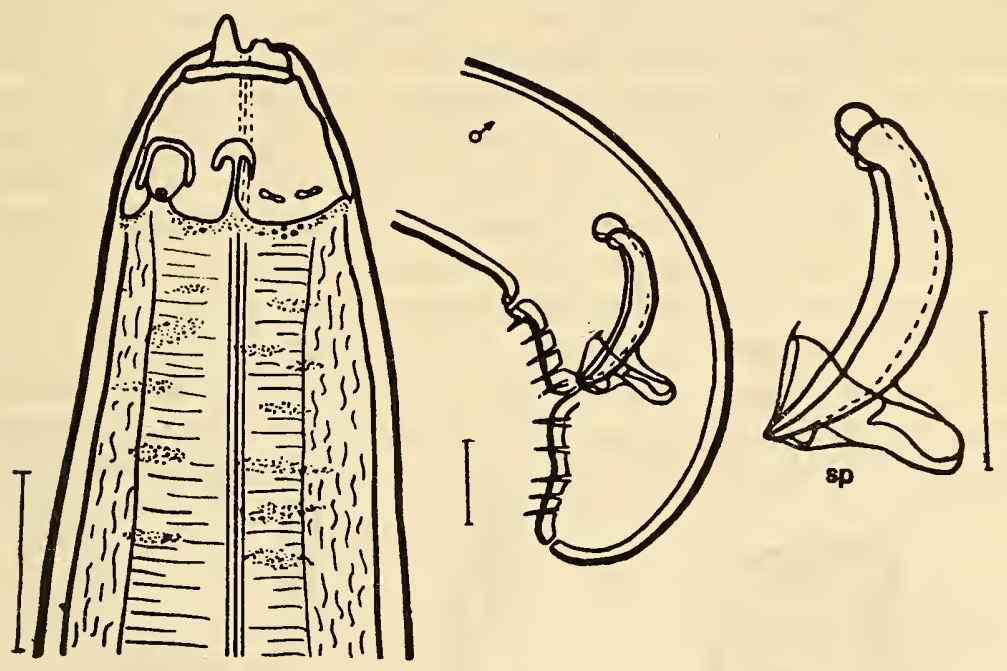

Figure 38. Pseudocella saveljevi.

Geographic distribution. Only isolated finds from the Barents Sea.

26. Pseudocella tenuis Filipjev, 1946 (Figure 39)

Filip'ev, 1946: 159-160, fig. 3a-c; Platonova, 1967: 832.

$$
\begin{aligned}
& 9 \text { ) } \\
& \times 6,171-9,574 \mu \mathrm{m} ; \mathrm{a}=69-83 ; \mathrm{b}=5-6 ; \mathrm{c}=40-65 \text {. }
\end{aligned}
$$

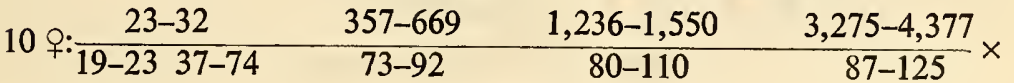




$$
\begin{aligned}
& \times \frac{4,017-3,819 \quad 4,532-7,158 \quad 6,032-8,909}{90-122} 6,132-9,021 \mu \mathrm{m} \text {; } \\
& \mathrm{a}=67-72 ; \mathrm{b}=5-6 ; \mathrm{c}=59-81 ; \mathrm{V}=58-64 \% \text {. }
\end{aligned}
$$

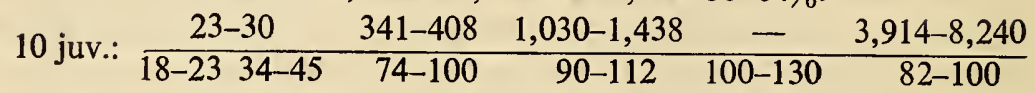

$$
\begin{aligned}
& \times 4,014-8,340 \mu \mathrm{m} ; \mathrm{a}=39-64 ; \mathrm{b}=4-6 ; \mathrm{c}=40-83 \text {. }
\end{aligned}
$$

Body average in size, tapers to $1 / 3$ midbody diameter at anterior end and almost does not taper toward posterior end. Cuticle $8.2 \mu \mathrm{m}$ (5.8 to $10.4 \mu \mathrm{m})$ thick. Cephalic capsule highly similar to that of Pseudocella elegans but notably narrower and appears longitudinally stretched. Subdorsal and subventral interlobular grooves anchor-shaped. Amphids situated in furrows and not in fenestrae of lateral grooves; hence fenestrae with their outgrowths seem to be situated at a level higher than that of amphids. Interlobular grooves 11 to $15 \mu \mathrm{m}$ deep. Lobes of cephalic capsule round, without marginal grooves. Extremely small number of slightly sclerotized granules located behind cephalic capsule. Cephalic ring narrow and situated in upper part of capsule. Amphids round, longitudinally stretched, and 8.1 to $9.2 \mu \mathrm{m} \times 4.6$ to $5.8 \mu \mathrm{m}$. Cephalic setae rather long, 6.9 to $8.1 \mu \mathrm{m}$, cervical setae 4.6 to $12.5 \mu \mathrm{m}$, and anal setae in male 10.0 to $12.5 \mu \mathrm{m}$. Photosensitive pigment dispersed throughout anterior end of body. Length of anterior female genital tube 669 to $1,545 \mu \mathrm{m}$, of 97 posterior tube 824 to $1,339 \mu \mathrm{m}$, and of reflexed parts 412 to $927 \mu \mathrm{m}$ and 515 to $721 \mu \mathrm{m}$ respectively. Two eggs, 255 to $357 \mu \mathrm{m} \times 76$ to $91 \mu \mathrm{m}$, found in each uterus. Length of spicules 100 to $145 \mu \mathrm{m}$. Spicular body without distinct neck or cervix. Accessory organ situated 62 to $100 \mu \mathrm{m}$ anterior to anus. Four to six pairs of papillae situated anterior to accessory organ.
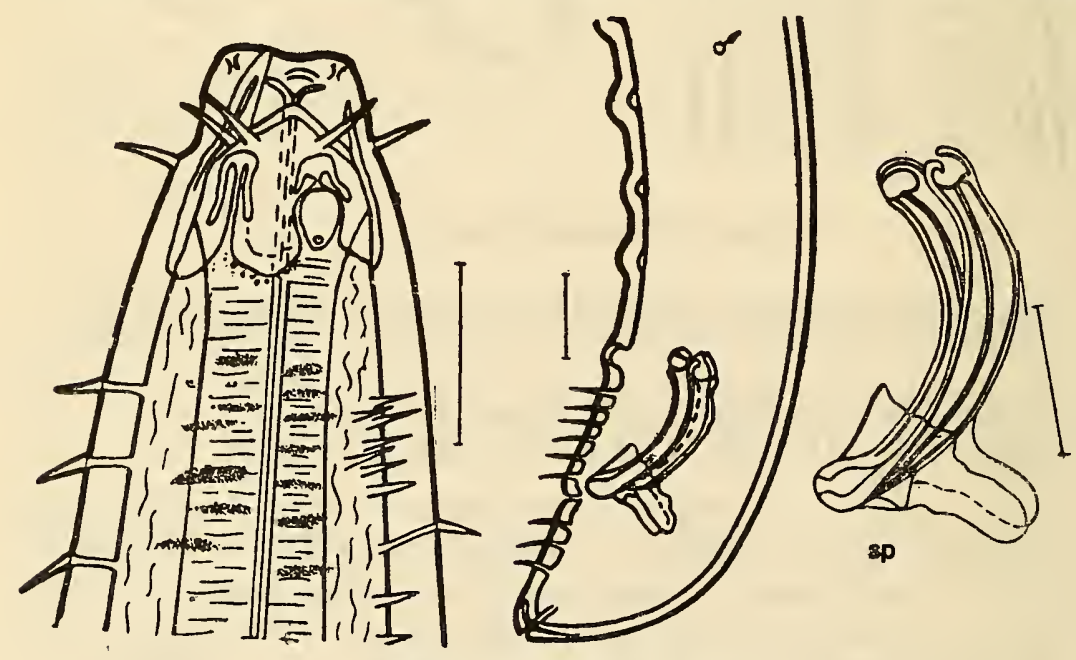

Figure 39. Pseudocella tenuis. 
This species closely resembles $P$ seudocella elegans but differs from it in the following features: 1 ) significantly smaller width of body (in $P$. elegans a $=35-56$, in $P$. tenuis $\mathrm{a}=68-72) ; 2$ ) shape of interlobular lateral grooves (in $P$. elegans wide and without distinctly expressed fenestrae; in $P$. tenuis narrow fenestrae with outgrowths situated above wide furrows); and 3) shape of spicules (curved in P. elegans with clearly distinguishable capitulum and neck; in $P$. tenuis long and massive with barely distinguishable capitulum, and neck totally absent).

Geographic distribution. Found only in the Kara Sea in depths ranging from 100 to $360 \mathrm{~m}$, mainly in sandy silt.

\section{Pseudocella coecum (Saveljev, 1912) (Figure 40)}

Savel'ev, 1912: 124 (Thoracostoma); Filip'ev, 1927: 98-100, pl. 3, fig. 14a-g (Thoracostoma); Platonova, 1967: 832.

$$
\begin{aligned}
& 1 \text { ㄱ: } \begin{array}{cccccc}
34 & 510 & 1,530 & - & 9,099 \\
23 & 58 & 110 & 162 & 200 & 137
\end{array} 9,261 \mu \mathrm{m} ; \mathrm{a}=48 ; \mathrm{b}=6 ; \mathrm{c}=57 \text {. } \\
& 2 \text { ㅇ: } \begin{array}{cccccc}
34-38 & - & 463 & 1,441-1,493 & 4,325-4,480 & 5,973-6,437 \\
\hline 25-29 & 58 & 125 & 172-175 & 175-212 & 187-200
\end{array} \\
& \times \frac{7,621-8,394}{172-212}-\frac{8,859-9,630}{137-140} 9,009-9,805 \mu \mathrm{m} ; \quad a=46-48 ; \\
& \mathrm{b}=6 ; \mathrm{c}=56-60 ; \mathrm{V}=66 \% \text {. }
\end{aligned}
$$

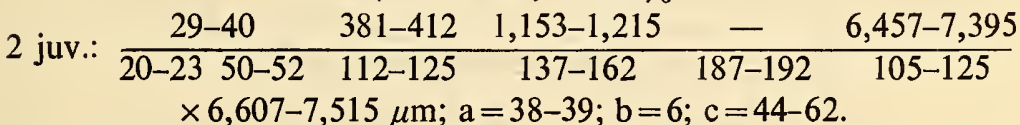

Body average in size, tapers to $1 / 3$ to $1 / 4$ midbody diameter at anterior end at base of cephalic capsule, and almost does not taper toward posterior end. Cuticle $8.1 \mu \mathrm{m}$ thick. Cephalic capsule narrows to $2 / 5$ from base toward middle [sic]. Narrow cephalic ring situated in middle of cephalic capsule. Lobes of cephalic capsule with large number of perforations, mostly minute, but in midlobular part merge to form rather large, round or slit-shaped loculi. In addition, lobular margins with thin transverse folds and consequently appear rugulose. Occasionally, extremely fine sclerotized granules present under median lobe. Margins of cephalic lobes form small peripheral grooves. Subdorsal and subventral grooves anchorshaped and $17.4 \mu \mathrm{m}$ long. Lateral interlobular grooves wide, round, with canal-shaped depression in their upper part. Amphids located in lateral grooves large and only slightly elongated longitudinally. Amphids 9.2 $\mu \mathrm{m} \times 6.9 \mu \mathrm{m}$. Labial papillae rather large. Cephalic setae $12 \mu \mathrm{m}$ long, cervical setae $8.0 \mu \mathrm{m}$, and anal setae in males $12.5 \mu \mathrm{m}$. Photosensitive pigment dispersed in spots with irregular outlines. Length of female genital tubes 1,648 to $1,957 \mu \mathrm{m}$ and reflexed parts 772 to $824 \mu \mathrm{m}$. Two to three eggs, 255 to $452 \mu \mathrm{m} \times 102$ to $125 \mu \mathrm{m}$, found in each branch of 
uterus. Vulva shifted posterior to midbody (posteromedian in position). Spicules unequal in length; left $212 \mu \mathrm{m}$, right $192 \mu \mathrm{m}$. Gubernaculum with process $62.2 \mu \mathrm{m}$ long and $15.0 \mu \mathrm{m}$ wide at top. Accessory organ $87.5 \mu \mathrm{m}$ anterior to anus. Preanal papillae barely visible in my preparations. Fourteen pairs of setae situated in anal region of male. Extremely small setae also present around outlet of caudal glands in both males and females. Extremely fine, isolated setae likewise present on dorsal surface of tail.
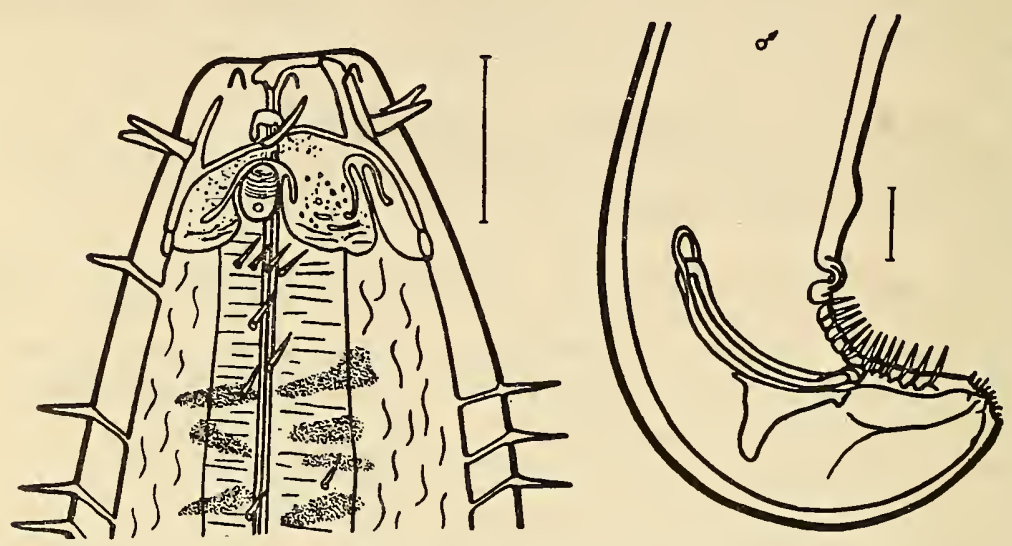

Figure 40. Pseudocella coecum.

Distinguishing features of this species: 1) structure of cephalic capsule: lobes with large number of punctations, lobular margins with fine transverse folds, subdorsal and subventral interlobular grooves anchorshaped with extremely narrow furrows, small peripheral grooves present, and extremely minute sclerotized granules situated posterior to median lobe; 2) spicules unequal in length, rather narrow, smoothly arcuate, with round capitulum; and 3) extremely short setae, situated in groups in region of pore of caudal glands in both male and female. Short setae also present on dorsal aspect of tail.

Geographic distribution. Arctic species. Found in the Barents Sea (mainly in the littoral zone among brown algae), White Sea, and Kara Sea. Specimens primarily found at a depth of $30 \mathrm{~m}$ in sandy silt.

99 28. Pseudocella gracilis sp. nov. (Figure 41)

Holotype s: $^{*}$ Institute of Zoology, Academy of Sciences, USSR. Collection No. 5117.

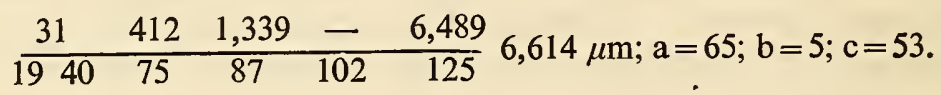


Body tapers to $2 / 5$ midbody diameter at anterior end, and broadens slightly posteriorly in region of spicular apparatus. Cuticle $5.8 \mu \mathrm{m}$ thick. Cephalic capsule narrows to $1 / 2$ from base toward top. Cephalic ring narrow and situated in anterior third of cephalic capsule. Cephalic lobes with one to two large perforations. Subventral and subdorsal interlobular grooves anchor-shaped and $11.6 \mu \mathrm{m}$ in depth. Lateral interlobular grooves wide, round, and with canalicular depression in upper part. Amphids located in grooves, elongated longitudinally, and $9.3 \mu \mathrm{m} \times 5.8$ $\mu \mathrm{m}$. Labial papillae small. Cephalic setae $9.3 \mu \mathrm{m}$; cervical setae 5.8 $\mu \mathrm{m}$; anal setae $12.5 \mu \mathrm{m}$. Photosensitive pigment dispersed in small spots throughout anterior part of esophagus. Spicules unequal in length; left $125 \mu \mathrm{m}$ and right $150 \mu \mathrm{m}$ long. Capitulum of spicules unique, not rounded as usually seen in Pseudocella but truncated at proximal end. Gubernaculum paired; structures fuse to form funnel. Length of gubernacular processes $30 \mu \mathrm{m}$. Accessory organ $87.5 \mu \mathrm{m}$ anterior to anus. Six pairs of papillae situated anterior to accessory organ, and thirteen pairs situated in anal region.
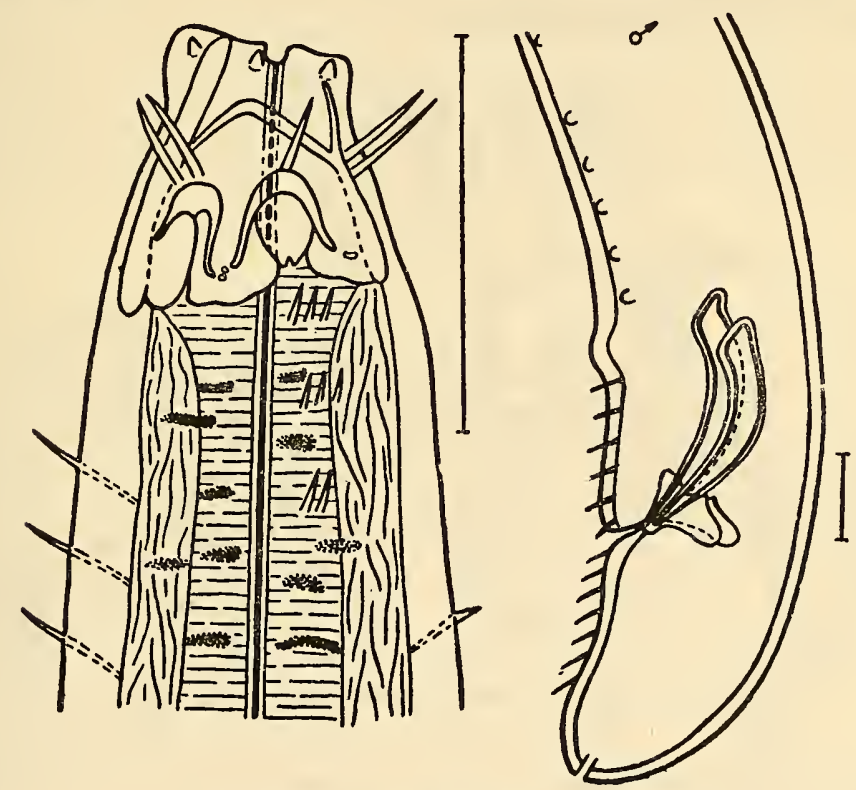

Figure 41. Pseudocella gracilis sp. nov.

This species is close to $P$. saveljevi but differs from it in these features: 1) greater body width; 2) larger number of anal papillae and setae; and 3) spicular structure-the primary distinguishing feature: spicules of $P$. gracilis with truncated almost rectangular capitulum, significantly longer, and much more smoothly arcuate than in $P$. saveljevi. 
Geographic distribution. Found along the shores of Novaya Zemlya in the Strait of Matochkin Shar at a depth of $12 \mathrm{~m}$ in silted sand.

Filip'ev 1916: 86-88, tab. IV, fig. 6(Thoracostoma coecum nec Savel'ev, 1912) (description): 1927: 94.

$$
1 \text { 우 } \mathrm{L}=13 ; \mathrm{a}=57 ; \mathrm{b}=7 ; \mathrm{c}=71 \text {. }
$$

Body tapers to $1 / 4$ midbody diameter at anterior end and to $1 / 2$ posterior end. Cuticle $8.0 \mu \mathrm{m}$ thick. Length of cephalic setae $12 \mu \mathrm{m}$. Amphids large, elongated-oval, and $13.0 \mu \mathrm{m} \times 8.0 \mu \mathrm{m}$. Of all the interlobular grooves only lateral ones open widely posteriorly; remainder closely compressed in furrowed region. Cephalic lobes with perforations and transverse slits. Cephalic suture sinuous. Small sclerotized granules present behind median lobes. Small pointed onchia, curved upward, situated in oral cavity. Photosensitive pigment absent. Eggs, $150 \mu \mathrm{m} \times$ $260 \mu \mathrm{m}$, found in uterine branches.

Geographic distribution. Barents Sea.

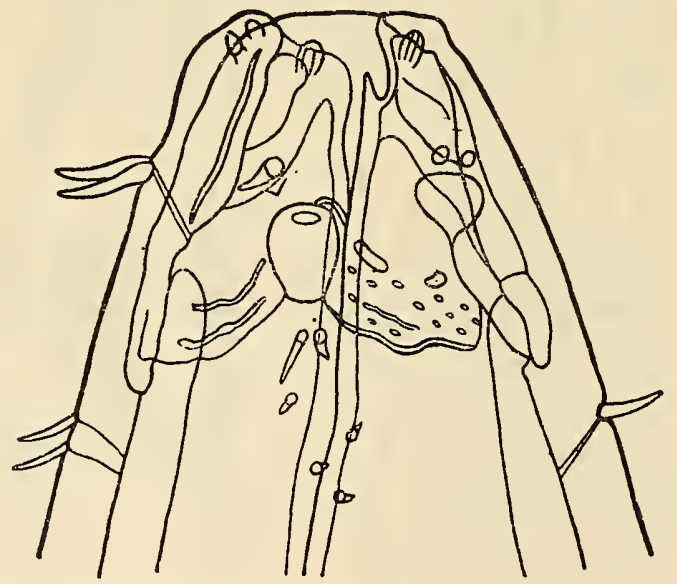

Figure 42. Pseudocella pseudocellum (from Filip'ev, 1916).

30. Pseudocella bursata Platonova, 1962 (Figure 43)

Platonova, 1962: 208, fig. 3A-G.

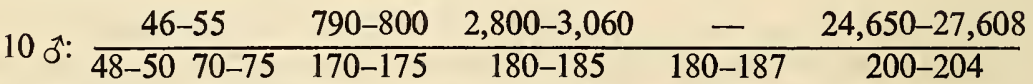

$$
\begin{aligned}
& \times 25,000-28,000 \mu \mathrm{m} ; \mathrm{a}=148-151 ; \mathrm{b}=8-9 ; \mathrm{c}=69-71 \text {. } \\
& 10 \text { \%: } \begin{array}{cccc}
48-55 & 875-896 & 2,987-3,150 & 13,000-15,500 \\
\hline 40-5075-82 & 162-182 & 175-197 & 180-200
\end{array} \times
\end{aligned}
$$




$$
\begin{gathered}
\times \frac{16,600-19,000 \quad 20,036-21,635}{198-210} 26,613-28,592 \\
220-224 \quad 27,000-29,000 \mu \mathrm{m} ; \\
a=135-140 ; b=8-10 ; c=61-70 ; \mathrm{V}=58-64 \% .
\end{gathered}
$$

Body very long, tapers to $2 / 5$ midbody diameter at anterior end. Cuticle thickness 11 to $13 \mu \mathrm{m}$; outer layer 7.5 to $8.0 \mu \mathrm{m}$. Cervical setae $17 \mu \mathrm{m}$ long and situated in longitudinal rows. Interlobular grooves 16 to $20 \mu \mathrm{m}$ deep and distinctly divided into fenestrae and furrows. Closed irregular groove present above fenestrae. Amphids $9.3 \mu \mathrm{m}$ in diameter, located in each so-called lateral fenestra. Lobes of cephalic capsule with numerous minute and irregularly situated perforations. Margin of cepha-

101 lic lobes sinuate, with marginal grooves. Band of large sclerotized granules situated posterior to cephalic capsule. Cephalic setae thick and long, 16 to $20 \mu \mathrm{m}$. Relatively large oral cavity with three onchia opens anterior to cephalic capsule. Six stout labial papillae situated around oral opening. Cephalic ring rather wide and irregular in shape. Neither photosensitive spots nor a trace of photosensitive pigment present. Length of anterior female genital tube 3,600 to $3,900 \mu \mathrm{m}$, of posterior tube 2,900 to $4,600 \mu \mathrm{m}$, and of reflexed parts 1,200 to 2,500 and 1,900 to $2,100 \mu \mathrm{m}$ respectively. One very large egg $(1,200 \mu \mathrm{m} \times 173 \mu \mathrm{m})$ seen in uterus of some females. Spicules unequal in length; left 240 to $250 \mu \mathrm{m}$ and right 190 to $200 \mu \mathrm{m}$. Gubernacular processes $67.5 \mu \mathrm{m}$ long and differ in shape:
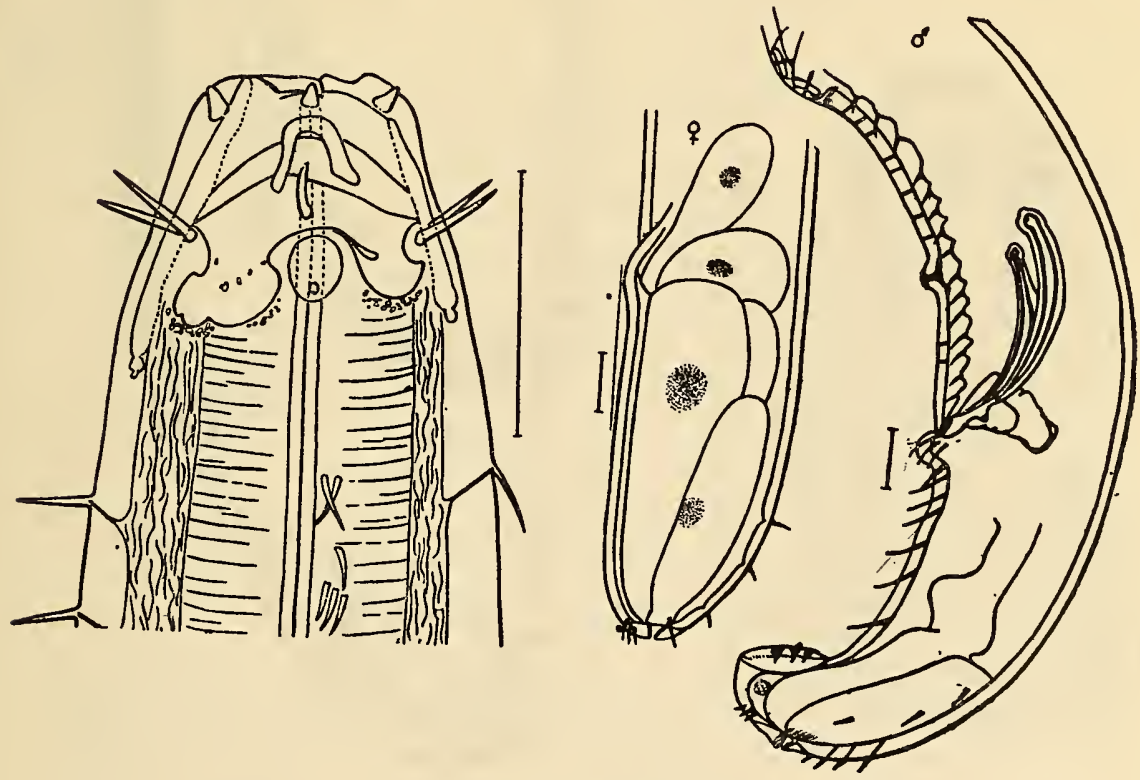

Figure 43. Pseudocella bursata. 
one rounded at tip and the other rectangular. Accessory organ $75 \mu \mathrm{m}$ anterior to anus. Pair of additional organs of different structure $100 \mu \mathrm{m}$ anterior to accessory organ. Each consists of thin sclerotized duct running through a large papilla. Walls of papillae supported by annulated sclerotized thickenings. Eighteen to nineteen pairs of preanal papillae, each provided with a seta $27.5 \mu \mathrm{m}$ long, and seven pairs of postanal setae $37.5 \mu \mathrm{m}$ long, situated in anal region of male.

The characteristic cuticular structure on the ventral aspect of the tail of males resembles a bursa and is an interesting feature of this species; length of structure $76 \mu \mathrm{m}$ and width at midlength $25 \mu \mathrm{m}$.

This species significantly differs from other species of the genus in: 1) large size; 2) presence of oral cavity armed with teeth; 3) total lack of photosensitive pigment; and 4) presence of paired structures in addition to usual accessory organ.

Geographic distribution. Known only from the Bay of Aniva, Sea of Okhotsk, where it was found in gravel at a depth of $23 \mathrm{~m}$.

102 31. Pseudocella minor Platonova, 1962 (Figure 44)

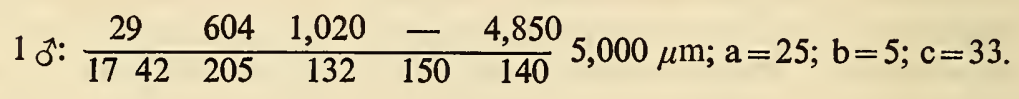
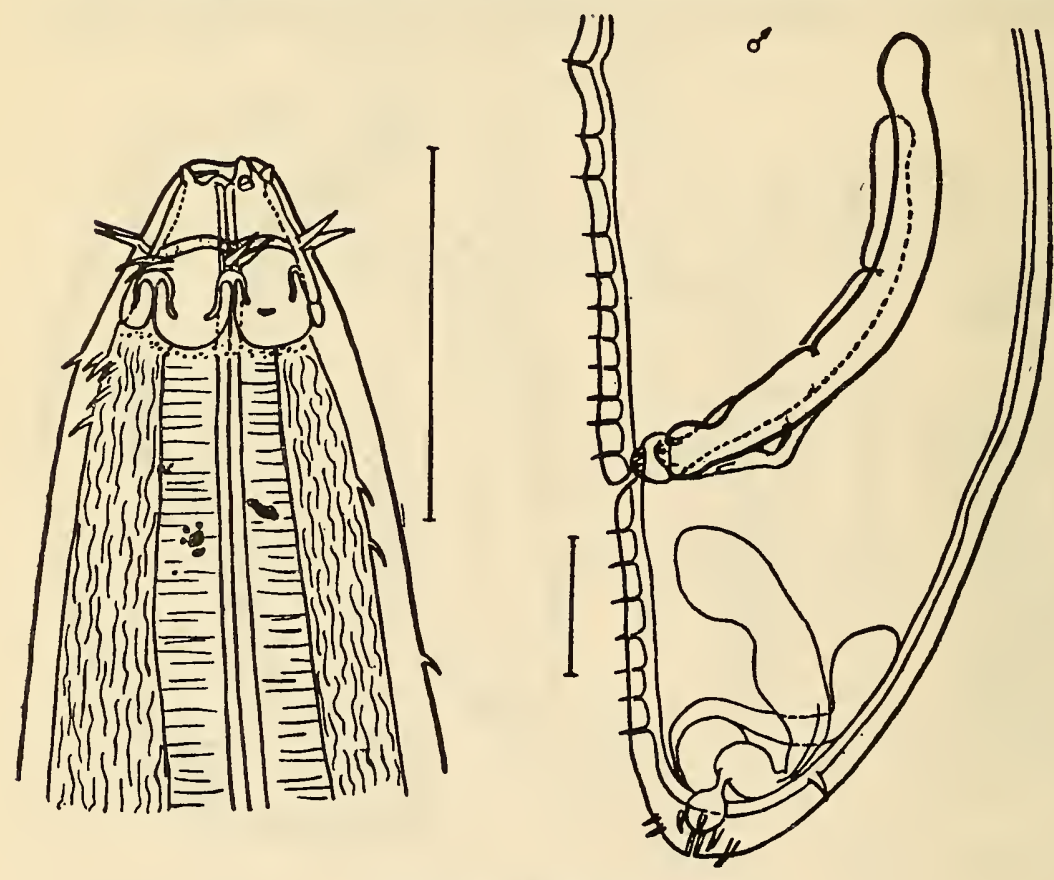

Figure 44. Pseudocella minor. 


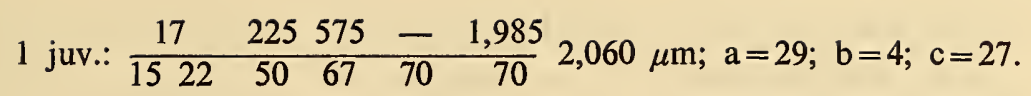

Body tapers to $2 / 7$ midbody diameter at anterior end. Cuticle $5.8 \mu \mathrm{m}$ thick. Cephalic setae $4.8 \mu \mathrm{m}$ and situated irregularly in groups or individually. Cephalic capsule opens in small oral cavity devoid of armature. Lobes of cephalic capsule separated by narrow interlobular anchor-shaped grooves $11.6 \mu \mathrm{m}$ deep. Lobes with smooth margins devoid of peripheral grooves. Narrow band of extremely minute sclerotized granules lies posterior to cephalic capsule. Cephalic ring narrow and situated rather low in middle of cephalic capsule. Photosensitive pigment reduced to a few small granules. Genital armature of male represented by two thick, wide, arcuate spicules and gubernaculum with very short caudal processes. Spicules unequal in length, left $212 \mu \mathrm{m}$ long and right $175 \mu \mathrm{m}$. Five pairs of very poorly developed preanal papillae $170 \mu \mathrm{m}$ anterior to anus.

Distinguishing features of this species: 1) extremely small size; 2) cephalic ring situated in middle of cephalic capsule; 3 ) interlobular grooves anchor-shaped; 4) highly reduced photosensitive pigment; 5) gubernaculum with very short processes, not observed in other species of this genus; and 6) absence of accessory organ.

Geographic distribution. Found on the Pacific coast of Lake Shikotan (Kuril Islands) among littoral copses of Corallina sp.

32. Pseudocella kurilensis Platonova, 1962 (Figure 45)

Platonova, 1962: 210-213, fig. 5A, B, and 6.

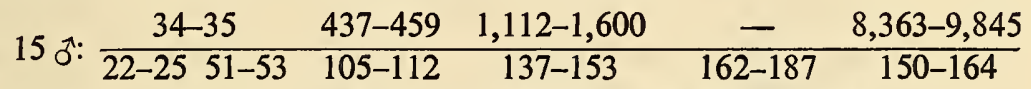

$$
\begin{aligned}
& \times 8,500-10,000 \mu \mathrm{m} ; \mathrm{a}=54-66 ; \mathrm{b}=5-9 ; \mathrm{c}=50-64 \text {. }
\end{aligned}
$$

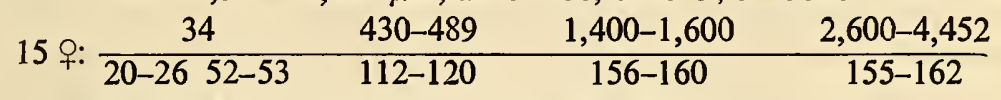

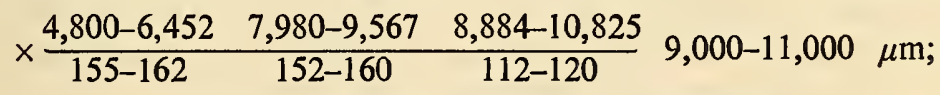

$$
\begin{aligned}
& a=60-70 ; b=6-7 ; c=56-62 ; V=56-68 \% \text {. }
\end{aligned}
$$

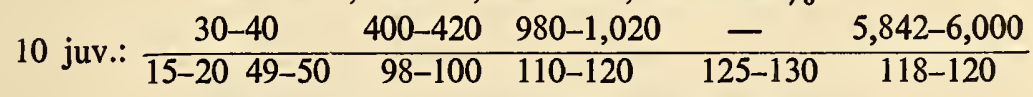

$$
\begin{aligned}
& \times 6,000-6,100 \mu \mathrm{m} ; \mathrm{a}=46-50 ; \mathrm{b}=6 ; \mathrm{c}=60-61 \text {. }
\end{aligned}
$$

Body tapers to $2 / 7$ midbody diameter at anterior end. Cuticle 4.6 to $6.9 \mu \mathrm{m}$ thick. Length of cervical setae 6.0 to $8.0 \mu \mathrm{m}$ in males and 5.0 to $5.8 \mu \mathrm{m}$ in females. Number and arrangement of setae irregular; sometimes arranged in longitudinal rows or in groups of five to eight setae each. Amphids $6.9 \mu \mathrm{m}$ in diameter. Subdorsal and subventral grooves 
narrow with narrow furrows and small fenestrae; contours of latter form long posterior prominences. Hence interlobular grooves, like those in $P$. minor, anchor-shaped and 11.6 to $13.9 \mu \mathrm{m}$ deep. Closed cleft present above grooves as in the case of $P$. bursata. Cephalic lobes with minute punctations which may merge into larger round or slit-shaped openings. Number and arrangement of punctations vary and probably not significant from a taxonomic point of view (Figure 45). Lobular margins occasionally with shallow peripheral grooves, sometimes sinuate, but otherwise smooth and rounded. Minute sclerotized granules, varying in size in some individuals, situated posterior to cephalic capsule. Some specimens had such granules only under some lobes. Length of cephalic setae 8.9 to $9.2 \mu \mathrm{m}$ in females and 9.2 to $11.6 \mu \mathrm{m}$ in males. Oral cavity devoid of oral armature and opens at top of cephalic capsule. Very wide cephalic ring situated slightly below oral cavity. Large irregular spots of red photosensitive pigment situated in anterior part of esophagus. Length of anterior female genital tube 2,000 to $2,678 \mu \mathrm{m}$, of posterior tube 2,500 to $2,700 \mu \mathrm{m}$, and of reflexed parts 700 to 721 and 720 to $824 \mu \mathrm{m}$ respectively. Mature eggs $280 \mu \mathrm{m} \times 75 \mu \mathrm{m}$. Spicular structure resembles that of P. bursata. Length of left spicule 175 to $200 \mu \mathrm{m}$ and right spicule 212 to $250 \mu \mathrm{m}$. Gubernaculum with comparatively long processes. Tip of one process curves toward distal part of spicules and that of other process toward proximal part. Length of gubernacular processes 53.0 to $63.8 \mu \mathrm{m}$. Seven to eight pairs of postanal setae, 15 to $17 \mu \mathrm{m}$ long, present in anal region. Accessory organ situated $87.5 \mu \mathrm{m}$ anterior to anus. Five to nine pairs of preanal papillae situated anterior to accessory organ.

This species exhibits several characters which bring it close to $P$. elegans, $P$. coecum, and $P$. saveljevi. Nevertheless it differs substantially from $P$. elegans in: 1) structure of cephalic lobes (margin in P. elegans not rounded but sinuate with peripheral grooves); 2 ) presence of sclerotized granules behind cephaplic capsule; 3) presence of punctations in cephalic lobes; 4 ) vulva situated midbody (in P. elegans vulva significantly displaced posterior to midbody- $\mathrm{V}=70 \%$ ); 5) much larger size and sharply differing indices. $P$. kurilensis differs from $P$. coecum in: 1) pigment dispersed throughout esophagus (not collected into small and compact clusters); 2) no exact localization of sclerotized granules (in $P$. coecum found only under median cephalic lobes); and 3 ) openings of amphids situated significantly low (in $P$. coecum situated in uppermost 105 part). $P$. kurilensis differs from $P$. saveljevi in structure of male copulatory apparatus, especially in structure of gubernaculum.

Geographic distribution. Found on the coast of the Sea of Okhotsk and in the Pacific Ocean along Kuril Islands. Numerous specimens have been collected in the littoral zone under thalli of algae and in the sublittoral zone at a depth of $25 \mathrm{~m}$ among thickly massed sponges. 

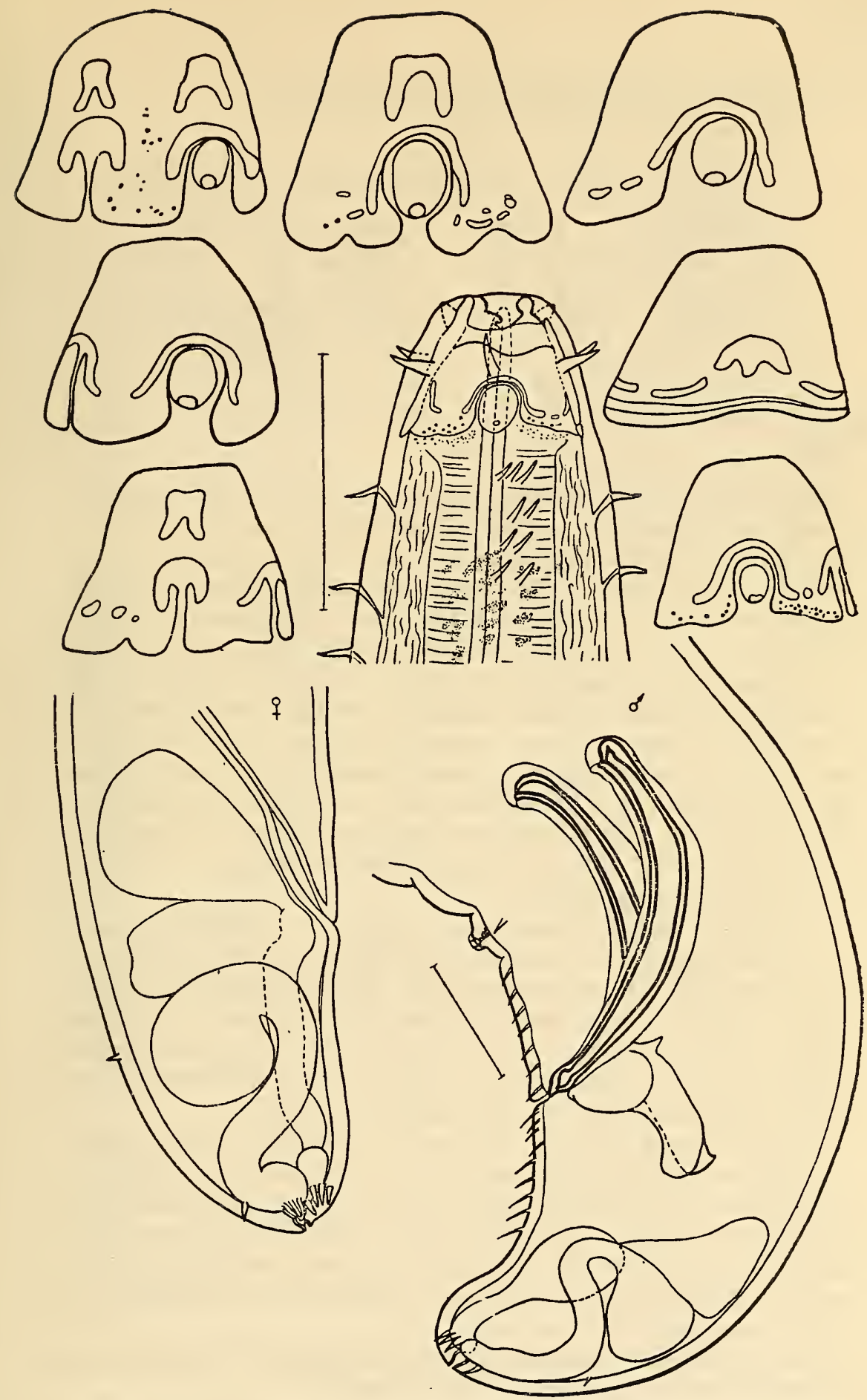

104 Figure 45. Pseudocella kurilensis. Various types of openings on cephalic capsule. 
33. Pseudocella mamillifera Platonova, 1962 (Figure 46)

Platonova, 1962: 214-215, fig. 7A-3.

106

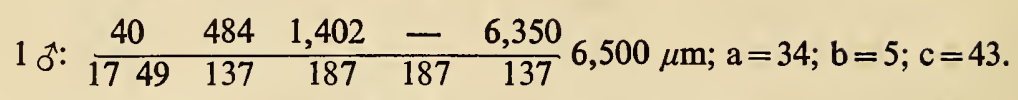

2 吕 \begin{tabular}{cccc}
$41-48$ & $433-475$ & $1,360-1,367$ & $2,020-2,580$ \\
\hline $23-2954-55$ & $150-153$ & $187-193$ & $190-195$
\end{tabular}

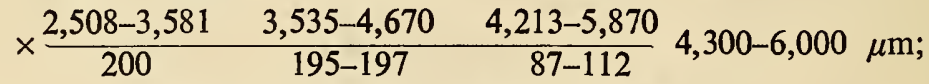

$$
\begin{aligned}
& a=21-30 ; b=3-4 ; c=46-49 ; V=53-59 \% \text {. }
\end{aligned}
$$

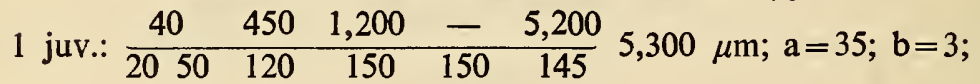

$$
\begin{aligned}
& \mathrm{c}=56 \text {. }
\end{aligned}
$$

Body tapers to $10 / 37$ midbody diameter at anterior end and $1 / 2$ at posterior end. Cuticle 8.1 to $9.2 \mu \mathrm{m}$ thick. Cervical setae very few and 7.0 to $11.6 \mu \mathrm{m}$. Cephalic capsule narrows gradually from base up to level of cephalic setae, then narrows abruptly, but broadens again toward top. Interlobular grooves, as in the preceding species, represented by narrow furrow and small fenestra $17.4 \mu \mathrm{m}$ deep. Depth of lateral grooves 11.6 $\mu \mathrm{m}$. Diameter of amphids $10.4 \mu \mathrm{m}$. Sublateral lobes of cephalic capsule with straight, slightly rounded margin; subventral lobes significantly longer and elongated in shape of tongue. Lobes lack peripheral grooves. Two round perforations present on each subventral lobe. Cephalic ring narrow and situated at level of cephalic setae. No trace of photosensitive pigment detected. Length of anterior female genital tube 927 to $947 \mu \mathrm{m}$, of posterior tube 927 to $1,030 \mu \mathrm{m}$, and of reflexed parts 515 to $721 \mu \mathrm{m}$ and 618 to $825 \mu \mathrm{m}$ respectively.

Copulatory system in male represented by two arcuate spicules unequal in length, left $200 \mu \mathrm{m}$ and right $190 \mu \mathrm{m}$. Length of gubernacular process $20 \mu \mathrm{m}$. Thirteen setae, $20 \mu \mathrm{m}$ long, arranged in anal region of male. Accessory organ situated $150 \mu \mathrm{m}$ anterior to anus. Five preanal papillae situated anterior to accessory organ. Male has characteristic tail, bearing prominence on ventral aspect as in $P$. trichodes. Tail of female varies significantly in shape and size (Figure 46).

$P$. mamillifera is similar in structure to $P$. trichodes but differs from it in: 1) thinner and longer spicules; 2 ) presence of stout setae anterior to anus; 3 ) better developed accessory organ; 4) absence of photosensitive pigment; and 5) general shape of head. In $P$. mamillifera the ventral prominence is better developed, the cephalic capsule narrows abruptly in region of cephalic setae, and entire capsule narrows much more from the base to the top than in $P$. trichodes.

Geographic distribution. Found in the Sea of Okhotsk near the southern bank of Sakhalin at a depth of $53 \mathrm{~m}$ in sand. . 

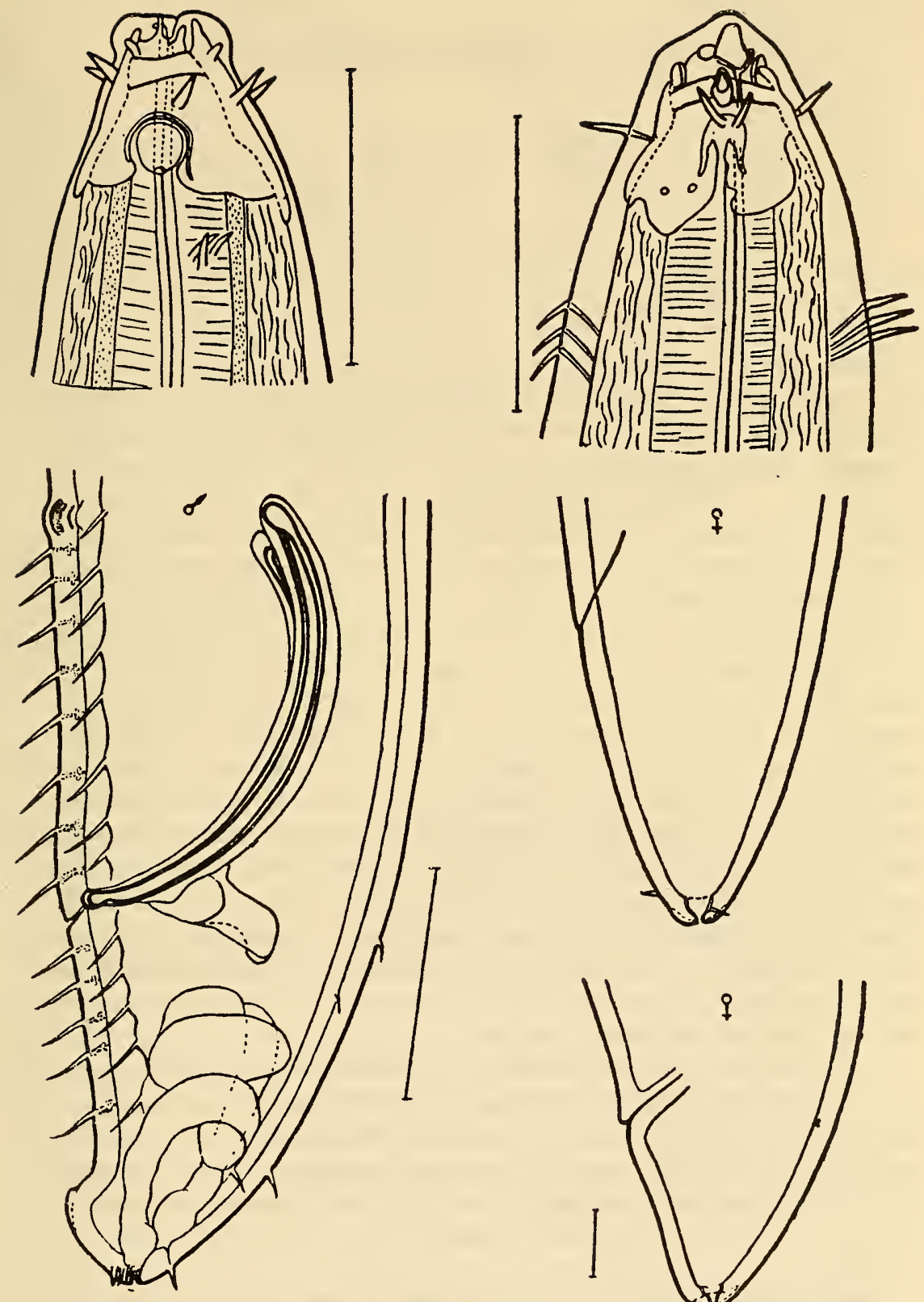

Figure 46. Pseudocella mamillifera. 
34. Pseudocella acuta sp. nov. (Figure 47)

Holotype $\delta$. Institute of Zoology, Academy of Sciences, USSR. Collection No. 6011.

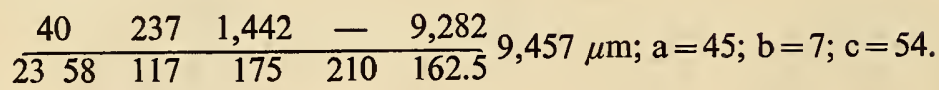

\section{Paratypes.}

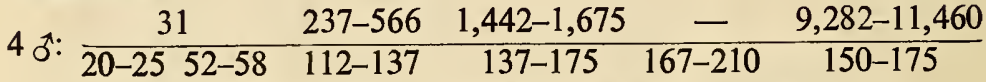

$$
\begin{aligned}
& \times 9,457-11,635 \mu \mathrm{m} ; \mathrm{a}=45-60 ; \mathrm{b}=6-7 ; \mathrm{c}=54-67 \text {. }
\end{aligned}
$$

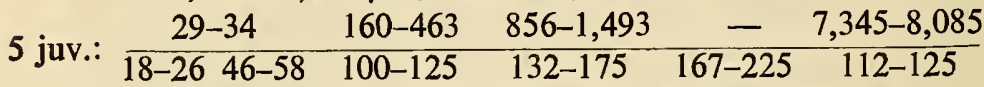

$$
\begin{aligned}
& \times 7,475-8,240 \mu \mathrm{m} ; \mathrm{a}=37-45 ; \mathrm{b}=55-87 ; \mathrm{c}=53-57 \text {. }
\end{aligned}
$$

Body tapers considerably, to $1 / 8$ to $1 / 10$ midbody diameter at anterior end and $5 / 6$ at posterior end. Cuticle 5.8 to $6.9 \mu \mathrm{m}$ thick. Cephalic capsule narrows by $1 / 2$ from base to top. Cephalic ring rather wide. Cephalic lobes with numerous minute perforations. Margin of each ce107 phalic lobe with distinct peripheral groove. Sublateral interlobular grooves characteristic: extremely narrow furrows dilate abruptly into wide round fenestrae; offshoots from contours of latter extend downward. Depth of interlobular grooves $13.2 \mu \mathrm{m}$. Narrow strip of minute sclerotized granules located immediately behind cephalic capsule. Amphids round and diameter 6.9 to $8.1 \mu \mathrm{m}$. Oral opening surrounded by extremely short labial papillae. Cephalic setae 6.9 to $8.1 \mu \mathrm{m}$, cervical setae 5.8 to $6.9 \mu \mathrm{m}$ and anal setae $17.4 \mu \mathrm{m}$. Photosensitive pigment totally absent. Nerve ring situated within limits of anterior third of esophagus. Length of anterior female genital tube 1,648 $\mu \mathrm{m}$, of posterior tube 1,854 , and of reflexed parts $824 \mu \mathrm{m}$ and $927 \mu \mathrm{m}$ respectively. Spicules unequal in length; right or left may be longer, and size 200 and 275 $\mu \mathrm{m}$. Spicules with distinct but small capitulum, narrowing into neck. Small velum present on ventral aspect of spicules. Gubernaculum with long rectangular process, 45 to $67 \mu \mathrm{m}$. Accessory organ situated 87 to $105 \mu \mathrm{m}$ anterior to anus. Nine to thirteen pairs of anal setae and six to nine pairs of preanal papillae present.

This species is closely related to $P$. kurilensis but differs in: 1 ) absence of photosensitive pigment; 2) furrows of interlobular grooves so narrow that lobes in region become contiguous (in $P$. kurilensis furrows usually much wider); 3) gubernacular process rectangular, slightly ventrally curved, and narrows toward tip up to $15 \mu \mathrm{m}$ (in P. kurilensis narrows to $25 \mu \mathrm{m}$ ); and 4) tail somewhat pointed at end (in P. kurilensis more rounded).

Geographic distribution. Discovered in the northwestern part of the Sea of Okhotsk at a depth of 12 to $15 \mathrm{~m}$ in silted sand. 

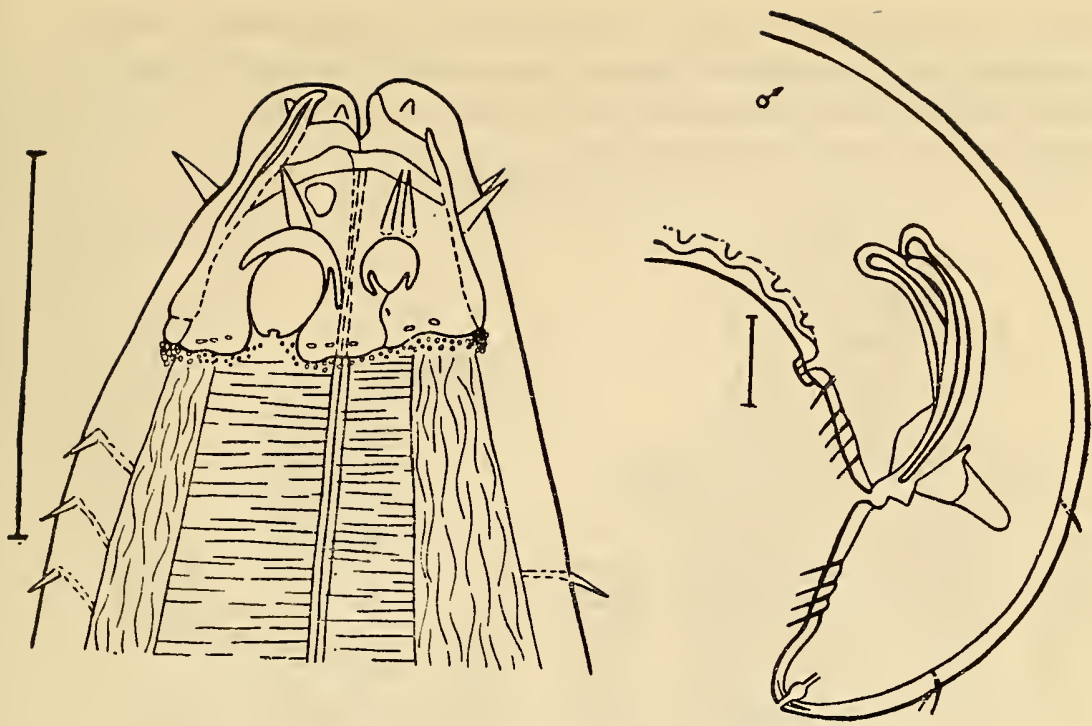

Figure 47. Pseudocella acuta sp. nov.

35. Pseudocella angusticeps sp. nov. (Figure 48)

Holotype $\sigma^{\tau}:$ Institute of Zoology, Academy of Sciences, USSR. Collection No. 5002.

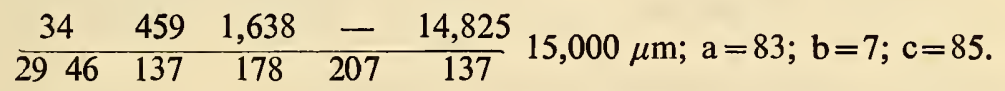

Body tapers to $1 / 6$ midbody diameter at anterior end and $2 / 3$ at posterior end. Cuticle $9.3 \mu \mathrm{m}$ thick. Cephalic capsule highly asymmetrical due to intense development of ventral outgrowth. Lateral interlobular grooves $11.6 \mu \mathrm{m}$ deep, contain rounded amphids $12.7 \mu \mathrm{m}$ in diameter. Lobes of cephalic capsule with narrow slit-shaped perforations. Periphery of lobes with very minute marginal grooves. Cephalic ring very wide. Labial papillae small. Length of cephalic setae $11.6 \mu \mathrm{m}$, and cervical setae $16.2 \mu \mathrm{m}$. Cervical setae cover anterior part of body rather densely. Twenty pairs of setae, $17.4 \mu \mathrm{m}$ long, situated in anal region. Photosensitive pigment totally absent. Nerve ring encircles esophagus a little posterior to anterior third. Copulatory apparatus represented by two equal and arcuate spicules, $187.5 \mu \mathrm{m}$ in length, with distinctly defined capitulum and neck broadening into spicular body. Gubernaculum with long rectangular process, $42.5 \mu \mathrm{m}$. Accessory organ situated 125 $\mu \mathrm{m}$ anterior to anus; another such organ $150 \mu \mathrm{m}$ anterior to accessory organ. Cuticular thickening present on ventral side of tail.

This species is close to $P$. kurilensis but differs in: 1) significantly larger development of ventral outgrowth of cephalic capsule (which imparts a 
different configuration to it); 2) absence of sclerotized granules posterior to cephalic capsule; 3 ) total absence of photosensitive pigment; 4) spicules equal in length and presence of two accessory organs; and 5) tail with cuticular thickening on ventral side.
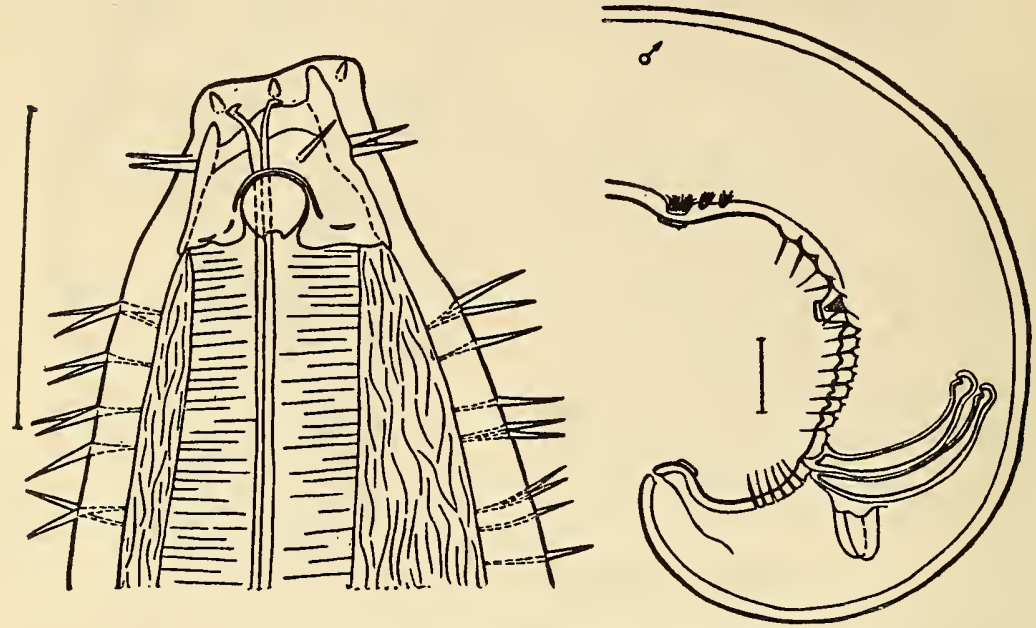

Figure 48. Pseudocella angusticeps sp. nov.

Geographic distribution. Found in Nagaev Bay (Sea of Okhotsk) at a depth of $28 \mathrm{~m}$ in silted sand.

\section{Pseudocella truncaticauda sp. nov. (Figure 49)}

Holotype đ: Institute of Zoology, Academy of Sciences, USSR. Collection No. 6594.

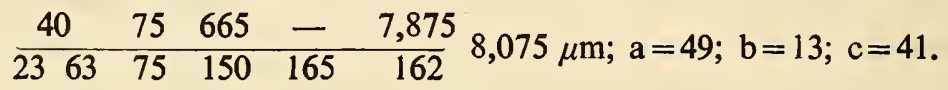

Body tapers to $1 / 7$ midbody diameter at anterior end but almost does not narrow toward posterior end. Cuticle $11.6 \mu \mathrm{m}$ thick. Cephalic capsule narrows rather abruptly; width at base three times greater than at top. Very narrow cephalic ring situated rather low, almost in middle of

109 cephalic capsule. Cephalic lobes smooth, almost without marginal grooves, but with a small number of minute irregular perforations. Lateral interlobular grooves with relatively narrow furrows. Depth of grooves $15 \mu \mathrm{m}$. Band of large sclerotized granules situated posterior to cephalic capsule. Amphids round, slightly elongated in transverse direction, and $8.0 \mu \mathrm{m}$ in diameter. Oral opening surrounded by short papillae. Length of cephalic setae $7.0 \mu \mathrm{m}$, cervical $10.4 \mu \mathrm{m}$, and anal $11.6 \mu \mathrm{m}$. Pigment spots irregular in shape and commence $34.8 \mu \mathrm{m}$ posterior to cephalic capsule. Spicules unequal in length: left $237.5 \mu \mathrm{m}$ and right $212.5 \mu \mathrm{m}$. 
Both curve uniformly, are almost even in width throughout their length, and have a poorly delineated capitulum. First accessory organ situated $175 \mu \mathrm{m}$ anterior to anus, and second $200 \mu \mathrm{m}$ from first. Fourteen pairs of setae located in anal region. Body tapers rather abruptly posterior to anus in caudal region and widens slightly at tip of tail due to rather large protuberance on ventral side.
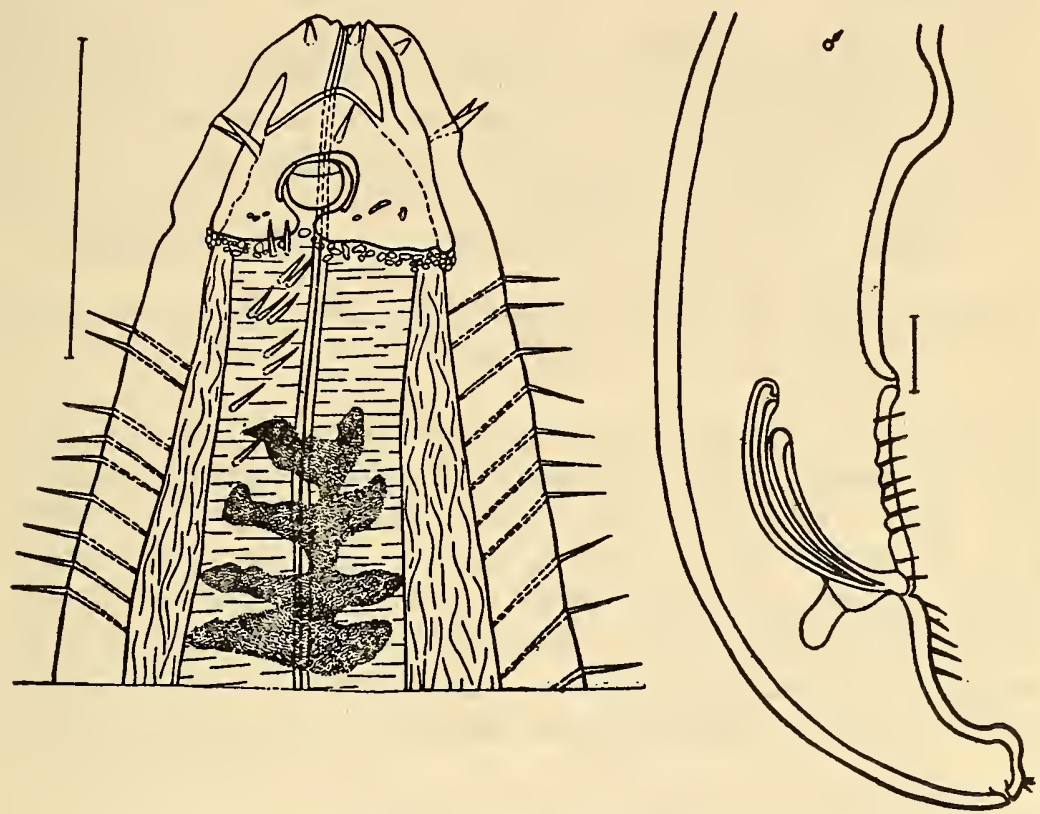

Figure 49. Pseudocella truncaticauda sp. nov.

This species is close to the male of $P$. angusticeps in structure of the posterior body part. Males of both species have two accessory organs and a protuberance on the ventral side of the tail. Males of $P$. truncaticauda differ however in: 1) spicules unequal in length, capituli poorly developed, and no cervix-like constriction (spicules of Pseudocella angusticeps equal in length with distinct capituli and long neck); 2) cephalic ring several times narrower and situated much lower than in the case of $P$. angusticeps; 3) lateral interlobular furrows much narrower than those in $P$. angusticeps; 4) band of large sclerotized granules situated posterior to cephalic capsule; and 5) photosensitive pigment present (in $P$. angusticeps there are neither granules nor pigment spots).

Geographic distribution. Found in the Sea of Okhotsk near Kuril Islands between Kunashir and Iturup, at a depth of $28 \mathrm{~m}$ among shingles (pebbles) with a mixture of silted sand. 
110 37. Pseudocella rarisetosa sp. nov. (Figure 50)

Holotype ô: Institute of Zoology, Academy of Sciences, USSR. Collection No. 7873.

\begin{tabular}{|c|c|c|c|c|}
\hline 45 & 391 & 1,390 & - & 7,312 \\
\hline 2540 & 150 & 242 & 242 & 127 \\
\hline
\end{tabular}

\section{Paratypes.}

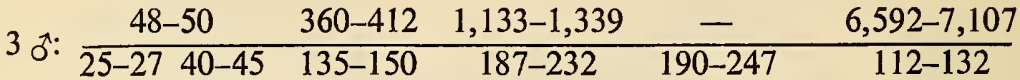

$$
\begin{aligned}
& \times 6,756-7,230 \mu \mathrm{m} ; \mathrm{a}=28-36 ; \mathrm{b}=5-6 ; \mathrm{c}=41-59 \text {. } \\
& 2 \text { ?: } \begin{array}{ccccc}
45-51 & 370-432 & 1,236-1,339 & 4,326-4,480 & 6,695-7,621 \\
\hline 2542 & 137 & 220 & 225 & 112
\end{array} \\
& \times 6,849-7,785 \mu \mathrm{m} ; \mathrm{a}=30-34 ; \mathrm{b}=6 ; \mathrm{c}=45-48 ; \mathrm{V}=51-63 \% \text {. } \\
& 1 \text { juv.: } \begin{array}{ccccc}
40 & 391 & 1,287 & - & 7,158 \\
2240 & 137 & 220 & 220 & 117
\end{array} 7,302 \mu \mathrm{m} ; \mathrm{a}=33 ; \mathrm{b}=6 \text {; } \\
& \mathrm{c}=51 \text {. }
\end{aligned}
$$

Body tapers to $1 / 9$ midbody diameter at anterior end and $1 / 2$ at posterior end. Cuticle $7.0 \mu \mathrm{m}$ thick. Width of cephalic capsule near basal part narrows to $2 / 7$ at tip. Wide cephalic ring more or less situated at border of anterior third of cephalic capsule. Cephalic lobes smooth, without marginal grooves, and with a few minute perforations. Depth of interlobular grooves $15 \mu \mathrm{m}$. Rather broad accessory cleft extends in upper part of interlobular grooves. Amphids longitudinally elongated and $8.0 \mu \mathrm{m} \times 12.0 \mu \mathrm{m}$. Labial papillae fairly large. Cephalic setae $14 \mu \mathrm{m}$,

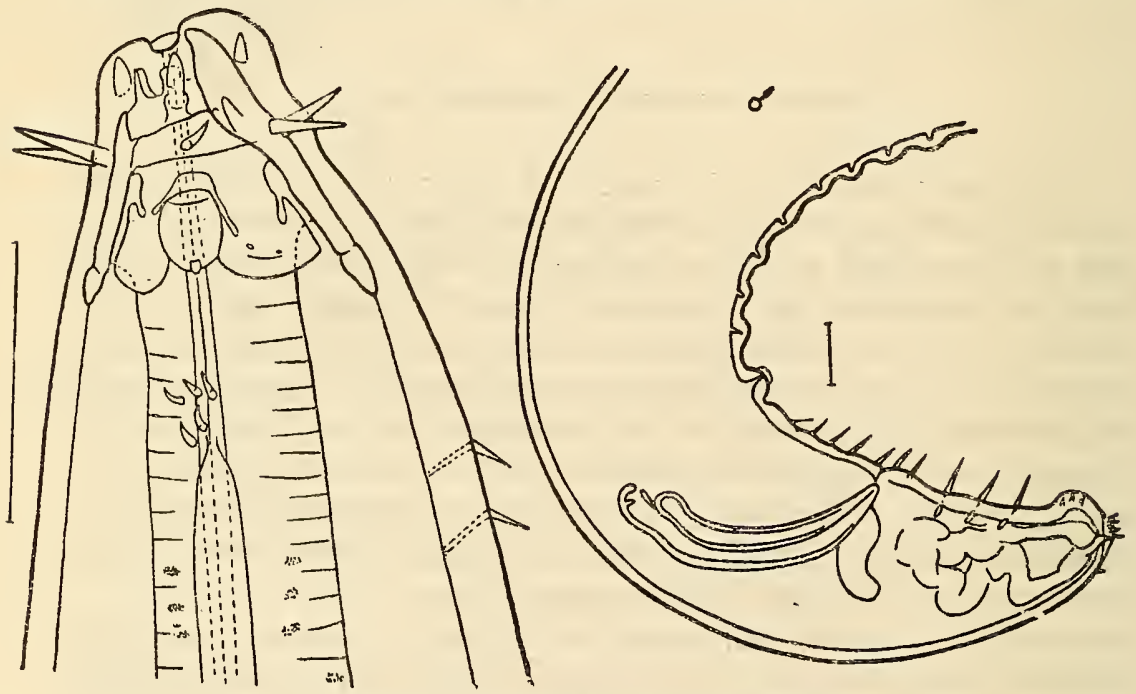

Figure 50. Pseudocella rarisetosa sp. nov. 
cervical setae $6.0 \mu \mathrm{m}$, and anal setae of male $25 \mu \mathrm{m}$. Small pigment spots situated 80 to $100 \mu \mathrm{m}$ from anterior end of body. Nerve ring encircles esophagus at border of anterior third. Length of female genital tubes 1,600 to $1,700 \mu \mathrm{m}$. Spicules curve smoothly, unequal in length, with small capitulum; length 130 to $150 \mu \mathrm{m}$. Gubernaculum with dorsal process and curves smoothly to ventral side. Accessory organ situated 80 to $100 \mu \mathrm{m}$ anterior to anus; row of papillae situated anterior to accessory organ.

111 Protuberance on ventral surface of tail of male with three to four small setae. Similar small setae encircle opening of caudal glands.

$P$. rarisetosa resembles $P$. angusticeps in cephalic structure and caudal end but differs distinctly in: 1) small size; 2 ) shape of lateral interlobular grooves; and 3) absence of additional accessory organs.

Geographic distribution. Barents Sea.

38. Pseudocella raddae sp. nov. (Figure 51)

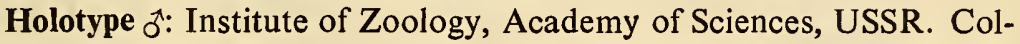
lection No. 7916.

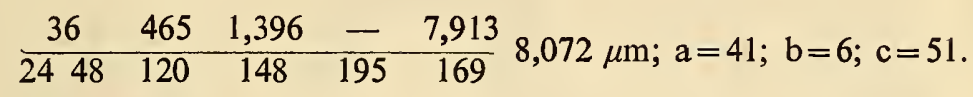

\section{Paratypes.}

112

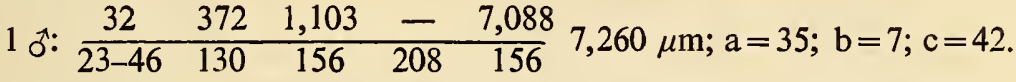

$$
\begin{aligned}
& 5 \text { ㅇ: } \begin{array}{cccc}
32-38 & 399-465 & 1,263-1,529 & 2,952-4,423 \\
\hline 22-2446-50 & 110-130 & 119-135 & 120-140
\end{array}
\end{aligned}
$$

$$
\begin{gathered}
\times \frac{4,946-6,883 \quad 6,542-9,117}{135-161 \quad 7,176-9,915} \\
a=47-75 ; b=5-6 ; c=41-59 ; \mathrm{V}=64-68 \% .
\end{gathered}
$$

Body tapers to $1 / 5$ to $1 / 6$ midbody diameter at anterior end and not less than $2 / 3$ at posterior end. Cuticle $12 \mu \mathrm{m}$ thick. Cephalic capsule narrows from base by slightly less than $1 / 2$ toward top. Cephalic lobes with rather larger perforations. Margins of cephalic lobes without grooves. Sublateral interlobular grooves with extremely narrow furrows and wide rounded fenestrae; offshoots from contours of latter extend downward. Depth of interlobular grooves $16.8 \mu \mathrm{m}$. Band of minute sclerotized granules situated posterior to cephalic capsule. Oral opening surrounded by large labial papillae. Cephalic setae $9.6 \mu \mathrm{m}$, and cervical $7.2 \mu \mathrm{m}$. Photosensitive pigment clusters in small irregularly shaped spots. Nerve ring encircles esophagus in anterior third. Length of anterior female genital tube 1,800 to $2,400 \mu \mathrm{m}$, of posterior tube 1,500 to $2,200 \mu \mathrm{m}$, and of reflexed parts 700 to $900 \mu \mathrm{m}$. Vulva shifted slightly posterior to midbody (posteromedian position). Spicules slightly curved, with poorly developed capitulum, and distinct neck; length $182 \mu \mathrm{m}$. Gubernaculum with large 
process, $57 \mu \mathrm{m}$ long. Cleft present on dorsal surface at base of process. Accessory organ situated $120 \mu \mathrm{m}$ anterior to anus. Anal region of male armed with setae $12 \mu \mathrm{m}$ in length. Small setae, $4.8 \mu \mathrm{m}$, situated at very tip of male tail.

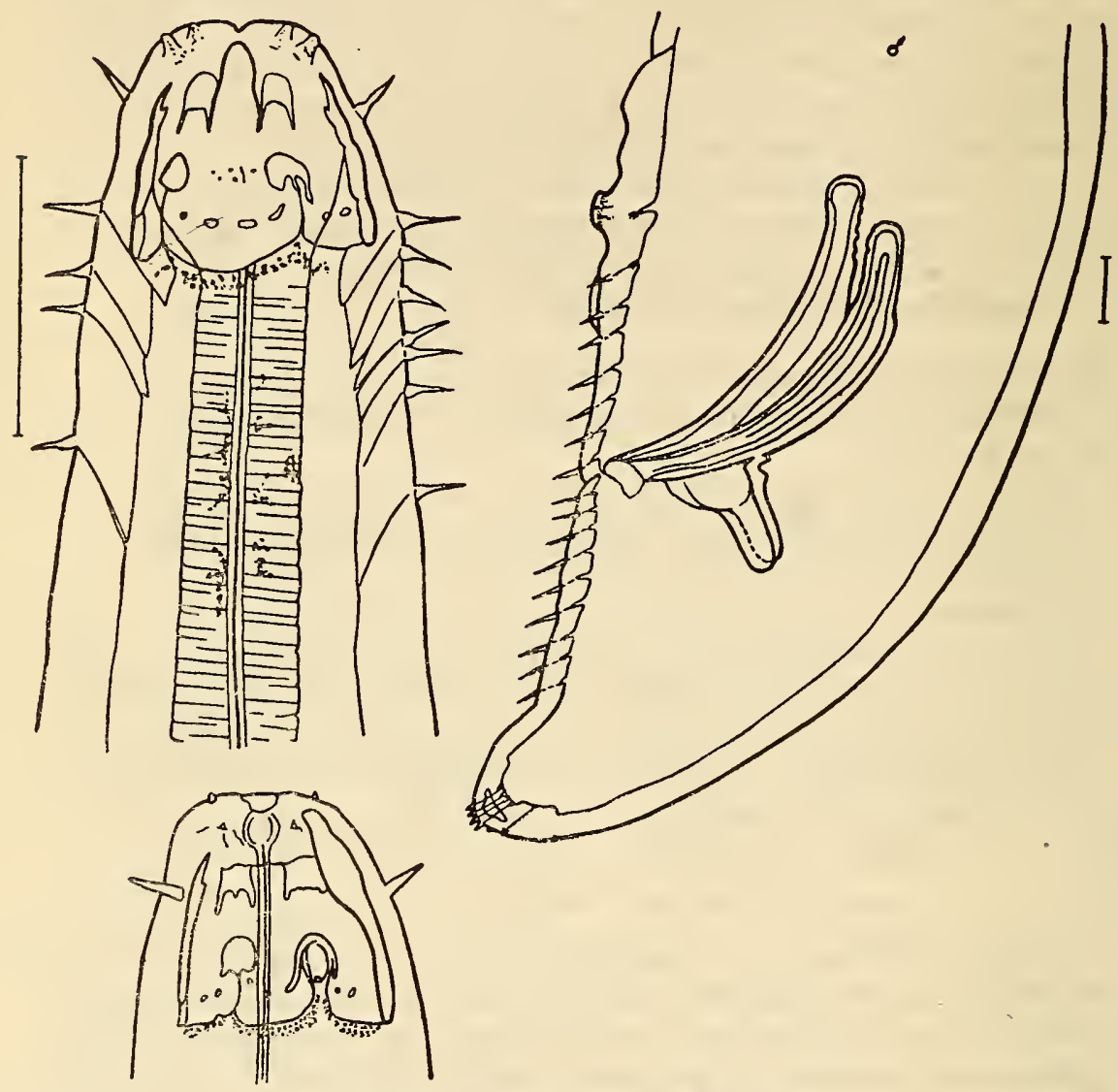

Figure 51. Pseudocella raddae sp. nov.

This species is close to $P$. acuta but differs in: 1) shape of cephalic capsule; 2) presence of photosensitive pigment; 3 ) absence of spicular velum; and 4) presence of setae at tip of tail.

Geographic distribution. Discovered in littoral pools on the Pacific coast of Iturup (Kuril Islands).

\section{Family ANTICOMIDAE Filipjev, 1918}

Relatively minute forms; size more or less ranges from 2.0 to $10 \mathrm{~mm}$. Body of majority of representatives fusiform, tapering toward both ends. 
Cuticle thin and either single- or double-layered. Lips in most forms not developed and labial papillae, if present, extremely small. Nematodes of subfamily Platycominae with lips provided with large cuticular outgrowths constitute an exception. Oral cavity absent or poorly developed; occasionally armed with small onchia. Cephalic capsule poorly developed, and thin-walled; cephalic suture in most cases almost invisible. Cephalic setae arranged in one circle. Amphids cyathiform; only in representatives of subfamily Platycominae do amphids have unique contours, differing in shape in males and females. Photosensitive pigment absent. Esophagus gradually broadens toward base. Cardia longitudinally elongated. Gonads and genital tubes same structure as in representatives of Leptosomatidae. Spicular apparatus extremely diverse in different subfamilies. Accessory organ present in most cases. Caudal glands with highly stretched ducts; pores of latter open on tail terminally.

\section{Key to Subfamilies of Family Anticomidae}

1 (2). Cephalic setae long, many times exceeding cephalic diameter. Body tapers very slightly toward both ends..................

.6. Barbonematinae subfam. nov.

1132 (1). Cephalic setae short or insignificantly exceed cephalic diameter. Body distinctly tapers toward both ends.

3 (4). Tail long; posterior cylindrical part invariably exceeds conical part in length. Cervical setae often arranged in two longitudinal rows. . 4. Anticominae Filipjev, 1918.

4 (3). Tail comparatively short and often obtusely conical; cylindrical part, if present, significantly shorter than conical part. Cervical setae with different arrangement.

5 (6). Cephalic capsule developed. Individual cervical setae scattered throughout preneural part....Parabarbonematinae subfam. nov.

6(5). Cephalic capsule undeveloped. Cervical setae usually numerous

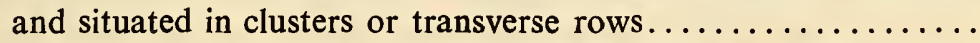

5. Platycominae subfam. nov.

\section{Subfamily ANTICOMINAE Filipjev, 1918}

Small nematodes. Body fusiform and tapers notably toward both ends. Cephalic setae relatively short. Cervical setae situated laterally on both sides in longitudinal rows with two to six setae in each. In genus Paranticoma instead of setae there is a tube into which the pore of renette opens (renette always present in representatives of subfamily Anticominae). Renette elongated with long excretory ducts. Nerve ring encircles eso- 
phagus in anterior third. Amphids round. Tail distinctly divided into two parts-wide conical part immediately behind anus followed by narrow cylindrical part, which may be very long and slender. Small protuberance usually present on terminal part of tail. Gubernaculum poorly developed or totally absent in most cases. Accessory organ tubular.

\section{Key to Genera of Subfamily Anticominae}

1 ( 2). Pore of renette situated on special setaceous outgrowth..... ....................Paranticoma Micoletzky, 1930.

2 ( 1). Setaceous outgrowth absent as renette pore lies directly on body.

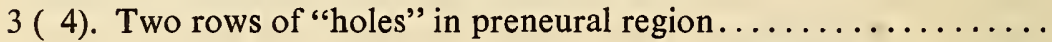
Antopus Cobb, 1933.

4 ( 3). No "holes" in preneural region.

5 ( 6). Cervical setae situated in a few longitudinal rows; spicules long .Stenolaimus Marion, 1870.

6 ( 5). Cervical setae situated in two longitudinal rows; spicules short.

7 ( 8). Accessory organ poorly developed and papillate in shape; gubernaculum absent........... Anticomopsis Micoletzky, 1930.

8 ( 7). Accessory organ well developed and tubular in shape; gubernaculum usually present.

9 (12). Cephalic capsule poorly developed; cephalic suture not discernible.

10 (11). Oral cavity absent............. Anticoma Bastian, 1865.

11 (10). Oral cavity present............ Odontanticoma gen. nov.

12 (9). Cephalic capsule relatively well developed; cephalic suture distinctly visible.............. Cephalanticoma gen. nov.

Type species: Anticoma chitwoodi Inglis, 1964.

Cephalic capsule relatively well developed, with thick walls, and distinct and straight cephalic suture. Lips with well-developed papillae. Oral cavity small with three well-defined small onchia, one situated in each section of esophagus. Amphids situated on line of cephalic suture. Spicules thin, arcuate, and provided with velum. Gubernacular funnel encircles spicules at distal end; dorsal process of gubernaculum long, straight, and directed anteriorly along spicular axis. Tail very long and filiform.

\section{Genus Odontanticoma gen. nov.}

Type species: Odontaticoma dentifer sp. nov.

Cephalic capsule highly reduced. Oral cavity well developed and 
armed with small distinct onchia. Oral opening encircled by well-developed lips. Labial papillae small. Amphids situated below line of cephalic suture. Spicules arcuate, wide in proximal part, with poorly developed capituli.

Figures given in Cobb's formula in the descriptions of genera Odontanticoma and Anticoma indicate distances from the anterior end up to the following parts: 1. posterior end of cephalic capsule or base of setae; 2. excretory pore of renette; 3 . nerve ring; 4 . basal part of esophagus; 5. commencement of anterior genital duct; 6 . vulva; 7. commencement of posterior genital duct; and 8. anus.

For males these measurements are fewer (see p. 74).

\section{Key to Species of Genus Odontanticoma}

1 (2). Cephalic setae vary in length; in each pair of setae one notably shorter than the other.... Odontanticoma vanoorti Allgen, 1933.

2 (1). Cephalic setae equal in length.

3 (4). Onchia in oral cavity large. Cylindrical part of tail twice conical in length..............39. Odontanticoma dentifer sp. nov.

4 (3). Onchia in oral cavity minute. Cylindrical part of tail equal to conical in length..... 40. Odontanticoma murmanica (Filipjev, 1927).

39. Odontanticoma dentifer sp. nov. (Figure 52)

Holotype $\delta^{*}$ : Institute of Zoology, Academy of Sciences, USSR. Collection No. 7451.

$$
\begin{array}{cccccc}
6 & 23 & 225 & 475 & - & 2,126 \\
3-11 & 16 & 44 & 66 & 75 & 40
\end{array} 2,396 \mu \mathrm{m} ; \mathrm{a}=31 ; \mathrm{b}=5 ; \mathrm{c}=9 \text {. }
$$

Paratypes.

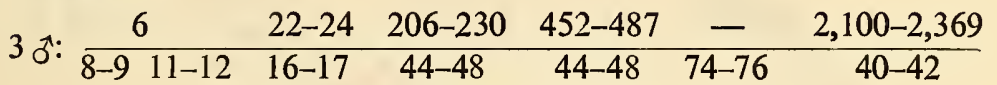

$$
\begin{aligned}
& \times 2,396-2,649 \mu \mathrm{m} ; \mathrm{a}=31-34 ; b=5 ; c=9 \text {. } \\
& 4 \text { ९: } \begin{array}{ccccc}
4-5 & 20-23 & 208-225 & 459-475 & 816-826 \\
\hline 8-9 \quad 11-12 & 17-18 & 49-52 & 79-86 & 91-98
\end{array} \\
& \times \frac{1,122-1,320}{1,402-1,545} \frac{2,063-2,537}{96-92} 2,343-2,812 \mu \mathrm{m} ; \\
& a=25-30 ; b=5-6 ; c=8-10 ; V=45-47 \% \text {. }
\end{aligned}
$$

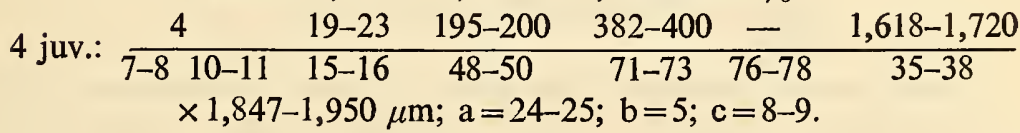

Body tapers to $1 / 8$ to $1 / 10$ midbody diameter at anterior end and $1 / 2$ at posterior end. Head anteriorly truncated with distinct lips. Tail long; 115 slender cylindrical part twice length of conical part. Cuticle thin, $2.3 \mu \mathrm{m}$. 
Cephalic capsule thin-walled. Cephalic width exceeds length by 1.5 times. Amphids situated one cephalic diameter from anterior end of body. Width of amphid $4.6 \mu \mathrm{m}$ (1/4 corresponding diameter). Cephalic setae long, $8.0 \mu \mathrm{m}$, longer than $1 / 2$ corresponding diameter. Cervical setae $4.6 \mu \mathrm{m}$, situated in groups of five at a distance of three cephalic diameters from anterior end of body. Cervical pore located midway between amphids and first cervical seta. Oral cavity extensive, with three relatively large teeth. Nerve ring encircles esophagus slightly above its middle. Length of anterior female genital tube 306 to $496 \mu \mathrm{m}$, of posterior tube 225 to $280 \mu \mathrm{m}$, and of reflexed parts 285 to $350 \mu \mathrm{m}$ and 200 to $250 \mu \mathrm{m}$ respectively. One to two eggs, 91 to $102 \mu \mathrm{m} \times 66 \mu \mathrm{m}$, observed in genital tract of female. Spicular length $70 \mu \mathrm{m}$. Velum thin and narrow, barely distinguishable. Gubernaculum small; encircles spicules at distal end and expands in ventral direction. Accessory organ situated 70 $\mu \mathrm{m}$ anterior to anus.

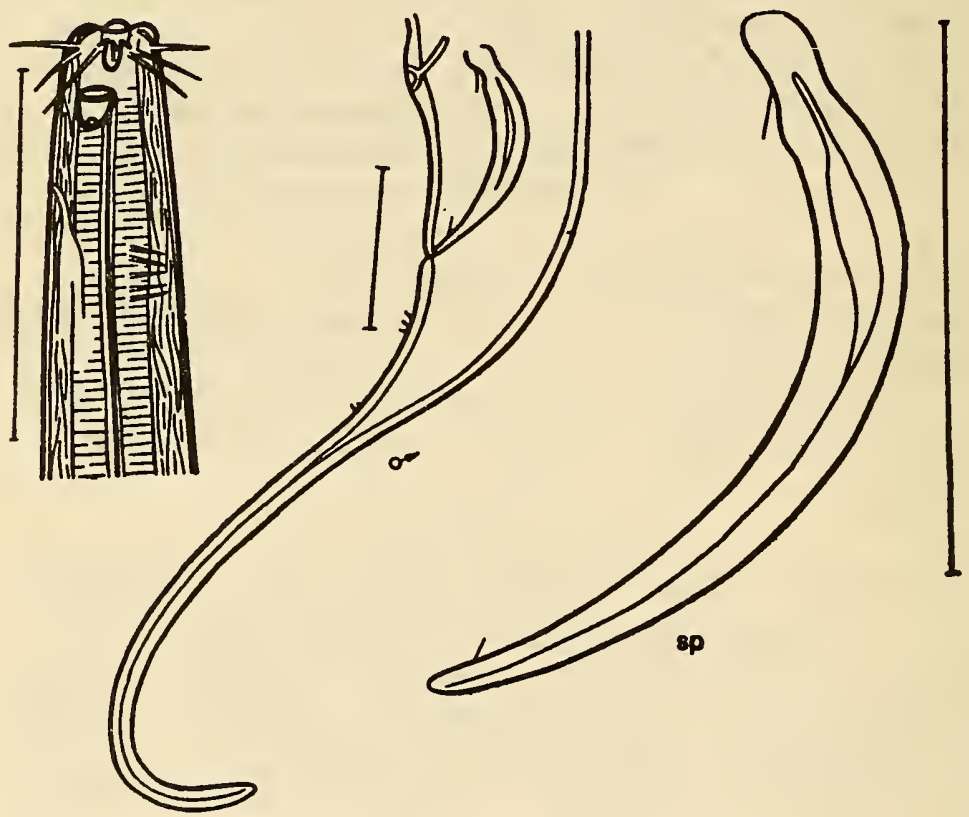

Figure 52. Odontanticoma dentifer gen. nov., sp. nov.

Distinguishing features of this species: 1) long cephalic setae; 2) welldeveloped oral cavity with onchia; 3 ) spicules arcuate, with slits, and expand in their widest part; and 4) gubernaculum expands toward anus.

Geographic distribution. Found in the Gulf of Terpeniya (Sakhalin, Sea of Okhotsk) at a depth of 36 to $39 \mathrm{~m}$ in a bed of fine sand. 
*40. Odontanticoma murmanica Filipjev, 1927 (Figure 53)

Filip'ev, 1927: 78-79, pl. 2, fig. 2a-e (Anticoma) (description).

$$
\begin{aligned}
& 3 \text { o : }: \begin{array}{ccccc}
- & 250 & 515 & - & 2,450 \\
\hline 16 & 64 & 95 & 116 & 60
\end{array} 2,700-2,930 \mu \mathrm{m} ; \mathrm{a}=24 ; \mathrm{b}=5 ; \mathrm{c}=10 \text {. } \\
& 2 \text { ㅇ: } \begin{array}{ccccccc}
- & 245 & 525 & 1,100 & 1,270 & 2,080 & 2,330 \\
\hline 16 & 62 & 90 & - & 105 & - & 52
\end{array} 2,500-2,900 \mu \mathrm{m} \text {; } \\
& a=27 ; b=5 ; c=9 \text {. }
\end{aligned}
$$

116 Conical and cylindrical parts of tail equal in length. Cuticle thick, 4.0 to $5.0 \mu \mathrm{m}$. Head slightly truncated. Labial papillae project slightly. Length of cephalic setae $8.0 \mu \mathrm{m}$ (1/2 corresponding diameter). Amphids larger in males $(4.0 \mu \mathrm{m} \times 5.0 \mu \mathrm{m})$ than in females $(2.0 \mu \mathrm{m} \times 3.0 \mu \mathrm{m})$. Cervical setae $6.0 \mu \mathrm{m}$, situated two cephalic diameters from anterior end. Cuticle of head thicker than in rest of body. Cephalic suture barely visible. Cervical glands $60 \mu \mathrm{m} \times 30 \mu \mathrm{m}$, situated against posterior part of esophagus. Pore of cervical gland situated at level of amphid or slightly above. Oral capsule thick-walled, $9.0 \mu \mathrm{m}$ deep, and with short anterior vestibulum. Esophageal glands open at base of oral capsule. Cardia 35 to $45 \mu \mathrm{m}$. Testes separated from vas deferens by constriction. Length of spicules 75 to $80 \mu \mathrm{m}$ (1/2 anal diameter). Gubernaculum narrow and

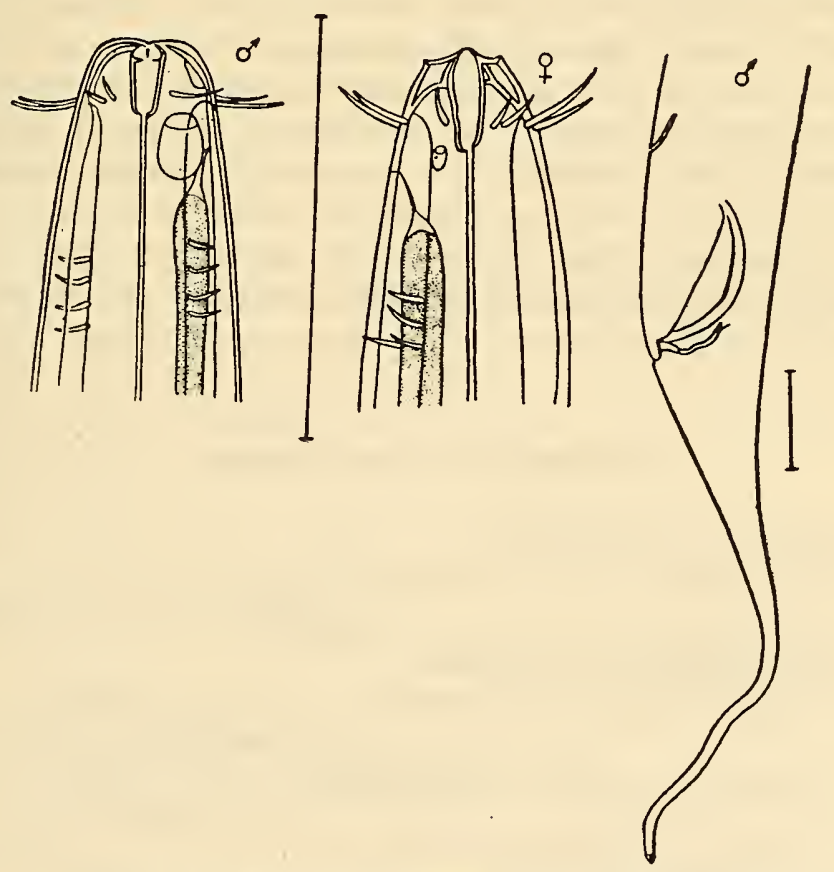

Figure 53. Odontanticoma murmanica (from Filip'ev, 1927). 
long. Bursal musculature highly developed and situated four anal diameters anterior to anus. Accessory organ consists of sclerotized ring encircling opening with tube $23 \mu \mathrm{m}$ long; situated two anal diameters anterior to anus. Two short anal setae present. Length of vagina $35 \mu \mathrm{m}$.

Distinguishing features of this species: 1) situation of cervical pore at amphid level; 2) presence of highly elongated oral cavity, armed with small onchia; and 3) presence of well-developed spicular velum.

Geographic distribution. Found in the Barents and Kara Seas at depths ranging from 120 to $300 \mathrm{~m}$ in silty and muddy substrata.

\section{Genus Anticoma Bastian, 1865}

Eberth, 1863: 28 (Odontobius, part.); Bastian, 1865: 141; Bütschli, 1874: 35; de Man, 1878: 98; 1886: 51; Cobb, 1891: 765; Filip'ev, 1918: 63-65; 1927: 73; Micoletzky, 1930: 248; Wieser, 1953c: 14-16; Inglis, 1964: 325 .

Type species: Anticoma eberthi Bastian, 1865.

Suture of cephalic capsule almost invisible. Lips not developed; labial papillae, if present, extremely small. Well-defined oral cavity absent. Amphids round or slightly elongated longitudinally. Nerve ring encircles esophagus slightly above its middle. Vulva anterior to midbody. Vulval glands well developed. Spicules differ in structure. Gubernaculum small.

As observed by Filip'ev (1927), this genus is extremely uniform and 117 hence identification of species rendered difficult. Important taxonomic features of this genus are: structure of the spicular apparatus; location of excretory pore of cervical gland; position of cervical setae and amphids; and relative lengths of cephalic, cervical, and caudal setae. The number of cervical setae changes with the age of the nematode (Micoletzky, 1930; Wieser, 1953c) and for this reason cannot serve as a taxonomic character.

\section{Key to Species of Genus Anticoma}

1 (6). Cervical setae absent.

2 ( 3 ). Spicules with velum with processes directed ventrally........ ................... curticauda (Platonova, 1968).

3 ( 2). Spicules without such velum.

4 ( 5). Cylindrical part of tail exceeds conical part in length........ A. longissima Allgen, 1958.

5 ( 4). Conical part of tail exceeds cylindrical part in length....... .A. aberrans Allgen, 1951.

6 ( 1). Cervical setae present.

7 (52). Excretory pore of renette anterior to cervical setae. 
8 (11). Cuticle finely annulated.

9 (10). Amphids situated immediately behind anterior end of body.... A. wieseri Mawson, 1958.

10 (9). Amphids situated one cephalic diameter away from anterior end of body................ australis Mawson, 1956.

11 ( 8). Cuticle smooth.

12 (17). Body extremely narrow $(a=60$ to 70 ).

13 (14). Cephalic setae extremely short, about one-sixth of corresponding diameter.................. tenuis Allgen, 1930.

14 (13). Cephalic setae perceptibly longer, not less than one-fourth of corresponding diameter.

15 (16). Amphids very large, occupying one-third of corresponding diameter................... procera Micoletzky, 1930.

16 (15). Amphids very minute: width does not exceed one-sixth of corresponding diameter.......... 44. A. arctica Steiner, 1916.

17 (12). Body relatively wide ( $a$-does not exceed 30 to 40).

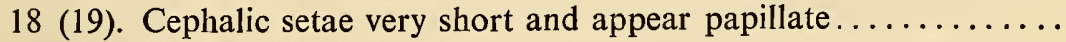

A. microseta Allgen, 1935.

19 (18). Cephalic setae significantly long and look like filaments.

20 (21). Gubernaculum with small caudally directed process..........

21 (20). Gubernaculum without caudal process.

22 (37). Cylindrical part of tail equal to conical in length.

23 (24). Cephalic setae short, constituting one-fifth of corresponding diameter..................... . curta sp. nov.

24 (23). Cephalic setae significantly long, constituting one-third to onehalf of corresponding diameter.

25 (26). Males with well-developed preanal setae................

26 (25). Males without preanal setae.

27 (28). Body large; length about $4.0 \mathrm{~mm}$.....51. A. grandis sp. nov.

28 (27). Body significantly smaller; length about $2.0 \mathrm{~mm}$.

29 (32). Spicules distinctly narrow in region of capituli.

30 (31). Cervical setae situated 1.5 cephalic diameters from anterior end .A. acuminata (Eberth, 1863).

11831 (30). Cervical setae situated three cephalic diameters from anterior end .................. pontica Filipjev, 1918.

32 (29). Spicules do not narrow in region of capituli but taper gradually from proximal end to distal end.

33 (36). Accessory organ situated at level of spicular capitulum.

34 (35). Amphids small; width less than one-fourth corresponding diameter.................... subsimilis Cobb, 1914.

35 (34). Amphids large, width more than one-third corresponding dia- 
meter..................... zostera Schulz, 1932.

36 (33). Accessory organ situated anterior to anus at a distance equal to twice length of spicules.......46. A. pellucida Bastian, 1865.

37 (22). Cylindrical part of tail twice or more length of conical part.

38 (39). Cephalic setae short; length not more than $1 / 4$ corresponding head diameter.............43. A. minor Filipjev, 1927.

39 (38). Cephalic setae unusually long; length constitutes $1 / 3$ to $1 / 2$ corresponding head diameter.

40 (41). Accessory organ absent........... allgeni Platonova, 1968.

41 (40). Accessory organ present.

42 (45). Excretory pore distinctly shifted forward and situated one cephalic diameter from anterior end.

43 (44). Spicular length about $30 \mu \mathrm{m}$....A. profunda Micoletzky, 1930.

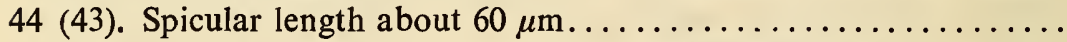

48. A. brevisetosa Platonova 1967.

45 (42). Excretory pore situated more than two cephalic diameters from anterior end.

46 (47). Amphids large; width constitutes $1 / 2$ corresponding head diameter.................. . . uschakovi sp. nov.

47 (46). Amphids significantly small; width constitutes $1 / 3$ to $1 / 4$ corresponding head diameter.

48 (49). Cervical setae situated 4.5 cephalic diameters from anterior end ...............47. A. novozemelica Filipjev, 1927.

49 (48). Cervical setae situated three cephalic diameters from anterior end.

50 (51). Preanal region and caudal end of male armed with setae...... A. cobbi Inglis, 1971.

51 (50). Preanal region and caudal end of male without setae....... ..................... . behringiana sp. nov.

52 ( 7). Excretory pore posterior to cervical setae.

53 (56). Length of cephalic setae either equal to or exceeds cephalic diameter.

54 (55). Body tapers sharply toward cephalic end. Cephalic diameter $1 / 6$ diameter at basal part of esophagus.

A. graciliceps Platonova, 1968.

55 (54). Body almost even in width throughout...A. strandi Allgen, 1940.

56 (53). Length of cephalic setae less than cephalic diameter.

57 (60). Excretory pore situated immediately behind cervical setae.

58 (59). Males with preanal and caudal setae...A. campbelli Allgen, 1932.

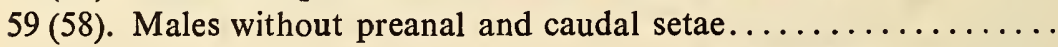

A. extensa Wieser, 1953.

60 (57). Excretory pore situated at significant distance from cervical setae. 11961 (62). Excretory pore situated near nerve ring: . A. tipica Cobb, 1891. 
62 (61). Excretory pore situated between cervical setae and nerve ring.

63 (64). Paired cephalic setae unequal in length.

A. litoris Chitwood, 1936.

64 (63). All cephalic setae equal in length.

65 (72). Body large; length about 5.0 to $6.0 \mathrm{~mm}$.

66 (67). Tail short ( $c$ more than 20); cylindrical part equal to conical part in length............... A. eberthi Bastian, 1865.

67 (66). Tail long ( $c$ not more than 10); cylindrical part twice length of conical part.

68 (69). Accessory organ situated 1.5 anal diameters from anus........

A. major Mawson, 1956.

69 (68). Accessory organ more than 2.5 anal diameters from anus.

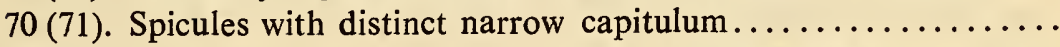
49. A. filipjevi Platonova, 1967.

71 (70). Spicules without capitulum

50. A. tenuicaudatoides Gerlach and Riemann, 1974.

72 (65). Body small; length not more than $3.0 \mathrm{~mm}$.

73 (74). Tail short ( $c$ about 30).....42. A. insulaealbae Filipjev, 1927.

74 (73). Tail long ( $c$ about 10 ).

75 (76). Spicular capitulum flat on ventral side.

76 (75). Spicular capitulum without flat ventral side.

77 (78). Cervical setae situated immediately behind a mphids.........

A. dahli Wieser, 1953.

78 (77). Cervical setae situated at a significant distance from amphids.

79 (80). Cylindrical part of tail four times longer than conical part.... A. trichura Cobb, 1898.

80 (79). Cylindrical part of tail not more than twice length of conical part.

81 (82). Preanal setae entirely absent in males.

A. kerguelensis Mawson, 1958.

82 (81). Preanal setae present in males.

83 (84). Length of cephalic setae $1 / 3$ corresponding cephalic diameter.. A. lata Cobb, 1898.

84 (83). Length of cephalic setae $1 / 2$ corresponding cephalic diameter.

85 (86). Amphids less than one cephalic diameter from anterior end.... A. columba Wieser, 1953.

86 (85). Amphids situated two cephalic diameters from anterior end.... A. ditlevseni Micoletzky, 1930.

41. Anticoma eberthi Bastian, 1865 (Figure 54)

Bastian, 1865: 141, pl. XI, figs. 143-145; de Man, 1889: 186, tab. 5, fig. 3; Southern, 1914: 22; Filip'ev, 1918: 64; Platonova, 1967: 834. 
1 ภ: \begin{tabular}{cccccc}
9 & 29 & 309 & 700 & - & 4,408 \\
\hline 1626 & 34 & 102 & 150 & $\begin{array}{c}187 \\
c=12 .\end{array}$ & 67
\end{tabular} 4,765 $\mu \mathrm{m} ; \mathrm{a}=25 ; \mathrm{b}=7$;

Body tapers to $1 / 10$ midbody diameter at anterior end and $1 / 2$ at posterior end. Head anteriorly truncated. Tail short; narrow cylindrical part equal in length to conical part. Cuticle $4.6 \mu \mathrm{m}$ thick. Width of cephalic capsule almost three times its length. Amphids not detected. Cephalic

120 setae $10 \mu \mathrm{m}$ ( $1 / 2$ corresponding diameter). Cervical setae situated 1.5 cephalic diameters from anterior end. Excretory pore of renette situated near nerve ring. Oral cavity funnel-shaped with thick sclerotized walls. Nerve ring encircles esophagus slightly above its middle. Length of spicules $100 \mu \mathrm{m}$; spicules curved at end of first and second thirds of their length. Spicular capitulum merges gradually into spicular body. Concave oval area present on ventral aspect of spicular capitulum. Gubernaculum short, encircles distal end of spicules, narrows dorsally, and widens ventrally. Accessory organ situated $100 \mu \mathrm{m}$ anterior to anus.

Distinguishing features of this species: 1) cephalic capsule broadens notably toward base (width at base exceeds that at top three times, whereas usually in species of genus Anticoma width exceeds length by two times); 2) extremely low position of excretory pore of cervical gland (situated near nerve ring); 3) characteristic concave oval area present on
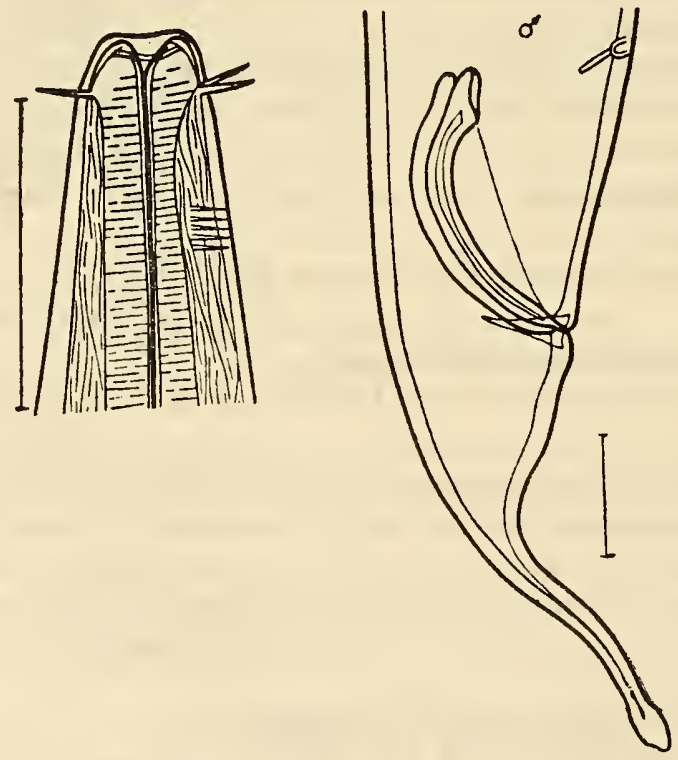

Figure 54. Anticoma eberthi. 
ventral surface of spicular capitulum; and 4) tail narrows sharply in first half (from anus to midtail, tapers to $1 / 6$ ).

Geographic distribution. Found in the Kara Sea (at a depth of $19 \mathrm{~m}$ on a sandy substratum), North Sea, and north Atlantic Ocean.

*42. Anticoma insulaealbae Filipjev, 1927 (Figure 55)

Filip'ev, 1927: 74, 75, pl. 1. fig. 1a-d (description).

$$
\begin{aligned}
& 1 \text { ㅇ: } \begin{array}{ccccccc}
- & 325 & 720 & 1,115 & 2,625 & 3,630 & 4,890 \\
\hline 30 & 90 & 115 & - & 177 & - & 60
\end{array} 5,080 \mu \mathrm{m} ; \quad a=29 \text {; } \\
& \mathrm{b}=7 ; \mathrm{c}=29 \text {. }
\end{aligned}
$$

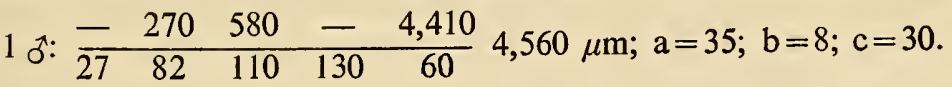

Tail conical, with dilatation at end, and in males curves toward ventral side. Cuticle smooth and 2.0 to $2.5 \mu$ m thick. Setae longer in lateral fields. Head round, slightly flattened anteriorly. Labial papillae very small. Length of cephalic setae $18 \mu \mathrm{m}(2 / 3$ corresponding diameter). Sublateral cephalic setae slightly shorter than remaining ones, $14 \mu \mathrm{m}$ long. Amphids small, $7.0 \mu \mathrm{m} \times 6.0 \mu \mathrm{m}$, and $6.0 \mu \mathrm{m}$ posterior to lateral cephalic setae. Four cervical setae situated about two cephalic diameters from anterior end. Lateral fields narrow. Renette situated opposite posterior part of
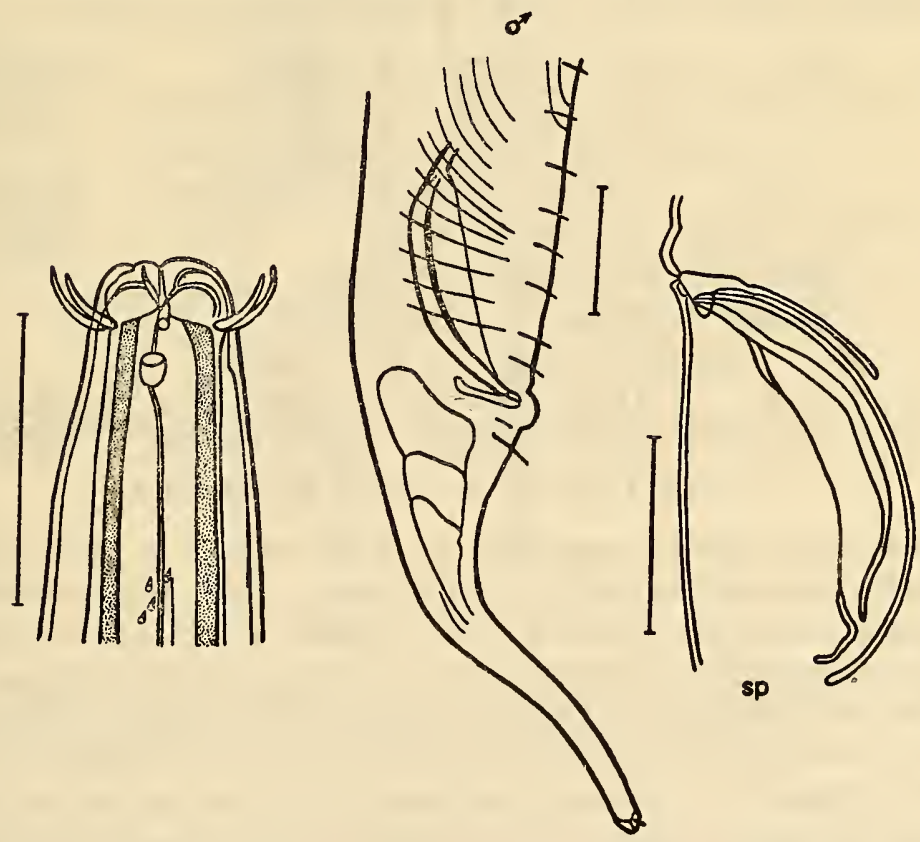

Figure 55. Anticoma insulaealbae (from Filip'ev, 1927). 
esophagus. Cervical pore situated near limit of posterior third of preneural part. Dorsal glands open in anterior part; both subventral glands open somewhat posteriorly. Cardia round, $27 \mu \mathrm{m}$ in diameter. Rectum long, $65 \mu \mathrm{m}$, and separated from intestine by distinct constriction. Anterior testis occupies $29 \%$, posterior testis $31 \%$, and vas deferens $71 \%$ of length of genital tube. Spicules curved, enlarged near capitulum, and with well-developed velum. Gubernaculum flat, closely apposed to spicules.

121 Length of spicules $100 \mu \mathrm{m}$ ( 1.5 times longer than anal diameter). Length of gubernaculum $40 \mu \mathrm{m}$. Accessory organ situated 1.6 anal diameters anterior to anus. Nine pairs of subventral setae situated anterior to accessory organ, two pairs located postanally, and several pairs between anus and accessory organ. Slightly shorter setae situated on tail.

$A$. insulaealbae belongs to that group of species in which the cervical pore is shifted posteriorly, but differs from other representatives of this group in smaller size and longer filiform tail. It differs from $A$. eberthi in longer cephalic and cervical setae, situated farther from the anterior end, longer tail, and smaller measurements.

Geographic distribution. Found in the Kara Sea at a depth range of 15 to $20 \mathrm{~m}$, predominantly in a sandy substratum.

43. Anticoma minor Filipjev, 1927 (Figure 56)

Filip'ev, 1927: 77, 78, pl. 2, fig. 5 a-d; Platonova, 1967: 834.

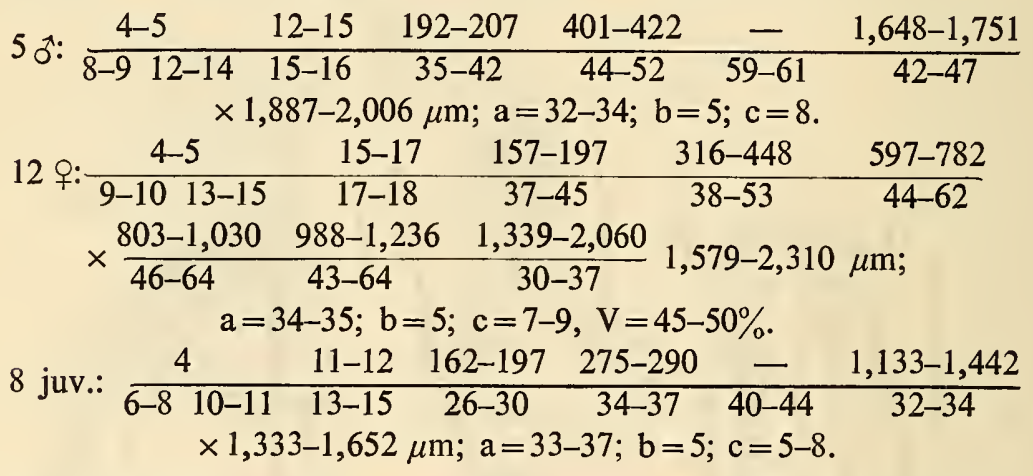

Small, rather slender nematodes. Body tapers to $1 / 5$ to $1 / 6$ midbody diameter at anterior end and $2 / 3$ to $1 / 2$ at posterior end. Head anteriorly truncated. Cuticle thin, 2.0 to $2.5 \mu \mathrm{m}$. Cephalic capsule extremely thin; 122 width at base exceeds length by 2.0 to 2.5 times. Amphids $5.8 \mu \mathrm{m}$ in diameter and situated 11 to $13 \mu \mathrm{m}$ from anterior end. Length of cephalic setae $3.5 \mu \mathrm{m}(1 / 3$ to $1 / 4$ corresponding diameter). Cervical setae (five in number) situated 37 to $41 \mu \mathrm{m}$ from anterior end (distance equal to three cephalic diameters). Length of cervical setae 5.0 to $6.0 \mu \mathrm{m}$. Renette commences at posterior end of esophagus and excretory pore opens at level 
of amphid. Wall of oral cavity slightly sclerotized. Esophagus long, dilating slightly toward base. Nerve ring encircles esophagus slightly below its middle. Length of anterior female genital tube 206 to $248 \mu \mathrm{m}$, of posterior tube 185 to $206 \mu \mathrm{m}$, and of reflexed parts 180 to $200 \mu \mathrm{m}$ and 160 to $190 \mu \mathrm{m}$ respectively. Vulva median or anteromedian. One mature egg, 100 to $120 \mu \mathrm{m} \times 40 \mu \mathrm{m}$, seen in each uterus. Male genital tubes commence 570 to $600 \mu \mathrm{m}$ from anterior end. Spicules arcuate, irregularly shaped, with large lamelliform velum; length 50 to $57 \mu \mathrm{m}$, i.e., almost equal to anal diameter. Gubernaculum simple; length 28 to $30 \mu \mathrm{m}$. Accessory organ 50 to $65 \mu \mathrm{m}$ anterior to anus.

According to Filip'ev (1927) this species resembles A. murmanica and A. limalis in structure. It differs from the former in location of the cephalic setae, situated much closer to the anterior end, and from the latter in shape of spicules and rather long cephalic setae.

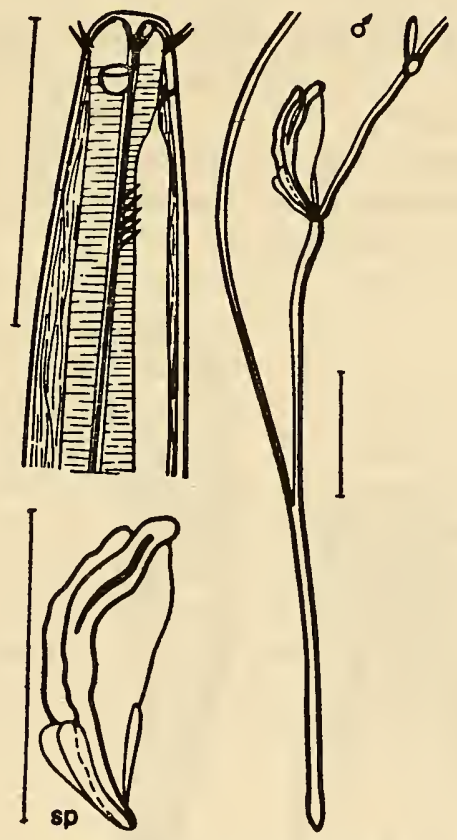

Figure 56. Anticoma minor.

Geographic distribution. Found in the Barents Sea from the coastal zone to a depth of $200 \mathrm{~m}$ on rocky and sandy substrata.

*44. Anticoma arctica Steiner, 1916 (Figure 57)

Steiner, 1916: 656-660, tab. 36, fig. 45a-f; Filip'ev, 1927: 75 (description); Allgen, 1928: 283; 1929a: 10. 


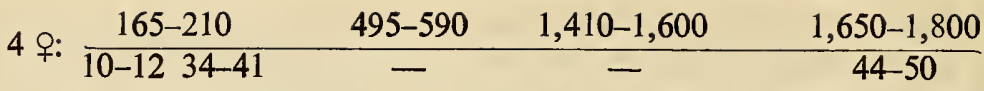

$$
\begin{aligned}
& \times \frac{2,260-2,480 \quad 2,720-3,135}{-30-34} 2,850-3,300 \mu \mathrm{m} ; \\
& a=56-69 ; b=6-7 ; c=18-19 \text {. }
\end{aligned}
$$

Characterized by unusually elongated and extremely slender body. Tail relatively short; width at narrowest part constitutes $1 / 10$ of anal diameter. Cervical setae situated less regularly in nematodes described by Filip'ev compared to specimens described by Steiner. Cervical setae of this species situated two or three cephalic diameters from anterior end. Cephalic capsule very poorly developed and its cuticle appears to be a direct extension of thicker cuticle forming buccal capsule. Renette occupies $1 / 8$ of esophagus, is slightly shifted toward right side, and opens at base of buccal capsule. Uteri in female short. Vaginal glands well developed.

Most important characteristics of this species: 1) highly elongated and slender body; 2) location of renette; 3) short tail; and 4) situation of cervical setae.

123 Geographic distribution. Found in the Barents Sea and western part of the Baltic Sea, predominantly in the coastal zone among algae and at a depth of about $30 \mathrm{~m}$ in a sandy bed.

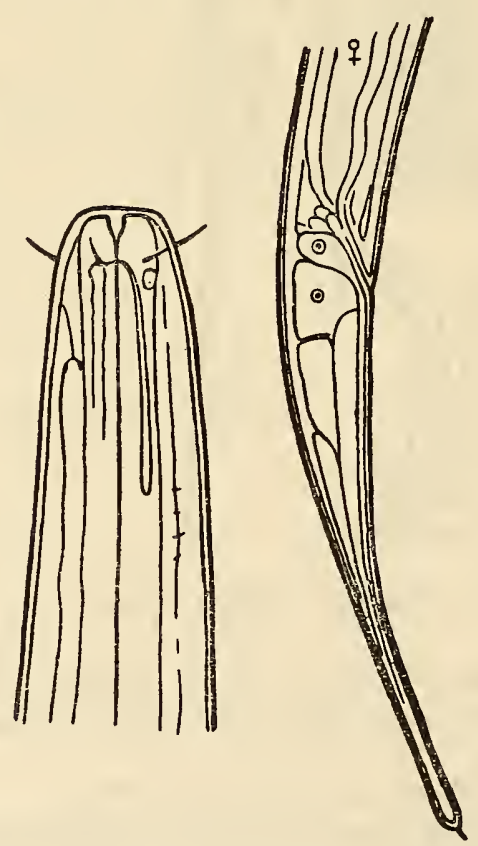

Figure 57. Anticoma arctica (from Steiner, 1916). 
45. Anticoma limalis Bastian, 1865 (Figure 58$)^{4}$

Bastian, 1865: 141, pl. XI, figs. 146-148; Bütschli, 1874: 271, 272, tab. IV, fig. 19a-c; Savel'ev, 1912: 108; Filip'ev, 1927: 76, pl. 12, fig. 3a-d; Allgen, 1931a: 97; 1931b: 211; 1932: 399; 1933: 11-12; 1935: 14-15; 1940b: 443; 1943: 267; 1954a: 5; 1957b: 6; Schuurmans-Stekhoven 1946: 35.

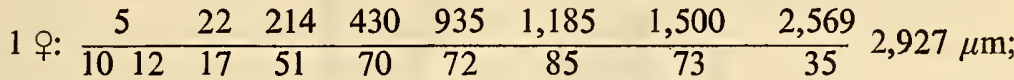

$$
\begin{aligned}
& \mathrm{a}=34 ; \mathrm{b}=7 ; \mathrm{c}=8 ; \mathrm{V}=40 \% \text {. } \\
& 8 \text { juv.: } \begin{array}{cccccc}
4-5 & 16-18 & 200-210 & 320-450 & - & 1,810-2,000 \\
810 & 15-17 & 42-45 & 48-52 & 58-60 & 42-45
\end{array} \\
& \times 2,110-2,305 \mu \mathrm{m} ; \mathrm{a}=36-38 ; \mathrm{b}=5-7 ; \mathrm{c}=7-8 \text {. }
\end{aligned}
$$

Body tapers to $1 / 8$ midbody diameter at anterior end and $5 / 12$ at posterior end. Head slightly truncated anteriorly. Tail long; slender cylindrical part equal in length to conical part. Cuticle 2.0 to $3.0 \mu \mathrm{m}$ thick. Cephalic capsule extremely thin; width twice length. Amphids situated almost immediately behind cephalic setae; extremely small, $3.0 \mu \mathrm{m} \times 2.0$ $\mu \mathrm{m}$, and somewhat longitudinally elongated. Length of cephalic setae $1246.9 \mu \mathrm{m}$ (slightly more than $1 / 2$ corresponding diameter). Cervical setae commence three cephalic diameters from anterior end; length of setae 5:0 $\mu \mathrm{m}$. Excretory pore of renette opens midway between cephalic and cervical setae. Oral cavity longitudinally elongated; walls sclerotized. Nerve ring encircles esophagus slightly anterior to its midlength. Length of anterior female genital tube $250 \mu \mathrm{m}$, of posterior tube $315 \mu \mathrm{m}$, and of reflexed parts $220 \mu \mathrm{m}$ and $300 \mu \mathrm{m}$ respectively. Eggs $100 \mu \mathrm{m} \times 70 \mu \mathrm{m}$. Vulva shifted anteriorly rather far away from midbody.

This species, as observed by Filip'ev (1927), resembles $A$. pellucida in size, various indexes (except $c$ ), and position of excretory pore of renette and vulva. The two species differ from each other in shape and size of tail (tail of $A$. limalis significantly longer and slender), location of amphids (in $A$. limalis situated somewhat nearer to anterior end), and length of cephalic setae (shorter in A. pellucida). They are more readily distinguished from each other by structure of spicular apparatus and gubernaculum.

4The taxonomic position of such species as Anticoma acuminata, A. pellucida, A. limalis, and $A$. similis has long been ambiguous. The first three species have been merged time and again, then separated on the basis of such characters as position of the excretory pore, length of tail, and position of the accessory organ in males (de Man, 1886; Filip'ev, 1918, 1927; Micoletzky, 1924, 1930; Schuurmans-Stekhoven, 1935a, 1950; and others). I have left the question of the identity of these species open because my material on $A$. limalis and $A$. pellucida is insufficient to determine their age and individual variability. Representatives of $A$. acuminata and $A$. similis were unfortunately absent in my material. 


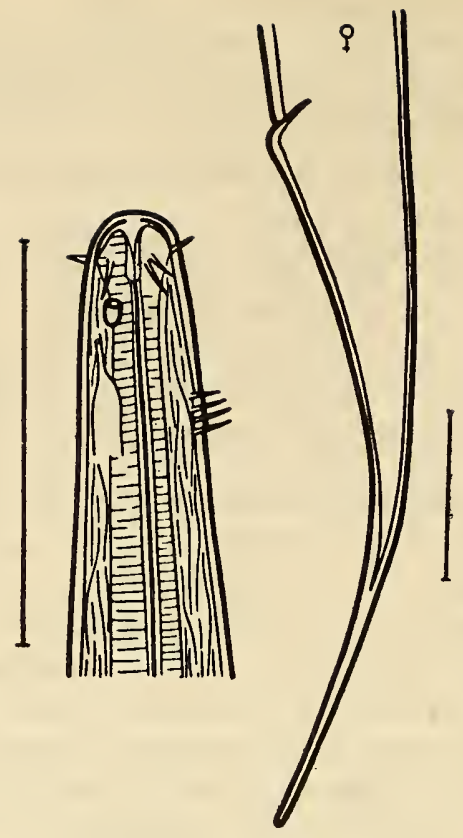

Figure 58. Anticoma limalis.

As there were no males in my material I cannot elaborate on a comparison of these two species.

Geographic distribution. Considering the information given in the literature, this species may be considered ubiquitous. However, it is found quite often in the Arctic, North Sea, and north Atlantic Ocean. Hence, I am inclined to consider $\boldsymbol{A}$. limalis arctico-boreal. Information about its occurrence in other parts of the world oceans could possibly be based on the fact that some very similar species of Anticoma have been recorded under the name $A$. limalis.

46. Anticoma pellucida Bastian, 1865 (Figure 59)

Bastian, 1865: 142, pl. XI, figs. 149, 150; de Man, 1886: 53, figs. 9, 10; Ditlevsen, 1919: 159-161; 1923: 182; 1926: 20; Allgen, 1927a: 49; 1927b: 249; Schuurmans-Stekhoven, 1950: 29, 30, fig. 3A-B.

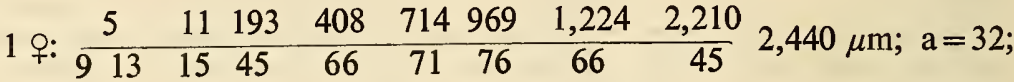

$$
\begin{aligned}
& \mathrm{b}=5 ; \mathrm{c}=10 ; \mathrm{V}=40 \% \text {. }
\end{aligned}
$$

Body tapers to $1 / 8$ midbody diameter at anterior end and $10 / 17$ at posterior end. Head anteriorly round. Tail relatively small compared to 
other species (significantly smaller than in $A$. limalis); conical part equal to cylindrical part in length; small bulge present at its terminus. Cuticle thin, only $2.3 \mu \mathrm{m}$. Walls of cephalic capsule distinctly visible in spite of insignificant size of head. Amphids located one cephalic diameter from anterior end, longitudinally elongated, and 2.3 to $3.4 \mu \mathrm{m}$ long. Length of cephalic setae $4.6 \mu \mathrm{m}$ (1/3 corresponding head diameter). Cervical setae $5.8 \mu \mathrm{m}$ long and commence 2.4 cephalic diameters from anterior end. Excretory pore of renette situated as in $A$. limalis, midway between cervical and cephalic setae. Oral cavity, as in $A$. limalis, also significantly elongated. Nerve ring encircles esophagus a little above its midlength. Length of anterior and posterior genital tubes of females $255 \mu \mathrm{m}$, and reflexed parts $178 \mu \mathrm{m}$. One egg, $102 \mu \mathrm{m} \times 51 \mu \mathrm{m}$, detected in genital tract. Vulva, as in $A$. limalis, significantly shifted anterior to midbody.
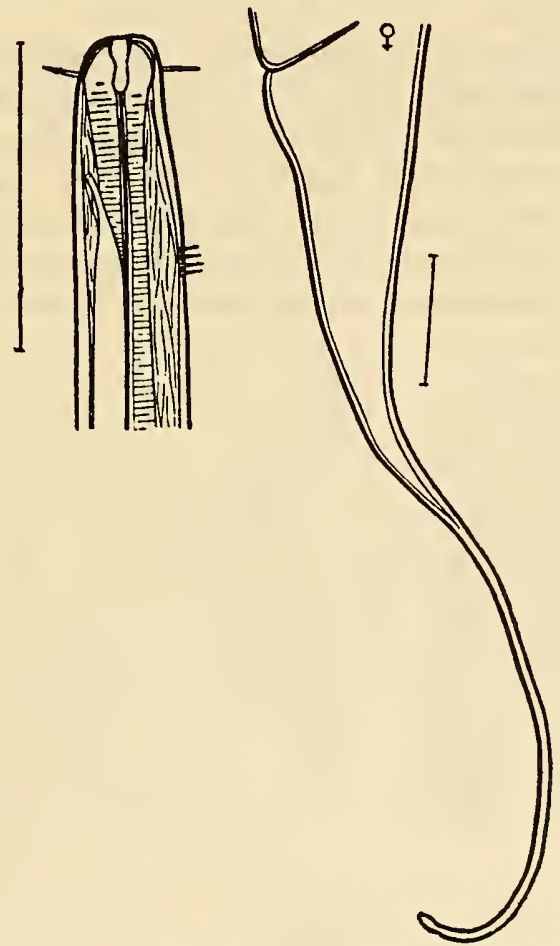

Figure 59. Anticoma pellucida.

Species highly similar to $A$. limalis; differences indicated under description of $A$. limalis.

Geographic distribution. Arctic and northern Atlantic, in the east up to the Kara Sea, and in the south up to the northern coast of France. 125 Extends even to western part of the Baltic Sea and the Mediterranean 
Sea. Southernmost point of distribution is the western coast of Africa (Canary Islands). Allgen's (1927) report of this species in the subantarctic near Campbell Island appears dubious.

*47. Anticoma novozemelica (Filipjev, 1927) (Figure 60)

Filip'ev, 1927: 77, pl. 2, fig. 4a-c (A. limalis var. novozemelica) (description).

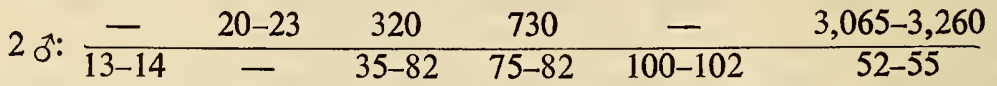

$$
\begin{aligned}
& \times 3,540-3,620 \mu \mathrm{m} ; \mathrm{a}=35-36 ; b=5 ; c=8-10 \text {. } \\
& 1 \text { ㅇ: } \begin{array}{ccccccc}
- & 330 & 715 & 1,300 & 1,800 & 2,160 & 3,230 \\
\hline 14 & 57 & 75 & - & 102 & - & 53
\end{array} 3,760 \mu \mathrm{m} ; \mathrm{a}=37 \text {; } \\
& \mathrm{b}=5 ; \mathrm{c}=7 \text {. }
\end{aligned}
$$

Filip'ev observed great similarity between this species and $A$. limalis. $A$. novozemelica differs from $A$. limalis in larger size, round and larger size of amphids (diameter $5.0 \mu \mathrm{m}$ ), and thinner walls of head. Oral cavity much more extensive than in $A$. limalis, and its thick sclerotized lining forms a small blunt outgrowth at the base. Spicules with velum and 80 $\mu \mathrm{m}$ long, or 1.7 to 1.8 times anal diameter. Gubernaculum relatively long, narrow, sharply expanded in distal part, and devoid of processes.

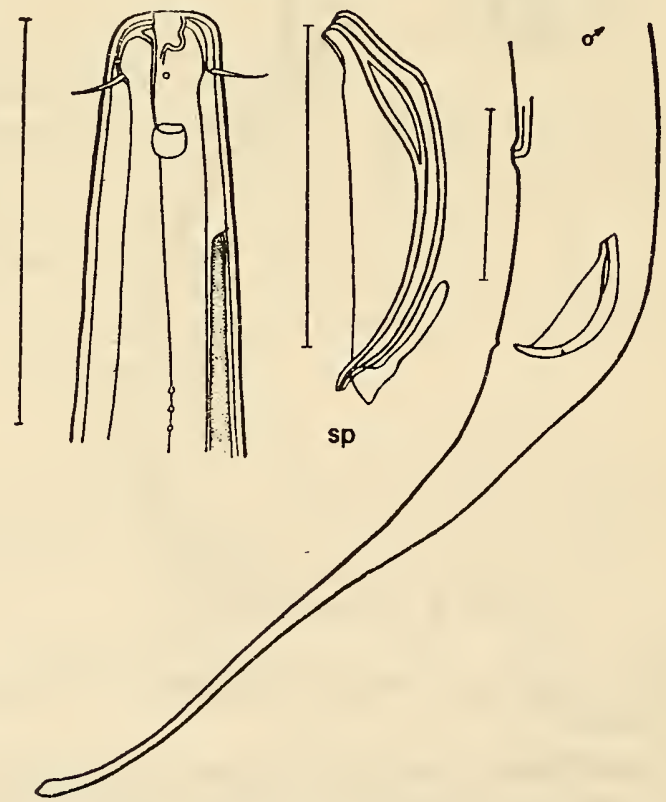

Figure 60. Anticoma novozemelica (from Filip'ev, 1927). 
Geographic distribution. This species was recorded from the shores of Novaya Zemlya in the Strait of Matochkin Shar in the coastal zone in rhizoids of Laminaria sp.

48. Anticoma brevisetosa Platonova, 1967 (Figure 61)

Platonov, 1967: 835, figs. 3-5.

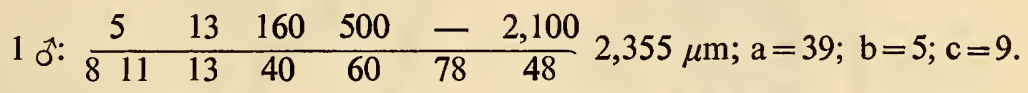

126

$$
\begin{aligned}
& 7 \text { f: } \begin{array}{ccccc}
4-5 & 11-13 & 220-230 & 425-440 & 800-820 \\
\hline 9-10 \quad 11-12 & 13-15 & 48-51 & 65-72 & 62-78
\end{array}
\end{aligned}
$$

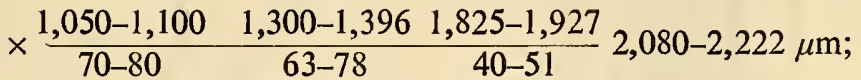

$$
\begin{aligned}
& a=27-29 ; b=5 ; c=8 ; V=49-50 \% \text {. }
\end{aligned}
$$

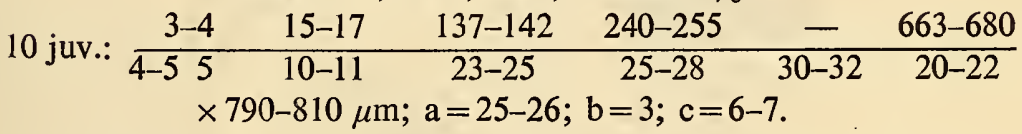

Body tapers to $1 / 8$ to $1 / 10$ midbody diameter at anterior end and not less than $1 / 2$ at posterior end. Head anteriorly truncated. Tail long; filiform cylindrical part twice length of conical part. Cuticle 3.5 to $4.6 \mu \mathrm{m}$ thick. Cephalic capsule barely distinguishable because minute in size; width at base twice its length. Amphids not observed. Length of cephalic setae 3.5 to $4.6 \mu \mathrm{m}$ (1/3 corresponding head diameter). Cervical setae situated 36 to $42 \mu \mathrm{m}$ from anterior end in groups of six (distance slightly more than three cephalic diameters). They are equal in length to cephalic setae. Excretory pore situated one cephalic diameter from anterior end. Oral cavity very small and cyathiform. Nerve ring encircles esophagus medially. Length of anterior female genital tube 250 to $280 \mu \mathrm{m}$, of posterior tube 240 to $306 \mu \mathrm{m}$; and of reflexed parts 180 to $193 \mu \mathrm{m}$ and 180 to $193 \mu \mathrm{m}$ respectively [sic]. Two mature eggs, $102 \mu \mathrm{m} \times 61 \mu \mathrm{m}$, observed in each uterus of female. Male genital tubes commence at a distance of $640 \mu \mathrm{m}$ from anterior end. Spicules $67 \mu \mathrm{m}$ long, smoothly arcuate, widen at proximal end, and gradually taper toward distal end. Spicules also taper slightly toward their capituli. Large elongated-oval cleft present in thickened part of spicules. Gubernaculum extremely small, almost invisible. Accessory organ situated $80 \mu \mathrm{m}$ anterior to anus.

Structurally close to A. limalis, A. brevisetosa differs in: 1) shorter setae; 2) large number of cervical setae; 3 ) extremely small size of oral cavity; 4) position of excretory pore (much closer to anterior end); and 5) spicules with reduced gubernaculum.

127 Geographic distribution. Found in the Gulf of Kola Bay of the Barents Sea at a depth of 3.0 to $5.0 \mathrm{~m}$ among Lithothamnion murmanicum. 

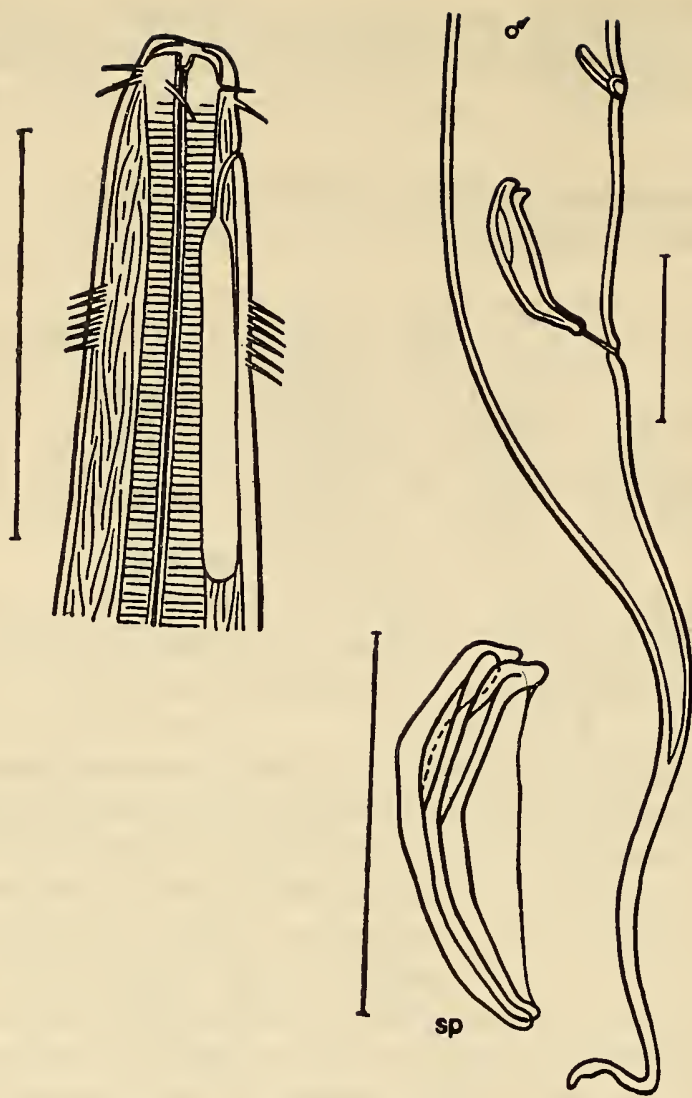

Figure 61. Anticoma brevisetosa.

49. Anticoma filipjevi Platonova, 1967 (Figure 62)

Platonova, 1967: 835, figs. 6-8.

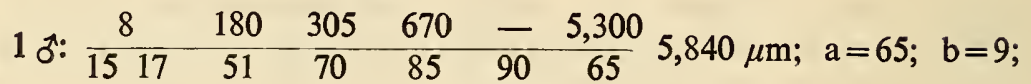
$\mathrm{c}=10$.

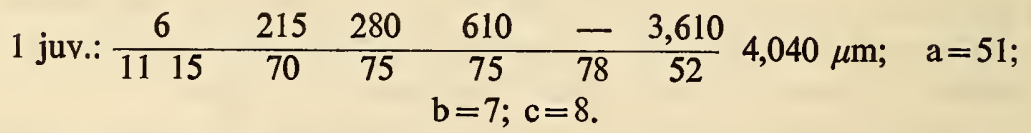

Body tapers to $1 / 5$ midbody diameter at anterior end and $10 / 13$ at posterior end. Head anteriorly rounded. Cylindrical part of tail twice longer than conical part. Cuticle $3.0 \mu \mathrm{m}$ thick. Cephalic capsule very thin-walled; width three times length. Amphids situated immediately behind cephalic capsule. Cephalic setae rather long, $11 \mu \mathrm{m}$ (about $1 / 2$ 
corresponding head diameter). First of five cervical setae situated two cephalic diameters from anterior end. Excretory pore of renette situated significantly posterior to cervical setae, at 10 cephalic diameters from anterior end. Oral cavity almost undeveloped. Nerve ring encircles 128 esophagus somewhat anterior to its midlength. Spicules $95 \mu \mathrm{m}$ long and curve at two points; capitulum small but distinctly developed. Spicular body dilates slightly and then tapers gradually toward distal end; wide slit extends along entire length of spicules. Velum extremely thin and narrow. Gubernaculum small and barely visible. Accessory organ 120 $\mu \mathrm{m}$ from anus.

Distinguishing features of this species: 1) large size; 2) location of
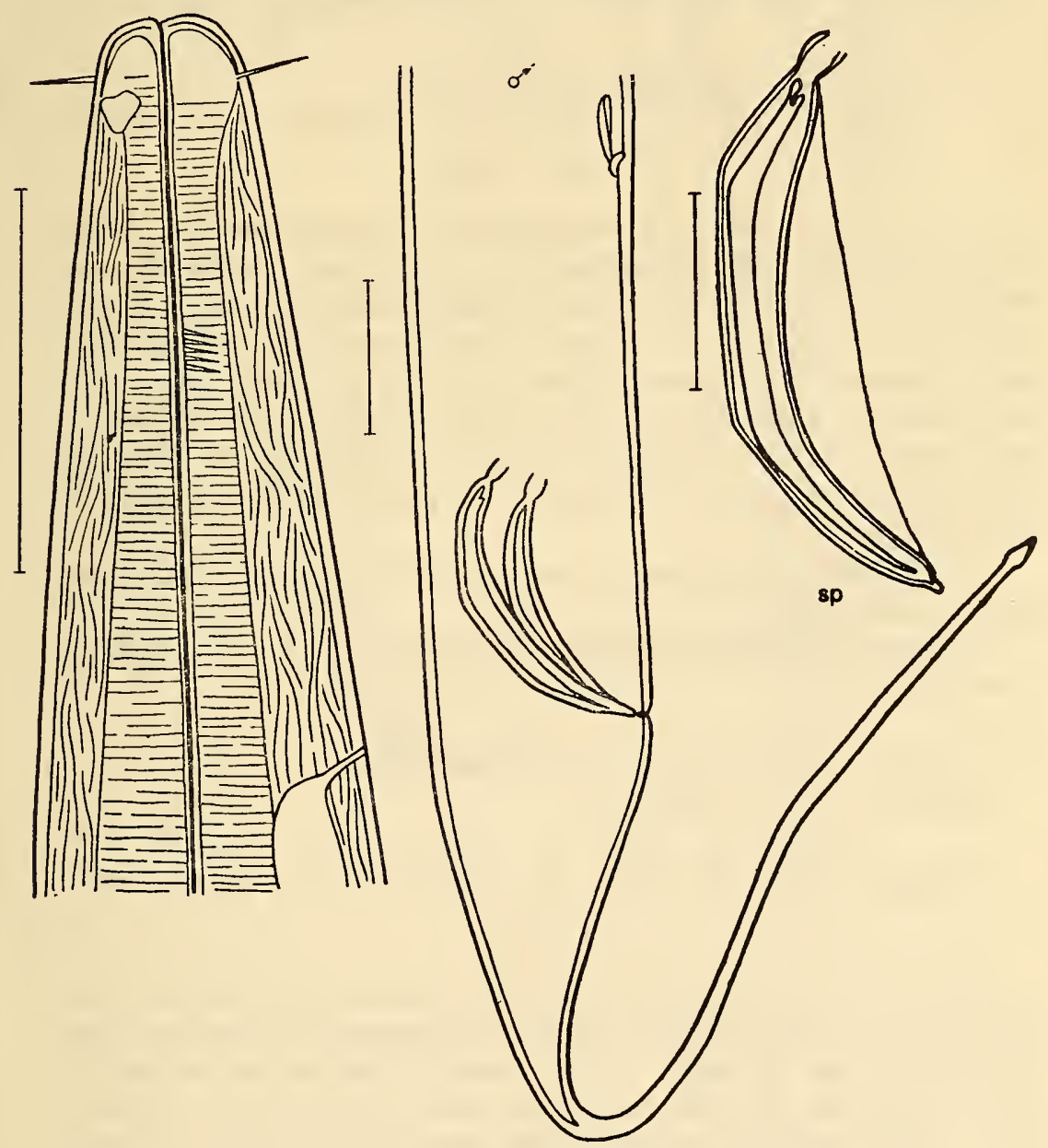

Figure 62. Anticoma filipjevi. 
amphids immediately behind cephalic capsule; 3 ) relatively long cephalic setae; 4) position of excretory pore of cervical gland far away from cephalic end; and 5) shape of spicules-not smoothly arcuate but with a sharp bend at two points and presence of wide slit throughout their length. Structurally, A. filipjevi is close to A. tenuicaudatoides.

Geographic distribution. Found in the Kara Sea at a depth of $698 \mathrm{~m}$ in brown-gray silt.

*50. Anticoma tenuicaudatoides Gerlach and Riemann, 1974 (Figure 63) Filip'ev, 1946: 158, 159, fig. 1A-C (tenuicaudata) (description).

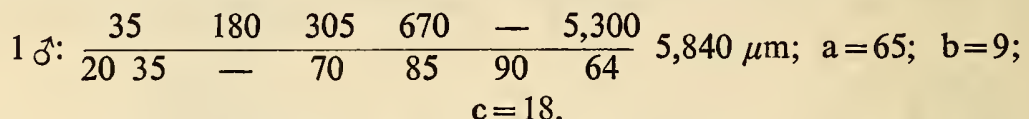

$$
\begin{aligned}
& 1 \text { 우: } \begin{array}{cccccc}
35 & 215 & 280 & 610 & 2,630 & 3,610
\end{array} 4,100 \mu \mathrm{m} ; \quad a=65 ; \quad b=9 ; \\
& c=11 ; V=64 \% \text {. }
\end{aligned}
$$

Body long. Tail extremely long (equal to 8.0 anal diameter in male and 9.5 in female), and very slender at tip, only $3.0 \mu \mathrm{m}$ in width. Cuticle smooth and thin, only 3.0 to $4.0 \mu \mathrm{m}$. Cephalic setae about 10 to $11 \mu \mathrm{m}$, approximately equal to half cephalic width. Amphids small. Cervical setae commence 1.75 cephalic diameters from anterior end; they number four or five and differ slightly in size. Spicules usual in type and $95 \mu \mathrm{m}$ long (equal to 1.4 anal diameter). Gubernaculum small, $30 \mu \mathrm{m}$ long (equal to 0.4 anal diameter). Distance from anus to small anal tube 2.5 anal diameters.

A. tenuicaudatoides belongs to that group of long-tailed species which possess a hind pore.

Geographic distribution. Found in the Kara Sea at a depth of $698 \mathrm{~m}$ in brown-gray silt.

51. Anticoma grandis Platonova, 1967 (Figure 64)

Platonova, 1967: 835, figs. 9-11.

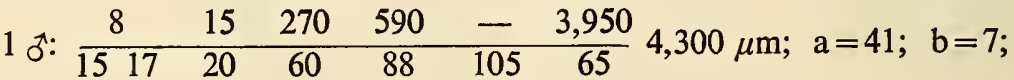

$$
\begin{aligned}
& \mathrm{c}=12 \text {. }
\end{aligned}
$$

Body tapers to $1 / 7$ midbody diameter at anterior end and 10/17 at posterior end. Head anteriorly flat. Tail rather long; conical part equal to cylindrical part in length. Cephalic capsule thin-walled and barely discernible; width twice length. Cuticle rather thick, $5.0 \mu \mathrm{m}$. Cephalic setae $6.0 \mu \mathrm{m}$ (about $1 / 2$ corresponding head diameter). Four cervical setae situated three cephalic diameters from anterior end; somewhat 

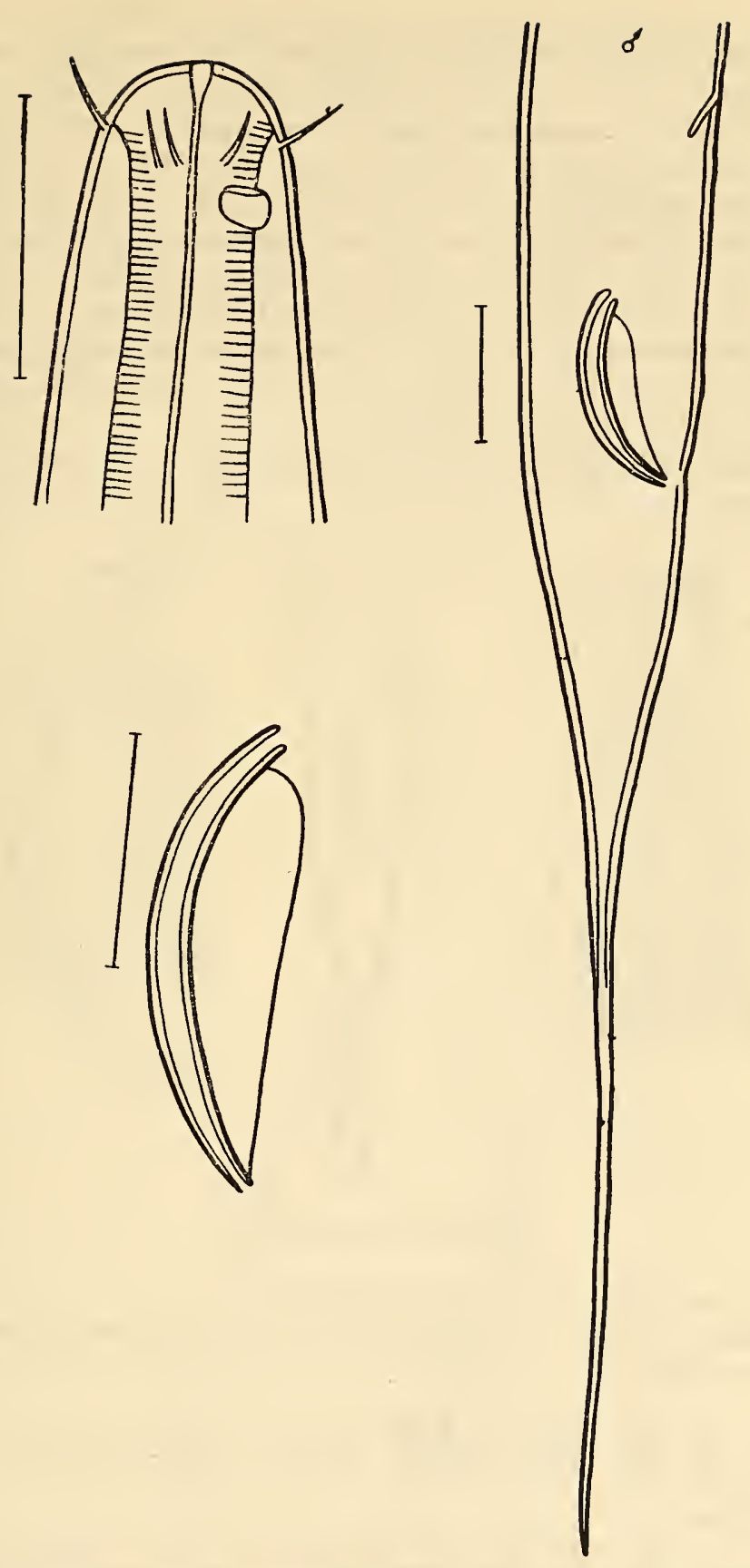

Figure 63. Anticoma tenuicaudatoides (from Filip'ev, 1946). 
smaller than cephalic setae, only $4.6 \mu \mathrm{m}$ long. Amphids $5.0 \mu \mathrm{m}$ and situated one cephalic diameter from anterior end. Excretory pore of renette opens almost at level of amphids. Oral cavity cyathiform and rather wide; wall highly sclerotized. Nerve ring encircles esophagus somewhat anterior to its midlength. Spicular length $105 \mu \mathrm{m}$, capitulum undeveloped, and body with two curves. Wide slit extends along entire spicular length. Distinct wide velum with transverse striations present on ventral aspect of spicules. Gubernaculum small ( $1 / 4$ spicular length) and simple in structure. Accessory organ situated $110 \mu \mathrm{m}$ anterior to anus.

130 This species resembles $A$. filipjevi in size and external appearance. It differs in position of excretory pore of renette, well-developed and cyathiform oral cavity, and shape of spicules.

Geographic distribution. Found in the Kara Sea at a depth of $360 \mathrm{~m}$ in sandy silt.
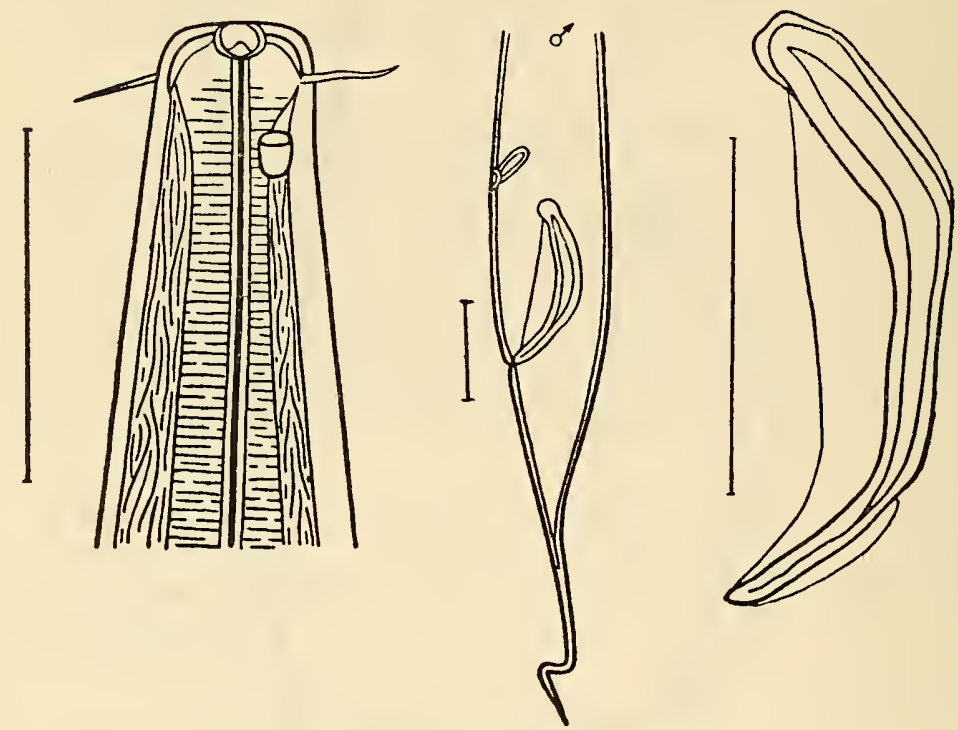

Figure 64. Anticoma grandis.

52. Anticoma behringiana sp. nov. (Figure 65)

Holotype ${ }^{\lambda}$ : Institute of Zoology, Academy of Sciences, USSR. Collection No. 7422.

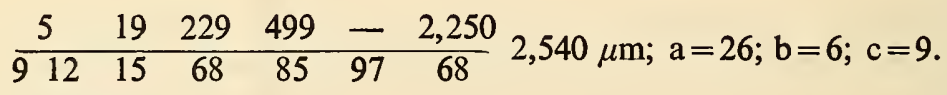

\section{Paratypes.}

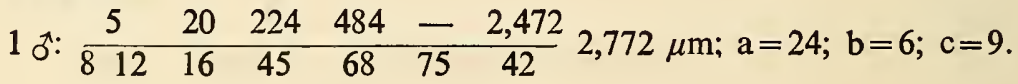




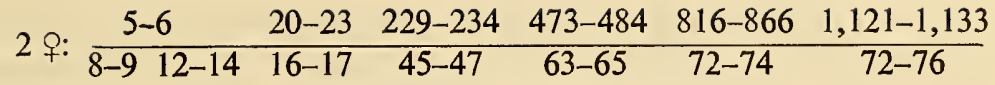

$$
\begin{aligned}
& \times \frac{1,401-1,442 \quad 2,064-2,163}{70-72} 2,400-2,771 \mu \mathrm{m} ; \\
& a=33-37 ; b=5-6 ; c=7-8 ; V=40-46 \% \text {. }
\end{aligned}
$$

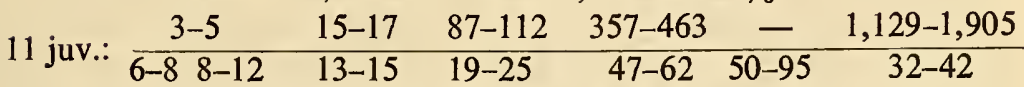$$
1,397-2,205 \mu \mathrm{m} ; \mathrm{a}=23-27 ; \mathrm{b}=4-5 ; \mathrm{c}=6-7 \text {. }
$$

Body slender and tapers to $1 / 5$ to $1 / 7$ midbody diameter at anterior end and $2 / 3$ at posterior end. Head anteriorly truncated. Cylindrical part of tail 2.5 times longer than conical. Protuberance at caudal tip barely discernible. Cuticle thin, $2.3 \mu \mathrm{m}$. Cephalic capsule extremely thin; width at base twice length. Amphids, $5.8 \mu \mathrm{m} \times 3.5 \mu \mathrm{m}$ (1/4 corresponding diameter), situated 13 to $14 \mu \mathrm{m}$ from anterior end (distance slightly more than one cephalic diameter). Length of cephalic setae 5.8 to 6.9
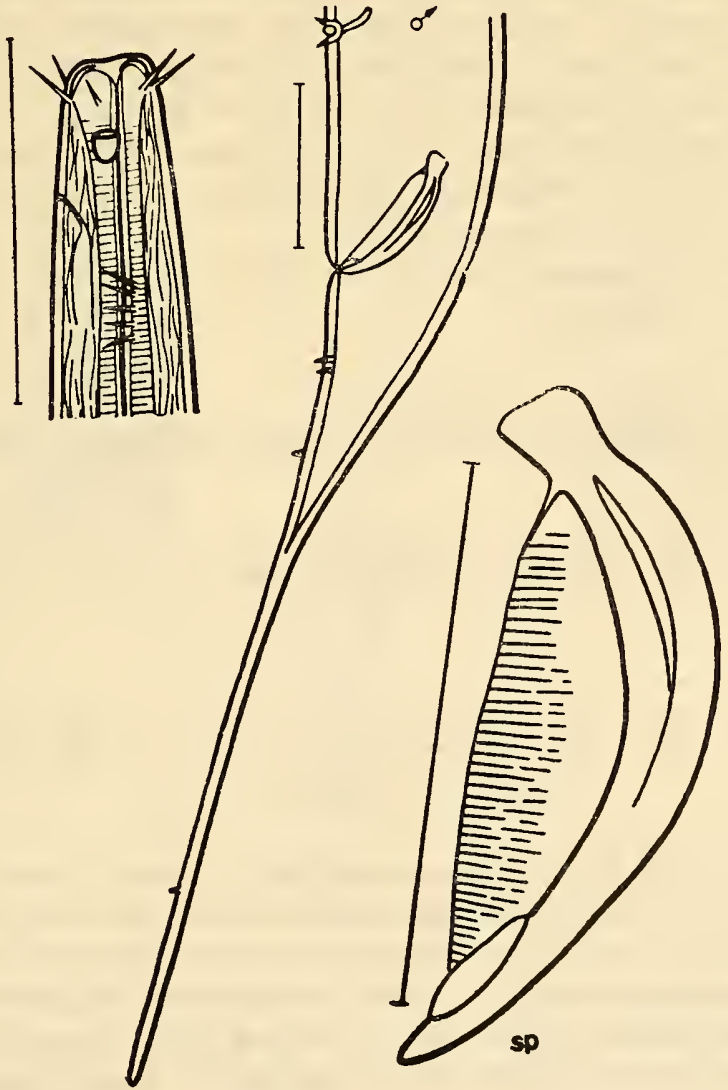

Figure 65. Anticoma behringiana sp. nov. 
$\mu \mathrm{m}$ ( $1 / 2$ corresponding head diameter). Cervical setae $5.0 \mu \mathrm{m}$; anterior setae situated $34.8 \mu \mathrm{m}$ from anterior end (distance equal to three cephalic diameters). Postanal part of tail covered with extremely short and 131 sparse setae. Excretory pore of renette situated 19.7 to $23.2 \mu \mathrm{m}$ from anterior end of body, i.e., about midway between amphids and first cervical seta. Oral cavity small and weakly sclerotized. Nerve ring encircles esophagus somewhat below its midlength. Length of anterior female genital tube 217 to $255 \mu \mathrm{m}$, of posterior tube 280 to $309 \mu \mathrm{m}$, and of reflexed parts 200 to $214 \mu \mathrm{m}$ and 205 to $229 \mu \mathrm{m}$ respectively. Vulva rather significantly shifted anterior to midbody. Females with mature eggs not detected. Spicules rather narrow, arcuate, slightly thickened in anterior third, and $60 \mu \mathrm{m}$ long. Spicular capitulum cloven near top. Arcuate cleft evident in thickened part of spicules. Velum extremely thin. Gubernaculum minute, almost invisible. Accessory organ situated 70 $\mu \mathrm{m}$ anterior to anus.

$A$. behringiana is close to $A$. brevisetosa in structure, size, and indexes. However, body tapers much less from midregion to anterior end (five to seven times less). Cephalic setae longer and excretory pore of cervical gland situated farther from anterior end than in $A$. brevisetosa. Vulva significantly shifted anterior to midbody in $A$. behringiana but lies exactly midbody in $A$. brevisetosa. This species also differs in spicular shape and situation of accessory organ.

Geographic distribution. Found in the Bering Strait at a depth of 48 $\mathrm{m}$ in dark gray silted sand.

132 53. Anticoma curta sp. nov. (Figure 66)

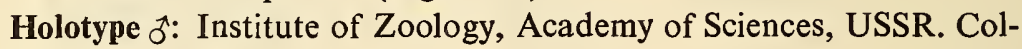
lection No. 7433.

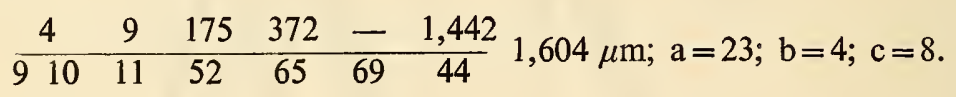

Paratype.

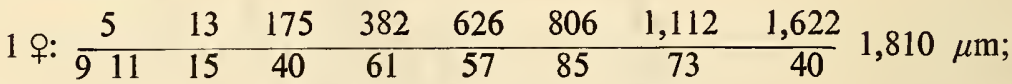

$$
\begin{aligned}
& a=21 ; b=5 ; c=10 ; V=45 \% \text {. }
\end{aligned}
$$

Extremely small nematodes, comparable to minute $A$. minor in size. Body tapers to $1 / 8$ to $1 / 9$ midbody diameter at anterior end and $5 / 13$ to $10 / 27$ at posterior end. Head anteriorly truncated. Narrow cylindrical part of tail equal to conical in length; protuberance at terminal part barely distinguishable. Cuticle 2.3 to $3.4 \mu \mathrm{m}$ thick. Cephalic capsule thin-walled; width at base twice length. Amphids in female (not detected in male) situated two cephalic diameters from anterior end, slightly 
longitudinally elongated, and $3.5 \times 2.3 \mu \mathrm{m}$. Cephalic setae 1.2 to $2.3 \mu \mathrm{m}$ ( $1 / 5$ to $1 / 6$ corresponding head diameter). Cervical setae fine and commence 29.0 to $34.8 \mu \mathrm{m}$ from anterior end (distance equal to 3.0 to 3.7 cephalic diameters). Cervical setae equal to cephalic setae in length. Excretory pore of renette situated slightly more than one cephalic diameter from anterior end. Oral cavity relatively large and cyathiform. Nerve ring encircles esophagus somewhat anterior to its midlength. Length of anterior female genital tube $280 \mu \mathrm{m}$, of posterior tube $306 \mu \mathrm{m}$, and of reflexed parts $229 \mu \mathrm{m}$ and $105 \mu \mathrm{m}$ respectively. Only one egg, $102 \mu \mathrm{m} \times 40 \mu \mathrm{m}$, observed in genital tract of female. Spicules $42 \mu \mathrm{m}$ long and relatively wide. Abrupt dilatation, occupying one-third spicular length, follows narrow capitulum; after dilatation spicules again narrow

133 abruptly. Rather wide cleft along side of spicule. Velum not wide and may be thin. Gubernaculum reduced. Accessory organ situated $60 \mu \mathrm{m}$ anterior to anus.

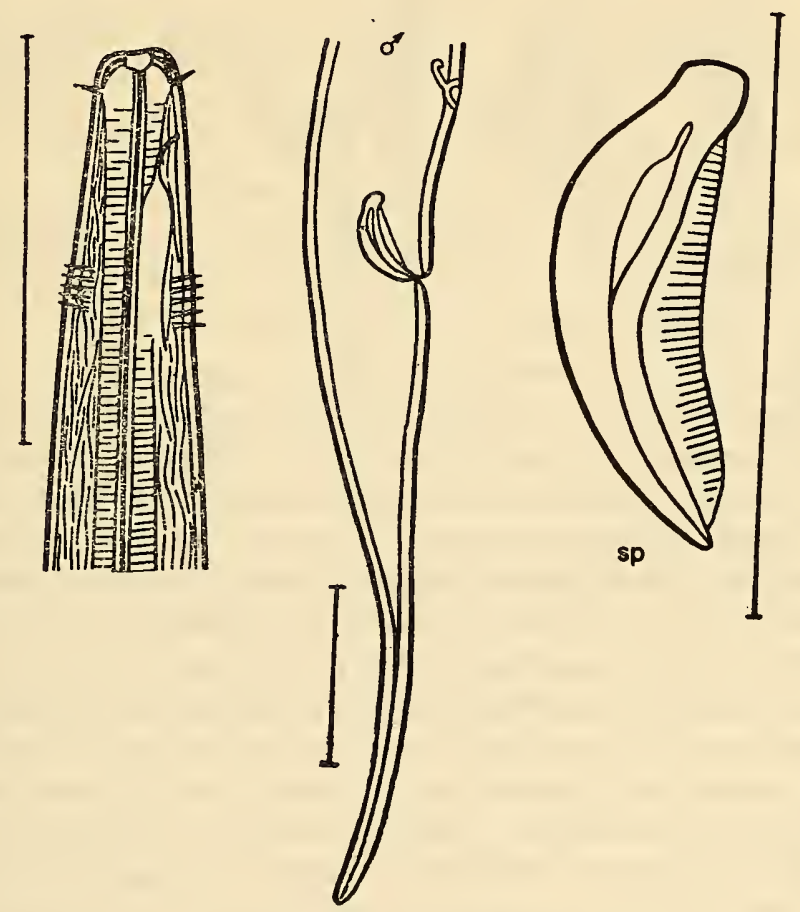

Figure 66. Anticoma curta sp. nov.

To some extent this species is close to $A$. minor but relatively thicker (in $A$. minor, a $=32-35$; in $A$. curta, $\mathrm{a}=16-21$ ) and with shorter cephalic setae (equal to $1 / 3$ to $1 / 4$ corresponding diameter). These two species 
differ in shape of oral cavity (funnel-shaped in $A$. minor and cyathiform in $A$. curta). Finally, it is very easy to distinguish these species on the basis of spicular structure.

Geographic distribution. Found in the Bering Strait at a depth of $48 \mathrm{~m}$ in dark gray sandy silt.

54. Anticoma uschakovi sp. nov. (Figure 67)

Holotype t: Institute of Zoology, Academy of Sciences, USSR. Collection No. 7467.

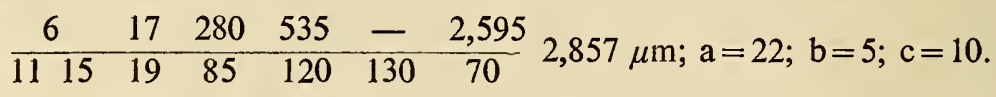

\section{Paratypes.}

$$
\begin{aligned}
& 1 \text { o } 1: \begin{array}{cccccc}
7 & 18 & 295 & 556 & - & 2,678 \\
\hline 10 & 14 & 20 & 71 & 96 \quad \begin{array}{c}
112 \\
c=10 .
\end{array} & 51
\end{array} 2,978 \mu \mathrm{m} ; \quad \mathrm{a}=26 ; \quad \mathrm{b}=5 \text {; }
\end{aligned}
$$

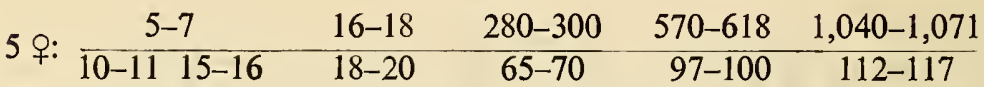

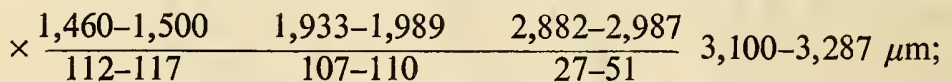

$$
\begin{aligned}
& a=27-28 ; b=5 ; c=10-11 ; V=46-47 \% \text {. } \\
& 5 \text { juv.: } \begin{array}{lllccc}
4-5 & 12-15 & 153-158 & 387-392 & - & 2,026-2,266 \\
\hline 88-12 & 13-15 & 31-34 & 37-40 & 37-42 & 30-32
\end{array} \\
& \times 2,213-2,456 \mu \mathrm{m} ; \mathrm{a}=52-60 ; \mathrm{b}=6 ; \mathrm{c}=12-13 \text {. }
\end{aligned}
$$

134 Body tapers to $1 / 10$ midbody diameter at anterior end and $1 / 2$ at posterior end. Head anteriorly truncated. Filiform cylindrical part of tail twice length of conical part. Distinct thickening evident at caudal terminus. Cuticle $5.8 \mu \mathrm{m}$ thick. Cephalic capsule with distinctly visible walls; width twice length. Amphids situated $11.6 \mu \mathrm{m}$ (two cephalic diameters) from anterior end of body; width of amphids $8.2 \mu \mathrm{m}(1 / 2$ corresponding body diameter). Length of cephalic setae $5.8 \mu \mathrm{m}$ (1/3 corresponding head diameter). First five cervical setae situated 34 to $40 \mu \mathrm{m}$ from anterior end (three to four cephalic diameters). Excretory pore of renette situated near posterior margin of amphids. Oral cavity rectangular, with sclerotized walls, spacious, and reaches level of cephalic setae. Nerve ring encircles esophagus at midlength. Length of anterior female genital tube 413 to $429 \mu \mathrm{m}$, of posterior tube 480 to $500 \mu \mathrm{m}$, reflexed parts almost reach vulva. Not more than one egg, $137 \mu \mathrm{m} \times 66 \mu \mathrm{m}$, seen in genital tract of female. Length of spicules $75 \mu \mathrm{m}$; shape smoothly arcuate. Large ventral hump forms an abrupt dilatation in spicule in proximal part next to spicular capitulum. Narrowing of spicule more gradual and stops in proximal third. Remaining part of spicule narrow but more or less equal in width throughout length of spicular body. Velum narrow and thin. Accessory organ situated $75 \mu \mathrm{m}$ anterior to anus. 
Distinguishing features of this species: 1) well-developed oral cavity; 2) characteristic shape of tail (conical part extremely short and changes rather abruptly into cylindrical part, which is twice its length; and 3) spicules very large and different in shape.
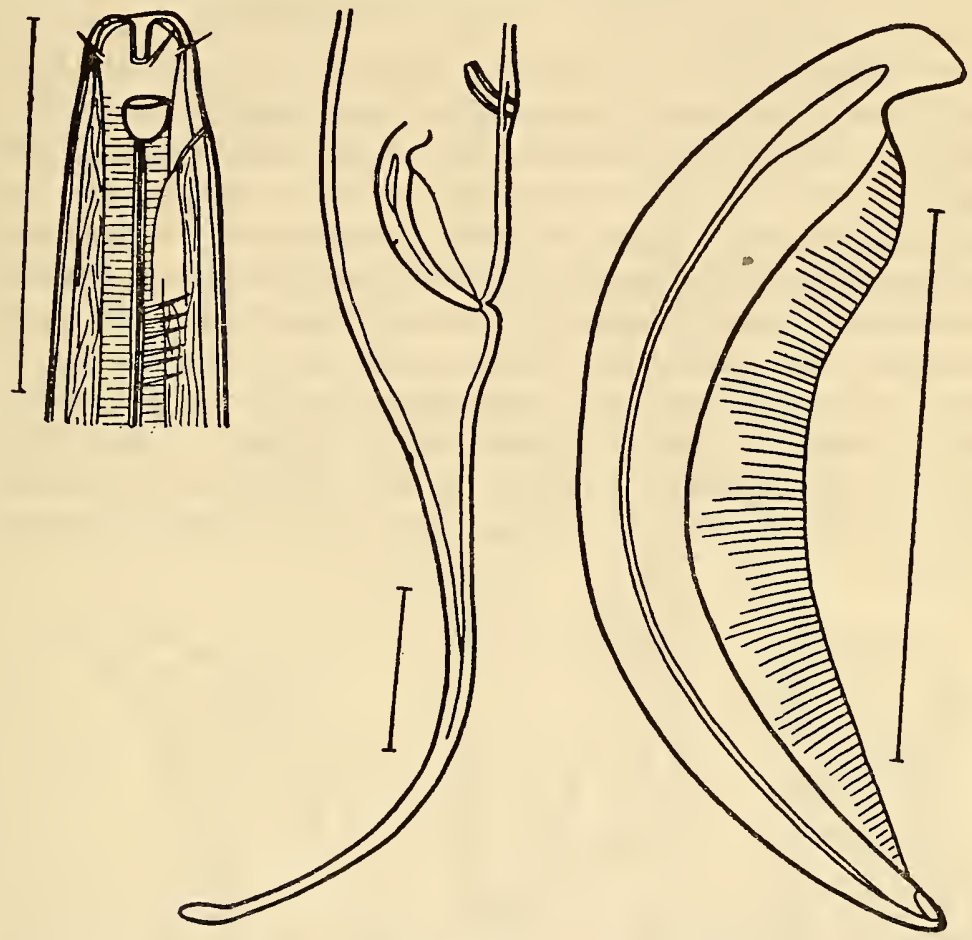

Figure 67. Anticoma uschakovi sp. nov.

Geographic distribution. Found in the Bay of Nagaev (Sea of Okhotsk) at a depth of $27 \mathrm{~m}$ among pebbles and silt.

55. Anticoma pacifica sp. nov. (Figure 68)

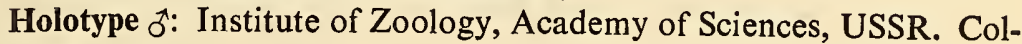
lection No. 7931.

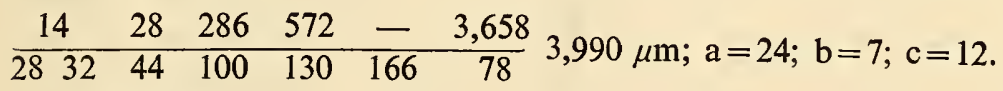

Paratypes.

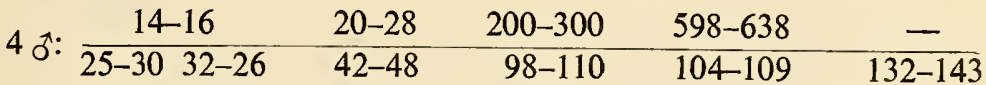

$$
\begin{aligned}
& \times \frac{3,125-3,524}{72-78} 4,055-4,414 \mu \mathrm{m} ; \mathrm{a}=31-32 ; \mathrm{b}=6-8 ; \mathrm{c}=14-17 \text {. }
\end{aligned}
$$




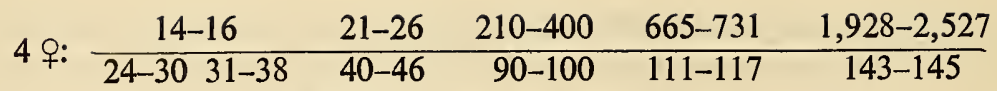

$$
\begin{aligned}
& \times \frac{4,455-5,785}{57-72} 4,774-6,104 \mu \mathrm{m} \text {; } \\
& a=32-42 ; b=7-9 ; c=15-19 ; V=40-42 \% \text {. }
\end{aligned}
$$

Body tapers to $2 / 9$ to $1 / 5$ midbody diameter at anterior end. Head anteriorly truncated. Length of cylindrical part of tail about equal to conical part. Distinct bulge evident at tip of tail. Cuticle $6.0 \mu \mathrm{m}$ thick. Cephalic capsule with rather thick walls; width 2.5 length. Amphids small, longitudinally elongated, and only $6.0 \mu \mathrm{m}$ wide $(1 / 3$ to $1 / 4$ corresponding neck diameter). Length of cephalic setae $12 \mu \mathrm{m}$ (slightly less than $1 / 2$ corresponding head diameter). Five cervical setae situated two cephalic diameters from anterior end. Renette short, pore opens at level of amphids. Oral cavity developed. Oral opening encircled by distinct lips. Nerve ring encircles esophagus more or less at midlength. Vulva slightly anterior to midbody length. Length of anterior female genital tube 480 $\mu \mathrm{m}$, of posterior tube $500 \mu \mathrm{m}$. Two to seven eggs, varying in size (114 to

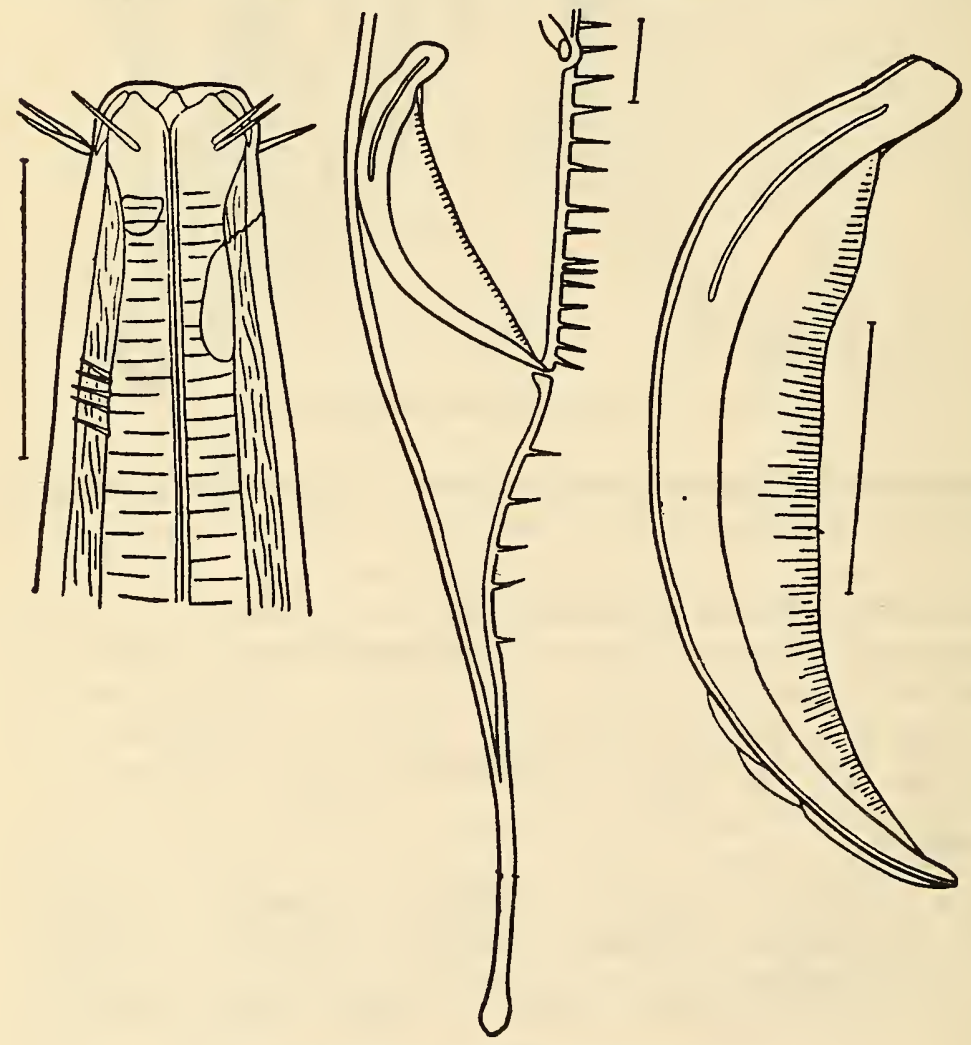

Figure 68. Anticoma pacifica sp. nov. 
$135163 \mu \mathrm{m} \times 80 \mu \mathrm{m}$ and 60 to $80 \mu \mathrm{m} \times 140 \mu \mathrm{m}$ ), observed in genital tract of females. Spicules without capituli but with transversely striated velum; length of spicules 140 to $160 \mu \mathrm{m}$. Gubernaculum narrow and thin. Accessory organ 130 to $160 \mu \mathrm{m}$ anterior to anus. Anal region of male armed with setae $13 \mu \mathrm{m}$ long. Twenty pairs of preanal setae present, two pairs postanal, and single seta on tail.

Distinguishing features of this species: 1) presence of lips; 2) large size of body; 3) presence of anal setae in male; and 4) transverse striations on velum.

Geographic distribution. Found on the southern coast of Sakhalin in the Gulf of Aniva at a depth of $15 \mathrm{~m}$ among pebbles and fine sand.

56. Anticoma pontica Filipjev, 1918 (Figure 69)

Filip'ev, 1918: 66-69, tab. 2, fig. 6.

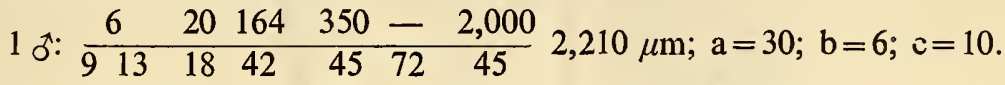

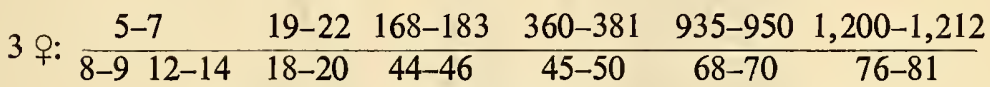

$$
\begin{aligned}
& \times \frac{1,525-1,562 \quad 2,256-2,298}{72-80} 2,561-2,611 \mu \mathrm{m} \text {; } \\
& a=32-33 ; b=6-7 ; c=8 ; V=46-47 \% \text {. }
\end{aligned}
$$

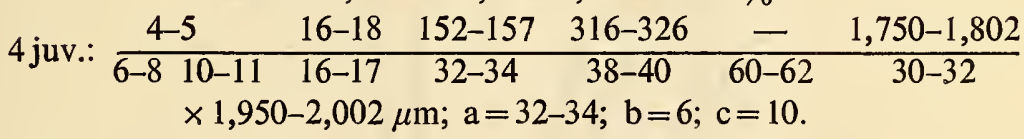

Body tapers to $1 / 9$ to $1 / 10$ midbody diameter at anterior end and $2 / 3$ to $1 / 2$ at posterior end. Head anteriorly round with slight flattening. Tail of female slightly longer than that of male. Narrow cylindrical part of 136 tail equal in length to conical part. Cuticle $1.2 \mu \mathrm{m}$ thick. Cephalic capsule poorly developed and barely distinguishable. Amphids round and $4.0 \mu \mathrm{m}$ in diameter ( $1 / 4$ corresponding neck diameter). Length of cephalic setae $7.0 \mu \mathrm{m}(1 / 2$ corresponding head diameter); five cervical setae commence three cephalic diameters from anterior end. Renette situated at posterior end of esophagus, with an extremely long duct opening 1.5 cephalic diameters from anterior end. Oral cavity small. Nerve ring encircles esophagus slightly anterior to its midlength. Length of anterior female genital tube 262 to $265 \mu \mathrm{m}$, of posterior tube 325 to $350 \mu \mathrm{m}$, and of reflexed parts 200 to $220 \mu \mathrm{m}$ and 300 to $320 \mu \mathrm{m}$ respectively. One egg, $75 \mu \mathrm{m} \times$ $42 \mu \mathrm{m}$, seen in genital tract of one female. Spicules $80 \mu \mathrm{m}$ long and curve mainly in anterior third. Capitulum of spicules elongated and rectangular. Velum located on ventral side of spicule. Gubernaculum small, $30 \mu \mathrm{m}$, envelops distal end of spicules, and broadens distally. Accessory organ situated $90 \mu \mathrm{m}$ anterior to anus. 
As noted by Filip'ev (1918), this species is very close to $A$. pellucida but differs in: 1) almost round amphids (longitudinally elongated in $A$. pellucida);2) excretory pore of renette situated relatively close to anterior end; 3) spicules significantly narrower, not so sharply curved, and with a rectangular capitulum and velum. Gubernaculum without ventral process and accessory organ situated at level of spicular capitulum (in

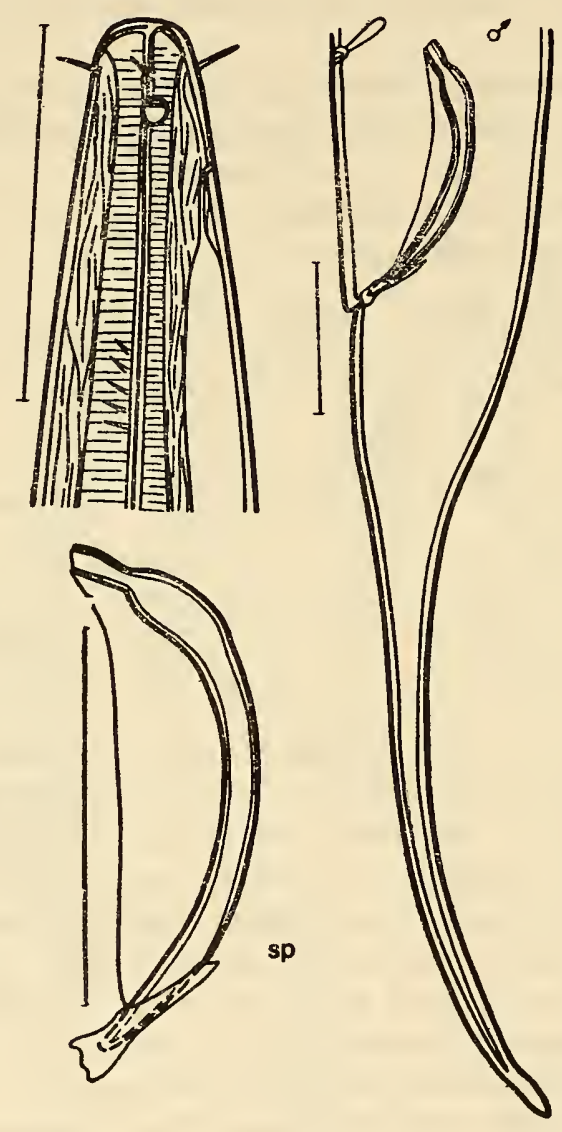

Figure 69. Anticoma pontica.

A. pellucida spicules sharply curved in middle part, their capitulum rounded, and ventral velum absent). Gubernaculum with ventral process. Accessory organ situated two anal diameters from anus.

Geographic distribution. Possibly endemic to the Black Sea as has not been found beyond this limit. 
57. Anticoma platonovae Sergeeva, 1972 (Figure 70)

Sergeeva, 1972: 1233, 1234, fig. 1 (description).

$$
\begin{aligned}
& 3 \text { o }: \begin{array}{cccccc}
- & 195-222 & 240-259 & 565-607 & - & 1,907-2,124 \\
\hline 5-6 & 32-34 & 34-46 & 45-48 & 49-52 & 34-38
\end{array} \\
& \times 2,008-2,254 \mu \mathrm{m} ; \mathrm{a}=42-44 ; \mathrm{b}=3-4 ; \mathrm{c}=17-20 \text {. }
\end{aligned}
$$

Nematodes of average size. Body tapers to $1 / 8$ to $1 / 9$ midbody diameter at anterior end and 5/7 at posterior end. Cuticle smooth and $1.9 \mu \mathrm{m}$ thick. Head anteriorly rounded. Cephalic setae short. Cervical setae and amphids situated $14 \mu \mathrm{m}$ from anterior end (2.1 cephalic diameters). Size of amphids $5.0 \mu \mathrm{m}$. Excretory pore of cervical glands opens not less than 32.8 to 37.5 cephalic diameters from anterior end, and $45.5 \mu \mathrm{m}$ anterior to nerve ring. Nerve ring encircles esophagus 42.2 to $44.8 \mu \mathrm{m}$ anteriorly from its midlength. Oral cavity undeveloped. Esophagus widens toward base. Spicules curved in first and last quarters. Dorsal side of spicules smooth. On ventral side spicular capitulum forms a platform with a triangular process at its base. Velum extends from capitular tip. Guber-
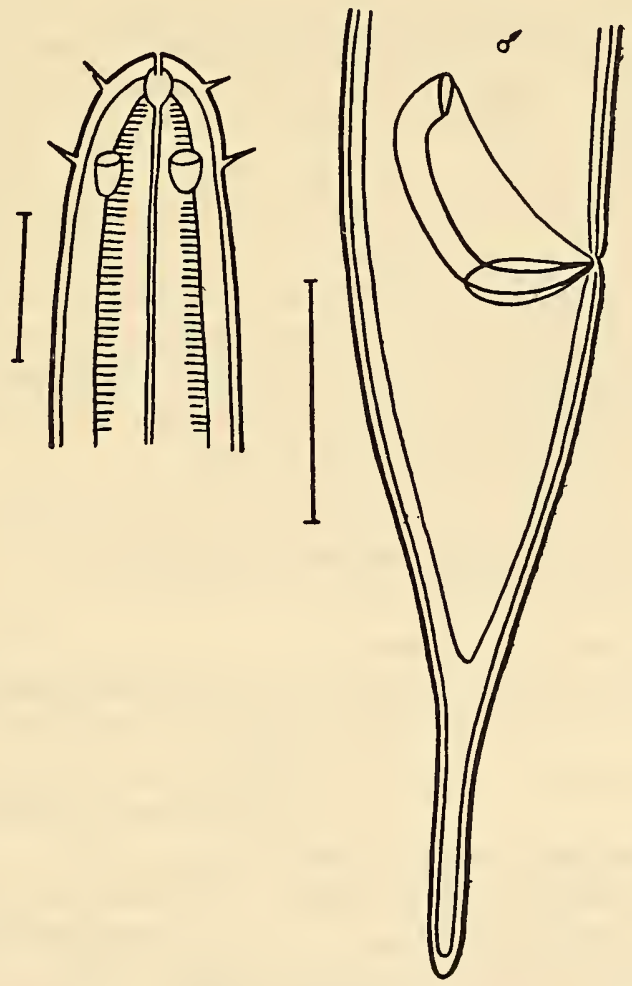

Figure 70. Anticoma platonovae (from Sergeeva, 1972). 
naculum foliate and contiguous. Length of spicules $45.5 \mu \mathrm{m}$, of gubernaculum $17.0 \mu \mathrm{m}$. Two to three preanal setae present in male; accessory organ absent. Tail short; cylindrical part $5 / 7$ of conical part.

Geographic distribution. Found in the Black Sea on the western coast (at a depth of $83 \mathrm{~m}$ in phaseolin silt), the southern coast (region of Yalta city in a depth range of 50 to $130 \mathrm{~m}$ in medium and phaseolin silts), and along the coast of Crimea.

A. reflexa Linstow, 1896, A. filicauda Mawson, 1956, and A. calveti Rouville, 1903 have not been included in the identification key due to their extremely brief and incomplete descriptions. A. longicauda Kreis, 1928 was described on the basis of females and the author assumed it might coincide with some known species in the future. $A$. brevicauda Kreis, 1963 was described on the basis of a sexually immature specimen, precluding its inclusion in the identification key.

\section{Subfamily Platycominae subfam. nov.}

Nematodes of average size. Body does not taper toward both ends as much as in representatives of previous subfamily. Some forms with well-developed labial cuticular outgrowths. Cephalic setae long. Cervical setae numerous and situated in clusters or transverse rows. Amphids usually large; their structure tends to indicate sexual dimorphism: in males amphids significantly larger or with more complex configuration than in females. Renette not developed. Nerve ring situated at approximately midlength of esophagus. Tail rather short and wide, often pointed at end. Spicules usually small or reduced; gubernaculum highly developed, almost double spicular length. Additional copulatory armature always present and represented by one to two papillate accessory organs. Postanal papillae with setae may also be present.

1 (4). Lips with cuticular outgrowths.

2 (3). Two flat setae situated near each amphid...Platycoma Cobb, 1894. (one species, P. cephalata Cobb, 1894).

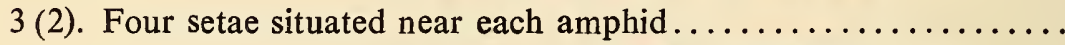
10. Platycomopsis Ditlevsen, 1926.

4 (1). Lips without cuticular outgrowths.

5 (6). Gubernaculum with dorsal process. Amphids in males differ in shape from those in females.......... Proplatycoma gen. nov.

6 (5). Gubernaculum without process. Amphids in males same shape as in females, but larger............... Pilosinema gen. nov. 
Ditlevsen, 1926: 30; Filip'ev, 1927: 81 (Dactylonema).

Type species: $P$. cobbi Ditlevsen, 1926.

Head demarcated from body by a distinct cervical constriction. Tail short, wide, and obtusely rounded or conical. Lips with cuticular outgrowths. Transverse row of four long setae situated posterior to each amphid. Slightly posterior to these, two subdorsal and subventral setae occur. Belt of granular cells situated in anterior part of body. Amphids very large, goblet-shaped. Spicules short. Gubernaculum curves slightly, without process. Accessory organ small, shifted rather far anterior to anus.

In the descriptions of species numbers in Cobb's formula denote distance from anterior end to: 1 . posterior end of cephalic capsule; 2 . amphids; 3 . nerve ring; 4 . base of esophagus; 5 . commencement of anterior genital tube; 6. vulva; and 7. commencement of posterior genital tube. Number of figures in formula fewer for males (see earlier explanation).

\section{Key to Species of Genus Platycomopsis}

1 (2). Cephalic setae thin; length equal to cephalic diameter......... ........................... cobbi Ditlevsen, 1926.

2(1). Cephalic setae thick; length not more than two-thirds cephalic diameter.

3 (4). Width of amphids exceeds one-half of corresponding diameter.... .58 P. mesjatzevi Filipjev, 1927.

4 (3). Width of amphids less than one-third of corresponding diameter.. .P. nuchapilosus Vitiello, 1970.

58. Platycomopsis mesjatzevi (Filipjev, 1927) (Figure 71)

Filip'ev, 1927: 82-84, pl. I, fig. 10a-c (Dactylonema).

Lectotype f: $^{*}$ Institute of Zoology, Academy of Sciences, USSR. Collection No. 7174.

\begin{tabular}{cccccc}
17 & 23 & 463 & 1,235 & - & 6,436 \\
\hline $23-32$ & 34 & 142 & 202 & 244 & 150
\end{tabular} 6,$648 \mu \mathrm{m} ; \mathrm{a}=27 ; \mathrm{b}=5 ; \mathrm{c}=31$.

Paralectotypes.

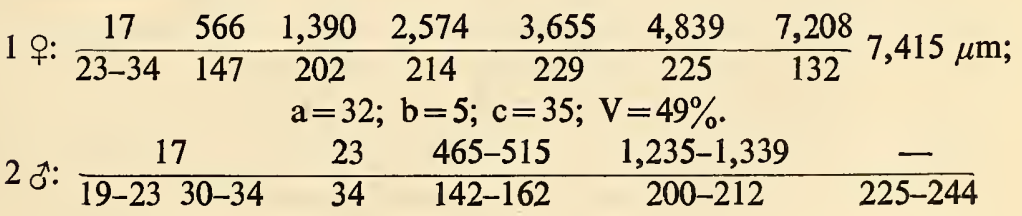




$$
\begin{aligned}
& \times \frac{6,436-7,261}{132-150} 6,648-7,441 \mu \mathrm{m} ; \mathrm{a}=27-32 ; \mathrm{b}=5-6 ; \mathrm{c}=31-41 \text {. }
\end{aligned}
$$

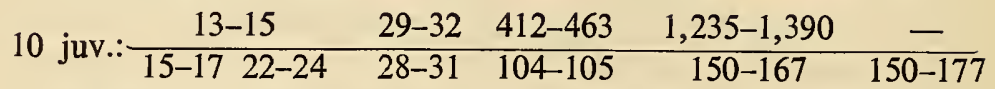

$$
\begin{aligned}
& \times \frac{4,892-5,870}{70-100} 5,042-6,040 \mu \mathrm{m} ; \mathrm{a}=25-34 ; \mathrm{b}=5-6 ; \mathrm{c}=33-38 \text {. }
\end{aligned}
$$

Body tapers to $1 / 6$ to $2 / 13$ midbody diameter at anterior end and $5 / 8$ to $10 / 17$ at posterior end. Cephalic end rounded. Tail conical, rounded at tip. Cephalic capsule thin-walled, tapers slightly anteriorly, and width twice greater than length. Narrow cephalic ring situated in middle of cephalic capsule. Cephalic suture very narrow and barely distinguishable. Cuticle bilayered and 6.0 to $8.0 \mu \mathrm{m}$ thick; thickness of outer layer $4.0 \mu \mathrm{m}$. Oral opening with three sclerotized lips. Cephalic setae thick and long, 19 to $25 \mu \mathrm{m}$ (1.5 corresponding head diameter). Cervical setae slightly thinner and shorter, 15 to $17 \mu \mathrm{m}$. Anal setae absent. Extremely large amphids, transversely elongated, situated $23 \mu \mathrm{m}$ from anterior end (1/6 esophageal length). Length of amphids $6.0 \mu \mathrm{m}$ and width $17.4 \mu \mathrm{m}(1 / 2$ corresponding neck diameter). Three minute denticles situated in anterior part of small oral cavity. Esophagus dilates slightly anteroposteriorly and only at very base forms rather significant dilatation. Nerve ring situated slightly posterior to midesophagus. Vulva situated anterior to midbody; cuticle around it with sclerotized granules. Spicules extremely short ( $60 \mu \mathrm{m}$ long), wide, uniform in width throughout their length, and bluntly rounded at proximal end. Gubernaculum paired, 137 to $160 \mu \mathrm{m}$

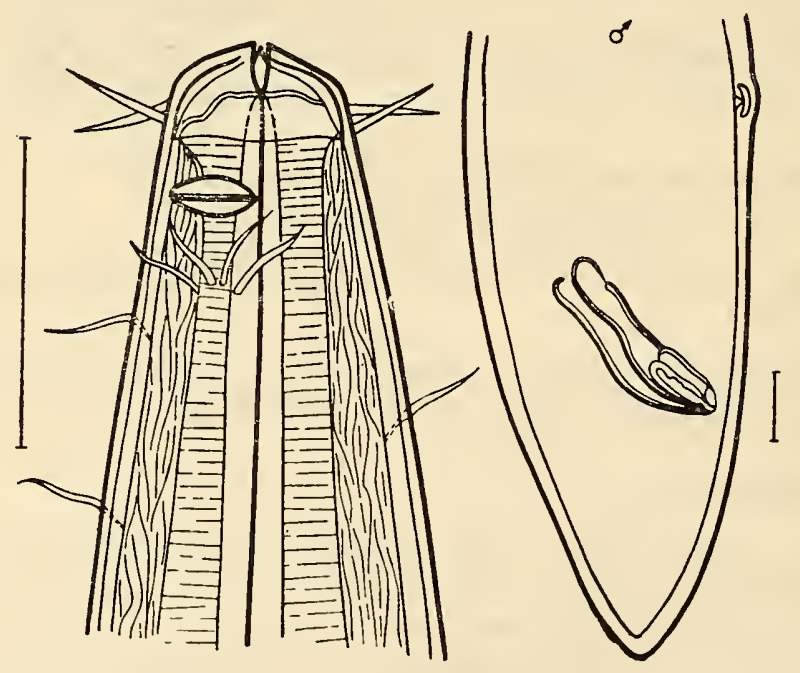

Figure 71. Platycomopsis mesjatzevi. 
long, faintly curved, and narrows perceptibly in middle part. Accessory organ situated 229 to $280 \mu \mathrm{m}$ anterior to anus.

Distinguishing features of this species: 1) extremely large amphids, elongated in transverse direction; 2) cephalic setae thick and long, exceeding corresponding diameter in length; 3) presence of group of four long setae situated behind each amphid; 4) narrow cephalic ring situated in middle of cephalic capsule; 5) presence of sclerotized granules in female on cuticle around vulva; and 6) conical tail rounded at tip.

Geographic distribution. Known only from the Barents Sea where it was found in a depth range of 30 to $200 \mathrm{~m}$ in silted sand.

\section{Genus Proplatycoma gen. nov.}

Type species: Platycoma sudafricana Inglis, 1966.

Nematodes characterized by sharp sexual dimorphism in structure of amphids. In female amphids typically cyathiform but slightly elongated 140 in longitudinal direction. In male anterior end of amphids elongated anteriorly and sometimes with unique processes. Cuticular labial outgrowths absent. Cervical setae may be numerous and may be scattered over the preneural region in groups or singly.

Spicules small, blunt, and reduced. Gubernaculum significantly longer than spicules, curved in the middle, with large blunt dorsal process. Tail wide, terminally acicular.

Key to Species of Genus Proplatycoma gen. nov.

1 (2). Anterior part of amphids in male branched...............

2 (1). Anterior part of amphids in male unbranched.

3 (4). Anterior part of amphids in male conically pointed........... P. africana (Gerlach, 1959).

4 (3). Anterior part of amphids in male arrow-shaped............ P. sudafricana (Inglis, 1966).

Genus Pilosinema gen. nov.

Type species: Platycomopsis filiappendicatus Micoletzky, 1930.

Nematodes devoid of cuticular labial outgrowths. Characteristic sexual dimorphism. Amphids in male much larger than in female. Cervical setae situated in transverse rows behind amphids: three rows in male and two in female. In addition, small groups of setae scattered over preanal region. Spicules and gubernaculum straight and simple. Usually spicular apparatus difficult to detect. Accessory organ small and papil- 
late. Tail distinctly divided into wide conical part and narrow cylindrical part which, however, may be extremely short.

Key to Species of Genus Pilosinema gen. nov.

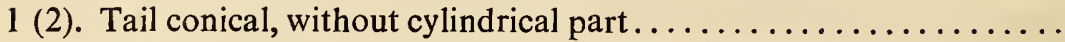

P. paracobbi (Mawson, (1956).

2 (1). Tail conical, with cylindrical terminal part.

3 (4). Conical part of tail twice length of cylindrical part. Accessory organ of male two spicular lengths anterior to anus............

P. filiappendicatus (Micoletzky, 1930).

4 (3). Conical part of tail thrice length of cylindrical part. Accessory organ of male one spicular length anterior to anus ............

.P. dimorphica (Mawson, 1956).

\section{Subfamily BARBONEMATINAE subfam. nov.}

Rather small nematodes. Body tapers markedly toward anterior end; tapering may be gradual or with abrupt constriction in preneural part. Tail tapers gradually and is rather slender. Oral cavity and lips not developed. Long cephalic setae arranged in two, three, or four circles. Cervical setae usually shorter than cephalic ones and quite sparse. Amphids observed in only one of the species described. Renette apparently absent. Position of nerve ring could not be determined. Spicules small and curved. Gubernaculum reduced. Accessory organ absent.

141 Probably the peculiarity of arrangement of cephalic setae made Gerlach $(1956,1957)$ transfer Barbonema to Oxystominidae. This appears questionable to me since in the type species ( $B$. setifera, described by Filip'ev) the amphids have an entirely different shape than those in oxystominids. In the species described by Gerlach-B. horridum and $B$. flagrum -nothing is said about the structure of the amphids. These two species very much resemble each other in structure of the cephalic end and arrangement of setae, but differ greatly from $B$. setifera, so much so that they warrant placement in an independent genus. The structure of the spicular apparatus, however, brings $B$. horridum close to B. setifera.

Due to the fact that only the three species mentioned above are known at present, it seems advisable to me to postpone division of Barbonema until the discovery of a larger number of forms permits an improvement in the taxonomic system of barbonematines. 
Filip'ev, 1927: 81 (description).

Body tapers markedly toward anterior end. Head devoid of lips and oral capsule; armed with ten well-developed setae and one seta with a pyriform base situated posterior to the others. Lateral organ saccate. Spicules of male curved.

*59. Barbonema setifera Filipjev, 1927 (figure 72)

Filip'ev, 1927: 81, pl. 2, fig. 6a-c; (description).

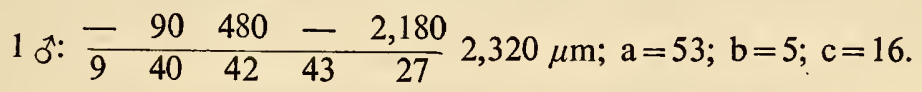

Body slender, filiform. Tail long, filiform, with a terminal bulge. Caudal length $52 \mu \mathrm{m}$; diameter at caudal end $0.23 \mu \mathrm{m}$. Cuticle smooth, thin, and 1.0 to $1.5 \mu \mathrm{m}$ thick. Head round; lips and papillae absent. Cephalic setae very long, $25 \mu \mathrm{m}$ (three cephalic diameters); four setae slightly more posterior than remaining six. Amphids situated immediately behind pyriform seta. Cardia very small. Intestine rudimentary. Spicules curved, S-shaped, flat in proximal part, and $35 \mu \mathrm{m}$ long. Gubernaculum and accessory organ absent.

Geographic distribution. Found only in the Barents Sea at a depth of $200 \mathrm{~m}$ in silted sand.

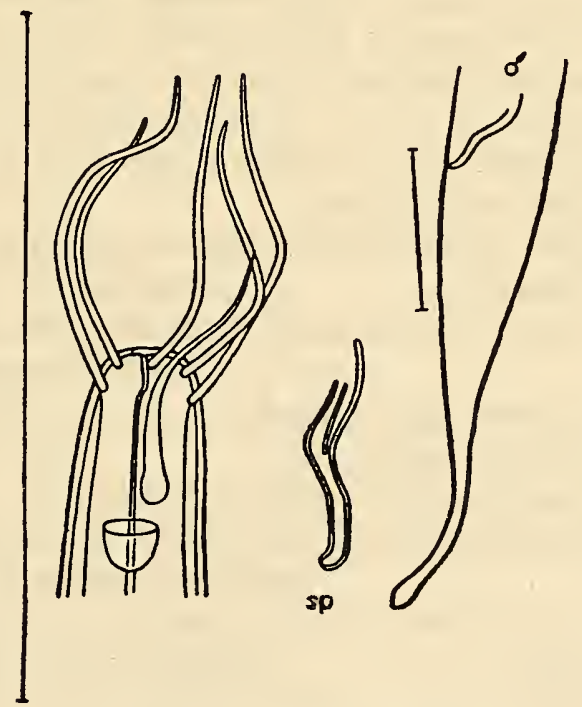

Figure 72. Barbonema setifera

(from Filip'ev, 1927). 


\section{Superfamily ENOPLOIDEA Baird, 1853}

Sclerotized cephalic capsule not developed in most representatives. Oral capsule in most cases well developed and divided into buccal and onchial parts, as a result of which armature of oral cavity represented not 142 only by onchia, but also by powerful jaws or buccal stylets-derivatives of buccal cavity. Entire esophageal musculature at anterior end of body, compared with that of Leptosomatoidea, appears markedly displaced posteriorly. Alveolate structure often observed in posterior half of esophagus. Cuticle similar in structure to that in representatives of superfamily Leptosomatoidea but significantly thinner. Amphids round or cyathiform.

\section{Key to Families of Superfamily Enoploidea}

1 (6). Oral cavity well developed, with powerful sclerotized lining, and of ten armed with well-developed onchia.

2( 3). Oral opening encircled by well-developed protruding lips; internal surface of latter often with distinct cuticular striations....

3 ( 2). Well-developed protruding lips absent.

4 ( 5). Sclerotized annular thickenings present on wall of oral cavity. Sexual dimorphism seen in structure of oral cavity. Latter absent in males of a number of forms.................. ................. Enchelidiidae Filipjev 1918 (part.).

5 (4). Annular thickenings on walls of oral cavity absent. Sexual dimorphism not observed in structure of oral cavity......... ................... Oncholaimidae (Perrier, 1897).

6( 1). Oral cavity less distinct; wall poorly sclerotized.

7 (10). Oral cavity armed with jaws.

8 (9). Three distinct onchia present, of which one significantly larger than remaining two......... Oxyonchidae de Coninck, 1965.

9 ( 8). Onchia absent; if present, small and uniform in length........ ................................... 1853.

10 ( 7). Oral cavity unarmed; if armed, only buccal stylets present or structures similar to them.

11 (14). Cephalic capsule well developed and conical.

12 (13). Onchial plates twisted into tubes which look like spears in lateral view............. Thoracostomopsidae Filipjev, 1927.

13 (12). Oral cavity with another type of armature, more often three small onchia.............Phanodermatidae Filipjev, 1927.

14 (11). Cephalic capsule not developed or insignificantly developed and different in shape.

15 (16). Esophagus commences at a notable distance from anterior end 
of body and buccal stylets situated anterior to it.......... Dayeliidae fam. nov.

16 (15). Esophagus commences at anterior end; buccal stylets absent.

17 (18). Esophagus alveolate in posterior half. Spicules thin and long. 3. Crenopharingidae fam. nov.

18 (17). Esophagus not alveolate. Spicules short............... ..Enchelidiidae Filipjev, 1918.

(males of some genera).

3. Family CRENOPHARYNGIDAE fam. nov.

Body fusiform due to tapering toward anterior and posterior ends. Tail divided into wide conical and narrow cylindrical parts. Cephalic capsule almost undeveloped. Oral cavity small; onchial part absolutely undeveloped and buccal part poorly developed. Cephalic setae arranged in single circle. Renette present. Amphids always cyathiform.

On the basis of the foregoing characters this family resembles Anticomidae. Nevertheless a series of extremely substantial features prompted me not only to isolate Crenopharyngidae in an independent family, but even to transfer it to another superfamily.

Spicules in crenopharyngids extremely long and narrow. Accessory organ absent. Esophagus with alveolate structure in posterior half.

The family comprises two genera.

\section{Key to Genera of Family Crenopharyngidae}

1 (2). Two well-defined eyes present in preneural area............. ....................... Nasinema Filipjev, 1927. 2 (1). Eyes always absent.........12. Crenopharynx Filipjev, 1934.

\section{Genus Crenopharynx Filipjev, 1934}

Linstow, 1900: 128 (Anoplostoma); Southern, 1914: 23 (Stenolaimus non Marion, 1870); Filip'ev, 1934a: 9.

Type species: Anoplostoma gracile Linstow, 1900.

Cephalic capsule very poorly developed, with narrow cephalic ring. Lips encircling oral opening poorly developed. Labial papillae very small. Cervical setae either irregularly scattered over preneural part or totally absent. Amphids usually small, round, and situated in region of cephalic suture. Tail long; cylindrical part usually filiform. Spicules very long and narrow, with small and distinct capituli. Gubernaculum small, often with process directed dorsally. Eyes absent.

In descriptions of species of genus Crenopharynx figures in Cobb's 
formula denote distance from anterior end of body to the following organs: 1. posterior end of cephalic capsule; 2 . nerve ring; 3 . base of esophagus; 4 . commencement of anterior genital tube; 5 . vulva; 6 . commencement of posterior genital tube; and 7. anus.

Number of figures for males fewer than for females (see p. 74).

\section{Key to Species of Genus Crenopharynx}

1 ( 2). Well-defined dilatation at distal end of spicules.............

2( 1). Dilatation on distal end of spicules absent.

3 ( 8). Cervical setae present.

4 ( 5). Filiform cylindrical part of tail constitutes two-thirds of total caudal length..C. paralepturus (Schuurmans-Stekhoven, 1950).

5 (4). Filiform cylindrical part of tail constitutes not more than onehalf of total caudal length.

6( 7). Body narrow $(a=50-60)$

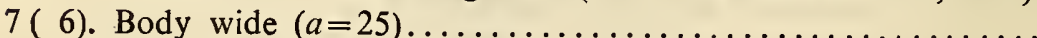

C. metagracilis (Schuurmans-Stekhoven, 1950).

8 ( 3). Cervical setae absent.

9 (10). Oral cavity armed with onchia......62. C. armatus sp. nov.

10 ( 9). Oral cavity without onchia.

11 (12). Cephalic setae not longer than one-third corresponding diameter................. antarcticus (Allgen, 1929).

12 (11) Cephalic setae significantly long, constituting not less than onehalf corresponding diameter.

14413 (14). Conical part of tail narrows abruptly into filiform cylindrical part................. crassus (Ditlevsen, 1930).

14 (13). Conical part of tail reduces gradually into filiform cylindrical part.

15 (18). Male with preanal setae.

16 (17). Tail long ( $c=$ about 13)....660. C. marioni (Southern, 1914).

17 (16). Tail significantly short ( $c=$ about 19)...... C. eina Inglis, 1964.

18 (15). Male without preanal setae........... afra Inglis, 1964.

60. Crenopharynx marioni (Southern, 1914) (Figure 73)

Southern, 1914: 23, tab. 4, fig. 12a-b; Ditlevsen, 1926: 10-11, pl. II, fig. 5, pl. III, figs. 3, 8, pl. IV, figs. 4, 5, pl. V, fig. 2, pl. VI, fig. 1; Schuurmans-Stekhoven, 1935a: 7, fig. 67, 1946: 32-33, fig. 7a-d; Allgen. 1954a: 12-13; 1957b: 6 (Stenolaimus). 


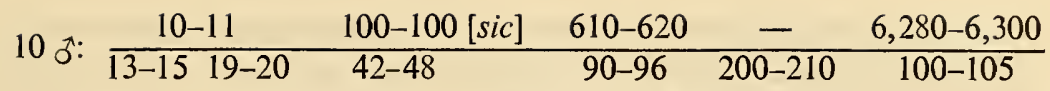

$$
\begin{aligned}
& \times 6,690-6,700 \mu \mathrm{m} ; \mathrm{a}=30-34 ; \mathrm{b}=6 ; \mathrm{c}=13-16 \text {. }
\end{aligned}
$$

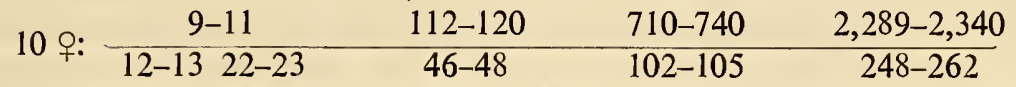

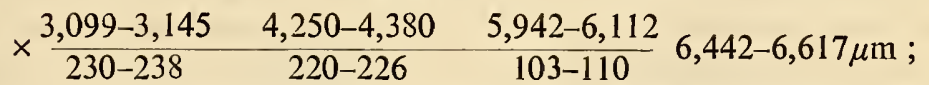

$$
\begin{aligned}
& a=26-29 ; b=6 ; c=13-15 ; V=45-47 \% \text {. } \\
& 10 \text { juv.: } \begin{array}{cccccc}
9-10 & 95-100 & 450-480 & - & 4,203-4,305 \\
\hline 12-13 & 13-17 & 38-40 & 60-70 & 170-192 & 80-100
\end{array} \\
& \times 4,503-4,607 \mu \mathrm{m} ; \mathrm{a}=24-26 ; \mathrm{b}=5 ; \mathrm{c}=12-15 \text {. }
\end{aligned}
$$

Body tapers to $1 / 14$ to $1 / 17$ midbody diameter at anterior end and $1 / 2$ at posterior end. Tail long, with bulge at terminus; narrow cylindrical part somewhat longer than conical part. Cephalic capsule relatively well developed; width twice length. Cuticle thick, $5.8 \mu \mathrm{m}$. Cephalic

145 setae long, $11.6 \mu \mathrm{m}(1 / 2$ corresponding head diameter). Setae absent in esophageal region. Setae $8.0 \mu \mathrm{m}$ long, sparse in anal region. Amphids situated immediately behind lateral cephalic setae and slightly elongated longitudinally; diameter of amphids $4.6 \mu \mathrm{m}$ (1/5 corresponding neck diameter). Cervical glands situated asymmetrically: one opens two cephalic diameters, and the other five cephalic diameters from anterior end. Oral cavity small, funnel-shaped, with thickly sclerotized walls. Nerve ring
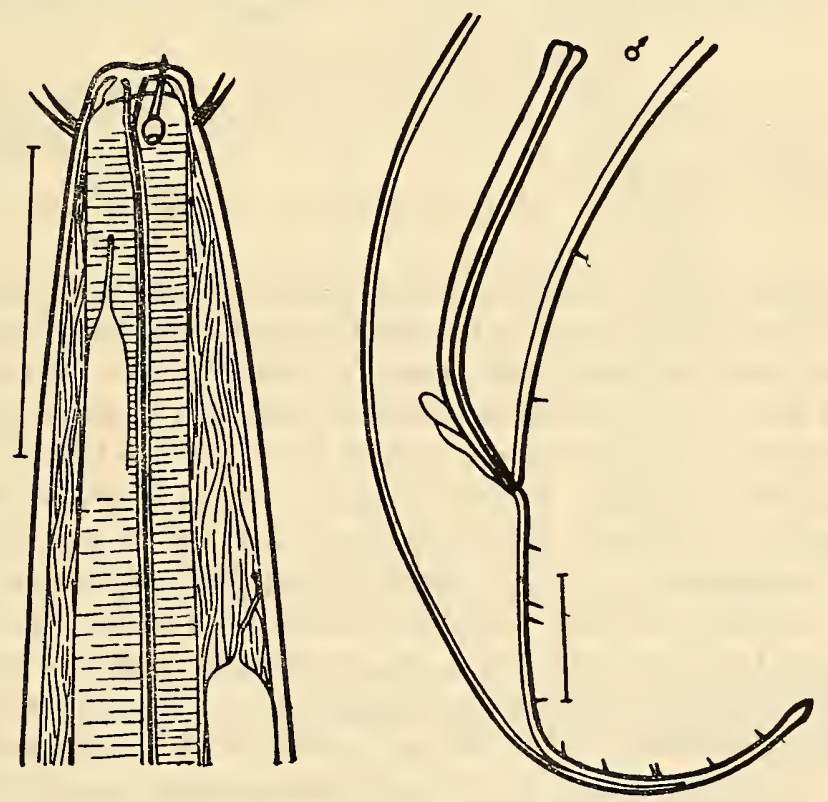

Figure 73. Crenopharynx marioni. 
encircles esophagus somewhat posterior to its midlength. Length of anterior female genital tube 805 to $824 \mu \mathrm{m}$, of posterior tube 1,151 to 1,236 $\mu \mathrm{m}$, and of reflexed parts 515 to $610 \mu \mathrm{m}$ and 721 to $880 \mu \mathrm{m}$ respectively. Vulva situated slightly anterior to midbody. Two to eight eggs, 154 to $185 \mu \mathrm{m} \times 123 \mu \mathrm{m}$, observed in genital tracts. Spicules almost equal in width throughout their length, with just a small bulge at proximal end and attenuate at distal end; length $357 \mu \mathrm{m}$. Gubernaculum simple; length $102 \mu \mathrm{m}$.

Distinguishing features of this species: 1) body tapers markedly toward anterior end; 2) long cephalic setae (length not less than $1 / 2$ corresponding diameter); 3) absence of setae in preneural region and presence in anal region; and 4) amphids slightly longitudinally elongated.

Geographic distribution. Arctico-boreal species. Found in the Arctic seas, north Atlantic Ocean, and western part of the Baltic sea. In seas around the Soviet Union, it has been found in the Barents near the coast of Novaya Zemlya in a depth range of 3 to $50 \mathrm{~m}$ in sandy and silty substrata and in the Laptev at a depth of $19 \mathrm{~m}$ in sand.

*61. Crenopharynx gracilis (Linstow, 1900) (Figure 74)

Linstow, 1900: 128, tab. 7, figs. 42, 43 (Anoplostoma); Filip'ev, 1927: 119, 120, pl. I, fig. 29a-e (Stenolaimus) (description).

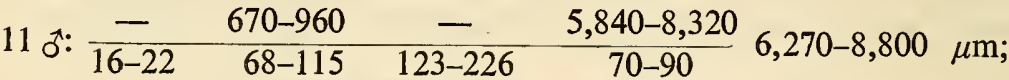

$$
\begin{aligned}
& a=35-36 ; b=3-5 ; c=13-19 \text {. } \\
& 12 \text { ㅇ: } \begin{array}{crccc}
- & 540-950 & 2,690-4,170 & 3,360-5,310 & 3,720-6,060 \\
\hline 17-20 & 72-172 & - & - & 120-224
\end{array} \\
& \times \frac{3,960-6,610 \quad 5,530-8,740}{-} 6,030-9,200 \mu \mathrm{m} ; \mathrm{a}=36-54 ; \mathrm{b}=4 ; \mathrm{c}=12-20 \text {. }
\end{aligned}
$$

Body fusiform. Tail uniform in shape in male but conical in proximal part and filiform in distal part in female. Cuticle $4.0 \mu$ m thick midbody and $2.0 \mu \mathrm{m}$ thick in anterior part. Lone cervical setae situated anterior to cervical pore. Head truncated, flattened anteriorly. Labial papillae well developed. Cephalic setae rather short, 8.0 to $10.0 \mu \mathrm{m}$ long (slightly less than cephalic diameter). Amphids large, $4.0 \mu \mathrm{m} \times 5.0 \mu \mathrm{m}$, and situated sublaterally. Oral cavity poorly developed and visible only on con-

146 traction of esophageal muscle. Esophageal glands fine; dorsal one opens at base of cephalic setae, and remainder open between cephalic setae and cervical pore. Cervical gland round, $110 \mu \mathrm{m}$ long, and situated in posterior part of esophagus, with pore opening at 110 to $140 \mu \mathrm{m}$ from anterior end. Spicules slender, 325 to $440 \mu \mathrm{m}$ long (4.2 to 6.0 anal diameter), uniform in width throughout their straight proximal part, curved in last quarter, greatly broadened, but terminally become acicular. Guberna- 
culum approximately equal to anal diameter and consists of two plates, which encircle terminal part of spicules from dorsal side; distal part of gubernaculum more complex and encircles spicules from lateral sides. Two to six eggs, 196 to $260 \mu \mathrm{m} \times 10$ to $170 \mu \mathrm{m}$, found in uteri.
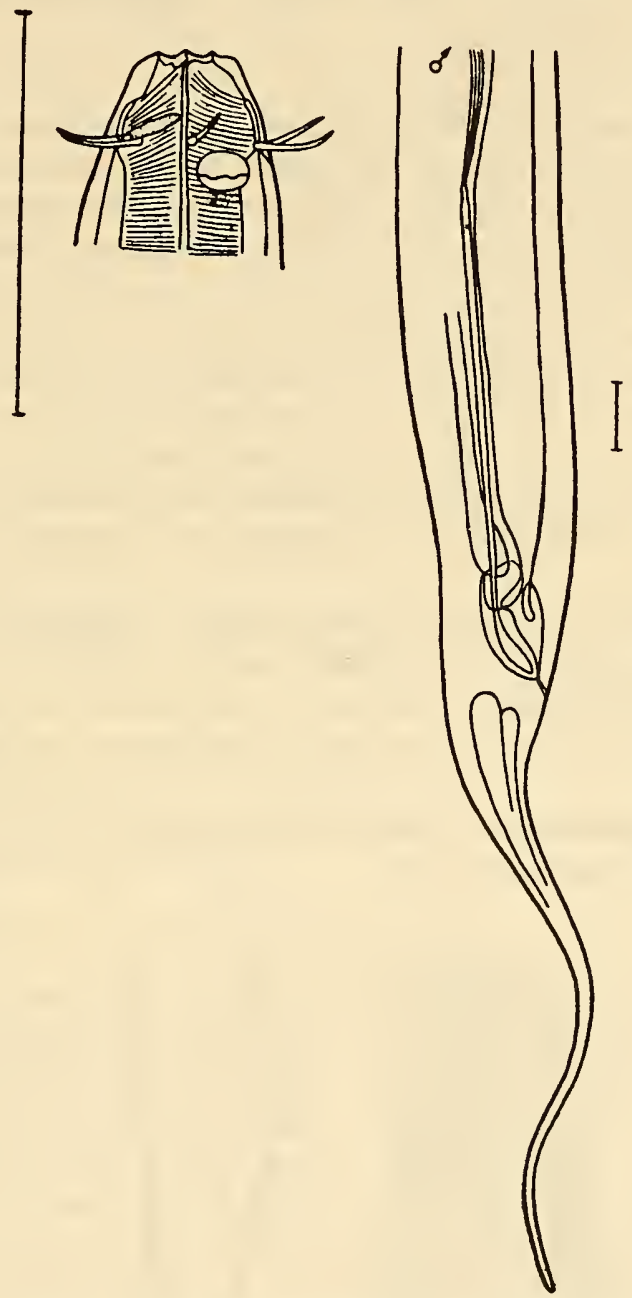

Figure 74. Crenopharynx gracilis (from Filip'ev, 1927).

This species is similar to C. marioni but differs in longer cephalic setae, more displaced cervical pore, slender tail, and absolutely different structure of spicules.

Geographic distribution. Found in the Barents and Kara Seas in silted beds in the sublittoral zone. 
62. Crenopharynx armatus sp. nov (Figure 75)

Holotype q: Institute of Zoology, Academy of Sciences, USSR. Collection No. 7546.

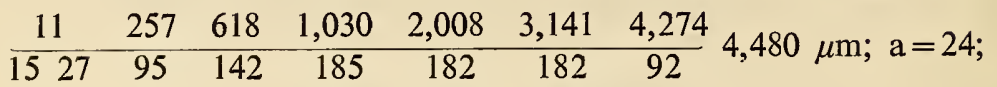

$$
\begin{aligned}
& \mathrm{b}=7 ; \mathrm{c}=21 ; \mathrm{V}=46 \% \text {. }
\end{aligned}
$$

Body tapers to $1 / 12$ midbody diameter at anterior end and $1 / 2$ at posterior end. Head truncated. Tail short; narrow cylindrical part $1 / 4$ length of conical part. Cephalic capsule well developed; width 2.4 length. Length of cephalic setae $11.6 \mu \mathrm{m}$ (slightly less than $1 / 2$ corresponding head diameter). Cuticle thick, $5.8 \mu \mathrm{m}$. Amphids round and small; diameter $4.0 \mu \mathrm{m}$ ( $1 / 8$ corresponding neck diameter). Pore of cervical gland situated 1.5 cephalic diameters from anterior end. Oral cavity rather spacious, with small onchia. Nerve ring encircles esophagus slightly anterior to its midlength. Length of anterior female genital tube $978 \mu \mathrm{m}$, of posterior tube $1,133 \mu \mathrm{m}$, and of reflexed parts $824 \mu \mathrm{m}$ and $1,030 \mu \mathrm{m}$ respectively. Vulva situated slightly anterior to midbody. No mature eggs observed in uterus.

In spite of only two females at my disposal, features differentiating this species from others of this genus could be delineated: 1) extremely short tail $(c=21) ; 2)$ relatively well-developed cephalic capsule with distinct cephalic ring and thick walls; and 3) well-defined oral cavity, armed with onchia.

Geographic distribution. Found in the Barents Sea in the littoral zone at a depth of $18 \mathrm{~m}$ in a sandy bed.
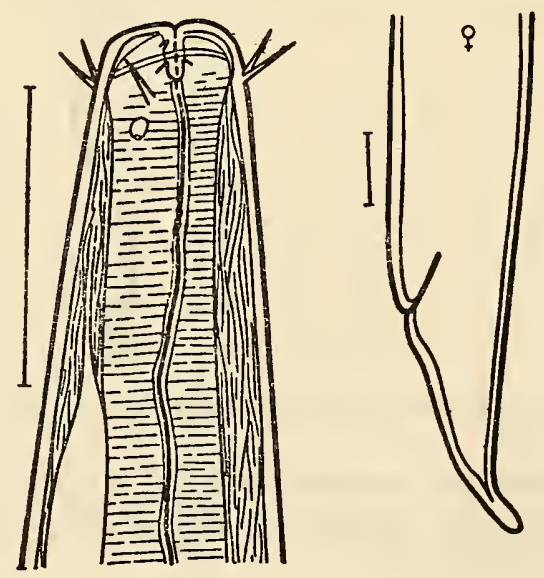

Figure 75. Crenopharynx armatus sp. nov. 


\section{Genus Nasinema Filipjev, 1927}

Steiner, 1916: 596 (Enchelidium); Filip'ev, 1927: 118.

Type species: Enchelidium polare Steiner, 1916.

147 Cephalic capsule totally reduced. Lips and labial papillae not developed. Tail perceptibly shorter than in preceding genus, without filiform part, but with clavate bulge on which tube of excretory duct of cervical [sic] gland terminates. Cervical setae totally absent. Structure of amphids not known. Well-developed pigmented eyes present; pigment bowl cyathiform. Spicules long and narrow. Gubernaculum simple, without processes.

\section{Key to Species of Genus Nasinema}

1 (2). Small nematodes, body length about $2.0 \mathrm{~mm} \ldots \ldots \ldots \ldots \ldots$ .N. stenolaima Wieser, 1954. 2 (1). Larger nematodes, body length 4.0 to $5.0 \mathrm{~mm}$.

3 (4). Body extremely slender ( $a=$ about 80 )...64. N. boreale sp. nov. 4 (3). Body considerably wider $(a=$ about 30$) \ldots \ldots \ldots \ldots \ldots \ldots$ 63. N. polare (Steiner, 1916).

*63. Nasinema polare (Steiner, 1916) (Figure 76)

Steiner, 1916: 596-600, tab. 16, fig. 28b, c, f, tab. 30, fig. 28a, d, e, g, h (Enchelidium) (description: 596).

1 우: $\mathrm{L}=5 \mathrm{~mm} ; \mathrm{a}=32 ; \mathrm{b}=4 ; \mathrm{c}=18 ; \mathrm{V}=50 \%$.

Body tapers toward both ends, but more significantly toward anterior end (about 1/9) than posterior end (about $1 / 2$ ). Head anteriorly truncated. Tail tapers gradually from anus, without distinct filiform part, and terminates in rather wide tube. Buccal cavity small, funnel-shaped, with highly sclerotized walls. Esophageal lumen bounded by extremely thin walls up to its midlength, where walls become highly sclerotized; posterior third of esophagus differs significantly in alveolate structure. Nerve ring encircles esophagus about at its midlength. Excretory pore of renette situated $150 \mu \mathrm{m}$ from anterior end. Eyes situated $40 \mu \mathrm{m}$ from anterior end. Steiner assumed the presence of light-refractive lenses in these eyes, but in the specimen on which the description of the species is based these lenses were not discernible. Pigment bowls of eyes cyathiform. Vulva situated immediately posterior to midbody. Female genital tubes reflexed; reflexed part reaches uterus.

Geographic distribution. Discovered in the isthmus of the White Sea. 

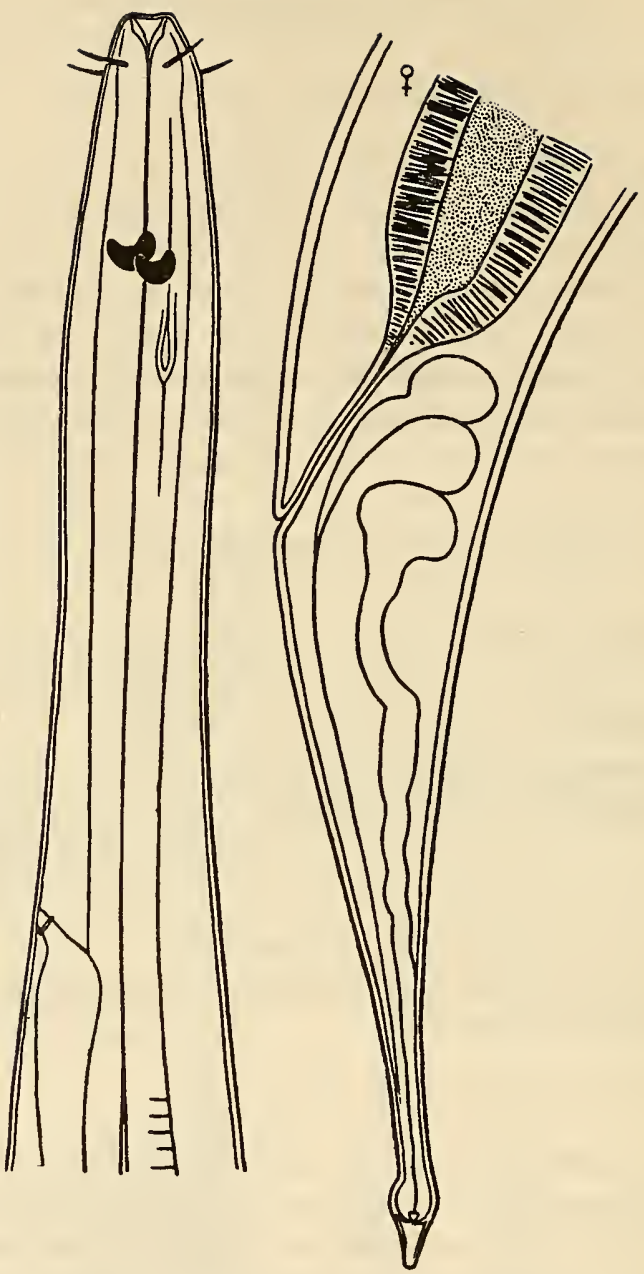

Figure 76. Nasinema polare (from Steiner, 1916).

148 64. Nasinema boreale sp. nov. (Figure 77)

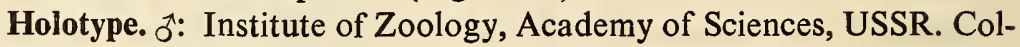
lection No. 7927.

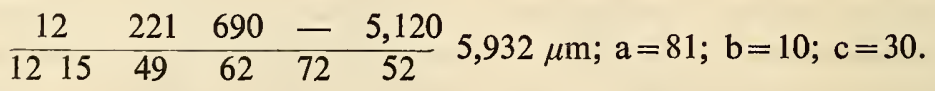

Paratype.

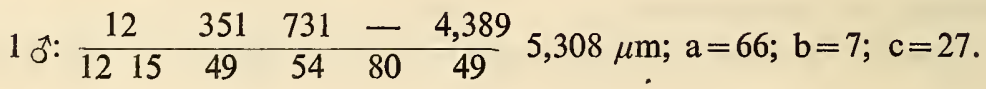


Body tapers to $1 / 6$ midbody diameter at anterior end and $2 / 3$ at posterior end. Head truncated. Tail rather long, without filiform part. Cuticle $2.0 \mu \mathrm{m}$ thick. Buccal cavity poorly developed. Length of cephalic setae $5.0 \mu \mathrm{m}$ and cervical $3.0 \mu \mathrm{m}$. Nerve ring encircles èsophagus in its anterior third. Posterior part of esophagus alveolate. Eyes considerably displaced toward anterior end and with distinct lens. In one specimen pigment a compact, oval, longitudinally elongated mass, and in another specimen scattered in small spots all over anterior part of body. Excretory pore of renette situated $50 \mu \mathrm{m}$ from anterior end. Spicules very long (200 to 230 $\mu \mathrm{m})$, narrow, with small capituli. Gubernaculum simple and small, length $40 \mu \mathrm{m}$. Sparsely scattered setae $5.0 \mu \mathrm{m}$ long located in anal region of male.
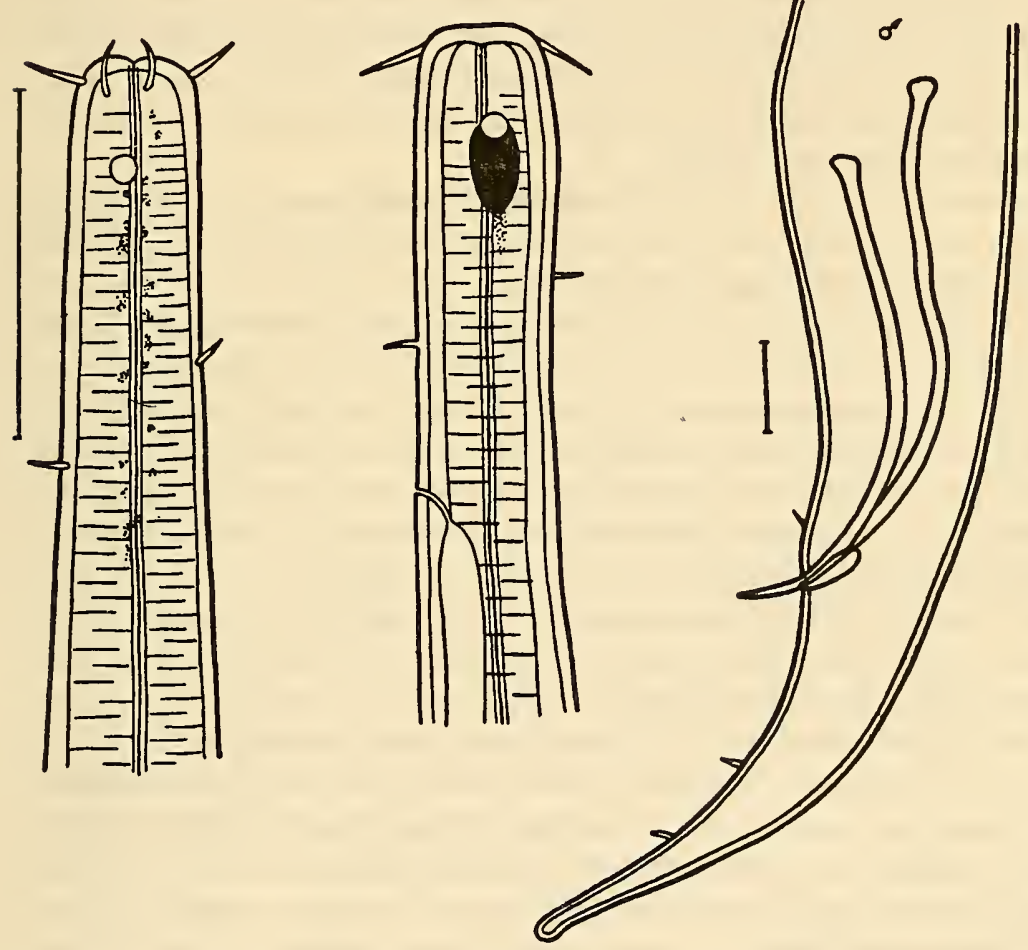

Figure 77. Nasinema boreale sp. nov.

$N$. boreale can be distinguished from the only other species known in the Soviet Union, namely $N$. polare, in position and shape of eyes, position of excretory pore of renette, more slender body, and shorter tail.

Geographic distribution. Found in the south terminus of Kunashir (Kuril Islands) at a depth of $5.0 \mathrm{~m}$ in sandy silt. 
This family includes only one genus-Rhabdodemania-and as such the basic characters coincide with those of the genus.

\section{Genus Rhabdodemania Baylis and Daubney, 1926}

Southern, 1914: 41 (Demania nec Lauvil, 1906); Ditlevsen, 1926: 15 (Demania); Baylis and Daubney, 1926; 112; Filip'ev, 1927: 90; Wieser, 1959: 9; Inglis, 1964: 322.

Type species: Demania major Southern, 1914.

Genus Rhabdodemania occupied an undefined taxonomic position for a long time. At present, there is a tendency to include it in family Enoplidae (de Coninck, 1965). I think this genus deserves isolation in an independent family which, indisputably, is phylogenetically close to family Enoplidae (Platonova, 1974).

Nematodes small in size, $2.8 \mathrm{~mm}$ long. Cuticle smooth. Body tapers slightly toward head but not toward anus; narrows slightly only in caudal region. Head distinctly demarcated from body. Oral cavity divided into buccal and onchial parts. Buccal cavity encircled by three well-developed lips with internal surface distinctly longitudinally striated. Striations vary in depth in different species. Sclerotized plate (mandible) enlarged and bifurcated in upper part, gradually narrows toward base, joins each lip from inner side. Anterior part of plate thickened and usually carries outgrowth directed outward (mandibular ring and mandibular outgrowth). Posterior part of mandible continues into onchial cavity where in most cases it is provided with an acicular and internally directed process, the onchium. Entire oral cavity with thick sclerotized lining, forming its wall. Cephalic end distinctly truncated. Tail relatively small, conical, and narrow slightly toward tip. Only cephalic setae present; cervical and preanal setae absent. Absence of amphids in type species is an interesting feature; no author has reported them to date. Esophagus and reproductive system as in leptosomatids, caudal glands tubular. Spicules weakly arcuate, wide in proximal part, and each terminates with distinct capitulum, which differs in structure in different species. Gubernaculum small, simple, and without process. Accessory organ absent.

In the descriptions of species of genus Rhabdodemania, figures in Cobb's formula denote distances from anterior end of body to the following parts: 1 . posterior margin of oral cavity; 2 . nerve ring; 3 . esophageal base; 4. commencement of anterior genital tube; 5 . vulva; 6 . commencement of posterior genital tube; and 7. anus. As mentioned before, the number of measurements are fewer for males. 
1 (24). All cephalic setae equal in length.

2(3). Tail short ( $c=$ about 40 ). Gubernaculum very long, almost equal

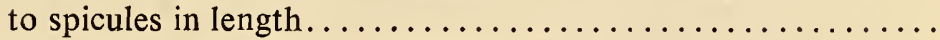

...R. calycolaimus Schuurmans-Stekhoven and Mawson, 1955.

3 ( 2). Tail much longer ( $c=$ about 20). Gubernaculum much shorter than spicules.

4 ( 5). Cephalic setae very long; length twice cephalic diameter...... 73. R. angustissima Platonova, 1974.

150 5 (4). Cephalic setae short; length significantly shorter than cephalic diameter.

6( 9). Oral cavity devoid of onchia.

7 ( 8 ). Lips poorly developed. Length of body $5.0 \mathrm{~mm} \ldots \ldots \ldots \ldots$ ........................ striata Schulz, 1932.

8 ( 7). Labia well-developed. Length of body $3.5 \mathrm{~mm} \ldots \ldots \ldots \ldots$ ..................67. R. edentula Platonova, 1974.

9 (6). Oral cavity armed with onchia.

10 (11). Spicular capitulum multiangular in shape

.R. laticauda Ditlevsen, 1926.

11 (10). Spicular capitulum undeveloped or different in shape (round and flattened ventrally or anteriorly).

12 (15). Small nematodes; length of body 2.0 to $3.0 \mathrm{~mm}$.

13 (14). Six onchia situated in onchial cavity (two on each mandible)... 69. R. hexonchia Platonova, 1974.

14 (13). Three onchia situated in onchial cavity (one on each mandible). 70. R. pontica Platonova, 1965.

15 (12). Larger nematodes; length of body greater than $3.0 \mathrm{~mm}$.

16 (17). Oral cavity very wide; length equal to width............ 68. B. latifaux Platonova, 1974.

17 (16). Oral cavity narrow; length exceeds width by 1.5 to 2.0 times.

18 (21). Spicules with well-developed capituli.

19 (20). Spicular capitulum round ........... R. scandinavica Schuurmans-Stekhoveen, 1946.

20 (19). Spicular capitulum flattened on ventral side............

21 (18). Spicules without distinctly developed capituli.

22 (23). Cephalic setae thin, relatively long (length constitutes about onehalf corresponding diameter). .72. R. orientalis Platonova, 1974.

23 (22). Cephalic setae thick and short (length constitutes one-fifth corresponding diameter)......66. R. gracilis (Ditlevsen, 1919).

24 ( 1). Cephalic setae unequal in length; four submedian shorter than rest. 
25 (34). Cephalic setae situated in one circle.

26 (27). Extremely small nematodes; body length less than $2.0 \mathrm{~mm} \ldots$. .R. minima Chitwood, 1936.

27 (26). Nematodes significantly larger, body length greater than $3.0 \mathrm{~mm}$. 28 (29). Only one dorsal onchium present........ dura Inglis, 1966. 29 (28). Three onchia present.

30 (31). All onchia equal in size......65. R. minor (Southern, 1914).

31 (30). Onchia differ in size; dorsal larger than ventrolateral.

32 (33). Tail in male with large setae. Capitulum present........... .R. mediterranca Boucher, 1971.

33 (32). Tail in male devoid of setae. Spicular capitulum absent......

34 (25). Cephalic setae situated in two circles.

35 (36). Cephalic setae of anterior circle less than $1 / 3$ length of setae in posterior circle................... illgi Wieser, 1959.

36 (35). Cephalic setae of anterior circle more than $1 / 2$ length of setae in posterior circle or equal to them.

37 (38). Spicules with distinctly developed capitulum...........

.R. major (Southern, 1914).

38 (37). Spicules without distinctly developed capitulum...........

R. coronata Gerlach, 1952.

151 65. Rhabdodemania minor (Southern, 1914) (Figure 78) ${ }^{5}$

Southern, 1914: 43, tab. 7, fig. 21a-c (Demania); Filip'ev, 1927: 92-93, pl. 3, fig. 9; Allgen, 1928: 283, 1929a: 10; 1935: 17; 1959: 29, fig. 11a-c.

$$
\begin{aligned}
& 2 \text { б }: \begin{array}{ccccc}
18-19 & 102-240 & 440-660 & - & 2,730-3,650 \\
\hline 19-20 & 55-62 & 75-80 & 90-100 & 65-68
\end{array} \\
& \times 2,840-3,800 \mu \mathrm{m} ; \mathrm{a}=32-38 ; \mathrm{b}=6 ; \mathrm{c}=23-26 \text {. } \\
& 3 \text { \%: } \begin{array}{ccrcc}
20-21 & 220-250 & 490-630 & 1,310-1,650 & 1,620-2,010 \\
\hline 20 & 64-85 & 78-102 & - & -
\end{array} \\
& \times \begin{array}{cccc}
1,940-2,260 & 2,180-2,600 & 2,500-2,840 & 3,130-3,610 \\
\hline 85-120 & - & - & 60-92
\end{array} \\
& \times 3,270-3,760 \mu \mathrm{m} ; \mathrm{a}=31-39 ; \mathrm{b}=6-7 ; \mathrm{c}=23-27 \text {. }
\end{aligned}
$$

Body rather short and thick. Cuticle thick, $5.0 \mu \mathrm{m}$. Cephalic setae differ in length; four submedian setae significantly shorter than remaining six. Onchia considerably displaced into depth of oral cavity. Cardia long and partially wedged into esophagus (up to $28 \mu \mathrm{m}$ ). Spicules straight, cuticular fold extends all along their length and over capitulum; spicular capitulum elongated. Eggs $200 \mu \mathrm{m} \times 70 \mu \mathrm{m}$.

5Description of species according to Southern (1914: 43) and Filip'ev (1927: 92, 93). 
This species resembles $R$. major and $R$. gracilis. It differs from the former in: 1) shorter and thicker body; 2) length of esophagus and tail; and 3) length of cephalic setae. It differs from the latter in: 1) longer cephalic setae; 2) shape of tail; 3) thicker body; 4) straighter spicules; and 5) cuticular fold extending all along spicular body.
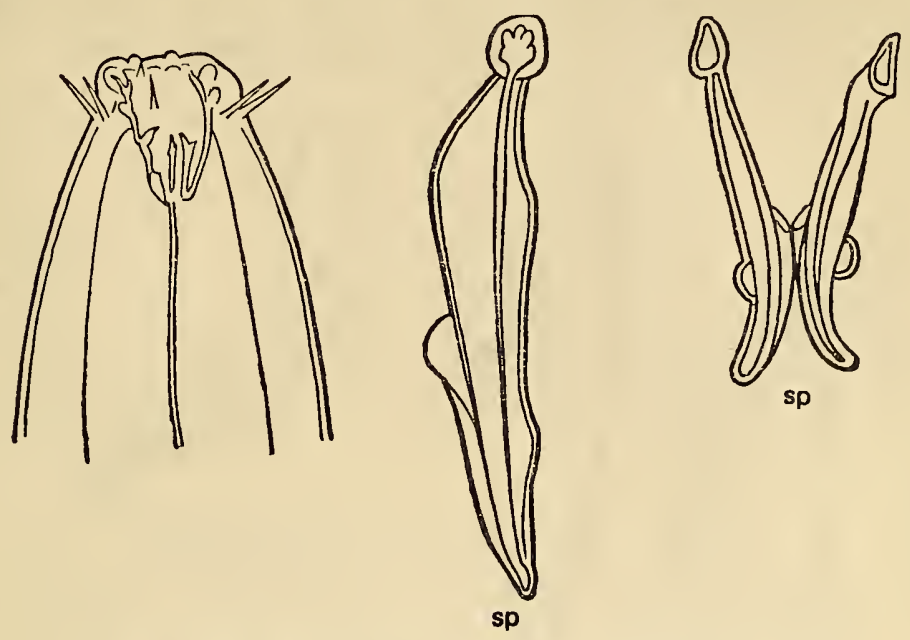

Figure 78. Rhabdodemania minor (from Southern, 1914).

Geographic distribution. Probably an Arctico-boreal species as mainly found in the Barents, Norwegian, and Baltic Seas, and in the north Atlantic Ocean. The discovery of this species in the subantarctic by Allgen appears dubious.

66. Rhabdodemania gracilis (Ditlevsen, 1919) (Figure 79) ${ }^{6}$

Ditlevsen, 1919: 187, tab. 10, fig. 6, tab. 11, figs. 1, 3, 7 (Demania); Filip'ev, 1927: 91-92, pl. 3, fig. 8; Schuurmans-Stekhoven, 1935a; 12, fig. 73A-B; Allgen, 1935: 17.

$$
\begin{aligned}
& 4 \text { ๙ }: \begin{array}{ccrcc}
21-23 & 255-375 & 535-770 & - & 4,150-5,380 \\
\hline 20-22 & 75-90 & 84-104 & 94-122 & 76-88
\end{array} \\
& \times 4,300-5,550 \mu \mathrm{m} ; \mathrm{a}=34-55 ; \mathrm{b}=6 ; \mathrm{c}=23-33 \text {. } \\
& 5 \text { ㅇ: } \begin{array}{rrrrc}
20-22 & 305-360 & 660-760 & 1,530-2,360 & 1,870-2,400 \\
\hline 19-25 & 82-112 & 102-135 & - & -
\end{array} \\
& \times \frac{2,620-3,630 \quad 3,090-4,540,3,480-5,150}{124-155 \quad-\quad, \quad 85-105} 5,000-6,220 \mu \mathrm{m} ; \\
& a=32-50 ; b=7-9 ; c=24-28 \text {. }
\end{aligned}
$$

6Description of species according to Ditlevsen (1919: 187) and Filip'ev, (1927: 91-92). 
Body short and thick; tapers considerably toward both ends but especially toward anterior end. Cephalic setae short and stout. Cuticle 5.0 to $7.0 \mu \mathrm{m}$ thick. Weak pigmentation discernible in esophagus. Vulva situated somewhat posterior to midbody. Ovaries short; anterior one somewhat shorter than posterior one. Uteri large and highly elongated. Vulval glands and musculature well developed. Spicules curved, dilated in middle, and cuticular fold occupies two-thirds spicule length.
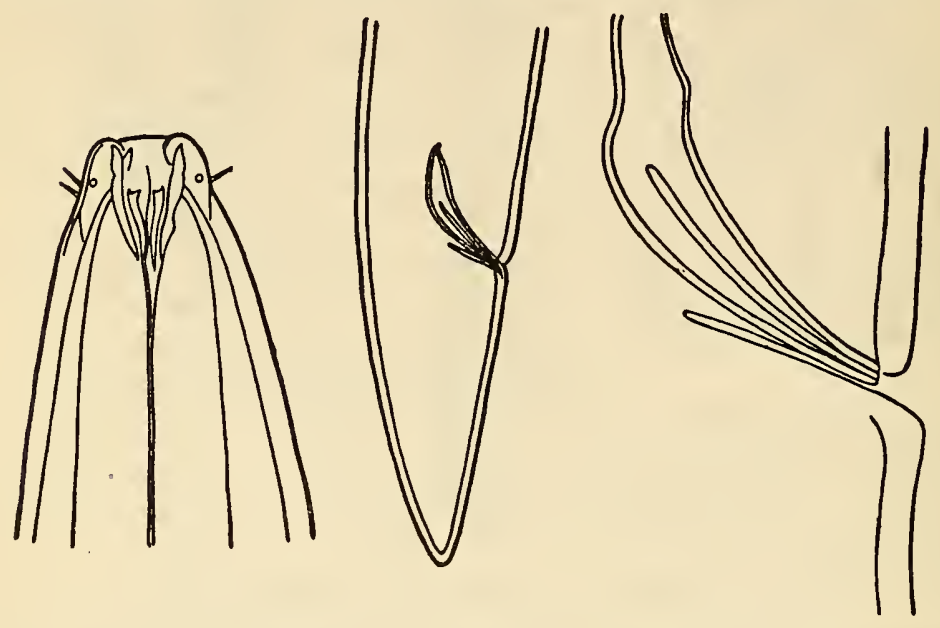

Figure 79. Rhabdodemania gracilis (from Ditlevsen, 1919).

This species resembles $R$. minor in many respects; however distinguishing features between the two species have been given in their descriptions.

Geographic distribution. Found mainly in the western part of the Baltic Sea. Recorded by Filip'ev in the Kara and Barents Seas.

67. Rhabdodemania edentula Platonova, 1974 (Figure 80)

Platonova, 1974: 1296, 1297, fig. 1.

$$
\begin{aligned}
& 5 \text { ส } 1 \text { : } \begin{array}{ccccc}
15 & 187-190 & 480-595 & - & 2,300-4,253 \\
\hline & 50-90 & 115-147 & 132-170 & 80-105
\end{array} \\
& \times 3,402-4,428 \mu \mathrm{m} ; \mathrm{a}=26-28 ; \mathrm{b}=7-8 ; \mathrm{c}=23-25 \text {. }
\end{aligned}
$$

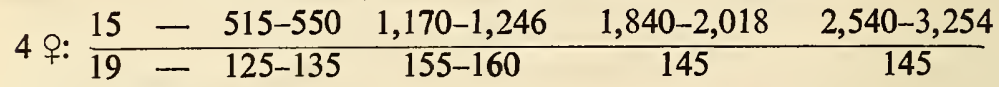

$$
\begin{aligned}
& \times \frac{3,333-3,666}{90-100} 3,500-3,816 \mu \mathrm{m} ; \mathrm{a}=24-26 ; \mathrm{b}=7 ; \mathrm{c}=20-25 ; \mathrm{V}=52-55 \% \text {. } \\
& 4 \text { juv.: } \begin{array}{ccccc}
13-14 & - & 370-412 & - & 1,918-1,957 \\
15-16 & - & 30-75 & 70-75 & 50
\end{array} \\
& \times 2,043-2,032 \mu \mathrm{m}[s i c] ; a=27-29 ; b=5-6 ; c=16 \text {. }
\end{aligned}
$$


Body short, rather thick, and tapers considerably, to $1 / 6$ to $1 / 7$ midbody diameter at anterior end and 5/8 to $10 / 17$ at posterior end. Cuticle

1537.0 to $8.0 \mu \mathrm{m}$ thick. Tail posteriorly pointed. Cephalic setae 3.5 to 4.6 $\mu \mathrm{m}$ long ( $1 / 4$ to $1 / 5$ corresponding head diameter). Lips well developed. Size of oral cavity $15.0 \mu \mathrm{m} \times 8.5 \mu \mathrm{m}$. Upper bifid ends of mandibles vary slightly in length. Mandibular ring well developed. Mandibular process large. Onchia absent. Pore of renette situated three cephalic diameters from anterior end. Length of anterior female genital tube 669 to $772 \mu \mathrm{m}$, and of reflexed part 381 to $535 \mu \mathrm{m} .{ }^{*}$ In one female four eggs, 112 to $125 \mu \mathrm{m} \times 62 \mu \mathrm{m}$, observed in posterior branch of uterus. Vulva situated slightly posterior to midbody. Spicules 87 to $100 \mu \mathrm{m}$ long, with capitulum flattened on ventral side, and an extremely short neck, which broadens into slightly curved spicular body. Length of gubernaculum $25 \mu \mathrm{m}$.

The most characteristic feature of this species is the absence of onchia. Other distinguishing features: cephalic setae, mandibular ends unequal in size, shape of spicules.

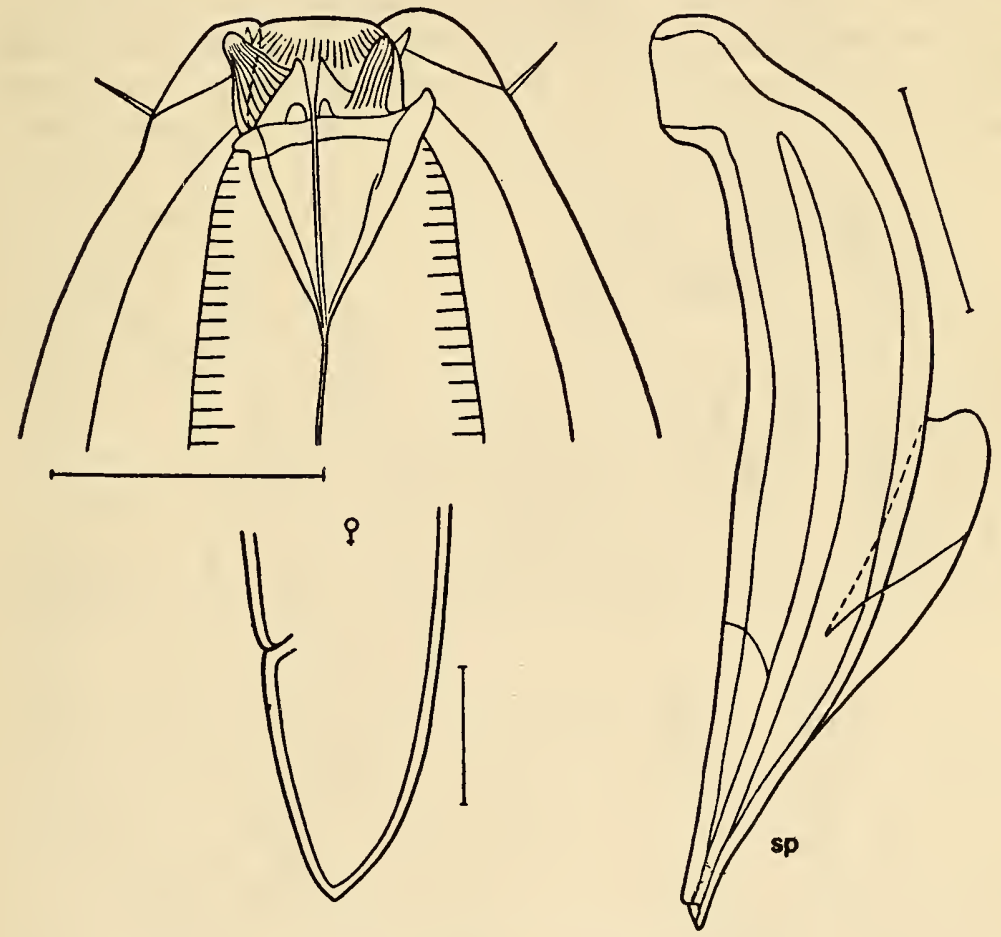

Figure 80. Rhabdodemania edentula.

*Measurements of posterior tube not given in Russian original-General Editor. 
Geographic distribution. Found in the Sea of Okhotsk (Bay of Nagaev) at a depth of $28 \mathrm{~m}$ in silted sand.

68. Rhabdodemania latifaux Platonova, 1974 (Figure 81)

Platonova, 1974: 1298, fig. 2.

$$
\begin{aligned}
& 1 \text { o : } \frac{16-566-122-3,862}{25-127 \quad 92} 4,048 \mu \mathrm{m} ; \mathrm{a}=32 ; \mathrm{b}=7 ; \mathrm{c}=21 \text {. } \\
& 2 \text { juv.: } \frac{15-339-350-750}{15-70-72 \quad 75-80} \frac{50}{15}-1,703-2,040 \mu \mathrm{m} \text {; } \\
& a=22-24 ; b=5-6 ; c=12-19 \text {. }
\end{aligned}
$$

Body tapers to $1 / 5$ midbody diameter at anterior end and $10 / 13$ at 154 posterior end. Tail tapers slightly and acicular at very tip. Cuticle 4.6 $\mu \mathrm{m}$ thick. Cephalic end blends with body. Length of cephalic setae 4.6 $\mu \mathrm{m}(1 / 3$ corresponding head diameter). In addition to cephalic setae, a few short cervical setae present and a pair of extremely small setae located near excretory pore of caudal gland. Lips well developed. Size of oral cavity $16 \mu \mathrm{m} \times 14 \mu \mathrm{m}$. Bifid ends of mandible equal. Mandibular ring poorly developed. Mandibular processes very small. Three small onchia situated in onchial part. Pore of renette situated two cephalic diameters from anterior end. There were no females of this species in my

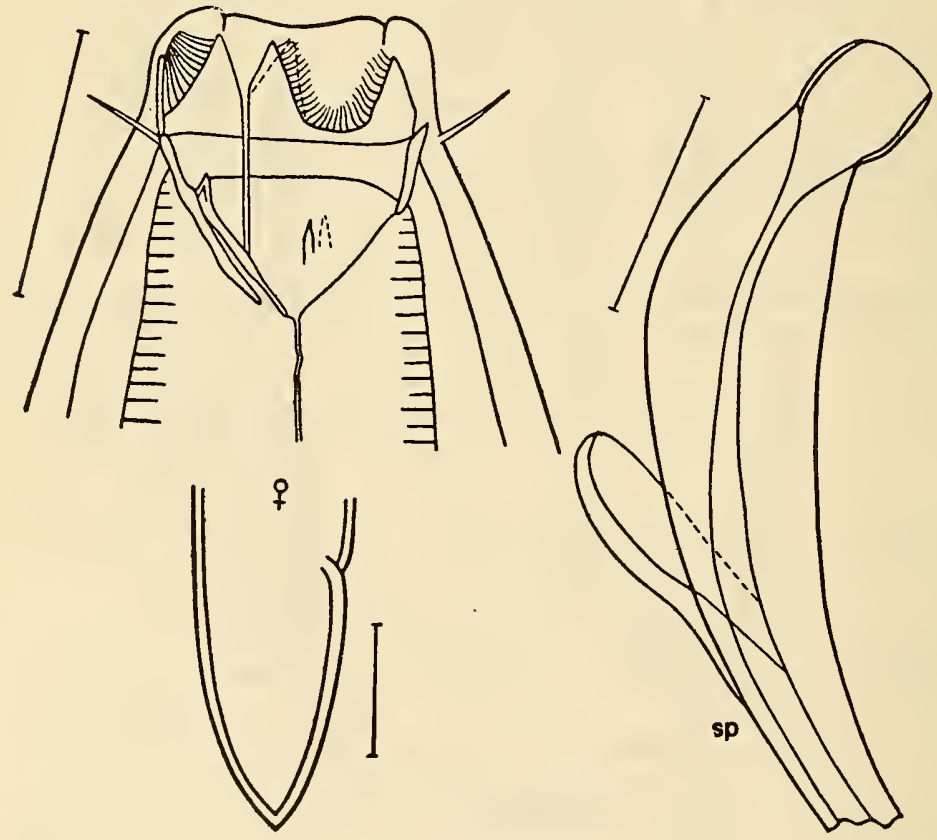

Figure 81. Rhabdodemania latifaux. 
material. Spicules with narrow capitulum and $75 \mu \mathrm{m}$ long. Gubernaculum trough-shaped and $17.5 \mu \mathrm{m}$ long.

Geographic distribution. Found in the Barents Sea (Bay of Provideniya) at a depth of $4.0 \mathrm{~m}$ in rhizoids of Laminaria sp.

69. Rhabdodemania hexonchia Platonova, 1974 (Figure 82)

Platonova, 1974: 1298, fig. 3.

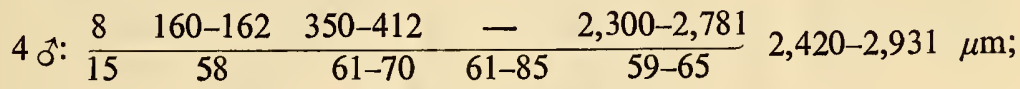

$$
\begin{aligned}
& \mathrm{a}=34-40 ; \mathrm{b}=7 ; \mathrm{c}=16-19 \text {. } \\
& 3 \text { ㅇ: } \begin{array}{ccccc}
8 & 170-174 & 380-391 & 900-1,050 & 1,670-1,822 \\
\hline 13-17 & 58 & 70 & 75-85 & 82-87
\end{array} \\
& \times \frac{2,400-2,697 \quad 2,862-2,906}{75-85} 2,962-3,000 \mu \mathrm{m} \text {; } \\
& a=34-36 ; b=8 ; c=21-29 ; V=56 \% \text {. }
\end{aligned}
$$

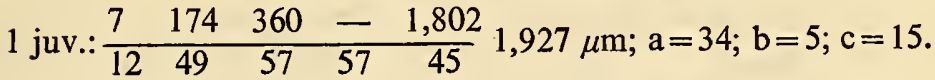

Body tapers to $1 / 4$ to $1 / 5$ midbody diameter at anterior end and not more than 10/13 at posterior end. Tail long, obtusely rounded, and uni155 form in width throughout most of its length. Cuticle $3.5 \mu \mathrm{m}$ thick. Cephalic setae long, 9.8 to $12.7 \mu \mathrm{m}$ (slightly shorter than corresponding head diameter). Small setae present near excretory pore of caudal gland. Cervical constriction absent. Lips poorly developed, with faint striations. Oral cavity small, $8.0 \mu \mathrm{m} \times 7.0 \mu \mathrm{m}$. Anterior end of mandible with shallow suture. Mandibular ring poorly developed and mandibular process absent. Onchia situated high, approximately on border between onchial and mandibular part. Two onchia present on each mandible, yielding a total of six. Excretory pore situated somewhat more than one cephalic diameter from anterior end. Length of anterior female genital tube $772 \mu \mathrm{m}$, of posterior tube 721 to $875 \mu \mathrm{m}$, and of reflexed parts 421 to $515 \mu \mathrm{m}$ and $412 \mu \mathrm{m}$ respectively. One egg, $200 \mu \mathrm{m} \times 62$ to $75 \mu \mathrm{m}$, present in each uterus. Vulva situated slightly posterior to midbody. Spicules weakly curved, with well-developed, round, and somewhat anteriorly flattened capitulum; spicular body narrows gradually toward distal end. Spicular length $50 \mu \mathrm{m}$. Gubernaculum lobate and $25 \mu \mathrm{m}$ long.

Distinguishing features of these species: 1) long cephalic setae; 2) small head with wide oral cavity; 3 ) poorly developed mandibular ring and absence of mandibular process; 4) presence of six onchia instead of usual three; and 5) distinct shape of spicules.

Geographic distribution. Found in the Sea of Okhotsk near the western coast of Kamchatka at a depth of $22 \mathrm{~m}$ on a sandy bed. 


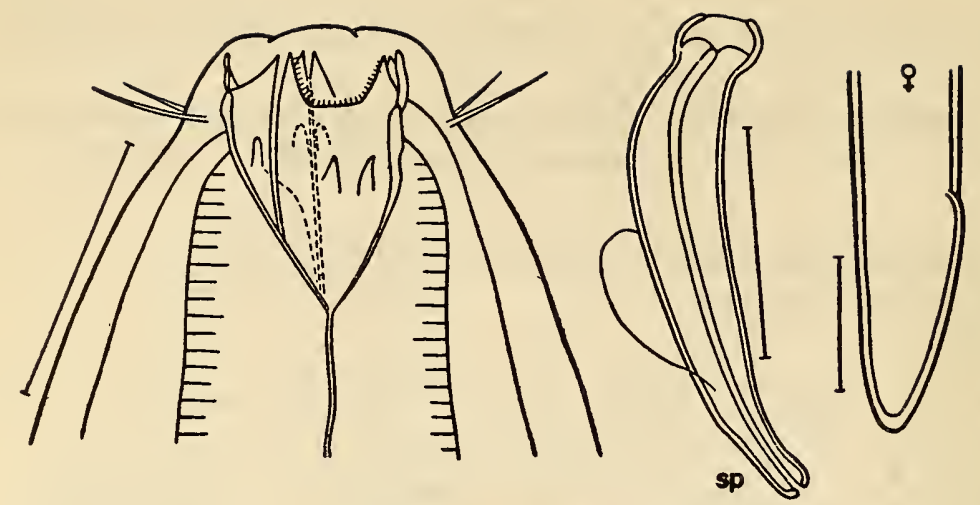

Figure 82. Rhabdodemania hexonchia.

70. Rhabdodemania pontica Platonova, 1965 (Figure 83)

Platonova, 1965; 100-102, fig. 1.

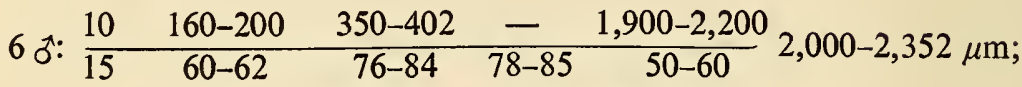

$$
\begin{aligned}
& a=24-26 ; b=5-6 ; c=14-16 \text {. } \\
& 4 \text { ㅇ: } \begin{array}{rrrrr}
10 & 200-209 & 460-470 & 927-990 & 1,339-1460 \\
16 & 56-58 & 76-86 & 90-94 & 86-89
\end{array} \\
& \times \frac{1,808-1,920}{90-92} \frac{2,220-2,500}{55-62} 2,382-2,656 \mu \mathrm{m} \text {; } \\
& a=25-28 ; b=5-6 ; c=14-17 \quad V=56 \% \text {. } \\
& 8 \text { juv.: } \begin{array}{ccccc}
8 & 150-174 & 309-360 & - & 1,390-1,545 \\
\hline 11 & 42-48 & 45-57 & 60-62 & 40-42
\end{array} \\
& \times 1,527-1,657 \mu \mathrm{m} ; \mathrm{a}=25-27 ; \mathrm{b}=4-5 ; \mathrm{c}=11-14 \text {. }
\end{aligned}
$$

Body tapers to $1 / 5$ to $5 / 27$ midbody diameter at anterior end and $10 / 13$ to $2 / 3$ at posterior end. Tail long, bluntly rounded. Cuticle 2.3 to

$1563.5 \mu \mathrm{m}$ thick. Length of cephalic setae $5.8 \mu \mathrm{m}(1 / 3$ corresponding head diameter). Except for cephalic, no other setae found on body. Head almost not demarcated from body. Lips poorly developed. Size of oral cavity $10.0 \times 5.0 \mu \mathrm{m}$. Mandibles with shallow suture anteriorly. Mandibular ring well developed but mandibular process absent. Onchia do not project much into oral cavity but rather long, occupying almost all of onchial cavity, and resemble highly sclerotized rays. Pore of renette situated two cephalic diameters from anterior end. Length of anterior female genital tube 412 to $469 \mu \mathrm{m}$, of posterior tube 463 to $469 \mu \mathrm{m}$, and of reflexed parts 257 to $309 \mu \mathrm{m}$ and $310 \mu \mathrm{m}$ respectively. Eggs, $206 \mu \mathrm{m} \times 72 \mu \mathrm{m}$, observed in posterior uterus in just one female. Vulva situated somewhat posterior to midbody. Spicules $50 \mu \mathrm{m}$ long, slightly curved, with rounded capitulum. Gubernaculum lobate and $17.5 \mu \mathrm{m}$ long. 

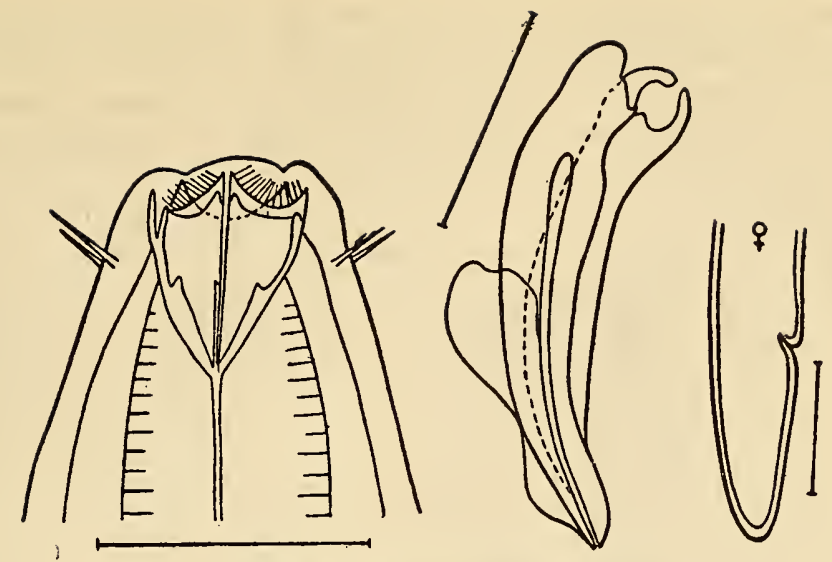

Figure 83. Rhabdodemania pontica.

R. pontica differs from other species of the genus in: 1) small size; 2) absence of mandibular processes; 3) peculiarity of onchial structure; and 4) shape of spicules.

Geographic distribution. Found in the Black Sea in depths ranging from 3 to $120 \mathrm{~m}$ in silted sand and phaseolin silt.

71. Rhabdodemania marisalbi Platonova, 1974 (Figure 84)

Platonova, 1974: 1299, fig. 5.

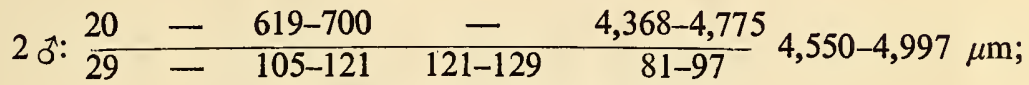

$$
\begin{aligned}
& a=35-41 ; b=7 ; c=23-25 \text {. } \\
& \text { 19: } \begin{array}{ccccccc}
20 & - & 503 & 2,007 & 2,559 & 4,602 & 5,705 \\
30 & - & 130 & 140 & 150 & 130 & 101
\end{array} 5,907 \mu \mathrm{m} ; \mathrm{a}=39 \text {; } \\
& b=10 ; c=29 ; V=43 \% \text {. }
\end{aligned}
$$

Large nematodes. Body tapers to $1 / 6$ to $1 / 7$ midbody diameter at anterior end and slightly more than $2 / 3$ at posterior end. Cervical constriction poorly expressed. Tail acticular at tip. Cuticle 4.0 to $6.0 \mu \mathrm{m}$ thick. Length of cephalic setae $6.0 \mu \mathrm{m}$ (1/3 corresponding head diameter). Lips poorly developed. Size of oral cavity $20 \mu \mathrm{m} \times 9.0 \mu \mathrm{m}$. Anterior end of mandible with deep notch. Mandibular ring wide and highly sclerotized. Mandibular processes well developed. Onchia massive. Excretory pore situated two cephalic diameters from anterior end. Length of anterior female genital tube $552 \mu \mathrm{m}$, of posterior tube $1,043 \mu \mathrm{m}$.* Vulva displaced anterior to midbody. Spicular body narrows gradually from proximal

*Reflexed parts not mentioned in Russian original-General Editor. 
157 to distal end; small velum on distal part extends to midlength of body; capitulum demarcated from body by distinct constriction and flattened on ventral side. Spicular length $81 \mu \mathrm{m}$. Gubernaculum dilates gradually from distal to proximal end and terminates in shape of rounded hook; length $40 \mu \mathrm{m}$.

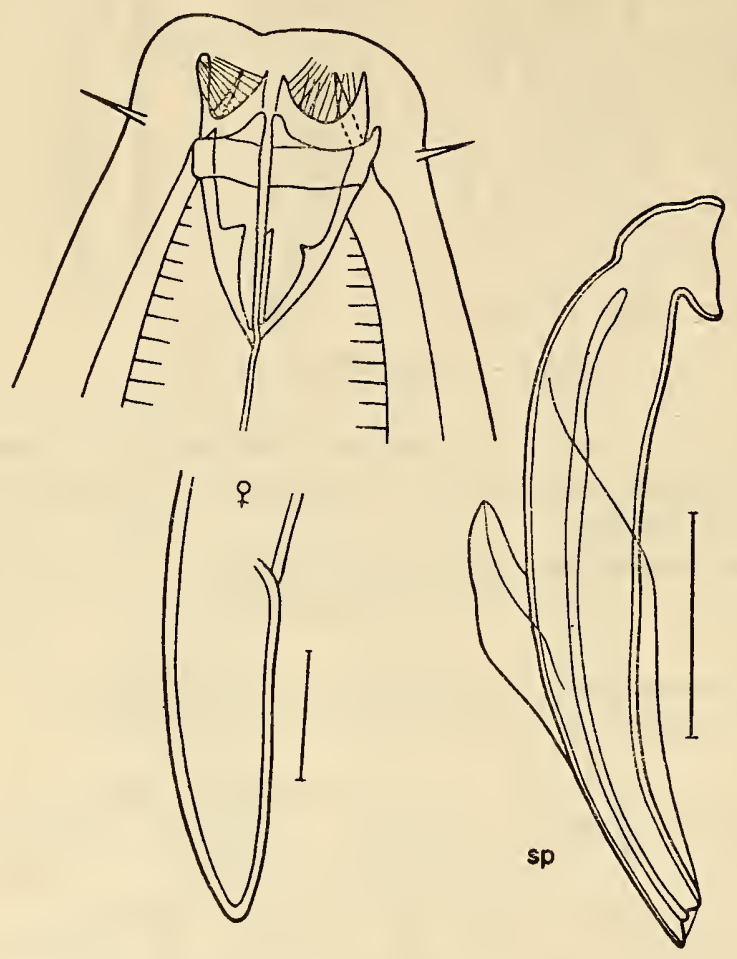

Figure 84. Rhabdodemania marisalbi.

Distinguishing features of this species: 1) large size; 2) highly stretched oral cavity (length twice greater than width); 3) wide, well-developed mandibular ring and well-developed mandibular processes; and 4) shape of spicules.

Geographic distribution. Found in Chupin Inlet of the White Sea at a depth of 4.0 to $8.0 \mathrm{~m}$ in silted sand containing pebbles.

72. Rhabdodemania orientalis Platonova, 1974 (Figure 85)

Platonova, 1974: 1300, fig. 6.

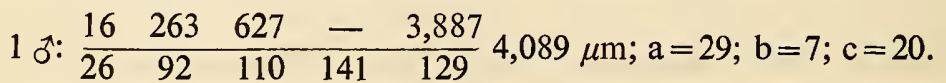




$$
3 \text { juv.: } \begin{array}{ccccc}
9 & 109 & 278-407 & - & 1,134-2,363 \\
20 & 39 & 40-48 & 32-52 & 28-44 \\
& & a=35-48 ; & b=5-6 ; & c=18-27 .
\end{array}
$$

Rather large nematodes. Body tapers to $1 / 10$ midbody diameter at anterior end and barely tapers toward posterior end. Tail blunt at tip. Cuticle $4.5 \mu \mathrm{m}$ thick. Cephalic setae $9.0 \mu \mathrm{m}$ long $(1 / 2$ corresponding head diameter). Lips well developed. Oral cavity $16.0 \mu \mathrm{m} \times 9.0 \mu \mathrm{m}$. Mandible with deep notch. Mandibular ring highly sclerotized, but rather narrow. Mandibular processes not large. Onchia well developed. Renette not readily discernible in my specimens; probably, its pore opens not far away from oral cavity. Females absent in my material. Spicules wide, 158 narrow smoothly toward both ends, but without distinctly expressed capitulum. Spicular length $64.8 \mu \mathrm{m}$. Gubernaculum small, funnel-shaped, and encloses distal end of spicules. Length of gubernaculum $25 \mu \mathrm{m}$.

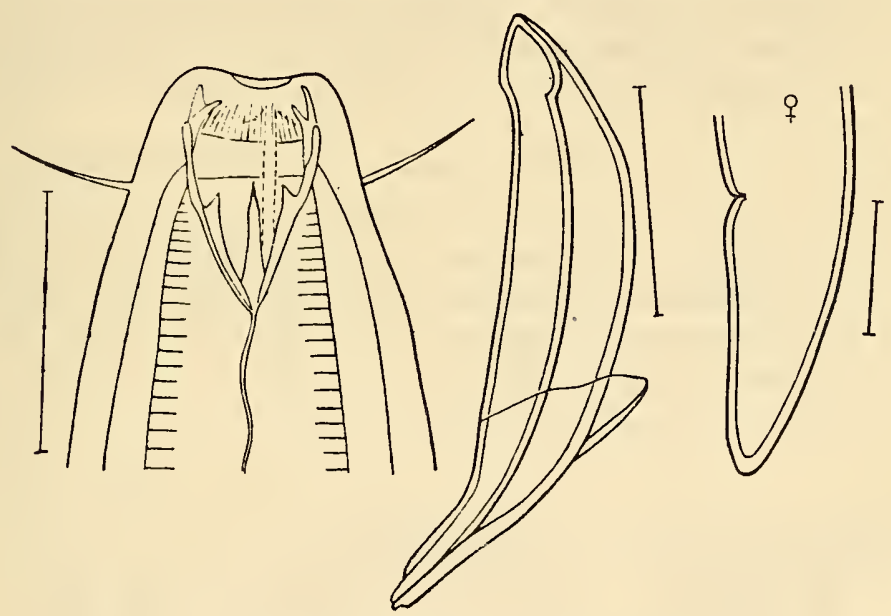

Figure 85. Rhabdodemania orientalis.

$R$. orientalis resembles the White Sea species $R$. marisalbi in many ways but differs from it in: 1) longer cephalic setae; 2) much narrower mandibular ring; 3) wider body; and 4) shape of spicules.

Geographic distribution. Found in the Gulf of Pos'et (Sea of Japan) at a depth of 13 to $17 \mathrm{~m}$ in silted sand with shells.

73. Rhabdodemania angustissima Platonova, 1974 (Figure 86)

Platonova, 1974: 1300, fig. 7.

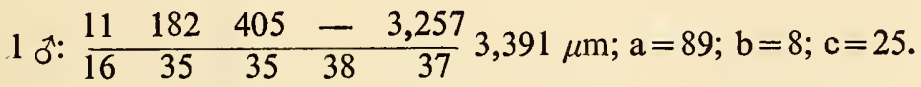




$$
\begin{aligned}
& 1 \text { ㅇ: } \frac{11 \quad 162405-2,116-3,106}{242024-40-32} 3,216 \mu \mathrm{m} ; \mathrm{a}=80 ; \mathrm{b}=8 \text {; } \\
& \mathrm{c}=29 ; \mathrm{V}=65 \% \text {. }
\end{aligned}
$$

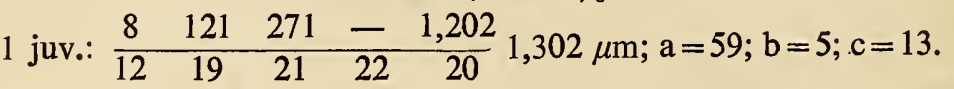

Body very narrow; tapers to $1 / 4$ to $1 / 5$ midbody diameter at anterior end and barely tapers toward anus. Tail wide, tip bluntly rounded. Head distinctly demarcated from body. Cuticle $5.0 \mu$ m thick. Lips well developed. Cephalic setae very long, $24 \mu \mathrm{m}$ (length twice corresponding head diameter). Oral cavity $11.0 \mu \mathrm{m} \times 7.0 \mu \mathrm{m}$. Anterior mandibular end with small notch. Mandibular ring poorly sclerotized. Mandibular processes not developed. Onchia narrow, long, and look like longitudinal rays. Pore of renette situated three cephalic diameters from anterior end of body. Genital tubes still undeveloped in specimen examined. Vulva shifted posteriorly to midbody. Spicules short and wide; proximal end wide and resembles capitulum. Spicular length $35.6 \mu \mathrm{m}$. Gubernaculum characteristic, extremely thin, narrow, and falcate at proximal end; length $10 \mu \mathrm{m}$.

Distinguishing features of this species: 1) extremely narrow body; 2) very long cephalic setae; 3 ) highly elongated oral cavity, with poorly developed mandibular ring, devoid of mandibular processes, and with long onchia that look like longitudinal rays; and 4) shape of spicules.

Geographic distribution. Found in the Sea of Okhotsk (Gulf of Aniva) in the littoral zone in a sandy bed.
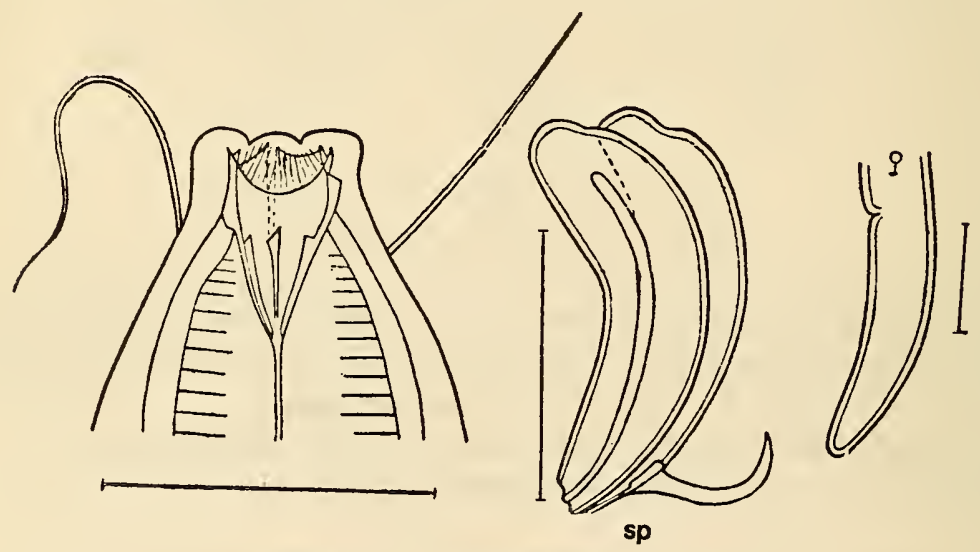

Figure 86. Rhabdodemania angustissima. 


\section{References}

159- Allgen, C.A. 1927a. Über einige freilebende marine Nematoden von der 164 schwedischen Küste des Öresundes, Zool. Anz., vol. 73, pp. 49-58.

Allgen, C.A. 1927b. Freilebends marine Nematoden von den Campbellund Staten Inseln, Nyt Mag. Naturvid., vol. 66, pp. 249-309.

Allgen, C.A. 1928. Neue oder wenig bekannte freilebende marine Nematoden von der schwedischen Westküste, Zool. Anz., vol. 77, pp. 281-307.

Allgen, C.A. 1929a. Freilebende marine Nematoden aus des Umgebung der staatlichen zoologischen Station Kristinenberg an der Westküste Schwedens, Capita Zool., 2, 8, 1-55.

Allgen, C.A. $1929 \mathrm{~b}$ Über einige antarktische freilebende marine Nematoden, Zool. Anz., vol. 84, pp. 126-140.

Allgen, C.A. 1930. Freilebende marine Nematoden von der Stateninsel (Feuerland-Archipel), I, Zool. Anz., vol. 89, pp. 246-258.

Allgen, C.A. 1931a. Weitere Beiträge zur Kenntnis des marinen Nematodenfauna der Campbell Insel, Nyt. Mag., Naturvid, vol. 70, pp. 97-198.

Allgen, C.A. 1931b. Freilebende Nematoden aus dem Dröbakabschnitt des Oslo-fjords, Zool, Jahrb. (Abt. Syst.) vol. 61, pp. 211-262.

Allgen, C.A. 1932. Uber einige freilebende marine Nematoden aus der Umgebung der biologischen Station auf der Insel Herdia (Norwegen), Arch. Naturgesch. (Neue Folge), vol. 26, pp. 399-432.

Allgen, C.A. 1933. Freilebende Nematoden aus dem Trondheimsfjord, Capita Zool., 4, 2, 1-162.

Allgen, C.A. 1934a. Freilebende marine Nematoden aus Hallands Värderö und der nahgelegenen Küste Schonens (Südschweden), Folia Zool. et Hydrobiol., 6, 3, 49-86. Riga.

Allgen, C.A. 1934b. Bipolarität in der Verbreitung freilebender mariner Nematoden, Zool. Anz., vol. 105, pp. 331-334.

Allgen, C.A. 1935. Die freilebende Nematoden des Öresunds, Capita Zool., 6, 3, 1-195.

Allgen, C.A. 1936. Über einige freilebende marine Nematoden aus der Strandfauna Norwegens, Nyt Mag. Naturvid., vol. 76, pp. 245-272.

Allgen, C.A. 1939. Über einige im reinen Schalensand der Westküste Norwegens freilebende Nematoden, Festschr. für E. Strand vol. 5, pp. 404-425.

Allgen, C.A. 1940a. Über einige neue freilebende Nematoden von der Nordwest- und Nordküste Norwegens, Folia Zool. et Hydrobiol., 10, 1, 258-281. Riga.

Allgen, C.A. 1940b. Weitere freilebende Nematoden insbesondere aus 
dem Schalensand- und Kiesboden der Strandzone Norwegens, Folia Zool. et Hydrobiol., 10, 2, 487-508. Riga.

Allgen, C.A. 1942. Die freilebenden Nematoden des Mittelmeers, Zool. Jahrb. (Abt. Syst.), 76, 1-2, 1-102.

Allgen, C.A. 1943. Norwegische marine Nematoden, Zool. Jahrb. (Abt. Syst.), 76, 4, 267-322.

Allgen, C.A. 1947a. Über einige Tiefsee-Nematoden aus dem Lopphavet im nördlichen Norwegen, Det Kongelige Norske Videnskab. Selskab. Forhandl., vol. 19, pp. 7-11.

Allgen, C.A. 1947b. On some free-living marine nematodes from Tobago, Vid. Medd. Dansk. Naturh. Foren., vol. 110, pp. 45-65.

Allgen, C.A. 1947c. West American marine nematodes, Vid. Medd. Dansk. Naturh. Foren., vol. 110, pp. 65-219.

Allgen, C.A. 1951. Pacific free-living marine nematodes, Vid. Medd. Dansk. Naturh. Foren., vol. 113, pp. 263-411.

Allgen, C.A. 1954a. Free-living marine nematodes from East Greenland and Jan Mayen, Medd. om Groenland, 107, 6, 5-44

Allgen, C.A. 1954b. Das Bipolaritäts problem freilebender mariner Nematoden, Det Kongelige Norske Videnskab. Selskab. Forhandl. (1953), 26, 8, 28-35.

Allgen, C.A. 1956a. Vergleich zwischen den marinen Nematodenfaunen Norwegens und denen antarktischen Gebietes, Det Kongelige Norske Videnskab. Selskab. Forhandl. (1955), 28, 15, 71-76.

Allgen, C.A. 1956b. Vergleich zwischen den marinen Nematodenfaunen Norwegens und denen der Atlantikküste Europas, Det Kongelige Norske Videnskab. Selskab. Forhandl. (1955), 28, 16, 77-83.

Allgen, C.A. 1956c. Vergleich zwischen den marinen Nematodenfaunen Norwegens und denen des Mittelmeers sowie angrenzender nordöstlicher Meeresabschnitt, Det Kongelige Norske Videnskab. Selskab. Forhandl. (1955), 28, 18, 84-95.

Allgen, C.A. 1957a. Vergleich zwischen den marinen Nematodenfaunen Norvegens und der Tropen, Det Kongelige Norske Videnskab. Selskab. Forhandl. (1956), 29, 9-10, 36-46.

Allgen, C.A. 1957b. On a small collection of free-living marine nematodes from Greenland and some other arctic regions, Medd. om Groenland, 159, 3, 1-42.

Allgen, C.A. 1958a. Zur Kenntnis norwegischen Nematoden, Det Kongelige Norske Videnskab. Selskab. Forhandl. (1957), 30, 4, 22-27.

Allgen, C.A. 1958b. Vergleich zwischen den marinen Nematoden Norwegens und denen der subtropischen Faunenengebiete in der südlichen Hemisphäre, Det Kongelige Norske Videnskab. Selskab. Forhandl. (1957), 30, 15, 93-98.

Allgen, C.A. 1958c. Über einige freilebende marine Nematoden von 
der Ostküste Südamerikas, Zool. Anz., vol. 160, pp. 206-217.

Allgen, C.A. 1959. Free-living marine nematodes, IV, Zool. Res. Swed. Antarct. Exp. 1901-1903, 5, 2, 293 pp.

Bastian, H.Ch. 1865. Monograph on Anguillulidae or free-living nematodes (marine, land, and fresh water), Trans. Linn. Soc., vol. 25, pp. 73-184. London.

Baylis, H.A. 1916. Some nemertines, free-living nematodes, and oligochaetes from the Falklands, Ann. Mag. Nat. Hist., ser. 8, vol. 17, pp. 288-299.

Baylis, H.A. and R. Daubney. 1926. A Synopsis of Families and Genera of Nematodes. Brit. Mus. (Nat. Hist.), London, 277 pp.

Berg, L.S. 1920. Bipolyarnoe rasprostranenie organizmov i lednikovaya epokha (Bipolar distribution of organisms and the glacial epoch). Izv. AN SSSR, vol. 14, pp. 273-302.

Bresslau, E. and J.H. Schuurmans-Stekhoven. 1940. Marine freilebende Nematoda aus der Nordsee, Ouvrage édité par le Patrimoine du Mus. Roy. Hist. Nat. Belg. Bruxelles, 74 pp.

Bütschli, O. 1873. Beiträge zur Kenntnis der freilebenden Nematoden, Nova Acta Leop.-Carol. Akad. Naturf., 36, 5, 144 pp.

Bütschli, O. 1874. Zur Kenntnis der freilebenden Nematoden, insbesonders der des Kieler Hafens, Abl. Senkenberg. Naturf. Ges. Frankf. -a.-Mein, vol. 9, pp. 237-368.

Chitwood, B.G. 1936a. Some marine nematodes of superfamily Enoploidea, Trans. Amer. Micr. Soc., 55, 2, 208-213.

Chitwood, B.G. 1936b. Some marine nematodes from North Carolina, Proc. Helminth. Soc. vol. 3, pp. 1-16. Washington.

Chitwood, B.G. 1937. A new genus and ten new species of marine nematodes from North Carolina, Proc. Helminth. Soc., vol. 4. pp. 54-59. Washington.

Chitwood, B.G. 1951. North American marine nematodes, part 4, Texas J. Sci., vol. 3, pp. 627-672.

Chitwood, B.G. 1960. A Preliminary contribution to marine nemas (Adenophorea) of northern California, Trans. Amer. Micr. Soc., 79, 4, 347-384.

Chun, C. 1897. Die Beziehung zwischen dem arktischen und antarktischen Plankton. E. Nägele, Stuttgart, 64 pp.

Cobb, N.A. 1891. Anticoma, a genus of free-living marine nematodes, Proc. Linn. Soc., 5, 3, 765-774. N.S. Wales.

Cobb, N.A. 1893a. Tricoma and other new Nematoda genera, Proc. Linn. Soc., 8, 2, 389-420. N.S. Wales.

Cobb, N.A. 1893b. Nematodes, mostly Austrálian and Fijian, Macleay Mém. Vol., Linn. Soc. Misc. Publ., no. 13, pp. 3-59. N.S. Wales. 
Cobb, N.A. 1898. Australian free-living marine nematodes, Proc. Linn. Soc., 23, 2, 383-407. N.S. Wales.

Cobb, N.A. 1914. Antarctic marine free-living nematodes of the Shackleton Expedition, part 1, Contrib. Sci. Nematology, pp. 1-33

Cobb, N.A. 1933. New nemic genera and species, with taxonomic notes, J. Parasitol., 20, 2, 81-94.

Deryugin, K.M. 1915. Fauna Kol'skogo zaliva i usloviya ee sushchestovovaniya (Fauna of Kola Bay and its living conditions). Zap. Akad. Nauk, Fiz.-Mat. Otd., 34, 1, 928. St. Petersburg.

Ditlevsen, H. 1919. Marine free-living nematodes from Danish waters, Vid. Medd. Dansk. Naturh. Foren. vol. 70, pp. 147-214.

Ditlevsen, H. 1922. Marine free-living nematodes from Auckland and Campbell Islands, Vid. Medd. Dansk. Naturh. Foren., vol. 73, pp. 1-32.

Ditlevsen, H. 1923. Sur quelques Nématodes libres (Côtes de Brétagne et Rockal), Bull. Soc. Zool., vol. 48, pp. 178-203. France.

Ditlevsen, H. 1926. Free-living nematodes, part 6. In The Ingolf Expeditions, vol. 4, pp. 1-42.

Ditlevsen, H. 1930. Marine free-living nematodes from New Zealand, Vid. Medd. Dansk. Naturh. Foren., vol. 87, pp. 201-242.

Dogel', V.A. 1954. Oligomerizatsiya gomologichnykh organov (Oligomerization of Homologous Organs). Izd. LGU, 367 pp.

Eberth, C.J. 1863. Untersuchungen über Nematoden. W. Engelmann, Leipzig, $77 \mathrm{pp}$.

Ekmann, S. 1935. Tiergeographie des Meeres. Akad. Verlagsgesellschaft, Leipzig, $542 \mathrm{pp}$.

Ekmann, S. 1953. Zoogeography of the Sea. Sidwick and Jackson, London, $417 \mathrm{pp}$.

Filip'ev, I.N. 1912. K voprosu o stroenii nervnoi sistemy u svobodnozhivushchikh nematod (Structure of the nervous system in freeliving nematodes). Tr. O-va Estestvoispyt, vol. 43, pp. 205-215. St. Petersburg.

Filip'ev, I.N. 1916. Svobodnozhivushchie nematody kollektsii Zoologicheskogo muzeya imperatorskoi Akademy Nauk (Free-living nematodes in the collection of the Zoological Museum, Imperial Academy of Sciences). Ezheg. Zool. Muz. Imp. AN, vol. 21, pp. 59-116. [English translation published by Amerind Pub. Co. Pvt. Ltd., New Delhi, India, 1973.]

Filip'ev, I.N. 1918-1921. Svobodnozhivushchie morskie nematody okrestnostei Sevastopolya (Free-living marine nematodes of Sevastopol' environs). Tr. Osoboi Zool. Lab. i Sevastopol'skoi Biol, St. Ross. AN, ser. 2, no. 4, vol. 1/2, 614 pp.

Filip'ev, I.N. 1922a. Novye dannye o svobodnykh nematodakh Chernogo 
morya (New data on free-living nematodes of the Black Sea). Tr. Stavropol'skogo S.-Kh. Inst., 1, 16, 184. pp.

Filip'ev, I.N. 1922b. Instruktsiya dlya sobiraniya svobodnykh nematod (Instructions for the Collection of Free-living Nematodes). Izd. Petrorg. Agronom. Inst. Petrograd, 14 pp.

Filip'ev, I.N. 1922c. O svobodykh nematodakh Azovskogo morya (Freeliving nematodes of the Sea of Azov). Tr. Stavropol'skogo S.-Kh., 1, $17,185-208$.

Filip'ev, I.N. 1934b. Nematody vrednnye i poleznye v sel'skom khozyaistve (Useful and Harmful Nematodes in Agriculture). Sel'khozgiz, Moscow-Leningrad, $440 \mathrm{pp}$.

Filip'ev, I.N. 1937. Klass kruglykh chervei (Nematoda). Rukovodstvo po zoologi. Bespozvonochnye [Class Nematoda (Roundworms). A Guide to Zoology. Invertebrates]. Biomedgiz, Moscow-Leningrad, vol. 1, pp. 556-628.

Filip'ev, I.N. 1946. Svobodnozhivushchie nematody iz Severnogo Ledovitogo Okeana (Free-living nematodes from the Arctic Ocean). Tr. Dreif. Eksp. Glavsevmorputi na Led. "G. Sedov" 1937-1940, vol. 3, pp. 158-184.

Filip'ev, I.N. [Filip'ev, I.N.]. 1927. Les nématodes libres des mers septentrionales appartenant à la famille des Enoplidae, Arch. Naturgesch., 91, A, 4 (1925), 216.

Filipjev, I.N. [Filip'ev, I.N.]. 1934a. Classification of free-living nematodes and their relation to parasitic nematodes, Smiths. Misc. Coll., $89,6,1-63$.

Gerlach, S.A. 1953. Biozönotische Gliederung der Nematodenbesiedlung an den deutschen Küsten, Ztschr. Morphol Ökol. Tiere, 41, 5-6, 411-512.

Gerlach, S.A. 1955. Zur Kenntnis der freilebenden marinen Nematoden von San Salvador, Ztschr. Wiss. Zool., 158, 2-4, 249-303.

Gerlach, S.A. 1956. Diagnosen neuer Nematoden aus der Kieler Bucht, Kieler Meeresforsch, vol. 12, pp. 85-109.

Gerlach, S.A. 1958. Die Nematodenfauna der sublitoralen Region in der Kieler Bucht, Kieler Meeresforsch, vol. 14, pp. 64-92.

Gerlach, S.A. 1959. Neue Meeres-Nematoden aus dem Supralitoral der deutschen Küsten, Intern. Rev. Ges. Hydrobiol., 44, 3, 463-467.

Gerlach, S.A. and F. Riemann. 1974. The Bremerhaven checklist of aquatic nematodes, Veröff. Inst. Meeresforsch. Bremerh., Suppl. 4, pp. 405-734.

Goldschmidt, R. 1904. Über die Cuticula von Ascaris. Zool. Anz., vol. 28, pp. 259-266.

Golovin, E.P. 1901, 1902. Nablyudeniya nad nematodami (Observations on Nematodes). Tipolitografiya Imp. Univ., Kazan, vol. 1, 149 pp.; vol. 2, $120 \mathrm{pp}$. 
Goodey, D.B. 1959. Laboratornye metody issledovaniya rastitel'nykh i pochvennykh nematod (Laboratory Methods of Studying Plant and Soil Nematodes). IL, Moscow, 85 pp.

Hyman, L.H. 1951. The Invertebrates. Vol. 3: Acantocephala, Aschelminthes and Entoprocta. The Pseudocoelomate Bilateria. McGraw-Hill, New York, 572 pp.

Inglis, W.G. 1958. A new species of the nematode genus Thoracostoma from the Antarctic, Ann. Mag. Nat. Hist., ser. 13, 1, 1, 45-48.

Inglis, W.G. 1964. The marine Enoplida (Nematoda): a comparative study of the head, Bull. Brit. Mus. (Nat. Hist.), 11, 4, 265-376.

Inglis, W.G. 1971. Marine Enoplida (Nematoda) from western Australia, Trans. Roy. Soc., 95, 2, 65-78. S. Austr.

Jägerskiöld, L.A. 1901. Wietere Beiträge zur Kenntnis der Nematoden, Kongeliga Svenska Vet. Akad. Handl., 35, 2, 1-80.

Kreis, H.A. 1928. Die freilebenden marinen Nematoden der Spitzbergen expedition von F. Römer und F. Schaudinn im Jahre 1898, Mitt. Zool. Mus., vol. 14, pp. 131-197. Berlin.

Kreis, H.A. 1934. Oncholaiminae Filipjev, 1916. Eine monographische Studie, Capita Zool., 4, 5, 1-271.

Leydig, F. 1854. Zoologisches, Arch. Anat. Phys. Jahrg. 1854, pp. 284-295.

Leucart, R. 1849. Zur Kenntnis der Fauna von Island. I. Beitrag (Würmer), Arch. Naturg., 15, 1, 149-208.

Linstow, O. 1892. Helminthen aus Südgeorgien, Jahrb. Hamburg. Wiss. Anstalten, 9, 2, 59-77.

Linstow, O. 1896. Nemathelminthen, Ergebnisse Hamburg. Magalhaensische Sammelreise, 3, 8, 3-21.

Linstow, O. 1900. Die Nematoden, Fauna Arctica, vol. 1, pp. 117-132. Jena.

Linstow, O. 1903. Entozoa des zoologischen Museums der keiserlichen Akademie der Wissenschaften zu St. Petersburg, Ann. Mus. Zool., vol. 8, pp. 265-294. St. Petersburg.

Linstow, O. 1906. Nematoda. National Antarctic Expedition 1901-1904, Nat. Hist., vol. 3, pp. 1-4.

Loos, C.A. 1896. Über den Bau der Öesophagus bei einiger Ascariden, Zentralb. Bakt. Parasitenk., vol. 19, pp. 5-13.

Luc, M. and L. de Coninck. 1959. Nématodes libres marins de la region Roscoff, Arch.Zool. Expérim. Génér., vol. 98, fasc. 2, pp. 103-165.

Man, J.G. de. 1876. Contribution à la connaissance des Nématodes marins du golf de Naples, Tijdscher. Nederl. Dierk. Vereeniging, vol. 2, pp. 78-196.

Man, J.G. de. 1878. Contribution à la connaissance des Nématodes 
marins du golf de Naples, Tijdschr. Nederl. Dierk.Vereeniging, vol. 3, pp. 88-118.

Man, J.G. de. 1886. Anatomische Untersuchungen über freilebende Nordsee-Nematoden. Paul Frohber, Leipzig, 82 pp.

Man, J.G. de. 1888. Sur quelques Nématodes libres de la mer du Nord, nouveaux ou peu connus, Mém. Soc. Zool., vol. 1, pp. 1-51. Françe.

Man, J.G. de. 1889. Troisième note sur les Nématodes libres de la mer du Nord et de la Manche, Mém. Soc. Zool., vol. 2, pp. 182-216. Françe.

Man, J.G. de. 1890. Quatrième note sur les Nématodes libres de la mer du Nord et de la Manche, Mém. Soc. Zool., vol. 2, pp. 169-194. Françe.

Man, J.G. de. 1893. Cinquième note zur les Nématodes libres de la mer du Nord et de la Manche, Mém. Soc. Zool., vol. 4, pp. 81-125. Françe.

Man, J.G. de. 1904. Nematodes libres-Res. Voy. S.Y. Belgica (18971898-1890)—Rap. Sci. J.E. Buschmann, Anvers, 55 pp.

Man, J.G. de. 1907. Sur quelques espèces nouvelles ou peu connus de Nématodes libres, habitant les côtes de la Zélande, Mém. Soc. Zool., vol. 20, pp. 33-90. France.

Man, J.G. de. 1922. Neue freilebende Nematoden aus der Zuiderzee, Tijdschr. Nederl. Dierk. Vereeniging, 18, 2, 124-134.

Marion, A. 1870. Recherces zoologiques et anatomiques sur des Nématodes non parasites marins, Ann. Sci. Nat., nos. 13-14, 102 pp.

Martini, E. 1903. Über Furchung und Gastrulation des Cuculanus elegans, Ztschr. Wiss. Zool., vol. 74, pp. 501-556.

Martini, E. 1906. Über Subcuticula und Seitenfelder einiger Nematoden, Ztschr. Wiss. Zool., vol. 81, pp. 699-766.

Martini, E. 1908a. Die Konstanz histologischen Elementen bei Nematoden, Verh. Anat. Gesellsch, vol. 22, pp. 132-134. Jena.

Martini, E. 1908b-1909. Über Subcuticula und Seitenfelder einiger Nematoden, Ztschr. Wiss. Zool., vol. 91, pp. 191-235; vol. 93, pp. 535-624.

Martini, E. 1916. Die Anatomie der Oxyuris curvula, Ztschr. Wiss. Zool., vol. 116, pp. 137-525.

Maupas, E. 1900. Modes et formes de reproduction chez les Nématodes, Arch. Zool. Exp., vol. 8, fasc. 3, pp. 463-624.

Mawson, P.M. 1953. Some marine free-living nematodes from the Australian coast, Trans. Roy. Soc., vol. 76, pp. 34-40. South Australia.

Mawson, P.M. 1956-1958. Free-living nematodes. Sect. 1. Enoploidea from Antarctic stations. Sect. 2. Additional Enoploidea from Antarctic stations. Sect. 3. Enoploidea from subantarctic stations, Brit. Aust. New Zeal. Antarct. Research Exped. 1929-1931. Reports-Series B. 
(Zool. and Bot.): 1956, vol. 6, pt. 3, pp. 39-74; 1958a, vol. 4, pt. 13, pp. 293-305; 1958b, vol. 4, pt. 14, pp. 310-358.

Meyl, A.H. 1956-1957. Beiträge zur freilebenden Nematodenfauna Brasiliens, I, Nematologica, 1, 4, 311-325; II, Kieler Meeresforsch, vol. 13, pp. 125-133.

Micoletzky, H. 1914. Freilebende Süsswasser-Nematoden der Ost-Alpen mit besonderer Berücksichtigung des Lunzer-Seengebietes, Zool. Jahrb. (Abt. Syst.), 36, 4-5, 331-546.

Micoletzky, H. 1922. Neue freilebende Nematoden aus Suez, Sitz.-ber. Acad. Wiss. Wien Math.-Naturw. Klasse, Abt. 1, vol. 131, pp. 77-103.

Micoletzky, H. 1924. Wietere Beiträge zur Kenntnis freilebender Nematoden aus Suez, Sitz.-ber. Acad. Wiss. Wien Math.-Naturw. Klasse, Abt. 1, vol. 132, pp. 225-262.

Micoletzky, H. and H. Kreis. 1930. Freilebende marine Nematoden von der Sunda-Inseln. I. Enoploidea, Vid. Medd. Dansk Natur. Foren., vol. 87, pp. 243-399.

Mordukhai-Boltovskoi, F.D. 1960. Katalog fauny svobodnozhivushchikh bespozvonochnykh Azovskogo morya (Catalogue of free-living invertebrates of the Sea of Azov). Zool. Zhurn., 39, 10, 1454-1466.

Ortmann, A. 1896. Über "Bipolarität" in der Verbreitung mariner Tiere, Zool. Jahrb. (Abt. Syst.), 9, 4, 571-595.

Paladian, G. 1962. Contribution à l'étude des Nématoden libres du littoral roumain de la mer Noir, Trav. Mus. d'Hist. Nat. "Gr. Antipa," vol. 3, pp. 69-74.

Paramonov, A.A. 1926. O sluchae bivul'varnosti u odnoi svobodnoi nematody (Case of bivulvarity in a free-living nematode). Russk. Gidrobiol. Zhurn., 5, 10-12, 218-222.

Paramonov, A.A. 1962. Osnovy fitogel'mintologii (Fundamentals of Phytohelminthology). Izd. AN SSSR, Moscow, $479 \mathrm{pp}$.

Platonova, T.A. 1958. K faune nematod semeistva Leptosomatidae iz raiona ostrova Kergelen (Nematodes of family Leptosomatidae from Kerguelen Islands). Byull. Sov. Antarkt. Eksp., no. 3, pp. 59-61.

Platonova, T.A. 1962a. Nekotorye materialy po ekologii svobodnozhivushchikh nematod chernogo morya (Some data on the ecology of free-living nematodes of the Black Sea). In Trudy 5-go Vsesoyuznogo Soveshchanya Fitogel'mintologov. Samarkandskogo. Izd. Samarkandskogo Univ., pp. 200-227.

Platonova, T.A. 1962b. Novye vidy nematod roda Pseudocella Filipjev i Kuril'skikh ostrovov i yuzhnogo Sakhalina (New species of nematodes of genus Pseudocella Filipjev from Kuril Islands and southern Sakhalin). Issledovaniya Dal'nevostochnykh Morei SSSR, vol. 8, pp. 200-218.

Platonova, T.A. 1965. Novyi vid svobodrozhivushchei nematody iz 
Chernogo morya (New species of free-living nematodes of the Black Sea). In Bentos. Izd. Naukova Dumka, Kiev, pp. 100-102.

Platonova, T.A. 1967. Svobodnozhivushchie morskie nematody semeistva Leptosomatidae Evropeiskoi Arktiki (Free-living marine nematodes of family Leptosomatidae of the European Arctic). Zool. Zhurn., $46,6,828-839$.

Platonova, T.A. 1970. O sistematike Leptosomatidae (Nematoda) Sredizemnogo morya i prilezhashchikh vod Atlantiki [Systematics of Leptosomatidae (Nematoda) of the Mediterranean Sea and adjoining waters of the Atlantic Ocean]. Zool. Zhurn., 49, 9, 1298-1305.

Platonova, T.A. 1974. Ob"em i sistematicheskoe polozhenie roda Rhabdodemania (Nematoda, Enoplida) [Composition and systematic position of genus Rhabdodemania (Nematoda, Enoplida)]. Zool. Zhurn., $53,9,1295-1303$.

Rauther, M. 1907. Über den Bau des Ösophagus und die Lokalisation der Nierenfunktion bei freilebenden Nematoden, Zool. Jahrb. (Abt. Anat.), vol. 23, pp. 703-740.

Rauther, M. 1909. Morphologie und Verwandschaftsbeziehung der Nematoden, Erg. Fortschr. Zool., vol. 1, pp. 491-596.

Rouville, E. 1903. Révision des Nématodes libres, marins de la région de Cette, Compt. Rend. Acad. Sci., vol. 137, pp. 1002-1003. Paris.

Rouville, E. 1904. Révision des Nématodes libres, marins de la région de Cette, Compt. Rend. Assoc. Franç. Avanc. Sci., vol. 33, pp. 788-797.

Saveljev, S. [Savel'ev]. Zur Kenntnis der freilebenden Nematoden des Kolafjords und des Reliktensee Mogilnoje, Tr. O-va Estestvoispyt, vol. 43, pp. 108-126. St. Petersburg.

Schimkewitsch. W.M. [Shimkevich, V.M.]. 1889. Über besondere Zellen in der Lebenshöle der Nematoden, Biol.Zentralbl., no. 19, p. 407.

Schneider, A. 1866. Monographie der Nematoden. G. Reimer, Berlin, $375 \mathrm{pp}$.

Schenider, G. 1906. Beiträge zur Kenntnis der im Uferschlamm des Finnischen Meerbusens freilebenden Nematoden, Acta Soc. Fauna et Flora Fennica, 27, 7, 1-42.

Schneider, K. 1902. Lehrbuch der vergleichenden Histologie der Tiere. G. Fischer, Jena, $691 \mathrm{pp}$.

Schneider, W. 1939. Fadenwürmer oder Nematoda, Tierwelt Deutschlands, vol. 36, $260 \mathrm{pp}$.

Schulz, E. 1932. Zur Kenntnis mariner Nematoden aus der Kieler Bucht, Zool. Jahrb. (Abt. Syst.), 62, 4, 329-430.

Schulz, E. 1935. Marine Nematoden von Sicilien und Gran Canaria, Zool. Anz., vol. 109, pp. 299-304.

Schuurmans-Stekhoven, J.H. 1931. Ökologische und morphologische 
Notizen über Zuiderseenematoden, Ztschr. Morph. Ökol. Tiere, 20, 4, 613-678.

Schuurmans-Stekhoven, J.H. 1935a. Nematoda errantia. In Tierwelt Nord- und Ostsee, vol 5, pt. 28, 174 pp. Leipzig.

Schuurmans-Stekhoven, J.H. 1935b. Nematodes libres capturés entre les hydraires dans le port de Plymouth, Bull. Mus. Roy. Hist. Nat., 11, $33,1-2$. Belgium.

Schuurmans-Stekhoven, J.H. 1943. Frelibende marine Nematoden des Mittelmeeres, Zool. Jahrb. (Abt. Syst.), 76, 4, 323-380.

Schuurmans-Stekhoven, J.H. 1946. Freilebende marine Nematoden des Skagerracks und der Umgebung von Stockholm, Ark. Zool., vol. 37A, pp. 1-91.

Schuurmans-Stekhoven, J.H. 1950. Free-living marine nemas of the Mediterranean. 1. The Bay of Villefranche, Mém. Inst. Roy. Sci. Nat., ser. 2, fasc. 37,220 pp. Belgium.

Schuurmans-Stekhoven, J.H. and W. Adam. 1931. Free-living marine nemas of the Belgian coast, Mém. Mus. Roy. Hist. Nat., no. 49, pp. 1-58. Belgium.

Schuurmans-Stekhoven, J.H. and P.M. Mawson. 1955. On some freeliving marine nematodes from Kerguelen Island, Journ. Helminth., $29,1-2,87-104$.

Sergeeva, N.G. 1972. Novye vidy svobodnozhivushchikh nematod otryada Enoplida Chernogo morya (New species of free-living nematodes of order Enoplida of the Black Sea). Zool. Zhurn., 51, 8, 12331237.

Southern, R. 1914. Nemathelmia, Kinorhyncha and Chaetognatha, Proc. Roy. Irish Acad., vol. 31, pt. 54, pp. 1-80.

Steiner, G. 1915. Freilebende marine Nematoden von der Ostküste Sumatras, Zool. Jahrb. (Abt. Syst.), vol. 38, pp. 233-244.

Steiner, G. 1916. Freilebende Nematoden aus der Barentssee, Zool. Jahrb. (Abt. Syst.), vol. 39, pp. 511-676.

Steiner, G. 1922a. Beiträge zur Kenntnis mariner Nematoden, Zool. Jahrb. (Abt. Syst.), vol. 44, pp. 1-68.

Steiner, G. 1922b. Untersuchungen über den allgemeinen Bauplan des Nematoden-körpers, Zool. Jahrb. (Abt. Anat.), vol. 43, pp. 1-96.

Steiner, G. 1933. The nematode Cylindrogaster longistoma and its relationships, J. Parasitol., 20, 1, 66-68.

Steiner, G. and F. Albin. 1933. On the morphology of Deontostoma californicum n. sp., J. Wash. Acad. Sci., vol. 23, pp. 25-30.

Strassen, O.L. zur. 1904. Antraconema, eine neue Gattung freilebender Nematoden, Zool. Jahrb., Suppl. 7, pp. 301-346.

Timm, R.W. 1951. A new species of marine nematode, Thoracostoma magnificum, with a note on possible "pigment cell" nuclei of the 
ocelli. J. Wash. Acad. Sci., vol. 41, pt. 10, pp. 331-333.

Timm, R.W. 1953. Observation on the monography and histological anatomy of marine nematode Leptosomatum acephalatum Chitwood, 1936 (Enoplidae, Leptosomatinae), Amer. Midl. Nat., 49, 1, 229-248.

Timm, R.W. 1959. New marine nematodes of superfamily Enoploidea from the Arabian Sea, J. Bomb. Nat. Hist. Soc., vol. 56, pt. 2, pp. 204-210.

Timm, R.W. 1960. A new species of Leptosomatum (Nematoda) from the Arabian Sea, J. Helminth., 34, 3-4, 217-220.

Türk, F. 1903. Über einige im Golf von Neapel freilebende Nematoden, Mitt. Zool. Stat. Neapel, vol. 16, pp. 281-347.

Villot, A. 1875. Recherches sur les helminthes libres ou parasites des côtes de la Bretagne, Arch. Zool. Exper., vol. 4, pp. 451-482.

Vitiello, P. 1970. Nématodes libres marins des vases profondes du golf du Lion. 1. Enoplida, Tethys, 2, 1, 139-210.

Wieser, W. 1951, 1954a. Untersuchungen über algenbewohnende Mikrofauna mariner Hartboden. I. Zur Ökologie und Systematik der Nematodenfauna von Plymouth, Österr. Zool. Ztschr., 3, 3-4, 425480; III. Zur Systematik der freilebenden Nematoden des Mittelmeeres, Hydrobiologia, 6, 12, (1954), 144-217.

Wieser, W. 1952. Investigations of microfauna inhabiting seaweeds on a rocky coast. IV. Studies on the vertical distribution of fauna inhabiting seaweeds below the Plymouth laboratory, J. Mar. Biol. Assoc., vol. 31, pt. 1, pp. 145-174. U.K.

Wieser, W. 1953a. On the morphology of the head in family Leptosomatidae (marine free-living nematodes), with a key to all genera described, Ark. Zool., ser. 2, 6, 1, 69-74.

Wieser, W. 1953b. Die Beziehungen zwischen Mundhölengetalt, Ernährungsweise und Vorkommen bei freilebenden marinen Nematoden, Ark. Zool., ser. 2, 4, 5, 439-484.

Wieser, W. 1953c. Free-living marine nematodes. I. Enoploidea, Lunds Univ. Arsskrift, N. F. Avd. 2, 49, 6, 155.

Wieser, W. 1954b. Beiträge zur Kenntnis der Nematoden submariner Höhlen. Ergebnisse der österreichischen Tyrrhenia Expedition, Österr. Zool. Ztschr., 5, 12, 172-230.

Wieser, W. 1956. Some free-living marine nematodes, Galathea Repts., vol. 2 (Sci. Res. Dan. Deep-Sea Exp. 1950-1952), pp. 243-253.

Wieser, W. 1959. Free-living nematodes and other small invertebrates of Puget Sound beaches, Univ. Wash. Publ. Biol., vol. 19, pp. 1-170.

Wieser, W. 1960. Benthic studies in Buzzard Bay. II. Meiofauna, Limnol. and Oceanogr., 5, 2, 121-137.

Wieser, W. and J. Kanwischer. 1961. Ecological and physiological studies 
on marine nematodes from a small salt marsh near Wood Hole, Massachusetts, Limnol. and Oceanogr., 6, 3, 262-270.

Winslow, W. 1960. Nematode ecology. In Nematology edited by J.N. Sasser and W.R. Jenkins. Univ. North Carolina Press, Chapel Hill, pp. 341-415. 
Free-living Marine Nematodes as a Component of the Meiobenthos of Chupa Inlet of the White Sea 



\section{Introduction}

165 In the last decade interest in the study of small benthic organisms (meiobenthos), the size of which does not exceed 0.1 to $3.0 \mathrm{~mm}$, has significantly increased. In the quantitative assessment of macrofauna these organisms are generally overlooked. Peterson and Boysen-Jenson (1911) pioneered the study of benthos on the shores of Denmark. However, early studies were biased toward the fish industry and concentrated on those benthic forms which serve as food for fish. An analysis of test samples was usually conducted by hand right at the site or the test samples washed through sieves with a mesh size larger than $2.0 \mathrm{~mm}$. Smaller organisms consequently eluded detection.

In the 1920's and 1930's almost no work was done on the quantitative distribution of meiofauna. But one should not construe that the study of minute multicellulur organisms was entirely ignored. During the period several taxonomic and morphological works appeared on separate groups, particularly on Nematoda, Harpacticoida, Ostracoda, Turbellaria, and Halacarida. In this context the works of Wieser (1959), Purasjoki (1945), Delamare Deboutteville (1960), Swedmark (1964), and a few others are quite noteworthy. An important contribution (Remane, 1933, 1952), which stimulated further interest in the study of the ecology of small benthic organisms as a whole, discussed the morphological adaptations of different groups of meiofauna to specific conditions of habitat.

The work of Mare (1942) was also a pioneering effort; she was the first to identify meiofauna as an estimable category of the benthos. In the 1950's and 1960's a significant number of reports on the quantitative distribution of meiobenthos and groups of organisms constituting it in littoral and deeper waters appeared in other countries. McIntyre (1969) has given quite a comprehensive list of these works in his review.

A study of the meiobenthos is of both theoretical and practical value. Large populations of organisms of meiobenthos in the superficial layers of the ground play an important role in the balance of organic substances in bottom sediments (Rauzer-Chernousova, 1935). Participating in the mineralization of the organic substances of bottom deposits, meiofauna contribute greatly to the formation of the biological regime of the sea.

Meiobenthic organisms represent an "intermediate" link between 
micro- and macrobenthos, accumulating and processing minute food particles, the direct utilization of which by macroforms would otherwise be wasted in the trophic structure (Kiseleva, 1965). As observed by Gilyarov (1944), extremely minute food does not justify the consumption of energy spent on its ingestion. Organisms of meiobenthos available in the surface layer of the ground (1.0 to $2.0 \mathrm{~cm}$ ) (Mare, 1942; Brotskaya, 1951) become a source of nutrition for predatory forms of macrobenthos (Rees, 1940). Information is available on the direct utilization of meiofauna (Nematoda and Harpacticoida) by the young of fishes (Mironova, 1951; Perkins, 1958; Milovidova, 1961). As evaluation of the trophic role of meiofauna in the ecosystem has been based on little information, assessment of their energetics is much more difficult. According to different authors, 3.0 to $30.0 \%$ of the amount of oxygen required by the entire community is consumed by meiobenthos (Wieser and Kanwisher, 1961; Teal and Wieser, 1966; McIntyre, 1969). The species composition of individual groups of meiobenthos is an important aspect in a study of meiofauna. In spite of the fact that a large number of works on individual groups of meiobenthos have been published, such organisms as Nematoda, Copepoda, Ostracoda, and a number of others are still not fully understood.

Existing works touch mainly on the distribution of meiobenthos in very large areas; this, in my opinion, interferes with the explanation of the general phenomena of distribution of organisms. It may be more pertinent to commence work on the study of meiobenthos as a pilot project in more restricted areas. A study of meiofauna is further complicated by the necessity for combining field and research station investigations. Such investigations are best conducted where there is a biological station. Guided by these considerations, the place selected for the present analysis was the Biological Station of the Institute of Zoology, Academy of Sciences, USSR, on the coast of the White Sea. It is extremely difficult to conduct thorough studies in the sublittoral zone; for this reason I worked in the littoral zone in small areas and collected frequent samples with respect to time and place.

During the course of my work I had to decide on the volume and number of representative samples to be taken from a small area which would later determine the frequency of collection of samples in a pilot study of the littoral zone.

Variation in methods usually adopted for the collection and processing of samples of meiobenthos, also makes a comparison of quantitative data from different regions of the world oceans difficult. One problem during the course of my studies was to make the method of processing of meiobenthos samples more precise. This process is extremely laborious. Improving methods of collection of sediment samples facilitates process- 
ing a larger quantity in a comparatively shorter period of time.

Meiobenthos should not be considered an accidental grouping of organisms taken together on the basis of their size or methodological peculiarities of their study. Meiobenthos constitute a complex of specific organisms adapted to conditions of living in capillary spaces between sediment particles. First of all, the general collective character of meiobenthos and the group of organisms entering into their composition is of great interest because one must know the limits of population dynamics of the biotope under study, in order to assess the role of meiofauna in the ecosystem.

It is also very important to know the character of distribution of meiofauna in the littoral zone and its seasonal variations. It may be assumed that organisms of the meiobenthos are uniformly distributed in the entire littoral zone or, contrarily, that their distribution is patchy.

167 As already mentioned, the dominant group of meiobenthos usually comprises free-living marine nematodes and harpacticoids. Chislenko $(1961,1965,1967)$ has published a number of works on harpacticoids of the coastal region of the White Sea, in which the species composition and quantitative distribution of this group of organisms have been detailed. The nematode fauna of the White Sea contrarily has hardly been touched; only two works exist-Filip'ev (1927) and Frolov (1972). In the former a few new species of nematodes from the isthmus (narrow part) of the White Sea have been described, and in the latter publication a list of nematodes from the sandy littoral zone is presented. Taking into account these facts, it is very important to analyze the species composition of this dominant group of meiobenthos. Moreover, it is interesting to postulate the natural phenomena governing the distribution of these organisms in the littoral zone, and to analyze the seasonal dynamics of their population and biomass.

Meiofauna of the littoral zone is of special interest because it has adapted to life in a zone periodically exposed to low and high tides, having an unstable regime with respect to temperature, salinity, availability of food, and other factors. As such, it is important to determine how some of these factors influence the population dynamics of meiofauna (on the basis of some dominant species of nematodes).

It appears possible to determine zoogeographic zones on the basis of the effect of temperature on the speed of multiplication of individual species of nematodes in different seasons. The problem of the zoogeographic origin and distribution of free-living marine nematodes is very complex. Some authors consider these free-living marine nematodes cosmopolitan (Steiner, 1916a; Kreis, 1934; Allgen, 1954). Others assume that such a wide distribution of nematodes is the result of inaccurate -identification in a number of cases (Platonova, 1967). In practice, it 
often turns out that the wide area attributed to one species is occupied by two or three species. At present, it is difficult to give the zoogeographic characters of free-living marine nematodes due to insufficiency of studies. However, guided by their adaptation to particular temperatures and the temperature limits of their multiplication, some inferences can be drawn about their zonal associations. As the entire area of my investigations is situated in the region of distribution of species belonging to the north Atlantic Ocean and the Atlantic sector of the polar basin, zonal association determined to a significant degree the zoogeographic characters.

It is very interesting to analyze the extent of influence of such factors as granulometric composition of sediments, presence and distribution of food material, and salinity on population dynamics and the nature of distribution of marine nematodes. In this work I do not attempt to comprehend the impact of all such factors on meiofauna and have only selected those which visibly influence its development.

Collection of material was carried out from different localities with similar physico-chemical conditions, oxygen regime, etc. during the period of investigation. Oxygen content obviously does not remain constant during a prolonged period of time, but taking into account the fact that studies were done in the littoral zone, it can be assumed that it would always be sufficiently high and not a factor limiting the distribution of these organisms in the littoral zone during the summer and autumn seasons.

This work was accomplished through the constant friendly help, support, and care of my research supervisor, Tatyana Alekseevna Platonova. A.A. Strelkov assisted extensively in editing the manuscript. Comments given by A.N. Golikov and Ya.I. Starobogatovyi on various occasions were extremely helpful in the preparation of this article. Lastly,

168 this work could not have been completed without the organizational support of V.K. Khlebovich, Director of the White Sea Biological Station, ZIN, Academy of Sciences, USSR.

\section{PHYSICAL AND GEOGRAPHIC CHARACTERS OF THE REGION UNDER STUDY}

The White Sea is a water mass in which features of the Arctic and boreal basin are combined, as evidenced in the temperature regime and composition of its fauna and flora (Gur'yanova, 1949). In summer the surface layer of the water heats up to $10^{\circ} \mathrm{C}$ and above, but in shallow waters and closed inlets may be as high as $23^{\circ} \mathrm{C}$; in winter intense freezing continues for 7.0 to 8.5 months (Gur'yanova, 1949; Chernovskaya, 1956). Thus, if during winter conditions in shallow waters are arctic, they 
approach boreal conditions during summer. Sharp seasonal changes in temperature occur as the result of the geographic position and topography of the White Sea; it is situated almost completely to the south of the polar circle in the temperate belt. This determines the boreal character of littoral and deeper waters. At the same time the distance of the sea in the east from the effect of the warm North Cape current leads to more severe conditions in the winter regime compared to the Barents Sea, which is outside the polar circle. Gur'yanova (1949) divided the White Sea into seven regions. My studies were conducted in the second one, i.e., shallow waters of the western half of the sea, from Cape Tur in the west up to Kandalaksha, south coast of Kandalaksha Bay, Karelian coast up to Onega Bay, Salovetskii Islands, and the Letnii coast up to Unskaya inlets. The coastal line of this zone is very cut up by shallow inlets and bays, high granite banks which protect them from turbulence, and breakers. Shallow calm waters of the coastal lagoons warm up to the very bottom.

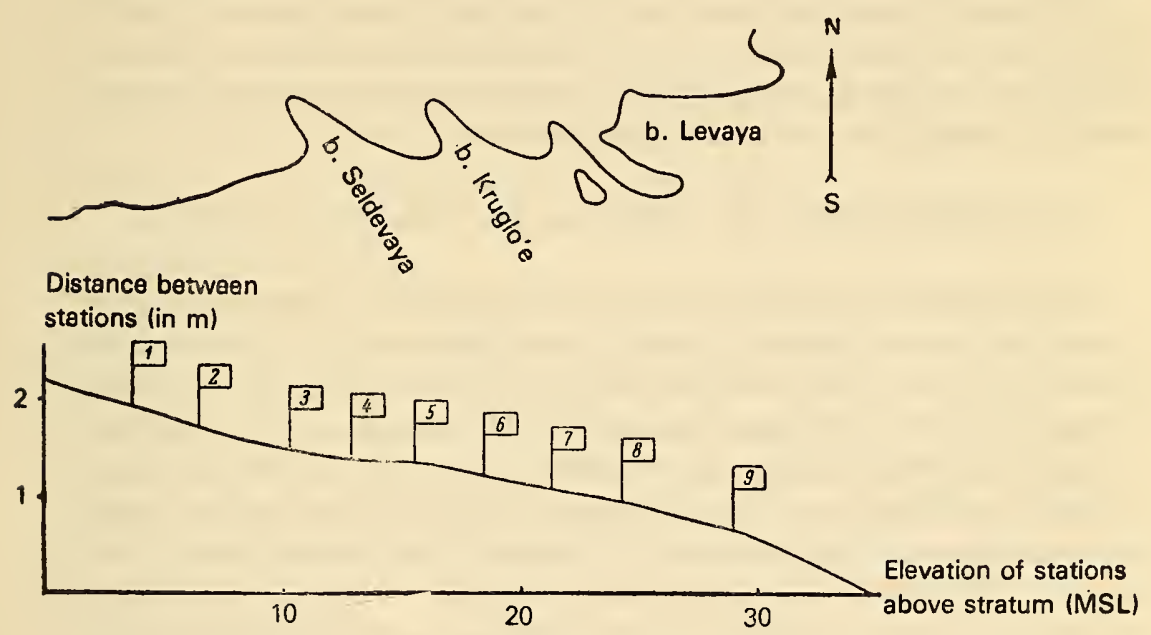

Figure 1. Diagrammatic depiction of stations in the littoral zone of Kruglo'e Bay.

The littoral zone of Kruglo'e Bay, which is a part of the inlets of Chupa Kandalaksha Gulf of the White Sea, was selected for my studies. The littoral zone of Kruglo'e Bay is a small stony-sandy beach $25 \mathrm{~m} \times$ $35 \mathrm{~m}$.

The upper part of the littoral zone is more stony than the lower. Among macrofauna only periwinkles are seen here during summer. As 169 observed by Gur'yanova (1949), the upper horizon of the littoral zone of the White Sea is a "dead zone" because hummocked ice on the banks 
adversely affects the entire macrofauna. The middle horizon is situated within the limits of fluctuations of the sea level, i.e., throughout the course of a month in syzygy as well as in quadrature it is daily flooded with water which dries up every day. Here on separate boulders clumps of fuci with colonies of mytilus are seen. Almost all the stones are seeded with cirripedian barnacles.

The lower horizon of the littoral, in contrast to the first two, is exposed for only a short time. Almost the entire horizon is covered with dense fuci.

Control points (areas) taken for study were selected in such a way as to cover all the conditions of living of meiofauna in all the horizons of the littoral zone. For this purpose a number of stations were established along the maximum length of the beach ranging from supralittoral to sublittoral. In each horizon there were not less than three stations. The selected stations were situated at different levels from zero depth and the distance between them did not exceed two to three meters (Figure 1).

To study the seasonal dynamics of population and biomass of meiofauna and their dependence on some factors of the surrounding medium, collection of material at the stations was done during the course of two seasons, namely, summer of 1970 and autumn of 1971.

\section{TERMINOLOGY, MATERIAL, AND METHODOLOGY}

Terminology. Mare (1942) introduced the term meiobenthos from the Greek word meion meaning "lesser". As a criterion of size, she used the size of the gauze sieve through which the test samples were washed. According to Mare all organisms passing through a sieve with a mesh of $1.0 \mathrm{~mm} \times 1.0 \mathrm{~mm}$ but retained in a sieve with a mesh $0.1 \mathrm{~mm} \times 0.1 \mathrm{~mm}$ belong to meiobenthos. All protozoans, except for Foraminifera, which pass through a sieve with a mesh of $0.1 \mathrm{~mm} \times 0.1 \mathrm{~mm}$, come under microbenthos, whereas all those organisms retained in a sieve with a mesh of $1.0 \mathrm{~mm} \times 1.0 \mathrm{~mm}$ are classed as macrobenthos. Such a categorization of benthos on the basis of size has been done purely from a practical point of view, as each category of benthos requires a special method of collection and separation of organisms from the ground. In this way meiofauna defined on the basis of sieve size is a purely statistical quantum related more or less to an arbitrarily selected part of the general size spectrum of the organisms. It includes not only species which remain within the limits of the given category during the course of their life cycle, but also sexually immature individuals of macrobenthos.

Bougis (1950) distinguishes permanent and temporary components within the limits of meiofauna. Permanent elements are those organisms which during the course of their life cycle belong to meiobenthos. These 
include such groups as ostracods, kynorhynths, water mites, nematodes, harpacticoids, and others. Most of the species of these groups pass through a sieve with a $1.0 \mathrm{~mm}$ mesh; hence it is better to regard permanent meiofauna not as a statistical but as a taxonomic category. This group of small multicellular organisms according to measurements, number and time of multiplication, and adaptation, may be considered separate from larger components of the benthos. Temporary elements comprise many representatives of macrofauna with benthic juvenile stages and hence could be related to meiobenthos in the earlier stages of their development.

Chislenko (1961) proposed the term eumeiobenthos (eumesobenthos) for the first category and pseudomeiobenthos (pseudomesobenthos) for the second. These two terms reflect the taxonomic composition and not the temporary or permanent nature of meiobenthos.

170 Sometimes the terms microbenthos, microfauna (Remane, 1933; Arnol'di, 1940; Brotskaya, 1951), and mesobenthos (Chislenko, 1961; Gurvich, 1967; Dekhtyar, 1969) are wrongly used to express the idea of meiobenthos. It seems to me extremely appropriate to use the terminology adopted at the First International Conference on Meiofauna, held at Tunisia in 1969 (Hulings, 1971). The basis of this terminology is the classification of benthos proposed by Mare (1942).

Using universally accepted international terminology avoids vagueness in defining meiofauna.

Material and Methodology. At present three types of equipment are used for the collection of meiofauna: a tubular device, bottom grab, and dredge. The choice of equipment depends on the zone of the sea under investigation (littoral, sublittoral, or deep waters). Collection of material from the littoral zone is generally effected with tubular devices operated manually. Many researchers use a simple metallic or plastic tube, which is cored into the bottom and then withdrawn, pruning the basic column of the bottom (Tseeb, 1937; Brotskaya, 1951; Jansson, 1967b; Dzyuban, 1968; Dekhtyar, 1969; Frolov, 1971).

Collection of samples from silted sediments poses a special problem. A number of authors have described tubular devices designed for this purpose (Moore and Neill, 1930; Krogh and Spärck, 1936; Mare, 1942). Similar devices are utilized for the collection of meiofauna at shallow depths, as most of the components of the meiofauna reside in the upper few centimeters of the bed (Smidt, 1951; Muus, 1964). A similar but slightly modified appartus for the collection of meiofauna from sandy sediments has been described by Willimoës (1964), Craib (1965) and Fenchel (1967).

Larger types of collecting devices-bottom grabs (Purasjoki, 1945; Kiseleva, 1965; Thiel, 1966; Stripp, 1969)—are mostly used at greater 
depths. These are the least satisfactory because they stir the substratum and, while hauling, the organisms are apt to be washed away. These deficiencies are partially removed if the bottom grabs are provided with bags made of fine gauze (Smith and McIntyre, 1954), Dredges for the collection of meiofauna are quite limited (Foster, 1953; Sanders, Hessler and Hampson, 1965).

For maximum value, the sample should contain a sufficient quantity of fauna-from the largest form to the smallest-so that it is possible to define the density of meiofauna more precisely. According to Gray (1971) the most rational device for the collection of meiobenthos on sandy ground is a tube $37 \mathrm{~mm}$ in diameter.

I used a tube with a diameter of $50 \mathrm{~mm}$, height of $25 \mathrm{~mm}$, with a lid of standard ground glass for the collection of meiobenthos. As 90 to $95 \%$ of the meiofauna in spring, summer, and autumn are found in the upper layer of sediment (1.0 to $2.0 \mathrm{~cm}$ ) (Brotskaya, 1951; Stripp, 1969), core samples of the sediment included complete meiofauna of the littoral area under study. In samples of the volume mentioned 300 to 4,000 specimens were usually present, which were quite enough to characterize the density of meiobenthos at a point of investigation. As for Gray's statement that the most rational diameter of the tube is $37 \mathrm{~mm}$, it is necessary to establish empirically the minimum volume of a sample which will characterize the population of meiobenthos in each specific region of study and in each biotype.

The second important aspect of meiobenthos collection is frequency of sampling from a definite area. To elucidate this problem three areas

171 one square meter each were selected and five random samples taken. In samples of the upper horizon of the littoral zone the total number of specimens (nematodes and other organisms combined) was $230,605,234$, 314 , and 323 per sample. On the basis of this data, I hypothesized that in $75 \%$ of the samples drawn from an area one square meter primarily organisms of one type would prevail, i.e., 200 to 300 specimens per sample.* This hypothesis was verified on the basis of results of selective investigations by way of calculating the degree of reliability in the difference between empirical and theoretical parts $\left(t_{p_{-}} P\right)$ according to the formula $t_{p-P}=p-P / \frac{P Q}{n}$ (Plokhinskii, 1970): where $p-P=$ difference between selected parts. The reliability coefficient of the difference $\left(t_{p-p}\right)$ in this case is equal to 0.3 with the degree of freedom (v) equal to 4 $(\mathrm{v}=\mathrm{n}-1)$, and the standard value of Student's test $\left(\mathrm{t}_{\mathrm{st}}\right)$ is equal to 2.8 to 4.6 to 8.6 , i.e., $t_{p-P}<t_{s t}$, which means that the difference between the general and the selected parts is insignificant. In other words, in $75 \%$ of

*Meaning not clear in Russian original-General Editor. 
a small number of samples collected from an area one square meter a correct picture of the meiofauna population is obtained.

In the middle horizon of the littoral zone 1,305, 497, 1,391, 1,253 and 1,010 organisms were collected in each sample. Taking for granted the hypothesis advanced in the first case and calculating the criterion of reliability, the difference between the general (combined) and the selected lots was $t_{p_{-} P}$ equals 0.8 and $t_{p_{-} P}<t_{s t}$, i.e., that in this case one to two samples from one square meter with a probability of 0.75 reflect the size of the organism population in the selected area.*

In the lower horizon of the littoral zone $741,539,653,628$ and 765 specimens were recorded in each probe. The coefficient of reliability in the difference between the general and the selected lots, as in the first case, was equal to 0.3 and less than the standard value for Student's test.

Hence one to two probes from one square meter will give the real population of meiofauna at a given spot in the littoral zone with $75 \%$ accuracy.

Core samples were washed in the laboratory through a fine mesh (No. 68) three to four times in order to separate finer fractions of the substratum.

For further processing of the samples of meiobenthos in the laboratory several methods were followed: 1. "Plankton" method (Dzyuban, 1968 ) in which the sample is taken in a beaker, diluted with water, stirred, and then withdrawn by means of a $5-\mathrm{ml}$ pipette provided with a bulb. The sample so processed is examined in 15 to 20 portions. The main drawback of this method is the difference in sedimentation rate of various groups of meiobenthos, as a result of which organisms with a small specific gravity usually enter the pipette in larger numbers, which may lead to a wrong interpretation of the ratio of groups of meiobenthos in the sample.

2. Organisms can also be separated from the sample by the flotation method. Sugar (Fast, 1970) or salt (Monakov and Mordukhai-Boltovskii, 1959) can be used to make a flotation solution. But this method too has limitations as it is possible to separate only individual groups. For example, in a flotation solution of sugar oligochaetes and mollusks can be separated from the sample, but it is absolutely impossible to isolate nematodes. A salt solution is useful for the separation of copepods and water mites, but unsuitable for ostracods, oligochaetes, and nematodes.

3. Screening the entire sample or some part in the chamber of Bogorova under binoculars is a third method of processing. To expedite analysis of the sample it should be stained. I used Rose Bengal for staining samples, which method more or less coincides with the staining

*Meaning not clear in Russian original-General Editor. 
technique of Thiel (1966). The preparation is simple: to $100 \mathrm{ml}$ water add $0.5 \mathrm{ml}$ concentrated solution of Rose Bengal and 2.0 to $3.0 \mathrm{ml}$ concentrated solution of phenol. The stain persists for three to four hours. With such a preparation all groups of meiobenthos are stained, which helps in

172 distinguishing them from soil particles at the time of screening.

If the sample is rich in meiofauna, it is advisable to examine only a part of the sample at one time and not the whole. To divide the sample into ten approximately similar parts, Chislenko devised an apparatus (Figure 2) which consists of a container and a divider. The divider has ten sections or compartments almost equal in area (from 8.15 to 11.28 $\mathrm{cm}^{2}$ ). It is technically quite difficult to prepare a divider in which all the walls or septa of the divider and the container ideally approximate each other, and for this reason the problem of the parametrical data of the divider was examined.

For this purpose a series of counts were done. To simplify, each series of counts were done with one and the same sample. The sample was introduced in the container, stirred, the divider then lowered to the bottom, and the sample allowed to settle. After settling organisms were sorted from each compartment by means of a pipette and counted under binoculars in the chamber of Bogorova.

I was interested in the following aspects: 1) distribution of organisms

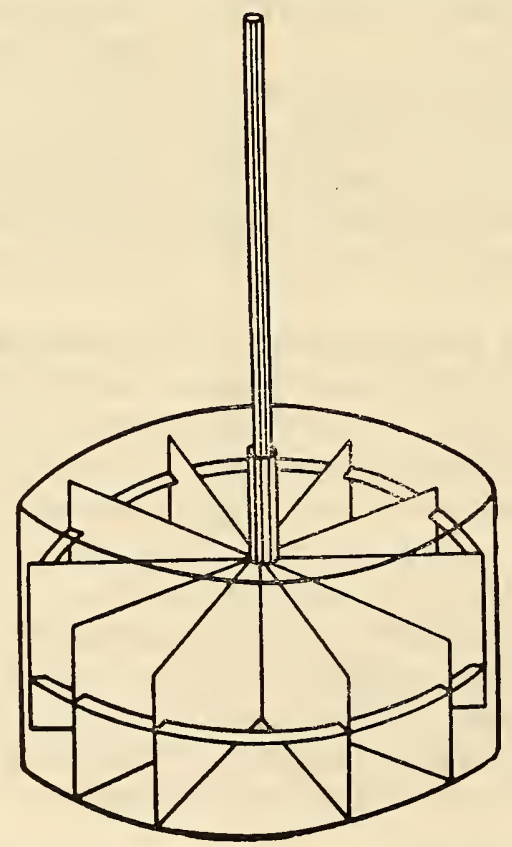

Figure 2. Divider equipment of L.L. Chislenko. 
1.0 to $2.0 \mathrm{~mm}$ long, i.e., those which could not pass through the chinks between the septa (walls) of the divider and the container; 2 ) influence of the manner of selection of organisms on the ultimate results; and 3) distribution of organisms below $1.0 \mathrm{~mm}$ in each section.

Copepods, crustaceans of genus Calanus ( 1.0 to $2.0 \mathrm{~mm}$ ), exemplified large organisms, 2,500 specimens of which were present in the sample (Gal'tsova, 1971). The least number of organisms (159) fell into the compartment with an area of $8.87 \mathrm{~cm}^{2}$ and the greatest number (302) fell into the compartment with an area of $10.55 \mathrm{~cm}^{2}$. Relative variations in the number of Calanus within the limits of each compartment ranged from 1.25 to 2.00 , and in the whole series 1.49 on the average.

As the areas of all the compartments differ slightly from each other, the question arose as to what relation exists between the area of the compartment and the number of organisms in it. With this in mind, I calculated $\sigma_{1}$ and $\sigma_{2}-$ mean square deviation of the number of organisms in each compartment and of the area, along with $\mathrm{r}$ - the correlation coefficient expressing the relation between the area of the compartment and the number of organisms falling into a given compartment. These values for the first series of counts were $\sigma_{1}=36.0, \sigma_{2}=0.71$ and $\mathrm{r}=0.603$. For a level of 0.05 no relation between number of organisms in a compartment and area of compartment was found.

On the whole the relative variation in copepod number in the compartments of the divider did not exceed 1.5. In other words, if counting of large organisms is done in only two or three compartments of the divider and, on the basis of this, the number in the whole sample determined, then the probable figure will differ from the actual maximum by 1.5 times.

Hence the predicted number of organisms in the sample will differ insignificantly from the actual one. Time spent on processing the sample is significantly shortened. The limit of absolute number of organisms for

173 which such error is insignificant is calculated on the basis of a hundred individuals.

The second aspect-parameters of the divider-depicts the influence of the order of selection of organisms from the compartments on the end results. Samples were drawn, containing about 2,000 copepods, from alternate compartments. The first samplings were taken from compartments $1,3,5,7$, and 9 and the second series from $2,4,6,8$, and 10 . The minimum number of copepods was recorded in compartments with an area of $9.12 \mathrm{~cm}^{2}(165)$ and the maximum in compartments with an area of $10.09 \mathrm{~cm}^{2}(248)$. Relative variations in number of copepods ranged from 1.19 to 1.70 , equal to 1.40 on the average for the counts of these series. Squares of standard deviation of specimen number for the first and second series of collection were: $\sigma_{1}=22.4, \sigma_{2}=25.6$. The correlation 
coefficient ( $r$ ), expressing the relation of order of selection to number of organisms in compartments, was 0.137 . At a level of 0.05 significance no relation between these two features was found.

In an ideal case $10 \%$ of the total number of organisms contained in a sample must fall in each compartment. Practically, less than $10 \%$ fall in some compartments and more than $10 \%$ in others, yet almost the same results are obtained in the sum total as anticipated for an ideal case. It follows that the order of separating organisms from the sectors does not affect the results obtained (coefficient of correlation confirms the same). Organisms may be sorted from two or three compartments successively or selectively form different places in the divider, and the error will not exceed 1.4 to 1.5 in either case.

Larvae of copepods (Nauplii) (average size of individual $0.2 \mathrm{~mm}$ ) served as a model for smaller organisms. Organisms were selectively drawn from five sectors. The least number of larvae was recorded for a compartment with an area of $8.15 \mathrm{~cm}^{2}(185)$ and the maximum number in a compartment with an area of $10.09 \mathrm{~cm}$ (290). Relative variations in the compartments constituted 1.32 to 1.66 and for this series on the average 1.52 . When the results obtained were compared with the two preceding series, the quantities were of the same order (1.4 to 1.5).

Standard deviations and correlation coefficient for the third series were: $\sigma_{1}=34.1, \sigma_{2}=0.81$, and $\mathrm{r}=0.633$. As in the first series, the correlation coefficient revealed an absence of relation between the area of the compartment and the number of organisms falling into it. Hence small differences in the areas of the compartments of the divider may be disregarded, and the distribution of organisms taken as equal for all compartments.

To ensure a more uniform distribution of samples in this device, a subsidiary divider with smaller diameter of septa than in the main one may be added, but the plates of this divider must be cut like teeth in a comb.

The method of processing samples of meiobenthos in this case is as follows: the sample is placed in the container, diluted with water up to the mark, mixed with the supplementary divider, which is then quickly withdrawn and the main divider with septa reaching up to the container walls substituted. The sample is allowed to settle for a period of 10 to 15 minutes. Subsequently the contents of two or three compartments are drawn out and examined in the Bogorov chamber and differential counts according to groups carried out. The number of organisms in the whole sample is determined on the basis of these sortings. For organisms fewer in number in the sample, it is advisable to examine the sediments of the sample.

In this way the Chislenko divider may be recommended for processing 
sample in the Bogorov chamber. It expedites counts of organisms of meiobenthos. In using the Chislenko divider the error in number of organisms does not exceed 1.4 to 1.5 times; the lower limit of the absolute number of organisms for which such an error is inconsequential is measured in hundreds of individuals. The distribution of organisms in

174 the compartments of the divider may be considered equal irrespective of minor differences in the area of individual compartments. The order of selection of organisms from compartments of the divider exerts almost no influence on the ultimate result. In order to obtain more precise information, a supplementary divider may be used for agitating the sample.

The average weight of a single individual in each group had to be established in order to determine the biomass. For this purpose 50 to 100 specimens of each group were measured, the average length of each individual determined, and the average weight calculated according to nomograms (Chislenko, 1968). The young of mollusks (50 to 100 specimens) were weighed directly and the average individual weight then determined. The average weights derived for various groups were as follows:

\begin{tabular}{lcc}
\multicolumn{1}{c}{ Group } & Length, mm & $\begin{array}{c}\text { Weight } \\
10^{-2}(\mathrm{mg})\end{array}$ \\
Foraminifera & 0.5 & 1.300 \\
Nematoda & 1.1 & 0.014 \\
Polychaeta & 1.5 & 5.100 \\
Oligochaeta & 1.0 & 1.100 \\
Harpacticoida & 0.5 & 0.800 \\
Ostracoda & 0.5 & 0.650 \\
Isopoda & 1.3 & 2.500 \\
Nauplii & 0.2 & 0.063 \\
Tardigrada & 0.3 & 0.065 \\
Halacarida & 0.8 & 6.800 \\
Bivalvia & 1.4 & 40.000 \\
Gastropoda & 1.2 & 63.000
\end{tabular}

My data correspond very well with the scanty data available in literature on the average weight of representatives of meiofauna. For example, Stripp (1969) gives the weight of nematodes as $0.03 \times 10^{-2} \mathrm{mg}$ and that of harpacticoids $0.8 \times 10^{-2}$.

In calculating biomass the number of specimens was multiplied by the average weight of a given group of organisms in the meiofauna.

As mentioned earlier, material for the present work was collected during the course of two seasons at one and the same control points (summer of 1970 and autumn of 1971). In all, 114 samples were collected, processed, and fixed in $4.0 \%$ formalin. Together with collection of material, temperature and salinity of water in the littoral zone (see pp. 
331,348 ) were also measured by methods usually followed in studies of hydrobiology (Bruevich and Demenchenok, 1944; Voronkov 1953). Control samples for an analysis of granulometric composition of the bottom were collected from stations at which meiofauna was being studied. Analysis of the granulometric composition was undertaken by the central laboratory of SZGU (Table 1). To compare the results composite curves were drawn (Figure 3). On the abscissa log measurements of sediment granules are given (in $\mathrm{mm}$ ) and on the ordinate the percentage content of one or the other fraction. To interpret the data of granulometric analysis served granulometric coefficients were calculated, namely, the average 175 (median) size of the granules and the coefficients of sorting and asymmetry (Table 2). To calculate the coefficients quadrants were first made: hori-

Table 1. Granulometric composition of the substratum ( $d$ in $\mathbf{m m}$ ) in the littoral stations of Kruglo'e Bay (in \%)

\begin{tabular}{|c|c|c|c|c|c|c|c|c|c|}
\hline 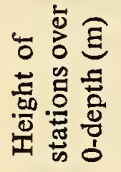 & $\begin{array}{l}\underset{\mathrm{E}}{\mathrm{E}} \\
\stackrel{0}{\wedge}\end{array}$ & $\begin{array}{l}E \\
\text { E } \\
\sim \\
\stackrel{1}{0}\end{array}$ & $\begin{array}{l}E \\
\Xi \\
\mathfrak{E} \\
\mathfrak{r} \\
n\end{array}$ & 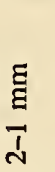 & $\begin{array}{l}E \\
\Xi \\
n \\
0 \\
1\end{array}$ & 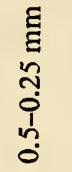 & 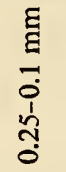 & $\begin{array}{l}\frac{E}{E} \\
\frac{0}{0} \\
\frac{1}{0}\end{array}$ & $\begin{array}{l}\tilde{E} \\
\tilde{E} \\
\tilde{O} \\
\stackrel{0}{0} \\
\mathrm{~V}\end{array}$ \\
\hline \multicolumn{10}{|c|}{ - - - - - - - - - - - - - - - - - - - - - - - - - - - - - - } \\
\hline 1.95 & 2.1 & 10.5 & 10.2 & 4.7 & 16.3 & 31.0 & 22.0 & 2.6 & 06 \\
\hline 1.78 & 10.7 & 14.5 & 10.7 & 3.3 & 3.6 & 9.7 & 39.0 & 6.9 & 1.6 \\
\hline 1.55 & - & 5.0 & 9.9 & 4.3 & 7.0 & 14.1 & 42.2 & 13.5 & 4.0 \\
\hline 1.44 & - & 3.8 & 11.9 & 7.2 & 12.5 & 21.2 & 33.7 & 7.6 & 2.1 \\
\hline 1.41 & - & 20.5 & 21.9 & 7.2 & 12.1 & 17.3 & 15.6 & 3.9 & 1.5 \\
\hline 1.37 & 19.1 & 14.1 & 19.1 & 5.4 & 11.6 & 14.6 & 12.4 & 2.3 & 1.4 \\
\hline 1.25 & - & 5.0 & 8.8 & 5.4 & 11.0 & 15.6 & 36.4 & 14.1 & 3.7 \\
\hline 1.15 & - & 6.1 & 6.5 & 4.0 & 14.3 & 37.8 & 27.6 & 3.1 & 0.6 \\
\hline 0.99 & - & 1.0 & 5.7 & 7.2 & 22.4 & 24.2 & 29.8 & 8.4 & 1.3 \\
\hline
\end{tabular}

Table 2. Granulometric coefficients for samples collected September 9, 1977 from the littoral zone of Kruglo'e Bay at different heights over 0-depth

\begin{tabular}{|c|c|c|c|c|c|}
\hline $\begin{array}{l}\text { Height in } \mathrm{m} \\
\text { (station No.) }\end{array}$ & Q3 & $Q_{1}$ & $S_{0}$ & $\mathrm{M}_{\mathrm{d}}$ & $\mathbf{S}_{\mathrm{k}}$ \\
\hline$-\overline{1.95}(1)$ & 2.09 & 0.31 & 26 & 0.64 & $-\bar{s}-1$ \\
\hline $1.78(2)$ & 5.37 & 0.22 & 2.0 & & \\
\hline 1.55 (3) & 0.79 & 018 & 4.9 & 0.40 & 7.37 \\
\hline 1.44 (4) & 152 & 0.10 & 2.1 & 0.29 & 1.65 \\
\hline & & 0.20 & 2.8 & 0.50 & 1.36 \\
\hline 1.41 (J) & 7.50 & 0.44 & 4.1 & 1.32 & 1.89 \\
\hline $1.37(6)$ & 8.71 & 0.62 & 3.8 & 2.27 & 1.04 \\
\hline $1.25(7)$ & 0.79 & 0.21 & 1.9 & 0.37 & 1.16 \\
\hline $1.15(8)$ & 0.79 & 0.31 & 1.6 & 0.52 & 0.88 \\
\hline $0.99(9)$ & 0.79 & 0.25 & 1.8 & 0.51 & 0.72 \\
\hline
\end{tabular}




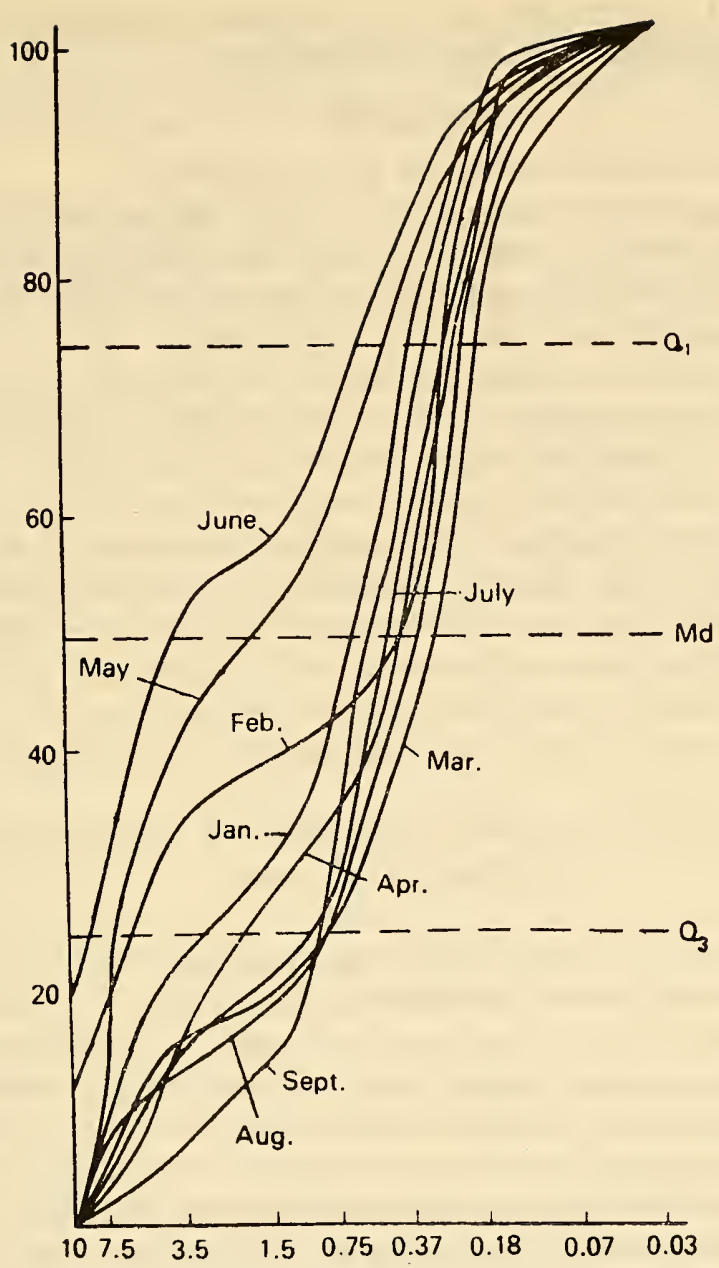

Figure 3. Granulometric composition of substratum samples collected from Kruglo'e Bay September 17, 1971.

Abscissa-grain size of substratum ( $d$ in $\mathrm{mm}$ ); Ordinate-percentage content of fractions.

zontal lines were drawn on graph paper from the points on the axis of the ordinate correponding to 25,50 and $75 \%$. The abscissa of the points of intersection of the horizontal and cumulative curve provided the initial data for calculating granulometric coefficients (Rukhin, 1953). The two extreme numbers represent quadrants and the middle number the median. The coefficient of sorting was determined according to the formula-

$$
\mathrm{S}_{0}=\sqrt{\mathrm{Q}_{3} / \mathrm{Q}_{1}}
$$


where $Q_{1}$ and $Q_{3}$ are the first and third quadrants. Coefficients of asymmetry were calculated according to the formula-

$$
\mathrm{S}_{\mathrm{k}}=\mathrm{Q}_{1} \mathrm{Q}_{3} / \mathrm{Md}^{2}
$$

where $M d$ is the median and $Q_{1}$ and $Q_{3}$ the quadrants.

Medium sand with an average size of 300 to $600 \mu \mathrm{m}$ predominated in almost all the stations investigated. Large sand granules, average diameter 1,000 to $2,000 \mu \mathrm{m}$, predominated only at two stations (5 and 6) situated in the middle horizons of the littoral zone.

All nine cumulations were represented by extremely steep curves, bespeaking the homogeneity of the ground. Coefficients of sortings confirmed this. According to Trask (Trask et al., 1932), if $S_{0}$ is $<2.5$, the sand is well sorted, if $S_{0}$ is 2.5 to 4.5 moderately well sorted, and if $S_{0}$ is $>4.5$, poorly sorted. Sediment at the selected section is well or moderately sorted sand if $S_{k}$ (coefficient of asymmetry) shows the position of the maximum ordinate (mode) in relation to average diameter (median), i.e., asymmetry of distribution of granules in relation to median. If $S_{k}$ is more than 1.0, then finer fractions predominate in the sediment, i.e., the mode is situated in this case in the finely granular part of the spectrum.

\section{QUANTITATIVE CHARACTERS OF THE MEIOBENTHOS OF KRUGLO'E BAY}

In the last 10 to 15 years rather numerous studies have appeared on the population and biomass of small benthic organisms. Yet little infor-

176 mation is available on the systematics and populations of different groups of meiobenthos. Attempts to carry out a collateral analysis of meiofauna while investigating macrobenthos have not been successful. A need thus arose to undertake specialized studies of minute benthic organisms, not exceeding 2.0 to $3.0 \mathrm{~mm}$ in size. Such studies usually consisted of a "once only" collection of samples from an area, or larger areas were subjected to study from which an extremely insignificant number of samples were taken (Krogh and Spärck, 1935; Mare, 1942; Bougis, 1946; Purasjoki, 1945; Brotskaya, 1951; Wieser, 1960; Chislenko, 1961; Wieser and Kanwisher, 1961; Kiseleva, 1965; Muus, 1967; Tietjen, 1969, 1971; Belogurov and Koroleva, 1970; Belogurova, 1970; Gray and Rieger, 1971; Thiel, 1971; Gal'tsova, 1971a).

If one takes into account that the methods of collection and processing adopted in every concrete case differ, then it is not difficult to predict that the data on population of meiobenthos as a whole and its different groups are highly heterogeneous. For the sandy littoral zone of the Baltic Sea for example, 5,000 specimens $/ \mathrm{m}^{2}$ (Purasjoki, 1945), 376,000 specimens $/ \mathrm{m}^{2}$ (Fenchel and Jansson, 1966), and 968,000 specimens $/ \mathrm{m}^{2}$ (Muus, 
1967) have been recorded. With respect to density of an individual group (for example, marine nematodes), 2,000 (Purasjoki, 1945), 789,000 (Bregnballe, 1961), and 658,000 (Muus, 1967) specimens $/ \mathrm{m}^{2}$ have been recorded.

Subsequent stages of study attempted to investigate the population dynamics of meiobenthos and its different groups with respect to seasons and for the whole year (Smidt, 1951; McIntyre, 1964; Hopper and Meyers, 1966; Yeates, 1968; Tietjen, 1969; Schmidt, 1969; Stripp, 1969; Coull, 1970; Warwick and Buchanan, 1971; Skoolmun and Gerlach, 1971; Frolov, 1971; Harris, 1972). For the coast of the North Sea various authors have given different data on the population of meiofauna as a whole during the course of one year: Schmidt (1968-1969) indicates that the limits of fluctuation in density of meiofauna range from 131,000 to 375,000 specimens $/ \mathrm{m}^{2}$, while Stripp (1969) gives the figures 500,000 to $1,000,000$ specimens $/ \mathrm{m}^{2}$. McIntyre (1964) indicates that the average population of meiobenthos during the course of one year is $1,959,000$ specimens $/ \mathrm{m}^{2}$.

It follows from these examples that a "once only" collection of material cannot reflect the picture of distribution of organisms of meiofauna with sufficient accuracy because such samples were usually collected from points separated by rather long distances. With regard to seasonal and year-round observations (even when sample collecting was done from strictly defined points), sampling was not done often enough-only once in one or two months (Skoolmun and Gerlach, 1971; Warwick and Buchanan, 1971; and others). Such minimal sampling, in my opinion, cannot yield an objective assessment of the population dynamics of meiobenthos and its different groups. Taking all this into account I decided to initiate a study of meiofauna of the White Sea in just a small

177 section of the littoral zone. Distances between stations did not exceed two to three meters and samples were collected from them not less than once in seven to ten days. Work continued in the same area for two years and was conducted in different seasons. In 1970 the population dynamics and biomass of meiobenthos were assessed during the spring-summer season and in 1971 during the summer-autumn season.

\section{Spring-Summer Season of 1970 (Table 3)}

The following groups of meiobenthos were found in the littoral zone of Kruglo'e Bay in the spring-summer season of 1970: eumeiobenthos (Foraminifera, Nematoda, Harpacticoida, Halacarida, and Turbellaria), pseudomeiobenthos (Oligochaeta, Polychaeta, and the young of mollusks Bivalvia and Gastropoda). The population of the entire meiofauna ranged from 70,600 to $2,606,640$ specimens $/ \mathrm{m}^{2}$. When the distribution of orga- 


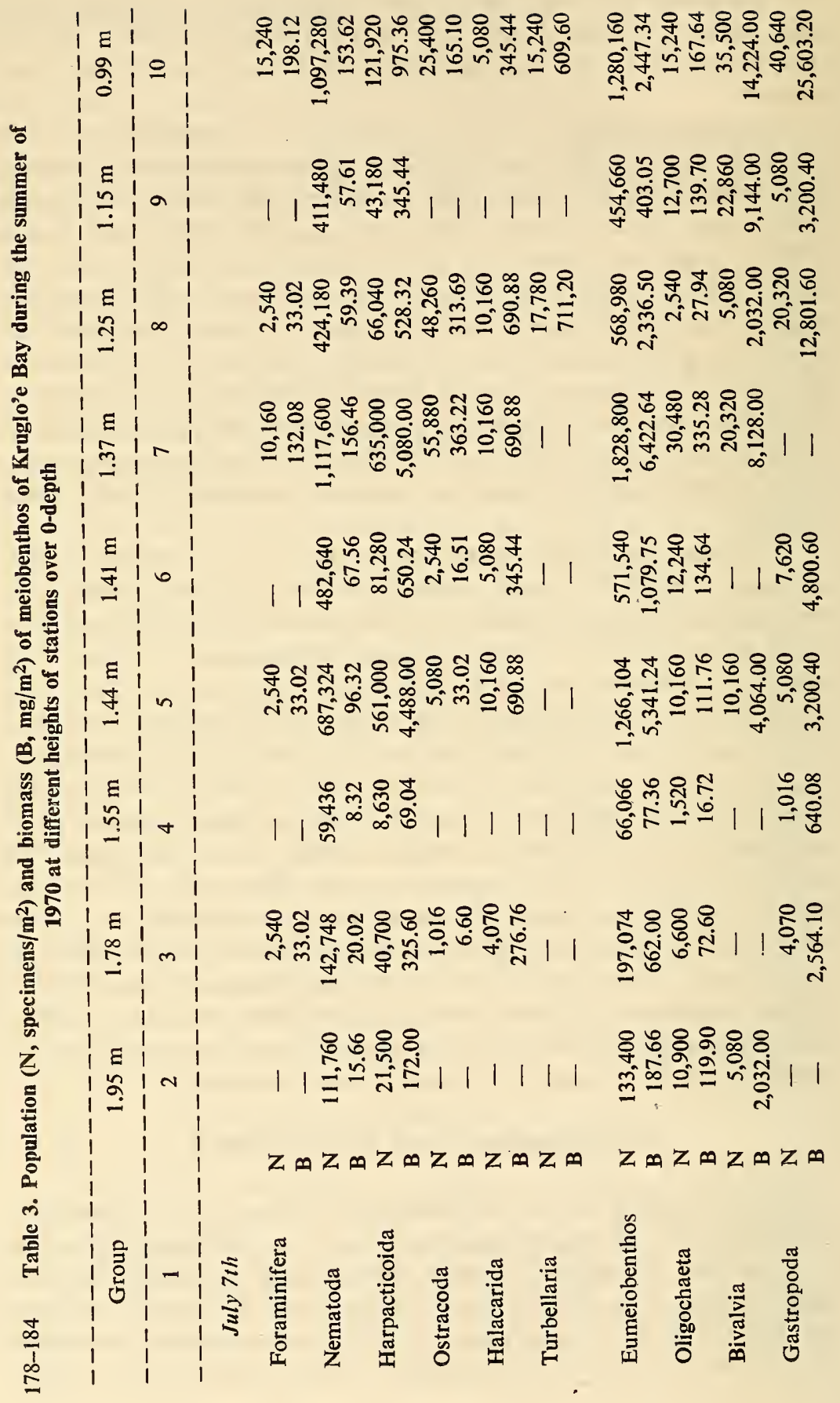




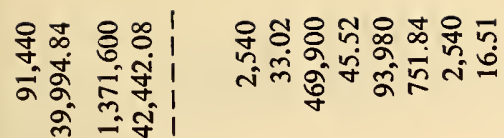

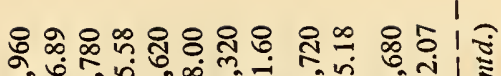

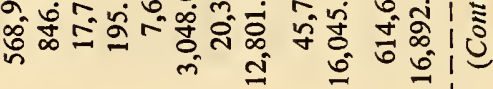

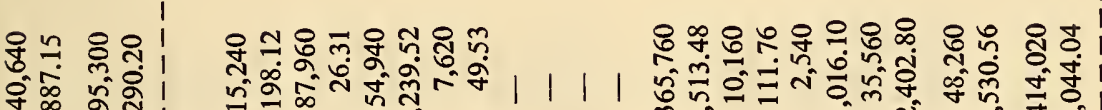

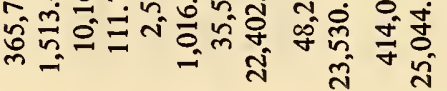

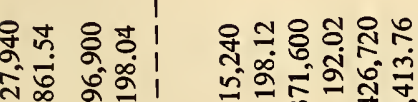

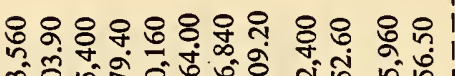

更

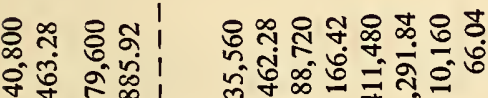

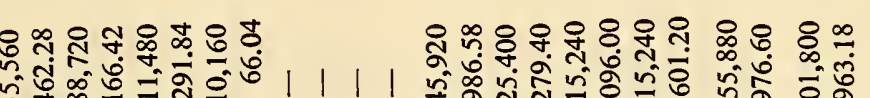

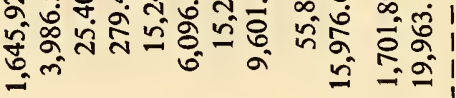

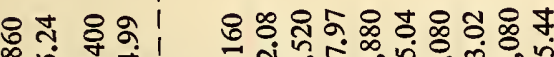

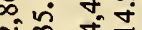

สู่

on

은

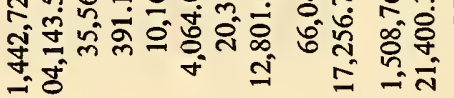

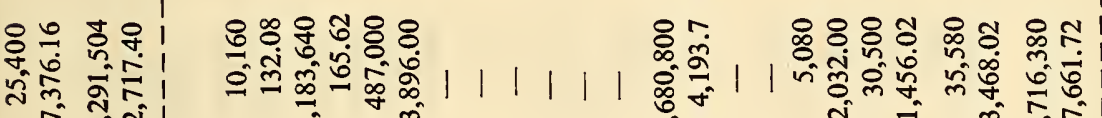

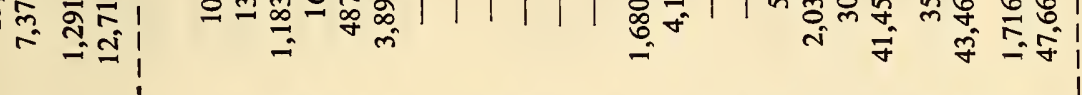

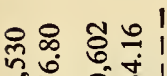

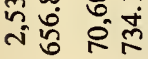

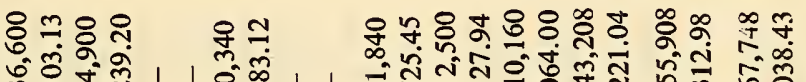

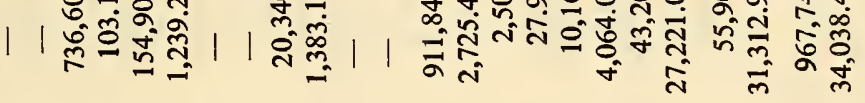

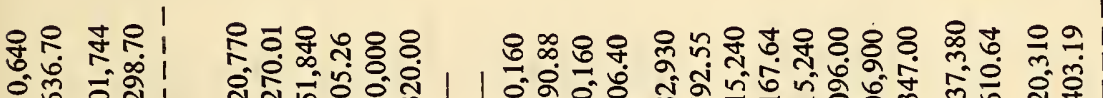

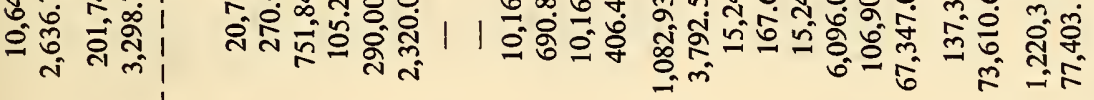

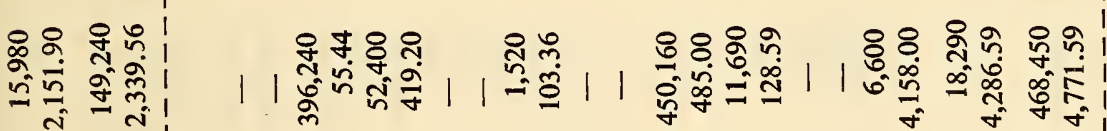

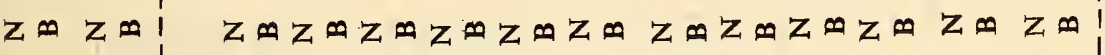

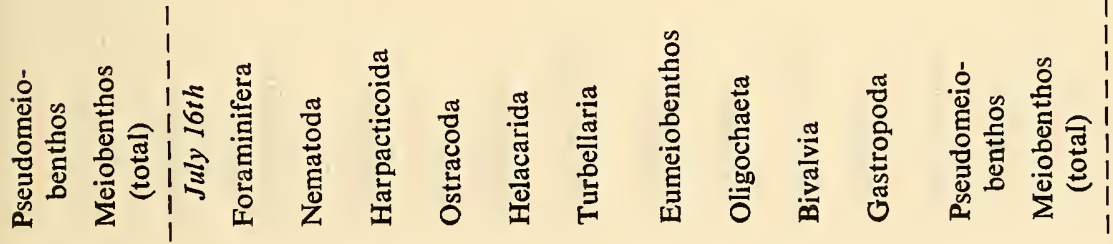




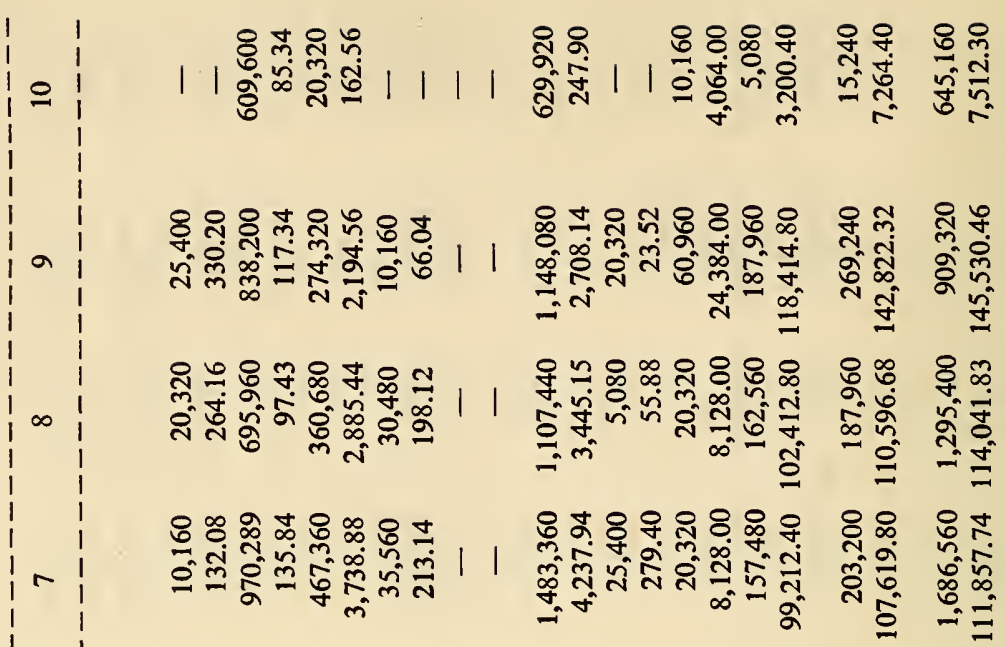

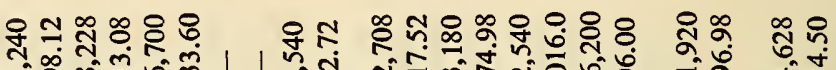
ปू.

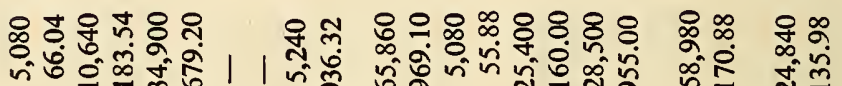

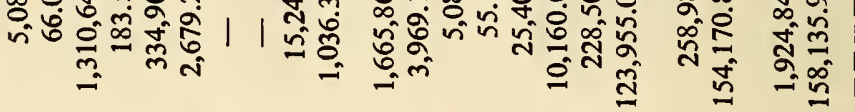

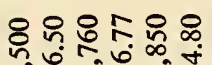

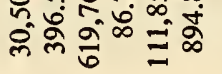

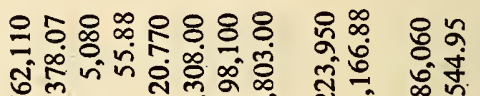

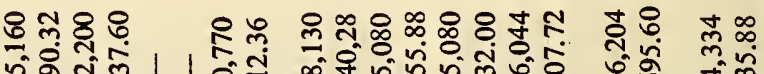

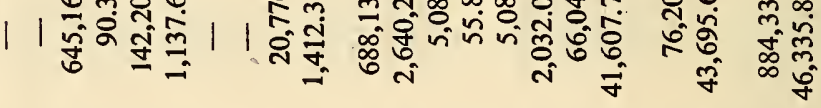

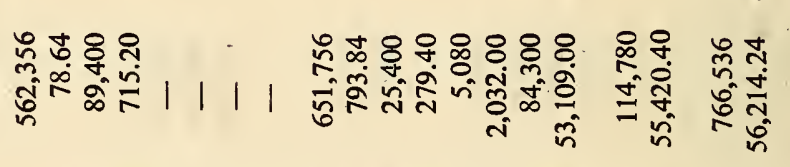

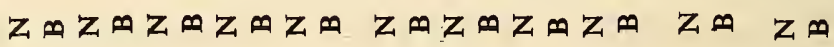

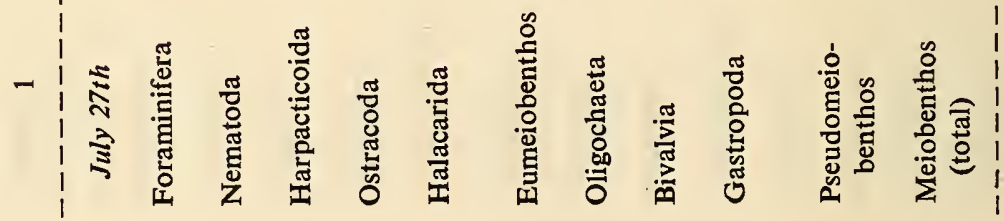




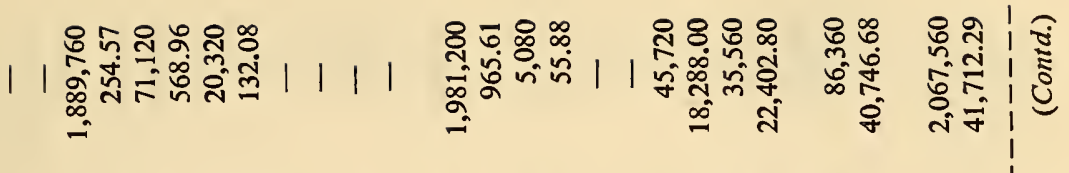

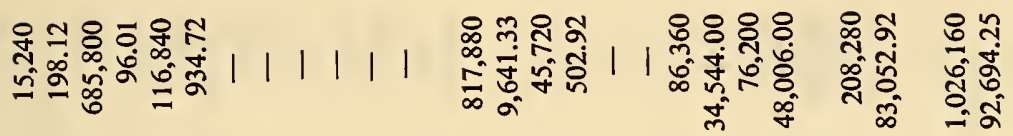

응유:

बेल

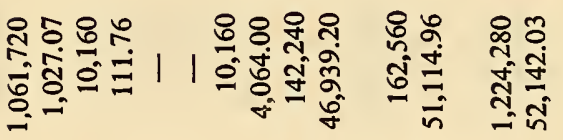

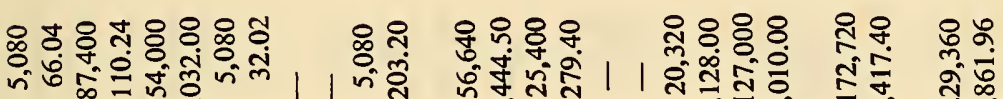

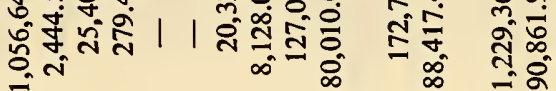

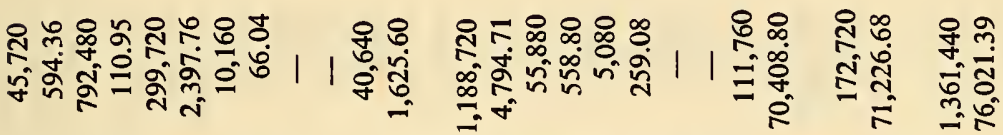
융 8088 웅

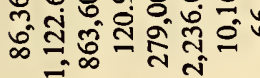

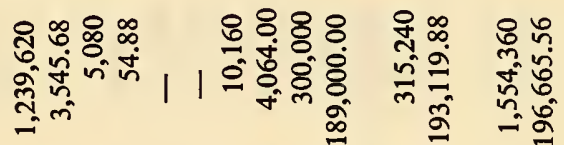
웅ㅇํㅇㅇㅇㅇ

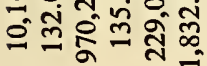

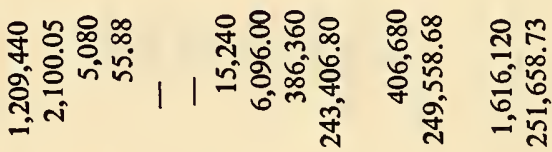

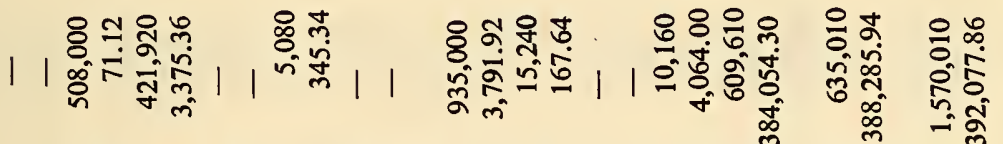

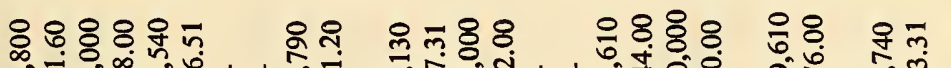
| |ूুm $\mathrm{Z} \oplus \mathrm{Z} \oplus \mathrm{Z} \oplus \mathrm{Z} \oplus \mathrm{Z} \oplus \mathrm{Z} \oplus \mathrm{Z} \oplus \mathrm{Z} \oplus \mathrm{Z} \oplus \mathrm{Z} \oplus \mathrm{Z} \oplus \mathrm{Z} \oplus \mathrm{Z} \oplus$

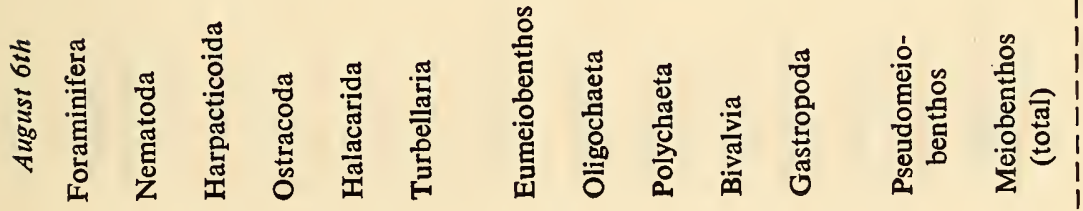




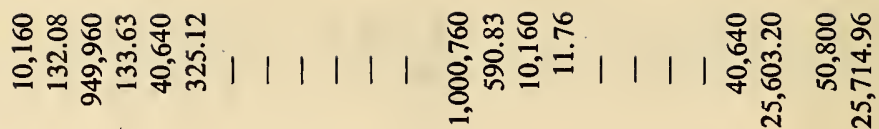

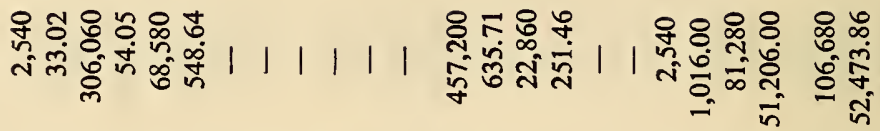

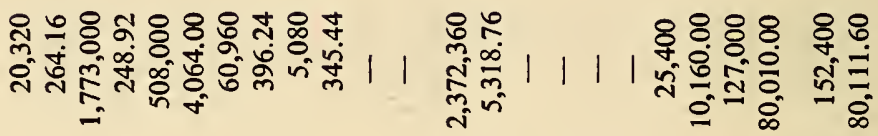

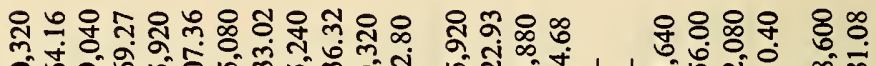

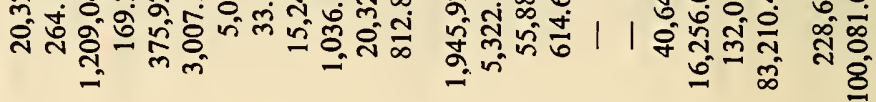

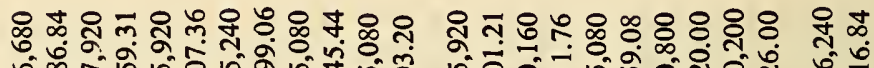

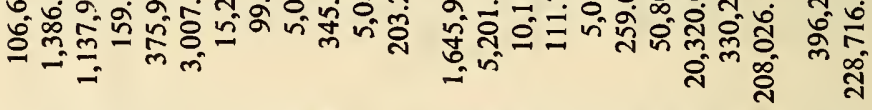

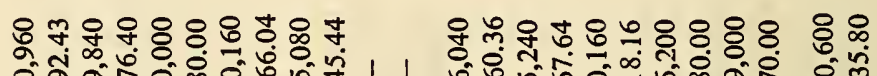
क人

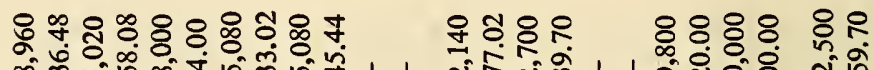

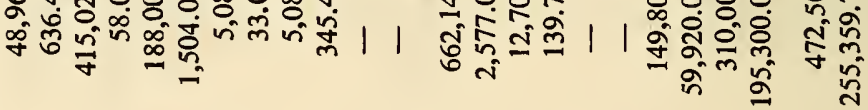

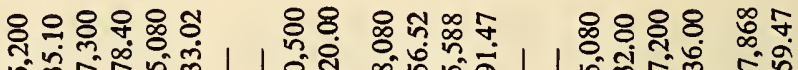

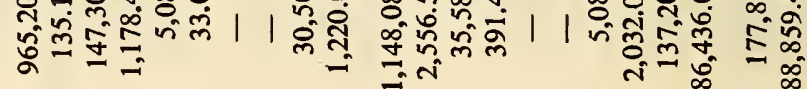

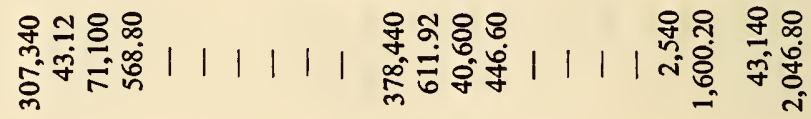
$\mathrm{Z} \oplus \mathrm{Z} \oplus \mathrm{Z} \oplus \mathrm{Z} \oplus \mathrm{Z} \oplus \mathrm{z} \oplus \mathrm{Z} \oplus \mathrm{z} \oplus \mathrm{z} \oplus \mathrm{z} \oplus \mathrm{z} \oplus \mathrm{Z} \oplus$

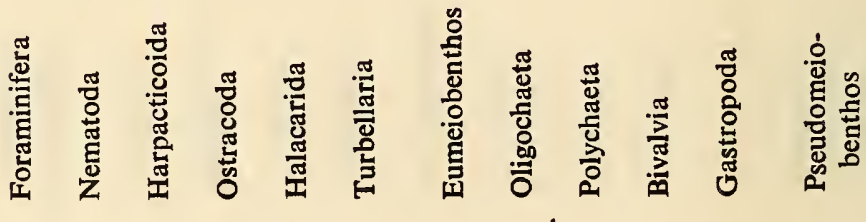




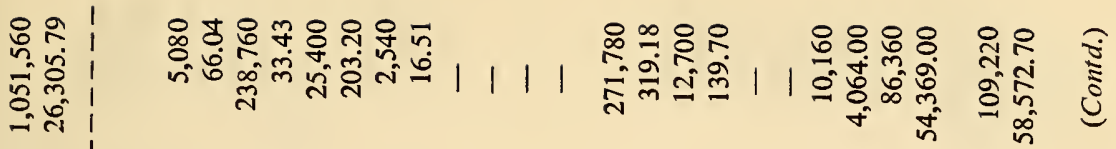

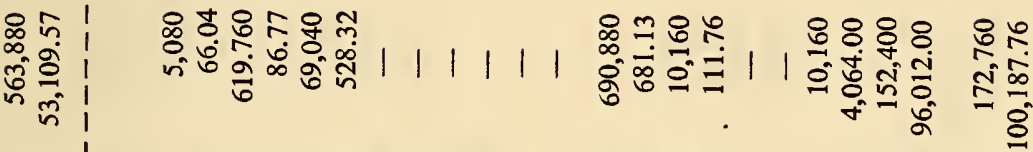

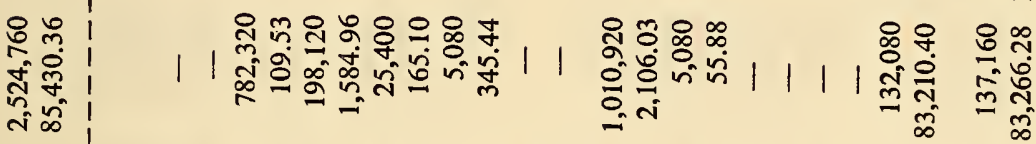

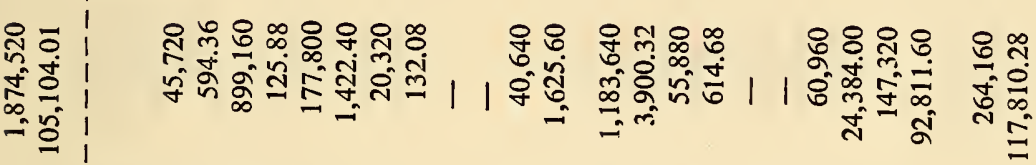

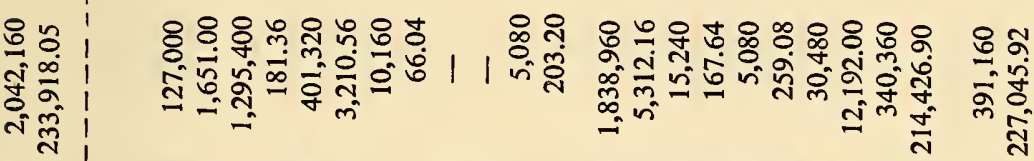

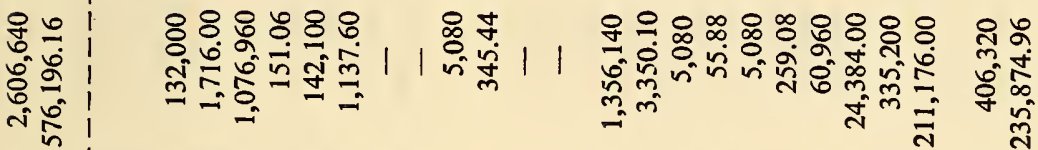

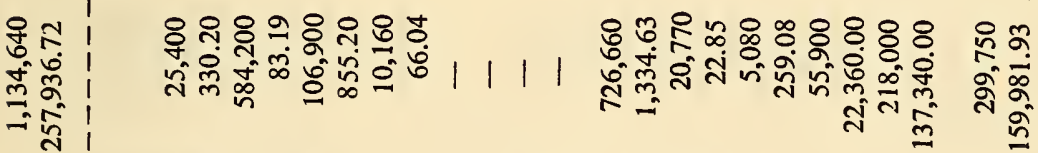

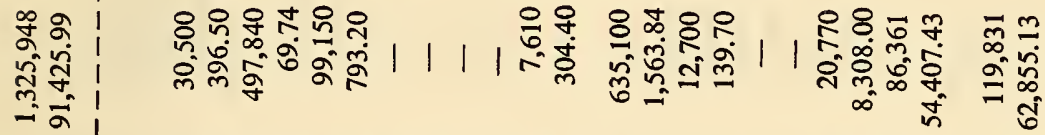

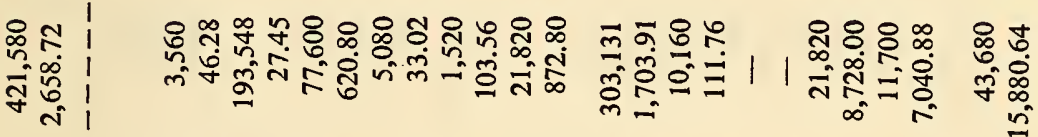

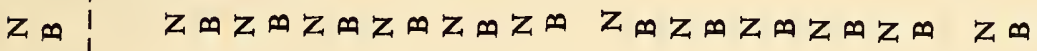

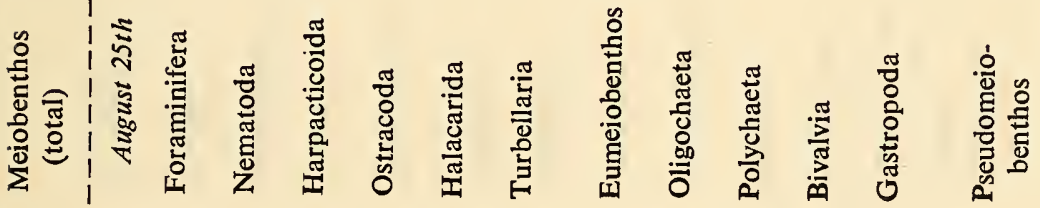




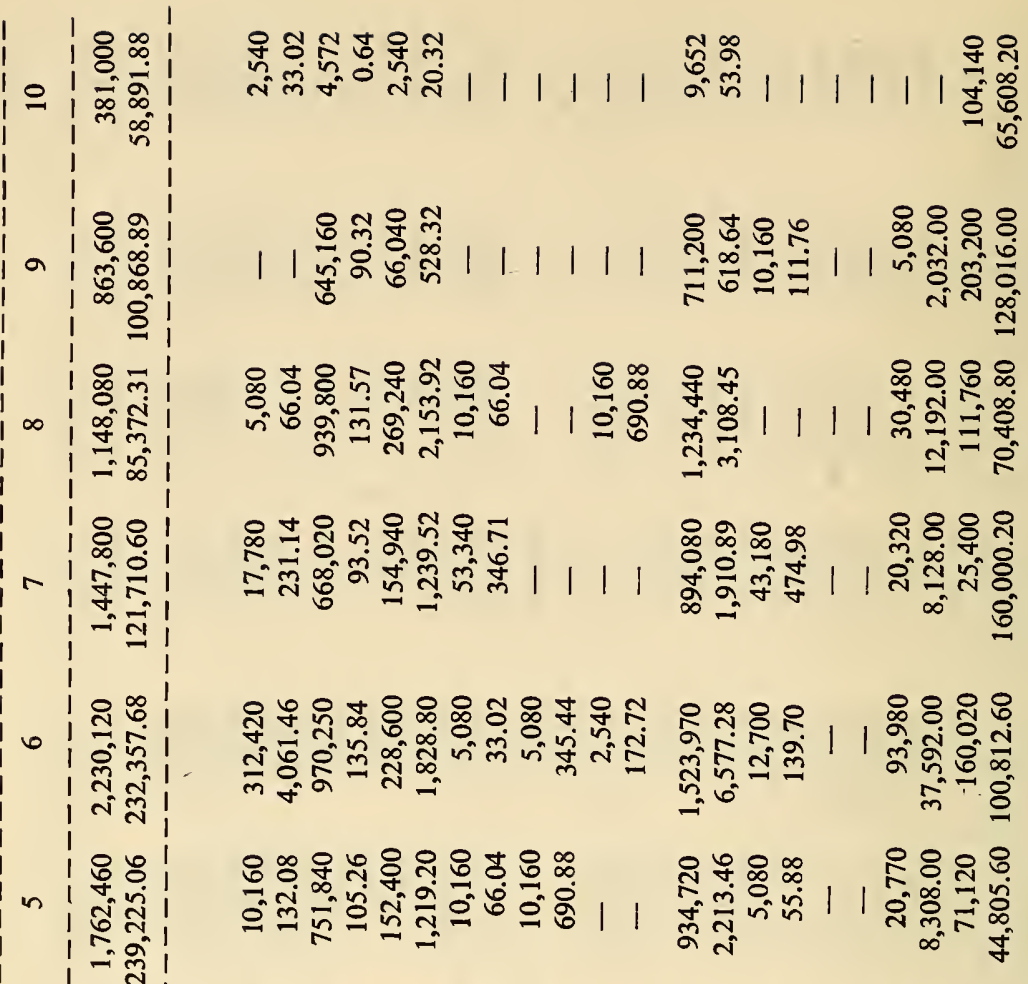

운

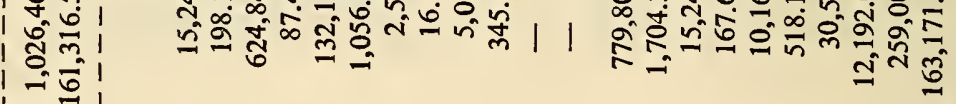

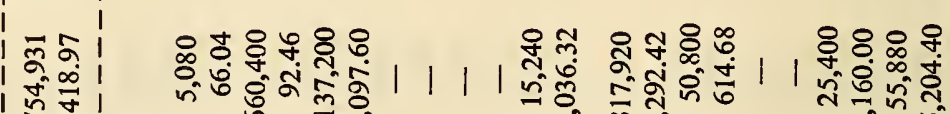
ह है

ठ

Ion

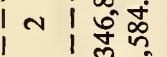

I

$\mathrm{zm}$

$\mathrm{Z} \oplus \mathrm{Z} \oplus \mathrm{Z} \oplus \mathrm{Z} \oplus \mathrm{Z} \oplus \mathrm{Z} \oplus \mathrm{Z} \oplus \mathrm{Z} \oplus \mathrm{Z} \oplus \mathrm{Z} \oplus \mathrm{Z} \oplus$

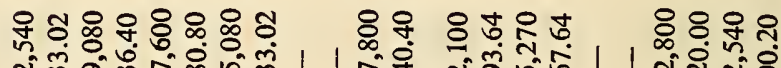

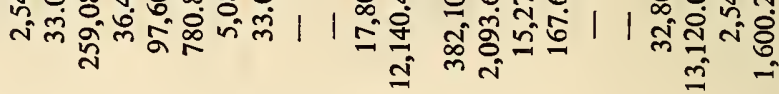

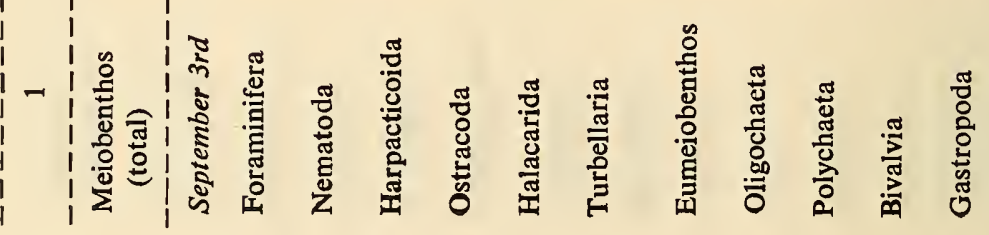




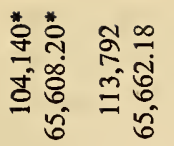

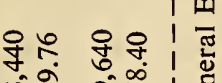

๙

तळ बूं।

웡용ำ

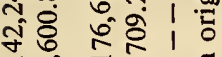

ली ले । .

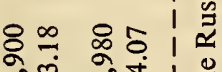

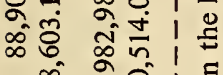

की की। I.

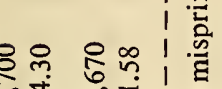

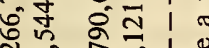

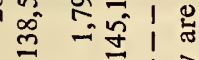

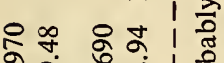

ूั ठิ

กी - กै।

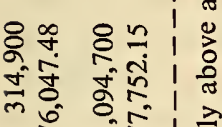

요

$\circ \%$

त穴 진

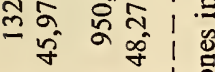

응 후을 定

คंक तिं।

‡

Z电 $\mathrm{Z} \oplus$

, 边

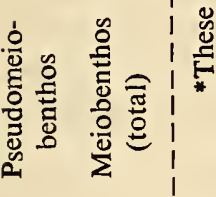


nisms of meiofauna was examined according to sections its irregularity even within the limits of a single horizon was notable. For example, at the three stations located at a distance of not more than 2.7 to $2.9 \mathrm{~m}$ in the middle horizon the lowest population was recorded (July 7,1970 ) in the middle station $\left(594,400 / \mathrm{m}^{2}\right)$, the highest at the lower one $(1,879,600 /$ $\left.\mathrm{m}^{2}\right)$, and an intermediate population $\left(1,291,500 / \mathrm{m}^{2}\right)$ at the junction of the upper and middle horizons. Moreover the same pattern was observed for the lower horizon on July 16, 1970, the upper horizon on August 25, 1970 , and so no. One possible reason for this unequal distribution of meiobenthic organisms must have been unequal distribution of food resources (p. 346).

During the course of the entire season the greatest density of meiobenthos was associated with the middle horizon of the littoral zone, rarely going below $1,000,000$ specimens $/ \mathrm{m}^{2}$. This tallies very well with the data of some authors (Meadows and Anderson, 1968) concerning the maximum density of bacteria in the middle (intermediate) horizon of the littoral zone. Bacteria, as is known, enter into the food composition of many representatives of meiobenthos (constituting up to $50 \%$ of the food of marine nematodes). The upper horizon of the littoral zone is the most poorly populated, although here too the population does not drop below 400,000 specimens $/ \mathrm{m}^{2}$ from the end of July to the end of August. The lower horizon of the littoral occupies an intermediate position with respect to density of meiofauna.

The population dynamics for the entire summer were as follows: during the first half of July the density of meiofauna remained at approximately the same level, from the middle of July to the middle of August the density gradually increased throughout the whole section, the highest being recorded on August 17, 1970 (1,300,000 to 2,600,000 specimens $/ \mathrm{m}^{2}$ ), followed by a gradual decline at the beginning of September, going down to 950,000 to $1,790,000$ specimens $/ \mathrm{m}^{2}$ (p. 340). August is considered the warmest month of the White Sea (Chernovskaya, 1956) and probably large-scale multiplication of organisms of meiofauna, which prefer warmer temperatures for reproduction, is associated with this period.

Of the two large subdivisions of meiobenthos, eumeiobenthos plays a leading role, constituting not less than 80 to $95 \%$ of the general population; this is because it includes permanent representatives which do not exceed 2.0 to $3.0 \mathrm{~mm}$ in size. It is difficult to say anything about the population dynamics of pseudomeiobenthos as after growing out of the dimensional limits they become members of macrobenthos. Consequently, it appears advisable to dwell in greater detail on the population dynamics of different groups of eumeiobenthos. 
Foraminifera ${ }^{1}$ constituted 2.0 to $7.0 \%$ of the total number of meiobenthos. During the summer season their number ranged from 2,540 to 312,420 specimens $/ \mathrm{m}^{2}$. In the littoral zone their distribution was irregular mainly in the middle and lower horizons. Their greatest density was recorded in the middle horizon at the end of August.

185 Harpacticoids constituted 10 to $20 \%$ of the total population of meiofauna. During summer their population ranged from 8,630 to 635,000 specimens $/ \mathrm{m}^{2}$. Their occurrence was considerably irregular on the beach. Such a varied picture of distribution is associated to some degree with their great mobility (up to $10 \mathrm{~cm} / \mathrm{min}$ ). In spite of this it should be noted that during the course of the entire summer they preferred to stay on the lower stratum of the upper horizon, and the midupper levels of the 186 lower horizon. The maximum population throughout the entire section was recorded in the middle of July $(411,000$ to 487,000$)$ and in the middle of August (310,000 to 508,000 specimens $/ \mathrm{m}^{2}$ ).

Ostracods constituted 0.5 to $1.5 \%$ of the total number of meiobenthos or 1,016 to 60,960 specimens $/ \mathrm{m}^{2}$; they were found mainly in the middle and lower horizons of the littoral zone. The maximum density of population throughout the entire section was recorded on August 17, 1970.

Halacarids (marine mites) constituted about $1.0 \%$ of the total number of meiofauna or 1,520 to 20,770 specimens $/ \mathrm{m}^{2}$. They were found mainly in the upper and middle horizons of the littoral zone. The maximum population throughout the section was recorded in the beginning to the middle of July.

Turbellarians also constituted 1.0 to $2.0 \%$ of the meiofauna population, or 2,540 to 40,640 specimens $/ \mathrm{m}^{2}$. They localized in the upper and middle horizons of the littoral zone.

Nematodes constituted 50 to $80 \%$ of the entire population of meiofauna. The leading role of nematodes in sandy beaches has been observed by many researchers (Purasjoki, 1945; Smidt, 1951; Wieser, 1960; Fenchel and Jansson, 1966; Muus, 1967; Tietjen, 1969; Coull, 1970). During the summer of 1970 the nematode density was 4,570 to $1,778,000$ specimens/ $\mathrm{m}^{2}$. The lowest population was recorded at the end of summer in the lower horizon of the littoral zone. Nematodes were distributed very irregularly in the littoral zone (Figure 4, Table 3). At the beginning of summer two peaks in the population were noted in the middle $(1,117,600)$ and lower $\left(1,097,280\right.$ specimens $\left./ \mathrm{m}^{2}\right)$ horizons. Population was lowest

1Only live specimens, well-stained with Rose Bengal were taken into consideration. 


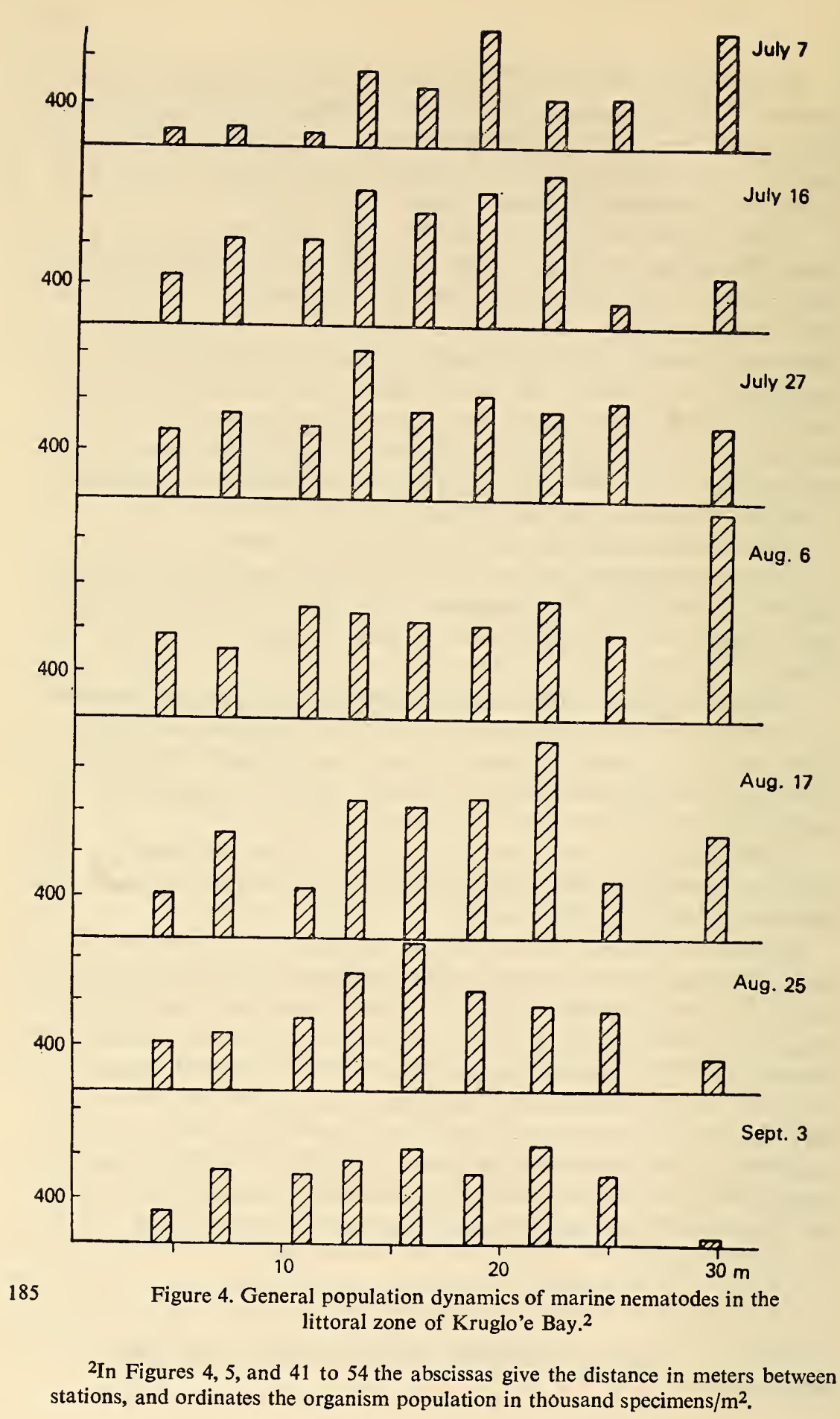


in the upper horizon $\left(59,436\right.$ to 112,740 specimens $\left./ \mathrm{m}^{2}\right)$. Increase in numbers throughout the section took place toward the middle of July, but the maximum remained in the middle (intermediate) horizon as before $\left(1,188,720\right.$ specimens $\left./ \mathrm{m}^{2}\right)$. The peak disappeared in the lower horizon, which was characterized by very low density. Toward the end of July the number of nematodes reduced a little, on the average 600,000 to 900,000 specimens $/ \mathrm{m}^{2}$. A peak population continued in the middle horizon. At the beginning of August it was more or less the same as at the end of July, but the maximum during this period shifted to the lower horizon of the littoral zone. The highest number of nematodes throughout the section was 900,000 to $1,200,000$ specimens $/ \mathrm{m}^{2}$ in the middle of the month, when the maximum population shifted again from the lower horizon to the middle. At the end of August and beginning of September a gradual fall in population throughout the section was observed. During this period the highest concentration remained in the middle (intermediate) horizon of the littoral zone.

Pseudomeiobenthos comprised, on the average, 5.0 to $20.0 \%$ of the population of meiofauna.

Oligochaetes constituted 2.0 to $3.0 \%$ of the total meiofauna $(1,520$ to 55,880 specimens $/ \mathrm{m}^{2}$ ) and were recorded in all horizons of the littoral zone. The lowest population was recorded in the month of July.

Polychaetes constituted less than $1.0 \%$ of the meiobenthos. Maximum population (on the basis of a few samples) did not exceed 10,160 specimens $/ \mathrm{m}^{2}$. They were not found in the month of July and in the month of August only a few in isolated samples were recorded from the middle horizon.

Young of lamellibranchs constituted 1.0 to $9.0 \%$ of the total meiofauna, or 2,540 to 149,800 specimens $/ \mathrm{m}^{2}$. During the month of July their population remained approximately at the same level, i.e., 10,000 to 20,000 . In August a gradual increase up to 20,000 to 40,000 specimens/ $\mathrm{m}^{2}$ took place and the maximum concentration was found in the middle horizon of the littoral zone.

Young of gastropods constituted 1.0 to $32.0 \%$ of the total population of meiofauna, or 1,010 to 859,000 specimens $/ \mathrm{m}^{2}$. The maximum appearance of the young was registered between the end of July and the beginning of August $\left(60,000\right.$ to 180,000 specimens $\left./ \mathrm{m}^{2}\right)$. During August the density throughout the littoral zone remained high.

Brotskaya (1951) has given some estimates of population of some groups of meiobenthos of the White Sea: nematodes-718,000 to $1,700,000$; harpacticoids $-80,000$ to 187,000 ; oligochaetes $-20,000$ to 60,000 ; turbellarians $-70,000$ to 170,000 ; and young of all mollusks 18750,000 to 160,000 specimens $/ \mathrm{m}^{2}$. Frolov (1971) estimated the population of the entire meiobenthos of the White Sea on sandy littoral beds during 
summer as $1,650,000$ to $1,900,000$ and nematodes alone as $1,000,000$ to $1,600,000$ specimens $/ \mathrm{m}^{2}$. The data of these two authors compare well with mine.

The biomass of each group was determined by multiplying the average weight of an individual by its number (Table 3 ). The total biomass of meiobenthos during the summer season was 0.7 to $576.2 \mathrm{~g} / \mathrm{m}^{2}$. In the biomass an inverse correlation to population was observed: 80 to $90 \%$ of the entire biomass was contributed by pseudomeiobenthos because young mollusks constituted its main bulk and the weight of one representative of pseudomeiofauna is ten to a hundred times more than the weight of representatives of eumeiobenthos. The dynamics of biomass of eumeiobenthos on the whole parallel the dynamics of population; for this reason I shall briefly discuss the values of biomass for different groups.

The biomass of forminiferans (in $\mathrm{mg} / \mathrm{m}^{2}$ ) comprised 33 to 1,716 (the highest throughout the entire section as recorded on August 25, 1970 was 300 to 10,000); of harpacticoids 69 to 5,080 (the highest in the section observed during the month of August was 1,000 to 3,000); ostracods 6.9 to 396.2 (the highest throughout the entire section was observed on August 17, 1970); halacarids (marine mites) 103.4 to $1,412.4$ (the highest throughout the entire section was recorded on August 7, 1970); and turbellarians 203.2 to 1,625 .

Nematodes constituted numerically the most predominent group of meiofauna, but the average weight of a single nematode was the least of all $(0.14 \mu \mathrm{m})$; they occupied one of the lowest positions with respect to biomass. Extreme values of biomass for the season ranged between 0.6 to $264.6 \mathrm{mg} / \mathrm{m}^{2}$ and the highest for the section was observed on August 17, 1970.

Values of biomass for pseudomeiobenthos during the season ranged between 6.5 to $527.3 \mathrm{~g} / \mathrm{m}^{2}$.

\section{Summer-Autumn Season of 1971 (Table 4)}

The meiofauna population during autumn of 1971 was 201,676 to $6,283,960$ specimens $/ \mathrm{m}^{2}$, i.e., the range was significantly wider than during the summer of 1970 . The highest density of meiofauna occurred in the middle of September, comprising $1,000,000$ to $6,000,000$ specimens $/ \mathrm{m}^{2}$. Organisms of meiofauna were irregularly distributed throughout the littoral zone. During this season the maximum density was observed in the upper and middle horizons, as distinguished from summer when the maximum population was recorded in the middle and lower horizons. 
The composition of meiofauna with respect to groups was the same as during summer. I shall dwell in greater detail on the population dynamics of different groups.

Foraminiferans constituted 1.0 to $3.0 \%$ of the total population, or 1,520 to 33,020 specimens $/ \mathrm{m}^{2}$, and were found mainly in the middle and lower horizons. The maximum population was recorded at the end of September.

Harpacticoids constituted 3.0 to $30.0 \%$ of the total number of meiofauna, or 5,080 to 215,900 specimens $/ \mathrm{m}^{2}$. The highest population throughout the section in the first ten days of September was 80,000 to 200,000 , followed by a gradual fall, so that during the month of October the number was 40,000 to 100,000 specimens $/ \mathrm{m}^{2}$, approximately twice less than in the summer season.

Ostracods constituted 1.0 to $4.0 \%$ of the entire meiofauna, or 1,520 to 35,560 specimens $/ \mathrm{m}^{2}$, and were recovered mainly from the middle or lower horizon.

Halacarids (marine ticks) constituted less than $1.0 \%$ of the entire meiofauna or 2,540 to 5,080 specimens $/ \mathrm{m}^{2}$. They inhabited the middle and lower horizons of the littoral zone.

Turbellarians constituted 1.0 to $5.0 \%$ of the total meiofauna or 1,520 to 60,960 specimens $/ \mathrm{m}^{2}$. Their maximum population was 10,000 to 20,000 in the middle of September. In the month of October the population decreased to 5,000 to 10,000 specimens $/ \mathrm{m}^{2}$.

Nematodes, as in the summer season of 1971 , constituted the leading group in the entire meiobenthos, comprising 90 to $96 \%$ of the population or 77,720 to $6,156,900$ specimens $/ \mathrm{m}^{2}$. Their distribution was more irregular in character but they were more numerous than during summer (Figure 5, Table 4).

The maximum concentration of all nematodes was recorded in the upper and middle horizons, as distinguished from the summer season 192 when their maximum density was observed in the middle and lower horizons. Only one population peak was observed in the middle horizon at the beginning of the autumn season. In the middle of September, the population peak shifted toward the limits of the upper and middle horizon $\left(6,156,960\right.$ specimens $\left./ \mathrm{m}^{2}\right)$ and at the end of September the density of population remained high in the upper horizon. In the upper level of the middle horizon of the littoral zone a sufficiently high density persisted $\left(1,000,000\right.$ to $2,000,000$ specimens $\left./ \mathrm{m}^{2}\right)$. During the course of the entire season the population density in the lower horizon did not exceed 193400,000 to 600,000 specimens $/ \mathrm{m}^{2}$. Thus a trend from the middle to the upper horizon of the littoral zone was observed in nematodes throughout the autumn season. Increase in number of organisms occurred due to intense multiplication of some species (pp. 334-343). 


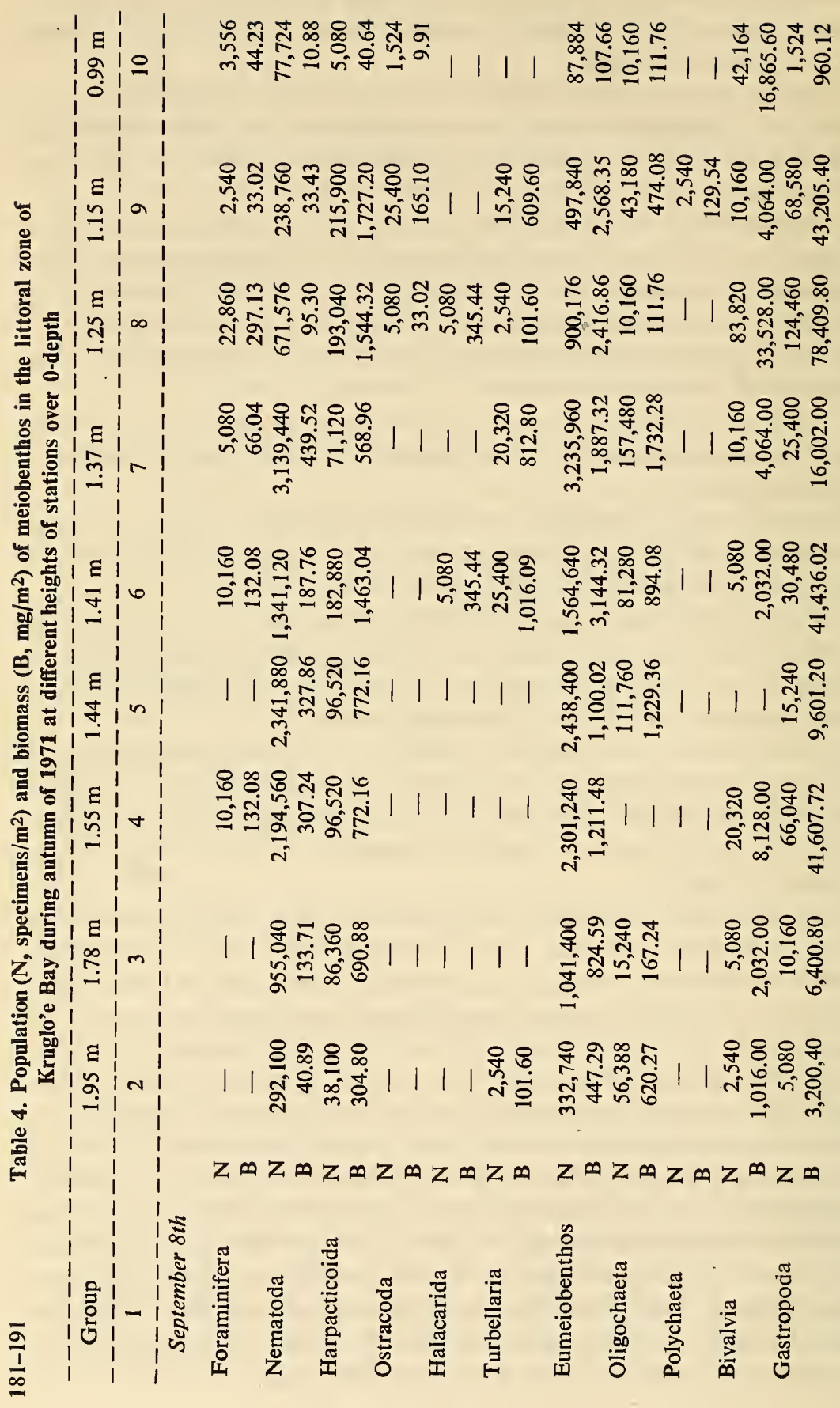




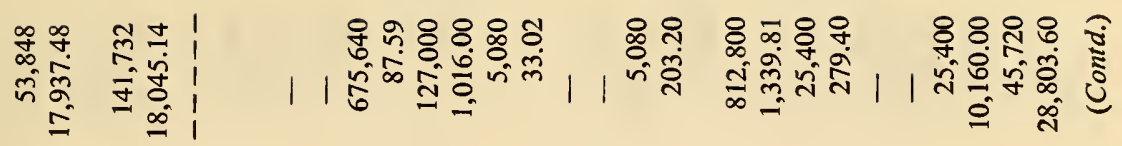

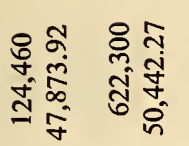

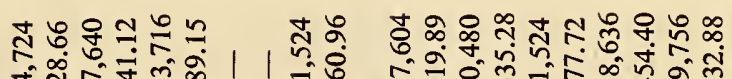

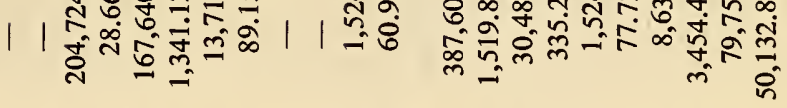

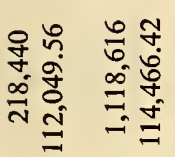

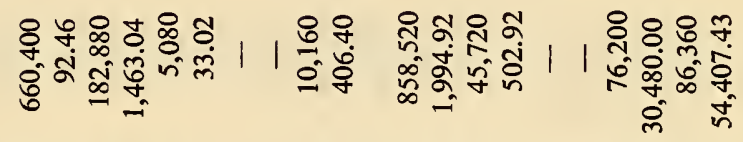

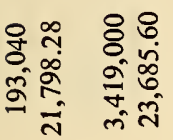

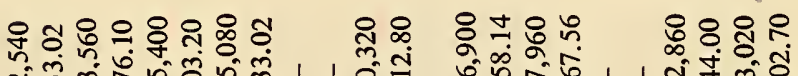

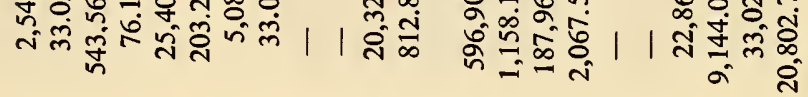

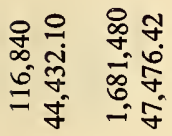

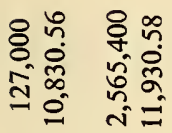

8 응 क्ष बे लें

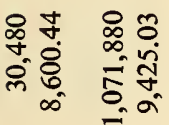

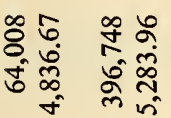

$z \infty \quad z \infty$

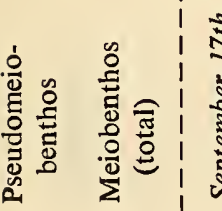

원

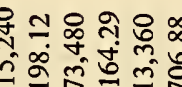

든

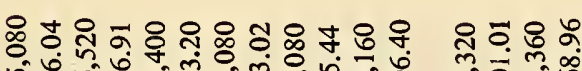

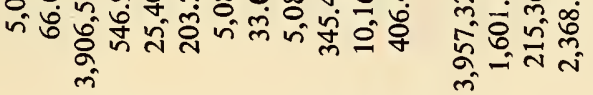

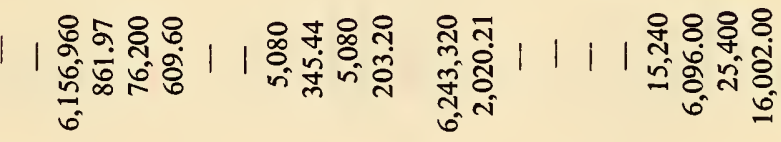

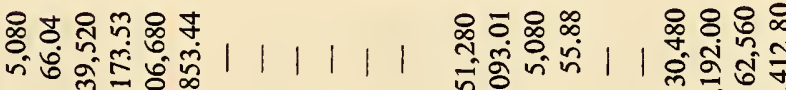

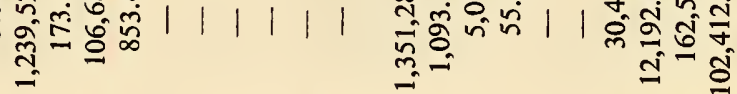

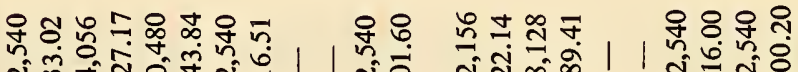

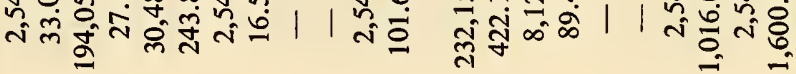

$\mathrm{Z} \oplus \mathrm{Z} \oplus \mathrm{Z} \oplus \mathrm{Z} \oplus \mathrm{z} \oplus \mathrm{z} \oplus \mathrm{Z} \oplus \mathrm{z} \oplus \mathrm{z} \oplus \mathrm{Z} \oplus \mathrm{z} \oplus$

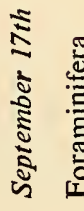

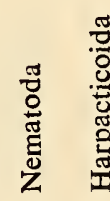

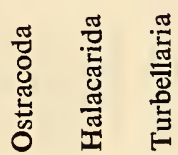

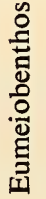

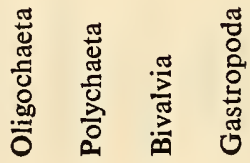


|

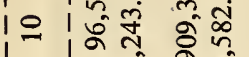

बें ूे के

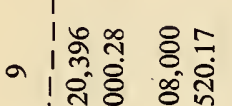
I

18 i 8 ก

กิ

की ठิ

$\sum_{-\infty}^{\infty}$

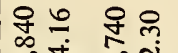

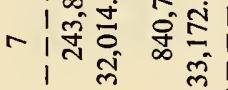

융ำ 운 0 र्ड

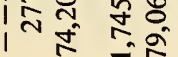
1 mo । ले

18.8 |융 \&ूㅠㅣ i. m

สิ तु Im go จำ 吾气

㑒

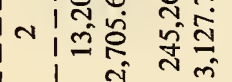

$z \infty \quad z \infty$

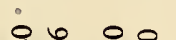

$8 \%$ on

용ㅇำ

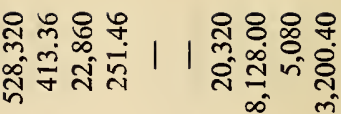

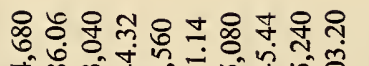

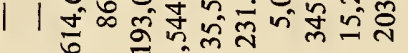

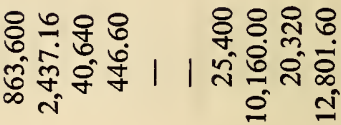

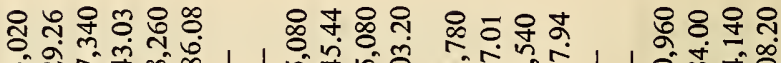

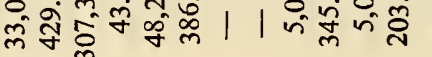

চ

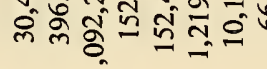

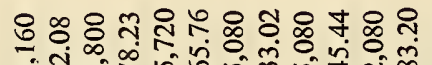

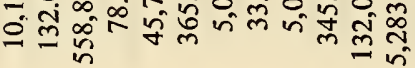

유융 유 \&8융

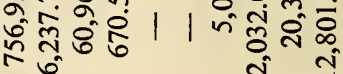

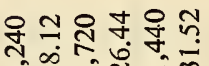
气ूa

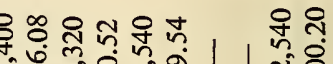

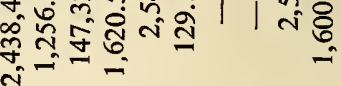

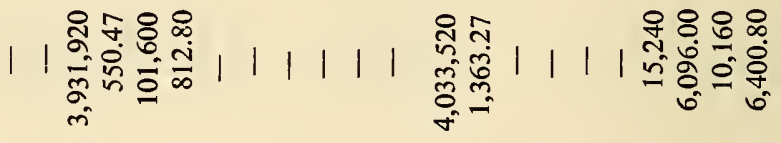

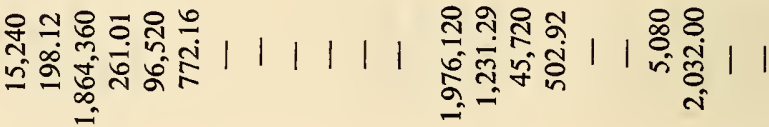

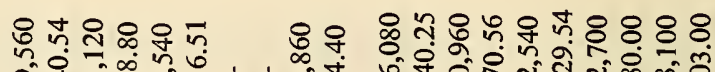

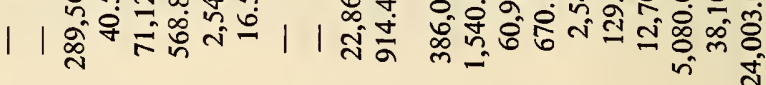
$\mathrm{Z} \oplus \mathrm{Z} \oplus \mathrm{Z} \oplus \mathrm{Z} \oplus \mathrm{Z} \oplus \mathrm{Z} \oplus \mathrm{Z} \oplus \mathrm{Z} \oplus \mathrm{Z} \oplus \mathrm{Z} \oplus \mathrm{Z} \oplus$

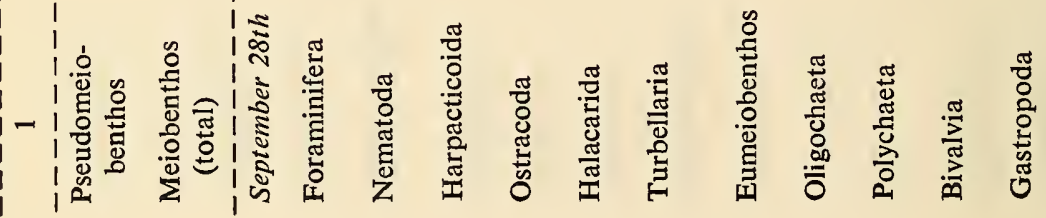




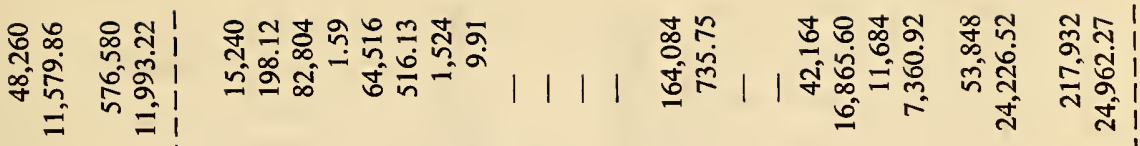

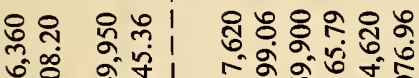

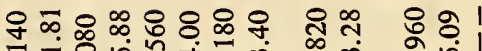

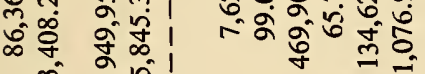

กิ ูิ ।

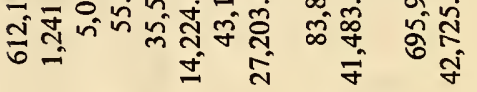

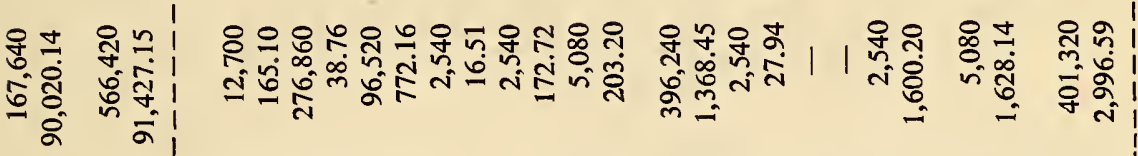

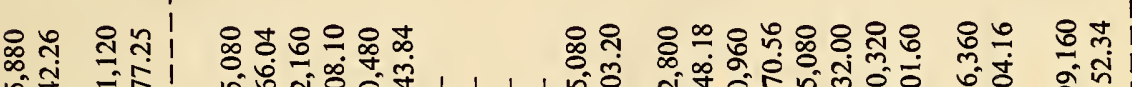
nू.

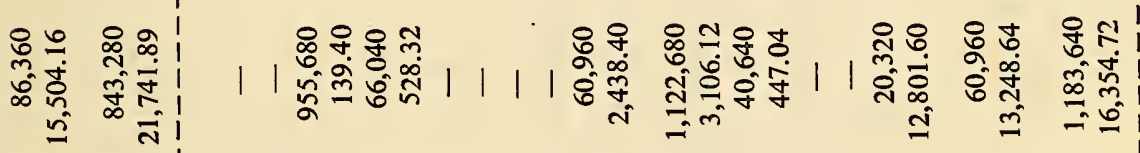

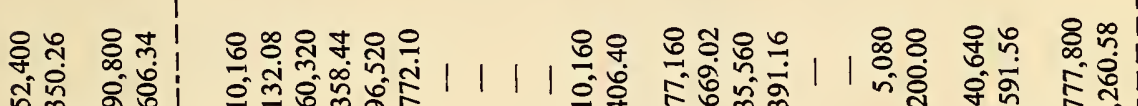

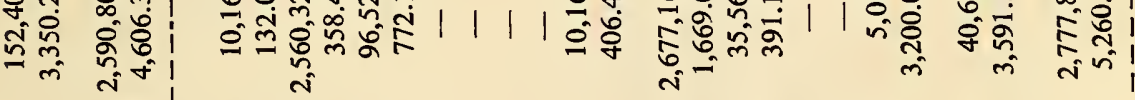

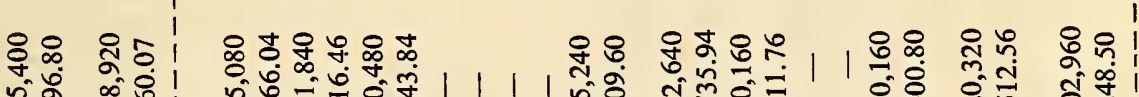

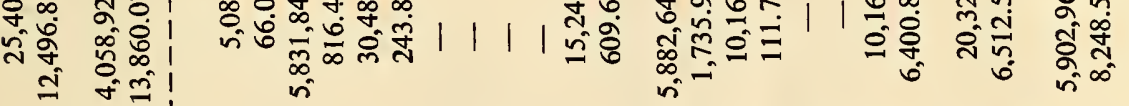

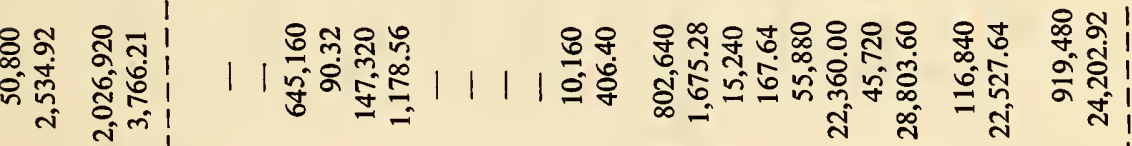

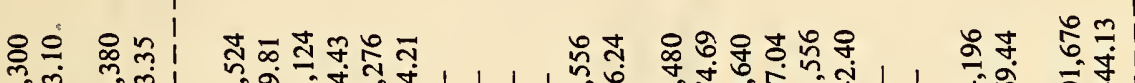

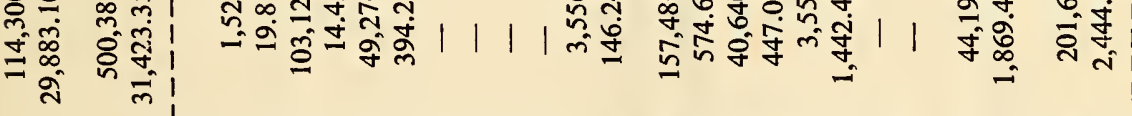

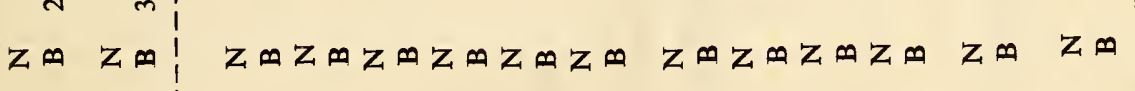

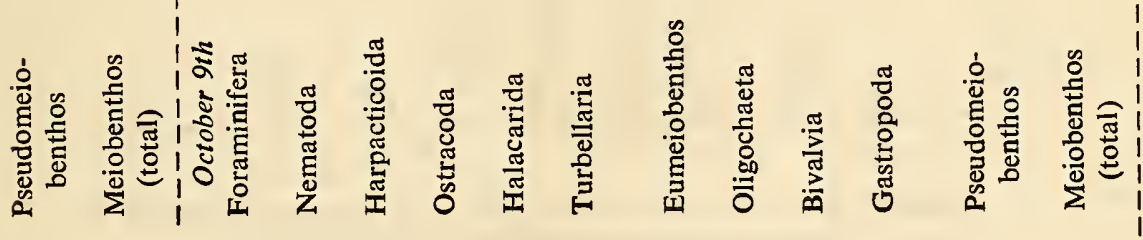


252

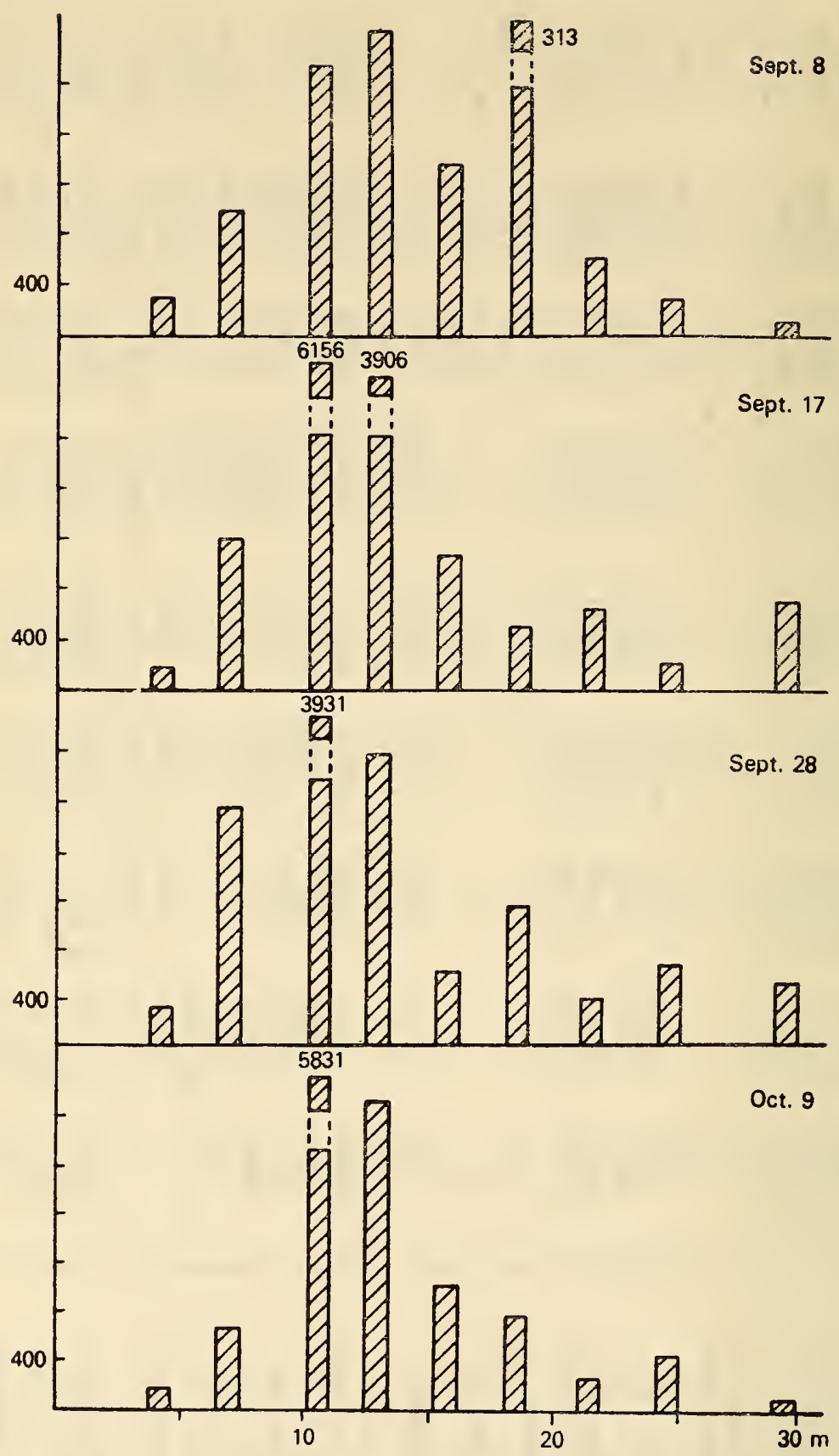

192

Figure 5. Dynamics of the total population of marine nematodes in the littoral zone of Kruglo'e Bay in autumn of 1971. 
The density of pseudomeiobenthos was lower in autumn than in summer, comprising 5,080 to 277,520 specimens $/ \mathrm{m}^{2}$. As in summer, the bulk of pseudomeiofauna constituted bivalves and gastropods.

Oligochaetes constituted 1.0 to $5.0 \%$ of the total population of meiofauna (2,540 to 215,360 specimens $\left./ \mathrm{m}^{2}\right)$, and were found throughout the entire section. The maximum density was observed during the middle of September $(150,000$ to 200,000$)$ and the maximum concentration in the middle horizon of the littoral zone.

Polychaetes constituted less than $1.0 \%$ or 1,000 to 2,000 specimens $/ \mathrm{m}^{2}$. They were found in small numbers in different probes.

The young of bivalves constituted 1.0 to $7.0 \%$ of the meiobenthos population $\left(2,540\right.$ to 83,820 specimens $\left./ \mathrm{m}^{2}\right)$. Their population gradually declined from the beginning of September toward mid-October, indicating that the growth of mollusks to 2.0 to $3.0 \mathrm{~mm}$ had taken place, i.e., beyond the limits of meiobenthos.

The young of gastropods constituted 1.0 to $10.0 \%$ of the total population of meiofauna $\left(1,520\right.$ to 162,560 specimens $\left./ \mathrm{m}^{2}\right)$. The same tendency seen in bivalves was observed in the population dynamics of gastropods.

During the autumn season the biomass of meiobenthos constituted 3.1 to $115.7 \mathrm{~g} / \mathrm{m}^{2}$ and that of eumeiobenthos 0.4 to $6.2 \mathrm{~g} / \mathrm{m}^{2}$.

Biomass of foraminiferans was 19 to 429 (maximum on September 28,1971 ), harpacticoids 40 to 1,727 (maximum on September 8, 1971), ostracods 9.0 to 23.1 , halacarids 172 to 1,727 , turbellarians 60 to 5,213 , and nematodes 10 to $761 \mathrm{mg} / \mathrm{m}^{2}$ (a few times higher than that in summer, with the maximum observed in the first half of September).

The biomass of pseudomeiobenthos constituted only 1.8 to $114.6 \mathrm{~g} / \mathrm{m}^{2}$ (five to six times less than the summer values). This was due to a significant reduction in population of young mollusks.

Having analyzed the distribution of meiofauna during both summer and autumn seasons, its irregularity in the horizons of the littoral zone could be recorded. The middle horizon was the most richly populated during both seasons. During summer a peak was recorded in the lower horizon and during autumn in the upper. The distribution of meiofauna was irregular in character even within the limits of a single horizon. For example, if the change in meiobenthos population at any station of the section is examined, it will be seen that during one season the density of organisms at a given station considerably changed after seven to ten days. That is why one sample from one horizon cannot reflect the population dynamics of a given area. According to my data an analysis of at least three samples is essential in order to characterize the density of a more or less homogeneous region. It is desirable that the distance between stations should not exceed 2.0 to $3.0 \mathrm{~m}$. A steady pattern of distribution of meiofauna was found during autumn, when the population peak in 
the upper horizon of the littoral zone remained constant throughout the entire month.

Of the two components of meiofauna, eumeiobenthos occupied a predominant position with respect to population. But pseudomeiobenthos occupied the leading position with respect to biomass due to the high average weight of young mollusks.

Considering both seasons, a higher population of meiofauna was observed in autumn and a higher biomass in summer.

Marine nematodes constituted the leading group, comprising half of the meiofauna population; as such their contribution played a main role in the pattern of distribution of the entire meiofauna in the littoral zone. 


\section{List of Species of Nematodes of the White Sea}

Subclass $A D E N O P H O R E A$

\section{Order ENOPLIDA}

1. Family ENOPLIDAE

1. Genus Enoplus Dujardin, 1845

1. E. demani nom. nov...................... 260

2. Genus Mesacanthion Filipjev, 1927

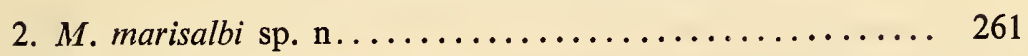

3. Genus Chaetonema Filipjev, 1927

3. C. longisetum (Steiner, 1916)................. 263

2. Family ONCHOLAIMIDAE

4. Genus Anoplostoma Buetschli, 1874

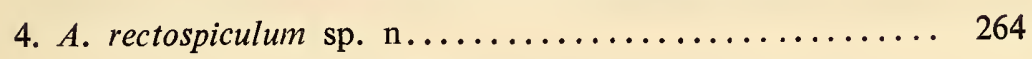

5. Genus Metoncholaimoides Wieser, 1953

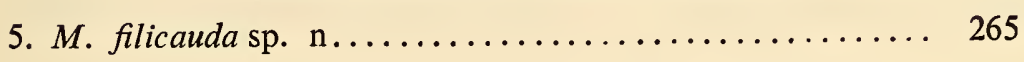

6. Genus Metaparoncholaimus de Coninck and

Schuurmans-Stekhoven, 1933

6. M. longispicula sp. n.................... 267 


\section{Family OXYSTOMINIDAE}

7. Genus Halalaimus de Man, 1888

7. H. zenkevitchi Filipjev, 1927................. 268

\section{Family IRONIDAE}

8. Genus Parironus Micoletzky and Kreis, 1930

8. P. tubulilaimus sp. n....................... 269

5. Family CRENOPHARYNGIDAE

9. Genus Crenopharynx Filipjev, 1934

9. C. gracilis (Linstow, 1900)

\section{Order CHROMADORIDA}

6. Family CHROMADORIDAE

10. Genus Hypodontolaimus de Man, 1886

10. H. inaequalis (Bastian, 1865) ................... 272

11. H. buetschlii (Buetschli, 1874)................. 273

11. Genus Chromadora Bastian, 1865

12. C. macrolaima de Man, $1889 \ldots . . \ldots \ldots \ldots \ldots \ldots . \ldots 274$

12. Genus Spiliphorella Filipjev, 1918

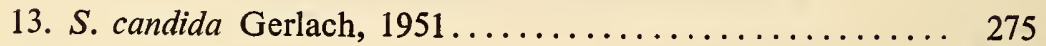

14. T. acuticauda sp. n......................... 276

14. Genus Prochromadorella Micoletzky, 1924

15. P. crassispicula sp. n...................... 277

15. Genus Prochromadora Filipjev, 1922

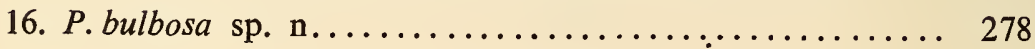




\section{Family CYATHOLAIMIDAE}

16. Genus Paracanthonchus Micoletzky, 1924

17. P. medius sp. n........................... 280

18. P. macrodon (Ditlevsen, 1910)................. 282

8. Family COMESOMATIDAE

17. Genus Sabatieria de Rouville, 1904

19. S. vulgaris (de Man, 1907).................. 282

\section{Family CHOANOLAIMIDAE}

18. Genus Halichoanolaimus (Bastian, 1865)

20. H. robustus (Bastian, 1865).................. 283

\section{Order MONHYSTERIDA}

10. Family SPHAEROLAIMIDAE

19. Genus Sphaerolaimus Filipjev, 1918

21. S. macrolasius Schulz, $1932 \ldots \ldots \ldots \ldots \ldots \ldots \ldots . \ldots . . \ldots 284$

\section{Family MONHYSTERIDAE \\ 20. Genus Theristus Bastian, 1865}

1. Subgenus Mesotheristus Wieser, 1956

22. T. (M.) setosus (Buetschli, 1874)............... 284

23. T. (M.) platonovae sp. $\mathrm{n} \ldots \ldots \ldots \ldots \ldots \ldots \ldots \ldots \ldots . \ldots \ldots$

2. Subgenus Pseudosteineria Wieser, 1956

24. T. (P.) horridus (Steiner, 1916)................ 287

3. Subgenus Daptonema Cobb, 1920

25. T. (D.) procerus Gerlach, $1951 \ldots \ldots \ldots \ldots \ldots \ldots \ldots \ldots . \ldots 288$

4. Subgenus Penzancia de Man, 1922

26. T. (P.) flevensis S. -Stekhoven, $1935 \ldots \ldots \ldots \ldots \ldots \ldots \ldots 288$ 


\section{Family LINHOMOEIDAE}

21. Genus Terschellingia de Man, $\mathbf{1 8 8 8}$

27. T. longicaudata de Man, $1907 \ldots \ldots \ldots \ldots \ldots \ldots \ldots \ldots . \ldots . \ldots$

22. Genus Metalinhomoeus de Man, 1907

28. M. obtusiceps sp. $\mathrm{n}$.

\section{Order ARAEOLAIMIDA}

\section{Family TRIPYLOIDIDAE}

23. Genus Tripyloides Filipjev, 1918

29. T. septentrionalis de Coninck and S.-Stekhoven, 1933 ..... 291

14. Family AXONOLAIMIDAE

24. Genus Axonolaimus de Man, 1889

30. A. paraspinosus S.-Stekhoven and Adam, 1931........ 292

25. Genus Odontophora Buetschli, 1874

31. O. deconincki nom. nov.

\section{Order DESMODORIDA}

15. Family MONOPOSTHIIDAE

26. Genus Monoposthia de Man, 1889

32. M. octalata sp. $\mathrm{n}$

\section{Family SPIRINIIDAE}

27. Genus Chromodoropsis Filipjev, 1918

33. C. vivipara (de Man, 1907).................... 296

34. C. nudicauda sp. n......................... 297

28. Genus Spirinia Gerlach, 1963

35. S. parasitifera $($ Bastian, 1865).................. 298 


\section{Taxonomic Review of Species}

The nematode fauna of the White Sea has hardly been studied to date. Filip'ev (1927) described a few species of enoplids from the isthmus of the White Sea, and Frolov (1972) has published a list of nematode species from the sandy littoral zone of the strait of Velikaya Salma. In describing nematodes from the inlets of Chupinskaya River I am simply supplementing the list of already known nematodes of the White Sea.

As many as 76 species of nematodes were recorded by me during investigations of material from the White Sea; 35 species were found in large numbers in silted sand in the littoral zone.

The nematode species detected belong to 5 orders, 16 families, and 28 genera. For species already known only a brief description has been given, while 13 new species are described in greater detail.

Cobb's formula (Cobb, 1891), modified by Filip'ev (1916), has been used in describing the new species, along with indices according to de Man $(a, b, c)$. Cobb's formula is represented by a fraction with numerical figures in microns. The numerator indicates distances from the anterior end to: 1. end of oral cavity, 2. nerve ring, 3. end of esophagus, 4. vulva (in the case of females), and 5. anus. The denominator gives the width of the corresponding body region. Total length of the nematode (also in microns) is indicated at the end of the fraction. 


\section{Family ENOPLIDAE Baird, 1853}

1. Genus Enoplus Dujardin, 1845

Synonym: Enoplostoma Marion, 1870.

1. Enoplus demani nom. nov. (Figure 6)

de Man 1886 (brevis) non Bastian, 1865.

4 б: $\mathrm{L}=4,103.0-5,511.0 \mu \mathrm{m} ; \mathrm{a}=26.6-32.4 ; \mathrm{b}=4.9-6.4 ; \mathrm{c}=20.6-29.0$.

4 䒠: $\mathrm{L}=4,696.0-5,247.0 \mu \mathrm{m} ; \mathrm{a}=26.6-32.5 ; \mathrm{b}=5.5-6.2 ; \mathrm{c}=19.1-24.5$;

$$
\mathrm{V}=49.2-53.3 \% \text {. }
$$
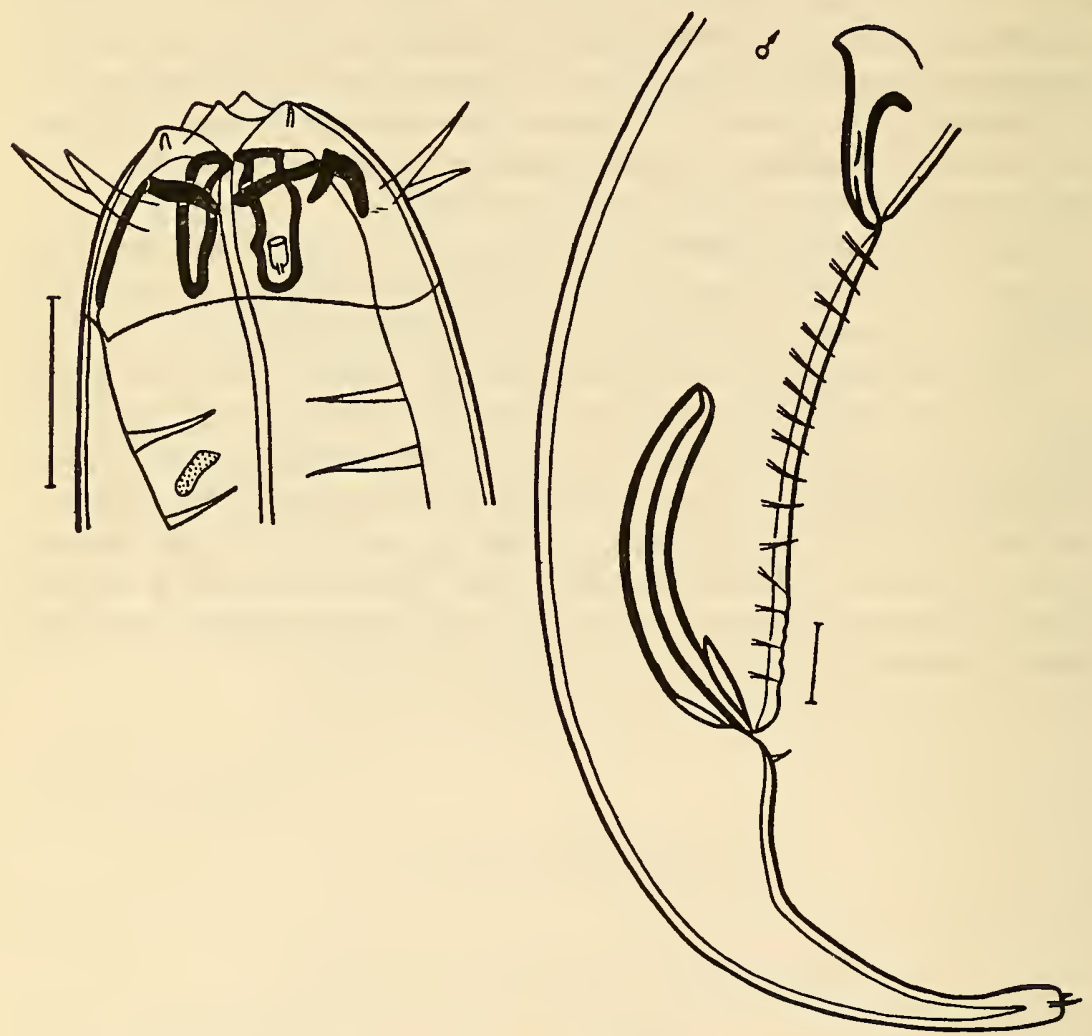

Figure 6. Enoplus demani nom. nov. ${ }^{3}$

3In Figures 6 to 40 the line corresponds to $20 \mu \mathrm{m}$. Tentative insertions in the figures: $b b$. $e=$ bulbus of esophagus; ba. $e=$ base of esophagus; $s p=$ spicules; and $t$. $0=$ tubular organ. 
The White Sea form collected by me and that described by de Man (1886) from the coast of the North Sea seem identical. Bastian (1865) described a new species, E. brevis, on the basis of a female specimen. Subsequently, de Man (1886) described this species, also recorded from the North Sea, on the basis of a male and a female. After carefully studying the works of these authors, I concluded that these are two different species, distinguished from each other in indices $a$ and $c$. The species of Bastian is devoid of cephalic papillae, which are present in the species of de Man. The former species has short jaws $(15.4 \mu \mathrm{m})$, which in the species of de Man are 1.5 to 1.7 times longer. This enables one to consider the two species independent. I have proposed a new name, E. demani, for species $E$. brevis described by de Man (1\$86), and retained the name E. brevis for the species described by Bastian (1865).

In the White Sea specimens of $E$. demani longitudinal striations on the labia are discernible. Amphids oval, with large openings, and 9.6 $\mu \mathrm{m} \times 3.6 \mu \mathrm{m}$ in size. Genital armature of male represented by spicules, accessory organ, and setae. Spicules thin, long, almost uniform in width throughout, and 124.2 to $164.7 \mu \mathrm{m}$ long. Gubernaculum simple, small, and 48.6 to $51.3 \mu \mathrm{m}$ long. Accessory organ funnel-shaped and situated 176.0 to $199.8 \mu \mathrm{m}$ from anus. Anal setae 14 to 15 pairs; situated between anus and accessory organ.

Geographic distribution. Found in the North and White Seas, mainly in slightly silted sand.

\section{Genus Mesacanthion Filipjev, 1927}

\section{Mesacanthion marisalbi sp. n. (Figure 7)}

Holotype ${ }^{*}$. Institute of Zoology, Academy of Sciences, USSR. Collection No. 3.

\begin{tabular}{ccccc}
- & 202.5 & 759.0 & - & $3,859.0$ \\
\hline 24.3 & 51.3 & 51.3 & $\begin{array}{l}72.9 \\
c=19.3 .\end{array}$
\end{tabular} 4,$037 \mu \mathrm{m} ; \mathrm{a}=52.4 ; \mathrm{b}=5.5$;

Paratypes.

$$
\begin{aligned}
& 2 \sigma^{*}: \begin{array}{cccc}
- & 198.0-209.0 & - & 2,805.0-3,773.0 \\
\hline 25.0-28.0 & 54.0-55.0 & 74.0-77.0 & 40.5-43.6
\end{array} \\
& \times 2,992.0-3,971.0 \mu \mathrm{m} ; \mathrm{a}=45.4-51.6 ; \mathrm{b}=4.3-5.1 ; \mathrm{c}=16.0-20.1 \text {. } \\
& 1 \text { ㅇ: } \begin{array}{ccccc}
- & 231.0 & 682.0 & 1,837.0 & 3,311.0 \\
\hline 29.0 & 55.0 & 66.0 & 88.0 & 44.0
\end{array} 3,509 \mu \mathrm{m} ; \mathrm{a}=45.6 \text {; } \\
& \mathrm{b}=5.2 ; \mathrm{c}=17.7 ; \mathrm{V}=54.6 \% \text {. } \\
& 1 \text { juv.: } \begin{array}{ccccc}
- & 220.0 & 660.0 & - & 2,915.0 \\
\hline 28.0 & 44.0 & 66.0 & 77.0 & 43.2
\end{array} 3,333.0 \mu \mathrm{m} ; \mathrm{a}=46.7 \text {; } \\
& b=5.1 ; c=16.8 \text {. }
\end{aligned}
$$




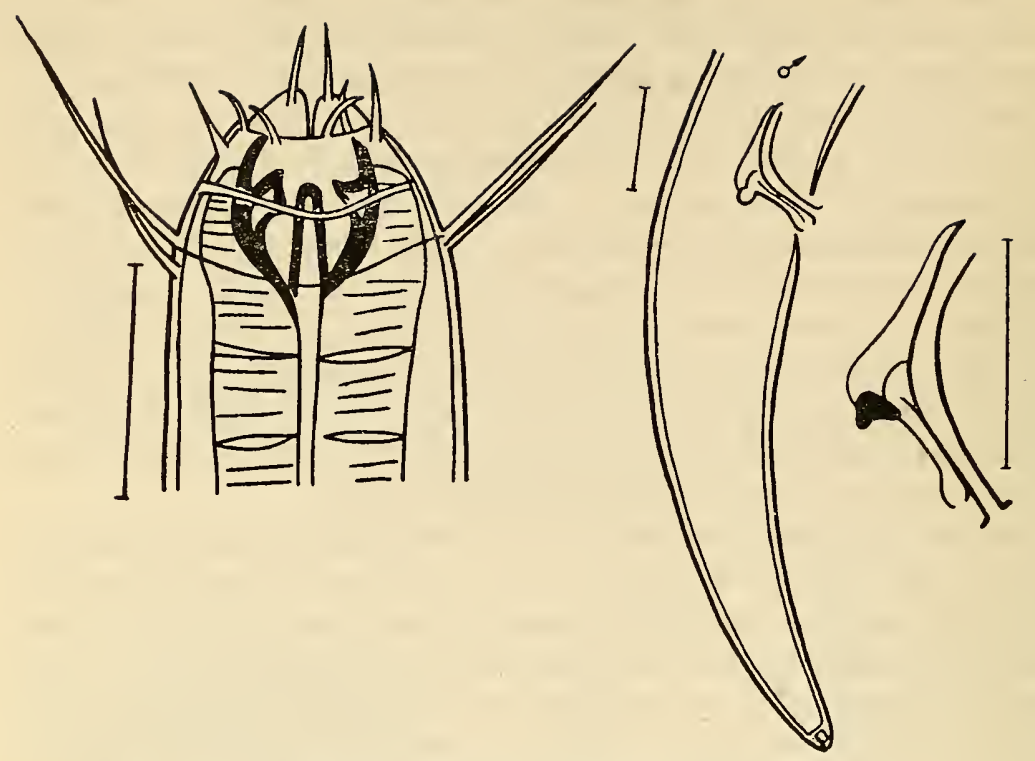

Figure 7. Mesacanthion marisalbi n. sp.

Body elongated; tapers to $1 / 3$ midbody diameter at anterior end and $5 / 9$ at posterior end. Head demarcated from body. Tail long and tapers gradually toward end; length 5.5 diameter at anus. Lips well developed and armed with setae 6.0 to $8.0 \mu \mathrm{m}$ long. Length of cephalic setae 61.2 to $64.0 \mu \mathrm{m}$; cervical setae rather short, $16.2 \mu \mathrm{m}$. Setae absent on tail. Cuticle smooth. Amphids not discernible. Photosensitive pigment absent. Oral cavity $26.4 \mu \mathrm{m} \times 15.6 \mu \mathrm{m}$, cylindrical changing to conical near base, armed with three equal-sized teeth $12 \mu \mathrm{m}$ long, and with a ring that extends approximately along the middle. Esophagus almost uniform in width throughout its length. Reproductive system of female represented by unflexed paired tubules. Sexual armature of male consists of accessory organ and spicules. Accessory organ tubular and situated $126.9 \mu \mathrm{m}$ from anus. Spicules curved, almost uniform in width throughout their length, and $56.7 \mu \mathrm{m}$ long. Gubernaculum with dorsal appendage closely attached to spicules; length $21.6 \mu \mathrm{m}$.

This species comes close to the description of $M$. longissimesetosus Wieser, 1953, recorded from the coast of Chile, but can be distinguished from it by indices $a$ and $c$, smaller size of cephalic setae, teeth, and spicules. In $M$. marisalbi the accessory organ is situated closer to the anus than in $M$. longissimesetosus. These distinguishing characters permit one to consider M. marisalbi a new species. 
Geographic distribution. Found in the White Sea, mainly in the middle and lower horizons of the littoral zone in slightly silted sand.

\section{Genus Chaetonema Filipjev, 1927}

3. Chaetonema longisetum (Steiner, 1916) (Figure 8)

Steiner, 1916; 600-602, tab. 25, fig. 16a-c (Anoplostoma); Filip'ev, 1925: 182.

1ㅇ: $\mathrm{L}=1,269.0 \mu \mathrm{m} ; \mathrm{a}=29.4 ; \mathrm{b}=4.9 ; \mathrm{c}=10.7 ; \mathrm{V}=49 \%$.

4 juv.: $\mathrm{L}=837.0-1,104.3 \mu \mathrm{m} ; \mathrm{a}=29.4-34.0 ; \mathrm{b}=3.5-4.8 ; \mathrm{c}=7.7-10.8$.

White Sea specimens distinguishable from those described by Steiner from the coast of the Barents Sea and by Filip'ev from the Kara Sea by larger size of cephalic setae ( 35.1 to 40.5 versus 21.0 to $27.0 \mu \mathrm{m}$ ). The White Sea population fully coincides with those specimens described earlier in all remaining features. To my regret males were lacking in my material. In the specimens examined amphids could not be detected.

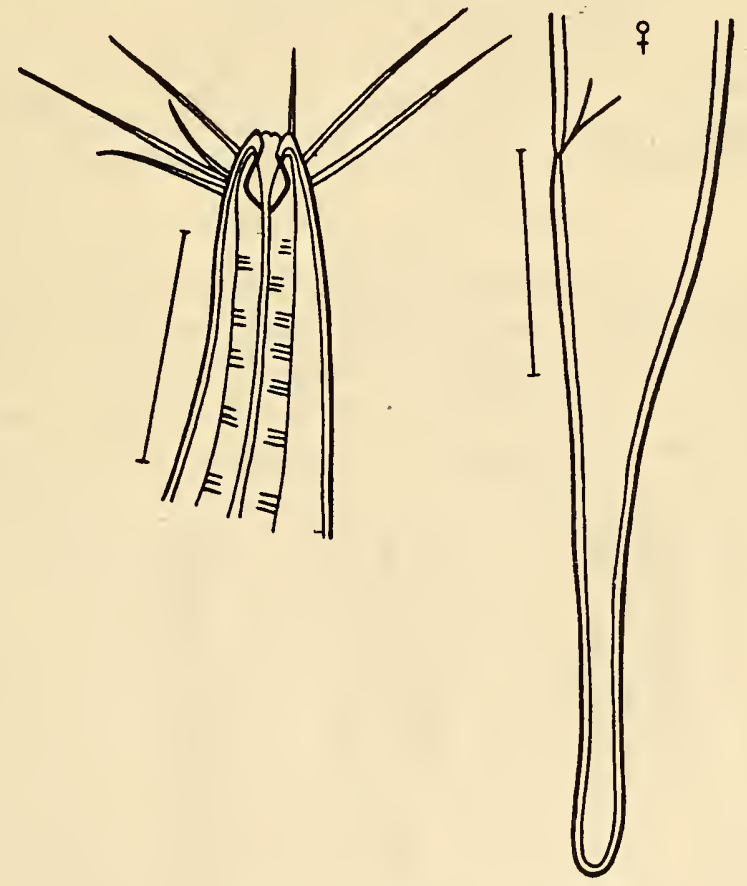

Figure 8. Chaetonema longisetum.

200 Geographic distribution. Recorded from the White, Barents and Kara Seas in small numbers in the lower, slightly silted horizons of the littoral zone. 
2. Family ONCHOLAIMIDAE Perrier, 1897

4. Genus Anoplostoma Buetschli, 1874

4. Anoplostoma rectospiculum sp. n. (Figure 9)

Holotype ot: Institute of Zoology, Academy of Sciences, USSR. Collection No. 7.

$$
\begin{array}{ccccc}
14.8 & 145.8 & 286.0 & - & 1,364.0 \\
\hline 8.1 & 32.4 & 39.0 & 44.0 & \begin{array}{c}
22.0 \\
\mathrm{c}=11.4
\end{array}
\end{array} 1,496.0 \mu \mathrm{m} ; \mathrm{a}=34.0 ; \mathrm{b}=5.2
$$

\section{Paratypes.}

$$
\begin{aligned}
& 3 \text { ㅇ: } \begin{array}{cccc}
13.5-16.2 & 162.0-172.8 & 330.0-352.0 & 935.0-1,144.0 \\
\hline 8.1-9.4 & 35.0-35.1 & 44.0-55.0 & 55.0-66.0
\end{array} \\
& \times \frac{1,694.0-2,024.0}{24.0-33.0} 1,837-2,178 \mu \mathrm{m} ; \mathrm{a}=32.4-39.6 ; \mathrm{b}=5.5-6.2 ; \\
& \mathrm{c}=12.8-15.6 ; \mathrm{V}=47.9-55.0 \% \text {. }
\end{aligned}
$$

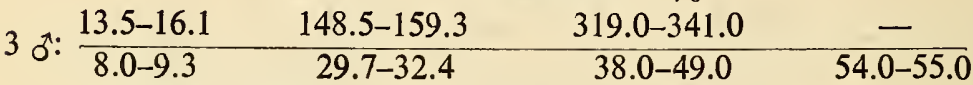

$$
\begin{aligned}
& \times \frac{1,540.0-1,705.0}{22.0-27.0} \quad 1,815.0-1,837.0 \mu \mathrm{m} ; \mathrm{a}=30.6-41.0 \text {; } \\
& \mathrm{b}=5.3-5.7 ; \mathrm{c}=11.7-13.9 \text {. }
\end{aligned}
$$

Body thin, long, and tapers to $1 / 5$ to $2 / 11$ midbody diameter at anterior end and $1 / 2$ to $10 / 23$ at posterior end. Head demarcated from body. Tail long ( 4.5 anal body diameters), initially conical, then narrows into a cylinder for three-fourths its length. Labia well developed and armed with papillae. Length of cephalic setae 9.2 to $9.6 \mu \mathrm{m}$. Setae also present
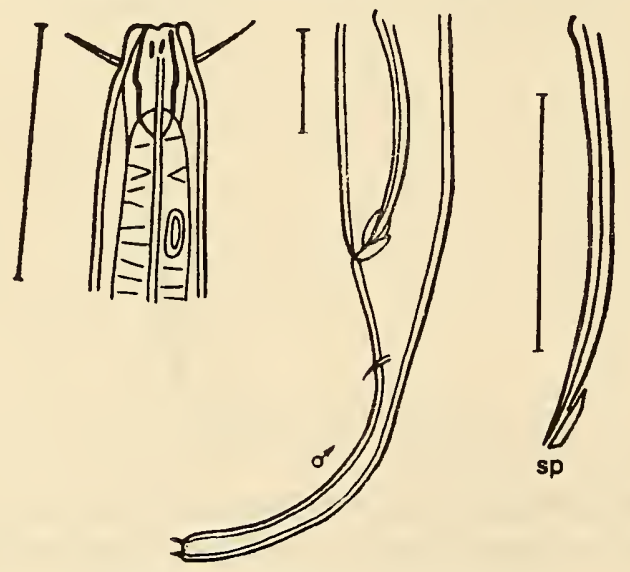

Figure 9. Anoplostoma rectospiculum 
on tail, 1.2 to $1.3 \mu \mathrm{m}$ long. Cuticle smooth. Amphids saccate and longitudinally elongated, thick-walled, and situated 2.5 cephalic diameters from anterior end. Amphids $7.2 \mu \mathrm{m} \times 3.6 \mu \mathrm{m}$; width $1 / 4$ corresponding body diameter. Oral cavity large, prismatic; length exceeds width about 2.5 times. Esophagus initially uniform in width, broadens gradually toward base. Reproductive system of female consists of pair of unflexed tubules, containing seven to eight eggs each. Diameter of eggs 65 to 70 $\mu \mathrm{m}$. Spicules thin, long (54 to $60 \mu \mathrm{m}$ ) and slightly curved. Gubernaculum simple and small ( 8.5 to $9.6 \mu \mathrm{m})$.

This species comes close to A. blanchardi de Man, 1888 but can be distinguished from it by larger body size, oral cavity, apparently the size and shape of amphids (de Man was not able to observe the amphids distinctly), and longer, thinner, and weakly curved spicules. All these characters permit one to consider A. rectospiculum a new species.

Geographic distribution. Found in large numbers in the White Sea in all horizons of the littoral zone in silted sand.

\section{Genus Metoncholaimoides Wieser, 1953}

5. Metoncholaimoides filicauda sp. n. (Figure 10)

Holotype ?: Institute of Zoology, Academy of Sciences, USSR. Collection No. 10.

$$
\begin{array}{lllll}
43.2 & 216.0 & 451.0 & 1,232.0 & 2,310.0 \\
35.1 & 56.7 & 77.0 & \begin{array}{l}
88.0 \\
c=20.0
\end{array} & 44.0 \\
& & & \mathrm{~V}=50.6 \%
\end{array}
$$

Paratypes.

$$
\begin{aligned}
& 2 \text { \% : } \begin{array}{cccc}
32.4-37.8 & 292.5-313.3 & 374.8-385.0 & - \\
\hline 27.0-29.7 & 56.7-59.4 & 55.0-66.0 & 66.0-71.0
\end{array} \\
& \times \frac{1,947.0-2,057.0}{43.0-44.0} 2,057.0-2,156.0 \mu \mathrm{m} ; \mathrm{a}=30.1-30.8 \text {; } \\
& \mathrm{b}=5.3-5.8 ; \mathrm{c}=18.1-21.8 \text {. } \\
& 1 \text { q: } \begin{array}{ccccc}
40.5 & 202.5 & 473.0 & 1,452.0 & 2,618.0 \\
\hline 29.7 & 54.0 & 55.0 & 88.0 & 44.0
\end{array} 2,750 \mu \mathrm{m} ; \mathrm{a}=29.7 \text {; } \\
& \mathrm{b}=4.3 ; \mathrm{c}=20.4 ; \mathrm{V}=52.8 \% \text {. } \\
& 2 \text { juv.: } \begin{array}{cccc}
32.4-35.1 & 180.9-199.8 & 341.0-374.0 & - \\
\hline 22.9-24.3 & 44.0-40.5 & 38.0-44.0 & 44.0-55.0
\end{array} \\
& \times \frac{1,463.0-1,749.0}{30.0-33.0} 1,501.0-1,848.0 \mu \mathrm{m} ; \mathrm{a}=32.6-35.3 ; \\
& b=4.6-4.9 ; c=17.6-18.7 \text {. }
\end{aligned}
$$

Body rather thick; tapers to $2 / 5$ midbody diameter at anterior end and to $1 / 2$ at posterior end. Head rounded and almost not demarcated from 
body as cervical constriction absent. Tail conical; length 2.0 to 2.5 anal diameters. Lips well developed and armed with papillae. Cephalic setae small, 1.4 to $1.5 \mu \mathrm{m}$. Extremely short setae (1.2 to $1.4 \mu \mathrm{m})$ present on tail. Cuticle smooth. Amphids cyathiform and situated almost at midlevel of oral cavity. Amphids $3.6 \mu \mathrm{m} \times 8.4 \mu \mathrm{m}$; width $1 / 4$ corresponding body diameter. Oral cavity large, almost cylindrical, its length twice its width, and armed with teeth of unequal length. Dorsal tooth $29.7 \mu \mathrm{m}$, ventral $24.3 \mu \mathrm{m}$. Esophagus almost equal in width up to $3 / 4$ its length, then gradually dilates toward base. Rectum unusually thick-walled.
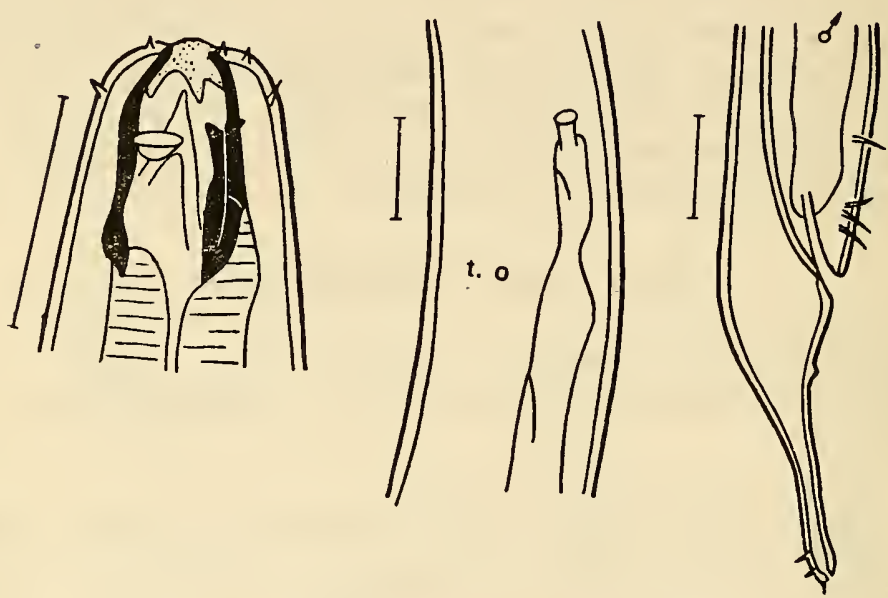

Figure 10. Metoncholaimoides filicauda sp. n.

Females with tubular organ $251.0 \mu \mathrm{m}$ long opening through pore situated $170.1 \mu \mathrm{m}$ anterior to anus. Reproductive system of female with paired unflexed tubes, containing seven eggs each. Diameter of eggs 77.0 to $80.0 \mu \mathrm{m}$. Spicules thin, very long $(102.6 \mu \mathrm{m})$, and weakly curved. Gubernaculum absent. Preanal setae present.

$M$. filicauda must be compared with the only other species of this genus, $M$. squalus Wieser, 1953, recorded from the coast of Chile. The White Sea form is much smaller than $M$. squalus. $M$. filicauda can also be distinguished from $M$. squalus in indices $a$ and $c$ and spicules five to six times shorter. Females with smaller number of eggs than in $M$. squalus. These characters permit one to consider $M$. filicauda an independent species.

Geographic distribution. Found in the White Sea in silted sand, mainly in the upper and middle horizons of the littoral zone. 
6. Metaparoncholaimus longispicula sp. n. (Figure 11)

Holotype ?. Institute of Zoology, Academy of Sciences, USSR. Collection No. 13.

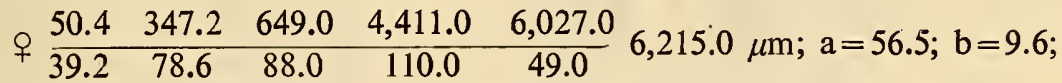

$$
\begin{aligned}
& \mathrm{c}=70.6 ; \mathrm{V}=71.2 \% \text {. }
\end{aligned}
$$

Paratypes.

$$
\begin{aligned}
& 3 \text { 우: } \begin{array}{ccccc}
37.8-56.7 & 189.0-272.7 & 585.0-583.0 & \text { [sic] } & 1,705.0-4,290.0 \\
32.4-39.0 & 75.6-81.0 & 66.0-82.0 & & 77.0-121.0
\end{array} \\
& \times \frac{2,277.0-5,709.0}{44.0-55.0} 2,332.0-5,808.0 \mu \mathrm{m} ; \mathrm{a}=30.5-49.0 ; \\
& \mathrm{b}=6.0-9.9 ; \mathrm{c}=42.5-58.6 ; \mathrm{V}=72.5-74.0 \% \text {. } \\
& 2 \text { o. } \begin{array}{cccc}
40.5-43.2 & 286.2-313.2 & 561.0-660.0 & - \\
32.4-37.8 & 56.7-72.9 & 55.0-99.0 & 77.0-110.0
\end{array} \\
& \times \frac{3,432.0-5,016.0}{44.0-55.0} 3,520.0-5,104.0 \mu \mathrm{m} ; \mathrm{a}=45.7-46.4 \text {; } \\
& \mathrm{b}=6.3-7.7 ; \mathrm{c}=40.0-57.9 \text {. }
\end{aligned}
$$

Body thick, long, and tapers to $2 / 5$ to $1 / 3$ midbody diameter at anterior end and $1 / 2$ at posterior end. Head rounded and almost not demarcated from body. Tail blunt, short; length approximately 1.5 times anal body diameter. Labia well developed and armed with papillae. Cephalic setae $10.8 \mu \mathrm{m}$ long. Short setae $(1.2$ to $1.3 \mu \mathrm{m})$ present on tail. Cuticle smooth. Amphids cyathiform and situated at midlevel of oral cavity. Amphid size $4.8 \mu \mathrm{m} \times 12.0 \mu \mathrm{m}$; width $1 / 4$ to $1 / 5$ corresponding cephalic diameter. Oral cavity large, almost cylindrical, its length twice greater than width, and armed with three teeth of unequal size. Two ventral teeth large $(27.0 \mu \mathrm{m})$ and dorsal one smaller $(21.6 \mu \mathrm{m})$. Esophagus almost 203 uniform throughout its length.

Females with tubular organ $693.0 \mu \mathrm{m}$ long with numerous pores on dorsal, ventral and lateral surfaces. Reproductive system of female consists of unpaired curved tubes, containing four large eggs. Diameter of eggs $165.0 \mu \mathrm{m}$. Spicules rather thick and long $(45.9 \mu \mathrm{m})$. Gubernaculum absent. Six to seven preanal setae present.

This species can be compared with one of the two known species of this genus-M. campylocercus (de Man) de Coninck and Stekhoven (1933)-found along the Belgium coast. It differs from the latter in larger body size, index $a$, and shorter tail $[1.5$ times anal body diameter versus 3.5 times in $M$. campylocercus (de Man)]. Females of $M$. longispicula can 


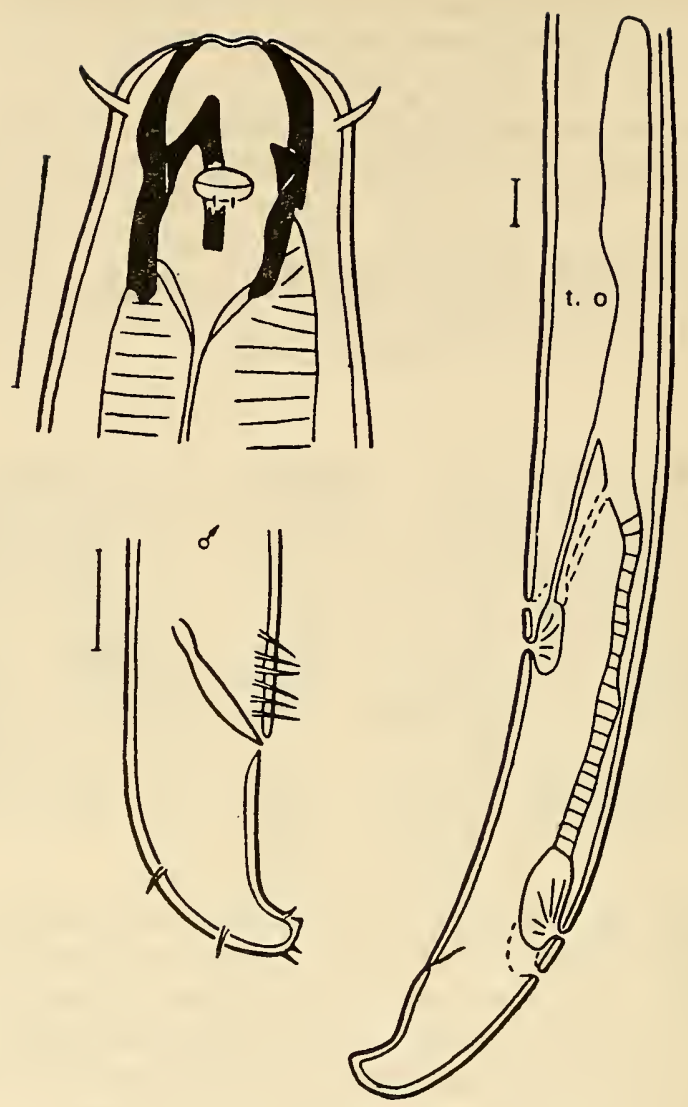

Figure 11. Metaparoncholaimus longispicula sp. n.

be distinguished from those of $M$. campylocercus by the presence of a tubular organ opening into a large number of excretory pores (in $M$. campylocercus there are only two pores) and more posteriorly displaced vulva. All these features permit one to consider $M$. longispicula a new species.

Geographic distribution. Found in large numbers in the White Sea, mainly in the upper and middle horizons of the littoral zone in silted sand:

3. Family OXYSTOMINIDAE Chitwood, 1935

7. Genus Halalaimus de Man, 1888

Synonyms: Halalaimoides Cobb, 1933 and Nuada Southern, 1914. 

zenkevitchi.

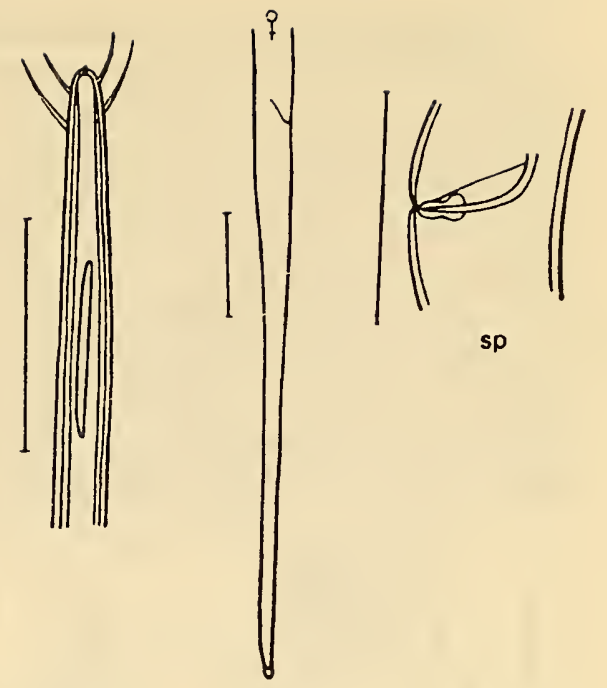

7. Halalaimus zenkevitchi Filipjev, 1927 (Figure 12)

4 年: $\mathrm{L}=1,353.0-1,419.0 \mu \mathrm{m} ; \mathrm{a}=62.0-71.0 ; \mathrm{b}=4.0-5.1 ; \mathrm{c}=7.0-10.4$.

1 ㅇ: $\mathrm{L}=1,331.0 \mu \mathrm{m} ; \mathrm{a}=60.5 ; \mathrm{b}=4.1 ; \mathrm{c}=6.4 ; \mathrm{V}=48.6 \%$.

1 juv.: $\mathrm{L}=1,166.0 \mu \mathrm{m} ; \mathrm{a}=42.5 ; \mathrm{b}=3.9 ; \mathrm{c}=8.8$.

White Sea specimens can be distinguished from those described by Filip'ev by smaller size and proportionately smaller length of spicules and amphids. Judging from the diagram of Filip'ev the White Sea specimens have longer cephalic setae (5.0 to $5.4 \mu \mathrm{m})$. The lateral membrane mentioned by Filip'ev was not found in my specimens.

Geographic distribution. Found in small numbers in the White, Barents and Kara Seas in all horizons of the littoral zone.

\section{Family IRONIDAE}

8. Genus Parironus Micoletzky and Kreis, 1930

8. Parironus tubulilaimus sp. n. (Figure 13)

Holotype $9:$ Institute of Zoology, Academy of Sciences, USSR, Collection No. 17.

$$
\begin{aligned}
& \begin{array}{ccccc}
88.0 & 242.0 & 473.0 & 1,694.0 & 3,069.0 \\
\hline 22.0 & 88.0 & 99.0 & 115.0 & 66.0
\end{array} 3,289.0 \mu \mathrm{m} ; \mathrm{a}=28.4 ; \mathrm{b}=6.9 ; \\
& c=14.9 ; \mathrm{V}=51.5 \% \text {. }
\end{aligned}
$$

Paratype.

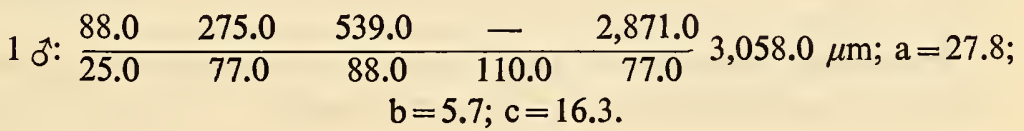


Body elongated, thick, and tapers to $1 / 5$ midbody diameter at anterior end and $2 / 3$ to $10 / 17$ at posterior end. Head poorly demarcated from body. Tail conical and length equal to 3.5 to 4.0 anal body diameters. Labia well developed and with papillae. Cephalic setae extremely short (1.1 to $1.2 \mu \mathrm{m}$ ). Setae absent on tail. Amphids slightly elongated longitudinally, $6.7 \times 5.4 \mu \mathrm{m}$, width $1 / 3$ corresponding head diameter. Oral cavity cylindrical and large $(59.4 \times 8.1 \mu \mathrm{m})$; length $13.7 \%$ of esophageal length; cavity armed with three teeth of equal size, $4.0 \mu \mathrm{m}$. Esophagus widens

205 gradually toward base. Genital tubes of female paired and reflexed. Spicules almost straight but their proximal ends curve ventrally at an angle of $90^{\circ}$; length of spicules $51.3 \mu \mathrm{m}$. Gubernaculum large, wide at distal end, and narrows sharply in proximal part.
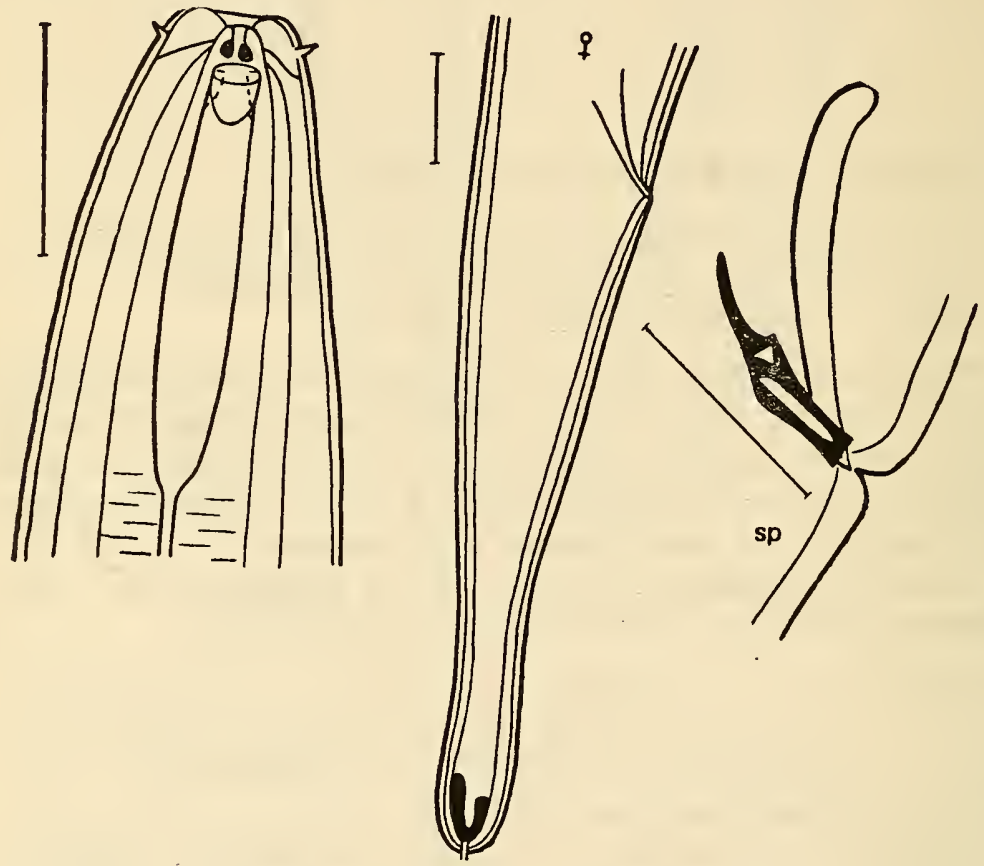

Readily distinguishable from the three species of the genus Parironus described earlier, and hence a comparison is not necessary. The distinguishing features of this species are: short cephalic setae, broad amphids, large oral cavity, and characteristic structure of spicules.

Geographic distribution. Found singly in the White Sea, in the middle horizon of the littoral zone in slightly silted sand. 
5. Family CRENOPHARYNGIDAE Platonova, 1976

9. Genus Crenopharynx Filipjev, 1934

Synonyms: Anoplostoma Linstow, 1900 non Bütschli, 1874; Stenolaimus Southern, 1914 et auctrium non Marion, 1870.

9. Crenopharynx gracilis (Linstow, 1900) (Figure 14)

Filip'ev, 1927: 119-122, tab. 1, fig. 29a-3 (Stenolaimus); 1934: 9.

1 ऊ̊: $\mathrm{L}=6,060.0 \mu \mathrm{m} ; \mathrm{a}=23.3 ; \mathrm{b}=3.9 ; \mathrm{c}=13.7$.

My specimen of Crenopharynx gracilis fully coincides with the description given by Filip'ev (1927) with respect to all measurements and characters. However, I could detect neither amphids nor renette.
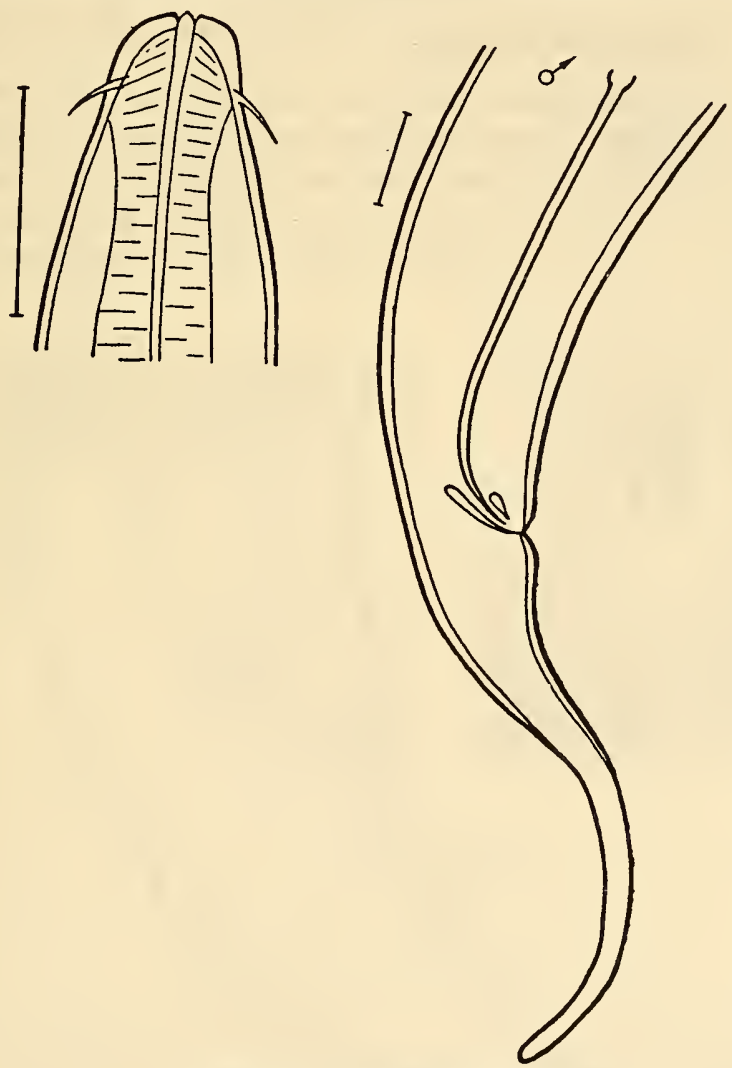

Figure 14. Crenopharynx gracilis.

Geographic distribution. Found singly in the White, Barents, and Kara Seas in the upper and middle horizons of the littoral zone in silted sand. 


\section{Order CHROMADORIDA}

\section{Family CHROMADORIDAE}

10. Genus Hypodontolaimus de Man, 1886

Synonyms: Iotadorus Cobb, 1920 and Ptycholaimellus Cobb, 1920.

10. Hypodontolaimus inaequalis (Bastian, 1865) (Figure 15)

Bastian, 1865; (Spilophora) non Bütschli, 1874; de Man, 1888.

5 ㅅ: $\mathrm{L}=869.0-1,430.0 \mu \mathrm{m} ; \mathrm{a}=14.5-17.2 ; \mathrm{b}=4.9-6.6 ; \mathrm{c}=8.6-14.5$.

2 实: $L=1,221.0-1,364.0 \mu \mathrm{m} ; \mathrm{a}=17.1-17.7 ; b=5.3-6.2 ; \mathrm{c}=10.1-11.3$; $\mathrm{V}=50.0-52.2 \%$.

2 juv.: $\mathrm{L}=759.0-847.0 \mu \mathrm{m} ; \mathrm{a}=11.5-15.4 ; \mathrm{b}=4.6-4.8 ; \mathrm{c}=8.1-8.6$.

The White Sea population coincides very well with the description given by de Man (1888) with respect to all measurements and characters. However, de Man did not succeed in observing amphids in his material. My specimens had amphids. Width of amphids $10.8 \mu \mathrm{m}$, greater than length, and about $1 / 3$ corresponding cephalic width. Amphids situated

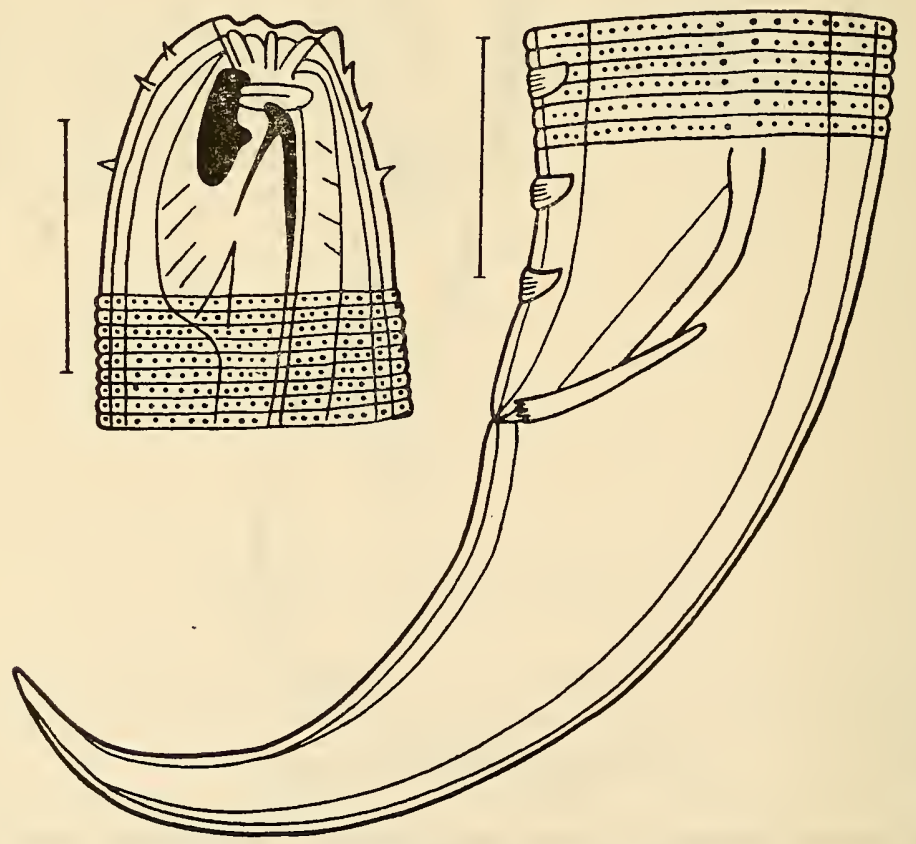

Figure 15. Hypodontolaimus inaequalis. 
$6.0 \mu \mathrm{m}$ from anterior end. Spicules $59.4 \mu \mathrm{m}$ long or 1.5 anal body diameters.

Geographic distribution. Found in the White, Baltic, Norwegian, and North Seas in all horizons of the littoral zone in slightly silted sand.

11. Hypodontolaimus buetschlii (Buetschli, 1874) (Figure 16)

Bütschli, 1874: 44, pls. 5, 6, fig. 23, non Bastian, 1865 (Spiliphera); Ditlevsen, 1919: 194, tab. 10, fig. 2 (striatus); Filip'ev, 1918: 211.

4 o : $\mathrm{L}=825.0-1,419.0 \mu \mathrm{m} ; \mathrm{a}=12.7-16.2 ; \mathrm{b}=5.0-6.5 ; \mathrm{c}=9.4-12.9$.

1 ㅇ: $\mathrm{L}=1,133.0 \mu \mathrm{m} ; \mathrm{a}=14.9 ; \mathrm{b}=6.5 ; \mathrm{c}=13.0 ; \mathrm{V}=47.6 \%$.

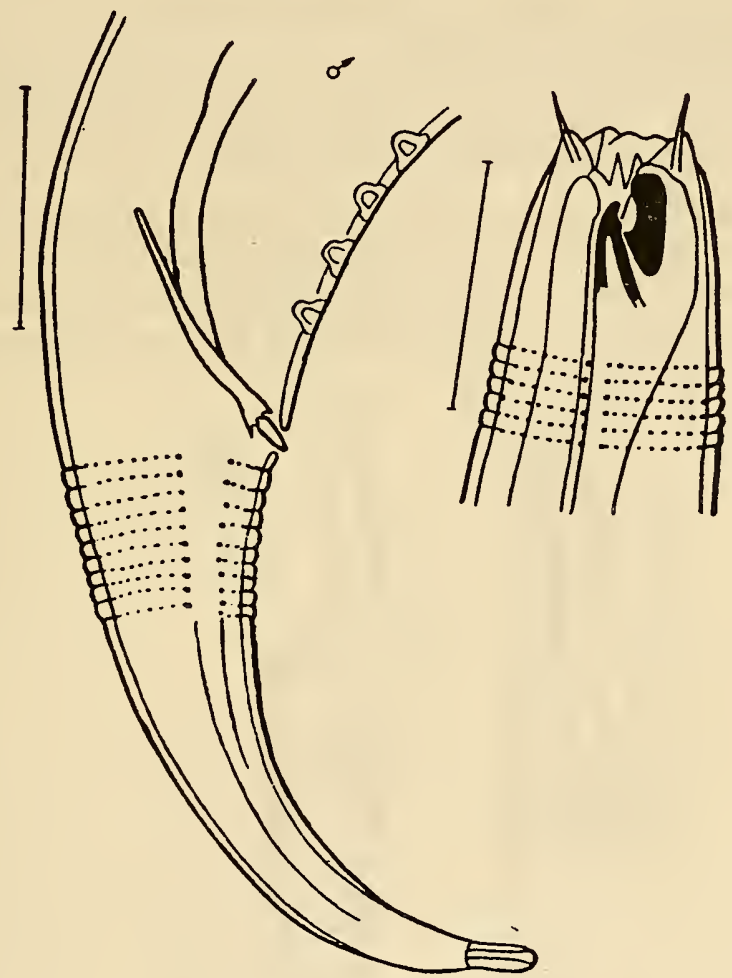

Figure 16. Hypodontolaimus buetschlii.

Most of the characters of the White Sea specimens coincide with the brief description given by Bütschli (1874). The following may be added 207 to this description on the basis of my material: cephalic setae $5.4 \mu \mathrm{m}$ long. Spicules long, slightly curved, and $70.4 \mu \mathrm{m}$ long, or about 1.5 anal body diameters. Gubernaculum massive, slightly dilated at its distal end, 
and $25.1 \mu \mathrm{m}$ long. Accessory organs 23 in males and situated anterior to anus.

Geographic distribution. Found in the White, Baltic, Norwegian, and North Seas, mainly in the middle and lower horizons of the littoral zone in slightly silted sand.

\section{Genus Chromadora Bastian, 1865}

Synonyms: Tridontolaimus Micoletzky, 1913 and Parachromadora, Micoletzky, 1914.

12. Chromadora macrolaima de Man, 1889 (Figure 17)

Allgen, 1933; 69 (var. pigmentata).

4 ㅈ: $\mathrm{L}=543.0-704.0 \mu \mathrm{m} ; \mathrm{a}=21.1-23.3 ; \mathrm{b}=5.1-6.0 ; \mathrm{c}=6.2-7.1$.

1 juv.: $L=616.0 \mu \mathrm{m} ; \mathrm{a}=28.0 ; \mathrm{b}=5.6 ; \mathrm{c}=7.0$.

My specimens conform very well to the description given by de Man with respect to characters and measurements. Peculiarities of the White Sea specimens are: smaller size than those described by de Man and 10 to 11 accessory organs. To the description of de Man the following may be

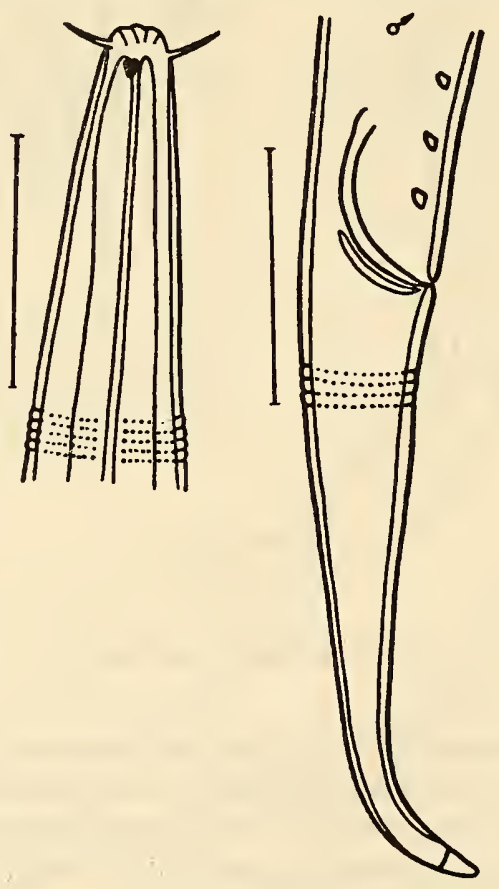

Figure 17. Chromadora macrolaima. 
added: cephalic setae 5.5 to $6.0 \mu \mathrm{m}$ long. Spicule length approximately 1.2 anal body diameters.

Geographic distribution. Found in the White, Barents, and North Seas in all horizons of the littoral zone in slightly silted sand.

13. Spilophorella candida Gerlach, 1951 (Figure 18)

1 ส: $\mathrm{L}=1,007.0 \mu \mathrm{m} ; \mathrm{a}=22.0 ; \mathrm{b}=5.6 ; \mathrm{c}=8.5$.

1 juv.: $\mathrm{L}=821.0 \mu \mathrm{m} ; \mathrm{a}=23.0 ; \mathrm{b}=5.9 ; \mathrm{c}=7.0$.

This species conforms to the description given by Gerlach (1951) with respect to all characters and measurements, except that in my specimen the spicules were more curved than in the North Sea form.

Geographic distribution. Found in the White and North Seas in all horizons of the littoral zone in slightly silted sand.
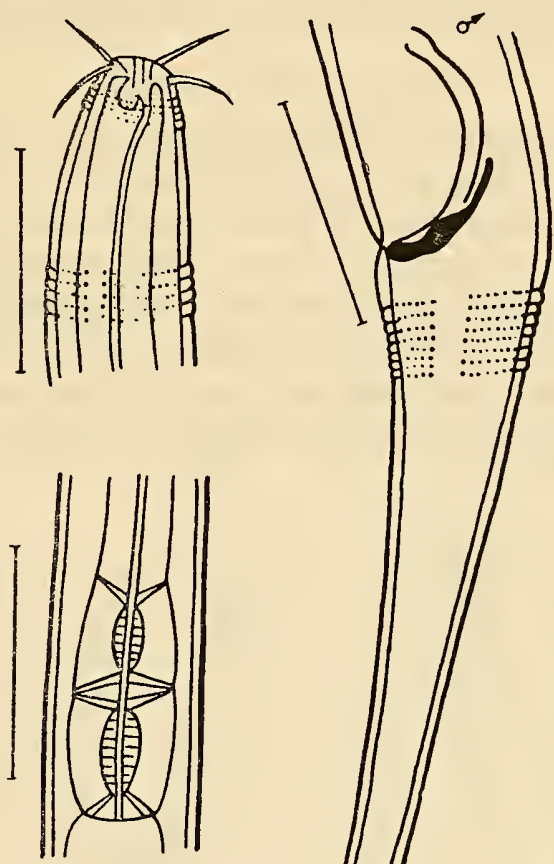

bb. e

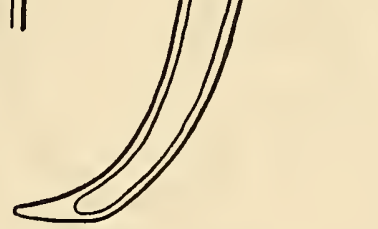

Figure 18. Spilophorella candida. 
13. Genus Timmia Hopper, 1961

Synonym: Parachromadora Timm., 1952.

14. Timmia acuticauda sp. n. (Figure 19)

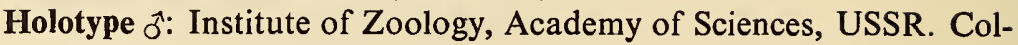
lection No. 25.

$\begin{array}{ccccc}- & 67.5 & 110.7 & - & 486.0 \\ 10.8 & 18.9 & 21.6 & 27.0 & 21.6\end{array} 54.3 \mu \mathrm{m} ; \mathrm{a}=20.9 ; \mathrm{b}=5.1 ; \mathrm{c}=7.2$.

Paratypes.

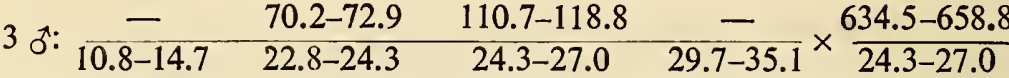

$$
\begin{aligned}
& 726.3-731.7 \mu \mathrm{m} ; \mathrm{a}=20.7-27.0 ; \mathrm{b}=6.2-6.6 ; \mathrm{c}=7.9-11.9 \text {. } \\
& \text { 2 ㅇ: } \begin{array}{cccc}
- & 67.5-70.2 & 110.7-118.8 & 313.2-342.9 \\
\hline 13.3-13.5 & 16.2-24.3 & 26.0-27.0 & 32.4-37.8
\end{array} \\
& \times \frac{556.2-648.0}{21.6-27.0} 656.1-750.6 \mu \mathrm{m} ; \mathrm{a}=19.8-20.2 ; \mathrm{b}=5.9-6.3 \text {; } \\
& c=6.3-6.4 ; V=47.5-47.7 \% \text {. }
\end{aligned}
$$

Body elongated, tapers to $1 / 2$ midbody diameter at anterior end and $2 / 3$ at posterior end. Head not demarcated from body. Tail acicular and length three anal body diameters. Four cephalic setae present, $6.0 \mu \mathrm{m}$ long, or more than $1 / 2$ cephalic diameter. Setae absent on tail. Cuticle ornamented with dots of almost equal size; lateral differentiation absent. Amphids not detected. Saccate photosensitive pigment spots situated 22 $\mu \mathrm{m}$ from anterior end. Oral cavity $(5.0 \mu \mathrm{m} \times 10.0 \mu \mathrm{m})$ armed with three small teeth almost uniform in length $(2.8 \mu \mathrm{m})$. Esophagus with bulb 24.3 $\mu \mathrm{m} \times 27.0 \mu \mathrm{m}$ in size.
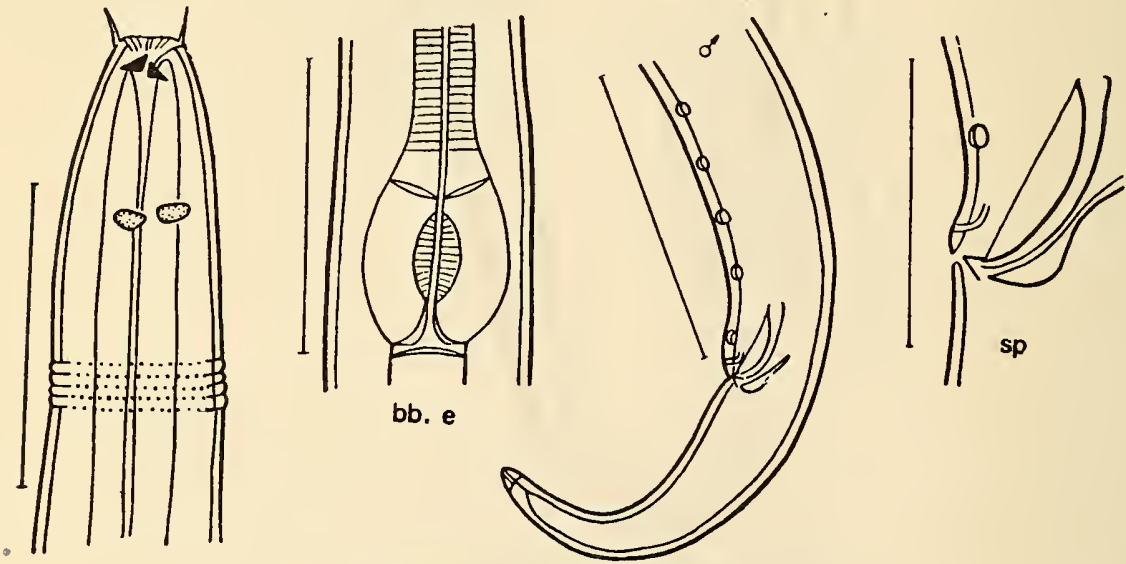

Figure 19. Timmia acuticauda sp. n. 
Reproductive system of female consists of paired and reflexed tubes. Male with five pairs of accessory organs and one unpaired in shape of

209 tube situated 3.0 to $4.0 \mu \mathrm{m}$ anterior to anus. Spicules curved, slightly wider in distal part, and $30 \mu \mathrm{m}$ long, or 1.2 anal body diameters. Gubernaculum simple and $18.0 \mu \mathrm{m}$ long ( 0.6 spicular lengths).

Of the two species of Timmia described to date, this species is more similar in description to Timmia parva (Timm, 1952), but can be distinguished from it by smaller cephalic setae, shape and situation of pigment spots, larger number of accessory organs, absence of velum in spicules, and terminal tooth on gubernaculum. This enables one to consider the White Sea population a new species.

Geographic distribution. Found in the White Sea in all horizons of the littoral zone in slightly silted sand.

\section{Genus Prochromadorella Micoletzky, 1924}

\section{Prochromadorella crassispicula sp. n. (Figure 20)}

Holotype $\sigma^{-}$: Institute of Zoology, Academy of Sciences, USSR. Collection No. 27.

$$
\begin{array}{ccccc}
- & 110.0 & 231.0 & - & 1,584.0 \\
22.0 & 33.0 & 44.0 & 77.0 & 55.0 \\
& \multicolumn{1}{c}{=10.6 .}
\end{array}
$$

Paratypes.

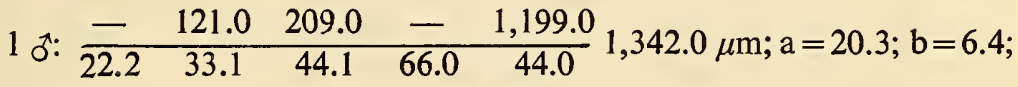

$$
\begin{aligned}
& \mathrm{c}=9.4 \text {. } \\
& 1 \text { ㅇ: } \begin{array}{ccccc}
- & 104.0 & 181.0 & 858.0 & 1,276.0 \\
\hline 22.4 & 33.0 & 38.0 & 71.0 & 33.0
\end{array} 1441.0 \mu \mathrm{m} ; \mathrm{a}=20.1 \text {; } \\
& \mathrm{b}=7.9 ; \mathrm{c}=8.8 ; \mathrm{V}=44.3 \% \text {. }
\end{aligned}
$$

Body rather long and tapers to $1 / 3$ to $2 / 7$ midbody diameter at anterior end and $3 / 4$ to $1 / 2$ at posterior end. Head poorly demarcated from body. Tail conical, acicular at end; length 4.5 anal body diameters. Cephalic setae long $(10.8 \mu \mathrm{m})$; setae sparsely scattered throughout body. Setae 5.4 to $8.1 \mu \mathrm{m}$ long also present on tail. Cuticle smooth in cephalic region, but becomes annulate approximately at level of cephalic setae; ornamentation at anterior margin in form of minute punctation; posteriorly replaced by oval and then virgate sclerites. In anal region sclerites again round. Lateral differentiation lacking. Amphids not detected. Oral cavity small and armed with three teeth of unequal size; larger dorsal 210 tooth $3.6 \mu \mathrm{m}$ long and two subventral ones $2.4 \mu \mathrm{m}$ long. Esophagus with elongated bulb $32.4 \mu \mathrm{m} \times 24.3 \mu \mathrm{m}$.

Reproductive system of female consists of paired reflexed tubes. 
Large egg, $62.1 \mu \mathrm{m}$ in diameter, found in one genital tube. Sexual armature of male represented by nine accessory organs, spicules, and gubernaculum. Spicules curved, $61.2 \mu \mathrm{m}$ long, or 1.1 to 1.2 anal body diameters. Gubernaculum simple and $34.8 \mu \mathrm{m}$ long.
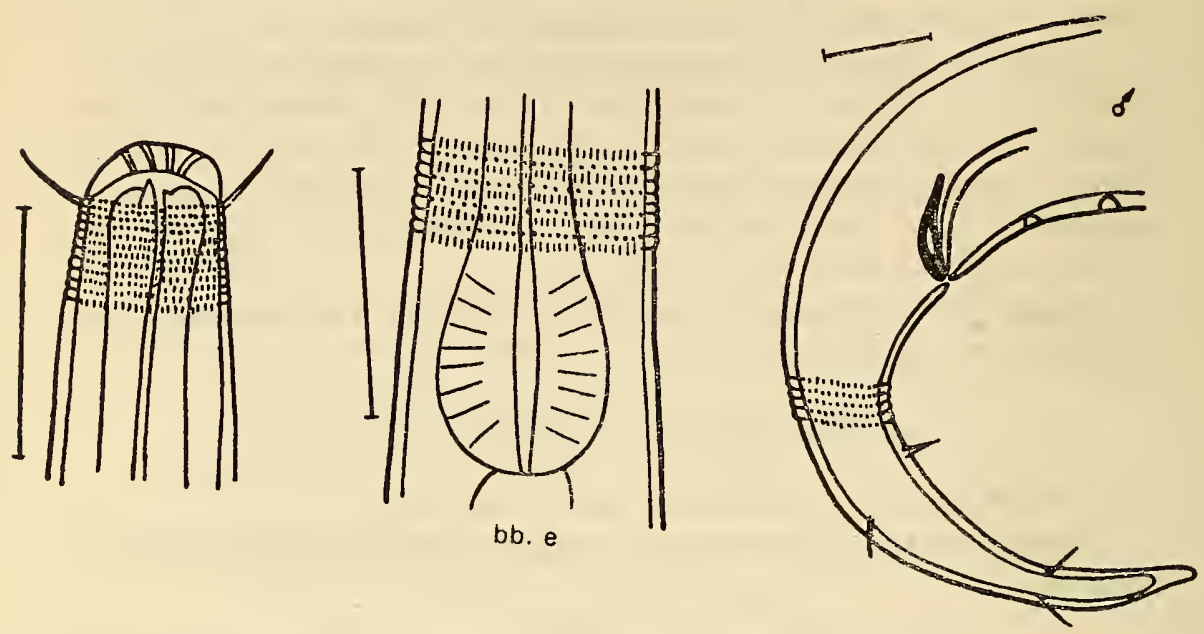

Figure 20. Prochromadorella crassispicula sp. n.

Of all the known species of the genus, the White Sea species may be compared with $P$. obtusidens (Stekhoven and Adam, 1931) from the Belgian coast, which has been described on the basis of only males. P. crassispicula can be distinguished from $P$. obtusidens by the much longer cephalic setae, presence of setae throughout body, and shape of large dorsal tooth (in the White Sea species absolutely straight). On the basis of these characters it seems feasible to isolate $P$. crassispicula as a new species. It should be noted that had it been possible to compare males the distinguishing features would undoubtedly be more.

Geographic distribution. Found in the White Sea in all horizons of the littoral zone in slightly silted sand.

\section{Genus Prochromadora Filipjev, 1922}

16. Prochromadora bulbosa sp. n. (Figure 21)

Holotype $\bar{\sigma}$ : Institute of Zoology, Academy of Sciences, USSR. Collection No. 30 .

$$
\begin{array}{ccccc}
- & 59.4 & 90.4 & - & 332.1 \\
13.5 & 21.6 & 24.3 & 27.0 & 24.3
\end{array} 413.1 \mu \mathrm{m} ; \mathrm{a}=15.3 ; \mathrm{b}=4.6 ; \mathrm{c}=5.1 \text {. }
$$

\section{Paratypes.}

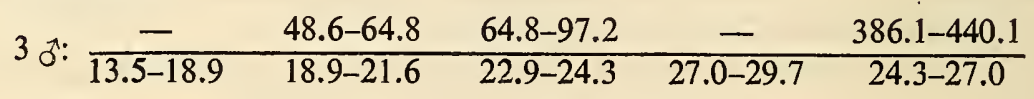




$$
\begin{aligned}
& \times 469.8-523.8 \mu \mathrm{m} ; \mathrm{a}=17.4-18.2 ; \mathrm{b}=5.4-8.3 ; \mathrm{c}=5.5-6.2 \text {. } \\
& 1 \text { juv.: } \begin{array}{crrrr}
- & 54.0 & 91.8 & - & 351.0 \\
\hline 16.2 & 20.2 & 21.6 & \begin{array}{c}
24.3 \quad 18.9 \\
\mathrm{c}=6.0 .
\end{array}
\end{array} 431.2 \mu \mathrm{m} ; \mathrm{a}=17.3 ; \mathrm{b}=4.6 \text {; }
\end{aligned}
$$

Body short and tapers to $2 / 3$ midbody diameter at anterior end and $10 / 11$ to $5 / 6$ at posterior end. Head not demarcated from body. Tail conical but acicular at end. Cephalic setae $7.2 \mu \mathrm{m}$, equal to 0.5 cephalic diameter. Setae absent on rest of body. Cuticle annulate, and ornamented with round sclerites; latter smaller on head than on rest of body. Lateral differentiation absent. Amphids not detected. Oral cavity small 211 and armed with tooth $3.6 \mu \mathrm{m}$ long. Esophagus with bulb $22.8 \mu \mathrm{m} \times 18.0$ $\mu \mathrm{m}$. Spicules curved, large, $33.6 \mu \mathrm{m}$ long, or 1.5 anal body diameters. Gubernaculum small $(12.0 \mu \mathrm{m})$ and resembles a walking stick with the handle turned upward.
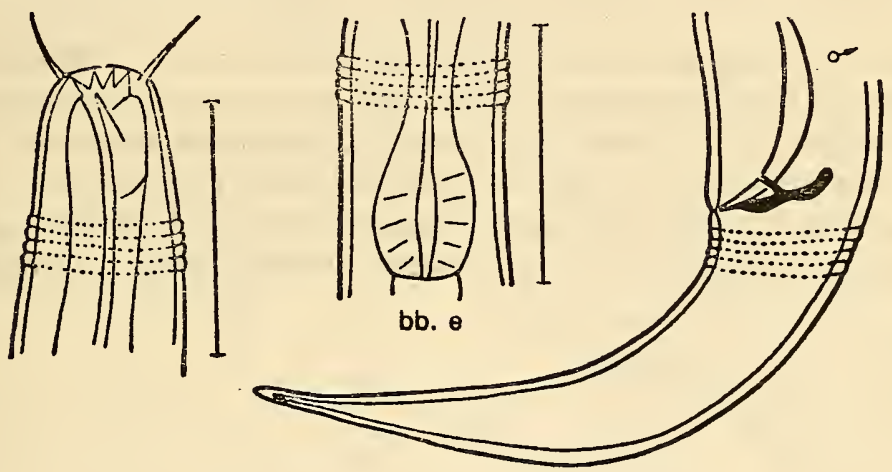

Figure 21. Prochromadora bulbosa sp. $\mathrm{n}$.

P. bulbosa may be compared with one of the closest species of the genus- $P$. oerlayi (de Man)-from which the White Sea species differs in index $c$, absence of setae throughout body (except for head), absence of eye pigment spots, shape of spicules and gubernaculum, larger size, and absence of accessory organ. This enables one to consider the species from the White Sea new.

Geographic distribution. Found in the White Sea, mainly at the upper and lower horizons of the littoral zone in slightly silted sand.

7. Family CYATHOLAIMIDAE Filipjev, 1918

16. Genus Paracanthonchus Micoletzky, 1924

Synonyms: Harveyjohnstonia Mawson, 1953; Metacanthonchus Wieser, 1954; Paraseuratiella Stekhoven, 1950. 
17. Paracanthonchus medius sp. n. (Figure 22)

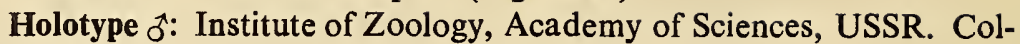
lection No. 31.

$$
\begin{array}{ccccc}
- & 99.0 & 198.0 & - & 990.0 \\
22.0 & 33.0 & 38.0 & 44.0 & 34.0 \\
& & & c=11.08
\end{array}
$$

Paratypes.

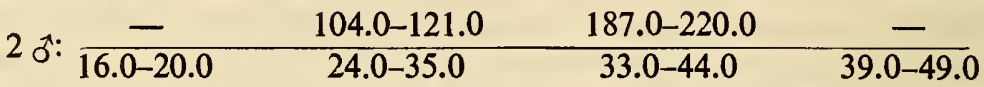

$$
\begin{aligned}
& \times \frac{814.0-1,155.0}{31.0-44.0} 913.0-1,254.0 \mu \mathrm{m} ; \mathrm{a}=23.7-25.3 ; \\
& \mathrm{b}=4.9-5.7 ; \mathrm{c}=9.2-12.7 \text {. } \\
& 1 \text { o: } \begin{array}{crrrr}
- & 110.0 & 231.0 & 671.0 & 1,122.0 \\
22.1 & 33.0 & 41.0 & 55.0 & 30.0
\end{array} \text {, } 232.0 \mu \mathrm{m} ; \mathrm{a}=22.4 \text {; }
\end{aligned}
$$

Body rather long and tapers to $1 / 2$ midbody diameter at anterior end and 5/6 to $10 / 13$ at posterior end. Head anteriorly truncated; not demarcated from body. Tail conical and length 3.5 anal body diameters. Cephalic setae situated in two circles (Figure 22) and $10.8 \mu \mathrm{m}$ long, i.e., approximately $1 / 2$ cephalic diameter. Setae absent on tail. Cuticle annulate and ornamented with round, punctate sclerites, larger in cephalic
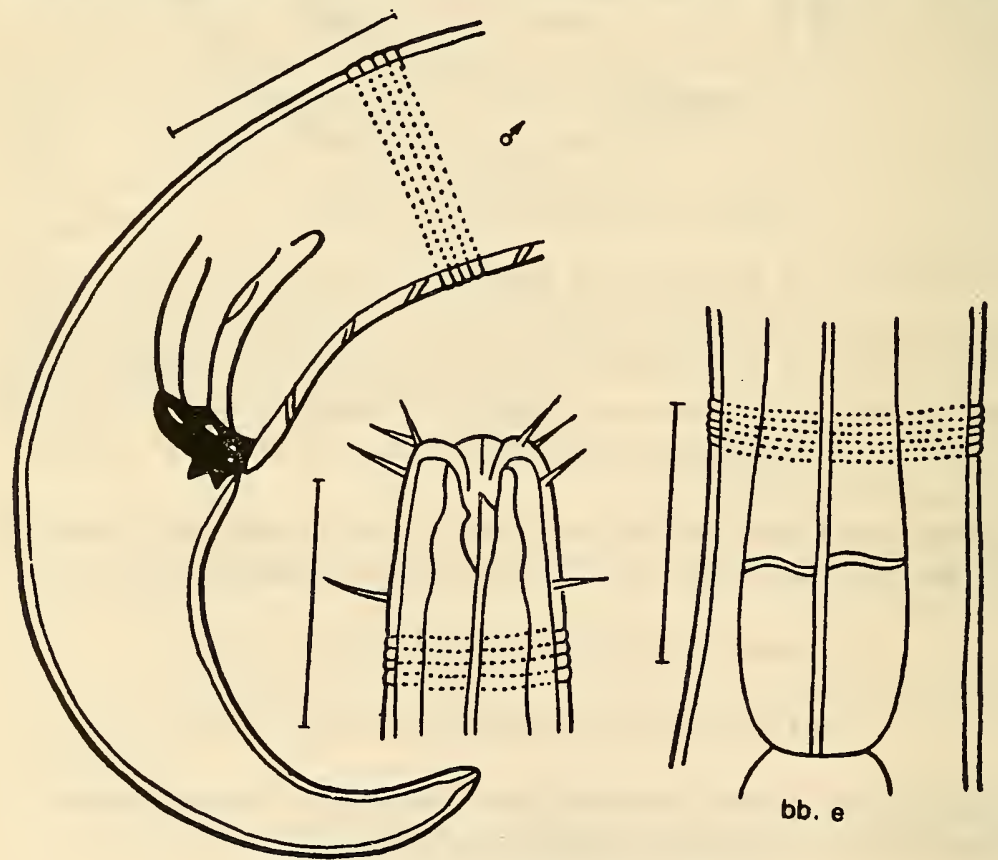

Figure 22. Paracanthonchus medius.sp. n. 
region than on rest of body. Amphids not detected. Oral cavity large, $15.6 \mu \mathrm{m} \times 8.4 \mu \mathrm{m}$, and armed with single tooth $4.8 \mu \mathrm{m}$ long. Esophagus without bulb and dilates gradually toward base.

Reproductive system of female consists of paired unflexed tubes. Genital armature of male represented by four tubular accessory organs, spicules, and gubernaculum. Spicules curved, rather long $(48.0 \mu \mathrm{m})$, and slightly broader in distal part. Gubernaculum well developed, length almost equal to spicular length $(44.4 \mu \mathrm{m})$, and armed with several small denticles at distal end.

This White Sea species is very close to $P$. uniformis (Stekhoven, 1950), described from the coast of the Mediterranean Sea, but can be distinguished from it by indices $a$ and $b$, longer cephalic setae, absence of pigmented eyes, and shape and size of gubernaculum and spicules. These characters enable one to consider $P$. medius a new species.

Geographic distribution. Found in the White Sea in all horizons of the littoral zone in slightly silted sand.
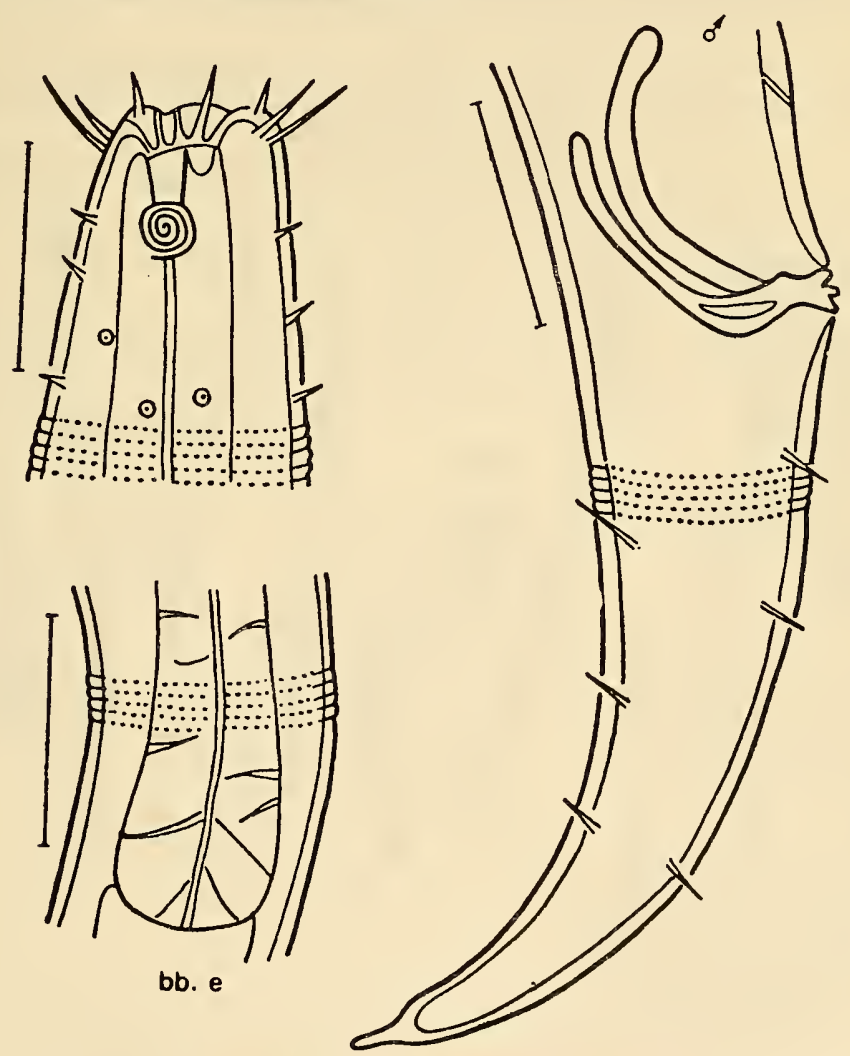

Figure 23. Paracanthonchus macrodon. 
18. Paracanthonchus macrodon (Ditlevsen, 1910) (Figure 23)

Ditlevsen, 1919: 200, pls. 11, 12, figs 6-8 (Cyatholaimus); Micoletzky, 1924: 138.

4 3ै: $\mathrm{L}=990.0-1,320.0 \mu \mathrm{m} ; \mathrm{a}=19.5-29.4 ; \mathrm{b}=5.3-6.3 ; \mathrm{c}=9.1-12.9$.

1 ㅇ: $\mathrm{L}=902.0 \mu \mathrm{m} ; \mathrm{a}=23.4 ; \mathrm{b}=5.6 ; \mathrm{c}=10.2 ; \mathrm{V}=51.1 \%$.

The White Sea population coincides with those specimens described earlier with respect to major characters and measurements, but is slightly smaller in size than species described from the coast of the North Sea.

Geographic distribution. Found in the White, Norwegian, Baltic and North Seas in all horizons of the littoral zone in slightly silted sand.

\section{Family COMESOMATIDAE Filipjev, 1918}

17. Genus Sabatieria de Rouville, 1904

19. Sabatieria vulgaris (de Man, 1907) (Figure 24)

de Man, 1907: 66-67, fig. 12a-i (Parasabatieria); Filip'ev, 1934: 27.

2 ㅊ: $\mathrm{L}=2,167.0-2,299.0 \mu \mathrm{m} ; \mathrm{a}=49.4-52.3 ; \mathrm{b}=7.2-8.6 ; \mathrm{c}=16.1-16.4$.

2 䒠: $\mathrm{L}=1,815.0-2,035.5 \mu \mathrm{m} ; \mathrm{a}=37.0-39.3 ; \mathrm{b}=10.2-10.3 ; \mathrm{c}=14.8$

$16.5 ; \mathrm{V}=50.6-53.0 \%$.

1 juv.: $\mathrm{L}=1,133.0-1,166.0 \mu \mathrm{m} ; \mathrm{a}=34.3-35.4 ; \mathrm{b}=5.6-6.9 ; \mathrm{c}=8.6-9.1$.
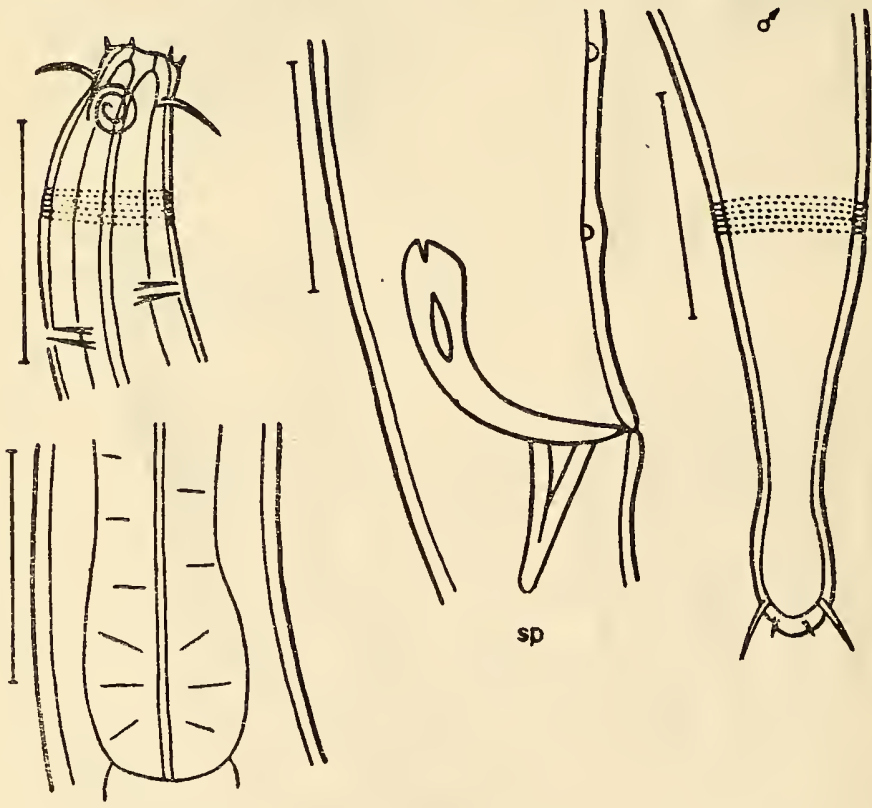

bo. e

Figure 24. Sabatieria vulgaris. 
The White Sea population coincides very well with that described earlier by de Man, but individuals are smaller in size than those of the species described from the coast of the North Sea. Judging from the drawing given by de Man, the White Sea species also has longer cephalic setae $(3.6 \mu \mathrm{m})$.

Geographic distribution. Found in the White, Baltic, and North Seas, mainly at the middle and lower horizons of the littoral zone in slightly silted sand.

\section{Family CHOANOLAIMIDAE Schuurmans-Stekhoven and Adam, 1931}

\section{Genus Halichoanolaimus de Man, 1886}

20. Halichoanolaimus robustus (Bastian, 1865) (Figure 25)

Bastian, 1865; 166, pl. 13, fig. 226 (Spilophora); de Man, 1888; 38, pl. 4, fig. 17; Allgen, 1929; 454, fig. 16a, b (Smalsundia punctata).

$1 \sigma^{1}: \mathrm{L}=2,112.0 \mu \mathrm{m} ; \mathrm{a}=27.4 ; \mathrm{b}=6.7 ; \mathrm{c}=19.2$.

1우: $\mathrm{L}=1,419.0 \mu \mathrm{m} ; \mathrm{a}=16.2 ; \mathrm{b}=5.9 ; \mathrm{c}=18.1 ; \mathrm{V}=45.0 \%$.

1 juv.: $\mathrm{L}=1,529.0 \mu \mathrm{m} ; \mathrm{a}=27.8 ; \mathrm{b}=5.4 ; \mathrm{c}=17.4$.

214 The White Sea population conforms very well to the description given by de Man (1888), but individuals are somewhat smaller than those of the species described earlier from the coast of the North Sea.

Geographic distribution. Found in the White, Baltic, Irish, Norwegian, and North Seas, mainly in the middle and lower horizons of the littoral zone in slightly silted sand.
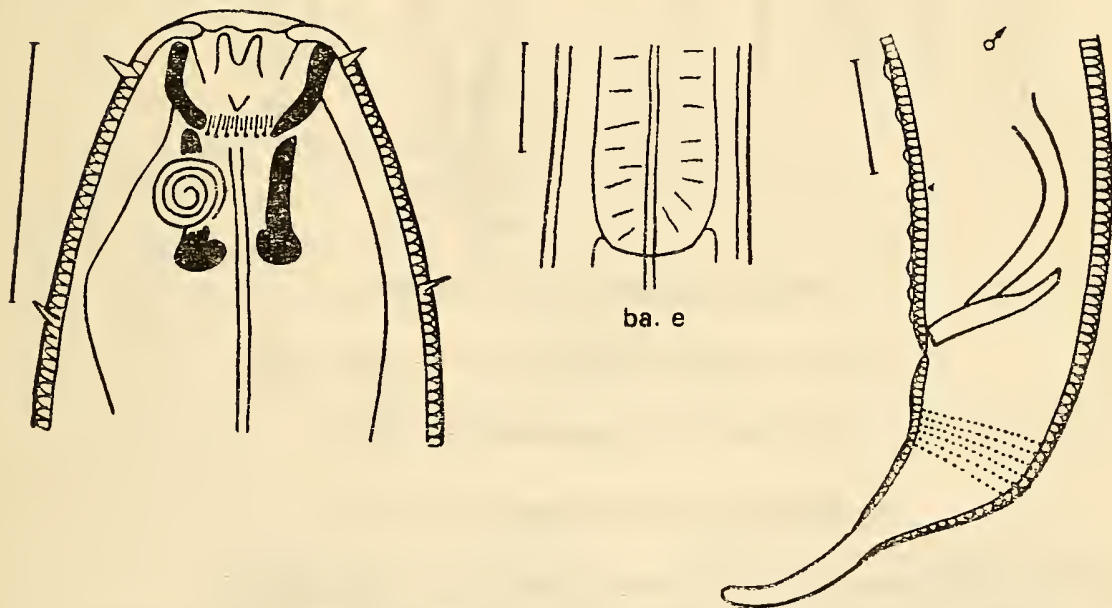

Figure 25. Halichoanolaimus robust us. 


\section{Order MONHYSTERIDA}

10. Family SPHAEROLAIMIDAE Filipjev, 1918

19. Genus Sphaerolaimus Bastian, 1865

Synonym: Parasphaerolaimus Ditlevsen, 1919.

21. Spharolaimus macrolasius Schulz, 1932 (Figure 26)

1 娄: $\mathrm{L}=1,859.0 \mu \mathrm{m} ; \mathrm{a}=16.9 ; \mathrm{b}=4.5 ; \mathrm{c}=9.9$.

3 ㅇ: $\mathrm{L}=1,639.0-1,947.0 \mu \mathrm{m} ; \mathrm{a}=14.8-19.2 ; \mathrm{b}=4.8-5.4 ; \mathrm{c}=8.8-9.1$; $\mathrm{V}=69.9-73.5 \%$.

1 juv.: $L=1,276.0 \mu \mathrm{m} ; \mathrm{a}=16.6 ; \mathrm{b}=4.5 ; \mathrm{c}=7.2$.

The White Sea population conforms completely to the description given by Schulz with respect to characters and measurements, but individuals are smaller than those from the North Sea.

215 Geographic distribution. Found in the White and North Seas in all horizons of the littoral zone in slightly silted sand.
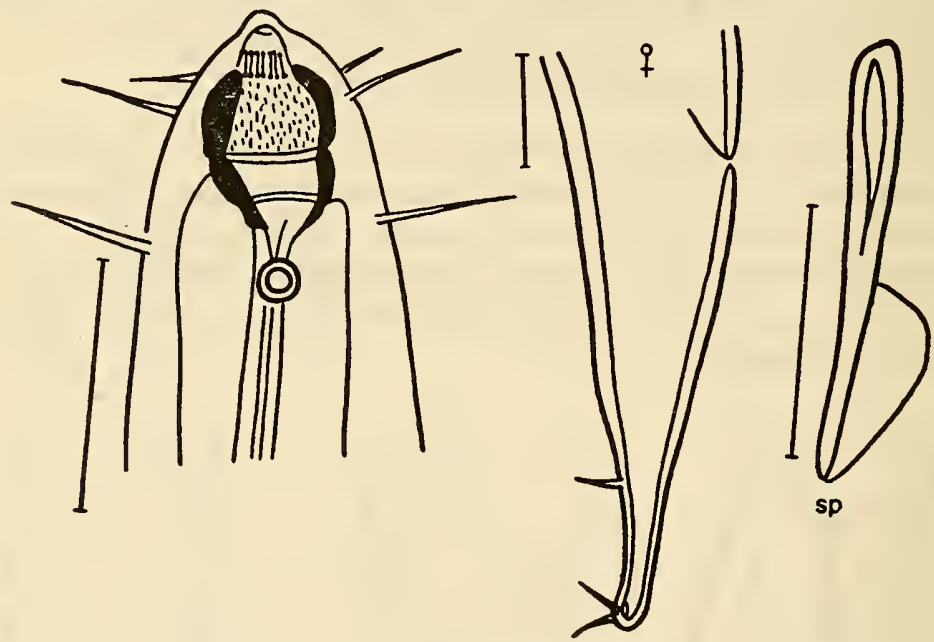

Figure 26. Sphaerolaimus macrolasius.

11. Family MONHYSTERIDAE de Man, 1867

20. Genus Theristus Bastian, 1865

1. Subgenus Mesotheristus Wieser, 1956

22. Theristus (Mesotheristus) setosus (Buetschli, 1874) Figure 27

Bütschli, 1874; 29, pls. 5, 6, fig. 4 (Monhystera setosa); Filip'ev, 1918: 277. 
4 ऊँ: $\mathrm{L}=1,227.0-1,496.0 \mu \mathrm{m} ; \mathrm{a}=17.5-20.8 ; \mathrm{b}=3.4-3.7 ; \mathrm{c}=5.8-6.4$.

2 우 $\mathrm{L}=1,914.0-2,200.0 \mu \mathrm{m} ; \mathrm{a}=16.6-17.4 ; \mathrm{b}=3.6-4.1 ; \mathrm{c}=7.0-7.4$; $\mathrm{V}=68.0-74.2 \%$.

This White Sea species fully conforms to the earlier description by Bütschli (1874) with respect to all characters and measurements.
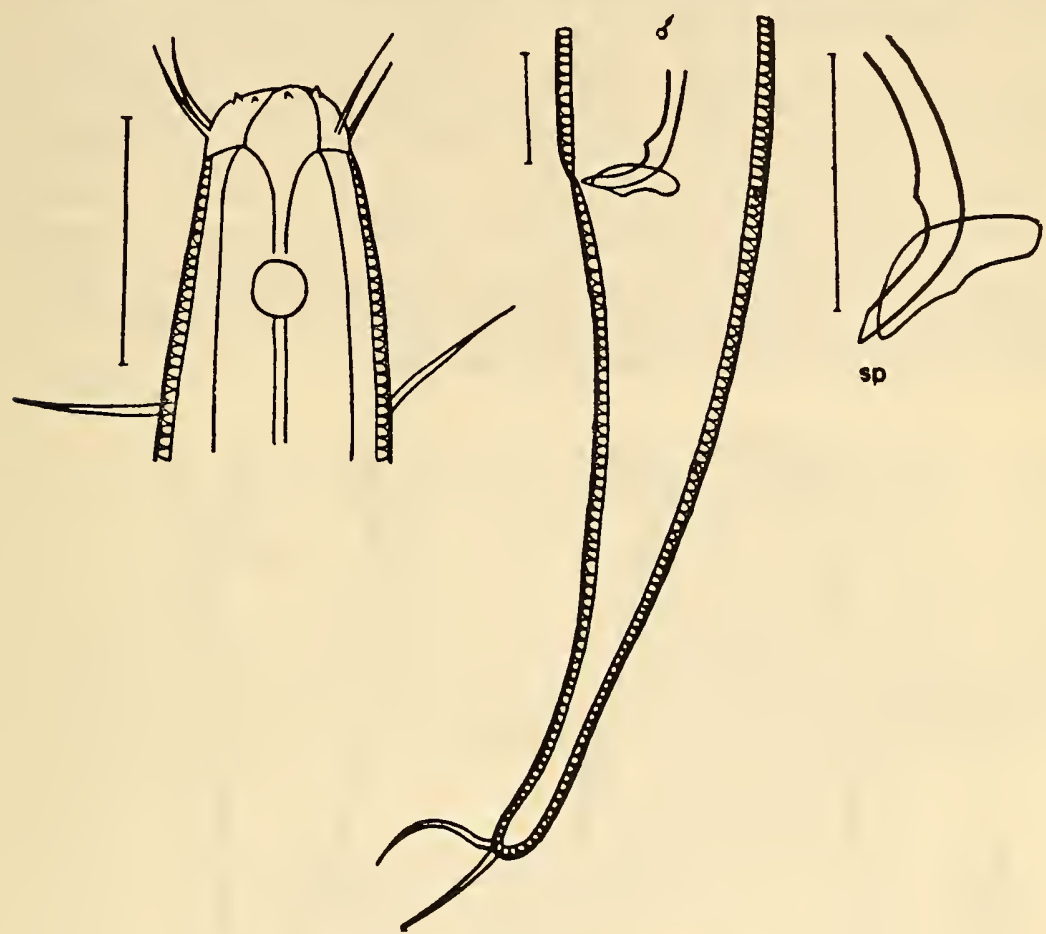

Figure 27. Theristus setosus.

Geographic distribution. Found in the White, Baltic and North Seas in all horizons of the littoral zone in slightly silted sand.

23. Theristus (Mesotheristus) platonovae sp. $\mathrm{n}$. (Figure 28)

Holotype $\sigma^{*}$ : Institute of Zoology, Academy of Sciences, USSR. Collection No. 50.

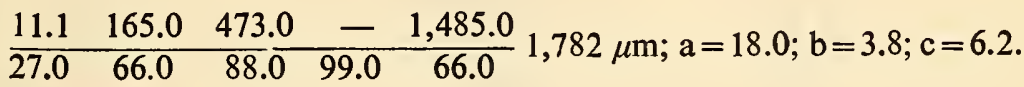

Paratypes.

$$
\begin{aligned}
& 2 \text { o }: \begin{array}{cccc}
12.0-13.0 & 165.0-176.0 & 482.0-484.0 & - \\
\hline 27.0-34.0 & 71.0-73.0 & 82.0-94.0 & 93.0-104.0
\end{array} \\
& \times \frac{1,529.0-1,562.0}{60.0-66.0} 1,782.0-1,859.0 \mu \mathrm{m} ; \mathrm{a}=17.1-19.8 ; \mathrm{b}=3.7-3.8 \\
& c=6.3-7.0 \text {. }
\end{aligned}
$$




$$
\begin{aligned}
& 1 \text { ㅇ: } \begin{array}{ccccc}
11.0 & 187.0 & 495.0 & 1,408.0 & 1,620.0 \\
33.0 & 77.0 & 99.0 & 115.0 & 66.0
\end{array} 1,892.0 \mu \mathrm{m} ; \mathrm{a}=16.4 \\
& \mathrm{~b}=3.8 ; \mathrm{c}=7.2 ; \mathrm{V}=74.4 \% \text {. }
\end{aligned}
$$

Body long and wide; tapers to $2 / 7$ midbody diameter at anterior end and $2 / 3$ at posterior end. Tail long and divided into two parts: conical part $2 / 3$ caudal length and cylindrical $1 / 3$. Cephalic setae unequal in size; one seta in each pair much thicker and rather longer $(13.5 \mu \mathrm{m})$ and the other one thinner and shorter $(10.1 \mu \mathrm{m})$. Cervical setae thin and long $(38.0 \mu \mathrm{m})$. Some setae present on tail and 10.0 to $12.0 \mu \mathrm{m}$ long. Cuticle annulate. Amphids round, thin-walled, $7.8 \mu \mathrm{m}$ in diameter $(1 / 5$ corresponding head diameter), and located $43.2 \mu \mathrm{m}$ from anterior end. Oral cavity well developed, $18.9 \mu \mathrm{m} \times 10.8 \mu \mathrm{m}$, and internally supported by sclerotized ring. Labia with rough folds on inner side. Esophagus cylindrical and uniform in width throughout its length.
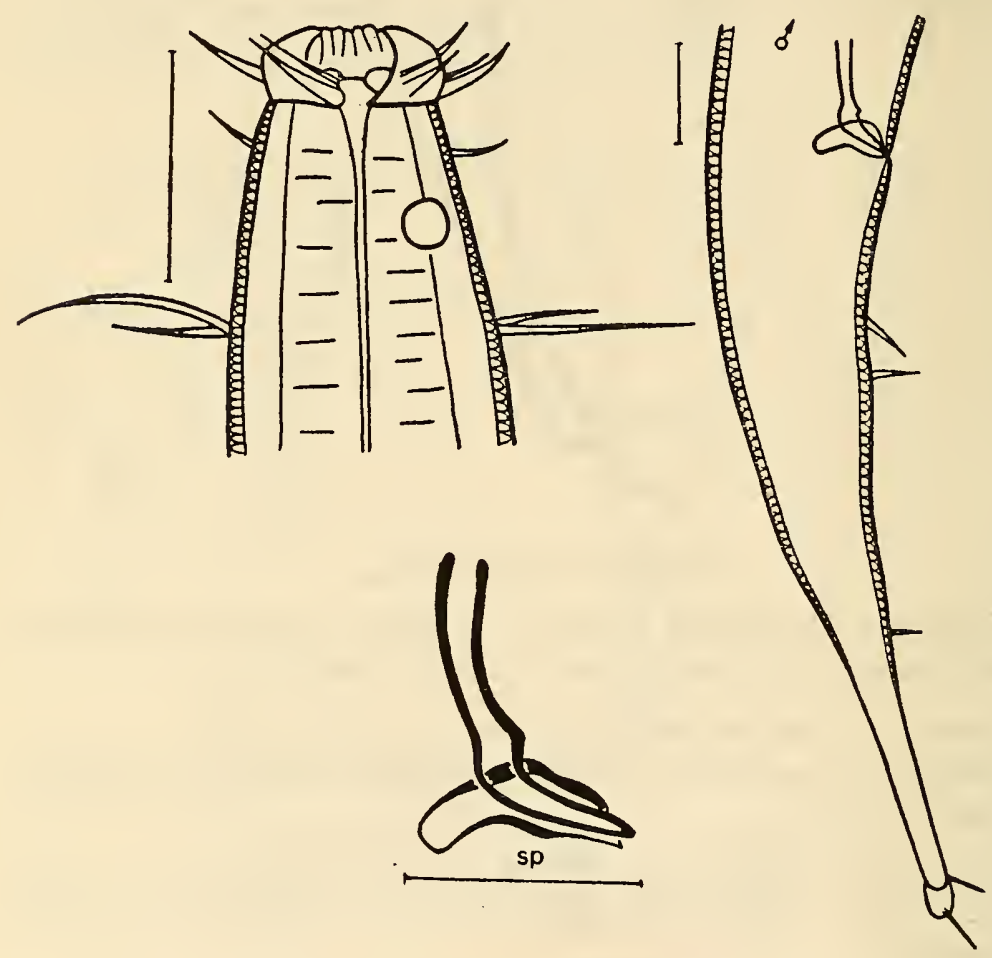

Figure 28. Theristus platonovae sp. $\mathbf{n}$.

Reproductive system of females consists of paired (anterior) unflexed tubes. Spicules of male slightly curved and $56.7 \mu \mathrm{m}$ long. Gubernaculum large $(45.9 \mu \mathrm{m})$, with an appendage $13.5 \mu \mathrm{m}$ long. 
Of all the known species of this subgenus, this species is comparable to $T$. (M.) hirtus Gerlach, 1951, described from the coast of the North Sea. It can be distinguished from the remaining species by its much larger size and width of body (index $a$ ), different structure of the gubernaculum, characteristic structure of the cephalic setae, small number of setae on the body, and labia with rough folds. All this enables one to consider T. platonovae an independent species.

Geographic distribution. Found in the White Sea, mainly in the lower and middle horizons in slightly silted sand.

24. Theristus (Pseudosteineria) horridus (Steiner, 1916) (Figure 29)

Steiner, 1916b: 643, tab. 33, fig. 40a-c (Monhystera horrida); Filip'ev, 1918: 278.

1 कै: $\mathrm{L}=1,101.0 \mu \mathrm{m} ; \mathrm{a}=21.4 ; \mathrm{b}=3.7 ; \mathrm{c}=6.6$.

2 ㅇ: $\mathrm{L}=1,412.0-1,584.0 \mu \mathrm{m} ; \mathrm{a}=17.4-18.1 ; \mathrm{b}=4.3-4.5 ; \mathrm{c}=6.8-7.8$; $\mathrm{V}=66.0-68.0 \%$.

3 juv.: $\mathrm{L}=902.0-1,485.0 \mu \mathrm{m} ; \mathrm{a}=16.4-18.0 ; \mathrm{b}=3.4-4.0 ; \mathrm{c}=5.9-7.1$.

The White Sea population conforms to the description given earlier by Steiner, but certain supplementary characters need to be added as the previous description was based only on a female. Spicules of male somewhat curved and almost uniform in width throughout their length
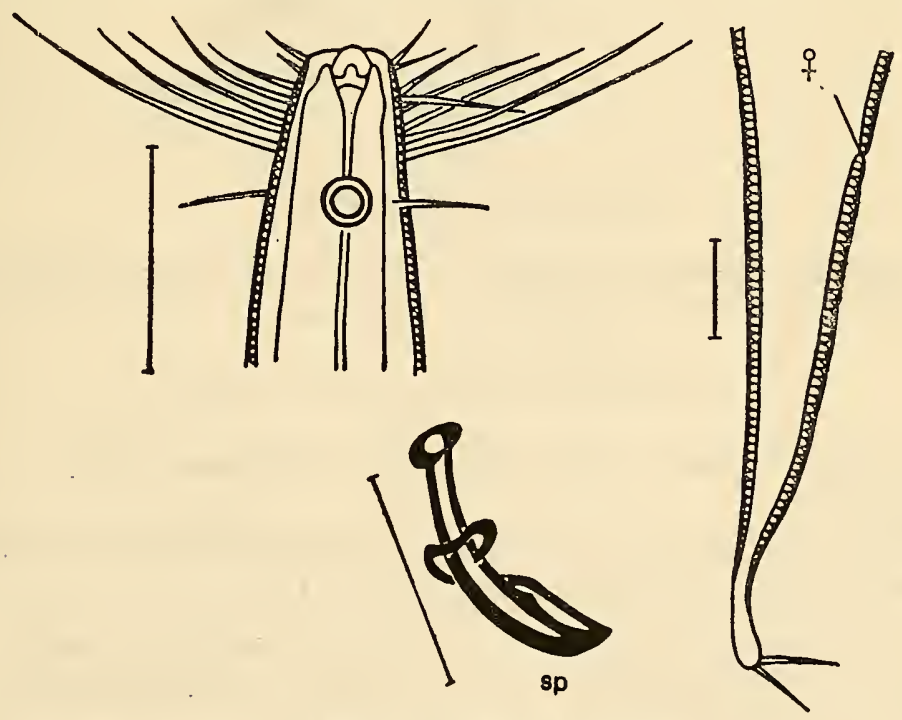

Figure 29. Theristus horridus. 
$(43.2 \mu \mathrm{m})$. Capitulum distinctly present at proximal end of spicule. Gubernaculum closely apposed to spicules, with proximal part terminating in dilatation, length $27.0 \mu \mathrm{m}$ (about $2 / 3$ spicular length).

Geographic distribution. Found in the White and Barents Seas in all horizons of the littoral zone in slightly silted sand.

\section{Subgenus Daptonema Cobb, 1920}

25. Theristus (Daptonema) procerus Gerlach, 1951 (Figure 30)

3 o : $\mathrm{L}=677.0-803.0 \mu \mathrm{m} ; \mathrm{a}=17.9-20.6 ; \mathrm{b}=3.3-4.6 ; \mathrm{c}=6.1-6.9$.

1ㅇ: $\mathrm{L}=675.0 \mu \mathrm{m} ; \mathrm{a}=22.8 ; \mathrm{b}=3.1 ; \mathrm{c}=6.8 ; \mathrm{V}=64.6 \%$.

The White Sea population conforms very well to the earlier description with respect to all characters and measurements given by Gerlach (1951b).
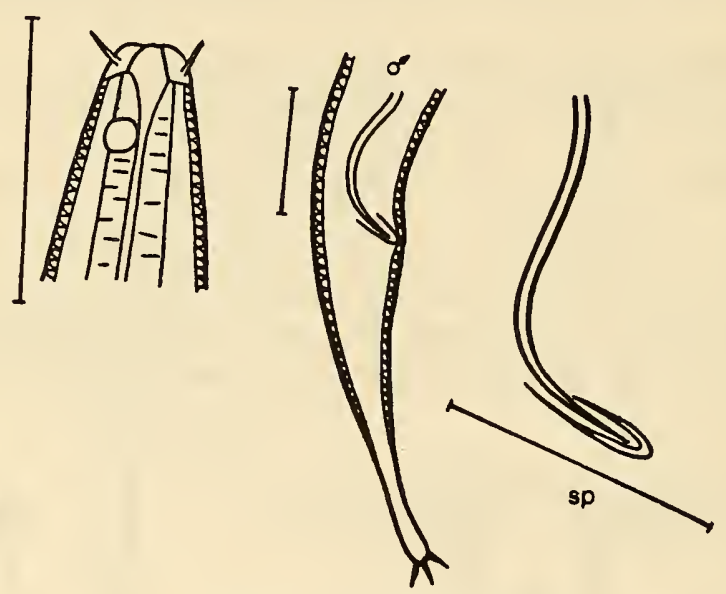

Figure 30. Theristus procerus.

Geographic distribution: Found in the White and North Seas in all horizons of the littoral zone in slightly silted sand.

4. Subgenus Penzancia de Man, 1922

26. Theristus (Penzancia) flevensis Schuurmans-Stekhoven,' 1935 (Figure 31)

de Man 1922: 221, fig. 6a-e [Monhystera (Penzancia) velox] et auctorum non Bastian, 1865 (synonyms: see Wieser, 1956).

4 ऊँ: $\mathrm{L}=913.0-1,071.0 \mu \mathrm{m} ; \mathrm{a}=33.2-44.0 ; \mathrm{b}=4.4-5.5 ; \mathrm{c}=5.9-6.9$.

2 juv.: $\mathrm{L}=990.0-1,034.0 \mu \mathrm{m} ; \mathrm{a}=31.4-42.4 ; \mathrm{b}=4.7-4.9 ; \mathrm{c}=6.9-7.2$.

The White Sea population conforms to the earlier description and 

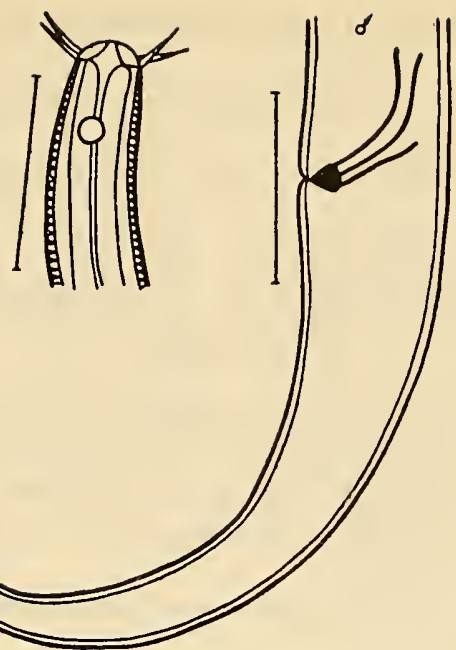

Figure 31. Theristus flevensis.

measurements given by de Man. Gerlach (1951b) has described this species in greater detail.

Geographic distribution. Found in the White, Baltic, and North Seas in all horizons of the littoral zone in slightly silted sand.
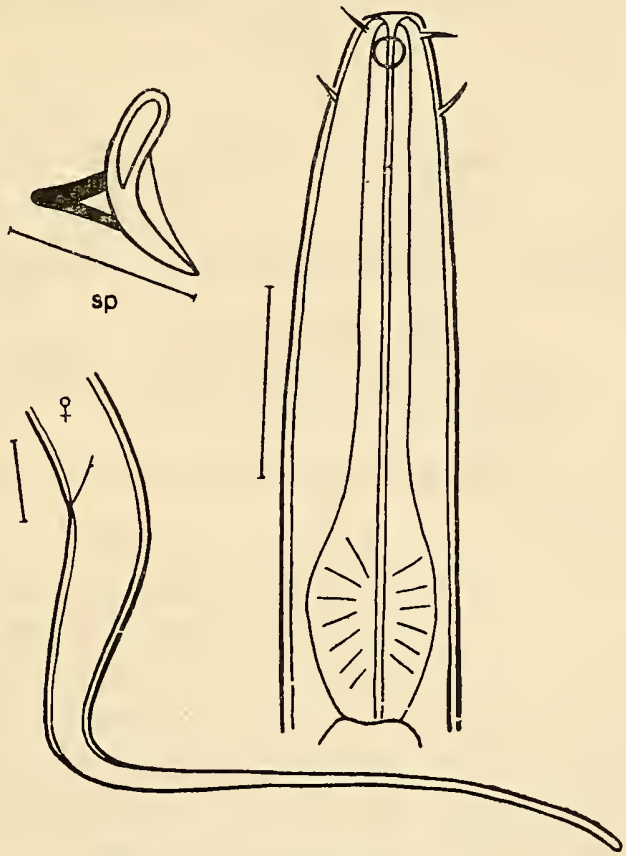

Figure 32. Terschellingia longicaudata. 


\section{Family LINHOMOEIDAE Filipjev, 1922}

\section{Genus Terschellingia de Man, 1888}

27. Terschellingia longicaudata de Man, 1907 (Figure 32)

1 o $: \mathrm{L}=1,804.0 \mu \mathrm{m} ; \mathrm{a}=41.0 ; \mathrm{b}=10.8 ; \mathrm{c}=4.1$.

1 우: $\mathrm{L}=1,593.0 \mu \mathrm{m} ; \mathrm{a}=37.0 ; \mathrm{b}=11.6 ; \mathrm{c}=4.3 ; \mathrm{V}=44.1 \%$.

2 juv.: $\mathrm{L}=1,342.0-1,430.0 \mu \mathrm{m} ; \mathrm{a}=38.1-40.6 ; \mathrm{b}=10.1-11.8$;

$$
\mathrm{c}=3.5-3.6 \text {. }
$$

The White Sea population conforms entirely to the earlier description given by de Man with respect to all characters and measurements.

Geographic distribution. Found in the White, Baltic, Norwegian and North Seas in all horizons of the littoral zone in slightly silted sand.

\section{Genus Metalinhomoeus de Man, 1907}

Synonym: Deltanema Kreis, 1929.

28. Metalinhomoeus obtusiceps sp. n. (Figure 33)

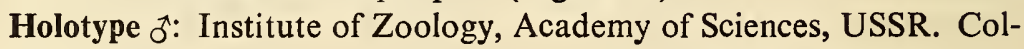
lection No. 56.

$$
\begin{array}{ccccc}
- & 99.0 & 187.0 & - & 1,595.0 \\
22.0 & 38.0 & 44.0 & 55.0 & \begin{array}{r}
44.0 \\
\mathrm{c}=9.5 .
\end{array}
\end{array} 1,782.0 \mu \mathrm{m} ; \mathrm{a}=32.4 ; \mathrm{b}=9.5 ;
$$

Paratypes.

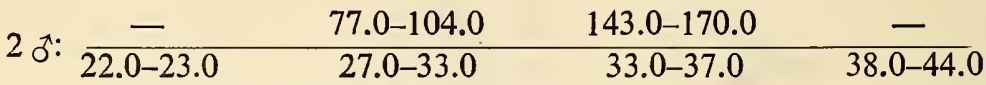

$$
\begin{aligned}
& \times \frac{1,100.0-1,540.0}{34.0-41.0} 1,232.0-1,727.0 \mu \mathrm{m} ; \mathrm{a}=28.0-34.9 ; \\
& \mathrm{b}=8.6-9.5 ; \mathrm{c}=9.2-9.4 \text {. }
\end{aligned}
$$

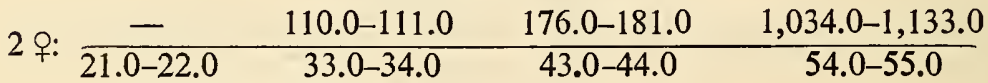

$$
\begin{aligned}
& \times \frac{2,013.0-2,090.0}{32.0-33.0} 2,178.0-2,266.0 \mu \mathrm{m} ; \mathrm{a}=40.5-41.4 \text {; } \\
& \mathrm{b}=12.0-12.2 ; \mathrm{c}=12.2-13.2 ; \mathrm{V}=47.5-49.5 \% \text {. }
\end{aligned}
$$

Body long and tapers to $2 / 5$ midbody diameter at anterior end and $10 / 13$ at posterior end. Head flat and not demarcated from body. Tail conical and length equal to four anal body diameters. Cephalic setae long $(7.2 \mu \mathrm{m})$ and situated in one circle. Setae absent on tail. Cuticle smooth. Amphids resemble an incomplete spiral, $7.1 \mu \mathrm{m}$ in diameter, situated $12.0 \mu \mathrm{m}$ from anterior end. Oral cavity small with supporting internal sclerotized ring. Esophagus with bulb $16.5 \mu \mathrm{m} \times 14.3 \mu \mathrm{m}$. 

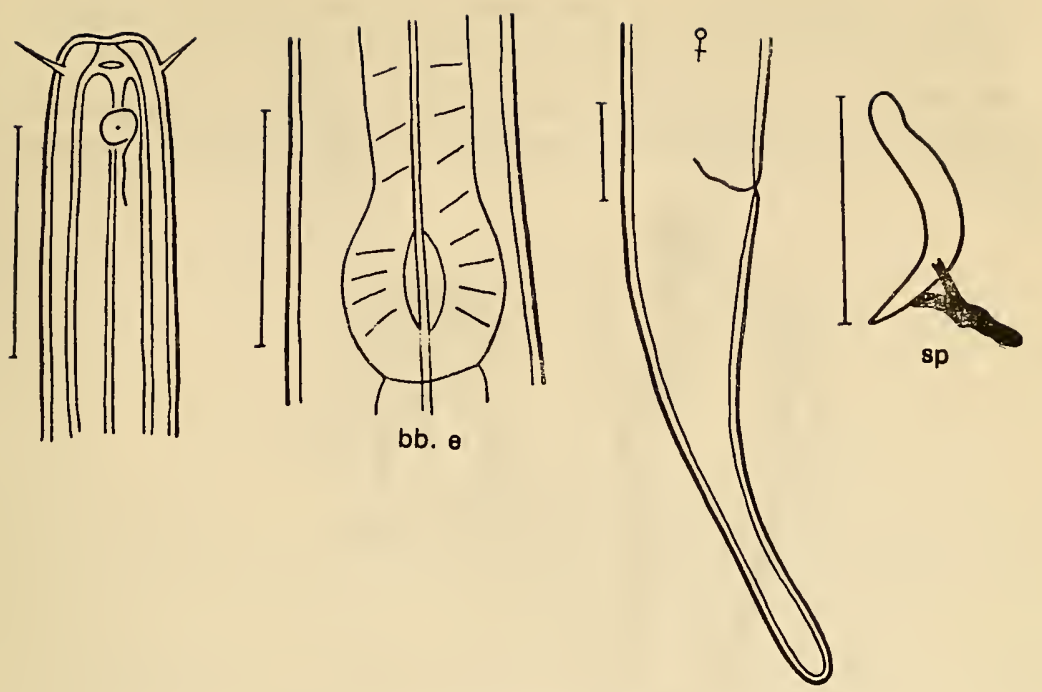

sp

bb. 8

Figure 33. Metalinhomoeus obtusiceps sp. n.

Reproductive system of female consists of paired unflexed tubes. Spicules arcuate, taper in distal part, and $44.4 \mu \mathrm{m}$ long. Gubernaculum $13.2 \mu \mathrm{m}$ long, with an appendage with a bifurcate base.

Of all the known species of this genus, this species is comparable to M. zosterae Filipjev, 1918, but differs in much smaller body size (index $a$ ), smooth cuticle, shape of amphids, and spicules and gubernaculum twice as large.

Geographic distribution. Found in the White Sea in all horizons of the littoral zone in slightly silted sand.

13. Family TRIPYLOIDAE Filipjev, 1918

23. Genus Tripyloides de Man, 1886

Synonym: Nannonchus Cobb, 1913.

29. Tripyloides septentrionalis de Coninck and SchuurmansStekhoven, 1933 (Figure 34)

de Man 1922: 229, fig. 18 (T. marinus); Ditlevsen, 1919: 190, tabs. 9, 10, figs. 3,4 (Cothonolaimus gracilis). 
3 ๙ 1 juv.: $\mathrm{L}=913.0 \mu \mathrm{m} ; \mathrm{a}=29.7 ; \mathrm{b}=4.6-6.9 ; \mathrm{c}=10.4$.

The White Sea population conforms well to the description given by de Coninck and Stekhoven with respect to all characters and measurements.

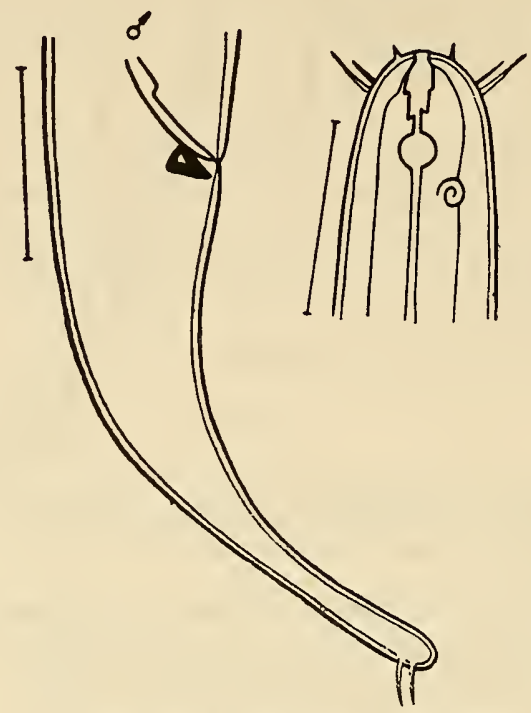

Figure 34. Tripyloides septentrionalis.

Geographic distribution. Found in the White, Norwegian, Baltic and North Seas, mainly in the upper horizon of the littoral zone in slightly silted sand.

14. Family AXONOLAIMIDAE Filipjev, 1918

24. Genus Axonolaimus de Man, 1889

30. Axonolaimus paraspinosus Schuurmans-Stekhoven and Adam, 1931 (Figure 35)

de Man, 1888: 19, pl. 19, fig. 11 (Anoplostoma spinosum).

2 б $\mathrm{L}=1,566.0-1,925.0 \mu \mathrm{m} ; \mathrm{a}=35.0-38.6 ; \mathrm{b}=6.7-7.6 ; \mathrm{c}=10.4-10.6$.

3 juv.: $\mathrm{L}=1,133.0-1,551.0 \mu \mathrm{m} ; \mathrm{a}=29.5-40.9 ; \mathrm{b}=5.7-6.7 ; \mathrm{c}=8.2-10.1$.

The White Sea specimens conform entirely to the earlier description given by de Man.

Geographic distribution. Found in the White, Baltic, and North Seas in all horizons of the littoral zone in slightly silted sand. 


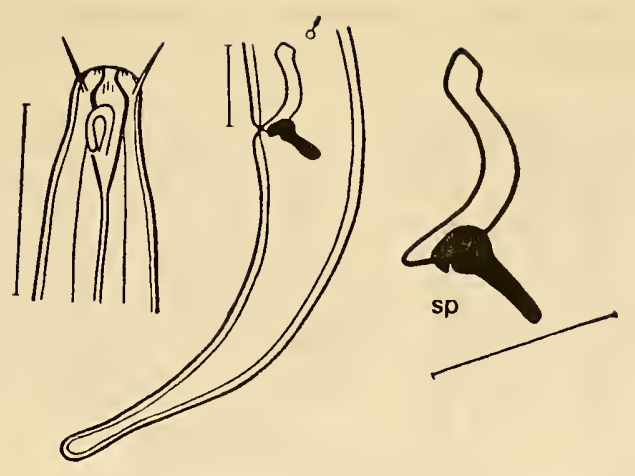

Figure 35. Axonolaimus paraspinosus.

25. Genus Odontophora Buetschli, 1874

Synonyms: Conolaimus Filipjev, 1918 and Trigonolaimus Ditlevsen, 1919.

31. Odontophora deconincki nom. nov. (Figure 36)

de Coninck and Schuurmans-Stekhoven, 1933: 108, figs. 89-95 (armata), non Trigonolaimus armatus; Ditlevsen, 1919: 178, figs. 1, 4, 6, 7.

2 ㅇ: $\mathrm{L}=3,102.0-3,278.0 \mu \mathrm{m} ; \mathrm{a}=59.6-70.0 ; \mathrm{b}=17.6-18.6 ; \mathrm{c}=18.8-$ $24.8 ; \mathrm{V}=51.5-54.2 \%$.

The White Sea specimens conform well to the description given by de Coninck and Stekhoven for species from the coast of the North Sea.

Ditlevsen established a new genus in 1919, Trigonolaimus, which de Coninck and Stekhoven considered synonymous with genus Odontophora Bütschli, 1874. They considered Odontophora armata, described by them, identical to Trigonolaimus armatus Ditlevsen, 1919. After analyzing the works of these authors in detail, I came to the conclusion that these are two independent species. The species described by de Coninck and Stekhoven is distinguishable from that described by Ditlevsen with respect to indices of species given by de Man, a more truncated head, and longer cephalic setae. In the species described by Ditlevsen setae are absent throughout the body and amphids situated in the anterior part of the oral cavity; in the species described by de Coninck and Stekhoven the amphids are situated posteriorly. The later species (Odontophora armata) also has a finely annulate cuticle, which is smooth in the species described by Ditlevsen. Furthermore, these species differ from each other in shape of spicules and gubernaculum. All these features enable one to consider them separate species. For O. armata de Coninck and Stekhoven, 1933 I 
have proposed a new name, $O$. deconincki. $O$. armata is retained for the species described by Ditlevsen.

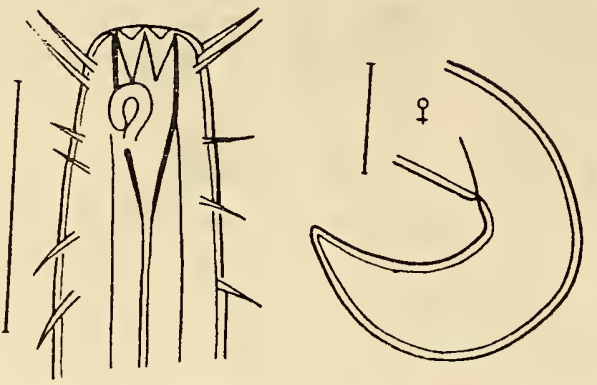

Figure 36. Odontophora deconincki nom. nov.

Geographic distribution: Found in the White, Baltic and North Seas, mainly in the lower and middle horizons of the littoral zone in slightly silted sand.

\section{Order DESMODORIDA}

15. Family MONOPOSTHIIDAE Filipjev, 1934

26. Genus Monoposthia de Man, 1889

32. Monoposthia octalata sp. n. (Figure 37)

Holotype 3: Institute of Zoology, Academy of Sciences, USSR. Collection No. 62.

$$
\begin{array}{ccccc}
- & 104.0 & 204.0 & - & 1,210.0 \\
22.0 & 33.0 & 38.0 & 50.0 & 34.0 \\
c=10.5 .
\end{array} \quad 1,336.0 \mu \mathrm{m} ; \mathrm{a}=26.3 ; \mathrm{b}=6.2
$$

Paratypes.

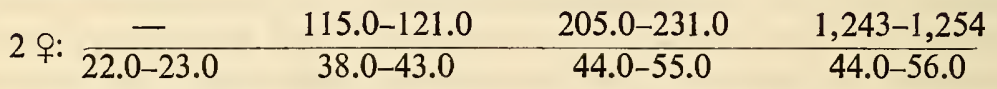

$$
\begin{aligned}
& \times \frac{1,342-1,406}{32.0-33.0} 1,463.0-1,507.0 \mu \mathrm{m} ; \mathrm{a}=22.8-24.2 ; \mathrm{b}=6.4-7.3 ; \\
& c=12.1-12.4 ; \mathrm{V}=83.2-85.0 \% \text {. }
\end{aligned}
$$

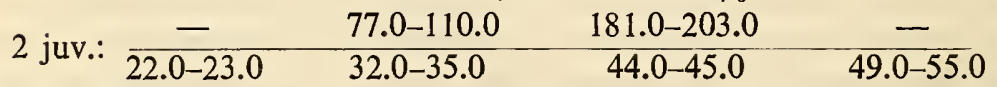

$$
\begin{aligned}
& \times \frac{929.0-1,023.0}{24.0-27.0} 1,034.0-1,144.0 \mu \mathrm{m} ; \mathrm{a}=20.4-20.8 ; \mathrm{b}=5.6-5.7 ; \mathrm{c}=9.5-9.9 \text {. }
\end{aligned}
$$

Body not very long and tapers to $10 / 23$ midbody diameter at anterior end and $5 / 7$ at posterior end. Head flat and not demarcated from body. Tail conical. Cephalic setae $10.8 \mu \mathrm{m}$ long. Small number of setae, 3.0 to $4.0 \mu \mathrm{m}$ long, also present on tail. Cuticular annulations intersected by 
eight longitudinal rays commencing at level of amphids. Amphids small, round, $4.0 \mu \mathrm{m}$ in diameter ( $1 / 5$ corresponding head diameter), and situated $3.1 \mu \mathrm{m}$ from anterior end. Large vestibule, strengthened by wide sclerotized longitudinal rays, situated before oral opening. Oral cavity small and armed with single dorsal tooth $5.4 \mu \mathrm{m}$ long. Esophagus with dilatations at anterior and posterior ends. Anterior dilatation $29.7 \mu \mathrm{m} \times$

$22218.9 \mu \mathrm{m}$ and posterior bulb $54.0 \mu \mathrm{m} \times 29.1 \mu \mathrm{m}$.

Reproductive system of female consists of anterior unflexed tubes. Vulva considerably displaced toward anus. Spicules slightly arcuate and $35.1 \mu \mathrm{m}$ long. Gubernaculum absent.
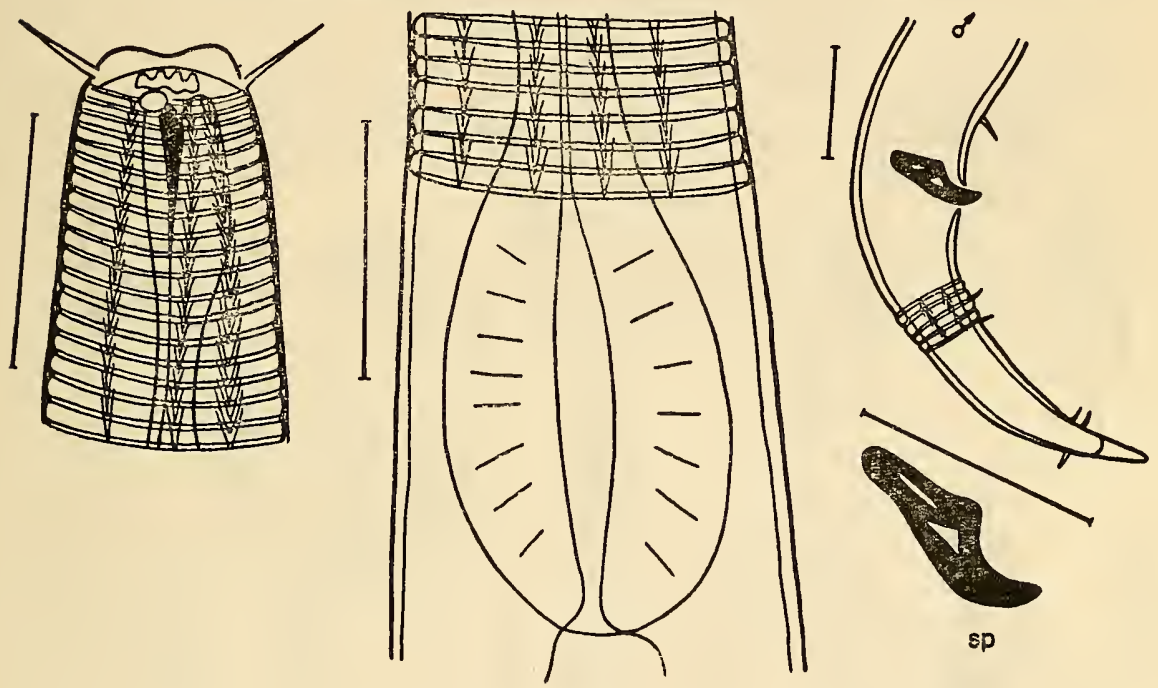

bb. $\theta$

Figure 37. Monoposthia octalata sp. n.

With respect to characters and measurements, this species is closest to $M$. loricata Kreis, 1929 , but distinguished by number of longitudinal rays ( 8 versus 12 in $M$. loricata) and presence of only one tooth (versus two in $M$. loricata). These two features suffice to separate $M$. octalata as an independent species.

Geographic distribution. Found in the White Sea in all horizons of the littoral zone in slightly silted sand.

16. Family SPIRINIIDAE Gerlach and Murphy, 1965

27. Genus Chromodoropsis Filipjev, 1918

Synonym: Chromadora de Man, 1907 nec Bastian, 1865. 
33. Chromodoropsis vivipara (de Man, 1907) (Figure 38)

De Man 1907, pls. 3-4, fig. 13a-e (Chromadora); Filip'ev, 1918: 211.

2 o $: \mathrm{L}=1,584.0-1,892.0 \mu \mathrm{m} ; \mathrm{a}=15.6-18.0 ; \mathrm{b}=6.1-7.2 ; \mathrm{c}=15.6-17.0$.

1 ㅇ: $\mathrm{L}=1,518.0 \mu \mathrm{m} ; \mathrm{a}=18.4 ; \mathrm{b}=6.0 ; \mathrm{c}=12.5 ; \mathrm{V}=58.7 \%$.

2 juv.: $\mathrm{L}=1,144.0-1,617.0 \mu \mathrm{m} ; \mathrm{a}=23.1-24.5 ; \mathrm{b}=4.9-6.1 ; \mathrm{c}=9.9-12.2$.

The White Sea specimens conform well to the species described earlier by de Man with respect to all characters and measurements.

Geographic distribution. Found in the White, Barents, and North Seas in all horizons of the littoral zone in slightly silted sand.
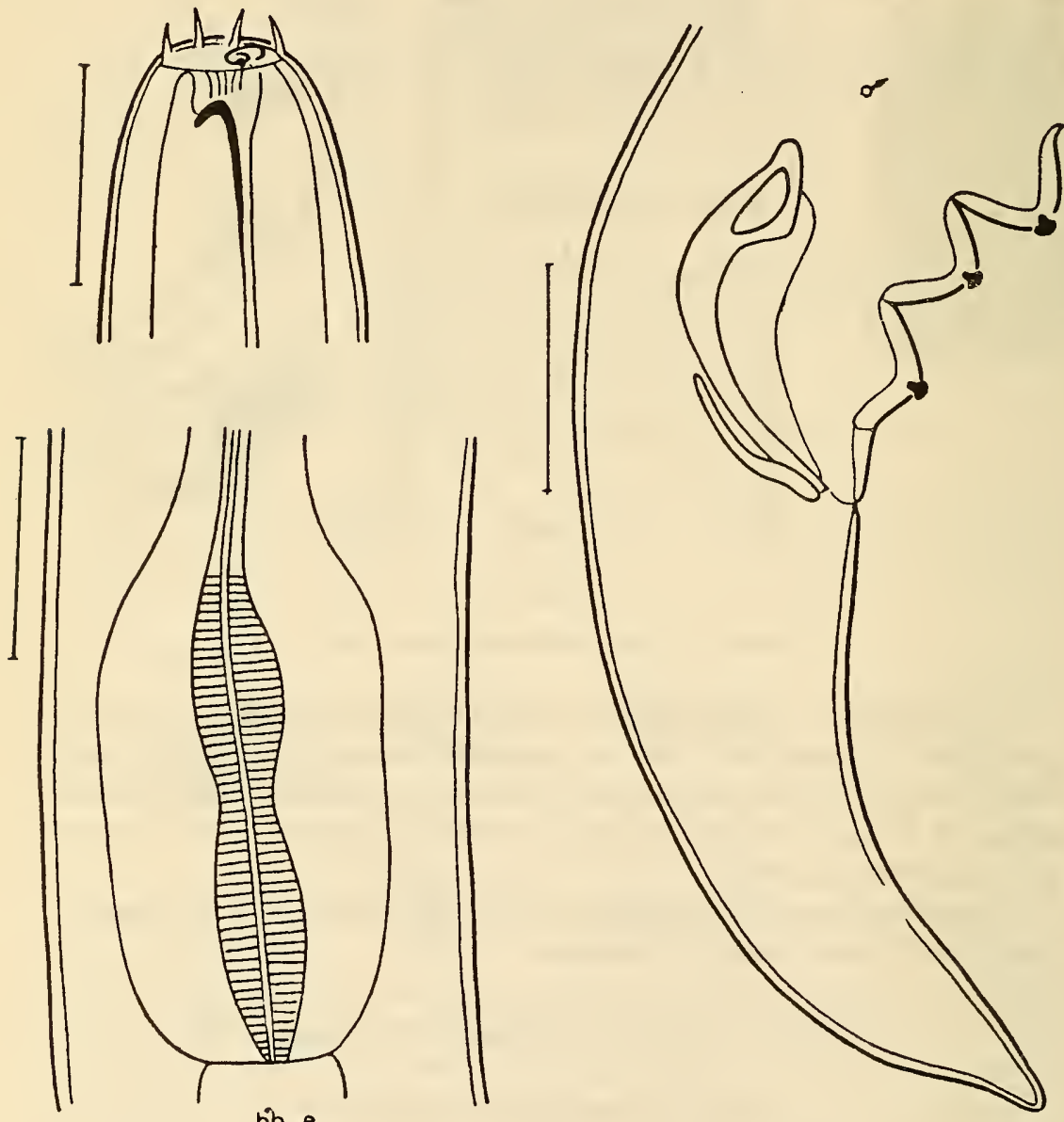

Figure 38. Chromodoropsis vivipara. 
34. Chromodoropsis nudicauda sp. n. (Figure 39)

Holotype $\sigma^{*}$ : Institute of Zoology, Academy of Sciences, USSR. Collection No. 68.

$$
\begin{array}{ccccc}
- & 99.0 & 225.0 & - & 1,276.0 \\
35.0 & 82.0 & 89.0 & 100.0 & \begin{array}{c}
55.0 \\
c=12.6
\end{array}
\end{array} \text { 1,386.0 } \mu \mathrm{m} ; \mathrm{a}=13.9 ; \mathrm{b}=6.1 ;
$$

Paratypes.

$$
\begin{aligned}
& 1 \text { ธ. } \frac{-}{44.0} \begin{array}{cccc}
132.0 & 242.0 & - & 1,441.0 \\
82.0 & \begin{array}{c}
96.0 \\
b=6.5 ;
\end{array} \begin{array}{c}
99.0 \\
c=12.9 .
\end{array} & 77.0
\end{array} \\
& 3 \text { juv.: } \begin{array}{cccc}
- & 110.0-143.0 & 247.0-264.0 & - \\
\hline 27.0-34.0 & 82.0-93.0 & 95.0-99.0 & 104.0-111.0
\end{array} \\
& \times \frac{1,243.0-1,353.0}{55.0-77.0} 1,342-1,507 \mu \mathrm{m} ; \mathrm{a}=12.1-13.9 ; b=5.4-5.8 ; \\
& \mathrm{c}=12.0-13.6 \text {. }
\end{aligned}
$$

Body thick and tapers to $5 / 14$ midbody diameter at anterior end and $10 / 13$ to $5 / 7$ at posterior end. Head rounded and not demarcated from body. Tail short and conical. Head with four very short setae $(10.9 \mu \mathrm{m})$.
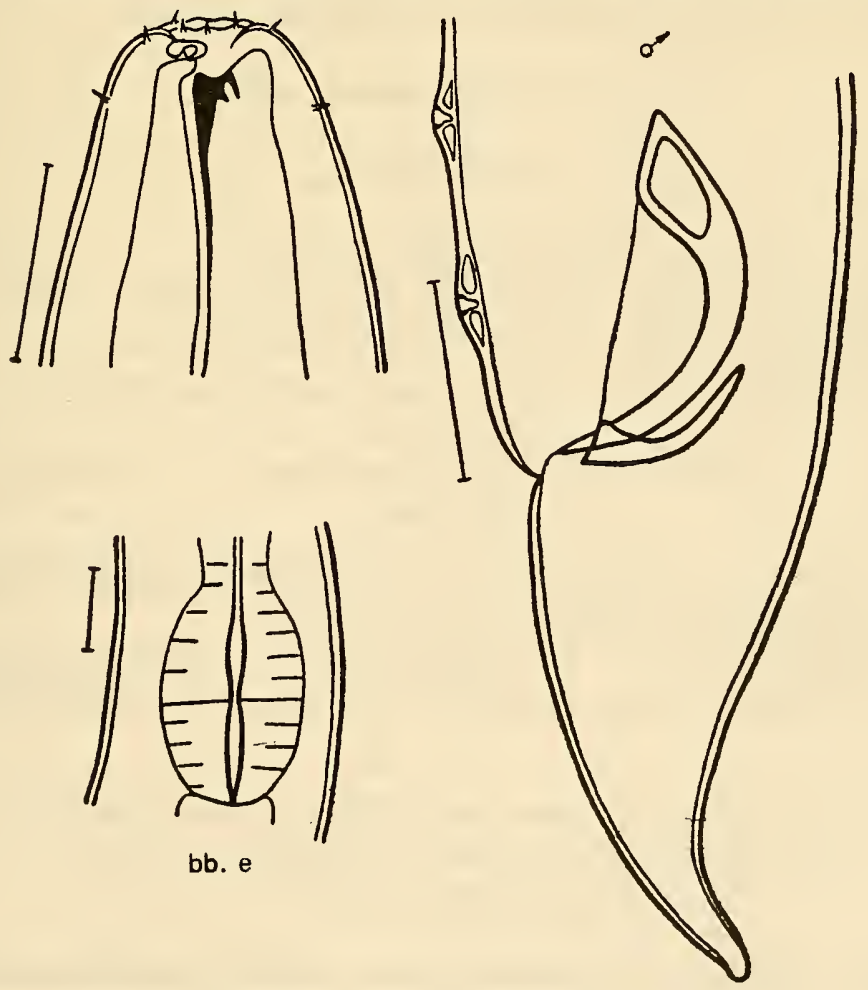

Figure 39. Chromodoropsis nudicauda sp. n. 
Setae absent on tail. Cuticle finely annulate. Dark brownish strip occurs in sexually immature forms on ventral surface of body from anterior end to anus. It is probably pigmented. Such a pigmented strip is absent in sexually mature forms. Amphids, situated $1.4 \mu \mathrm{m}$ from anterior end, resemble incomplete spiral $5.7 \mu \mathrm{m}$ wide and $4.0 \mu \mathrm{m}$ long $(1 / 4$ corresponding body diameter). Oral cavity small and armed with one dorsal tooth $7.5 \mu \mathrm{m}$ long. Esophagus with large bulb $83.7 \mu \mathrm{m} \times 62.1 \mu \mathrm{m}$, equal to $1 / 3$ esophageal length.

Sexual armature of male consists of 20 accessory organs, two spicules, and gubernaculum. Wall of accessory organs highly sclerotized and occupies approximately half distance from anus to esophagus. Spicules arcuate, broadened in proximal part, with velum, and $91.8 \mu \mathrm{m}$ long. Gubernaculum simple and $43.2 \mu \mathrm{m}$ long.

224 The White Sea specimens come closest to C. vivipara de Man, 1907, recorded from the coast of the North Sea. But $C$. nudicauda can be distinguished from $C$. vivipara with respect to indices $a$ and $c$, length and shape of spicules and gubernaculum, accessory organs with densely sclerotized walls, and complete absence of setae on tail.

Geographic distribution. Found in the White Sea, predominantly in the lower horizon of the littoral zone in slightly silted sand.

\section{Genus Spirinia Gerlach, 1963}

Synonyms: Spira Bastian, 1865 and Spirina Filipjev, 1918.

35. Spirinia parasitifera (Bastian, 1865) (Figure 40)

Bastian, 1865: 159, pl. 13, figs. 201-203 (Spira); Filip'ev, 1918: 232 (Spirina); Allgen, 1933: 60, fig. 33 (? Spirina nidrosiensis)

3今ิ: $\mathrm{L}=2,937.0-3,256.0 \quad \mu \mathrm{m} ; \quad \mathrm{a}=41.1-48.5 ; \quad \mathrm{b}=17.8-24.2 ; \quad \mathrm{c}=$ $17.8-21.1$.

2 juv.: $\mathrm{L}=2,684.0-3,113.0 \mu \mathrm{m} ; \mathrm{a}=40.5-40.6 ; \mathrm{b}=18.8-20.2 ; \mathrm{c}=$ 15.2-18.9.

The White Sea specimens conform well to the description given earlier with respect to main characters and measurements.

Geographic distribution. Found in the White, Barents, Norwegian, Baltic, and North Seas in all horizons of the littoral zone in slightly silted sand.

\section{QUANTITATIVE DISTRIBUTION OF LEADING SPECIES OF NEMATODES IN THE LITTORAL ZONE OF KRUGLO'E BAY}

To date no information has been given on the quantitative distribution of nematodes and the dynamics of their population in small areas of 


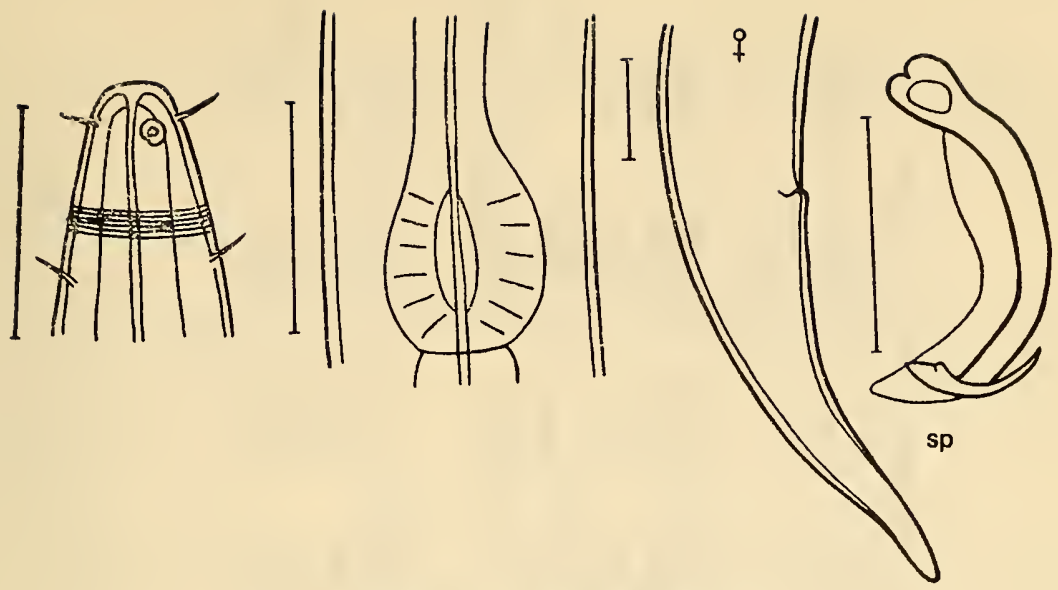

Figure 40. Spirinia parasitifera.

the littoral zone with respect to random collection at small intervals of time (for details see p. 233).

Of the 35 species recorded here, 7 occurred in large numbers in both seasons: Timmia acuticauda, Anoplostoma rectospiculum, Axonolaimus paraspinosus, Enoplus demani, Paracanthonchus macrodon, Hypodontolaimus inaequalis, and Theristus setosus. These species constituted 80 to $90 \%$ of the entire nematode population. An attempt has been made to characterize the population dynamics of the leading species in different seasons and to investigate their distribution throughout the section.

Timmia acuticauda (Figures 41 and 42, Table 5). The population of this species was low throughout the section during the summer of 1970 . Some increase was observed on July 16, 1970 in the upper and middle horizons of the littoral zone (108,712 to 210,312 specimens $\left./ \mathrm{m}^{2}\right)$. Toward the end of July the population in these horizons diminished to 71,120 to 116,840 specimens $/ \mathrm{m}^{2}$. Later, during the course of August and through226 out the beginning of September an extremely low population level was observed throughout the section, never exceeding 20,000 to 30,000 specimens $/ \mathrm{m}^{2}$. In early September this species was found to be entirely absent in the lower horizon of the littoral zone.

In autumn of 1971 the population of T. acuticauda was very high. In the beginning of September two population peaks were observed, one in the middle horizon $(1,107,440)$ and the other in the upper horizon $227\left(1,026,160\right.$ specimens $\left./ \mathrm{m}^{2}\right)$. This species was almost absent in the lower horizon. During mid-September one population peak was distinctly evident in the upper horizon of the littoral zone $\left(3,287,260\right.$ specimens $\left./ \mathrm{m}^{2}\right)$, which persisted here until the end of the observation period. 


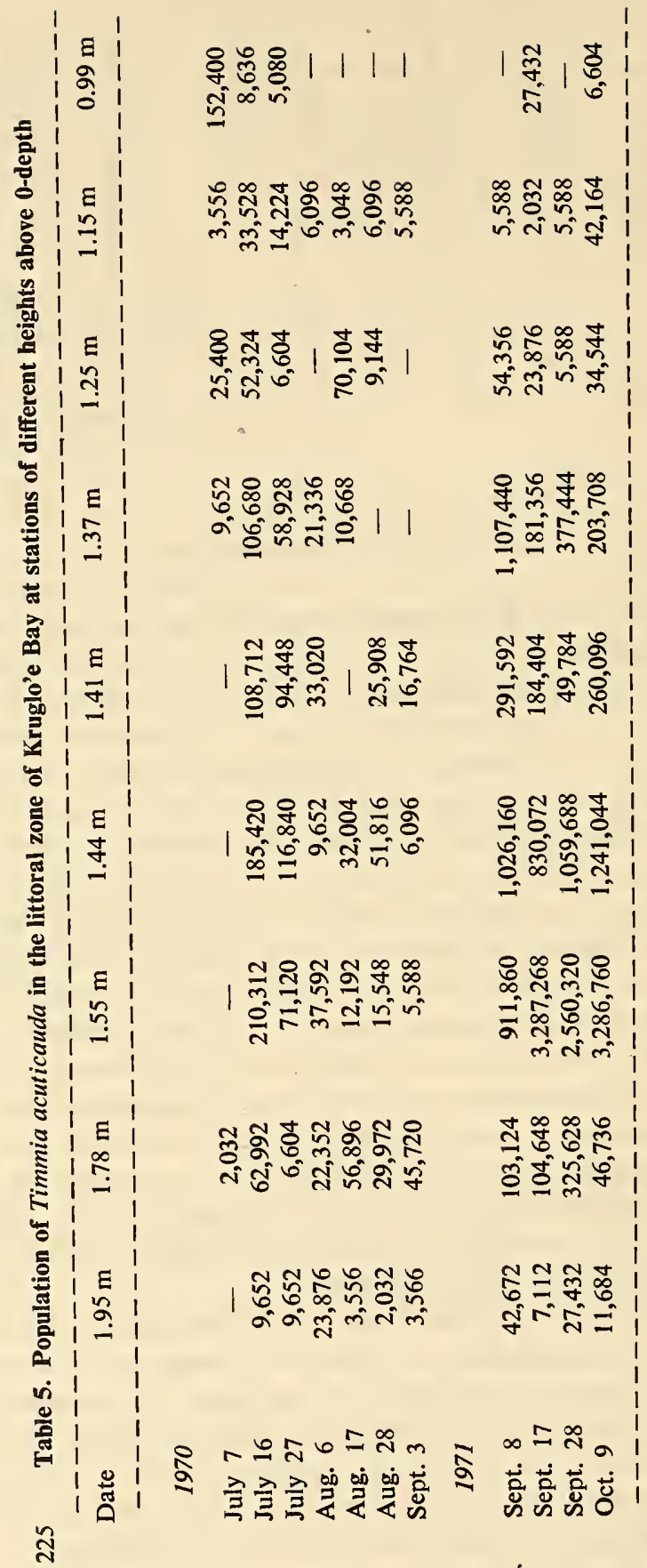




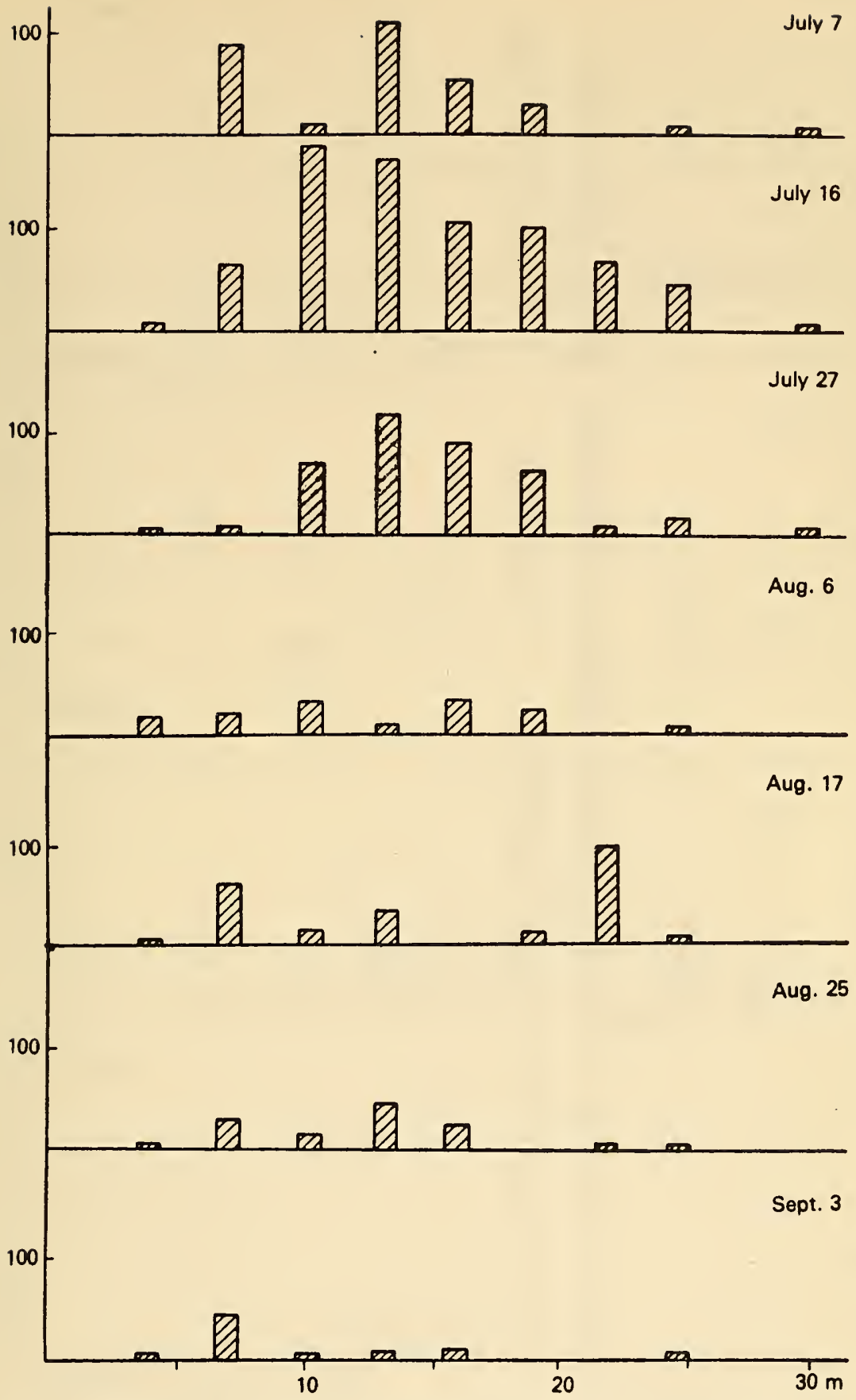

226

Figure 41. Population dynamics of Timmia acuticauda in the littoral zone of Kruglo'e Bay during summer of 1970. 


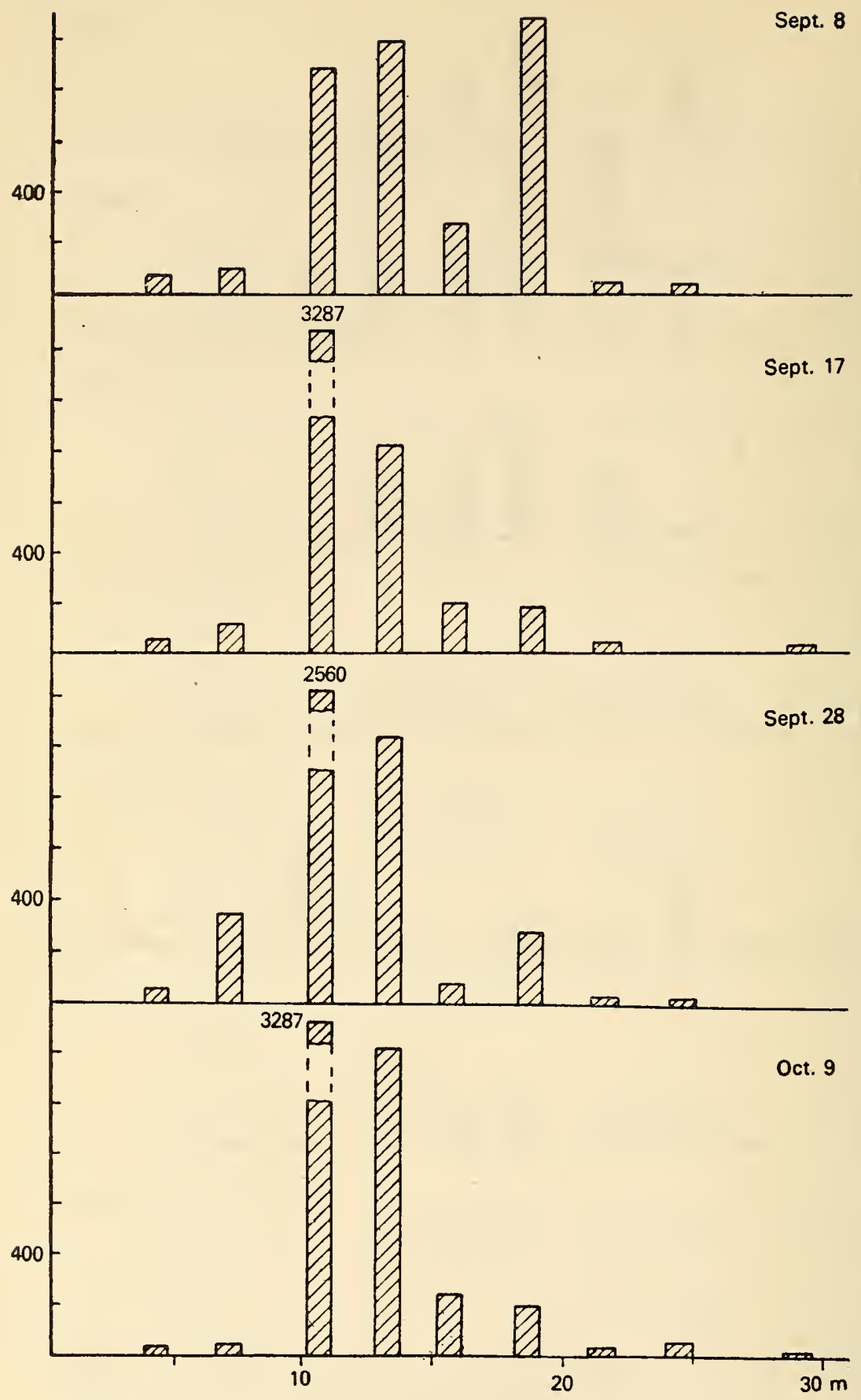

Figure 42. Population dynamics of Timmia acuticauda in the littoral zone of Kruglo'e Bay during autumn of 1971 . 


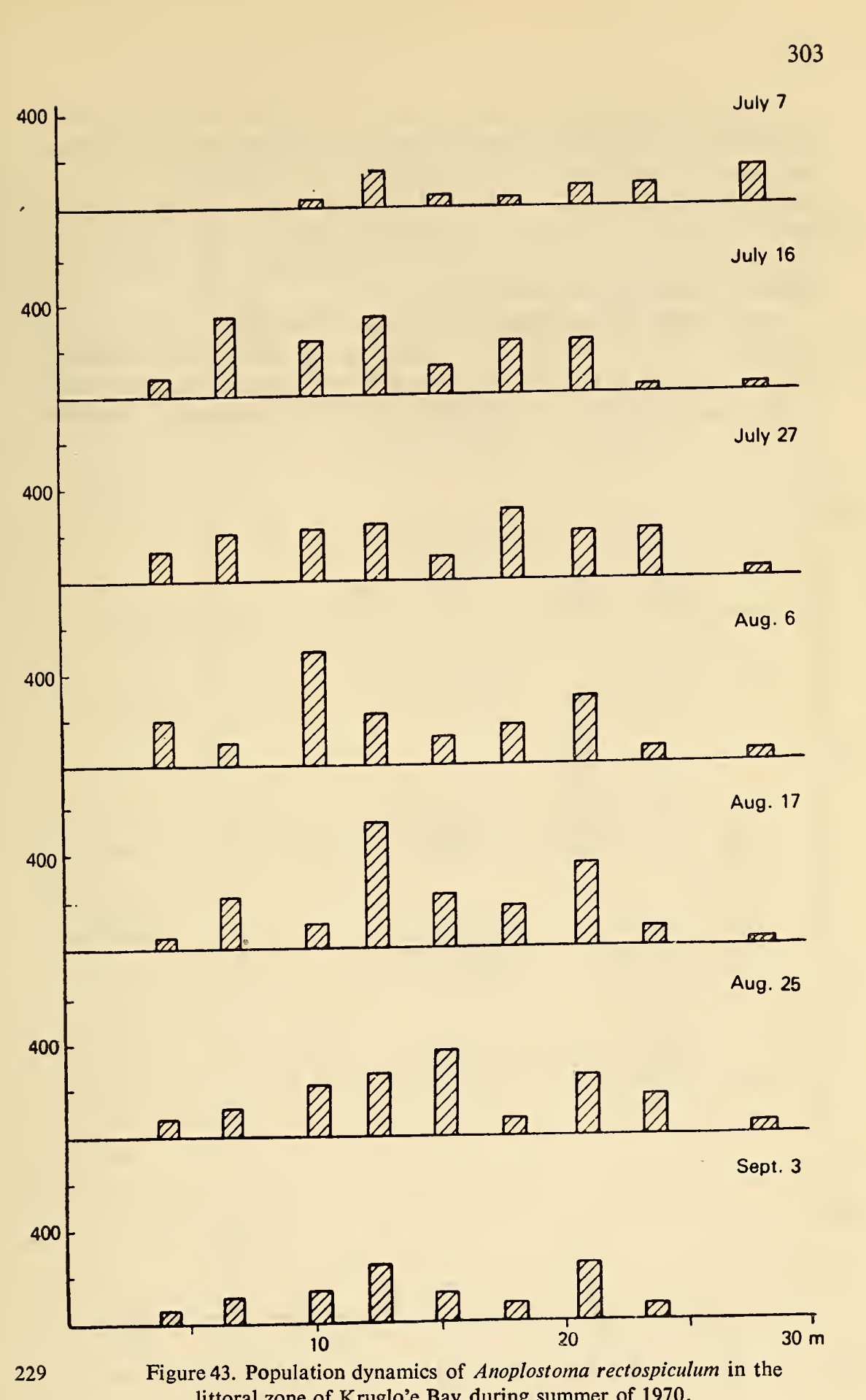


The population dynamics of $T$. acuticauda could therefore be characterized as: low population during summer, great increase during autumn, localization of specimens in a small area of the littoral zone (lower stratum of upper horizon and part of midde horizon), and sharp reduc228 tion in population toward the lower horizon. Probably this species finds more favorable conditions of existence at the junction of the upper and middle horizons of the littoral zone.

Anoplostoma rectospiculum (Figures 43 and 44, Table 6). In the beginning of July, 1970 the species population was rather low throughout the section $\left(4,064\right.$ to 162,560 specimens $\left./ \mathrm{m}^{2}\right)$ with a slightly higher density in the lower horizon. In the middle of June the population rose to

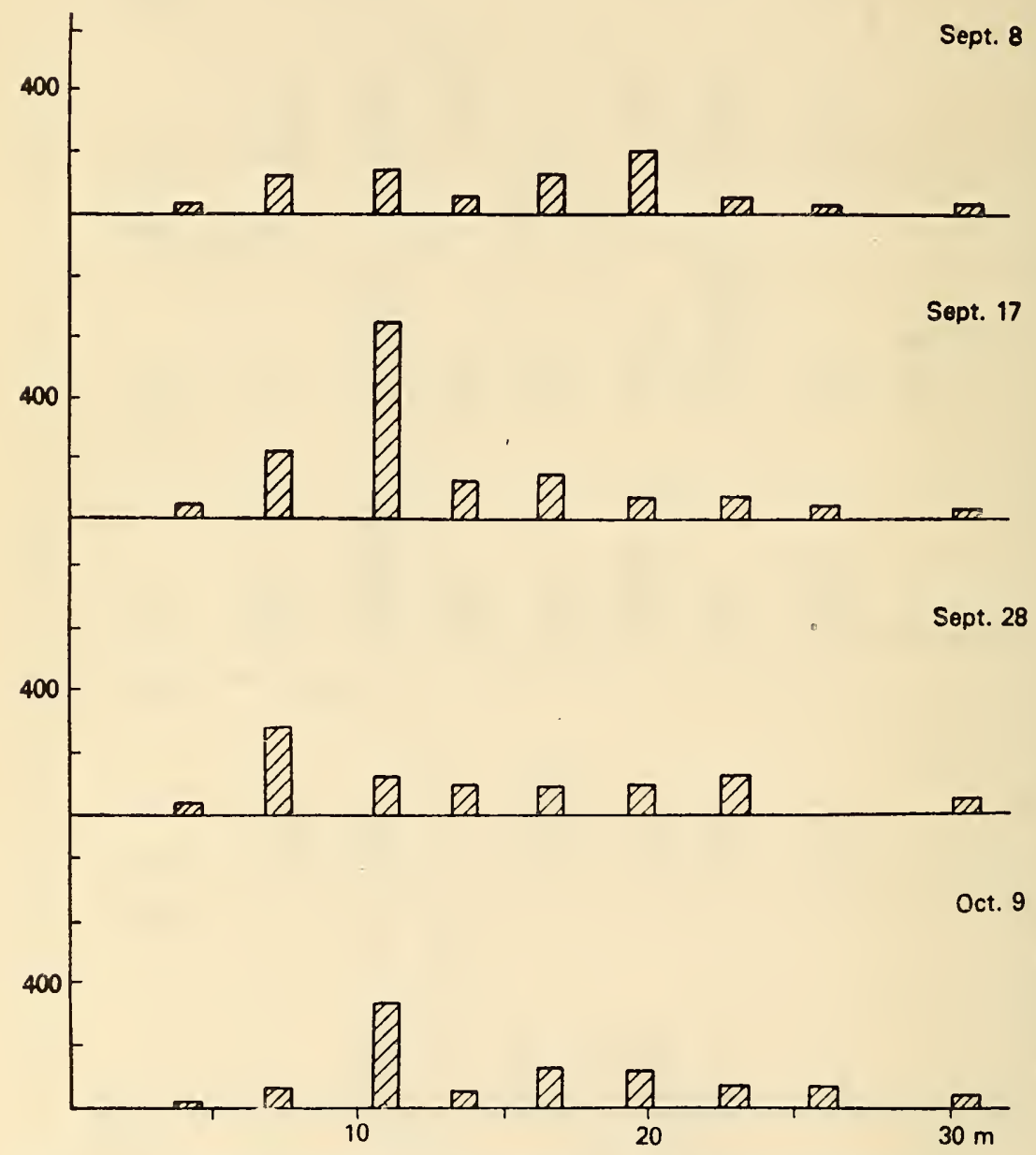

Figure 44. Population dynamics of Anoplostoma rectospiculum in the littoral zone of Kruglo'e Bay during autumn of 1971. 


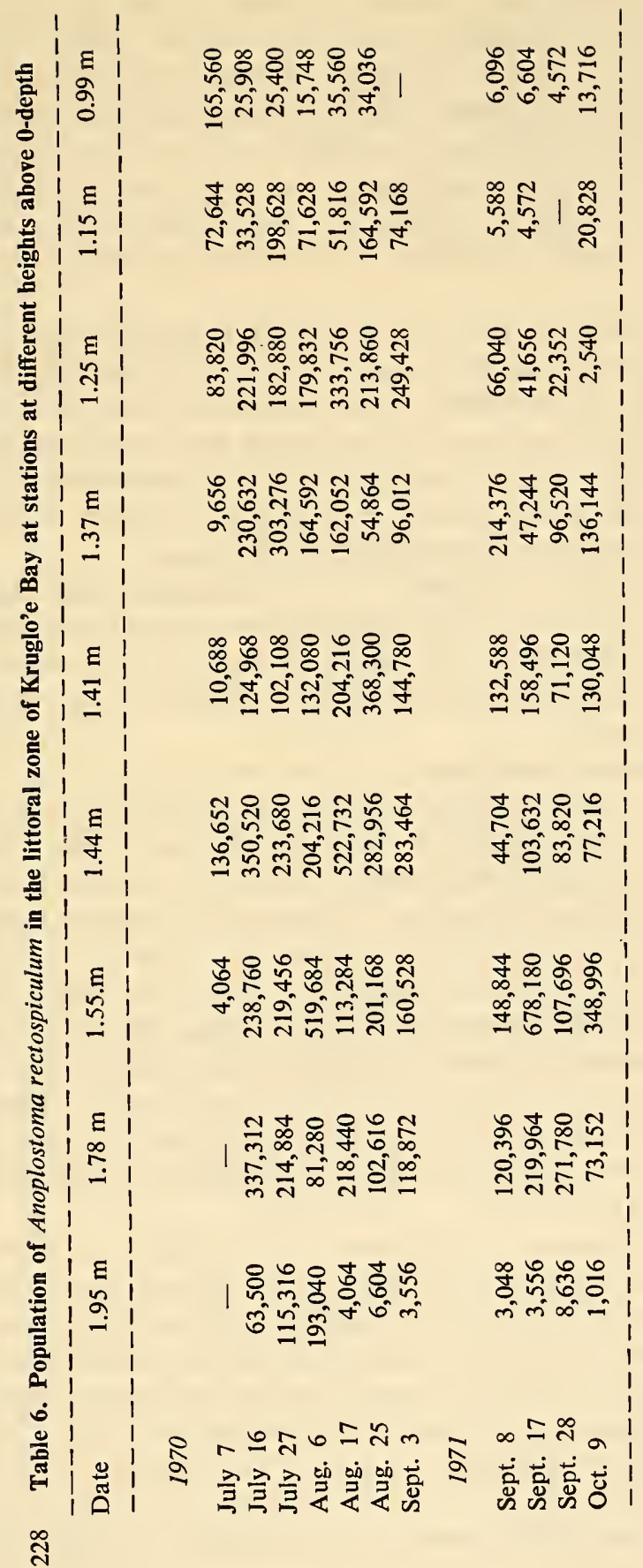


200,000 to 300,000 with a maximum density in the upper $(337,312)$ and middle $\left(350,520\right.$ specimens $\left./ \mathrm{m}^{2}\right)$ horizons. At the end of July approximately the same pattern of distribution persisted throughout the section. In the beginning of August only one population peak occurred in the upper horizon $\left(519,684\right.$ specimens $\left./ \mathrm{m}^{2}\right)$. In the middle of the month the maximum population was found in the middle horizon $(522,732$ specimens $/ \mathrm{m}^{2}$ ). At the end of August and early in September the population gradually reduced throughout the section to 100,000 to 200,000 specimens/m².

During autumn, 1971 a low density throughout the section was observed with a maximum population in the upper and middle horizons. In the middle of September the population was maximum in the upper horizon $(678,180)$ and varied in the middle and lower horizons $(4,572$ to 158,496 specimens $/ \mathrm{m}^{2}$ ). Toward the end of September and early in October a gradual reduction in population occurred throughout the section, remaining maximal in the upper horizon.

The population dynamics of $A$. rectospiculum could therefore be characterized as almost uniform during the summer and autumn seasons, (although somewhat higher during summer). This species is mainly localized in the middle horizon during summer and in the upper horizon during autumn.

Axonolaimus paraspinosus (Figures 45 and 46, Table 7). In the beginning of summer, 1970 this species was distributed along the section symmetrically with respect to the middle horizon where the maximum density occurred $\left(93,436\right.$ specimens $\left./ \mathrm{m}^{2}\right)$; in the upper and lower horizons the population density was low. In the middle of July the high density of population in the middle horizon was still evident $(61,468$ to 75,184 specimens $/ \mathrm{m}^{2}$ ); the population rose however in the upper horizon but remained as low as before in the lower horizon. Toward the end of July maximum populations were still evident in the upper $(84,836)$ and middle $(109,728)$ horizons. In the beginning of August only one peak $(168,656)$ in the upper horizon was detected, which persisted to the end of summer. In the other two horizons the population remained low $(10,000$ to 40,000 specimens $/ \mathrm{m}^{2}$ ).

In the beginning of September, 1971 a higher population with a maximum in the middle horizon of the littoral zone was observed $(249,428)$, but a small rise also evident in the upper horizon $(103,124$ specimens $/ \mathrm{m}^{2}$ ). In mid-September the population peak shifted to the upper horizon $\left(197,100 / \mathrm{m}^{2}\right)$; approximately the same pattern of distri-

229 bution continued until the end of the month. In the first ten days of October the population peak reappeared in the middle horizon $(335,280$ specimens $/ \mathrm{m}^{2}$ ).

$A$. paraspinosus thus revealed a lower density of population during 


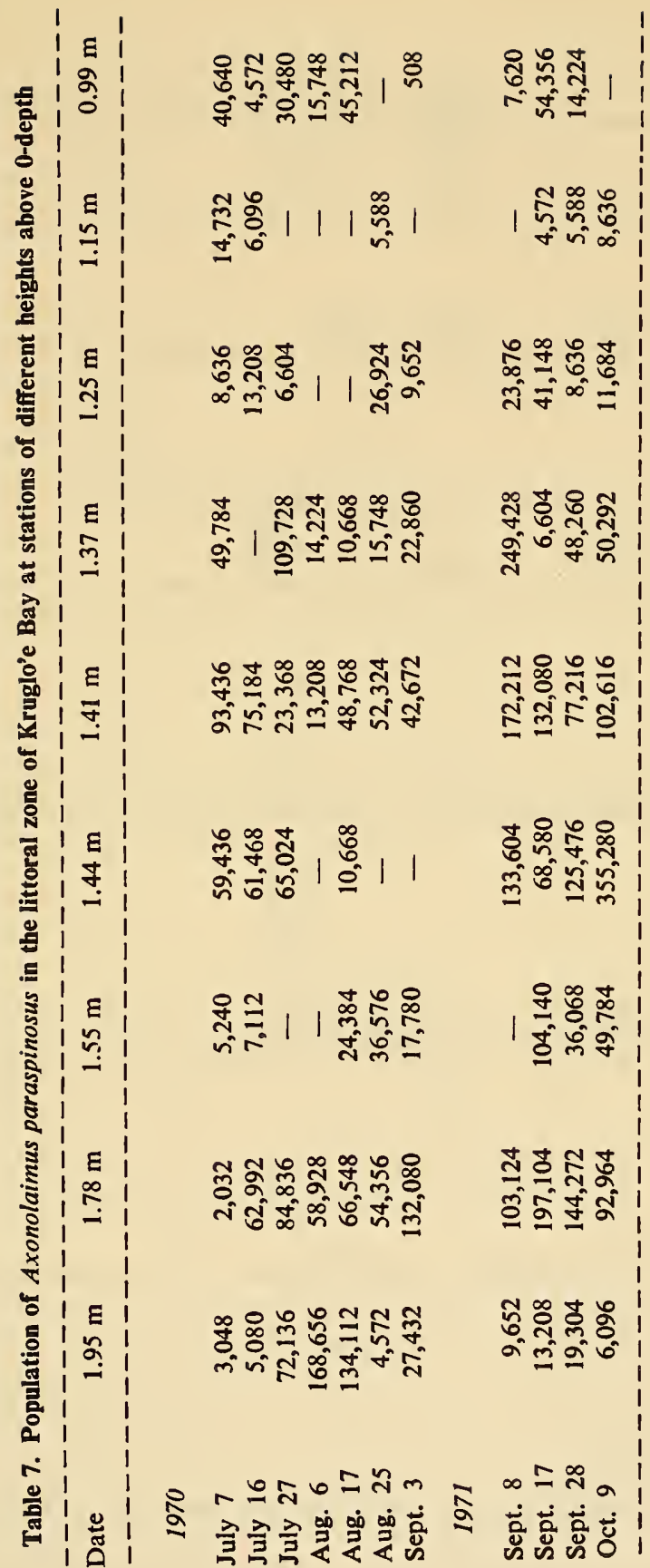




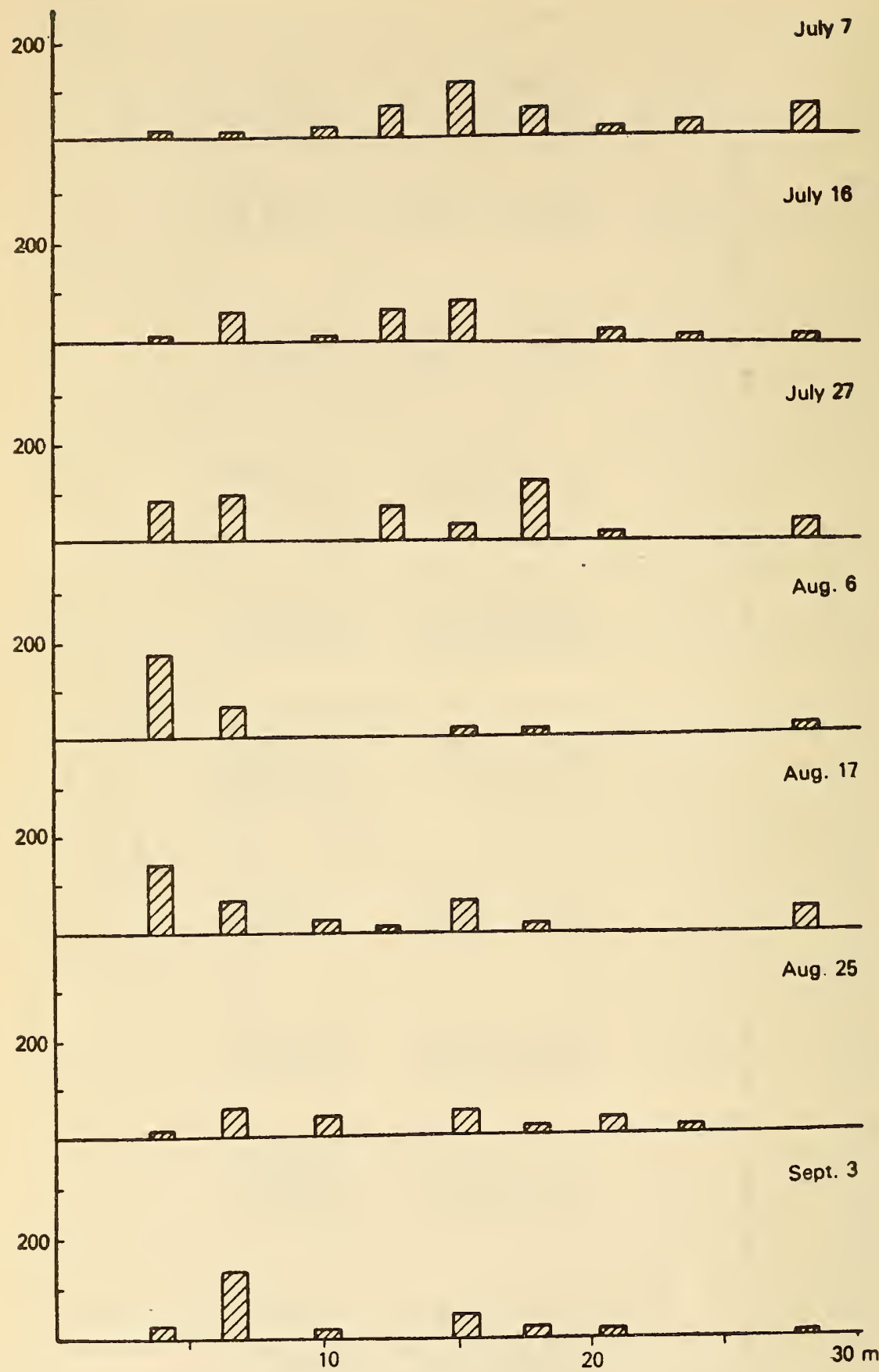

232

Figure 45. Population dynamics of Axonolaimus paraspinosus in the littoral zone of Kruglo'e Bay during summer of 1970. 
309

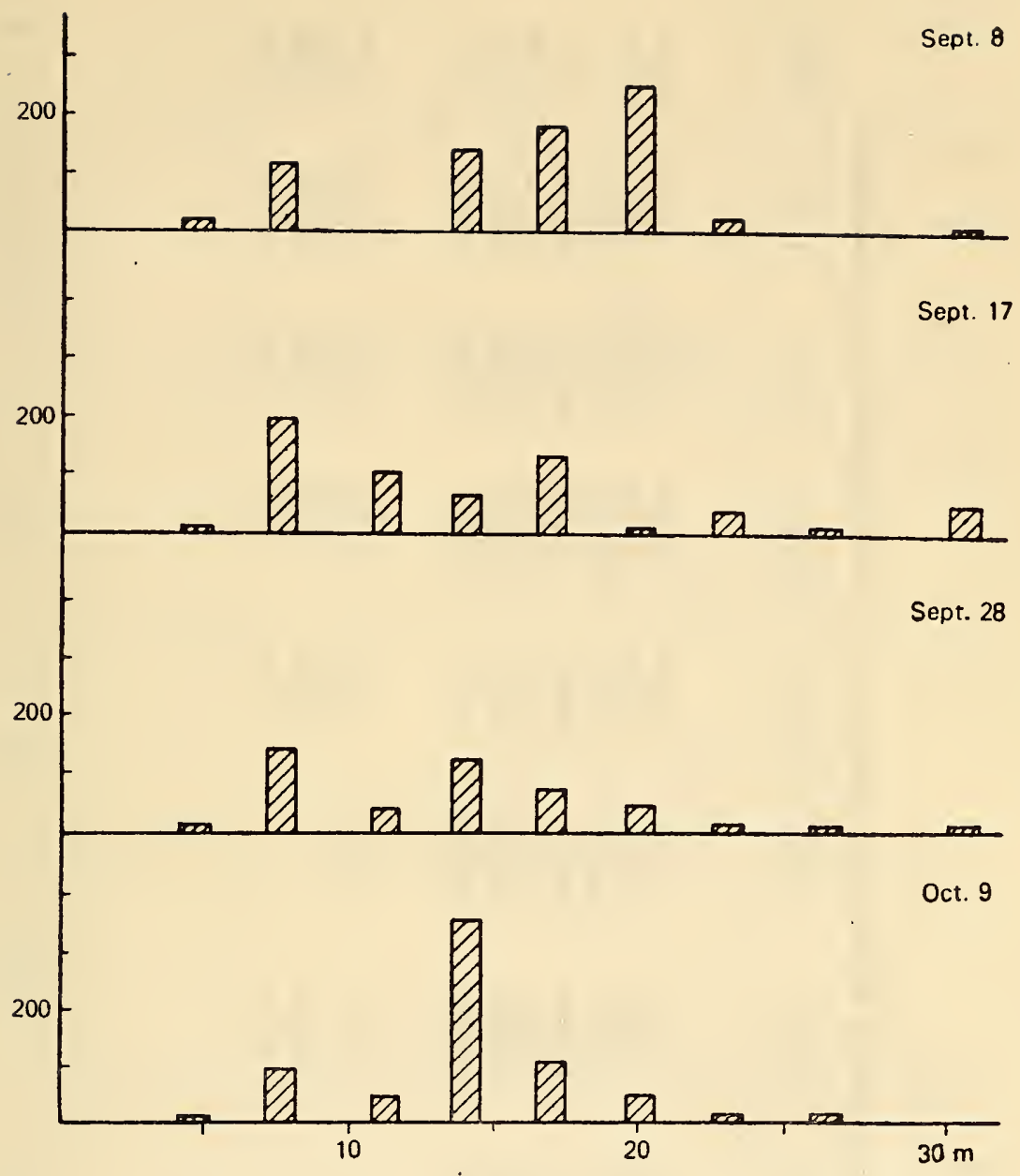

233

Figure 46. Population dynamics of Axonolaimus paraspinosus in the littoral zone of Kruglo'e Bay during autumn of 1971.

summer than in autumn. It remained mainly in the upper and middle 230 horizons of the littoral zone where peaks of population appeared by turns due to the appearance of a large number of young (p. 339). During both seasons the population remained low in the lower horizon.

Enoplus demani (Figures 47 and 48, Table 8). In the beginning of July the population was low throughout the section $(30,000$ to 60,000 specimens $/ \mathrm{m}^{2}$ ). In mid-July a gradual rise in population took place: in the middle horizon to 310,896 , in the lower to 267,208 specimens $/ \mathrm{m}^{2}$. Approximately the same pattern persisted at the end of July. In early 


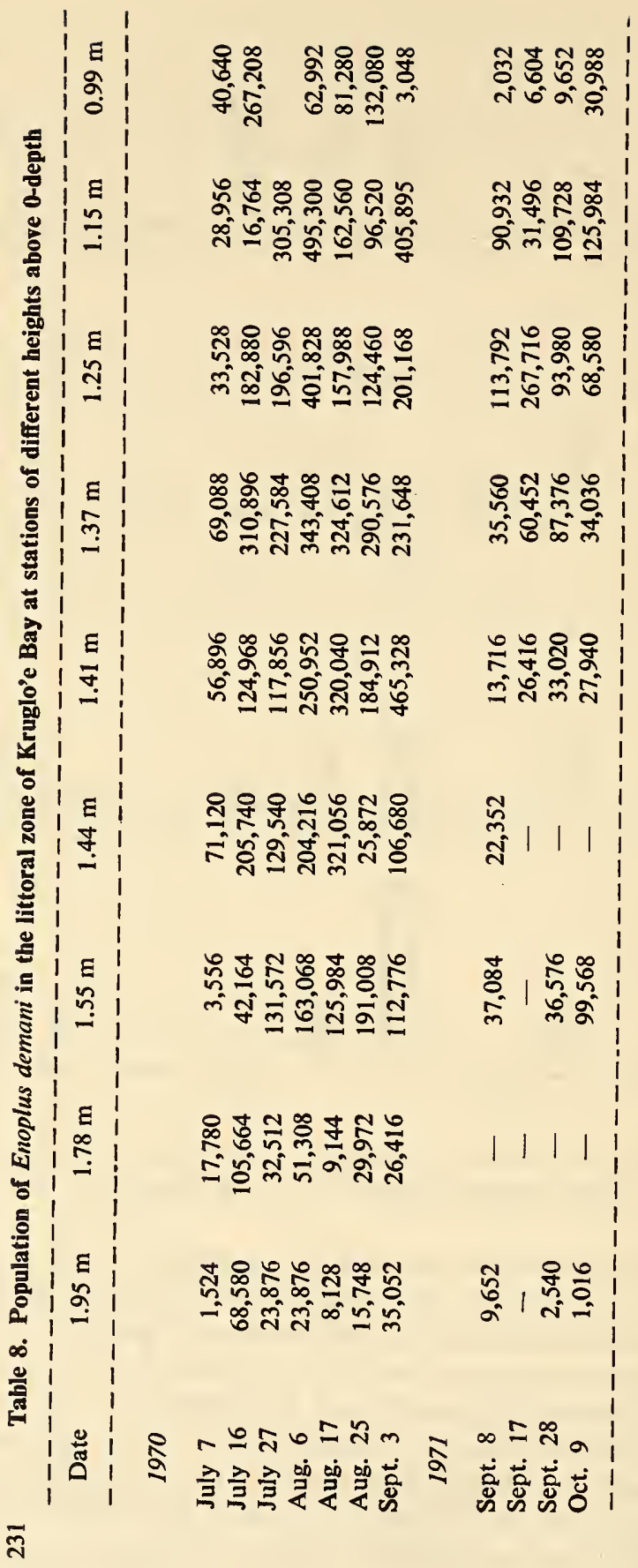




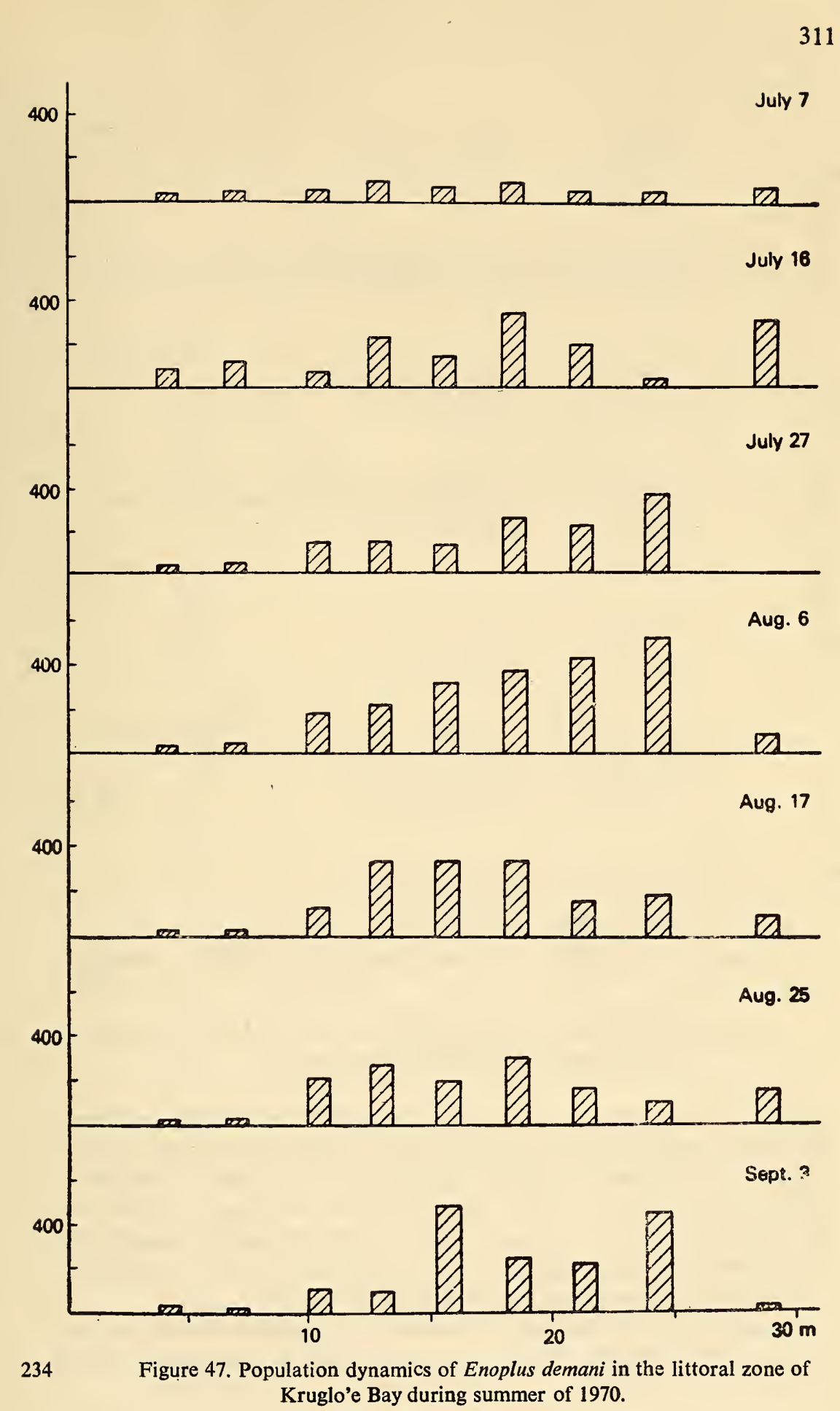




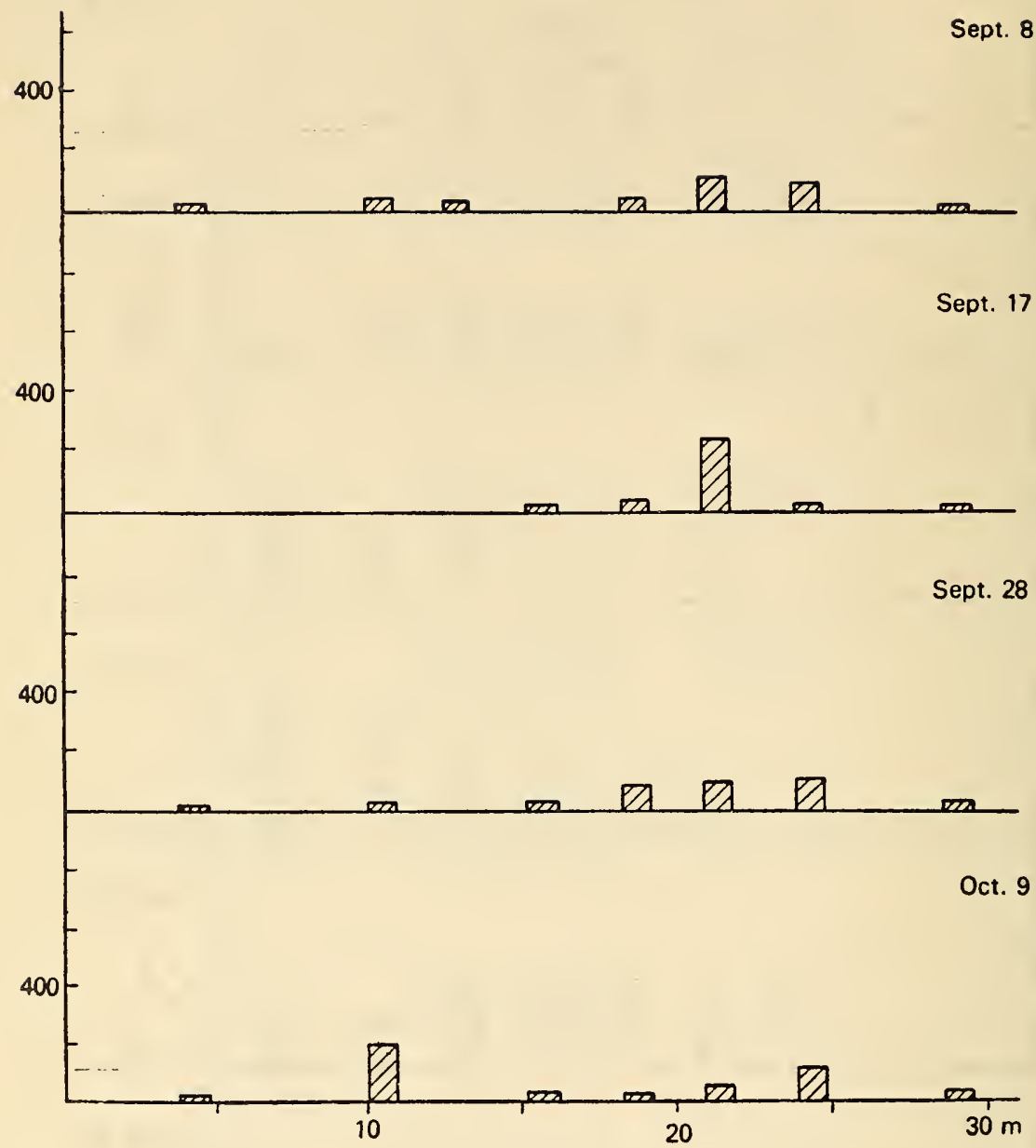

Figure 48. Population dynamics of Enoplus demani in the littoral zone of Kruglo'e Bay during autumn of 1971.

August the population rose in the middle $(204,216$ to 343,408$)$ and lower $\left(410,828\right.$ to 495,300 specimens $\left./ \mathrm{m}^{2}\right)$ horizons. By the middle and end of August it had gradually declined throughout the section to 100,000 to 200,000 specimens $/ \mathrm{m}^{2}$. In early September two increases in populations were observed, one in the middle horizon $(465,328)$ and the other in the lower $\left(405,895\right.$ specimens $\left./ \mathrm{m}^{2}\right)$. In the upper horizon the population remained rather low throughout the summer season.

In autumn, 1971 the density of this species throughout the section was low $(10,000$ to 30,000$)$, being somewhat higher in the lower horizon 


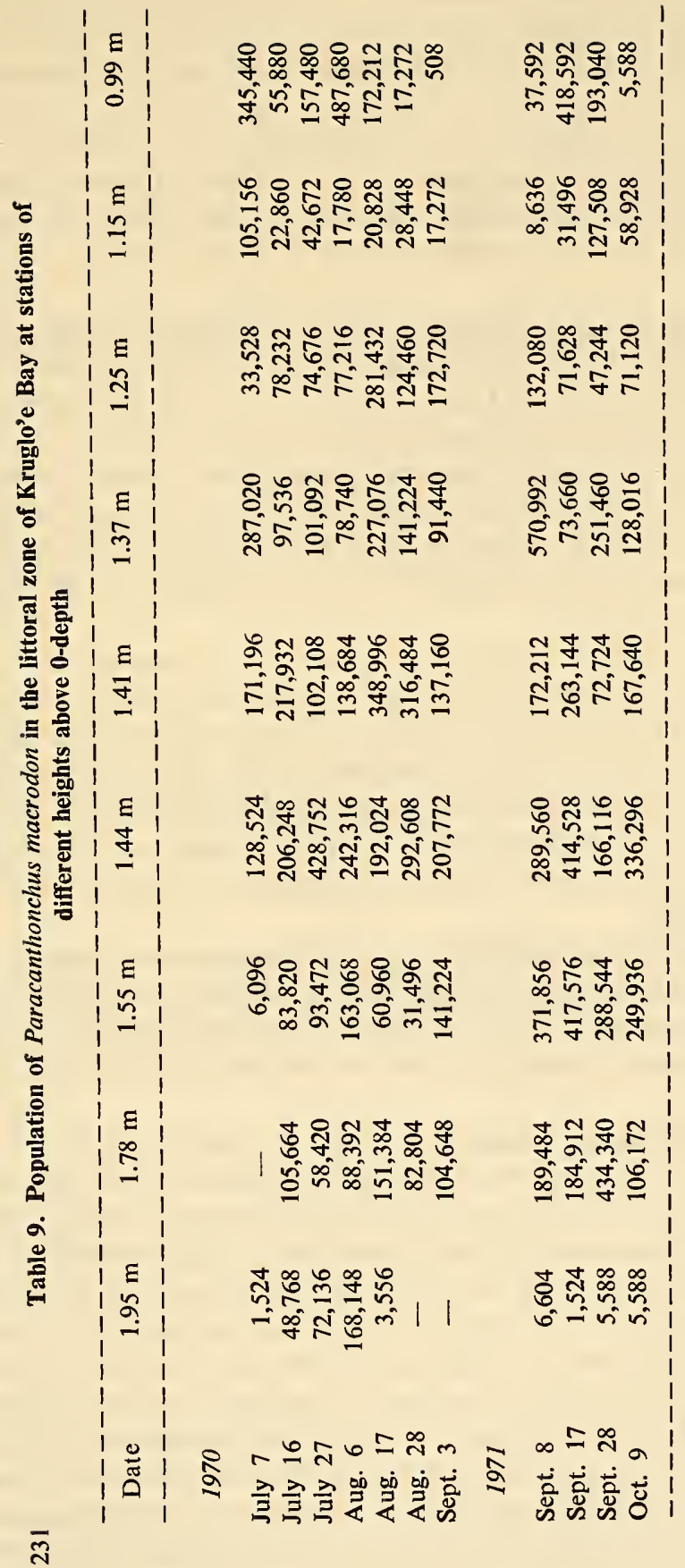


$\left(90,000\right.$ to 100,000 specimens $\left./ \mathrm{m}^{2}\right)$. In mid-September a population peak $\left(267,716\right.$ specimens $\left./ \mathrm{m}^{2}\right)$ was observed in the lower horizon. Until the end of autumn the population density remained low throughout the section.

The highest population of E. demani was observed during the summer season. Localization took place in the middle and lower horizons but 232 maximum density was usually observed in the middle horizon of the littoral zone. Population density was low in the upper horizon in both seasons.

Paracanthonchus macrodon (Figures 49 and 50, Table 9). In the beginning of summer, 1970 two population peaks were observed; in the middle horizon $(287,020)$ and in the lower $(345,440)$ specimens $/ \mathrm{m}^{2}$. Nematodes were encountered singly in the upper horizon. In the third and fourth weeks of July a population maximum occurred in the middle horizon (217,930 to 428,750 specimens $\left./ \mathrm{m}^{2}\right)$. In early August a population increase occurred in the lower horizon $\left(487,680\right.$ specimens $\left./ \mathrm{m}^{2}\right)$. Population density remained high in the middle horizon throughout the season.

During autumn, 1971 two maxima were observed in the upper $(371,856)$ and middle $\left(570,992\right.$ specimens $\left./ \mathrm{m}^{2}\right)$ horizons. In the middle of September the two peaks merged at the border of the upper and middle horizons $\left(414,528\right.$ to 417,576 specimens $\left./ \mathrm{m}^{2}\right)$. Another population peak was observed in the lower horizon $\left(418,592\right.$ specimens $\left./ \mathrm{m}^{2}\right)$. Toward the end of September the population declined throughout the section, but with the onset of October rose in the middle horizon (128,016 to 336,296 specimens $/ \mathrm{m}^{2}$ ).

The highest population of $P$. macrodon was observed during autumn. This species preferred the middle horizon of the littoral zone during both seasons. However it drifted toward the lower horizon during summer, while maximum density shifted toward the upper horizon during winter.

Hypodontolaimus inaequalis (Figures 51 and 52, Table 10). In the beginning of summer, 1970 two population peaks were observed in the middle horizon $\left(101,092\right.$ and 158,496 specimens $\left./ \mathrm{m}^{2}\right)$, while in the upper and lower horizons the population was low. A slight increase in population density occurred in the middle of July throughout the section, but the maximum density remained in the middle horizon $(58,420$ to 164,084 specimens $/ \mathrm{m}^{2}$ ); it was also high in the lower stratum of the upper horizon $(98,044)$ and in the upper stratum of the lower horizon $(104,140$ specimens $/ \mathrm{m}^{2}$ ). Increase in population continued to the end of July with a maximum in the middle horizon $\left(220,980\right.$ specimens $\left./ \mathrm{m}^{2}\right)$; toward the beginning of August a small slump to 80,000 to 100,000 specimens $/ \mathrm{m}^{2}$ was seen. In the middle of the month the population peak shifted to the 
315

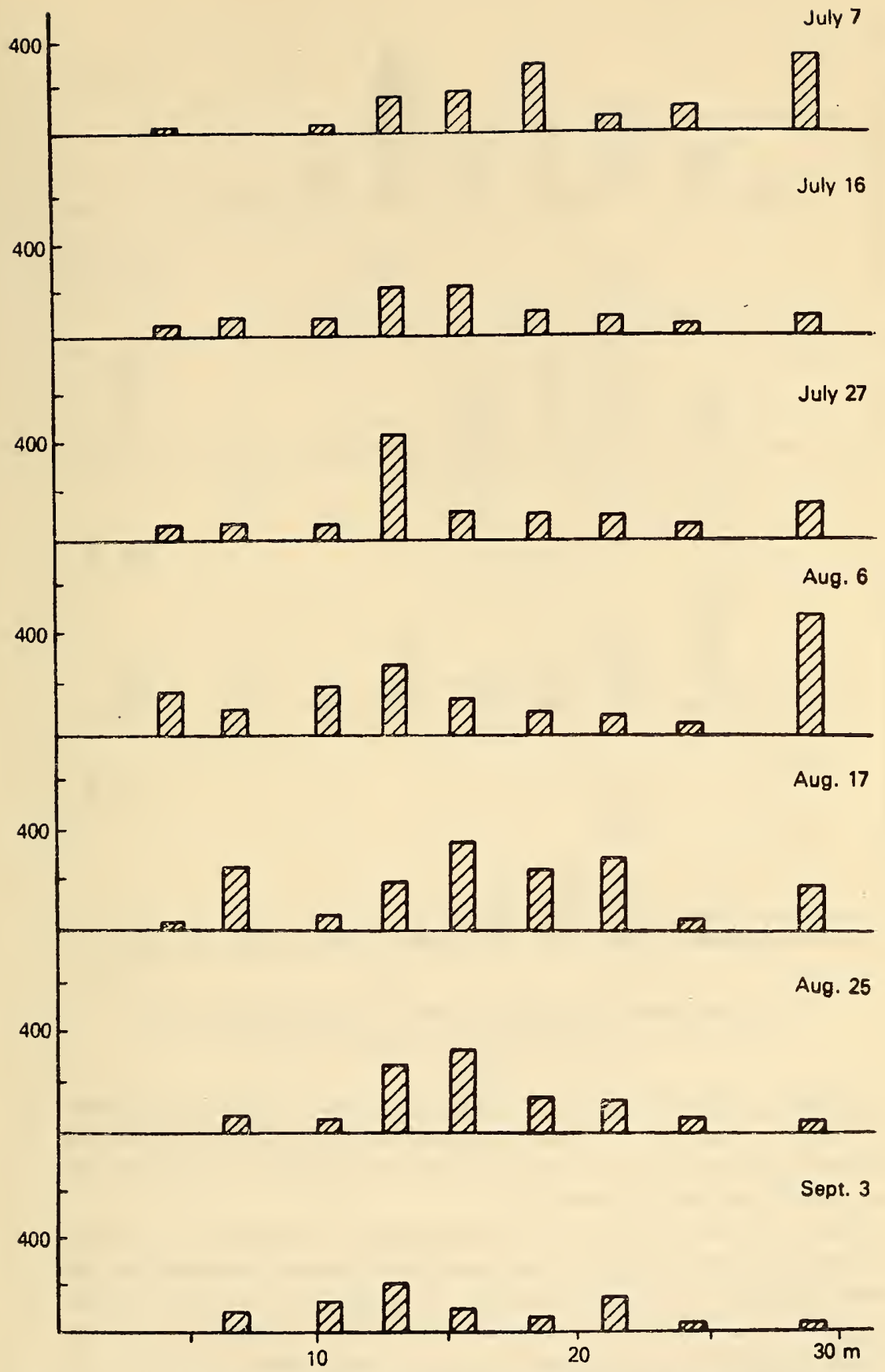

236

Figure 49. Population dynamics of Paracanthonchus macrodon in the littoral zone of Kruglo'e Bay during summer of 1970. 
316

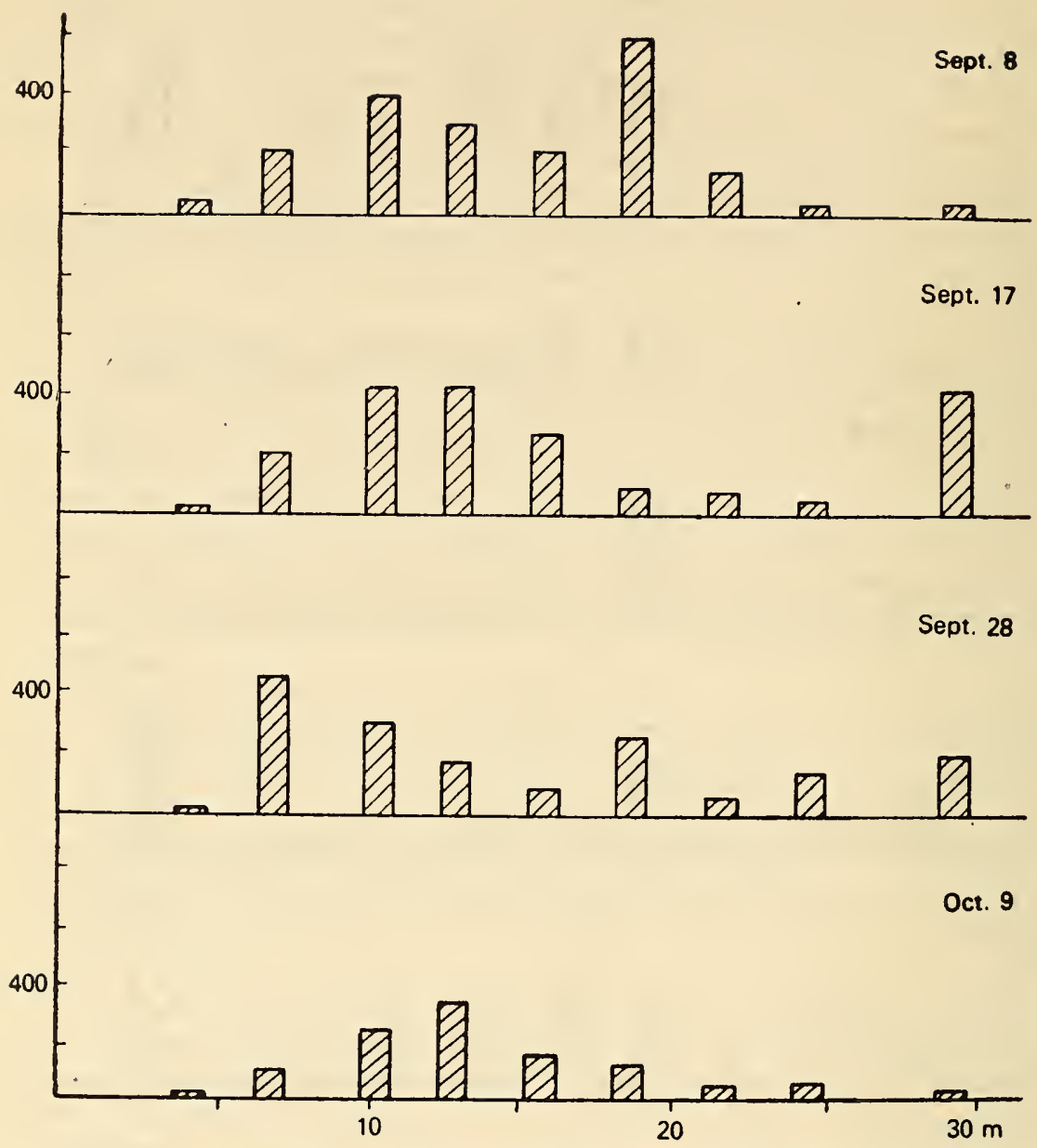

237

Figure 50. Population dynamics of Paracanthonchus macrodon in the littoral zone of Kruglo'e Bay during autumn of 1971.

upper part of the lower horizon of the littoral zone (281,432 specimens/ $\mathrm{m}^{2}$ ). Toward the end of August and early in September the population

235 gradually reduced throughout the section, but the peak continued to be localized in the middle horizon.

During autumn of 1971, at the beginning of September, the populaton was less than that in summer; the greatest number was seen from the lower stratum of the upper horizon of the littoral zone to the upper stratum of the lower horizon $\left(44,704\right.$ to 132,588 specimens $\left./ \mathrm{m}^{2}\right)$. In the middle of September two population peaks were observed: one in the upper horizon $(208,788)$ and the other in the lower horizon $(131,064$ 


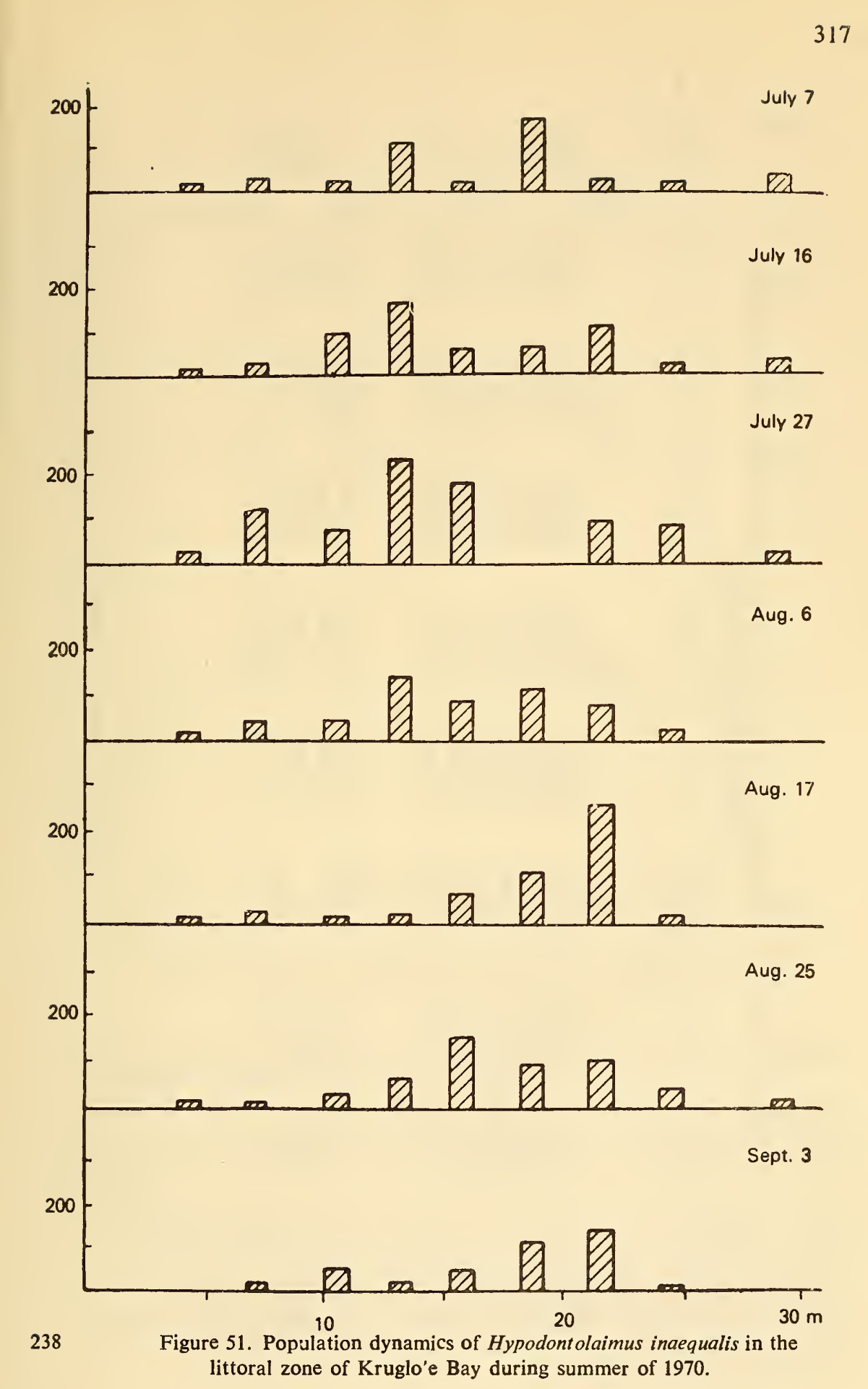




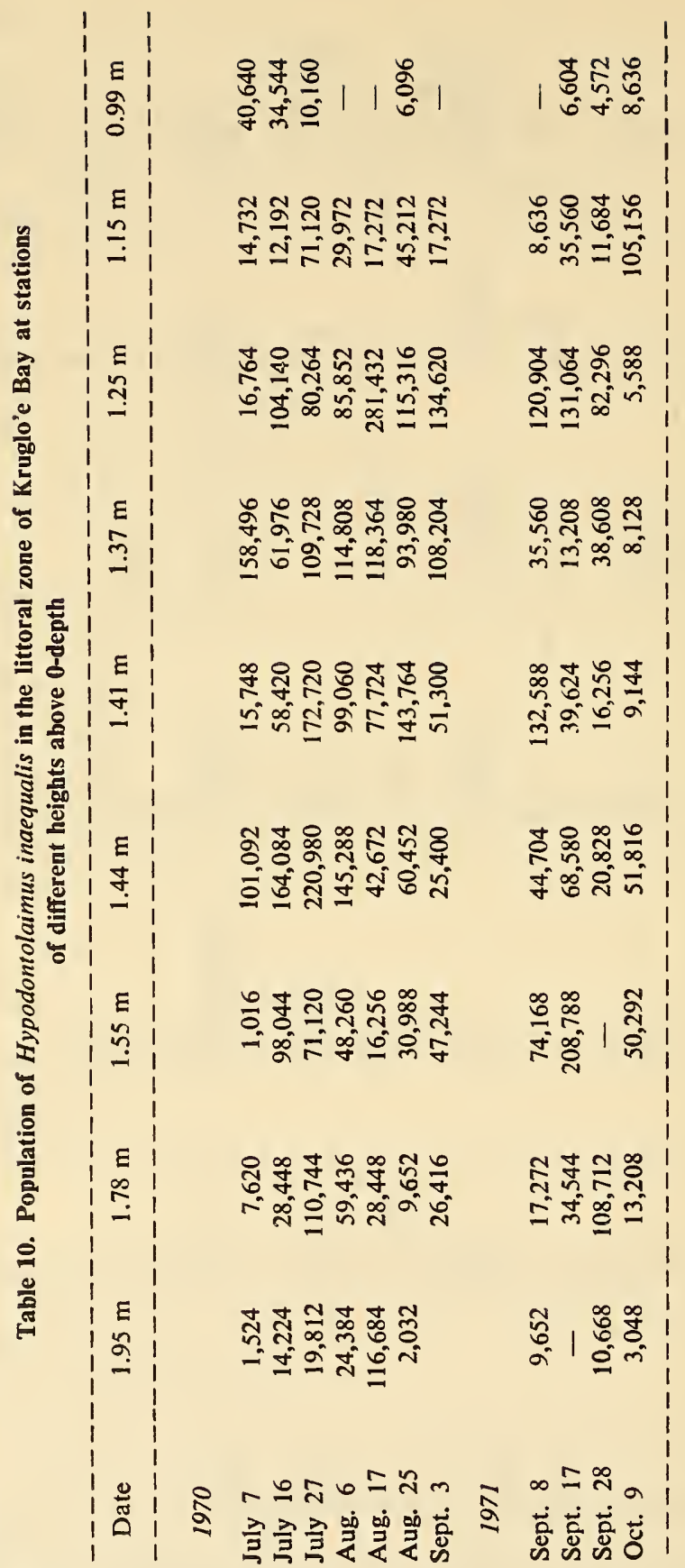

มี 
319

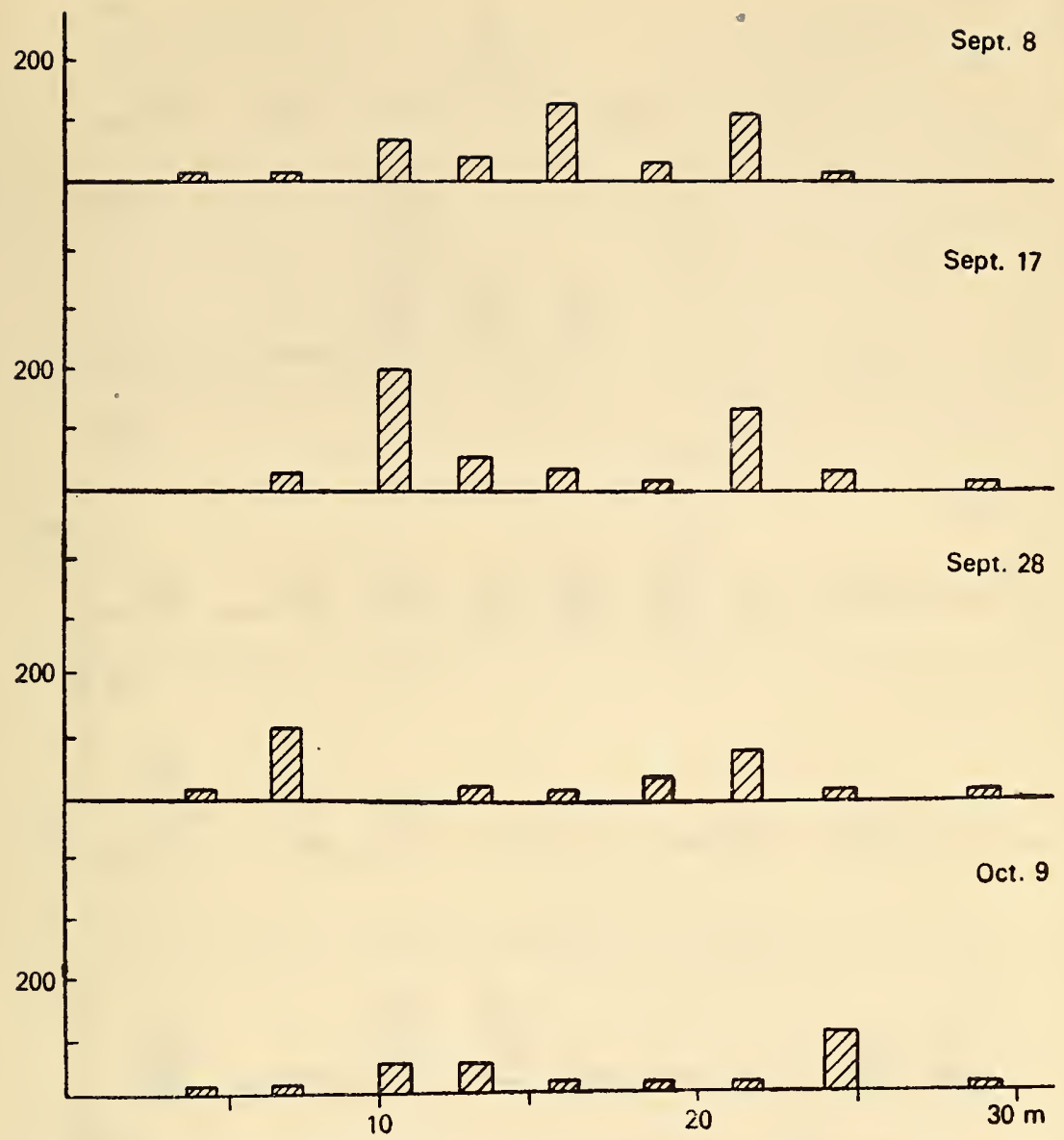

239

Figure 52. Population dynamics of Hypodontolaimus inaequalis in the littoral zone of Kruglo'e Bay during autumn of 1971.

specimens $/ \mathrm{m}^{2}$ ). Toward the end of September and the onset of October a reduction in population occurred throughout the section.

Thus, during summer a greater population, compared to autumn, was seen. $H$. inaequalis was mainly found in the lower stratum of the upper horizon to the upper stratum of the lower horizon during both seasons.

Theristus setosus (Figures 53 and 54, Table 11). The population was low throughout the section $(30,000$ to 90,000$)$ in the beginning of July, 1970 with one peak in the middle horizon $\left(326,644\right.$ specimens $\left./ \mathrm{m}^{2}\right)$. Toward the middle of July an increase occurred in population in the middle horizon $\left(250,952\right.$ to 626,872 specimens $\left./ \mathrm{m}^{2}\right)$ due to the appearance of a 


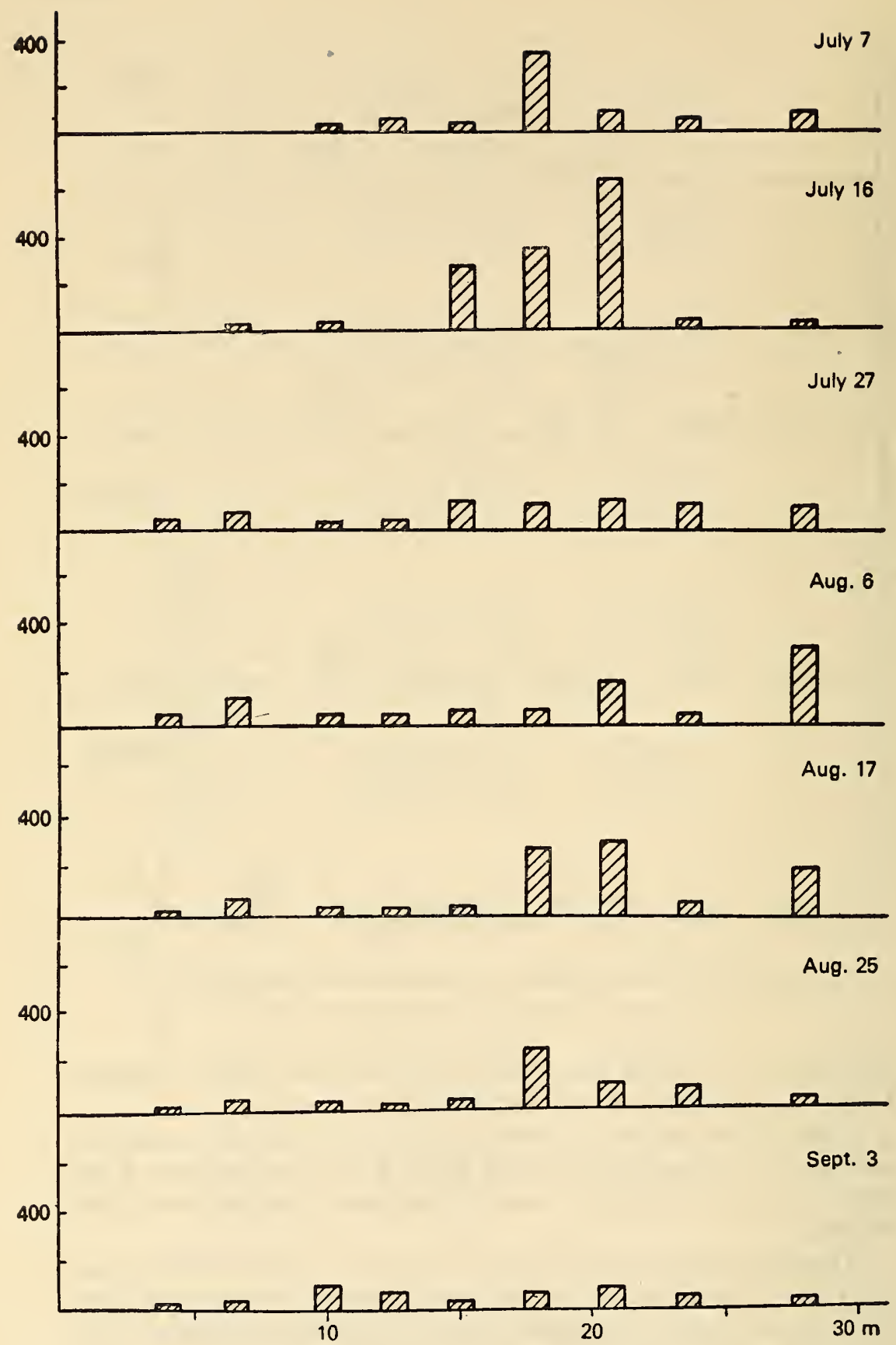

240

Figure 53. Population dynamics of Theristus setosus in the littoral zone of Kruglo'e Bay during summer of 1970. 
large number of young (p. 342). At the end of July the population was again low throughout the section and did not exceed 90,000 to 110,000 specimens $/ \mathrm{m}^{2}$. In the beginning of August approximately the same pattern persisted, with a rise in population to 314,960 only in the lower horizon. Toward the middle of August the peak declined to 180,340, but

on the border of the middle and lower horizons an increase to 259,588 to 281,940 specimens $/ \mathrm{m}^{2}$ was seen. Toward the end of August the population maximum remained only in the middle horizon (226,568 specimens/ $\mathrm{m}^{2}$ ), and in early September a general decline in population occurred throughout the section.

In the beginning of September, 1971 approximately the same pattern was seen as recorded at the end of August, 1970 (peak of population in

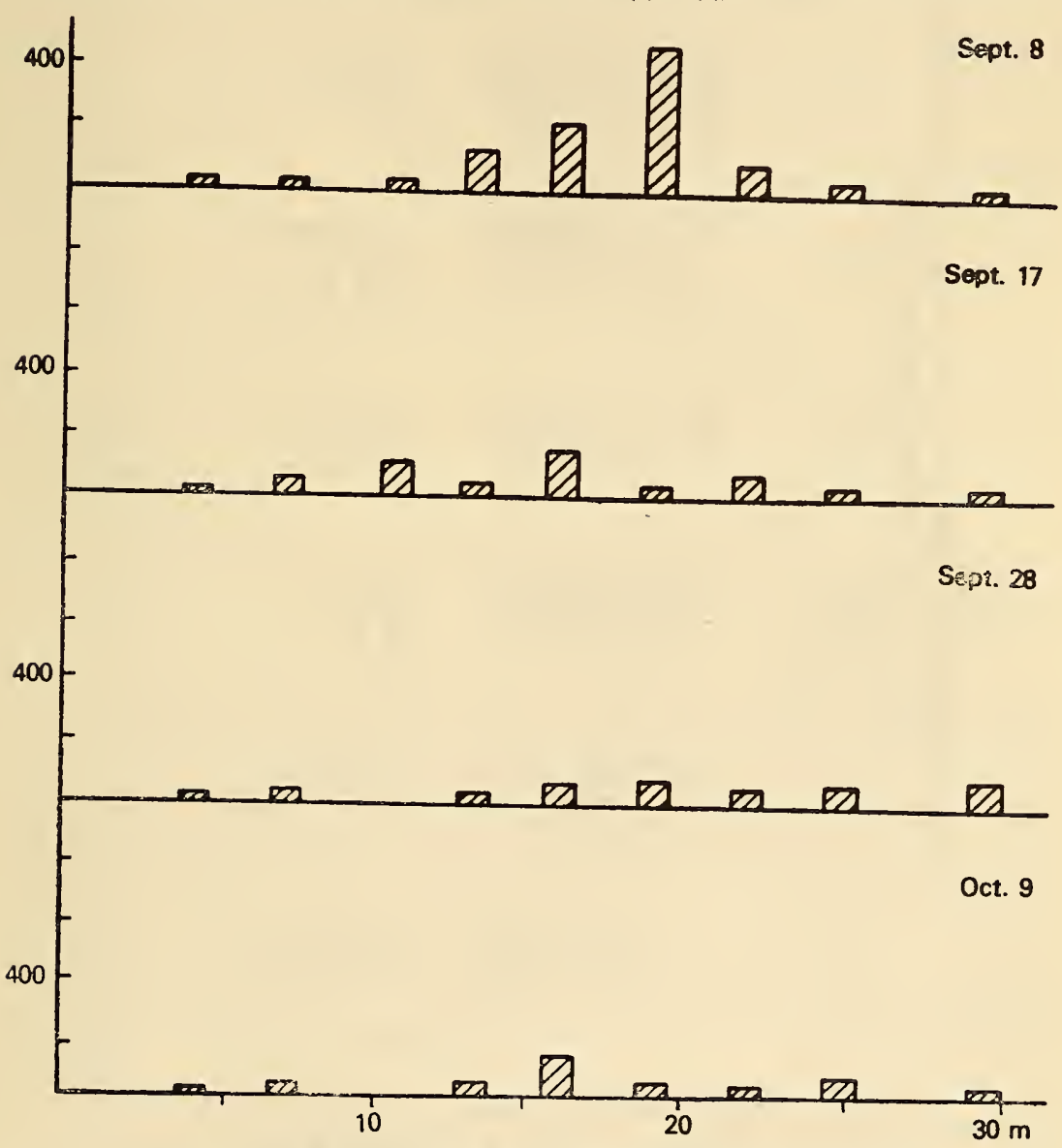
of Kruglo'e Bay during autumn of 1971. 


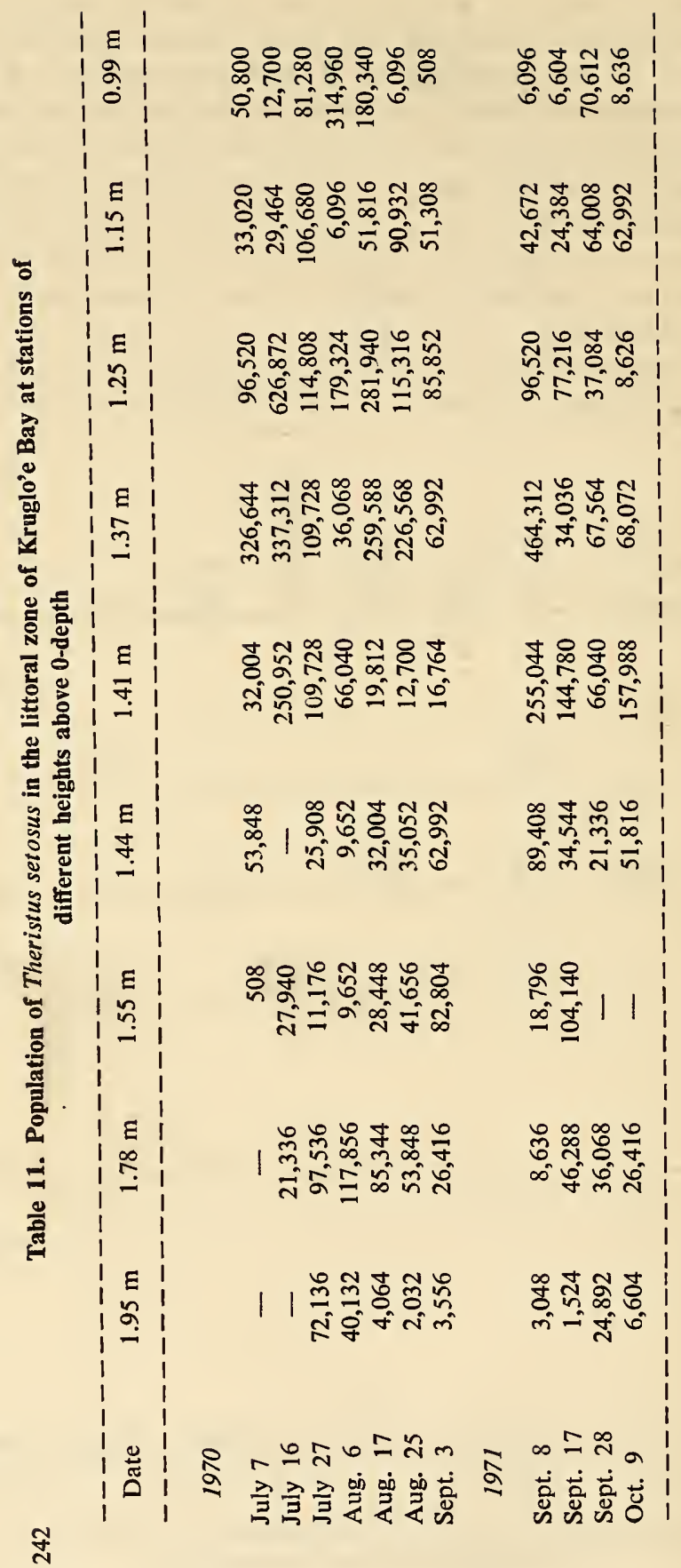


the middle horizon 464,312 specimens $/ \mathrm{m}^{2}$ ). Later a decrease in population occurred throughout the section with the maximum being retained in the middle horizon.

237 Thus the population of $T$. setosus was maximum during the summer season. The middle and lower horizons of the littoral zone were preferred for habitation.

Reviewing the foregoing analysis, it can be said that almost all the leading species of nematodes preferred the middle horizon of the littoral zone for habitation in summer as well as in autumn. Only Timmia acuticauda revealed a tendency to concentrate in the upper horizon during the autumn season. Anoplostoma rectospiculum was found mainly in the middle horizon during summer and in the upper horizon during autumn. Axonolaimus paraspinosus alternated between the upper and middle horizons. Enoplus demani and Theristus setosus preferred the middle and lower horizons during summer but only the middle horizon during autumn. Paracanthonchus macrodon concentrated in the middle and lower horizons during summer and in the middle and upper horizons during autumn. Hypodontolaimus inaequalis concentrated between the lower stratum of the upper horizon and the upper stratum of the lower horizon of the littoral zone during both summer and autumn.

One could probably say that these species exhibit selective habitation in the littoral zone because, even within the limits of such a small area of study, an extremely varied picture of distribution of individual species was evident.

To explain the distribution phenomenon of organisms of meiobenthos, hydrobiological studies have been undertaken to elucidate those factors which exert considerable influence on them. Data is presented in six elaborate works by authors abroad in a more generalized form (Delamare Deboutteville, 1960; Swedmark, 1964; Jansson, 1968, 1971; McIntyre, 1969; Pollock, 1971). As shown in these works, the distribution and population dynamics of meiofauna are influenced by the following factors: granulometric composition of sediments, size of capillary passages occupied by some species of nematodes, presence of sufficient quantity of interstitial water, effects of temperature, salinity, oxygen, and others.

Of the works published in the Soviet Union giving exhaustive characteristics of the living conditions of organisms in the littoral zone such as temperature, salinity, etc., one should mention those of Gur'yanova, Zaks and Ushakov for the littoral zone of Western Murmansk 
(1930a) and the littoral zone of Kol'sk Gulf (1930b), and Gur'yanova and Ushakov (1927) for the littoral zone of Eastern Murmansk. Kuznetsov (1947) has detailed the effects of light and temperature on organisms of the littoral zone of the White Sea under permanent ice cover. Zatsepina, 240 Zenkevich and Filatova (1948) have presented data characterizing the temperature and hydrochemical conditions in the drier zone of the northern part of Kol'sk Bay. A very detailed work on the thermodynamics and hydrochemistry of the littoral zone of Eastern Murmansk and some regions of the White Sea has been published by Chernovskaya $(1956,1957,1958)$. Of foreign works on the hydrobiology and hydroche-

241 mistry of littoral waters, articles by Wohlenberg (1937) and Linke (1939) on the littoral zone of the North Sea are noteworthy.

It was not the purpose of the foregoing authors to include every factor affecting the living conditions of organisms in the littoral zone. The parameters scrutinized were selected in such a way as to show the different degrees of their influence on such living conditions and the population dynamics of meiofauna (using examples of the predominant group of nematodes). The factors studied comprised only the granulometric composition of the sediments, temperature, presence of sufficient feeding base, and salinity.

\section{Granulometric Composition of Sediments}

Of the factors influencing the surrounding medium inhabited by sanddwelling meiofauna, a granulometric analysis of sediments must be given first place. It may not be the size of the particles which limits the distribution of organisms, but aspects such as interstitial spaces and the amount of pore water with minerals and organic substances dissolved in them (Jansson, 1967c).

Works on the nature of the bed and its influence on meiofauna are comparatively few in number (Delamare Deboutteville, 1960; Swedmark,

242 1964; Jansson, 1966, 1967c; and others). An experimental approach to the study of the correlation between granulometric composition of sediments and meiofauna has seldom been employed (Wallace, 1958; Gray, 1966a, 1966b, 1966c; Jansson, 1966, 1967c).

The purpose of my study was to establish whether any correlation exists between size of particles of sediment and population density of nematodes and their individual species, and to compare size of capillary passages in which nematodes live with body size of organisms.

To show the correlation between nematode density and particle size of the sediment they inhabit, correlation coefficients were worked out (Table 12). For the total population of nematodes the correlation coefficient $(r)$ was 0.39 , its error $\left(m_{r}\right) 0.28$, and its reliability (t) 1.39 . 
When $\mathrm{n}=9$, the standard criterion value of Student's test $\left(\mathrm{t}_{\mathrm{st}}\right)$ was 2.3. Thus I obtained an unreliable (negative) correlation between total population of nematodes and average size of sediment particles inhabited by them. In other words, I found no direct relation between total nematode population and granular composition of the sediment.

Table 12. Correlation between density of leading species of nematodes and average size of particles

\begin{tabular}{|c|c|c|c|c|c|}
\hline Leading species & $\mathbf{r}$ & $\mathrm{m}_{\mathbf{r}}$ & $\mathrm{t}$ & $t_{\text {st }}$ & $\begin{array}{l}\text { Reliability of } \\
\text { correlation }\end{array}$ \\
\hline \multicolumn{6}{|c|}{--------------------------------} \\
\hline Anoplostoma rectospiculum & -0.29 & 0.31 & 0.9 & 2.3 & Not reliable \\
\hline Paracanthonchus macrodon & -0.60 & 0.21 & 2.9 & 2.3 & Reliable \\
\hline Hypodontolaimus inaequalis & -0.47 & 0.26 & 1.8 & 2.3 & Not reliable \\
\hline Timmia acuticauda & -0.27 & 0.31 & 0.9 & 2.3 & Not reliable \\
\hline Axonolaimus paraspinosus & 0.70 & 0.17 & 4.1 & 2.3 & Reliable \\
\hline Theristus setosus & 0.44 & 0.27 & 1.6 & 2.3 & Not reliable \\
\hline All nematodes & -0.39 & 0.28 & 1.4 & 2.3 & Not reliable \\
\hline
\end{tabular}

Of the six leading species of nematodes examined, four exhibited no direct correlation between the characters listed above. Paracanthonchus macrodon revealed a positively reliable correlation, i.e., one may speak 243 of some affinity of individuals of this species for sediment with a high content of fractions 300 to $500 \mu \mathrm{m}$. In Axonolaimus Paraspinosus a positively reliable correlation was also obtained and in this case one may speak of some sort of adaptation of individuals to a sediment with an average particle size of 300 to $400 \mu \mathrm{m}$. For these two species correlation with type of sediment is possibly related to the fact that maximum population can be achieved in sediments with a definite size of particles, but after a certain time the population shifts to other stations where the size of particles differs. For this reason the granular composition probably does not influence the distribution of one or the other nematode species in sections with sand of medium granular size.

There are a number of works on microbenthos in which the problems of distribution of some groups of organisms in relation to type of sediment have been discussed. In particular, Agamaliev (1967) and Burkovskii (1969) have shown a correlation between particle size of sediment and distribution of psammophytic infusoria.

As mentioned above, it is not the particle size itself which determines the population density of organisms but the interstitial spaces of the sediment in which they live. For this reason it is more appropriate to compare not the length of the organism with the particle size, but the 
diameter of the organism with the diameter of the capillary passages in which it lives. In this case the terms "micro-, meso-, and euryporal species," used by Agamaliev and Burkovskii, acquire a greater meaning. Renaud-Debyser (1963) examined the main types of capillary spaces occurring in different "packings" of sediment. Sand particles may be situated either on the tops of cubes or on the tops of rhomboids; in the first case pores with maximum space form and in the second with minimum space. In this connection she distinguishes two types of arrangement of sand particles-cubic and rhomboid. Pores formed in this way merge in slits of different sizes. She derived coefficients expressing the correlation between particle size of sediment and diameter of the corresponding type of capillary space and slits. Utilizing these coefficients, I drew a graph reflecting these relations (Figure 55). Four curves reflect the relation between particle size and type of space. The limiting factor influencing the habitation of organisms is probably the minimum size of the capillary passages which these organisms may inhabit. Such spaces are slits existing in a rhomboidal arrangement of particles and later I shall discuss just such types of spaces. Proceeding from the foregoing,

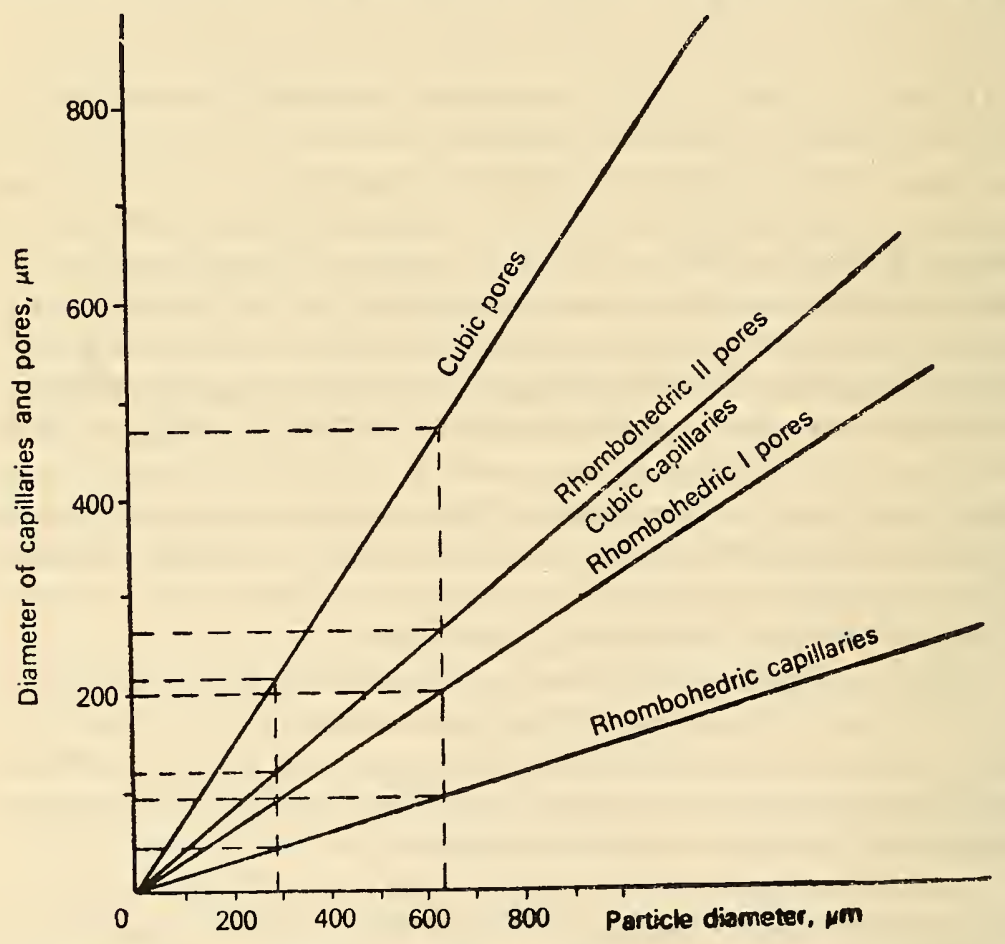

Figure 55. Correlation of slit and pore size with the granular composition of the sediment in different packings (textures). 
the percent content of slits (capillaries) for each station was calculated. This corresponded with the percent fraction of particles of this or that size (Table 13, Figure 56). For each species of nematode inhabiting one station or the other the maximum diameter of the body was calculated and the content of each measured class with respect to diameter cal244 culated in percent (Table 13). The data is graphically presented in Figure 56.

Rhomboidal slits of 20 to $80 \mu \mathrm{m}$ diameter predominated at stations 1 to $4,8,9$. At these stations nematodes with an average body diameter of 20 to $80 \mu$ m predominated. In the given case one can see the coincidence of maximum distribution of capillaries of different diameter and nematodes of almost that same diameter.

The predominating species in these stations were: Metoncholaimoides filicauda, Anoplostoma rectospiculum, Timmia acuticauda, Paracanthonchus macrodon, Theristus flevensis, and others. For the prevalence of these

245 species there must have been sufficient capillary passages, the diameter of which was either equal or greater.

At station No. 5 slits of larger size ( $300 \mu \mathrm{m}$ and above) predominated. About $90 \%$ of the nematodes at this station had a body diameter of 20 to $110 \mu \mathrm{m}$, i.e., for habitation they had capillary passages in which the diameter was 1.5 to 2.0 times the body diameter. In other words, at this station minimum slit size was not a limiting factor for the organisms.

At station No. 7 most of the capillaries had a diameter of 40 to 60 $\mu \mathrm{m}$. The diameters of the remaining capillary passages were represented more or less equally. Two maxima were distinguished in the distribution of nematodes. One comprised nematodes with an average diameter of 40 to $110 \mu \mathrm{m}$, and the other comprised nematodes with a body diameter of $165 \mu \mathrm{m}$. The first peak was formed by P. macrodon, Hypodontolaimus inaequalis, and Theristus setosus, and the second by Enoplus demani. In this case the average diameter of the organisms somewhat exceeded the minimal diameter of the capillaries. It may be assumed that $H$. inaequalis and $T$. setosus, with an average diameter of 60 to $100 \mu \mathrm{m}$, were capable of slightly dilating capillary passages in which the diameter was less than their body diameter. The presence of capillaries with small diameters had no impact on the distribution of $E$. demani in the section under study, because representatives of this species are rather large organisms (average length, $4.8 \mathrm{~mm}$ ) and capable of boring a passage corresponding to their body size.

This situation allows one to assume another criterion for drawing dimensional limits for meiofauna. Those organisms that are capable of living in minimum capillary passages of a given sediment by virtue of their size and without harm to themselves belong to meiofauna. Organisms capable of actively making for themselves a "living space" in 
<smiles>C#CC(C)(C)C(=C)C</smiles> 


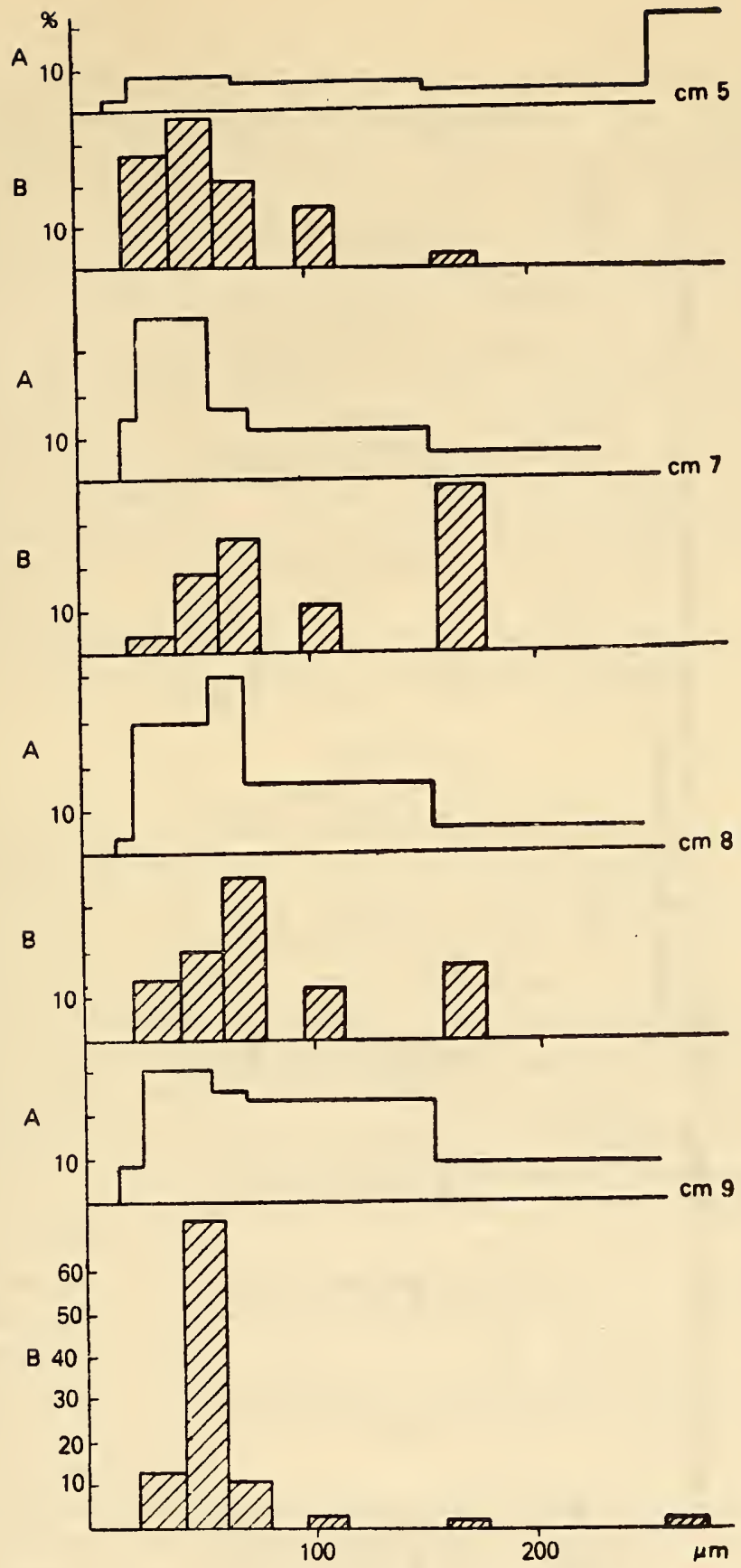

Figure 56. Number (in \%) of rhomboid capillaries (A) and nematodes of definite diameter (B) in samples collected on September 17, 1971 in the littoral zone of Kruglo'e Bay. 


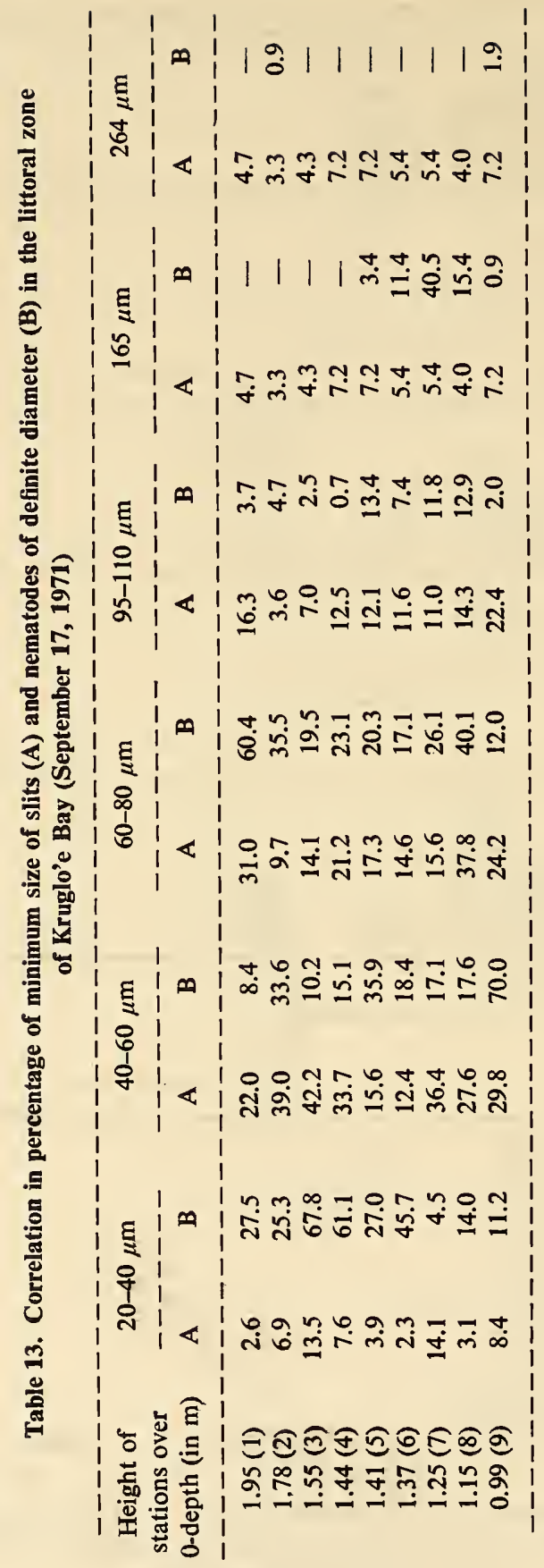


which conditions of existence in no way depend on minimal capillaries in the sediment may be categorized as macrofauna.

To summarize, I could establish no direct relation between density of nematodes and granulometric composition of the sediment in the section under study. Probably in a section with median-granular sand the granular composition is not a factor influencing the distribution of one or the other species. The limiting factor is the minimal size of capillary in which other representatives of meiobenthos can also live. For the sediment investigated the minimal capillary size was 20 to $80 \mu \mathrm{m}$. Such capillaries suffice for the inhabitation of $M$. filicauda, $A$. restospiculum, $T$. acuticauda, $P$. macrodon, $T$. flevensis, and others. H. inaequalis and $T$. setosus are capable of widening the minimal capillary passage. The presence of minimal capillaries exerts almost no influence on the distribution of $E$. demani, which is capable of actively making for itself a "living space".

The criterion for the upper limit of meiobenthos, i.e., their capacity to live in minimal capillary passages, has been established.

\section{Temperature}

Temperature conditions on sandy coasts of seas have long attracted the attention of researchers. Summarizing the data obtained by a number of authors (Pennak, 1940; Angelier, 1953; Ruttner-Kolisko, 1954; McIntyre, 1964; Johnson, 1965; Jansson, 1966, 1967a, 1968, and 1971; Salvat, 1964; Smidt, 1951), some generalizations for a temperate Arctic region can be made. During winter (season of minimum temperatures) negative temperatures are observed at depths of $1.0 \mathrm{~m}$ and more. During spring (autumn) when gradual warming up (thawing) of coastal waters takes place day and night, the amplitude of air temperature achieves a

248 significant value and vertical stratification of ground temperature is seen. The greatest fall in temperature (more than $10^{\circ} \mathrm{C}$ ) takes place in the upper $2.0 \mathrm{~cm}$ layer of sand. My study commenced at the end of springbeginning of summer. In determining seasons for the White Sea the classification of Chernovskaya (1956) was followed: spring-May, June and beginning of July; summer-second half of July, August and September; autumn-end of September and October. As such the period of collecting material in 1970 comprised spring-summer and the period in 1971 summer-autumn.

In the conditions of the continental situation of the White Sea, waters in the littoral zone warm up significantly. For example, in 1970 the temperature of water washing the littoral zone rose from 14.8 to $16.0^{\circ} \mathrm{C}$ from the 1 st to the 5 th of July, declined to $11.5^{\circ} \mathrm{C}$ from the 6 th to the 8 th of July, and then throughout the rest of the month gradually rose to 15 to 
$16^{\circ} \mathrm{C}$. August is the warmest month on the White Sea (Chernovskaya, 1956). During this month a considerable warming of surface waters to $17.5^{\circ} \mathrm{C}$ took place in the first ten days. Later a gradual cooling of waters in the littoral zone occurred toward the end of August to $14.1^{\circ} \mathrm{C}$ and on September 8 th to $12.5^{\circ} \mathrm{C}$.

In 1971 studies were conducted in the summer-autumn season. On September 7 th the water temperature in the littoral zone was $8.5^{\circ} \mathrm{C}$, i.e., $4^{\circ}$ lower than the temperature in the similar period in the previous year. Toward the end of September and beginning of October the water temperature gradually dropped to $2.5^{\circ} \mathrm{C}$, by which time initial freezing had covered the upper horizon with a thin crust of ice.

I attempted to correlate temperature changes during the two seasons with the population dynamics of the leading group of meiobenthos, namely, nematodes. Dynamics of the average population during the spring-summer period of 1970 have been given in Figure 57. The average population from nine stations throughout the section was calculated each day. The temperature of the day of collection was calculated as the average of 7 to 10 days preceding the day of sampling and including the day of collection.

By means of monofactorial dispersion analysis the extent of influence of time on the population dynamics of nematodes was derived. It was found that the index of intensity of influence $\left(\eta_{\mathrm{x}}^{2}\right)=0.825$, its error $\left(\mathrm{m}_{\eta}\right)=0.019$, and its reliability $(F)=43.4$ when Fischer's standard criterion is $F_{\text {st }} 2.3-3.1-4.3$ (degree of freedom; $v_{1}=6, v_{2}=56$ ).

Finally the index of intensity of influence may be written: $\eta_{x}^{2} \sim$ $0.825 \pm 0.044$. In other words, the influence of the time factor on nematode population is reliable with a probability of $\beta=0.999$ and may not constitute less than $78 \%$, because the time factor is interconnected with changes in many parameters (such as temperature in the first place, salinity, chemistry of water, etc.). In the given case I shall first of all concentrate on changes in temperature because in my opinion changes

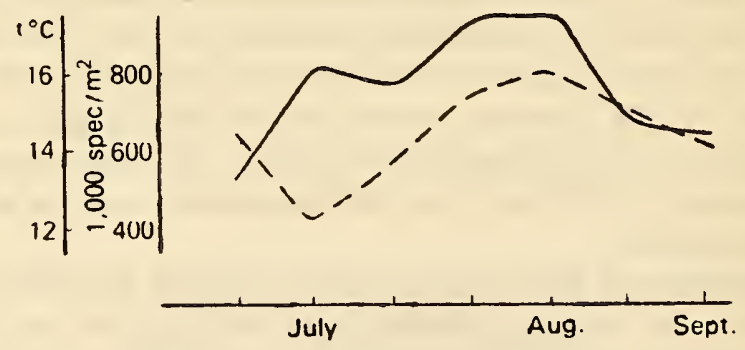

Figure 57. Graph depicting changes in average temperature and average population of nematodes during summer of 1970 (broken linetemperature; continuous line-population). 


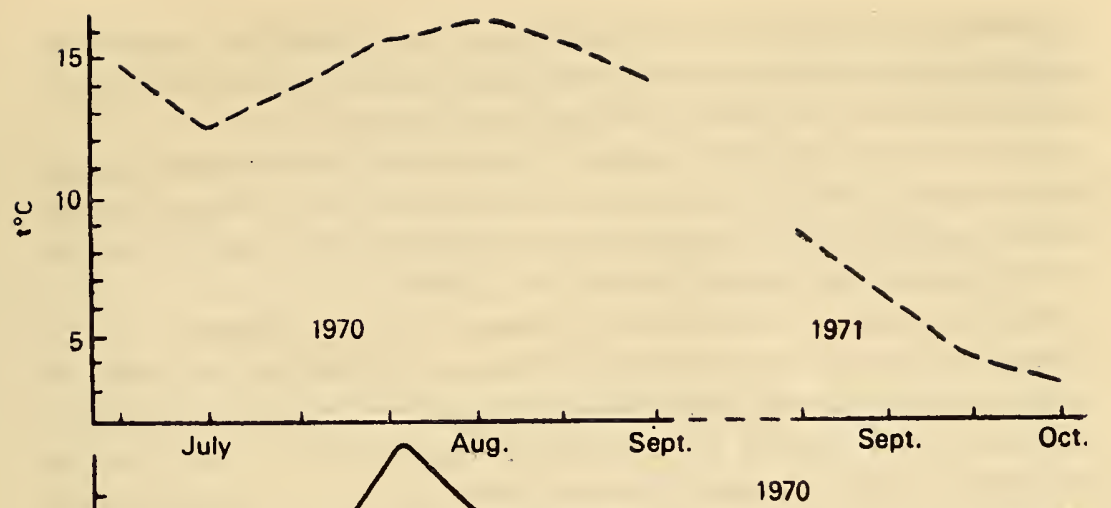

July 16
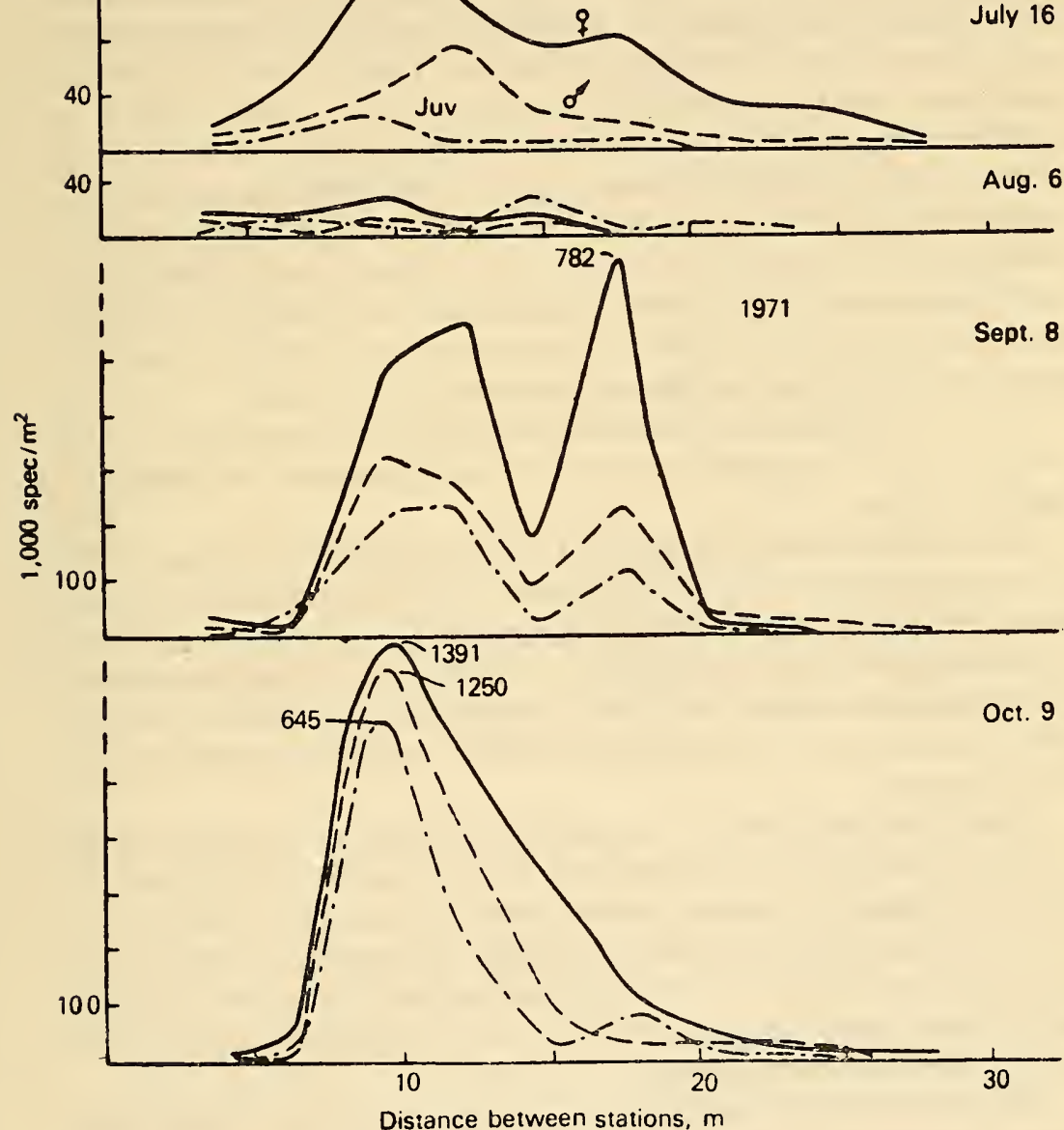

Figure 58. Dynamics of Timmia acuticauda population during summer of 1970 and autumn of 1971.

Graph of temperature variations. 
in salinity, chemistry of interstitial water, etc., could not have substantially influenced the nematode population during the period of study (the reason for this is given in the section on salinity).

As seen in Figure 57, a direct correlation between temperature 249 variations and population dynamics is discernible. This to some extent justifies my hypothesis about the predominant position of the temperature parameter with relation to the time factor.

Air temperature has a direct influence on the temperature of the ground as well as water which the organisms inhabit (Kinne, 1963); it influences fauna, for example, through speed of multiplication of individual species (Orton, 1919; Gerlach and Schrage, 1971). As $90 \%$ of the nematode population comprised seven dominant species, it was interest-

250 ing to analyze subsequently in what way temperature influenced the speed of multiplication in different seasons. This in turn indicated to some extent the geographic affinities of the species under study. It is practically impossible to project a zoogeographic pattern on the basis of analysis of marine fauna of nematodes due to considerable inaccuracies in the identification of species within the limits of this group; species described by some authors may prove to be different species (Platonova, 1967). Some researchers (Steiner, 1916a; Kreis, 1934; Allgen, 1954, 1957) regard the majority of nematodes as cosmopolitan, but due to reasons given earlier, this question remains controversial even now.

Let us now separately analyze the population composition of the leading species of nematodes during the spring-summer and summerautumn seasons.

Timmia acuticauda (Figure 58). In the beginning of summer, 1970 females predominated in the population (for example, on July 16th their population was 30,000 to 100,000 specimens $/ \mathrm{m}^{2}$ ). Juveniles were fewer in number $\left(4,000\right.$ to 8,000 specimens $\left./ \mathrm{m}^{2}\right)$. The lowest average temperature during the season studied occurred at the beginning of summer $\left(12.5^{\circ} \mathrm{C}\right)$. The low population of this species persisted throughout the section to the end of summer.

During autumn of 1971 an increase in population of this species up to $2,000,000$ specimens $/ \mathrm{m}^{2}$ occurred, with the temperature falling from 8.5 to $2.5^{\circ} \mathrm{C}$. Females, as before, predominated (for example, on September 17 th their number was 400,000 to $1,400,000$ specimens $/ \mathrm{m}^{2}$ ). Males were somewhat less $(300,000$ to $1,300,000)$ and juveniles almost half the number of males. Approximately the same ratio between the sexes persisted to the end of the autumn season.

Thus from the above account it follows that the speed of multiplication of this species at high temperatures was extremely low and maximum multiplication took place in autumn. This species could probably be regarded as Arctic since it multiplied at low positive temperatures. The 
species tolerates high summer temperatures without harm because almost all nematodes are eurythermal and euryhaline, adapting to sharp changes in temperature and salinity (Jansson, 1967a, 1968). However, it is known that some organisms which are eurythermal during the period of growth may be stenothermal during the period of multiplication (Ekman, 1953).

Enoplus demani (Figure 59). In the beginning of the spring-summer season the number of males, females, and juveniles was not large and their total population did not exceed 71,120 specimens $/ \mathrm{m}^{2}$. From the middle of July a gradual increase in number of juveniles was recorded and in the beginning of August their number reached 346,450 to 367,790 specimens $/ \mathrm{m}^{2}$ in the lower horizon, and throughout the course of August their population remained at 100,000 to 250,000 specimens $/ \mathrm{m}^{2}$. It should be noted that $90 \%$ of the population concentrated in the middle and

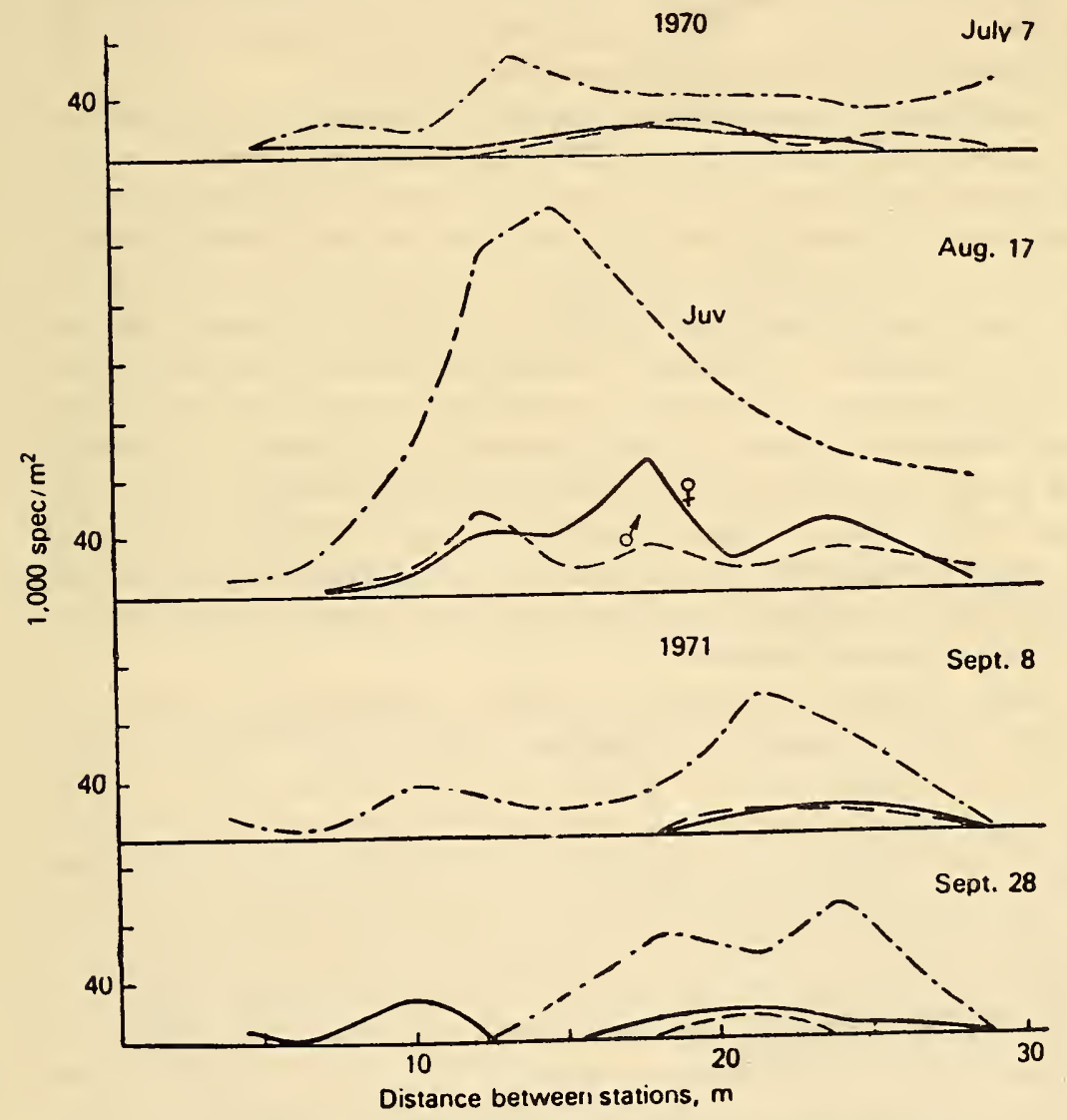

Figure 59. Population dynamies of Enoplus demani during summer of 1970 and autumn of 1971. 
lower horizons of the littoral zone. Probably, the upper horizon of the littoral zone was least favorable for this species due to sharp changes in daily temperatures, high salinity of interstitial waters because of evaporation, and several other factors. The ratio of males to females was 1:1. Females numbered from 61,970 to 97,530 and males 39,110 to 83,310 specimens $/ \mathrm{m}^{2}$. Males and females were three to four times fewer than juveniles. During autumn a general decline in population from 9,650 to 113,790 (September 8,1971 ) to 2,540 to 93,980 specimens $/ \mathrm{m}^{2}$ occurred toward the end of September with a lowering of temperature. Reduction in the total population was mainly due to the reduction of juveniles; their number in summer was 110,100 to 178,000 but in autumn 35,500 to 52,100 specimens $/ \mathrm{m}^{2}$. Correspondingly, the number of males and females also declined.

Probably the most favorable temperature condition for multiplication lies between 12 to $16^{\circ} \mathrm{C}$. The least intensive process occurs during autumn. Hence this species may be considered arctico-boreal.

Anoplostoma rectospiculum (Figure 60). In the beginning of July the population was relatively low, 85,500 specimens $/ \mathrm{m}^{2}$ on the average, in the section and the proportion of males, females, and juveniles approximately 1:1:1. Toward the middle of July the number of males, females, and juveniles increased 2.0 to 2.5 times. Throughout the rest of summer the total population averaged 152,500 to 197,000 specimens $/ \mathrm{m}^{2}$ and the same proportion between males, females, and juveniles was maintained.

During autumn a rise in general population was recorded, mainly due to an increase in number of juveniles, which predominated in the population of this species throughout the summer-autumn season. Their maximum number was observed in mid-September $\left(626,300\right.$ specimens $/ \mathrm{m}^{2}$ in the upper horizon of the littoral zone). Toward the end of September the total population declined a little and remained at about the same level in the first ten days of October.

Thus this species maintained a sufficiently high population during the course of the two seasons investigated. During summer the same ratio persisted between adults and juveniles, but during autumn, i.e., under low positive temperature conditions $\left(2^{\circ}\right.$ to $\left.8^{\circ} \mathrm{C}\right)$ juveniles predominated. Males and females were somewhat fewer in autumn compared to their number in the spring-summer season. During the summer of 1970 the female population was 35,900 to 88,900 but during autumn of 1971 only 27,200 to 37,500 specimens $/ \mathrm{m}^{2}$. Probably this species could be considered arctico-boreal but, as distinguished from $E$. demani, finds more favorable

252 temperatures for multiplication during autumn. However, even during summer at temperatures of 12 to $16^{\circ} \mathrm{C}$ multiplication was fairly intense.

Paracanthonchus macrodon (Figure 61). During the summer season the total population ranged from 97,300 to 183,900 specimens $/ \mathrm{m}^{2}$. Juve- 


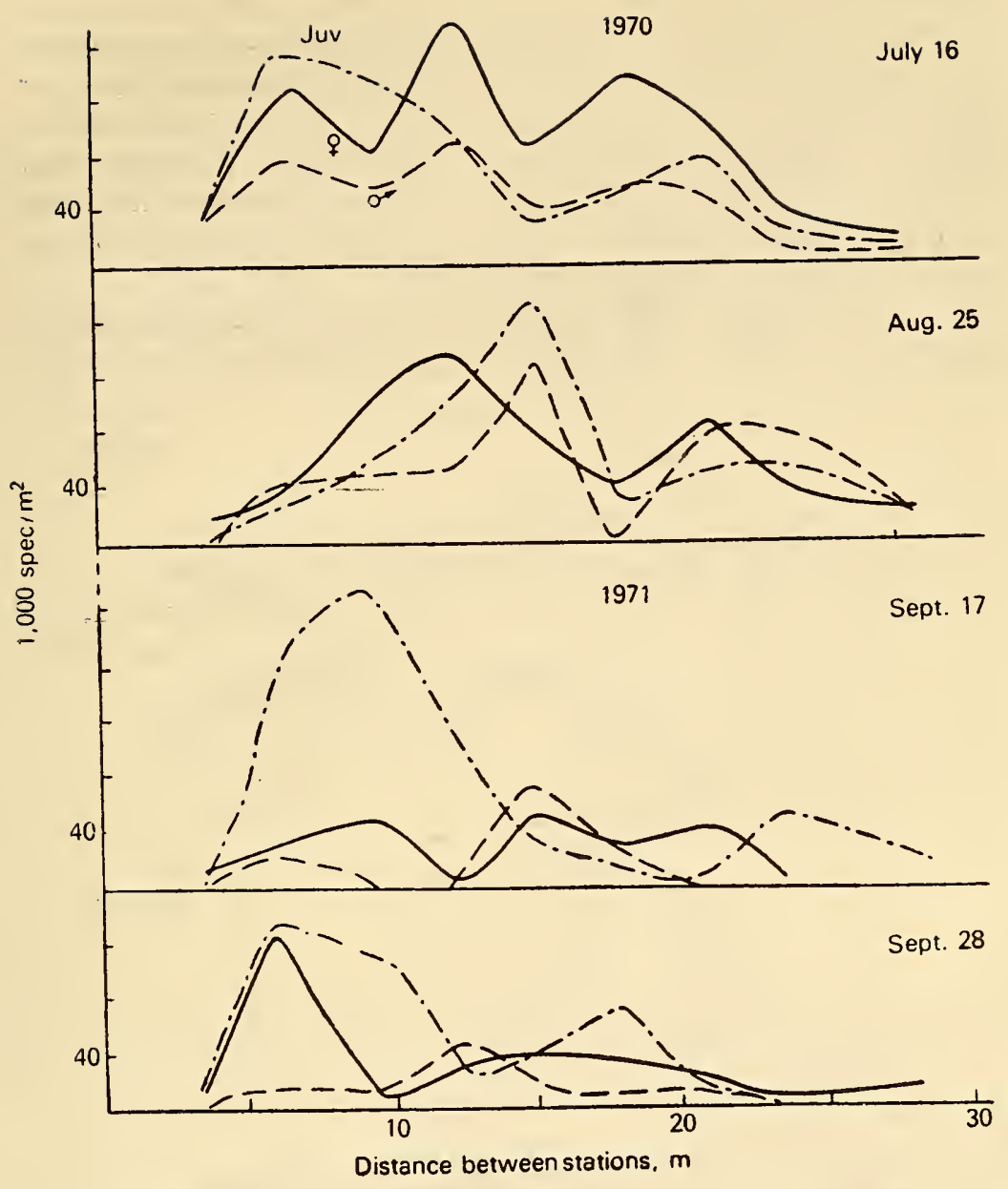

Figure 60. Population dynamics of Anoplostoma rectospiculum during summer of 1970 and autumn of 1971.

niles predominated insignificantly during summer but were maximal at the beginning of August. The maximum total population was recorded in the lower horizon of the littoral zone $(251,960)$. The maximum number of males $(122,930)$ and females $\left(116,330\right.$ specimens $\left./ \mathrm{m}^{2}\right)$ was recorded in the middle of August.

During autumn (as in the case of $A$. rectospiculum) a sharp rise occurred in total population $\left(132,150\right.$ to 238,000 specimens $\left./ \mathrm{m}^{2}\right)$. Juveniles occupied a leading position and reached their maximum in mid-September. Two population peaks were observed in the middle $(414,520)$ and 
lower $\left(363,220\right.$ specimens $\left./ \mathrm{m}^{2}\right)$ horizons of the littoral zone. Later a gradual decline in numbers was observed with a lowering of temperature from $6^{\circ}$ to $3^{\circ} \mathrm{C}$. In October however their population was higher or at least equal to their maximum during summer. Males $(31,400$ to 61,000$)$ and females $\left(18,050\right.$ to 52,400 specimens $\left./ \mathrm{m}^{2}\right)$ were higher in number than in summer. The maximum population in 1971 was recorded in the upper horizon of the littoral zone (females on September 17th-208,780; and males on October 9 th $-207,260$ specimens $/ \mathrm{m}^{2}$ ).

253 Thus, multiplication of the species took place in a wide range of temperatures $\left(2\right.$ to $\left.16^{\circ} \mathrm{C}\right)$ but multiplication was more intense from $2^{\circ}$ to $8^{\circ} \mathrm{C}$

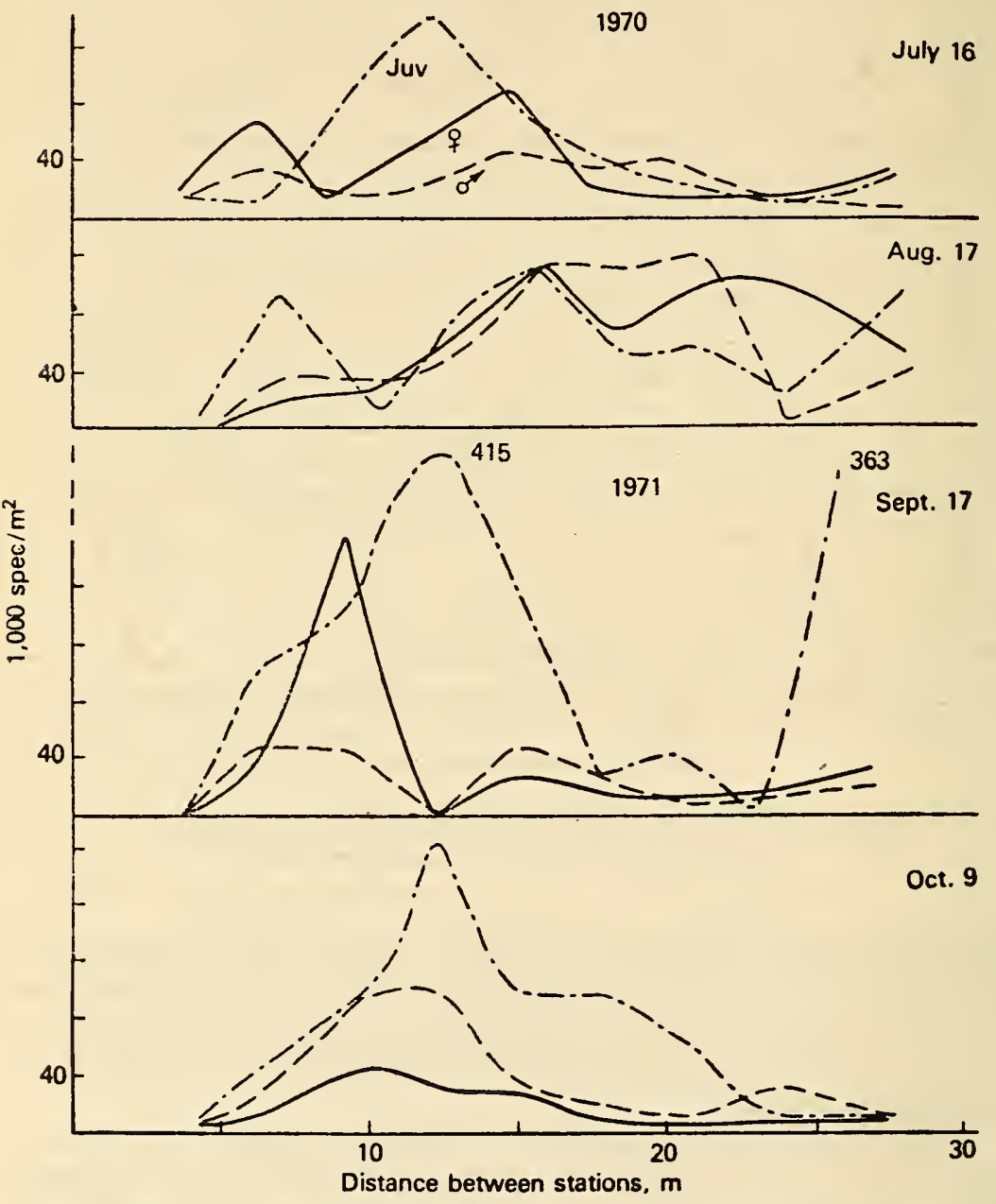

Figure 61. Population dynamics of Paracanthonchus macrodon during the summer of 1970 and autumn of 1971. 
during autumn. This species may be considered arctico-boreal, preferring lower positive temperatures than $E$. demani.

Axonolaimus paraspinosus (Figure 62). The population was high toward the beginning of summer. On July 16, 1970 the maximum population $\left(75,180\right.$ specimens $\left./ \mathrm{m}^{2}\right)$ was recorded in the middle horizon. During August an extremely low population was observed throughout the section. Toward the end of August the average population ranged from 26,920 to 50,000 specimens $/ \mathrm{m}^{2}$. Juveniles slightly dominated in the population throughout the summer season $(14,000$ to 38,600$)$, followed by females $(9,040$ to 33,600$)$, and lastly males $\left(8,270\right.$ to 38,600 specimens $\left./ \mathrm{m}^{2}\right)$.

During autumn a much larger population was observed compared to
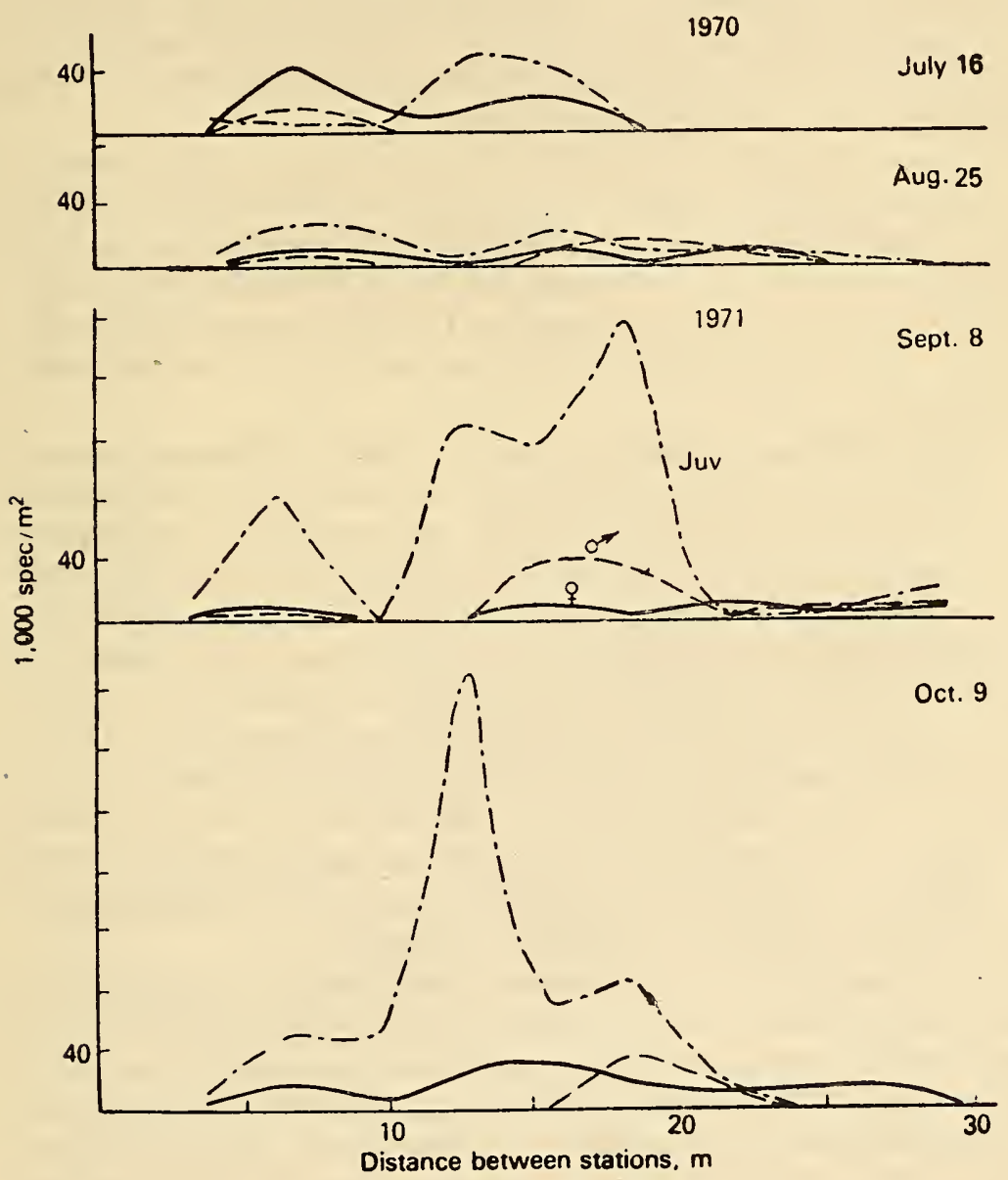

Figure 62. Population dynamics of Axonolaimus paraspinosus during summer of 1970 and autumn of 1971. 
the summer season. In the beginning of September, for example, the average density of population constituted 121,550 specimens $/ \mathrm{m}^{2}$ with a maximum value in the middle horizon of the littoral zone-249,420 specimens $/ \mathrm{m}^{2}$. With a decline in temperature to $5^{\circ}$ to $6^{\circ} \mathrm{C}$ in the middle and at the end of the month, the general population declined (average, 87,800 ). In the month of October a rise in population took place and in the middle horizon a peak occurred $\left(335,280\right.$ specimens $\left./ \mathrm{m}^{2}\right)$. Juveniles 254 predominated in the population with an average density during the season of 41,200 to 94,700 specimens $/ \mathrm{m}^{2}$. The number of females remained almost the same as recorded in 1970 . Males were somewhat more numerous in autumn than in summer $\left(14,400\right.$ to 30,100 specimens $\left./ \mathrm{m}^{2}\right)$. Multiplication of $A$. paraspinosus took place in a wide temperature range ( 2 to $16^{\circ} \mathrm{C}$ ) but more intensely during autumn in a temperature range of $2^{\circ}$ to $8^{\circ} \mathrm{C}$. This species may be placed with arctico-boreal forms, preferring multiplication at low positive temperatures.

Hence I isolated four arctico-boreal species, out of which $E$. demani prefers much higher positive temperatures for multiplication $\left(12^{\circ}\right.$ to $16^{\circ} \mathrm{C}$ ), and $P$. macrodon and $A$. paraspinosus tend toward lower positive temperatures $\left(2^{\circ}\right.$ to $\left.8^{\circ}\right)$. A. rectospiculum is an intermediate form since during summer in a temperature range of 12 to $16^{\circ} \mathrm{C}$ the process of multiplication took place rather intensely but even more so at still lower temperatures.

Hypodontolaimus inaequalis (Figure 63). During the summer season of 1970 the maximum population was recorded in July and August (average ranged from 50,640 to 103,400), which declined toward the end of August and beginning of September to 63,600 to 69,600 specimens $/ \mathrm{m}^{2}$. During the course of July juveniles predominated in the population, mainly in the middle horizon of the littoral zone where, for example, on July 27, 1970 the maximum density was 220,980 specimens $/ \mathrm{m}^{2}$. In early

255 August the proportion of males, females, and juveniles was $1: 1: 1$. From mid-August to the end of the season the juvenile average declined from 31,800 to 14,100 specimens $/ \mathrm{m}^{2}$. The number of males and females throughout the summer season remained about the same (females 16,200 to 30,700 , and males 16,520 to 36,500 specimens $/ \mathrm{m}^{2}$ ). Generally, males were slightly more than females in the population.

During autumn of 1971 the general population of $H$. inaequalis remained approximately the same as during summer (from 51,920 to 86,724 specimens $\left./ \mathrm{m}^{2}\right)$; maximum density occurred in the upper horizon of the littoral zone in mid-September $\left(208,780\right.$ specimens $\left./ \mathrm{m}^{2}\right)$. The population composition qualitatively differed from that in the preceding season; adults predominated in the population and until mid-September the number of males and females was approximately the same. For example, on September 17, 1971, the population density of females throughout the 
section was 26,410 to 104,140 and males 23,360 to 104,640 specimens $/ \mathrm{m}^{2}$. Toward the end of September females predominated in the population, but in October males predominated even though the absolute number of the latter declined compared to September. The juvenile population reduced from 26,600 to 5,920 specimens $/ \mathrm{m}^{2}$ toward the end of September: moreover juveniles were found mainly in the lower horizon of the littoral zone.

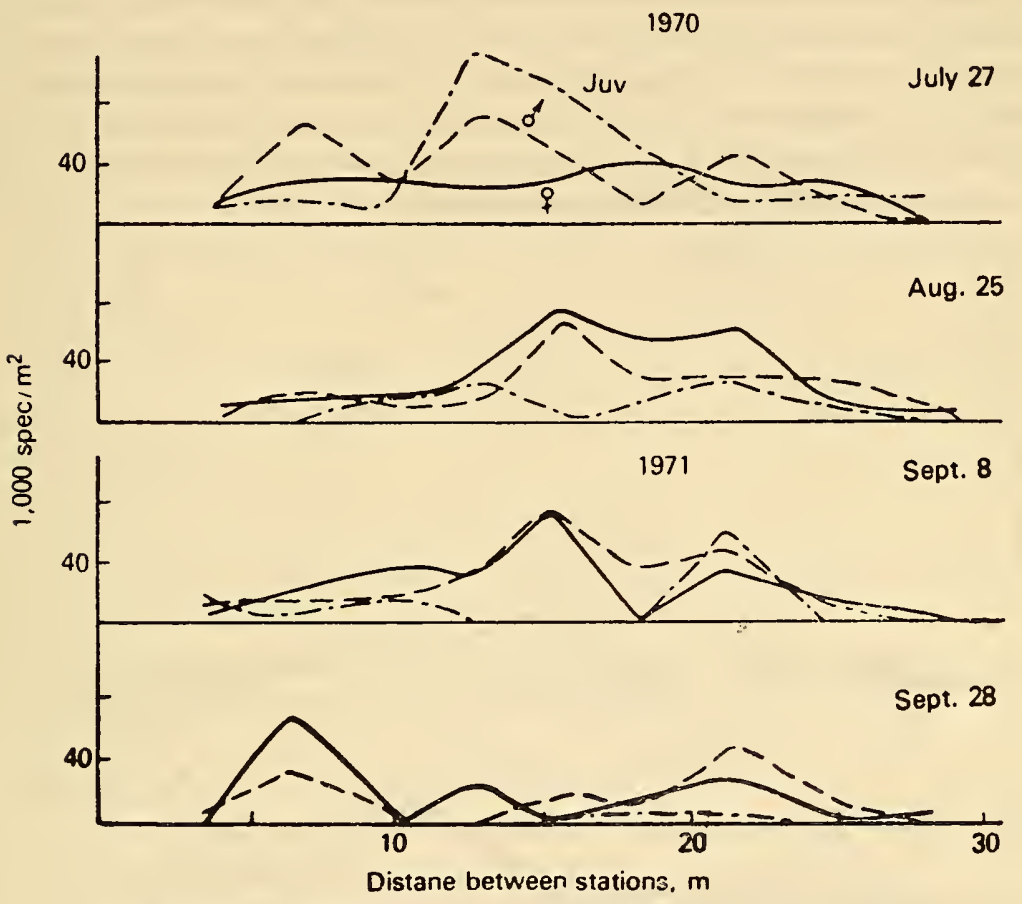

Figure 63. Population dynamics of Hypodontolaimus inaequalis during summer of 1970 and autumn of 1971.

From the pattern of distribution and an analysis of population composition of the species, the inference may be drawn that the process of multiplication takes place at high positive temperatures $\left(8^{\circ}\right.$ to $\left.16^{\circ} \mathrm{C}\right)$. This species prefers the middle horizon of the littoral zone for multiplication. In autumn reproduction was almost nil and only a few juveniles were found in the lower horizon because the process of cooling of water and initial freezing touches the lower horizon later than the upper and middle horizons. Hence this species may be classified as boreal.

Theristus setosus (Figure 64). The general population during the course of July, 1970 was rather high and maximum concentration occurred in the middle and upper strata of the lower horizon of the littoral 
256 zone. For example, on July 16, 1970 the density of species in these areas was 250,900 to 626,870 specimens $/ \mathrm{m}^{2}$. During August and in early September the average declined from 141,450 to 56,560 specimens $/ \mathrm{m}^{2}$. Juveniles distinctly predominated in the population; their maximum density during the season was 574,540 (July 16,1970 ) and occurred in the middle horizon of the littoral zone. In August their absolute number reduced from 88,600 to 23,400 specimens $/ \mathrm{m}^{2}$. The rate of reduction was approximately uniform in density of males and females. The number of males and females from the beginning of July to the beginning of August was approximately equal. The highest density of males and females was observed in the middle and end of August. For example, on August 17, 1970 the maximum number of females was 87,880 specimens $/ \mathrm{m}^{2}$ and of males August 25, 1970-20,100 specimens $/ \mathrm{m}^{2}$.
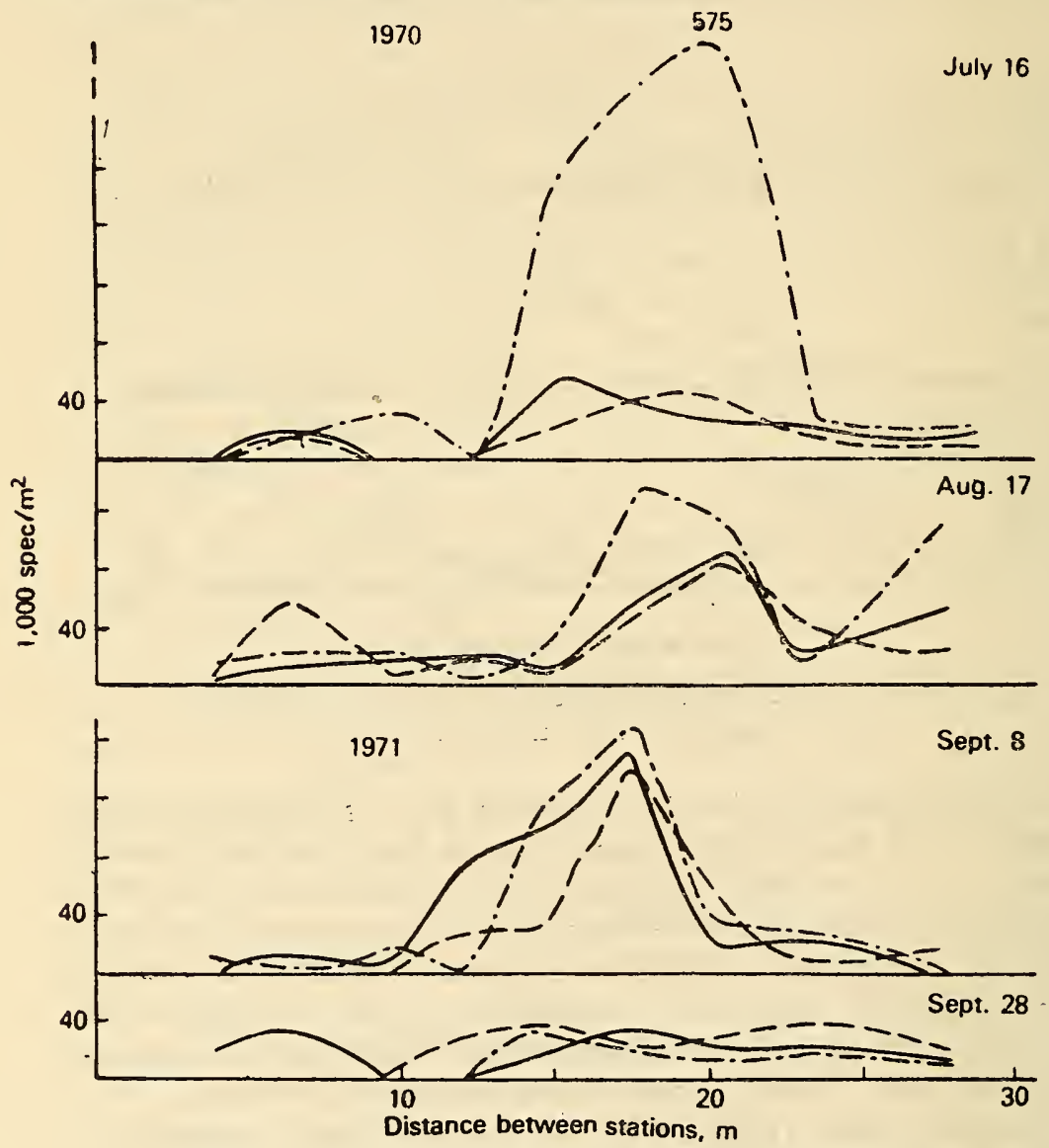

Figure 64. Population dynamics of Theristus setosus during summer of 1970 and autumn of 1971. 
During autumn of 1971, at the beginning of September, the pattern of distribution of males, females, and juveniles was similar to that at the end of summer, 1970, i.e., juveniles predominated but by small numbers (average density, 51,800). The number of females was slightly lower and that of males still lower $\left(42,100\right.$ specimens $\left./ \mathrm{m}^{2}\right)$. Toward the end of September the number of juveniles declined as did the absolute number of males (to 18,800 ) and females (to 18,300 specimens $/ \mathrm{m}^{2}$ ).

In the two seasons a distinct tendency is discernible. Reproduction was intense at the beginning of summer $\left(12^{\circ}\right.$ to $\left.14^{\circ} \mathrm{C}\right)$ but during autumn considerably slowed down, and at low positive temperatures $\left(2^{\circ}\right.$ to $\left.4^{\circ} \mathrm{C}\right)$ almost ceased. $T$. setosus should probably be grouped with boreal species.

Thus, of the seven leading species two proved boreal. In these two species of nematodes the period of appearance of maximum number of juveniles occurred during the summer season at high positive temperatures $\left(8^{\circ}\right.$ to $\left.16^{\circ} \mathrm{C}\right)$. As is known, boreal species living in arctic regions with high temperatures for a short period of the year have a short period of multiplication. The farther south, the longer the period of reproduction because at lower latitudes the period of high positive temperatures is prolonged (Ekman, 1953).

The seven species discussed above can be divided into three groups on the basis of their zoogeographic situation.

1. Arctic species: Timmia acuticauda, with maximum reproduction during autumn in a temperature range of $2^{\circ}$ to $8^{\circ} \mathrm{C}$.

2. Arctico-boreal species: (a) E. demani, preferring higher positive temperatures $\left(12^{\circ}\right.$ to $\left.16^{\circ} \mathrm{C}\right)$ for reproduction.

(b) $P$. macrodon and $A$. paraspinosus multiplying with greatest intensity at low positive temperatures $\left(2^{\circ}\right.$ to $\left.8^{\circ} \mathrm{C}\right)$.

(c) $A$. rectospiculum-intermediate type multiplying well in a wide range of positive temperature $\left(2^{\circ}\right.$ to $\left.16^{\circ} \mathrm{C}\right)$.

3. Boreal species: $H$. inaequalis and $T$. setosus, with maximum reproduction during summer in a temperature range of $8^{\circ}$ to $16^{\circ} \mathrm{C}$.

Such a grouping of species confirms the boreal nature of the littoral zone of the White Sea (Gur'yanova, 1948, 1949). Here Kuznetsov (1947) may be mentioned who conducted winter observations in the upper waters of Kandalaksh Bay. According to his data coastal ice acts as a powerful insulation against severe winter conditions. At the time of ebbtide the ice, without damaging the integrity of the ice cover, sinks to the bottom and, lodging on projecting rocks, forms a sort of roof. Under this roof the temperature remains close to $0^{\circ}$ even at the time of severe freezing. Consequently the littoral zone of the western region of the White Sea remains under more favorable temperature conditions than the littoral zone of the eastern part. During summer the littoral zone warms up very well due to the relatively southern situation of the sea and severe 
insolation. During winters it is not so severely cold due to the ice roof. In terms of temperature conditions this region is very close to boreal. This well confirms my analysis of the nematode fauna. Six of the seven leading species are boreal or arctico-boreal.

\section{Feeding}

Wieser $(1953 \mathrm{a}, 1959)$ proposed the division of marine nematodes into four ecolo-morphological groups on the basis of mode of feeding or nutrition (see p. 56).

Works devoted to the feeding habits of meiofauna are rather scarce. Perkins' work (1958) remains the most important to date; he studied the feeding habits of Turbellaria, Copepoda, and Nematoda. Examining the intestinal contents of a large number of nematodes, Perkins came to the conclusion that nematodes of group 1B (nondiscriminating detritophages) feed on diatoms and bacteria in equal measure. Representatives of group $2 \mathrm{~A}$ include in their ration bacteria and algae that inhabit the bottom. Nematodes of this group procure food by scraping the sandy surface. Nematodes of group 2B feed mainly on bacteria. Regarding this group Perkins differs from Wieser (1953a) who labels these nematodes predators. Perkins found a high percentage of bacteria and diatoms in their intestinal contents. In my opinion this contradiction is reconciled if one acknowledges that nematodes of group $2 \mathrm{~B}$ have a wide nutritional

258 spectrum. As a matter of fact they could well be classed as detritophages but due to inadequacy of food often change over to predation, employing the powerful armature of their oral cavity (I would tentatively classify them as predators).

Organic detritus, various types of microphytobenthos, and bacteria constitute the food base of nematodes and some other groups of meiobenthos (Bruce, 1928; Remane, 1952; Wieser, 1953a; Dahl, 1953; RenaudDebyser and Salvat, 1963; Chitwood and Murphy, 1964; Hopper and Meyers, 1966).

According to the classification given by Wieser the dominant species of the littoral zone of Kruglo'e Bay can be divided into the following groups: 1B-Anoplostoma rectospiculum, Axonolaimus paraspinosus, and Theristus setosus; 2A-Hypodontolaimus inaequalis and Timmia acuticauda; and 2B-Enoplus demani and Paracanthonchus macrodon. The correlation among these during the summer and autumn seasons is shown in Figure 65. Throughout the summer season nondiscriminating detritophages (1B) predominated, with an average population of 225,550 to 425,830 specimens $/ \mathrm{m}^{2}$. At the beginning of summer their population was low, then rose to dominancy, and gradually dwindled to 263,200 toward the end of summer. Predators (2B) were close to the dominating group, 
with an average density of 194,350 to 395,300 specimens $/ \mathrm{m}^{2}$. But a different pattern in population dynamics was evident: lowest at the beginning of summer the population became maximum in midsummer, but declined only slightly at the end of summer. Hence in early September group 2B predominated $\left(319,060\right.$ specimens $\left./ \mathrm{m}^{2}\right)$. Representatives of group $2 \mathrm{~A}$, which feed on overgrowths, came third. Their average population was 91,940 to 172,450 specimens $/ \mathrm{m}^{2}$. In general, nematodes of group $2 \mathrm{~A}$ showed a gradual reduction in population from the beginning of summer to its end.

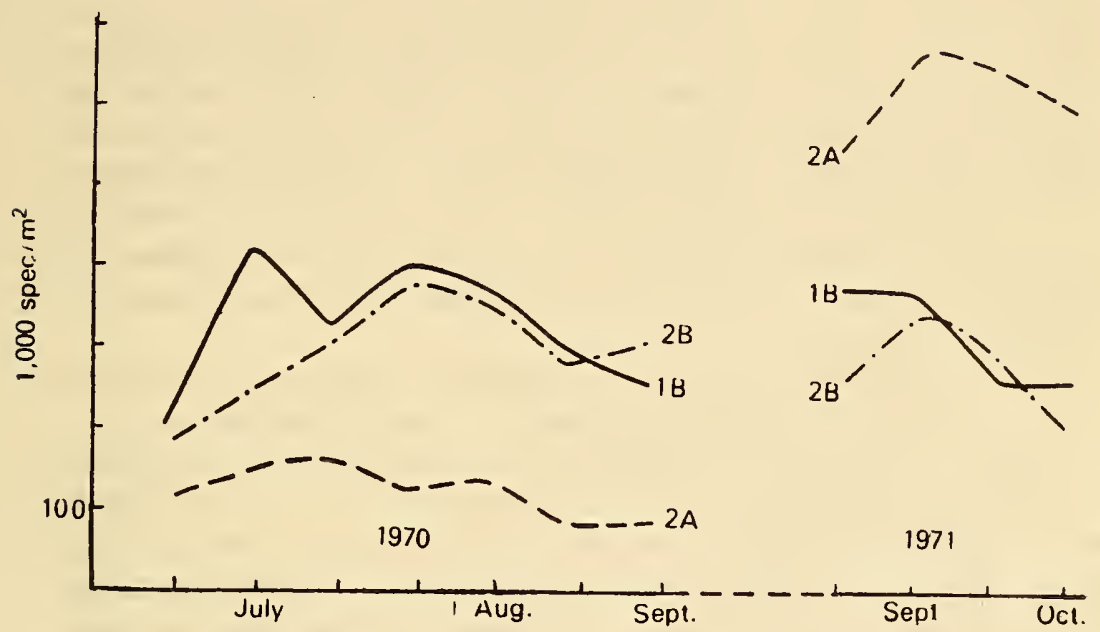

Figure 65. Population variations in groups of nematodes feeding during summer, 1970 and autumn, 1971.

1B-Anoplostoma rectospiculum, Axonolaimus paraspinosus, Theristus setosus; 2A-Hypodontolaimus inaequalis, Timmia acuticauda;

2B-Enoplus demani, Paracanthonchus mocrodon.

In autumn the ratio of nematode groups in Wieser's classification changed. First place was held by group $2 \mathrm{~A}$ with an average population of 560,300 to 684,324 specimens $/ \mathrm{m}^{2}$, i.e., five to six times higher compared to the average population in summer (for reasons see p. 346). The ratio between nondiscriminating detritophages and predators approximated the summer one. At the beginning of autumn detritophages (group 1B) predominated $(380,250)$; by October their population had declined (to 273,060) and was almost the same as that of predators (group 2B), especially in midautumn $\left(281,012\right.$ specimens $\left./ \mathrm{m}^{2}\right)$. The general tendency toward population reduction continued in predators, however, right to the end of autumn. 
Wieser (1953a) correlated the species composition of nematodes from nine main biotopes with the four nutritional types described above. Perkins (1958), using Wieser's classification, observed that on the coast of Uitsteblya* a correlation of nutritional types characteristic of biotopes three and four could be established (third biotope-finely silted sand of the littoral zone with a predominance of group $1 \mathrm{~B}$ and $2 \mathrm{~A}$; fourth biotope-weakly silted sand with predominance of groups $1 \mathrm{~B}$ and $2 \mathrm{~B}$ ).

Looking at my material I found that for slightly silted sand (fourth type of biotope) the correlation mentioned by Wieser and Perkins was possible for summer, but in autumn group $2 \mathrm{~A}$ predominated; the correlation between groups $1 \mathrm{~B}$ and $2 \mathrm{~B}$ showed almost no change during autumn except that at the end of the season their population declined somewhat. From these findings one may conclude that in one and the same biotope different correlations of nutritional groups are likely in different seasons of the year. This is probably due to changes in some factors of the surrounding medium (temperature, food base, etc.). In my study the autumnal development of microphytobenthos helped to increase the population of this group of nematodes, which predominantly feeds on diatomaceous algae.

The distribution of nutritional substances in the littoral zone is a primary factor in controlling the population density of meiofauna.

Organic detritus is an important source of nutrition for meiofauna (especially nematodes). Detritus is irregularly distributed on sandy beaches (Schmidt, 1969; Jansson, 1971). The irregular distribution of nematodes and other groups of meiobenthos might be partially explained by this fact. However, some authors (Ganapati and Rao, 1962; RenaudDebyser, 1963) deny any direct relation between the quantity of detritus and density of meiofauna. This would indicate the utilization of other sources of nutritional substances by meiofauna (Jansson, 1968). A large accumulation of organic debris helps to increase the number of bacteria (Jansson, 1971). Some researchers (Zobell and Anderson, 1936; Zobell and Feltham, 1938; Zobell, 1942; Meadows and Anderson, 1966, 1968), having studied the distribution of bacteria on sandy beaches, arrived at the conclusion that the number of bacteria reaches maximum near the sandy surface in intermediate levels of high and low waters. Matveeva, Nikitina and Chernovskaya (1955) also observed a rise in the content of decay in the midhorizon of the littoral zone (up to 10,000 specimens bacteria/gram ground). All these facts confirm my data nicely, i.e., occurrence of high population of nematodes in the midhorizon of the littoral zone in both seasons $-500,000$ to $1,000,000$ on the average during summer and $1,000,000$ to $2,000,000$ specimens $/ \mathrm{m}^{2}$ during autumn.

*Direct transliteration of Russian; actual geographic place not traceable as Perkins' work not available-Translator. 
Temperature may have an indirect influence on the population dynamics of nematodes. For example, it may stimulate the development of growth of one or the other nutritional substance. Much higher temperatures may facilitate the development of large numbers of bacteria. The predominance of groups $1 \mathrm{~B}$ and $2 \mathrm{~B}$ during summer is obviously related to bacterial development. Autumnal development of microphytobenthos (1971) serves as another example of the indirect influence of temperature. A rapid blooming of phytoplankton and microphytobenthos commences with the onset of cooling during the autumn season (V.S. Shuvalov). The sharp rise in nematode population of group $2 \mathrm{~A}$, reaching $2,000,000$ to $3,000,000$ specimens $/ \mathrm{m}^{2}$ could be attributed to this, since their chief source of nutrition is diatomaceous algae.

As already mentioned, the chief sources of food of nematodes are organic detritus, bacteria, and microphytobenthos. Nematodes in turn serve as food for organisms of a higher trophic level. For some invertebrates nematodes are the primary food item. Crangon crangon feeds on 260 nematodes and harpacticoids (Plagmann, 1939) and Nereis diversicolor feeds on nematodes, copepods, ostracods, and turbellarians (Rees, 1940; Perkins, 1958). Among representatives of meiofauna there are predators which feed on smaller meiofauna. Among nematodes, representatives of genera Halichoanolaimus, Enoplolaimus, Sphaerolaimus, and others may be categorized as predators capable of feeding on each other and also on other organisms of meiofauna such as turbellarians (Remane, 1952; Wieser, 1953b; Chitwood and Timm, 1954). Data on nematodes constituting a dietary item of fish are available (Mironov, 1951; Milovidova, 1961; Bregnballe, 1961; Muus, 1967). According to Gerlach (1971) representatives of meiofauna constitute not less than $15 \%$ of the food utilized by different groups of organisms. In summarizing the little data available

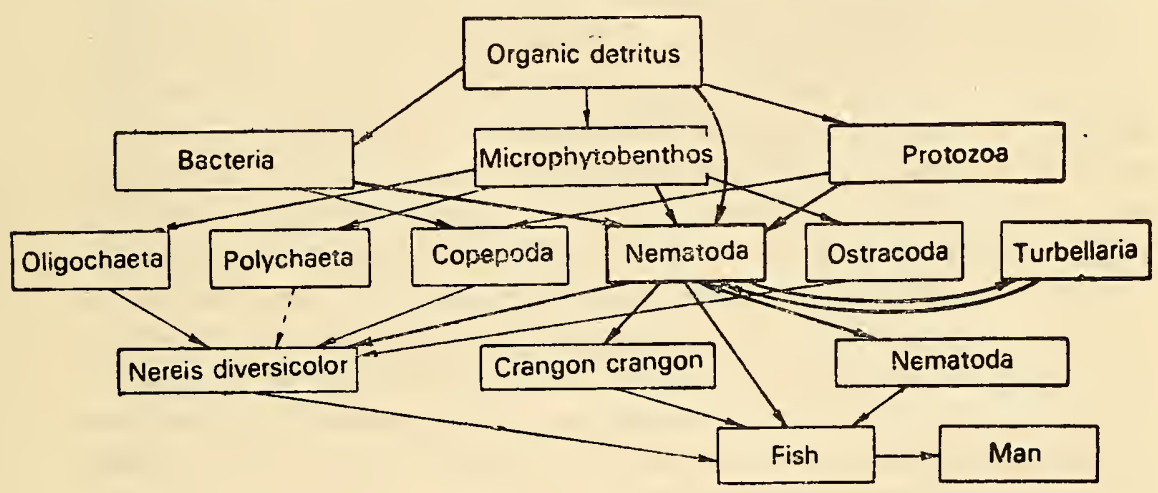

Figure 66. Scheme of food chain of major groups ${ }^{-}$(from data of Plagmann, 1939; Rees, 1941; Perkins, 1958; and others). 
on the feeding of nematodes and some other groups of meiofauna, a simplified scheme of trophic relation of nematodes with other groups of animals can be drawn (Figure 66). Obviously, meiobenthos (nematodes included) constitutes to some extent an intermediate link between microand macrobenthos, accumulating and processing minute food particles, which if directly utilized by macroforms would be disadvantageous from the point of view of energetics (Kiseleva, 1965). Gilyarov (1944) has also noted that extremely fine food does not justify the energy expended on its procurement.

Taking into account the large number of nematodes and the great speed of their multiplication, it may be construed that they play an important role in the energetic processes occurring in the sea.

\section{Salinity}

Because of the rivers emptying into the White Sea its salinity drops from 22 to $25 \%$ (Gur'yanova, 1948; Chernovskaya, 1956, 1958). As observed by Chernovskaya, the littoral zone of the White Sea is characterized by high salinity during high tide and rather low during ebbtide.

During the two seasons studied I assessed the salinity of waters of the littoral zone of Kruglo'e Bay every three to five days (Figure 67). During the spring-summer period of 1970 salinity was 9.5 to $24.8 \%$. In July the salinity was 20 to $21 \%$. Probably the surface drainage of fresh water influenced the saline value (Chernovskaya, 1956). From August 10 to 15 a considerable drop in salinity of water of the littoral zone occurred due to heavy rains. Later, during the second half of August and in early September, salinity rose to $24.0 \%$ and remained approximately at this level until the end of my observations (October 8th). In other words, in autumn the average value of salinity rose by 2.0 to $3.0 \%$. During autumn of 1971 the salinity ranged from 4.3 to $25.6 \%$. Such a wide range of fluctuation in salinity is apparently due to dilution effected by streams

261 draining into Kruglo'e Bay as a result of heavy autumnal rains. This was particularly notable at the end of September. In early October the streams froze and the salinity of coastal waters increased from 21.2 to $25.6 \%$. Chernovskaya (1956) has also reported a general rise in salinity of littoral waters of the White Sea at the end of September and in early October.

Thus the following generalizations can be drawn with regard to changes in salinity of littoral waters of the region under investigation. A drop in salinity characterizes the beginning of summer (July), an increase of 2.0 to $3.0 \%$ in the middle and end of summer, and a most unstable regime in the beginning of autumn.

Looking at Figure 68, it can be stated that fluctuations in salinity had practically no effect on the nematode population. For example, the 


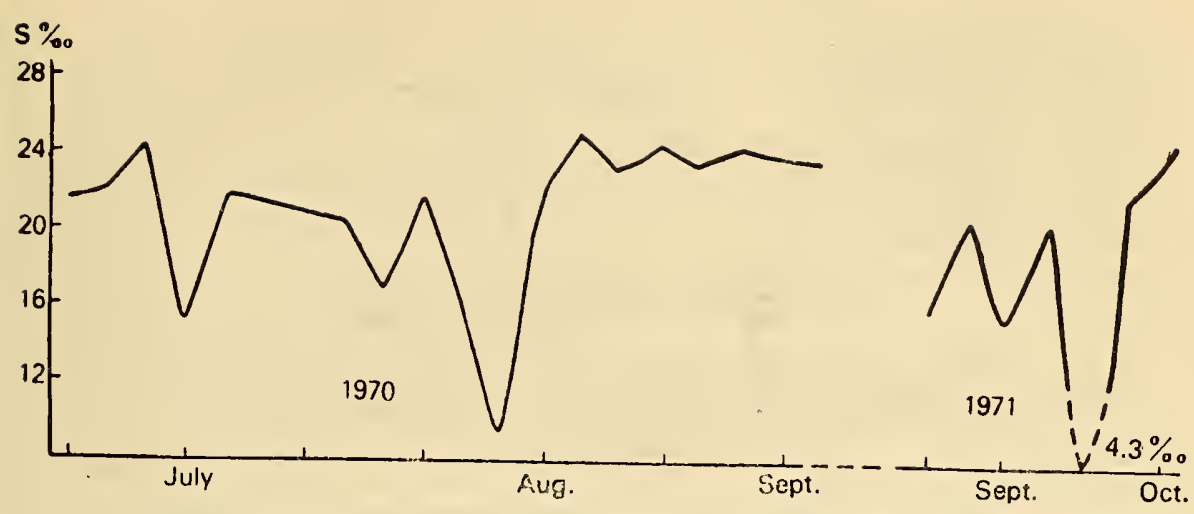

Figure 67. Changes in salinity of water of the littoral zone in Kruglo'e Bay during summer and autumn seasons.

highest average density $\left(980,000\right.$ specimens $\left./ \mathrm{m}^{2}\right)$ corresponded to the lowest average salinity $(16.0 \%$ ) on August 17,1970 . Had there been some correlation between salinity and nematode population, reduction in salinity should have caused a corresponding reduction in the latter. This was never seen. Hence one may conclude that the nematode population in no way depends on variations in salinity of coastal waters. What could be the reason for this phenomenon?

The problem of effect of salinity on aquatic animals has been studied by the German researcher Kinne (1964a, 1964b, 1966). It is known that salinity of interstitial waters is governed to a significant degree by high and low tides. Hence, quite a large number of studies have been done on the salinity of water in regions covered by high and low tides (Gur'ya262 nova and Ushakov, 1927; Bruce, 1928a; Gur'yanova, Zaks and Ushakov, 1930a, 1930b; Linke, 1939; Chernovskaya, 1948, 1956, 1957, 1958; Münch and Perzold, 1956; Ganapati and Rao, 1962; Renaud-Debyser, 1963; Salvat, 1964; Ax, 1966; Govindankutti and Nair, 1966; Jansson, 1967; Johnson, 1967; Fenchel, Jansson and Thun, 1967). It would seem that overlying waters of the littoral zone should be subject to extensive changes in salinity. However, even during spring in the period of ice melt or during autumn in the season of heavy rains, salinity remains fairly high. This is explained by the capacity of the bed to retain denser water. This capacity to retain water increases from a coarser to a silty bottom (Bruevich, 1946). In conditions of a minutely granular ground the salinity of interstitial water is on the average higher than the salinity of overlying water of the littoral zone (Gerlach, 1954; Chernovskaya, 1958; Ganapati and Rao, 1962; Jansson, 1967, Johnson, 1967; McIntyre, 1968; Barnett, 1968). Jansson (1967b, 1968) established the existence of a permanent gradient of salinity in the ground for a prolonged period of time. The 


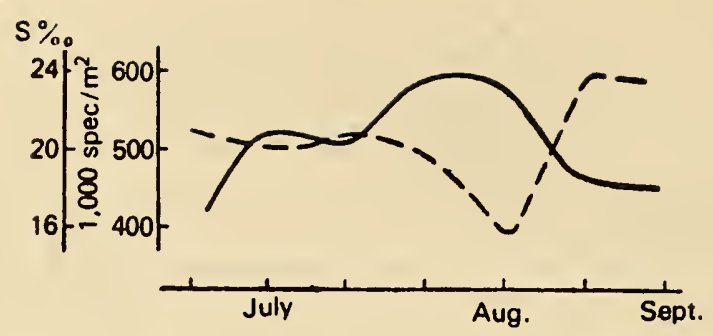

Figure 68. Change in average salinity and average number of nematodes in summer of 1970 (broken line-salinity, and thick line-number of nematodes).

capacity of the ground to preserve a relatively high salinity at ebbtide is the most important factor in the life of littoral organisms living in grounds subject to considerable dilutions (Chernovskaya, 1958). Meiofauna thus exists in more favorable conditions of salinity than epifauna or pelagic forms of shallow waters.

On silted grounds where salinity of interstitial waters of the upper $2.0 \mathrm{~cm}$ depends mainly on the salinity of overlying waters, variations may be significant (Smith, 1956; Barnett, 1968). For this reason littoral organisms inhabiting these beaches are capable of tolerating considerable changes in salinity. In this context the problem arises about the capacity of meiofauna living in the littoral zone to tolerate great fluctuations in salinity. Capstick (1959) has recorded a great toleration in nematodes with respect to a wide range of salinity. Such a capacity to tolerate notable fluctuations in salinity has been demonstrated experimentally for a number of other groups of meiofauna-Turbellaria (Jansson, 1968) and Harpacticoida (Jansson, 1967b, 1968) for example.

With reference to my material, the small degree of influence of salinity on the population of nematodes could be explained in two ways:

a) Capacity of interstitial waters to retain a much higher salinity than coastal waters;

b) Capacity of marine nematodes to tolerate great variations in salinity.

\section{Conclusions}

262 One to two samples from one square meter can yield with $75 \%$ accuracy the real population pattern of meiofauna in a given area in the littoral zone.

Chislenko's divider, which expedites counting of organisms of meio- 
benthos, can be recommended for compartmental processing of the sample. The error in estimating number of organisms in the entire sample, using the divider, does not exceed 1.4 to 1.5. The lower limit of the absolute number of organisms for which such an error is not significant, is 100 individuals. Distribution of organisms in the sectors of the divider may be considered equally reliable, ignoring the slight differences in size of compartments. The order of selection of organisms from compartments does not affect the end results. To obtain more accurate data an auxiliary divider for stirring the samples may be utilized.

In the summer season of 1970 and the autumn season of 1971 the following groups of meiobenthos were found in the littoral zone of 263 Kruglo'e Bay: eumeiobenthos-Foraminifera, Nematoda, Harpacticoida, and Turbellaria; pseudomeiobenthos-Oligochaeta, Polychaeta, and juveniles of mollusks Bivalvia and Gastropoda. The population of the entire meiobenthos during the summer season ranged from 70,600 to $2,524,760$ specimens $/ \mathrm{m}^{2}$ and the biomass from 0.7 to $576.2 \mathrm{~g} / \mathrm{m}^{2}$; during autumn the population ranged from 141,730 to $6,283,960$ specimens $/ \mathrm{m}^{2}$ and the biomass from 3.1 to $115.7 \mathrm{~g} / \mathrm{m}^{2}$.

During the two seasons selected for investigations an irregularity of distribution of meiofauna in the littoral zone was observed. Meiofauna of the middle horizon was the richest and that of the lower horizon the poorest. One possible reason for this phenomenon could be the irregular distribution of food material. Eumeiobenthos constituted 80 to $95 \%$ of the total meiofauna population.

The leading group of meiobenthos consisted of free-living marine nematodes. Their population during the summer of 1970 ranged from 4,570 to $1,778,000$ specimens $/ \mathrm{m}^{2}$ and the biomass from 0.6 to $264.6 \mathrm{~g} / \mathrm{m}^{2}$; during autumn of 1971 the population ranged from 77,720 to $6,156,900$ specimens $/ \mathrm{m}^{2}$ and the biomass from 10.0 to $861.0 \mathrm{~g} / \mathrm{m}^{2}$.

During the summer season shifts in population maxima were seen. In July to early August the population peak shifted from the middle horizon of the littoral zone to the lower stratum of the upper horizon; from midAugust the population peak reversed, i.e. toward the lower horizon of the littoral zone. During autumn the population peak shifted from the lower and middle horizons of the littoral zone to the upper horizon, and a sharp rise in population was observed in the latter from 200,000 to $6,000,000$ specimens $/ \mathrm{m}^{2}$.

An examination of the White Sea material revealed 76 species of nematodes; 35 were found in the littoral zone. Brief descriptions of 22 fairly common species have been given and more detailed descriptions of 13 species new to science.

Of the 35 species recorded during both seasons, 7 predominated: Timmia acuticauda, Anoplostoma rectospiculum, Axonolaimus paraspinosus, 
Enoplus demani, Paracanthonchus macrodon, Hypodontolaimus inaequalis, and Theristus setosus. The highest population observed during summer comprised $E$. demani, $H$. inaequalis, and $T$. setosus. A rapid increase in population density was observed for $T$. acuticauda, $A$. paraspinosus, and $P$. macrodon during the autumn season. Population density was approximately the same for $A$. rectospiculum during the summer of 1970 and the autumn of 1971.

Except for T. acuticauda, almost all the leading species of nematodes preferred the middle horizon of the littoral zone for habitations in both summer and autumn. E. demani, P. macrodon, and T. setosus also revealed rapid increases in population in the lower horizon of the littoral zone. $T$. acuticauda, A. rectospiculum, and A.paraspinosus revealed a high density of population during autumn in the upper horizon of the littoral zone. One may speak of "selectivity of habitats" among species in the littoral zone during different seasons.

A direct relation between density of all nematodes or individual species and size of particles of the sediment in which they live could not be established.

The limiting factor influencing the distribution of most nematode species is the minimal diameter of the capillaries in which they exist (in my study, from 20 to $80 \mu \mathrm{m}$ ). Such a diameter of capillaries suffices for the habitation of $M$. filicauda, A. rectospiculum, $T$. acuticauda, $P$. macrodon, $T$. flevensis, and others. $H$. inaequalis and $T$. setosus are capable of widening the minimal capillary passages. The presence of minimal capillary diameters exerts little influence on the distribution of $E$. demani, which actively constructs the minimal space essential for its life. On the basis of this a criterion for the upper limit of meiobenthos has been suggested, namely, the capacity of organisms to inhabit minimal capillary passages.

Of the seven species examined on the basis of temperature optimum for reproduction, three groups can probably be identified on the basis of zoogeographic affinities:

1. Arctic species: $T$. acuticauda with maximum reproduction in the temperature range of 2 to $8^{\circ} \mathrm{C}$.

2. Arctico-boreal species: $E$. demani, preferring high positive temperatures for multiplication; $P$. macrodon and $A$. paraspinosus, multiplying intensely during autumn at low positive temperatures $\left(3\right.$ to $\left.8^{\circ} \mathrm{C}\right)$; and $A$.

264 rectospiculum, an intermediate type in which the process of reproduction takes place at both high and low positive temperatures.

3. Boreal species: $H$. inaequalis and $T$. setosus, with maximum reproduction during summer in a temperature range of $8^{\circ}$ to $16^{\circ} \mathrm{C}$.

An analysis of the leading species of nematodes confirmed the boreal character of the littoral zone of the White Sea. 
During summer, 1970 nondiscriminating (omnivorous) detritophages predominated in the littoral zone of Kruglo'e Bay (1B). Predators (group 2B) came next, while the density of "eaters" of overgrowths (2A) was low. During autumn, 1971 the predominant position was held by the latter group. The ratio between detritophages and predators remained approximately the same as during summer. Thus in one and the same biotope different ratios of nutritional types (groups) of nematodes were observed. This is probably related to changes in some factors of the surrounding medium (temperature, quantity and distribution of food substances, and others).

The high population of nematodes in the middle horizon of the littoral zone during both seasons can be explained by the presence of a rich food base here, namely, bacteria. The autumnal population increase of "eaters" of overgrowths (T. acuticauda) is associated with the vigorous development of microphytobenthos.

Interstitial waters are capable of retaining a higher salinity over a prolonged period than coastal waters. Free-living nematodes are euryhaline and tolerate wide variations in salinity. Considering these two factors it can be stated that the influence of salinity on the population dynamics of nematodes is negligible.

Considering the vast population of meiofauna, the paucity of taxonomic and ecological studies of its many groups, and the great role played by representatives of meiobenthos in the energetic processes of the sea, one hopes that hydrobiologists will soon be motivated to raise the level of study of meiobenthos to that achieved for macrobenthos. 


\section{References}

264- Agamaliev, F.G. 1967. Materialy po ekologii infuzorii mesopsammona 270 zapadnogo poberezhya Kaspiiskogo morya (Data on infusorian mesopsammon of the western coast of the Caspian Sea). Dokl. AN SSSR, $176,60,1425-1427$.

Allgen, C.A. 1929. Neue freilebende marine Nematoden von der Westküste Schweden, Zool. Jahrb. (Abt. Syst.), 57, 5, 431-496.

Allgen, C.A. 1933. Freilebende Nematoden aus dem Trondheimsfjord, Capita Zool., 4, 2, 1-162.

Allgen, C.A. 1954. Das Bipolaritäts problem freilebender mariner Nematoden, Det Kongelige Norske Videnskab. Selskab. Forhandl. (1953), 26, 8, 28-35.

Allgen, C.A. 1957. Vergleich zwischen den marinen Nematodenfaunen Norwegens und der Tropen, Det Kongelige Norske Videnskab. Selskab. Forhandl. (1956), 29, 9-10, 36-46.

Angelier, E. 1953. Recherches écologiques et biogeographiques sur la fauna des sables, Arch. Zool. Expérim. et Generale, vol. 90, fasc. 2, pp. 37-161. Paris.

Arnol'di, L.V. 1940. Novye dannye po kolichestvennomu uchetu mikrobentosa (New data on the quantitative estimation of microbenthos). Ref. Rabot Uchrezhdenii Otd. Biol. Nauk AN SSSR, za 1940-1941, p. 210.

Ax, P. 1966. Die Bedeutung der interstitiellen Sandfauna für allgemeine Probleme der Systematik, Ökologie und Biologie (6 Meeres biol. Symp., 18-20 Okt., 1965, Bremerhaven), Veröff. Inst. Meeresforsch. Bremerh. Sonderbd. 2, pp. 15-65.

Barnett, P.R.O. 1968. Distribution and ecology of Harpacticoid Copepoda of an intertidal mud flat, Internat. Rev. Ges. Hydrobiol., 53, 2, 177-209.

Bastian, Ch. 1865. Monograph on Anguillulidae or free-living marine, land, and fresh-water nematodes, Trans. Linn. Soc., vol. 25, pp. 73-184. London.

Belogurov, I. and N.I. Koroleva. 1970. Kolichestvennoe raspredelenie svobodnozhibushchikh morskikh nematod na litorali bukhty Tronitsy v zavisimosti ot nekotoryikh ekologicheskikh uslovii (Quantitative distribution of free-living marine nematodes in the littoral zone of Tronitsa Bay in relation to some ecological conditions). In Biologicheskie Protsessy v Morskikh $i$ Kontinental'nykh Vodoemakh. Izd. AN MoldSSR, Kishinev, p. 41.

Belogurova, L.S. 1970. O kolichestvennom raspredelenii meiobenthos na litorali ostrova Shikotan (Quantitative distribution of meiobenthos 
in the littoral zone of Shikotan Island). In Biologicheskie Protsessy $v$ Morskikh i Kontinental'nykh Vodoemakh. Izd. AN MoldSSR, Kishinev, p. 40.

Bougis, B. 1946. Analyse quantitative de la microfauna d'une vase marine à Banyuls, Compt. Rend. Hebd. Séanc. Acad. Sci., vol. 222, pp. 1122-1124. Paris.

Bougis, B. 1950. Méthode pour l'étude quantitative de la microfaune des fonds marins (Meiobenthos), Vie et Milieu, 1, 1, 23-38.

Bregnballe, F. 1961. Place and flounder as consumers of microscopic bottom fauna, Medd. Dan. Fisk. Havunders, vol. 3, pp. 132-182.

Brotskaya, V.A. 1950. Mikrobentos littorali Belogo morya (Microbenthos of the littoral zone of the White Sea). Tr.Vses. Gidrobiol. Ob-va, vol. 3, pp. 179-193.

Bruce, I.R. 1928. Physical factors of a sandy beach. Part I: Tidal, climatic, and edaphic; Part II: Chemical changes, J. Mar. Biol. Ass., vol. 15, pp. 535-565. U.K.

Bruevich, S.V. 1937. Gidrokhimiya srednogo i yuzhnogo Kaspiya (po rabotam 1934 g.) [Hydrochemistry of the Central and Southern Caspian Sea (Studies of 1934)]. Izd. AN SSR, 352 pp. Moscow.

Bruevich, S.V. 1946. Solenost' gruntovykh rastvorov Kaspiiskogo morya (Salinity of ground solutions of the Caspian Sea). Dokl. AN SSSR, $54,3,239-243$.

Bruevich, S.V. and S.N. Demenchenok. 1944. Instruktsiya po proizvodstvu khimicheskikh issledovanii morskoi vody (Instruction Manual for Chemical Studies of Sea Water). Izd. Glavsevmorputi, $84 \mathrm{pp}$.

Burkovskii, I.V. 1969. Kolichestvennye dannye o raspredelenii psammofil'nykh infuzorii po gruntam i gorizontam litorali i sublitorali Velikoi Salmy (Quantitative data on the distribution of psammophilic infusoria along the grounds, littoral zone, and sublittoral zone of the Great Salmya). Okeanologii, 9, 5, 874-880.

Bütschli, O. 1874. Zur Kenntnis der freilebenden Nematoden, insbesonders der des Kieler Hafens, Abh. Senckenberg. Naturf. Ges. Frankfurt a. Main, vol. 9, pp. 237-368.

Capstick, C.K. 1959. The distribution of free-living nematodes in relation to salinity in the middle and upper reaches of the Blyth River estuary, J. Anim. Ecol., 28, 2, 189-210.

Chernovskaya, E.N. 1956. Gidrologicheskie i gidrokhimicheskie usloviya na litorali vostochnogo Murmana i Belogo morya (Hydrological and Hydrochemical Conditions in the Littoral Zones of Eastern Murmansk and the White Sea). Izd. AN SSSR, Moscow-Leningrad, $113 \mathrm{pp}$.

Chernovskaya, E.N. 1957. O gidrokhimicheskikh osobennostyakh pribrezhnoi zone Vostochnogo Murmana (Hydrochemical properties 
of the coastal zone of eastern Murmansk). Tr. Murmanskoi Biol.St., vol. 3, pp. 33-52.

Chernovskaya, E.N. 1958. Nekotorye dannya po khimizmu gruntovykh rastvorov litorali Vostochnogo Murmana (Some data on the chemism of ground waters of the littoral zones of eastern Murmansk). Tr. Murmanskoi Biol. St., vol. 4, pp. 7-17.

Chernovskaya, E.N., P.P. Voronkov and N.S. Uralov. 1948. Osnovnye cherty gidrokhimicheskogo rezhima pribrezhnoi zone Murmana (Main features of the hydrochemical regime of the coastal zone of Murmansk). Tr. Murmanskoi Biol. St., vol. 1, pp. 39-101.

Chislenko, L.L. 1961. Rol' Harpacticoida v biomasse mezobentosa nekotorykh biotopov fitali Belogo morya (Role of Harpacticoida in the biomass of mesobenthos of some phytolittoral biotopes of the White Sea). Zool. Zhurn., 40, 7, 983-996.

Chislenko, L.L. 1965. Kolichestvennoe raspredelenie Harpacticoida na nekotorykh biotopakh fitali melkovod'ya Belogo morya (Quantitative distribution of Harpacticoida in some phytolittoral biotopes in shallow waters of the White Sea). In Voprosy Gidrobiologii. Izd. Nauka, Moscow, vol. 1, pp. 448-450.

Chislenko, L.L. 1967. Garpaktitsidy (Copepoda, Harpacticoida) Karelskogo poberezh'ya Belogo morya [Harpacticoids (Copepoda) of the Karelian coast of the White Sea]. In Issledovaniya Fauny Morei SSSR. Izd. Nauka, Leningrad, vol. 7, pp. 48-96.

Chislenko, L.L. 1968. Nomogrammy dlya opredeleniya vesa vodnykh organizmov po razmeram i forme tela (morskoi mezobentos i plankton) [Nomograms for Determination of Weight of Aquatic Organisms on the Basis of Size and Shape of Body (Marine Mesobenthos and Plankton)]. Izd. Nauka, Leningrad, $106 \mathrm{pp}$.

Chitwood, B.G. and D.G. Murphy. 1964. Observations on two marine monhysterids-their classification, cultivation, and behavior, Trans. Amer. Micr. Soc., vol. 83, pp. 311-329.

Chitwood, B.G. and R.W. Timm. 1954. Free-living nematodes of the Gulf of Mexico. Gulf of Mexico, its origin, waters, and marine life, Fishery Bull. Fish Wildl. Serv., 55, 89, 313-325. U.S.

Cobb, N.A. 1891. Arabian nematodes, Proc. Linn. Soc., vol. 5, pp. 449468. New South Wales.

Cobb, N.A. 1920. One hundred new nemas, Contrib. Sci. Nematology, no. 9, pp. 217-343.

Cobb, N.A. 1933. New nemic genera and species with taxonomic notes, J. Parasitol., 20, 2, 81-94.

Coninck, L. de and J.H. Schuurmans-Stekhoven. 1933. Free-living marine nemas of the Belgian coast, with general remarks on the structure and system of nemas, Mém. Mus. Roy. Hist. Nat., vol. 58, pp. 1-163. Belgium. 
Coull, B.C. 1970. Shallow-water meiobenthos of the Bermuda Platform, Oecologia, vol. 4, pp. 325-367. Berlin.

Craib, J.S. 1965. A sampler for taking short, undisturbed marine cores, J. Cons. Perm. Int. Explor. Mer., vol. 30, pp. 34-39.

Dahl, E. 1953. Some aspects of the ecology and zonation of fauna on sandy beaches, Oikos, vol. 4, pp. 1-27.

Davant, P. and B. Salvat. 1961. Recherches écologiques sur la microfauna intercotidale du bassin d'Arcachon. I. La milieu physique, Vie et Milieu, vol. 12, fasc. 3, pp. 405-472.

Dekhtyar, M.N. 1969. Mikro- i mezobentos vodoemov Kiliiskoi delty Dunaya (sostav kolichestvennaya kharakteristika i ekologicheskaya organizatsiya) [Micro- and mesobenthos of water reservoirs of Kiliisk delta of the Danube River (composition of quantitative characters and ecological organization)]. Avtoref. Kand. Diss., Dnepropetrovsk, Kiev, 15 pp.

Delamare Deboutteville, C. 1960. Biologie des eaux souterraines littorales et continentales. Herman, Paris, $740 \mathrm{pp}$.

Ditlevsen, H. 1919. Marine free-living nematodes from Danish waters, Vid. Medd. Dansk. Natur. Foren., vol. 70. pp. 147-214.

Dujardin, F. 1845. Histoire naturelle des helminthes ou vers intestinaux. Roret, Paris, $654 \mathrm{pp}$.

Dzyuban, N.A. 1968. Rekomendatsii po metodike kolichestvenogo ucheta presnovodnykh bespozvonochnykh (Recommendations for the Method of Quantitative Estimation of Fresh-Water Invertebrates). Izd. AN SSSR, Leningrad, $22 \mathrm{pp}$.

Ekman, S. 1953. Zoogeography of the Sea. Sidwick and Jackson, London, $417 \mathrm{pp}$.

Fast, A.M. 1970. An evaluation of the efficiency of zoobenthos separation by sugar flotation, Progr. Fish-Cult., 32, 4, 212-216.

Fenchel, T. 1967. Ecology of marine microbenthos. I. Quantitative importance of ciliates compared with metazoans in various types of sediments, Ophelia, vol. 4, pp. 121-137.

Fenchel, T. and B.O. Jansson. 1966. Vertical distribution of microfauna in the sediments of a brackish-water beach, Ophelia, vol, 3, pp. 161177.

Fenchel, T., B.O. Jansson and W. Thun. 1967. Vertical and horizontal distribution of metazoan microfauna and some physical factors in a sandy beach in the northern part of Oresund, Ophelia, vol. 4, pp. 227-243.

Filip'ev, I.N. 1916. Svobodonozhivushchie nematody kollektsii Zoologicheskogo Muzeya Imperatorskoi Akademii Nauk (Free-living nematodes in the collection of the Zoological Museum of the Imperial Academy of Sciences). Ezheg. Zool. Muz. Imp. AN, vol. 21, pp. 59-116. 
Filip'ev, I.N. 1918-1921. Svobodnozhivushchie morskie nematody okrestnostei Sevastopolya (Free-living marine nematodes in the environs of Sevastopol'). Tr. Osoboi Zool. Lab. i Sevastopolskoi Biol. St. Ross., $A N$, ser. 2, no. 14 , issue $1-2,614$ pp.

Filip'ev, I.N. 1922. Novye dannye o svobodnykh nematodakh Chernogo morya (New data on free-living nematodes of the Black Sea). Tr. Sevastopol. S.-Kh. Inst., 1, 16, 184.

Filipjev, I.N. [Filip'ev, I.N.]. 1927. Les nématodes libres des mers septentrionales appartenant à la famille des Enoplidae, Arch. Naturgesch., 91, 1 (1925), 6, 216.

Filipjev, I.N. [Filip'ev, I.N.]. 1934. Classification of free-living nematodes and their relation to parasitic nematodes, Smiths. Misc. Coll., $89,6,1-63$.

Foster, G.R. 1953. A new dredge for collecting burrowing animals, $J$. Mar. Biol. Assoc., vol. 32, pp. 193-198. U.K.

Frolov, Yu.M. 1971. Nablyudeniya nad chislennost'yu nematod i meiobentos peschanoi litorali $\mathrm{v}$ letnye mesyatsy (Observations on the nematode population and meiobenthos of the sandy littoral zone during the summer months). In Ekologia Morskikh Organizmov. Izd. MGU, pp. 89-90.

Frolov, Yu.M. 1972. K fauna svobodnozhivushchikh nematod Belogo morya (Free-living nematodes of the White Sea). In Kompleksnye Issledovaniya Prirody Okeana, issue 2, pp. 254-256.

Gal'tsova, V.V. 1971a. Kolichesvennyi uchet meiobentosa (Quantitative estimation of meiobenthos). Gidrobiol. Zhurn., 7, 2, 132-136.

Gal'tsova, V.V. 1971b. Kolichestvennaya kharakteristika meiobentosa Chupinskoi guby Belogo morya (Quantitative characters of the meiobenthos of Chupa Inlet of the White Sea). Zool. Zhurn., 50, 5, 641647.

Ganapati, P.N. and C.O. Rao. 1962. Ecology of interstitial fauna inhabiting the sandy beaches of Waltair coast, Journ. Mar. Biol. Assoc. India, vol. 4, pp. 44-57.

Gerlach, S.A. 1951a. Nematoden aus der Familie der Chromadoridae von den deutscher Küsten, Kieler Meeresforsch, vol. 8, pp. 106-132.

Gerlach, S.A. 1951b. Freilebende Nematoden aus der Verwandtschaft der Gattung Theristus, Zool. Jahrb. (Abt. Syst.), 80, 3-4, 379-406.

Gerlach, S.A. 1954. Die Nematodenbesiedlung des Sandstrandes und des Küstengrundwassers an der italienischen Küste. II. Ökologischer Teil, Arch.Zool., vol. 39, pp. 311-359. Italy.

Gerlach, S.A. 1971. On the importance of marine meiofauna for benthos communities, Oecologia, vol. 6, pp. 176-190. Berlin.

Gerlach, S.A. and M. Schrage. 1971. Life cycles in marine meiobenthos. Experiments at various temperatures with Monhystera disjuncta and 
Theristus pertenius (Nematoda), Intern.J. on Life in Oceans and Coastal Waters, 9, 3, 274-280.

Gilyarov, M.S. 1944. Sootnoshenie razmerov i chislennosti pochvennykh zhivotnykh (Size ratios and population of soil fauna). Dokl. AN SSSR, $43,6,283-285$.

Govindankutti, A.G. and B.N. Nair. 1966. Observations on interstitial fauna of the southwest coast of India, Hydrobiologia, vol. 28, pp. $102-122$.

Gray, I.S. 1966a. The attractive factor of intertidal sands for Protodrilus symbioticus, J. Mar. Biol. Assoc., vol. 46, pp. 627-646. U.K.

Gray, I.S. 1966b. Factors controlling the localization of populations of Protodrilus symbioticus, J. Animal. Ecol., 35, 3, 435-442.

Gray, I.S. 1966c. Selection of sands by Protodrilus symbioticus, Veröff. Inst. Meeresforsch. Bremerhaven, vol. 2, pp. 105-115.

Gray, I.S. 1971. Sample size and sample frequency in relation to quantitative sampling of sand meiofauna, Smiths. Contrib. to Zool., no. 76, pp. 191-198.

Gray, I.S. and R.M. Rieger. 1971. A quantitative study of the meiofauna of an exposed sandy beach at Robin Hood's Bay, Yorkshire, J. Mar. Biol. Assoc., vol. 51, pp. 1-19. U.K.

Gurvich, V.V. 1967. Mikro- i mezobentos Dnepra i ego vodokhranilishch (Kremenchugskogo i Kakhovskogo) v pervye gody ikh sushchestvovaniya [Micro- and mesobenthos of the Dnieper River and its water reservoirs (Kremenchug and Khakhov) in the initial years of their existence]. In Gidrobiologicheskii Rezhim Dnepra $v$ Usloviyakh Zaregulirovaniya Stoka. Izd. Naukova Dumka, Kiev, pp. 270-289.

Gur'yanova, E.F. 1948. Beloe more i ego fauna (The White Sea and Its Fauna). Petrozavodsk, Gosizdat Karelo-Finskoi SSR, 132 pp.

Gur'yanova, E.F. 1949. Osobennosti Belogo morya kak morskogo basseina $\mathbf{i}$ perspektivy iskusstvenogo povysheniya ego produktivnosti (Properties of the White Sea as a marine basin and possible artificial increase of its productivity). Vesti $L G U$, no. 3, pp. 26-41.

Gur'yanova, E.F. and P.V. Ushakov. 1927. Litoral' Vostochnogo Murmana (Littoral zones of eastern Murmansk). Issled. Morei SSSR, vol. 10 , pp. 5-40.

Gur'yanova, E.F., I.G. Zaks and P.V. Ushakov. 1930b. Litoral' Kol'skogo zaliva. III. Usloviya sushchestvovaniya na litorali Kol'skogo zaliva (Littoral zones of Kol'sk Gulf. III. Conditions of existence in the littoral zones of Kol'sk Gulf). Tr. Len. Ob-va Estestvoisp., vol. 60, pp. 17-107.

Harris, R.P. 1972. Distribution and ecology of interstitial meiofauna of a sandy beach at Whitsand Bay, East Cornwall, J. Mar. Biol. Assoc., vol. 52, pp. 1-18. U.K. 
Hopper, B.E. 1961. Marine nematodes from the coast of the Gulf of Mexico, Canadian J. Zool., 39, 2, 183-199.

Hopper, B.E. and S.P. Meyers. 1966. Observations on the bionomics of marine nematodes, Nature, 209, 5026, 899-900.

Hulings, N.C. 1971. A quantitative study of the sand beach meiofauna in Tunisia (preliminary report), Bull. Inst. Oceanogr. Peche Salambo, 2, 2, 237-256.

Jansson, B.O. 1966. Microdistribution of factors and fauna in marine sandy beaches, Veröff. Inst. Meeresforsch. Bremerhaven, vol. 2, pp. $77-86$.

Jansson, B.O. 1967a. Diurnal and annual variations of temperature and interstitial water in sandy beaches, Ophelia, vol. 4, pp. 173-201.

Jansson, B.O. 1967b. The importance of tolerance and preference experiments for interpretation of mesopsammon field distribution, Helgoländer Wiss. Meeresunters, vol. 15, pp. 41-58.

Jansson, B.O. 1967c. Significance of grain size and pore water content for interstitial fauna of sandy beaches, Oikos, vol. 18, pp. 311-322.

Jansson, B.O. 1968. Quantitative and experimental studies of interstitial fauna in four Swedish sandy beaches, Ophelia, vol. 5, pp. 1-71.

Jansson, B.O. 1971. The "Umwelt" of interstitial fauna, Smiths. Contr. to Zool., no. 76, pp. 129-140.

Johnson, R.G. 1965. Temperature variation in the faunal environment of sand flats, Limnol. and Oceanogr., vol. 10, pp. 114-120.

Jonhson, R.G. 1967. Salinity of interstitial water in a sandy beach, Limnol. and Oceanogr., vol. 12, pp. 1-7.

Kinne, O. 1963. Effect of temperature and salinity on marine and brackish water animals. I. Temperature, Oceanogr. Mar. Biol. Ann. Rev., no. 1, pp. 301-340.

Kinne, O. 1964a. Nongenetic adaptation to temperature and salinity, Helgoländer Wiss. Meeresunters., vol. 9, pp. 433-458.

Kinne, O. 1964b. Effect of temperature and salinity on marine and brackish water animals. II. Salinity and temperature combinations, Oceanogr. Mar. Biol. Ann. Rev., no. 2, pp. 281-339.

Kinne, O. 1966. Physiological aspects of animal life in estuaries with special reference to salinity, Netherlands J. Sea Research, vol. 3, pp. 222-224.

Kiseleva, M.I. 1965. Kachestvennyi sostav i kolichestvennoe raspredelenie meiobentosa u zapadnogo poberezhya Kryma (Qualitative composition and quantitative distribution of the meiobenthos along the western coast of Crimea). In Bentos Kiev. Izd. Naukova Dumka, pp. 48-61.

Kreis, H.A. 1928. Freilebende marine Nematoden der Spitzbergen expedition von F. Römer und F. Schaudinn im Jahre 1898, Mitt. Zool. Mus. Berlin, vol. 14, pp. 131-197. 
Kreis, H.A. 1929. Freilebende marine Nematoden von der Nordwestküste Frankreichs, Capita Zool., 2, 7, 1-270.

Kreis, H.A. 1934. Oncholaiminae Filipjev, 1916, Capita Zool., 4, 5, 1-271.

Krogh, A. and R. Spärck. 1936. On the new bottom sampler for investigation of microfauna of the sea bottom with remarks on the quantity and significance of benthonic microfauna, Det Kongelige Danske Videnskab. Selskab. Biol. Medd., vol. 13, pp. 1-12.

Kuznetsov, V.V. 1947. Vliyanie ledyanogo pokrova na morfologiyu i naselenie litoral'noi zony (Influence of the ice cover on the morphology and population of the littoral zone). Dokl. AN SSSR, 57, 1, 163-166.

Linke, O. 1939. Die Biota des Jadebusenwatters, Helgoländer Wiss. Meeresunters., vol. 1, pp. 201-348.

Linstow, O. 1900. Die Nematoden, Fauna Arctica, vol. 1, pp. 117-132. Jena.

Man, J.G. de. 1881. Die einheimischen, frei in der reine Erde und süssen Wasser lebenden Nematoden, Tijdschr. Niderl. Dierk. Vereeniging, vol. 5, pp. 1-102.

Man, J.G. de. 1886. Anatomische Untersuchungen über freilebende Nordsee-Nematoden. Paul Frohberg, Leipzig, 82 pp.

Man, J.G. de. 1888. Sur quelques Nématodes libres de mer du Nord, nouveaux ou peu connus, Mém. Soc. Zool., vol. 1, pp. 1-51. Françe.

Man, J.G. de. 1889. Troisième note sur Nématodes libres de la mer du Nord et de la Manche, Mém. Soc.Zool., vol. 2, pp. 182-216. Françe.

Man, J.G. de. 1907. Sur quelques espèces nouvelles ou peu connus de Nématodes libres, habitant les côtes de la Zélande, Mém. Soc. Zool., vol. 20, pp. 33-90. Françe.

Man, J.G. de. 1922. Vrijlevende Nematoden. In Flora en Fauna der Zuiderzee, pp. 214-261.

Mare, M.F. 1942. A study of a marine benthic community with special reference to microorganisms, J. Mar. Biol. Assoc., vol. 25, pp. 517554. U.K.

Marion, A.P. 1870. Recherches zoologiques et anatomiques sur des Nématodes nonparasites marins, Ann. Sci. Nat., nos. 13-14, 102 pp.

Matveeva, T.A., N.S. Nikitina and E.N. Chernovskaya. 1955. Prichiny i sledstviya neravnomernosti raspredeleniya chervei Fabricia sabella Ehr. i Arenicola marina L. na litorali (Reasons for and results of irregular distribution of worms Fabricia sabella Ehr. and Arenicola marina L. in the littoral zones). Dokl. AN SSSR, 105, 2, 370-373.

Mawson, P.M. 1953. Some marine free-living nematodes from the Australian coast, Trans. Roy. Soc., vol. 76, pp. 34-40. South Australia.

McIntyre, A.D. 1964. Meiobenthos of sublittoral muds, Journ. Mar. Biol. Assoc., vol. 44, pp. 665-674. U.K. 
McIntyre, A.D. 1968. Meiofauna and macrofauna of some tropical beaches, Journ. Zool., vol. 156, pp. 377-392. London.

McIntyre, A.D. 1969. Ecology of marine meiobenthos, Biol. Rev. Cambridge Philos. Soc., 44, 2, 245-290.

Meadows, P.S. and I.G. Anderson. 1966. Microorganisms attached to marine and fresh-water sand grains, Nature, no. 212, pp. 367-387.

Meadows, P.S. and I.G. Anderson. 1968. Microorganisms attached to marine sand grains, J. Mar. Biol. Assoc., vol. 48, pp. 161-175. U.K.

Micoletzky, H. 1914. Freilebende süsswasser Nematoden der Ost-Alpen mit besonderer Berücksichtigung des Lunzer Seengebites, Zool. Jahrb. (Abt. Syst.), 36, 4-5, 331-546.

Micoletzky, H. 1924. Letzter Bericht über freilebenden Nematoden aus Suez, Sitz. Akad. Wissenschaft. Wien. Math.-Naturwiss. Klasse, Abt. 1, 133, 4-6, 138-179.

Micoletzky, H. 1930. Freilebende marine Nematoden von den SundaInseln. I. Enoplidae, Vid. Medd. Dansk Naturh. Foren., vol. 87, pp. 243-339.

Milovidova, M.Yu. 1961. Gidrobiologicheskaya kharakteristika Sudzhukskoi laguny (Hydrobiological characters of Sudzhuksk lagoons). Tr. Novorossiiskoi Biol. St., pp. 69-80.

Mironova, N.V. 1951. Veslonogie podotryada Harpacticoida kak pishcha molody treskovykh rub (Copepods of suborder Harpacticoida as food for young codfish). Dokl. AN SSSR, 79, 5, 891-894.

Monakov, A.V. and F.D. Mordukhai-Boltovskii. 1959. K metodike issledovaniya pridonnoi mikrofauny (A method of studying natural microfauna). Bull. Inst. Biologii.Vodokhr., no. 4, pp. 55-59.

Moore, H.B. and R. Neill. 1930. An instrument for sampling marine muds, J. Mar. Biol. Assoc., vol. 16, pp. 589-594. U.K.

Münch, H.D. and H.G. Petzold. 1956. Zur Fauna des Küstengrundwasser der Insel Hiddensee. I. Chemisch-physikalische Verhältnisse und ihr Einfluss auf die Grundwasserfauna, Wiss. Zeitschrift E. Moritz Arnat-Univ. Greifwald. Mat.-Wiss. Reihe, vol. 5, pp. 413-429.

Muus, B.J. 1964. A new quantitative sampler for meiobenthos, Ophelia, vol. 1, pp. 209-216.

Muus, B.J. 1967. Fauna of Danish estuaries and lagoons, Medd. Danmarks Fiskeri-og Havunders, vol. 5, pp. 1-316.

Orton, J.H. 1919. Sea temperature, breeding, and distribution of marine animals, J. Mar. Biol. Assoc., vol. 12, pp. 339-396. U.K.

Pennak, R.W. 1940. Ecology of microscopic metazoa inhabiting sand beaches of some Wisconsia [sic], Ecol. Monogr., vol. 10, pp. 537-615.

Perkins, E.J. 1958. Food relations of microbenthos with particular reference to that found at Whistable, Kent. Ann. Mag. Nat. Hist., ser. 13, vol. 1, pp. 64-77. 
Petersen, C.G.J. and P. Boysen-Jensen. 1911. Valuation of the sea. I. Animal life of the sea bottom, its food and quantity, Rept. Danish. Biol. St., vol. 20, pp. 1-81.

Plagmann, J. 1939. Ernährungsbiologie der Garnele (Crangon vulgaris Fabr.), Helgoländer Wiss. Meeresunters, vol. 2, pp. 113-162.

Platonova, T.A. 1967. Svobodnozhivushchie morskie nematody semeistva Leptosomatidae evropeiskoi Arktiki (Free-living marine nematodes of family Leptosomatidae in the European Arctic). Zool. Zhurn., 46, 6, 828-839.

Plokhinskii, N.A. 1970. Biometriya (Biometry). Izd. MGU, 367 pp.

Pollock, L.W. 1971. Ecology of intertidal meiobenthos, Smiths. Contrib. Zool., no. 76, pp. 141-148.

Purasjoki, K.J. 1945. Quantitative Untersuchungen über die Mikrofauna des Meeresbodens in der Umgebung der zoologischen Station Tvärminne an der Südküste Finnlandes, Comment. Biol. Soc. Sci., 9, 14, 1-24. Fennica.

Rauzer-Chernousova, D.M. 1935. Ob istochnikakh organicheskogo veshchestva $\mathrm{v}$ usloviyakh ego nakopleniya $\mathrm{v}$ donnykh osadkakh morskikh bukht (Sources of organic matter in conditions of its accumulation in bottom sediments of sea gulfs). Neft. Khoz-vo, no. 11, pp. $18-24$.

Rees, C.B. 1940. A preliminary study of the ecology of a mud flat, $J$. Mar. Biol. Assoc., vol. 24, pp. 185-199. U.K.

Remane, A. 1933. Verteilung und Organisation der bentonischen Mikrofauna der Kieler Bucht, Wiss. Meeresunters Abt. Kiel., vol. 21, pp. 161-222.

Remane, A. 1952. Die Besiedlung des Sandbodens im Meer und die Bedeutung Lebensformtypen für die Oecologie, Zool. Anz., Suppl. 16, pp. 327-359.

Renaud-Debyser, J. 1963. Recherches écologiques sur la fauna interstitielle des sables (Bassin d'Arcachon, île de Bimini, Bahamas), Vie et Milieu, Suppl. 15, 157 pp.

Renaud-Debyser, J. and B. Salvat. 1963. Ecologie des sediments meubles intertidaux et peuplements en microfauna; Proc. XVI Inter. Congr. Zool. Wash., vol. 1, 224 pp.

Renaud-Mornant, J., B. Salvat and C. Bossy. 1971. Macrobenthos and meiobenthos from the closed lagoon of a Polynesian atoll-Maturei, Vavao (Tuamotu), Biotropica, 3, 1, 36-55.

Rouville, E. 1904. Révision des Nématodes libres de la region de Cette, Compt. Rend. Assoc. Franç. Avanc. Sci., vol. 33, pp. 788-797.

Rukhin, L.B. 1953. Osnovy litologii (Uchenie ob osadochnykh porodakh) [Fundamentals of Lithology (Studies on Sedimentary Rocks)]. Gostoptekhizdat, Leningrad-Moscow, 672 pp. 
Ruttner-Kolisko, A. 1954. Psammostudien. II. Das Psammon des Erken in Mittelschweden, Sitzungsb. Osterr. Akad. Wiss. Mat.-Naturwiss. Kl., Abt. 1, 163, 4, 301-324.

Salvat, B. 1964. Les condition hydrodynamiques interstitielles des sédiments meubles intertidaux et la réparation verticale de la faune endogée, Compt. Rend. Acad. Sci., ser. D. vol. 259, pp. 1576-1579.

Sanders, H.L., R.R. Hessler and C.R. Hampson. 1965. An introduction to the study of deep-sea benthic faunal assemblages along the Gay Head-Bermuda Transect, Deep-Sea Research, vol. 12, pp. 845-868.

Schmidt, P. 1969. Die quantitative Verteilung und Populationsdynamik des Mesopsammons am Gezeiten-Sandstrand der Nordsee-Insel Sylt. II. Quantitative Verteilung und Populationsdynamik einzeiner Arten, Intern. Rev. Ges. Hydrobiol., 54, 1, 95-174.

Schulz, E. 1931. Betrachtungen über Augen freilebender Nematoden, Zool. Anz., vol. 95, pp. 241-244.

Schuurmans-Stekhoven, J.H. 1935. Nematoda errantia. In Tierwelt der Nord- und Ostsee (Teil V), Lief. 28. Leipzig, 174 pp.

Schuurmans-Stekhoven, J.H. 1950. Free-living marine nemas of the Mediterranean. I. Bay of Villenfrache, Mém. Inst. Roy. Sci. Nat., ser. 2, fasc. 37, 220 pp. Belgium.

Schuurmans-Stekhoven, J.H. and W. Adam. 1931. Free-living marine nemas of the Belgian coast, Mém. Mus. Roy. Hist. Nat., no. 49, pp. 1-58. Belgium.

Skoolmun, F. and G. Gerlack. 1971. Jahreszeitliche Fluktuationen der Nematodenfauna in Gezeitenbereich des Weser-Åstuars (Deutsche Bucht), Veröff Inst. Meeresforsch. Bremerhaven, vol. 13, pp. 119-138. Smidt, E.L.B. 1951. Animal production in the Danish Wadden Sea, Medd. Danmarks Fiskeri-og Havunders., vol. 11, pp. 1-151.

Smith, R.J. 1956. Ecology of the Tamar Estuary. VII. Observations on interstitial salinity of intertidal muds in the estuarine habitat of Nereis diversicolor, J. Mar. Biol. Assoc., vol. 33, pp. 81-104. U.K.

Smith, W. and A.D. McIntyre. 1954. A spring-loaded bottom sampler, J. Mar. Biol. Assoc., vol. 33, pp. 257-264. U.K.

Southern, R. 1914. Nemathelmia, Kinorhyncha and Chaetognatha, Proc. Roy. Irish. Acad., vol. 31, pp. 1-80.

Steiner, G. 1916a. Zur geographischen Verbreitung freilebenden Nematoden, Zool. Anz., vol. 46, pp. 120-128.

Steiner, G. 1916b. Freilebende Nematoden aus der Barentssee, Zool. Jahrb. (Abt. Syst.), vol. 39, pp. 511-676.

Stripp, K. 1969. Das Verhältnis von Makrofauna und Meiofauna in den Sedimenten der Helgoländer Bucht, Veröff. Inst. Meeresforsch. Bremerhaven, vol. 12, pp. 143-148. 
Swedmark, B. 1964. The interstitial fauna of marine sand, Biol. Rev., vol. 39, pp. 1-42.

Teal, J.M. and W. Wieser. 1966. The distribution and ecology of nematodes in a Georgia salt marsh, Limnol. Oceanogr., 11, 2, 217-222.

Thiel, H. 1966. Quantitative Untersuchungen über Meiofauna des Tiefseebodens, Veröff. Inst. Meeresforsch. Bremerhaven, vol. 2, pp. 131-148.

Thiel, H. 1971. Häufigkeit und Verteilung der Meiofauna im Bereich des Island-Färoer-Rückers, Berichte Deutschen Komission Meeresforschung, vol. 22, pp. 99-128.

Tietjen, J.H. 1969. The ecology of shallow-water meiofauna in two New England estuaries, Oecologia, vol. 2, pp. 251-291. Berlin.

Tietjen, J.H. 1971. Ecology and distribution of deep-sea meiobenthos of North Carolina, Deep-Sea Research, 18, 10, 941-959.

Timm, R.W. 1952. A survey of marine nematodes of Chesapeake Bay, Maryland, Chesapeake Biol. Lab. Solomons Islands, Maryland, publ. 95, pp. 1-70.

Trask, P.D., H.E. Hammar and C.C. Wu. 1932. Origin and Environment of Source Sediments of Petroleum. Hoston Gulf publ., 323 pp.

Tseeb, Ya.Ya. 1937. K metodike kolichestvennogo ucheta mikrofauna pelogena $\mathrm{v}$ svyazi ee primeneniem na solenykh ozerakh Kryma (Method of quantitative estimation of microfauna of Peleogen in connection with its utilization in the saline lakes of Crimea). Zool. Zhurn., 16, 1-3, 499.

Voronkov, P.P. 1953. Osnovy gidrokhimii (Fundamentals of Hydrochemistry). Gidrometizdat, $296 \mathrm{pp}$. Leningrad.

Wallace, H.R. 1958. Movement of eelworms. I. Influence of pore size and moisture content of the soil on the migration of larvae of the beet eelworm, Heterodera schachtii Schmidt, Ann. Appl. Biol., vol. 46, pp. 74-86.

Warwick, R.W. and J.B. Buchanan. 1971. Meiofauna of the coast of Northumberland. II. Seasonal stability of the nematode population, J. Mar. Biol. Assoc., 51, 2, 355-362. U.K.

Wieser, W. 1953-1959. Free-living marine nematodes, Lunds Univ. Arsskrift, N.F., avd. 2: I. Enoploidea (1953a), 49, 6, 155 pp.; II. Chromadoroidea (1954), no. 7, 148 pp.; III. Axonolaimoidea and Monhysteroidea (1956), 52, 13, 115 pp.; IV. General Part (1959), 55, 5, $111 \mathrm{pp.}$

Wieser, W. 1953b. Die Beziehung zwischen Mundholengestalt, Ernährungsweise und Vorkommen bei freilebenden marinen Nematoden, Ark. Zool., ser. 2, 4, 5, 439-484.

Wieser, W. 1960. Populationsdichte und Vertikalverbreitung der Meiofauna mariner Boden, Intern. Rev. Ges. Hydrobiol., 45, 4, 487-492.

Wieser, W. and J. Kanwisher. 1961. Ecological and physiological studies 
on marine nematodes from a small salt marsh near Woods Hole, Massachusetts, Limnol. Oceanogr., 6, 3, 262-270.

Willimöes, M. 1964. A ball-stoppered quantitative sampler for microbenthos, Ophelia, vol. 1, pp. 235-240.

Wohlenberg, E. 1937. Die Wattenmeer-Lebensgemeinschaften in Königshafen von Sylt, Helgoländ. Wiss. Meeresunters, vol. 1, pp. 1-92.

Yeates, G.W. 1968. An analysis of annual variation of nematode fauna in dune sand at Himatangi, New Zealand, Pedobiol., vol. 8, pp. 173-207.

Zatsepina, V.I., L.A. Zenkevich and Z.A. Filatova. 1948. Materialy po kolichestvennomy uchetu donnoi fauny litorali Kol'skogo zaliva (Data on quantitative estimates of pelagic fauna of the littoral zone of Kola Bay). Tr. Gos. Okeanol. Inst., 6, 18, 13-54.

Zobell, C.E. 1942. Bacterial flora of a marine mud flat as an ecological factor, Ecology, vol. 23, pp. 69-77.

Zobell, C.E. 1946. Marine microbiology, Chronica Botanica, 240 pp. Waltham, Massachusetts.

Zobell, C.E. and D.Q. Anderson. 1936. Observations on the multiplication of bacteria in different volumes of stored sea water and the influence on oxygen tension and solid surfaces, Biol. Bull., vol. 71, pp. 324-342.

Zobell, C.E. and C.B. Feltham. 1938. Bacteria as food for certain marine invertebrates, J. Mar. Res., vol. 1, p. 312. 





